\title{
Análise de discretizações e interpolações em malhas icosaédricas e aplicações em modelos de transporte semi-lagrangianos
}

\author{
Pedro da Silva Peixoto
}

TESE APRESENTADA

AO

Instituto De Matemática e EstatísticA

DA

UniversidAde DE SÃo PAUlo

PARA

OBTENÇÃO DO TÍTULO

$\mathrm{DE}$

DOUTOR EM CIÊNCIAS

Programa: Matemática Aplicada

Orientador: Prof. Dr. Saulo Rabello Maciel de Barros

Durante o desenvolvimento deste trabalho o autor recebeu auxílio financeiro da CAPES e do $\mathrm{CNPq}$

São Paulo

Junho de 2013 


\section{Análise de discretizações e interpolações em malhas icosaédricas e aplicações em modelos de transporte semi-lagrangianos}

Esta versão definitiva da tese contém as correções e alterações sugeridas pela

Comissão Julgadora durante a defesa realizada por Pedro da Silva Peixoto

em $12 / 6 / 2013$.

Comissão Julgadora:

- Prof. Dr. Saulo Rabello Maciel de Barros (Presidente) - IME-USP

- Prof. Dr. Pedro Leite da Silva Dias - LNCC

- Prof. Dr. Saulo Ribeiro de Freitas - CPTEC-INPE

- Prof. Dr. Carlos Frederico Mendonça Raupp - IAG-USP

- Prof. Dr. Alexandre Megiorin Roma - IME-USP 


\section{Prefácio}

Uma tese de doutorado é muito mais que apenas um conjunto de páginas escritas. A tese é na verdade um conjunto de experiências vividas. São as experiências que fazem o amadurecimento científico acontecer, e isso geralmente não está explícito na tese. Esta tese foi realizada num período de 4 anos, nos quais muitas coisas aconteceram e impactaram nos resultados que serão apresentados.

\section{Breve histórico}

O primeiro ano foi dedicado para as disciplinas, fundamentais para fortalecer a base do conhecimento científico. Em paralelo, o projeto da tese começou a ser pensado e a revisão de literatura começou. No ano que se seguiu, além de tentar compreender o que já havia sido feito na área, comecei a desenvolver o código de geração de malhas icosaédricas para a esfera. No final do segundo ano, alguns testes com pequenos exemplos de discretizações e algumas análises de interpolações já mostravam alguns problemas em aberto que mereciam atenção. No terceiro ano, analisamos diversos problemas e, tanto a parte de teoria desta tese, quanto a implementação de código que diz respeito a ela, tiveram um salto significativo. No quarto e último ano, tivemos um artigo aceito, mostrando que o trabalho feito até então estava num bom caminho.

Durante o último ano tive o privilégio de ficar 2 meses no Instituto Isaac Newton de Ciências Matemáticas da Universidade de Cambridge, Reino Unido, e participar do semestre temático de análise numérica para atmosfera e oceano. Lá pude conviver com pessoas brilhantes e grandes nomes da área. As experiências aprendidas certamente influenciaram muito o resultado final desta tese.

O trabalho desenvolvido exigiu muita programação e, com exceção do algoritmo de triangulação para a esfera (desenvolvido pelo pesquisador Robert Renka), todo o resto foi desenvolvido para este projeto. Porém o resultado vai além do doutorado. O produto final é uma plataforma robusta de geração de malhas geodésicas para a esfera, com implementações de diversos métodos de interpolações para campos escalares e vetoriais, além de discretizações por volumes finitos de operadores diferenciais como o divergente, laplaciano, gradiente e rotacional. Além disso, é claro, foi desenvolvido o modelo de transporte semi-lagrangiano. Espera-se que a plataforma desenvolvida sirva como base para futuros projetos de modelagem em malhas geodésicas.

O trabalho desenvolvido nesses 4 anos respondeu algumas perguntas, mas também gerou muitas outras. Há muito o que ser investigado na área de estudo e, com isso, fica claro que o doutorado é só o começo. 


\section{Agradecimentos}

Muitas pessoas contribuíram para o desenvolvimento deste trabalho de doutorado, mas sem dúvidas, o meu orientador, Saulo, é quem mais contribuiu, com muitas horas discussões e ensinamentos. Tenho que agradecer também os professores do IME que se dispuseram a me ensinar matemática de alto nível.

Agradeço também os membros da banca de qualificação, Pedro Dias e Abimael Loula, que deram sugestões que impulsionaram o trabalho e incentivaram a publicação dos resultados que havia obtido até então.

A base de trabalho foi o laboratório de matemática aplicada, LabMap, que não teria a qualidade que tem hoje sem o esforço do professor Alexandre Roma. Sempre que tinha um problema colocava na lousa do laboratório e discutia com alguém e daí diversas ideias surgiam, portanto tem um pouco de cada amigo do IME nesta tese. Aí vão alguns nomes importantes que merecem um obrigado: Wellington, Daniel, Tiago, Marcelo, Oda, Nelson, Anderson, Catalina, Priscila, Ricardo, Larissa, Nils, Marline, ...

Nem só de matemática se faz uma tese, pois foi preciso uma boa ajuda da família também. Minha esposa aguentou firmemente o meu mau humor quando algo não estava indo tão bem e me deu forças para seguir em frente. Ela contribuiu inclusive com algumas ideias, ao palpitar sobre algumas figuras. Minha mãe, além de me dar dicas do mundo acadêmico e revisar a tese, me deu muita segurança para encarar o desafio de trabalhar muito e ganhar pouco, que é a vida de um doutorando. Meu Pai, apesar de estar distante em quilômetros, acompanhou tudo de perto. Minha vó e minha tia Célia também estiveram sempre ao meu lado, apoiando a empreitada (apesar de minha vó sempre me perguntar quando eu ia parar de estudar e começar a trabalhar). Agradeço ao Marcelo, meu cunhado, pela excelente ajuda com a revisão da tese.

Os amigos ajudaram muito, me tirando do mundo acadêmico e tornado a jornada mais divertida. Valeu Leonel, Papa, Batata, Murilo, Lia, Marcelo, ...

Agradeço ainda algumas pessoas que conheci no estágio na Inglaterra, em especial a Hilary Weller, que fez que o estágio se tornasse possível, mas também diversos pesquisadores, Sergey Danilov, John Thuburn, Todd Ringler, William Skamarock, Daniel Le roux, Fracis Giraldo e alunos de pós-grad e pós-doc, Bruno Seny, Colin Zarzycki, Kevin Viner, Oliver Kunst, Andreas Mueller, Nicole Beisiegel e Katharina Elsen.

São Paulo, Maio de 2013

Pedro da Silva Peixoto 


\section{Resumo}

Peixoto, Pedro S. Análise de discretizações e interpolações em malhas icosaédricas e aplicações em modelos de transporte semi-lagrangianos. 2013. 241f. Tese (Doutorado) Instituto de Matemática e Estatística, Universidade de São Paulo, São Paulo, 2013.

A esfera é utilizada como domínio computacional na modelagem de diversos fenômenos físicos, como em previsão numérica do tempo. Sua discretização pode ser feita de diversas formas, sendo comum o uso de malha regulares em latitude/longitude. Recentemente, também para melhor uso de computação paralela, há uma tendência ao uso de malhas mais isotrópicas, dentre as quais a icosaédrica. Apesar de já existirem modelos atmosféricos que usam malhas icosaédricas, não há consenso sobre as metodologias mais adequadas a esse tipo de malha. Nos propusemos, portanto, a estudar em detalhe diversos fatores envolvidos no desenvolvimento de modelos atmosféricos globais usando malhas geodésicas icosaédricas.

A discretização usual por volumes finitos para divergente de um campo vetorial utiliza como base o Teorema da Divergência e a regra do ponto médio nas arestas das células computacionais. A distribuição do erro obtida com esse método apresenta uma forte relação com características geométricas da malha. Definimos o conceito geométrico de alinhamento de células computacionais e desenvolvemos uma teoria que serve de base para explicar interferências de malha na discretização usual do divergente. Destacamos os impactos de certas relações de alinhamento das células na ordem da discretização do método. A teoria desenvolvida se aplica a qualquer malha geodésica e também pode ser usada para os operadores rotacional e laplaciano.

Investigamos diversos métodos de interpolação na esfera adequados a malhas icosaédricas, e abordamos o problema de interpolação e reconstrução vetorial na esfera em malhas deslocadas. Usamos métodos alternativos de reconstrução vetorial aos usados na literatura, em particular, desenvolvemos um método híbrido de baixo custo e boa precisão.

Por fim, utilizamos as técnicas de discretização, interpolação e reconstrução vetorial analisadas em um método semi-lagrangiano para o transporte na esfera em malhas geodésicas icosaédricas. Realizamos experimentos computacionais de transporte, incluindo testes de deformações na distribuição do campo transportado, que mostraram a adequação da metodologia para uso em modelos atmosféricos globais.

A plataforma computacional desenvolvida nesta tese, incluindo geração de malhas, interpolações, reconstruções vetoriais e um modelo de transporte, fornece uma base para o futuro desenvolvimento de um modelo atmosférico global em malhas icosaédricas.

Palavras-chave: Malhas geodésicas, malha icosaédrica, volumes finitos, discretizações, transporte semi-lagrangiano, interpolações, reconstrução vetorial, malhas não estruturadas, malhas deslocadas. 


\section{Abstract}

Peixoto, Pedro S. Analysis of discretizations and interpolations on icosahedral grids and applications to semi-Lagrangian transport models. 2013. 241f. Thesis (Doctoral) - Instituto de Matemática e Estatística, Universidade de São Paulo, São Paulo, 2013.

Spherical domains are used to model many physical phenomena, as, for instance, global numerical weather prediction. The sphere can be discretized in several ways, as for example a regular latitude-longitude grid. Recently, also motivated by a better use of parallel computers, more isotropic grids have been adopted in atmospheric global circulation models. Among those, the icosahedral grids are promising. Which kind of discretization methods and interpolation schemes are the best to use on those grids are still a research subject. Discretization of the sphere may be done in many ways and, recently, to make better use of computational resources, researchers are adopting more isotropic grids, such as the icosahedral one. In this thesis, we investigate in detail the numerical methodology to be used in atmospheric models on icosahedral grids.

The usual finite volume method of discretization of the divergence of a vector field is based on the divergence theorem and makes use of the midpoint rule for integration on the edges of computational cells. The error distribution obtained with this method usually presents a strong correlation with some characteristics of the icosahedral grid. We introduced the concept of cell alignment and developed a theory which explains the grid imprinting patterns observed with the usual divergence discretization. We show how grid alignment impacts in the order of the divergence discretization. The theory developed applies to any geodesic grid and can also be used for other operators such as curl and Laplacian.

Several interpolation schemes suitable for icosahedral grids were analysed, including the vector interpolation and reconstruction problem on staggered grids. We considered alternative vector reconstruction methods, in particular, we developed a hybrid low cost and good precision method.

Finally, employing the discretizations and interpolations previously analysed, we developed a semi-Lagrangian transport method for geodesic icosahedral grids. Several tests were carried out, including deformational test cases, which demonstrated that the methodology is suitable to use in global atmospheric models.

The computational platform developed in this thesis, including mesh generation, interpolation, vector reconstruction and the transport model, provides a basis for future development of global atmospheric models on icosahedral grids.

Keywords: Geodesic grids, icosahedral grid, finite volume, discretization, semi-Lagrangian transport, interpolation, vector reconstruction, non structured grids, staggered grids. 


\section{Sumário}

$\begin{array}{lll}\text { Lista de abreviaturas } & \text { xi }\end{array}$

1 Introdução $\quad 1$

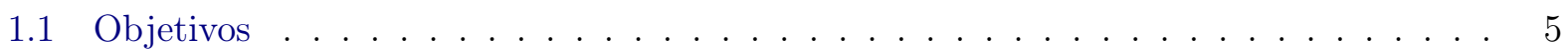

1.2 Organização da tese . . . . . . . . . . . . . . . . . . 5

$\begin{array}{lll}2 & \text { Malhas esféricas geodésicas icosaédricas } & 7\end{array}$

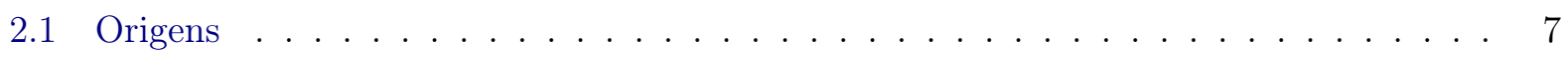

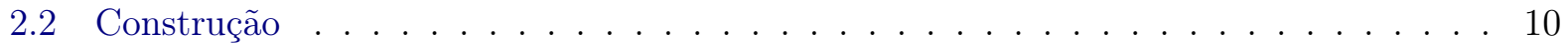

2.3 Definições . . . . . . . . . . . . . . . . . . . . . . . . . . . . . . . . 14

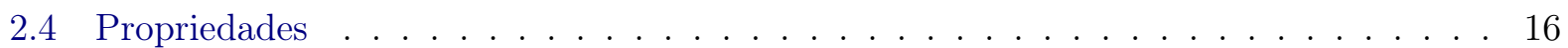

2.4.1 Comprimentos de arestas . . . . . . . . . . . . . . . 16

2.4 .2 Áreas . . . . . . . . . . . . . . . . . . . . . . 18

2.4 .3 Distorções . . . . . . . . . . . . . . . . . . . . . . . . . . . . . . 20

2.4 .4 Centros de massa . . . . . . . . . . . . . . . . . . . . . . . 22

2.4.5 Relação entre arestas da malha primal e dual . . . . . . . . . . . . . . 26

2.5 Posicionamento de campos . . . . . . . . . . . . . . . . . . . . . . 28

2.6 Estrutura computacional . . . . . . . . . . . . . . . . . . . 34

2.7 Otimizações . . . . . . . . . . . . . . . . . . . . . . . 36

2.7.1 Malhas centroidais de Voronoi . . . . . . . . . . . . . . . . . 36

2.7.2 Malhas otimizadas com spring dynamics . . . . . . . . . . . . . . . . 41

2.7.3 Malhas de Heikes and Randall (1995) . . . . . . . . . . . . . . . . . . . 46

3 Análise de interferência de malha na discretização do divergente $\quad \mathbf{5 1}$

3.1 Análise no plano . . . . . . . . . . . . . . . . . . . . . 51

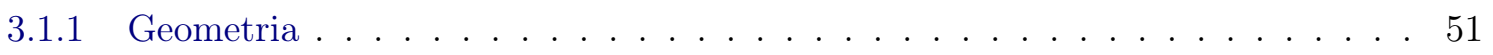

3.1 .2 Discretização do divergente . . . . . . . . . . . . . . . . . . . 54

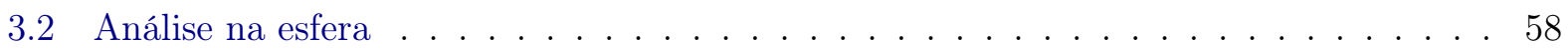

3.2 .1 Projeção radial de um polígono . . . . . . . . . . . . . . . . 58

3.2 .2 Projeção radial de campo vetorial . . . . . . . . . . . . . . . . . . . . 64

3.2 .3 Discretização do divergente . . . . . . . . . . . . . . . . . . . . . . 65

3.3 Alinhamento em malhas icosaédricas . . . . . . . . . . . . . . . . . . . 70

3.4 Resultados numéricos . . . . . . . . . . . . . . . . . . . . . . . . 74

3.4 .1 Campo de rotação . . . . . . . . . . . . . . . . . . . . . 74

3.4.2 Campo com divergência . . . . . . . . . . . . . . . . . . . . 78 
3.4.3 Em malhas otimizadas . . . . . . . . . . . . . . . . . . . . 80

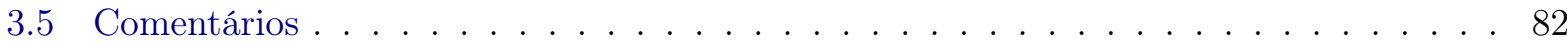

4 Análise de interpolações escalares e reconstruções vetoriais $\quad 83$

4.1 Localização de ponto em malha . . . . . . . . . . . . . . . . . . . . . . 85

4.2 Interpolações escalares . . . . . . . . . . . . . . . . . . . . . 88

4.2 .1 Coordenadas baricêntricas . . . . . . . . . . . . . . . . . . . . 88

4.2.2 Aproximação polinomial com MMQ . . . . . . . . . . . . . . . . . . 100

4.2 .3 Método C1 de Hermite . . . . . . . . . . . . . . . . . . . . . . . . . . . . . 107

4.2 .4 Funções de base radial . . . . . . . . . . . . . . . . . . . . . . . . . 112

4.2 .5 Comparativos . . . . . . . . . . . . . . . . . . . . . 123

4.3 Reconstruções vetoriais . . . . . . . . . . . . . . . . . . . 126

4.3 .1 Bases vetoriais triangulares f . . . . . . . . . . . . . . . . 128

4.3.2 Bases vetoriais em coordenadas baricêntricas generalizadas . . . . . . . . . . . 133

4.3 .3 Método de Perot . . . . . . . . . . . . . . . . . . . . . . 137

4.3 .4 Funções de base radial . . . . . . . . . . . . . . . . . . . . . . . . . . . . 144

4.3 .5 Método de mínimos quadrados . . . . . . . . . . . . . . . . . . . 148

4.3 .6 Método híbrido . . . . . . . . . . . . . . . . . . . . . . . . . . 154

4.3 .7 Comparativo . . . . . . . . . . . . . . . . . . . 158

5 Transporte semi-lagrangiano em malhas icosaédricas $\quad 161$

5.1 Modelo de transporte . . . . . . . . . . . . . . . . . . . . . . . . . 162

5.2 Método semi-lagrangiano . . . . . . . . . . . . . . . . . . . . . . . 162

5.3 Cálculo da trajetória . . . . . . . . . . . . . . . . . . . . . . 163

5.4 Análise de convergência . . . . . . . . . . . . . . . . . . . . . . 164

5.4 .1 Interpolação escalar . . . . . . . . . . . . . . . . . . . . . 167

5.4 .2 Trajetória . . . . . . . . . . . . . . . . . . . . 168

5.4 .3 Interpolação vetorial . . . . . . . . . . . . . . . . . . . . . 168

5.4 .4 Reconstrução híbrida . . . . . . . . . . . . . . . . . . . . . . 172

5.4 .5 Densidade . . . . . . . . . . . . . . . . . . . . . 175

5.5 Deformação com rotação . . . . . . . . . . . . . . . . . . . 177

5.6 Monotonicidade . . . . . . . . . . . . . . . . . . . . . . . . . 184

5.7 Deformação com divergência . . . . . . . . . . . . . . . . . . . . . . . 190

5.8 Conservação de massa . . . . . . . . . . . . . . . . . . . . . . . 194

5.9 Comentários . . . . . . . . . . . . . . . . . . . . . . 197

6 Conclusões $\quad 199$

A Modelos que usam malhas icosaédricas 203

A.1 GME . . . . . . . . . . . . . . . . . . . . . . . 203

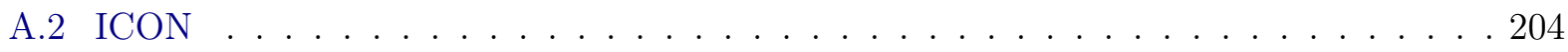

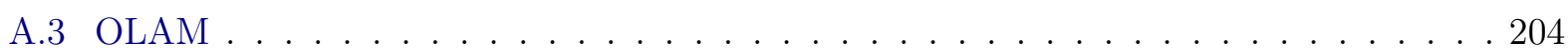

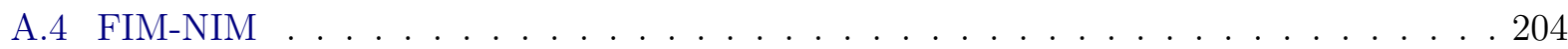

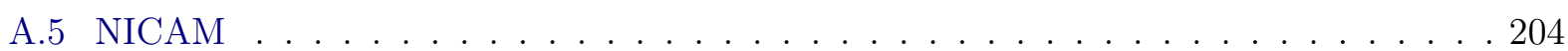

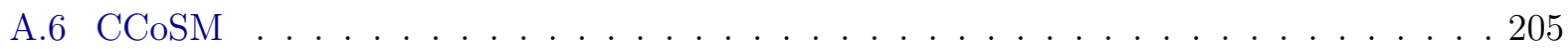




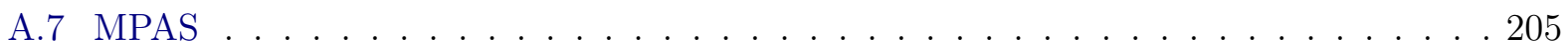

B Coordenadas geográficas e ferramentas de geometria esférica 207

B.1 Coordenadas geográficas . . . . . . . . . . . . . . . . . 207

B.2 Distâncias geodésicas . . . . . . . . . . . . . . . . . . . . 208

B.3 Áreas geodésicas . . . . . . . . . . . . . . . . . . . . . . 208

B.4 Vetores na esfera . . . . . . . . . . . . . . . . . . . . 208

B.5 Operadores diferenciais . . . . . . . . . . . . . . . . . . . . . 209

$\begin{array}{ll}\text { C Ordem de aproximação do método semi-lagrangiano } & 211\end{array}$

C.1 Análise do cálculo da trajetória . . . . . . . . . . . . . . . . . . . 211

C.2 Erro na concentração do traçador . . . . . . . . . . . . . . . . . . . . . . . 214

$\begin{array}{ll}\text { D Considerações técnicas } & 217\end{array}$

$\begin{array}{ll}\text { Referências Bibliográficas } & 219\end{array}$ 


\title{
Lista de abreviaturas
}

\author{
AGCM Modelo Geral de Circulação Atmosférica \\ Atmospheric General Circulation Model \\ C1RK Método $C^{1}$ de Renka \\ CBTR Coordenadas baricêntricas para triângulos \\ CCoSM Modelo Acoplado do Estado do Colorado \\ Coupled Colorado State Model - EUA
}

CPTEC Centro de Previsão de Tempo e Estudos Climáticos - INPE

CSU Model Universidade do Estado do Colorado

Colorado State University - EUA

DWD Serviço Alemão Nacional de Meteorologia

Deutscher Wetterdienst

ECMWF Centro Europeu de Previsões de Tempo Médio Prazo

European Centre for Medium-Range Weather Forecasts - Reading, Inglaterra

EUA Estados Unidos da América

EBB Base de funções de arestas

Edge-based basis

FIM Modelo Icosaédrico de Volumes Finitos que acompanha o fluxo

Flow-following finite-volume Icosahedral Model - NOAA

GCRM Modelo Global que Resolve Núvens

Global Cloud Resolving Model

GPU Unidade de Processamento Gráfico

Graphics Processing Unit

GME Modelo Global Europeu

GM - Global Model, EM - European Model - DWD

GMT Ferramenta Genérica de Mapeamento

Generic Mapping Tool - Software

GrADS Sistema de análise e exibição de malhas

Grid Analysis and Display System

GD Gradiente

HE Arestas de célula hexagonal/pentagonal

HX Célula hexagonal/pentagonal

HXE Célula hexagonal/pentagonal e todos os seus nós vizinhos 
ICON GCM Modelo de Circulação Geral Icosaédrico Não Hidrostático ICOsahedral Non-hydrostatic General Circulation Model - DWD/MPI-M

IPCC Painel Intergovernamental de Mudanças Climáticas Intergovernmental Panel on Climate Change

JAMSTEC Agência Japonesa de Ciência e Tecnologia Marinha e Terrestre Japan Agency for Marine-Earth Science and Technology

MMQ ou LSQ Método de mínimos quadrados

Least squares method

MPI-M Instituto de Meteorologia Max Planck Max Planck Institute for Meteorology

MPAS Modelo de previsão entre escalas Model for Prediction Across Scales - USA

NOAA Centro Nacional de Administração Oceânica e Atmosférica National Oceanic and Atmospheric Administration - EUA

NAT Coordenadas naturais

NCAR Centro Nacional de Pesquisas Atmosféricas National Center for Atmospheric Research - EUA

NIM Modelo Icosaédrico Não hidrostático Non-hydrostatic Icosahedral model - NOAA

NICAM Modelo Atmosférico Icosaédrico Não hidrostático Nonhydrostatic ICosahedral Atmospheric Model JAMSTEC e Universidade de Tokyo - Japão

NOAA Administração Nacional de Atmosfera e Oceano National Oceanic and Atmospheric Administration - EUA

OLAM Modelo de Atmosfera Terra e Oceano Ocean Land Atmosphere Model - Universidade de Duke - EUA

PER Método de Perot

RAMS Sistema de Modelagem Atmosférica Regional Regional Atmospheric Modeling System - EUA

RBF Funções de base radial (Radial Basis Functions)

RVC Reconstrução Vetorial para os Circuncentros dos triângulos

RVN Reconstrução Vetorial para Nós

SCVT Malha Esférica de Voronoi Centroidal Spherical Centroidal Voronoi Tesselation

SPRG Malha Icosaédrica optimizada com SPRinG dynamics

TACC Centro de Computação Avançada do Texas Texas Advanced Computing Center

TR Triângulo

TRC Circuncentro de triângulo

WC Coordenadas de Wachspress 


\section{Capítulo 1}

\section{Introdução}

Diversas áreas do conhecimento utilizam a esfera como base para a modelagem de fenômenos físicos, como a previsão do tempo, a modelagem oceânica, problemas de electromagnetismo e tantos outros. Dentre elas, a modelagem de fenômenos atmosféricos globais é de grande importância científica e também econômica, social e política. Os modelos atmosféricos são de alta complexidade e geralmente são formados por um conjunto de submodelos relativos a diversos fenômenos físicos. No núcleo dos modelos temos a dinâmica atmosférica que consiste basicamente em um conjunto de equações diferenciais parciais fundamentadas nas relações físicas entre velocidade, pressão e temperatura para o fluido atmosférico, o ar. Essa dinâmica contempla entre outras coisas a advecção, ou transporte, de propriedades do fluido como a vorticidade e temperatura, ou de substâncias contidas no fluido, como a umidade e o $\mathrm{CO}_{2}$.

Historicamente os modelos de previsão de tempo globais começam na década de 1960 com aplicações em previsão numérica do tempo, previsões sazonais e climatológicas (Williamson [2007]), contendo essencialmente as mesmas equações mas com escalas de tempo diferentes. As equações são tradicionalmente resolvidas em malhas uniformes em coordenadas esféricas (latitude-longitude). Nesse tipo de malha há uma concentração de pontos próximo aos polos, fazendo com que sejam necessários passos de tempos muito pequenos em métodos explícitos de diferenças finitas, ou de volumes finitos, devido à condição de Courant-Friedrichs-Lewy (CFL). Para viabilizar o seu uso é possível usar filtros próximos aos polos para eliminar as ondas rápidas computacionalmente instáveis. Em geral o uso de malhas uniformes em coordenadas esféricas fornece boas propriedades de discretização de EDPs, como ortogonalidade, mas pode exigir um esforço computacional adicional para resolver os problemas dos polos.

Diversas malhas mais isotrópicas foram sendo propostas ao longo dos anos. Uma delas, de interesse deste trabalho, é a malha geodésica icosaédrica. Essa malha foi proposta simultaneamente por Sadourny et al. [1968] e Williamson [1968], e estudada em mais detalhes nos trabalhos de Ohnishi e Masuda [1986] e Baumgardner e Frederickson [1985]. Ela é obtida a partir de um icosaedro regular inscrito na esfera, onde os vértices do icosaedro serão pontos da malha. Esses pontos são conectados por arcos geodésicos formando uma triangulação esférica. Para obter malhas com mais pontos (malhas mais finas), pode-se incluir pontos nas arestas geodésicas, por exemplo nos seus pontos médios, e conecta-los. O algoritmo pode ser aplicado recursivamente até se obter o espaçamento entre pontos desejado. A malha resultante é triangular, mas para a resolução de equações diferenciais esta não precisa ser necessariamente a malha base. É comum o uso da malha dual, definida pelo diagrama de Voronoi relativo à triangulação obtida com o icosaedro. Essa malha dual, de Voronoi, é formada por hexágonos e 12 pentágonos.

Os resultados obtidos nos primeiros trabalhos com malhas icosaédricas para as equações da vorticidade barotrópica eram satisfatórios, porém em modelos mais gerais, usando por exemplo as equações de águas rasas, começaram a se observar ruídos para métodos de ordens mais altas, especialmente ligados a ondas com número de onda 5 (Majewski et al. [2002], Steppeler et al. [2008]). Além disso, apresentavam custo computacional proibitivo em relação aos métodos espectrais que estavam em alta na época e que persistem até hoje. Na década de 1990, com o avanço do potencial 
computacional, os problemas das malhas icosaédricas se tornaram menos relevantes, pois em suma estavam ligados à baixa resolução das malhas usadas e discretizações inadequadas (Tomita et al. [2008]). Logo esse tipo de malha passou a se tornar de grande interesse da comunidade científica. Em Heikes e Randall [1995a] grandes avanços foram propostos para viabilizar o uso de malhas icosaédricas em modelagem atmosférica, entre eles, a construção de um método multigrid para resolver as equações de água rasa nesse tipo de malha. A partir de então muitos grupos de pesquisa apresentaram resultados relevantes nesta área, como em Thuburn [1997] e Stuhne e Peltier [1999]. O serviço nacional alemão de meteorologia (Deutscher Wetterdienst-DWD) desenvolveu o primeiro modelo de previsão de tempo operacional com malha icosaédrica, denominado GME (Global Model + European Model), substituindo o modelo espectral até então usado (Majewski et al. [2002], Majewski et al. [2008]). Com base nesse modelo, o DWD, em parceria com o Instituto de Meteorologia Max Planck ( Max Planck Institute for Meteorology - MPI-M), vem desenvolvendo o Modelo de Circulação Geral Icosaédrico Não Hidrostático (ICOsahedral Non-hydrostatic General Circulation Model - ICON GCM ), que se propõe a ser operacional num futuro próximo e irá substituir o GME (Bonaventura et al. [2004], Bonaventura e Ringler [2005]).

Diversos grupos passaram a produzir modelos atmosféricos usando esse tipo de malha. O grupo do Centro Nacional de Pesquisas Atmosféricas (National Center for Atmospheric Research - NCAR) do Colorado, Estados Unidos, desenvolve diversas pesquisas principalmente ligadas ao Modelo Acoplado do Estado do Colorado (Coupled Colorado State Model - CCoSM ), como pode ser visto em Ringler et al. [2000] e Randall et al. [2002]. O grupo do Centro Nacional de Administração Oceânica e Atmosférica dos EUA (National Oceanic and Atmospheric Administration - NOAA) desenvolveu o Modelo Icosaédrico de Volumes Finitos que acompanha o fluxo (Flow-following finite-volume Icosahedral Model - FIM), cuja documentação recente pode ser vista em Bao et al. [2011]. Hoje esse modelo está sendo aperfeiçoado para o Modelo Icosaédrico Não hidrostático (Non-hydrostatic Icosahedral model - NIM ), implementado inclusive para ser rodado em processadores gráficos (Govett et al. [2010]). Com base no Sistema de Modelagem Atmosférica Regional (Regional Atmospheric Modeling System - RAMS), foi desenvolvido o Modelo de Atmosfera Terra e Oceano (Ocean Land Atmosphere Model - OLAM ), atualmente mantido pela universidade de Duke nos Estados Unidos (Walko e Avissar [2008a]). Esse modelo tem sido testado no Brasil no Centro de Previsão de Tempo e Estudos Climáticos (CPTEC - INPE) com colaborações de outros institutos (Silva et al. [2009]). No Japão foi desenvolvido o Modelo Atmosférico Icosaédrico Não hidrostático (Nonhydrostatic ICosahedral Atmospheric Model - NICAM ) pela JAMSTEC em conjunto com a Universidade de Tóquio (Tomita e Satoh [2004]). Esse modelo traz avanços significativos no tratamento da malha icosaédrica com uma otimização conhecida por spring dynamics. Além disso, em Satoh et al. [2008], foram capazes de rodar um modelo capaz de resolver nuvens com resolução de apenas $3,5 \mathrm{~km}$. Detalhamos os principais modelos que usam malhas icosaédricas no apêndice A.

O desenvolvimento de um modelo atmosférico global com malhas geodésicas é um objetivo de longo prazo do grupo de pesquisa no qual este trabalho de doutorado está inserido. Dada a complexidade dos sistemas meteorológicos, para o desenvolvimento do modelo completo são necessárias etapas preliminares de desenvolvimento de modelos simplificados. Os modelos simplificados servem como base para modelos completos e também permitem análises mais detalhadas de comportamentos atmosféricos isolados. Uma importante parte do modelo envolve o transporte de substâncias e esta será a aplicação final deste estudo. Um modelo de transporte, além de ser essencial no desenvolvimento de um modelo atmosférico completo, tem uma importância por si só e pode ser incorporado diretamente em modelos atmosféricos globais para a evolução de substâncias. Apesar da criação de um modelo transporte ser um objetivo primário deste trabalho, ele não é o único. Há diversas etapas preliminares que possuem perguntas em aberto para serem exploradas e precisam ser investigadas.

$\mathrm{O}$ uso de malhas geodésicas na modelagem numérica exige que um conjunto de ferramentas computacionais sejam desenvolvidas, por exemplo no que diz respeito a métodos de geometria computacional, interpolações e métodos de visualização. Neste trabalho de doutorado foi desenvolvida uma plataforma computacional que servirá de base para modelos numéricos em malhas geodésicas. O arcabouço computacional contempla ferramentas de geração e uso de malhas icosaédricas, 
incluindo uma estruturação de dados com base em pontos, arestas, triângulos e polígonos, que permite um fácil acesso à informações locais e globais da malha. A estrutura foi desenvolvida de forma geral, podendo ser usado para qualquer malha geodésica formada por triângulos ou células de Voronoi. Além disso, há rotinas de busca de ponto em malha, diversos métodos de interpolações e métodos de visualização da malha ou campos escalares e vetoriais atribuídos a ela.

O avanço dos modelos atmosféricos usando malhas icosaédricas foi muito grande nesta última década, principalmente do ponto vista prático, mas alguns problemas mais teóricos ligados à discretização de certos operadores, e de interpolações, não estão bem resolvidos. Um primeiro problema interessante é a interferência de malha, também conhecido como grid imprinting (Weller et al. [2012]). Esse problema ocorre ao discretizarmos certos operadores diferenciais, ou realizarmos algumas interpolações, pois observamos um curioso padrão de malha na distribuição do erro. Esse tipo de problema pode gerar modos computacionais espúrios na solução numérica obtida para modelos atmosféricos, possivelmente gerando instabilidades. Esse padrão seguramente deve ter sido observado desde o princípio da modelagem com malhas icosaédricas, mas foi apenas em Tomita et al. [2001] que o problema foi descrito na literatura. A interferência de malha pode ser vista fortemente em uma discretização comum do divergente por um método de volumes finitos, na qual usa-se o Teorema da Divergência e a regra do ponto médio para integração nas arestas. No trabalho de Tomita et al. [2001] esse padrão é descrito para o divergente quando discretizado na malha de Voronoi formada por hexágonos e pentágonos. A origem do problema é atribuída a variações de distorções das células computacionais, mas não foi investigada em detalhes. Em Weller et al. [2012] o problema é apresentado para diversas malhas geodésicas, incluindo a icosaédrica. As malhas são comparadas no contexto de interferência de malha para as equações de água rasa e a malha icosaédrica, considerando as células hexagonais, é descrita como sendo a melhor do ponto de vista de minimizar modos computacionais. Porém, não foi descrita nenhuma análise sobre os motivos para ocorrência do grid imprinting, o que potencialmente poderia ajudar no desenvolvimento de métodos que inibam os seus efeitos danosos em modelos numéricos.

Em parte desta tese investigamos em detalhes os motivos da ocorrência de interferência de malha na discretização comumente adotada para o divergente. Percebemos que a distorção não é o fator preponderante na geração da interferência. Definimos o conceito de polígono alinhado, que no plano é um polígono com número par de arestas e lados opostos paralelos e com mesmo tamanho, e na esfera a definição é feita com auxílio de uma projeção no plano tangente. Mostramos que em células alinhadas a discretização do divergente é de segunda ordem. Porém, nas células que não são alinhadas, somente primeira ordem pode ser garantida. Com base em um índice de alinhamento da célula que propusemos, mostramos que a interferência de malha do divergente é justamente causada pela diferença de alinhamento das células, sendo que vemos em destaque erros maiores nas células mal alinhadas. As análises valem para qualquer malha geodésica e podem ser facilmente aplicadas para operadores diferenciais como o rotacional e laplaciano. Esses resultados foram publicados em Peixoto e Barros [2013].

Um outro problema relevante está ligado a interpolações escalares e vetoriais em malhas geodésicas. As interpolações dependem do esquema de posicionamento dos escalares e vetores na malha e também podem depender do método de discretização adotado para o modelo. Há diversas formas da posicionar os campos escalares e vetoriais em malhas icosaédricas. Uma forma interessante, que leva a uma melhor representação das ondas rápidas em modelos atmosféricos e reduz modos computacionais, é obtida com uma malha deslocada do tipo C de Arakawa para células de Voronoi (Nickovic et al. [2002], Thuburn et al. [2009]). Nesse tipo de malha os escalares são colocados nos nós (vértices dos triângulos) e as componentes normais dos vetores são guardados nos pontos médios das arestas das células de Voronoi. Esse tipo de malha traz desafios do ponto de vista de reconstrução do campo vetorial para pontos quaisquer da esfera, já que só conhecemos componentes do campo em pontos específicos. Investigamos diversos métodos de reconstruções vetoriais existentes, desde métodos de bases de elementos finitos a reconstruções polinomiais, métodos construídos no estilo de volumes finitos e de funções de bases radiais. Os métodos de funções de bases radiais vêm sendo usados na área de modelagem atmosférica em malhas geodésicas (Wan [2009], Bonaventura et al. 
[2011], Skamarock et al. [2012]), por garantirem boas aproximações com conjuntos de pontos pequenos e custo aceitável. Porém, esse tipo de método está sujeito a instabilidades numéricas em malhas muitos finas, tornando interessante o desenvolvimento de alternativas. Percebemos que o problema de interferência de malha também aparece no contexto de reconstruções vetoriais, assim, a teoria desenvolvida para o divergente pode ser facilmente estendida para alguns métodos de reconstruções vetoriais. Com base na teoria de alinhamento das células de Voronoi desenvolvida neste trabalho, propusemos um método de reconstrução híbrido, que usa um método de reconstrução de baixo custo e segunda ordem somente em células alinhadas e um método de custo mais elevado e segunda ordem nas células não alinhadas. Como as células não alinhadas são minoria na malha, isso nos fornece um método de baixo custo de segunda ordem.

Investigamos ainda diversos métodos de interpolações de variáveis escalares e destacamos as excelentes propriedades do sistema de coordenadas baricêntricas generalizadas (Gillette et al. [2012]) para interpolações em células poligonais em geral. As coordenadas baricêntricas garantem uma aproximação do polinômio interpolador de segunda ordem com baixo custo e podem ser usadas também na interpolação de vetores.

O transporte de substâncias na esfera pode ser modelado numericamente de diversas formas e se dividem basicamente em três categorias: os métodos lagrangianos, que acompanham as trajetórias das partículas, os eulerianos, os quais fixam uma malha e observam as variações das partículas com base nesta malha, e os semi-lagrangianos, que são um misto entre os anteriores. Em um método semi-lagrangiano são estimadas, com base em uma malha de referência, as trajetórias das partículas a cada passo de tempo, mas mantendo o referencial na malha. Os métodos semi-lagrangianos permitem passos de tempo maiores que os métodos eulerianos, porém, a um custo computacional maior, mas ainda menores que os métodos efetivamente lagrangianos. Esse custo adicional em relação aos métodos eulerianos pode ser diluído quando queremos na modelagem final obter o transporte de várias substâncias, ou dependendo da complexidade de outros modelos que estarão acoplados a esse transporte, por exemplo das forçantes. Os modelos de transporte que usam métodos semi-lagrangianos têm mostrado sua relevância na área de previsão numérica do tempo há algumas décadas. Hoje são usados em diversos modelos (Staniforth e Côté [1991]) e inclusive foram testados em malhas icosaédricas Majewski et al. [2002]. Atualmente, os modelos que usam malhas icosaédricas usam métodos eulerianos, geralmente com diferenças ou volumes finitos. Nota-se ainda que há um investimento crescente de alguns grupos em possíveis melhorias para os métodos de integração no tempo (Lipscomb e Ringler [2005], Miura [2007], Skamarock e Menchaca [2010a]), geralmente no sentido de obter um método monotônico e conservativo. Em Carfora [2007b] há um estudo simplificado a respeito de um método semi-lagrangiano para malha icosaédricas.

Um bom modelo semi-lagrangiano de transporte na esfera depende de diversos fatores, entre eles o cálculo da trajetória. Uma forma de cálculo de trajetória que vem sendo usado com sucesso em malhas do tipo latitude longitude é devido a Ritchie [1987]. Nessa abordagem a trajetória é calculada resolvendo-se uma equação não linear de forma iterativa, que pode ser feito com pouquíssimas iterações. A elaboração de um modelo de transporte semi-lagrangiano com essa abordagem é objeto de estudo do presente trabalho.

$\mathrm{Na}$ modelagem semi-lagrangiana de transporte são necessários bons métodos de interpolações escalares e vetoriais. Há dois momentos onde interpolações são necessárias: para o cálculo da trajetória, que envolve interpolações do campo de velocidades, e para estimar a quantidade da substância a ser transportada, que necessita de interpolação do campo escalar. Testamos os melhores métodos de reconstruções vetoriais investigados no modelo de transporte e percebemos que o método híbrido proposto neste estudo é adequado. Para a interpolação do campo escalar adotamos o método de Renka [1997], que garante uma função interpoladora globalmente $C^{1}$ e mostrou excelentes aproximações a custos aceitáveis. É possível tornar esse método monotônico impondo que o valor interpolado não ultrapasse o máximo dos valores usados na interpolação e nem seja menor que o mínimo.

Para um modelo de transporte de densidade (equação da continuidade) é preciso discretizar o operador divergente. Na literatura é comum o uso do método que considera a estimativa do 
divergente com base nos fluxos nos pontos médios das arestas descrito anteriormente. Mostramos que ao usar esse método o problema de interferência de malha é gerado a cada passo de tempo e também é transportado com o fluido. Ao final, observamos que a interferência de malha gera um ruído na solução numérica totalmente espúrio e não físico.

Como resultado final desta tese de doutoramento apresentamos um modelo semi-lagrangiano de transporte em malhas icosaédricas que incluem inclusive a possibilidade de conservação de massa global e monotonicidade. A conservação de massa adotada é uma correção a cada passo de tempo para garantir a conservação global.

\subsection{Objetivos}

O objetivo primário deste estudo é aprimorar as técnicas numéricas de resolução de equações diferenciais existentes para malhas esféricas geodésicas e o desenvolvimento de um modelo de transporte semi-lagrangiano para malhas geodésicas deslocadas.

\section{Objetivos específicos}

- Desenvolvimento de uma plataforma computacional para trabalhar com malhas geodésicas.

- Análise das propriedades das malhas geodésicas, com enfoque principal na icosaédrica.

- Análise da discretização do operador divergente em malhas geodésicas e do problema de interferência de malha na discretização pelo método do fluxo nos pontos médios das arestas.

- Análise de métodos de interpolações para malhas não estruturadas. Investigação de adequações e modificações, se necessário, para o problema na esfera geodésica icosaédrica.

- Desenvolvimento de um método de interpolação e reconstrução vetorial para malhas geodésicas deslocadas.

- Desenvolvimento de um modelo semi-lagrangiano de transporte para malhas geodésicas deslocadas.

\subsection{Organização da tese}

No capítulo 2 apresentamos uma revisão de literatura sobre as características das malhas numéricas para a esfera geradas a partir de um icosaédrico regular. Nesse capítulo vamos mostrar como construímos e estruturamos as malhas icosaédricas, bem como suas propriedades geométricas. Destacamos os três principais tipos de otimizações existentes na literatura para esse tipo de malha. Esse capítulo constitui-se basicamente de uma revisão de literatura que servirá de base para os demais.

No capítulo 3 descrevemos o método comumente usado na literatura de discretização do operador diferencial divergente. Em seguida apresentamos resultados teóricos, frutos deste trabalho, sobre algumas relações geométricas que interferem na ordem de discretização deste operador, além de testes numéricos exemplificando as propriedades teóricas discutidas. Nesse capítulo estão contidos os principais resultados recém publicados em Peixoto e Barros [2013].

No capítulo 4 fazemos uma revisão de métodos de interpolação adequados para malhas icosaédricas e discutimos diversas propriedades dos métodos, detalhando aquilo que será usado na modelagem do transporte. Ainda no capítulo 4, analisamos diversos métodos para resolver o problema de reconstrução de vetores definidos em arestas da malha. Com base nos métodos analisados, propomos um método de reconstrução vetorial híbrido, de baixo custo e segunda ordem.

No capítulo 5 é apresentado um método semi-lagrangiano para um modelo de transporte na esfera, construído com base nos métodos analisados nos capítulos anteriores. Para avaliar o método 
proposto realizamos diversos testes de transporte aonde ocorrem deformações do campo transportado.

Apesar do enfoque desta tese ser em malhas icosaédricas, muitos resultados apresentados aqui se estendem a malhas geodésicas em geral, tais como no caso da análise de interferência de malha realizada no capítulo 3 e do método de reconstrução híbrido proposto no capítulo 4.

Deixamos como apêndice algumas descrições de modelos atmosféricos que usam malhas icosaédricas (apêndice A). No apêndice B apresentamos algumas notações e propriedades das coordenadas esféricas e algumas ferramentas de geometria esférica pertinentes a malhas icosaédricas. Por fim, descrevemos em no apêndice D algumas considerações técnicas da plataforma computacional e softwares usados no desenvolvimento da tese. 


\section{Capítulo 2}

\section{Malhas esféricas geodésicas icosaédricas}

Neste capítulo vamos detalhar diversas características e propriedades das malhas esféricas geodésicas icosaédricas. Inicialmente vamos descrever a origem das malhas geodésicas icosaédricas e fazer comentários sobre outras malhas geodésicas, que não as icosaédricas, e em seguida entraremos em detalhes nas características das malhas icosaédricas. Detalharemos ainda as principais otimizações das malhas icosaédricas existentes.

Uma boa revisão sobre malhas para a esfera, com o foco na modelagem atmosférica, pode ser encontrada em Williamson [2007], ou em Washington et al. [2009]. Para malhas esféricas geodésicas de propósito geral vide Sahr et al. [2003].

\section{$2.1 \quad$ Origens}

Há diversas formas de discretizar a esfera. Historicamente são usadas discretizações em coordenadas geográficas (latitude e longitude). Esse tipo de coordenada gera naturalmente uma discretização para a esfera, em pontos de diferentes latitudes e longitudes, uniformemente espaçados. Na Figura 2.1 mostramos um exemplo de malha em coordenadas geográficas. Uma característica positiva desse tipo de malha é sua ortogonalidade, que facilita o desenvolvimento de métodos de interpolações e discretizações de equações diferenciais. Por outro lado, possui o problema de concentração de pontos próximos aos polos, conforme vemos na Figura 2.2. Com isso o tamanho das células computacionais e a distância entre dois pontos da malha ficam dependendo da latitude e temos uma malha anisotrópica. Para estudos ligados à dinâmica meteorológica essa propriedade é indesejada, pois as escalas dos fenômenos meteorológicos variam pouco com a latitude. Além disso, a convergência de pontos nos polos gera complicações computacionais, como limitações para obter esquemas numericamente estáveis. Existem diversas formas de contornar esse problema, tais como o uso de malhas reduzidas, o uso de filtros em algumas variáveis, ou adaptando o esquema numérico (Williamson [2007], Randall et al. [1998], Bates et al. [1990]). Apesar desses possíveis artifícios, o problema do polo pode levar a um mal aproveitamento dos recursos computacionais. Por exemplo, o uso de filtros para contornar o problema dos polos, conforme relatado por Randall et al. [1998], é um típico exemplo de resolução espacial excessiva que não usa eficientemente os recursos computacionais.

Com o aumento do poder computacional, e consequentemente o uso de malhas cada vez mais finas, o problema dos polos vem se tornando mais relevante. O principal desafio está no uso eficiente de processamento paralelo distribuído próximo aos polos, por conta de gargalos de comunicação entre os nós computacionais. Uma alternativa é uso de malhas mais uniformes, com células de tamanhos mais homogêneos. A decomposição da esfera em polígonos regulares é possível somente até 20 triângulos, com base no sólido platônico de maior número de faces, o icosaedro. Para modelagem numérica essa quantidade de células é muito pequena e portanto qualquer malha na esfera com mais de 20 polígonos terá irregularidades nos formatos das células. Apesar disso, os sólidos platônicos podem servir de base para o desenvolvimento de malhas quase uniformes. Um sólido platônico pode ser inscrito na esfera e suas faces podem ser projetadas na superfície, gerando uma malha base que por sua vez pode ser refinada até a resolução desejada. Na Figura 2.3 mostramos os 

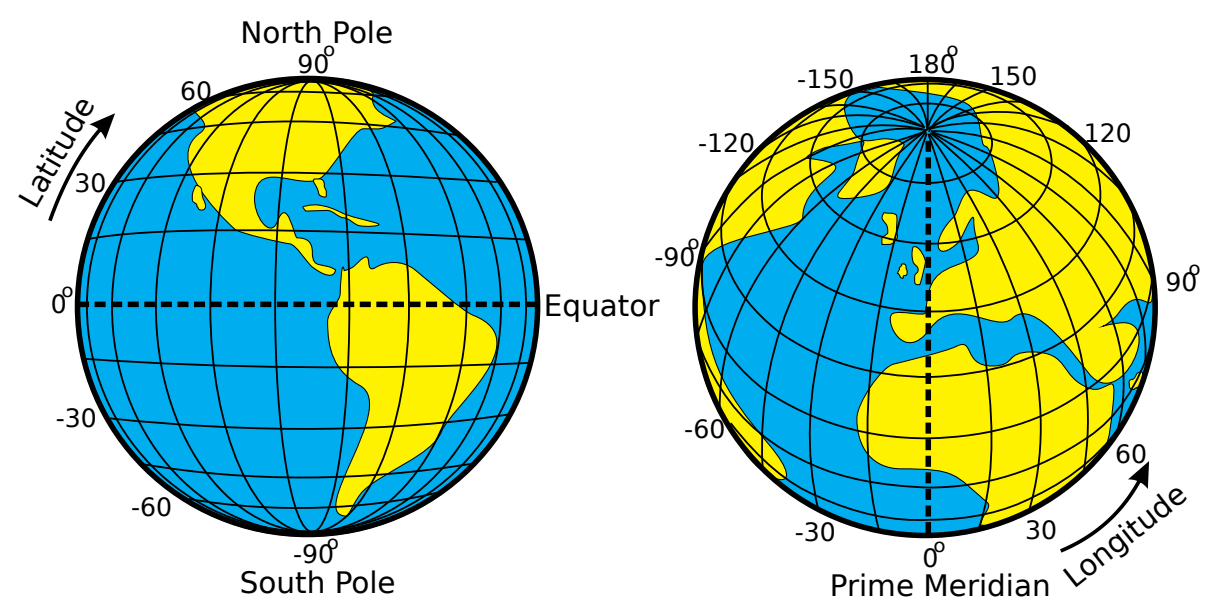

Figura 2.1: Caracterização de um mapa com uma malha em coordenadas geográficas, do tipo latitude longitude. Fonte: Wikipédia - Imagem de domínio público.

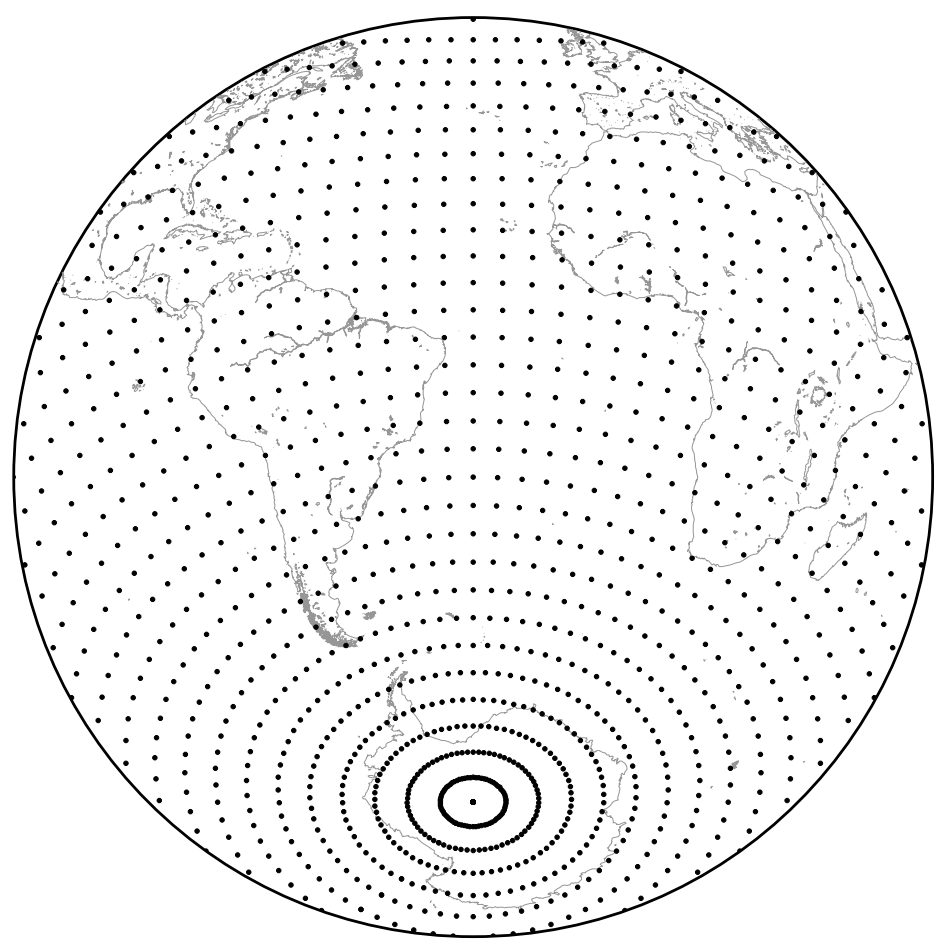

Figura 2.2: Concentração de pontos próximos aos polos em malhas que usam coordenadas esféricas do tipo latitude-longitude.

cinco sólidos platônicos e suas projeções para a esfera. Como geralmente são utilizadas projeções radiais, ou gnomônicas, as arestas do sólido platônico resultam em arestas geodésicas na esfera. Consequentemente esse tipo de malha é também denominada por malha geodésica para a esfera. Essa nomenclatura permite que qualquer conjunto de pontos na esfera seja denominado de geodésico, uma vez que a malha depende basicamente dos pontos e não das arestas. Porém, em geral, na literatura usa-se essa denominação para malhas geradas a partir de sólidos platônicos. Sua origem vem da forma geométrica conhecida por "domo geodésico", para o qual usa-se um icosaedro como base para construir uma esfera onde os triângulos são geodésicos (Sahr et al. [2003]). Nós adotaremos a denominação de esfera geodésica para nos referirmos à esfera discretizada a partir de sólidos platônicos e, mais adiante, quando isso não for trazer ambiguidade, essa notação irá se referir a esferas discretizadas a partir de um icosaedro.

Na discretização da esfera que usa um cubo como referência, também conhecida por esfera cu- 

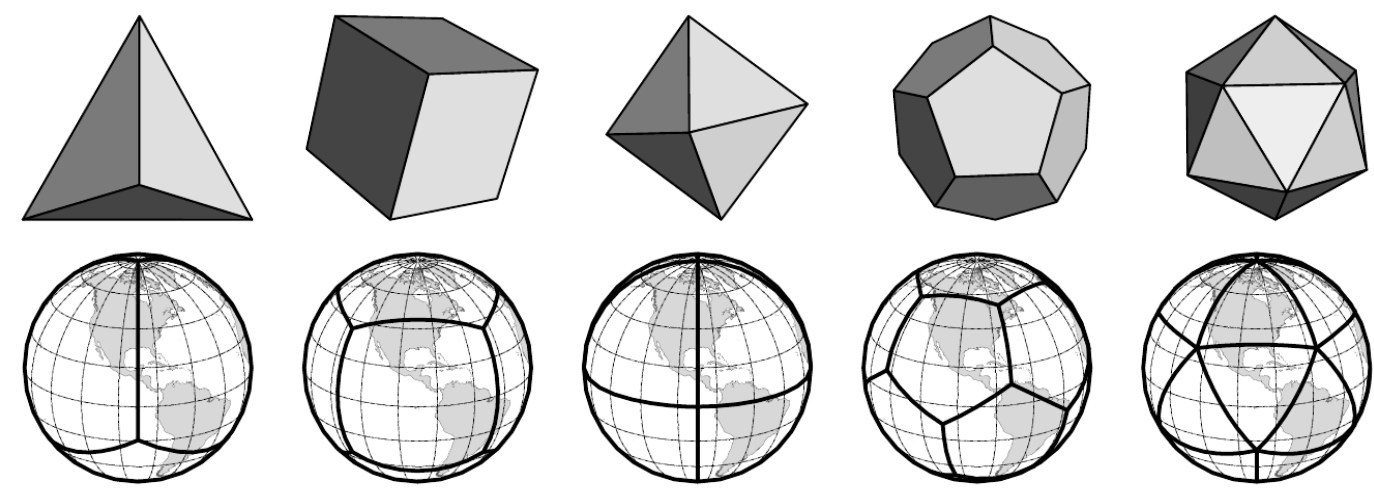

Figura 2.3: Visões planas e esféricas dos cinco sólidos platônicos: tetraedro, cubo, octaedro, dodecaedro, icosaedro. Adaptado de Gregory et al. [2008], com licença de reuso.

bada, repartimos cada quadrado esférico (projeções dos lados do cubo na esfera) uniformemente em novos retângulos esféricos para obter uma malha com espaçamento de grade adequado à representação da esfera. Apresentamos um exemplo de esfera cubada na Figura 2.4. Essa malha foi inicialmente proposta por Sadourny [1972] e re-inventada por Ronchi et al. [1996]. Atualmente vem sendo usada por alguns grupos de pesquisa na modelagem atmosférica (Chen e Xiao [2008], Nair et al. [2005], Ullrich e Jablonowski [2012]).

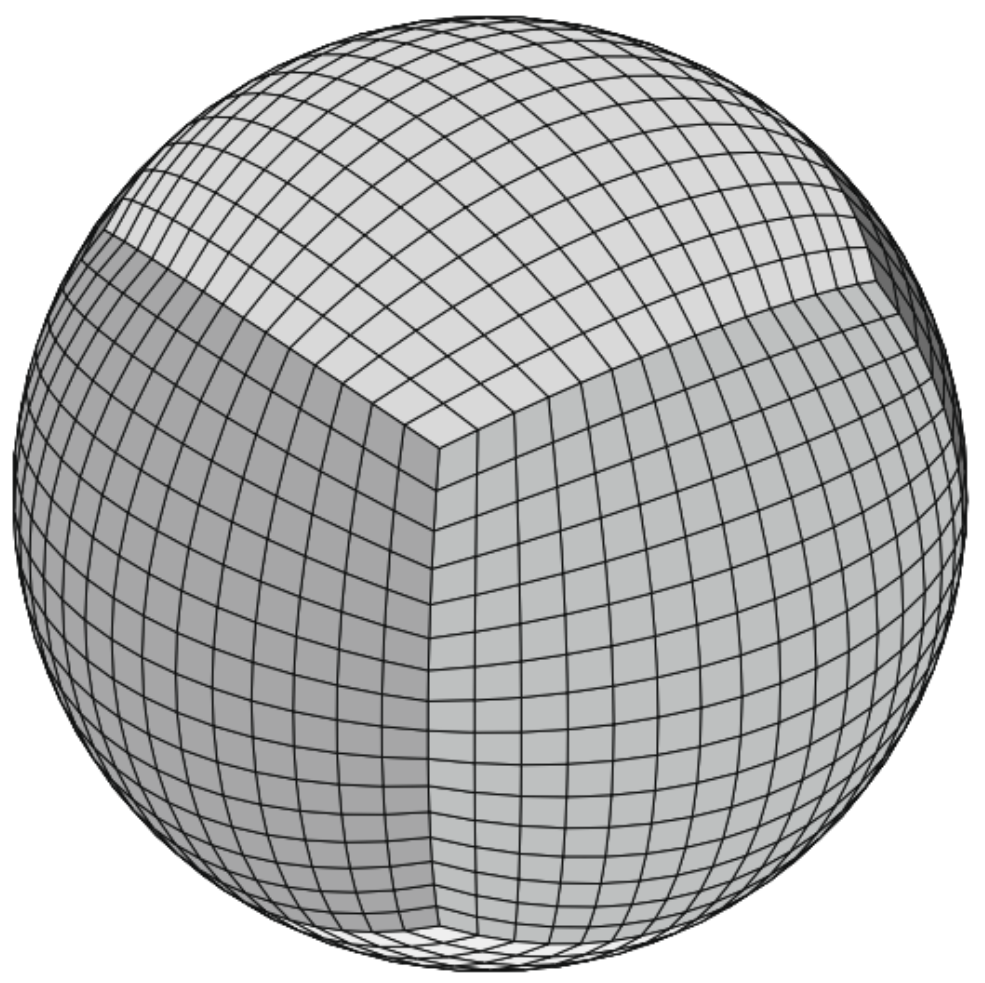

Figura 2.4: Discretização da esfera usando um cubo como sólido platônico básico. Fonte: Ullrich et al. [2010], com licença de reuso.

$\mathrm{Na}$ esfera cubada temos uma malha estruturada cujas faces podem ser descritas em termos de coordenadas locais. A resolução é quase uniforme e, por ser retangular, sua implementação é computacionalmente mais intuitiva. Nesse tipo de malha há uma deformação das células nas proximidades dos oito vértices do cubo. Possíveis aperfeiçoamentos deste tipo de malha existem e podem ser vistos em Rancic et al. [1996] ou em Putman e Lin [2007]. 
Dentre as malhas geodésicas para a esfera, certamente a que vem ganhando mais espaço dentro dos grupos de estudos de modelagem meteorológica é a do tipo icosaédrica. Inicialmente proposta por Sadourny et al. [1968] e Williamson [1968] para previsão numérica do tempo, a malha consiste numa triangulação da esfera partindo do icosaedro projetado na superfície da esfera. Esse tipo de malha ganhou mais espaço com os trabalhos de Baumgardner e Frederickson [1985], Ohnishi e Masuda [1986], Heikes e Randall [1995a], Giraldo [1997] e Thuburn [1997]. Atualmente ele é usado em diversos modelos de previsão de tempo, alguns já operacionais e outros em fase de pesquisa (Heikes e Randall [1995a], Majewski et al. [2002], Thuburn [1997], Tomita et al. [2008], Walko e Avissar [2008a], Williamson [2007]). No apêndice A fornecemos alguns detalhes de modelos que empregam malhas icosaédricas.

\subsection{Construção}

O posicionamento do icosaedro na esfera é arbitrário e há duas formas mais usadas. A primeira forma é obtida colocando-se dois vértices no equador e outro no meridiano de Greenwich. Com isso temos o icosaedro unicamente definido na esfera, cujos vértices, em coordenadas cartesianas do $\mathbb{R}^{3}$, são: $(0, b,-a),(b, a, 0),(-b, a, 0),(0, b, a),(0,-b, a),(-a, 0, b),(0,-b,-a),(a, 0,-b),(a, 0, b)$, $(-a, 0,-b),(b,-a, 0),(-b,-a, 0)$, onde

$$
\begin{aligned}
& a=\frac{1+\sqrt{5}}{\sqrt{10+2 \sqrt{5}}}, \\
& b=\frac{2}{\sqrt{10+2 \sqrt{5}}} .
\end{aligned}
$$

Na Figura 2.5 apresentamos a malha icosaédrica inicial, somente com os pontos dados pelos vértices do icosaedro. Esse posicionamento do icosaedro na esfera é simétrico em relação aos hemisférios.

Uma outra forma de posicionar o icosaedro na esfera é com um ponto em cada polo e os demais alinhados nas latitudes de $\pm \arctan (1 / 2)$ (Walko e Avissar [2008a]). Apresentamos essa forma de posicionamento na Figura 2.6. Apesar de gerar uma malha que não é simétrica em relação aos hemisférios norte e sul, esse é o tipo de posicionamento mais usado na literatura. Veja em Sahr et al. [2003] uma descrição completa dos tipos de malhas geodésicas e o posicionamento dos vértices do icosaedro na esfera.

O icosaedro é um sólido convexo que possui 12 vértices e 20 faces e 30 arestas, o que por ser verificado pela fórmula de Euler,

$$
\# \text { arestas }=\# \text { faces }+\# \text { vértices }-2 .
$$

As faces dos triângulos são projetadas radialmente (usando a projeção gnomônica), resultando em triângulos esféricos com arestas geodésicas.

A malha inicial pode ser refinada adicionando pontos nas arestas dos triângulos e depois conectando-os na malha. Isso pode ser feito de forma recursiva, incluindo pontos nos pontos médios das arestas geodésicas (Figura 2.7), ou não recursivamente, subdividindo-se uniformemente cada aresta de cada triângulo diretamente em $N$ partes (Figura 2.8). É claro que dependendo da escolha de $N$ as malhas podem ser equivalentes, por exemplo se $N=2^{m}$, onde $m=0,1,2, \ldots$ indica o nível de recursão. Neste trabalho adotamos uma malha icosaédrica do tipo recursiva. Mostramos na Figura 2.7 uma malha gerada com 642 pontos, com método recursivo e posicionamento sem pontos nos polos (simétrica com relação ao equador). Para o método recursivo, o número de pontos é calculado com base na equação $10 \cdot 2^{(2 m)}+2$. O nível de recursão é frequentemente denominado glevel-m, indicando um nível de malha (Miura e Kimoto [2005]). 


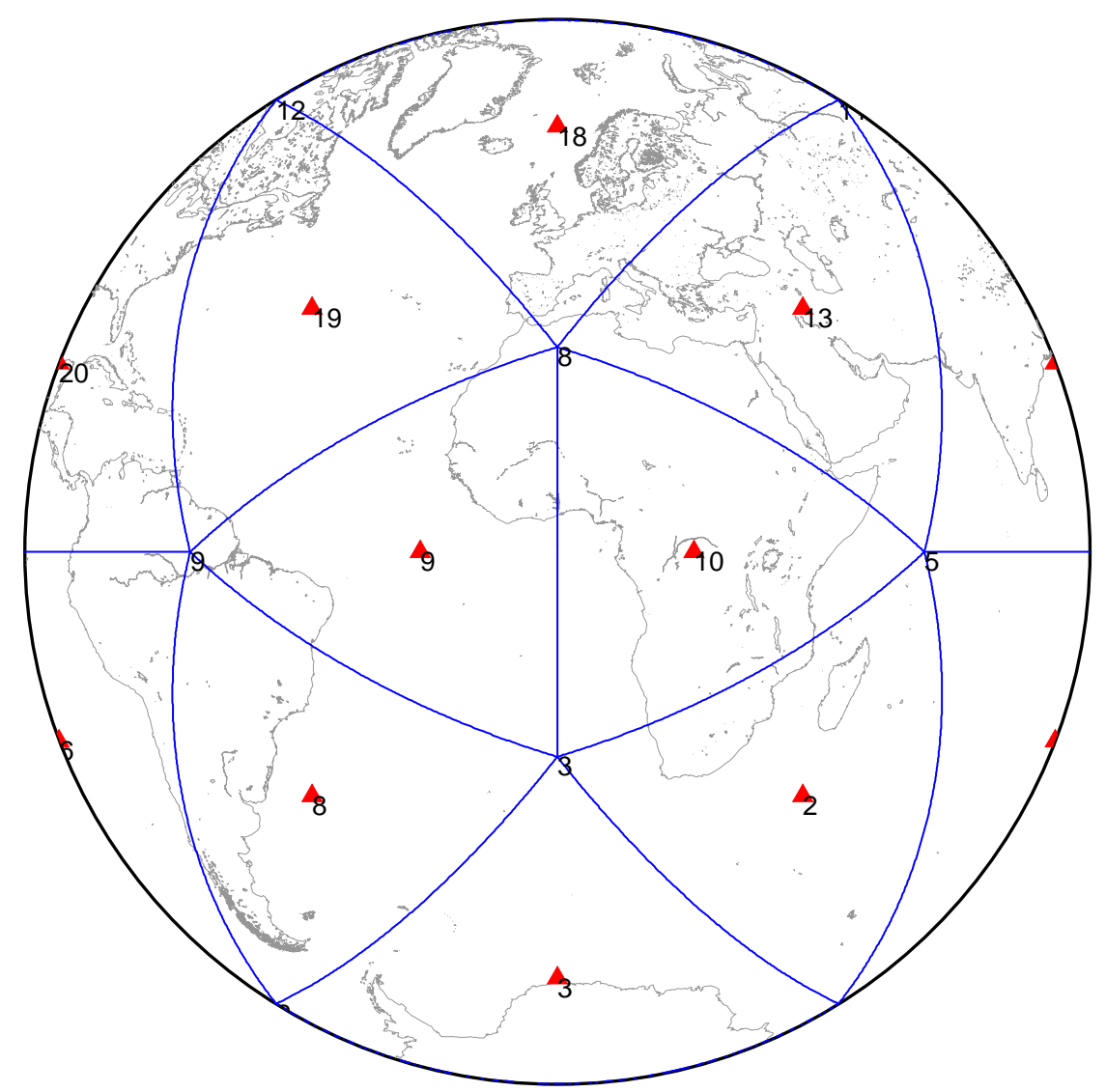

Figura 2.5: Icosaedro projetado na esfera. Os triângulos indicam os circuncentros dos triângulos formados por vértices de vértices do icosaedro. 


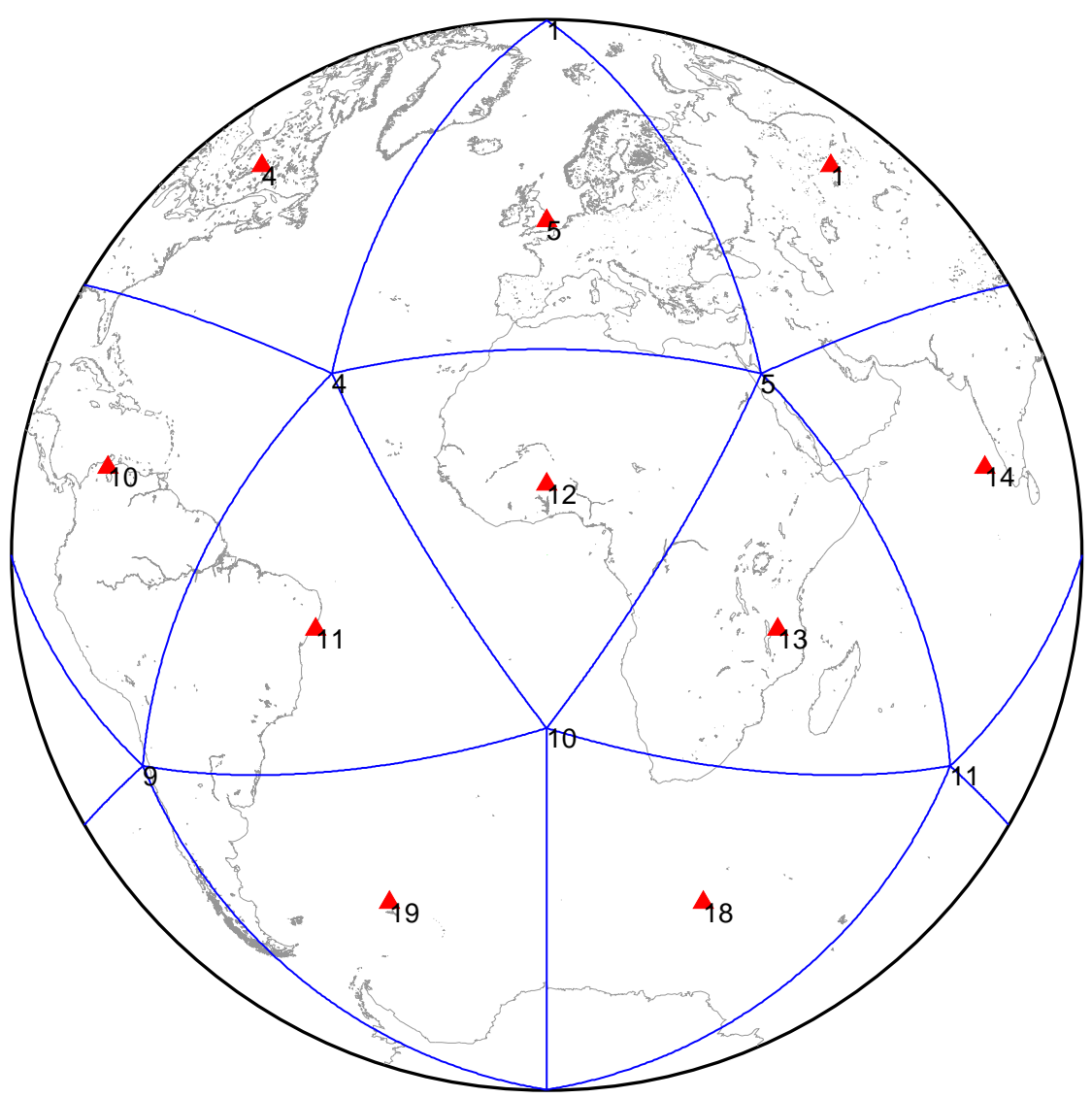

Figura 2.6: Icosaedro projetado na esfera com vértices posicionados com dois pontos nos polos e os demais nas latitudes $\pm \arctan (1 / 2)$. Os círculos indicam os vértices do icosaedro e os triângulos indicam os circuncentros dos triângulos formados por vértices de nós do icosaedro.

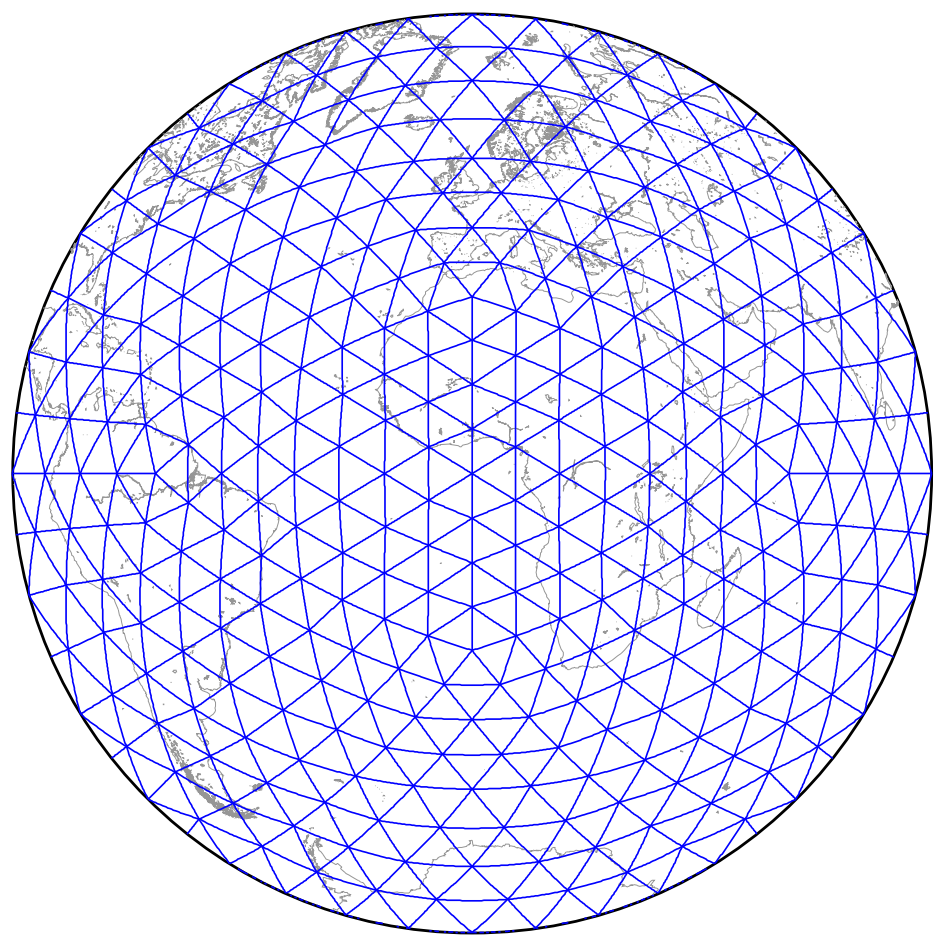

Figura 2.7: Malha icosaédrica de nível 3, com 642 nós, gerada recursivamente. 


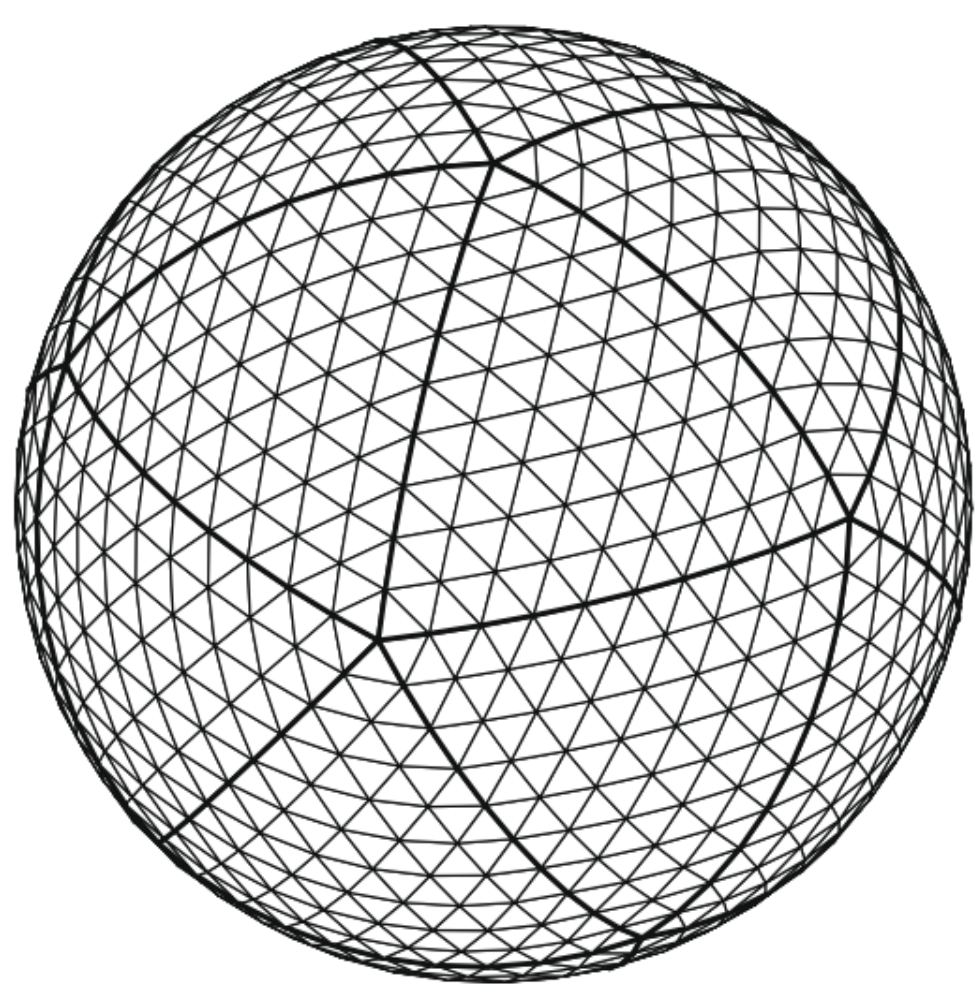

Figura 2.8: Malha icosaédrica com subdivisões não recursivas. Neste caso dividiu-se cada aresta em 10 pedaços. Fonte: Ii e Xiao [2010], com licença de reuso. 


\subsection{Definições}

A malha icosaédrica define um conjunto de triângulos esféricos, isto é uma triangulação. De forma geral, dadas as posições de pontos na esfera, uma triangulação da esfera é o conjunto de triângulos esféricos satisfazendo as seguintes propriedades:

(i) os vértices dos triângulos são nós;

(ii) nenhum triângulo contém outros vértices a não ser os seus próprios vértices;

(iii) os interiores dos triângulos são dois a dois disjuntos;

(iv) a união dos triângulos define a esfera toda.

Para um triângulo esférico definimos seu circuncentro como sendo um ponto da esfera equidistante em relação aos três vértices do triângulo. Deve-se considerar uma métrica condizente com a curvatura da esfera, como por exemplo medindo o ângulo entre pontos. Note que o circuncentro também pode ser visto como a projeção na esfera do ponto equidistante entre os vértices, no sentido euclidiano em $\mathbb{R}^{3}$. Para o caso da esfera, temos dois pontos que satisfazem essa condição e devemos considerar o ponto mais próximo dos vértices. Os três vértices definem uma circunferência, o circuncírculo.

Uma triangulação de Delaunay, ou de Thiessen, para a esfera é uma triangulação na qual o interior do circuncírculo de qualquer triângulo esférico não contém ponto de malha algum. A triangulação de Delaunay maximiza o menor de todos os ângulos dos triângulos, assim esse tipo de triangulação gera uma malha com os triângulos mais equiláteros possíveis. Além disso, dá boas bases para algoritmos de interpolação em malhas triangulares (Lawson [1984], Renka [1984]). A triangulação considerada a partir do icosaedro gerada por bipartições dos triângulos geodésicos constitui uma triangulação de Delaunay.

Apesar do algoritmo recursivo de geração da malha icosaédrica já fornecer uma triangulação de Delaunay, estaremos interessados mais adiante em malhas que são modificações das icosaédricas, aonde a definição da triangulação não é mais tão evidente. Por outro lado, a triangulação na esfera para pontos arbitrários envolve suas peculiaridades. Neste trabalho utilizamos o algoritmo desenvolvido por Renka [1997] e seu pacote STRIPACK para gerar triangulações de Delaunay na esfera.

As malhas icosaédricas geralmente partem de malhas triangulares, mas não necessariamente precisam usar os triângulos como células computacionais. Chamamos a malha triangular de Delaunay de malha primal e, associada a ela, podemos definir uma malha dual, formada a partir do seu diagrama de Voronoi.

Um diagrama de Voronoi para a esfera é uma decomposição de domínio determinado a partir de distâncias relativas a um conjunto de pontos na esfera $\left(\mathcal{S}^{2}\right)$. Dado um conjunto de pontos $\Pi=\left\{x_{i}, i=1, \ldots, N\right\}$ na esfera, definimos para cada ponto $x_{i}$ uma região de Voronoi $V_{i}$ caracterizada pela região em torno de $x_{i}$ tal que qualquer ponto desta região está mais perto de $x_{i}$ do que de qualquer outro ponto de $\Pi$, isto é,

$$
V_{i}=\left\{x \in \mathcal{S}^{2} \mid d\left(x, x_{i}\right)<d\left(x, x_{j}\right), j=1, \ldots, N, j \neq i\right\},
$$

onde $d(\cdot, \cdot)$ é uma métrica associada à distância geodésica entre pontos da esfera. Chamamos o conjunto $V_{\Pi}=\left\{V_{i}\right\}_{i=1, \ldots, N}$ de diagrama de Voronoi para a esfera associado ao conjunto de pontos de $\Pi$, também denominados por geradores.

Algumas propriedades de diagramas de Voronoi na esfera são:

(i) não intersecção, $V_{i} \bigcap V_{j}=\emptyset$, se $i \neq j$;

(ii) decomposição de domínio, $\bigcup_{i=1}^{N} \bar{V}_{i}=\mathcal{S}^{2}$, onde ${ }^{-}$indica o fecho do conjunto com a métrica $d(\cdot, \cdot)$ na esfera. 
Se usarmos os vértices da triangulação de Delaunay gerada a partir de bisseções do icosaedro na esfera como geradores, o diagrama de Voronoi gerado será formado por polígonos esféricos pentagonais ou hexagonais. No diagrama de Voronoi de malhas icosaédricas os 12 pontos originais do icosaedro formam regiões de Voronoi pentagonais, os demais pontos formam regiões hexagonais. Mostramos na Figura 2.9 exemplos de malhas icosaédricas e seus diagramas de Voronoi. Nessa figura é possível perceber que os hexágonos não são necessariamente regulares, assim como os triângulos da malha de Delaunay também não são necessariamente equiláteros.

Outro fato relevante é que os vértices dos hexágonos/pentágonos são geometricamente equivalentes aos circuncentros dos triângulos. Portanto a região de Voronoi pode ser facilmente construída conectando-se os circuncentros de 5 ou 6 triângulos que compartilhem um mesmo nó. Um bom texto sobre o uso de malhas de Voronoi para modelagem atmosférica é o trabalho de Ju et al. [2011].

0

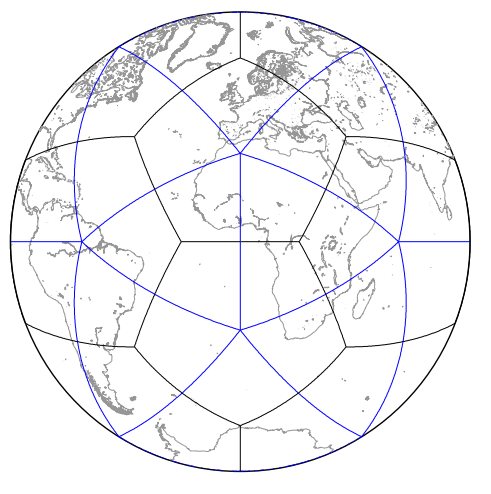

1

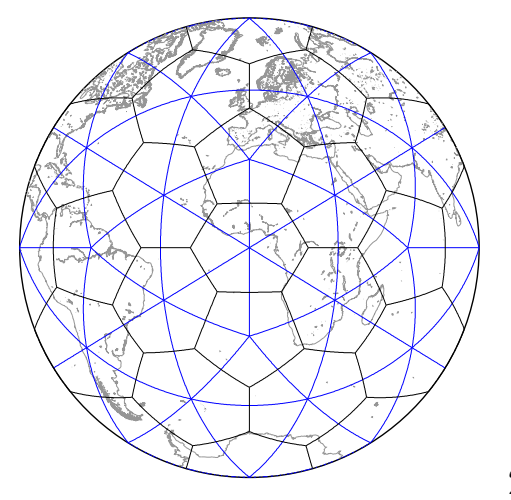

2

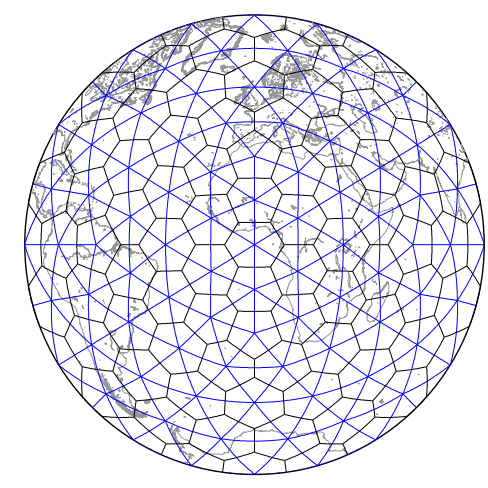

Figura 2.9: Diagrama de Voronoi para malhas icosaédricas de niveis 0, 1 e 2, respectivamente com 12, 42, 162 nós geradores. 


\subsection{Propriedades}

Vamos analisar as características das arestas, triângulos, pentágonos e hexágonos geodésicos gerados a partir de triangulações de Delaunay a partir do icosaedro e seus respectivos diagramas de Voronoi. Estamos buscando uma malha quase uniforme, então as características que vamos analisar irão servir de base para compreendermos a estrutura da malha.

\subsubsection{Comprimentos de arestas}

Começamos mostrando na Tabela 2.1 as relações de distâncias entre vértices dos triângulos (nós da malha) de diversos níveis de recursão para malhas icosaédricas. Isso é também uma medida de comprimento das arestas dos triângulos. A medida da razão entre a menor e maior distância dá uma ideia do grau de homogeneidade dos comprimentos das arestas dos triângulos. Percebe-se que as distâncias mínimas convergem para aproximadamente $83 \%$ das distâncias máximas nas malhas mais finas. Para o cálculo de distâncias utilizamos as equações descritas no apêndice B.

\begin{tabular}{|c|c|c|c|c|c|c|c|}
\hline \multicolumn{4}{|c|}{ Malhas Icosaédricas } & \multicolumn{3}{c|}{ Distância entre nós - graus (km) } \\
\hline Nível & Nós & Triângulos & Arestas & Mínima & Máxima & Média & Mín/Máx \\
\hline 0 & 12 & 20 & 30 & $63.43(7054)$ & $63.43(7054)$ & $63.43(7054)$ & 1.0000 \\
\hline 1 & 42 & 80 & 120 & $31.72(3527)$ & $36.00(4003)$ & $33.86(3765)$ & 0.8810 \\
\hline 2 & 162 & 320 & 480 & $15.86(1763)$ & $18.70(2079)$ & $17.22(1914)$ & 0.8481 \\
\hline 3 & 642 & 1280 & 1920 & $7.93(882)$ & $9.44(1050)$ & $8.64(961)$ & 0.8396 \\
\hline 4 & 2562 & 5120 & 7680 & $3.96(441)$ & $4.73(526)$ & $4.33(481)$ & 0.8375 \\
\hline 5 & 10242 & 20480 & 30720 & $1.98(220)$ & $2.37(263)$ & $2.16(241)$ & 0.8369 \\
\hline 6 & 40962 & 81920 & 122880 & $0.99(110)$ & $1.18(132)$ & $1.08(120)$ & 0.8368 \\
\hline 7 & 163842 & 327680 & 491520 & $0.50(55)$ & $0.59(66)$ & $0.54(60)$ & 0.8368 \\
\hline 8 & 655362 & 1310720 & 1966080 & $0.25(28)$ & $0.30(33)$ & $0.27(30)$ & 0.8367 \\
\hline
\end{tabular}

Tabela 2.1: Nivel de recursão, número de nós, triângulos e arestas para cada nível de recursão de malha icosaédrica. Nas colunas seguintes apresentamos as distâncias mínimas, máximas e médias entre os nós em graus e, entre parênteses, em quilômetros, para cada malha. Na última coluna apresentamos as razões entre as distâncias mínimas e máximas.

As distâncias entre os nós dos triângulos de malhas icosaédricas podem ser vistas como as distâncias geodésicas entre os centros das regiões de Voronoi (células hexagonais ou pentagonais), ou como os comprimentos das arestas dos triângulos. Outra medida de distância relevante é a distância entre os circuncentros dos triângulos. Essa medida é conveniente para indicar a distância entre células computacionais triangulares ou os comprimentos de arestas de regiões de Voronoi (hexágonos ou pentágonos esféricos). Naturalmente estas duas medições estarão correlacionadas. Na Tabela 2.2 mostramos as distâncias mínima, máxima e média entre os circuncentros dos triângulos em graus e quilômetros. Mostramos também a razão entre distância mínima e máxima, onde novamente temos convergência. Note que a menor distância converge para cerca de $52 \%$ da distância máxima. Isso indica que os vértices dos triângulos geram uma malha mais homogênea que os circuncentros dos triângulos. Portanto, do ponto de vista de uniformidade no espaçamento de pontos da malha, o uso dos vértices dos triângulos como referência parece ser mais adequado que o dos circuncentros dos triângulos. Por outro lado, ao usarmos células de Voronoi teremos que suas arestas, que são formadas por conexões entres os circuncentros dos triângulos, não terão comprimentos com distribuição tão uniforme quanto as arestas dos triângulos. 


\begin{tabular}{|c|c|c|c|c|}
\hline \multicolumn{5}{|c|}{ Distância entre circuncentros - graus (km) } \\
\hline Nível & Mínima & Máxima & Média & Mín/Máx \\
\hline 0 & $41.81(4649)$ & $41.81(4649)$ & $41.81(4649)$ & 1.0000 \\
\hline 1 & $18.03(2005)$ & $22.46(2497)$ & $20.24(2251)$ & 0.8028 \\
\hline 2 & $6.85(762)$ & $11.45(1273)$ & $10.03(1115)$ & 0.5988 \\
\hline 3 & $3.13(348)$ & $5.75(640)$ & $5.00(556)$ & 0.5441 \\
\hline 4 & $1.53(170)$ & $2.88(320)$ & $2.5(278)$ & 0.5303 \\
\hline 5 & $0.76(84)$ & $1.44(160)$ & $1.25(139)$ & 0.5269 \\
\hline 6 & $0.38(42)$ & $0.72(80)$ & $0.62(69)$ & 0.5260 \\
\hline 7 & $0.19(21)$ & $0.36(40)$ & $0.31(35)$ & 0.5258 \\
\hline 8 & $0.09(11)$ & $0.18(20)$ & $0.16(17)$ & 0.5257 \\
\hline
\end{tabular}

Tabela 2.2: Distâncias entre circuncentros dos triângulos esféricos para malhas icosaédricas para cada refinamento de malha icosaédrica. Apresentamos as distâncias mínimas, máximas e médias em graus e em quilômetros (entre parênteses). Na última coluna apresentamos as razões entre as distâncias minimas e máximas. 


\subsection{2 Áreas}

Na discretização de equações diferenciais na esfera geralmente o erro estará associado ao tamanho da célula computacional, logo uma medida relevante neste sentido é a área da célula. Na Tabela 2.3 mostramos as áreas mínimas, máximas e médias, além das razões entre as áreas mínimas e máximas, para malhas hexagonais/pentagonais geradas a partir do icosaedro. Verifica-se convergência da razão entre as áreas mínimas e máximas para 0.73 , indicando o grau de uniformidade das áreas das células na malha. Esse mesmo comportamento é observado na malha triangular também, já que pela construção das células de Voronoi, a área de uma célula hexagonal/pentagonal irá depender diretamente da área dos triângulos que a formam. Todas as áreas consideradas aqui são geodésicas, vide o apêndice B para detalhes de cálculos.

\begin{tabular}{|c|c|c|c|c|}
\hline \multicolumn{6}{|c|}{ Áreas das células de Voronoi } \\
\hline Nível & Mín & Máx & Média & Mín/Máx \\
\hline 0 & 1.047198 & 1.047198 & 1.047198 & 1.0000 \\
\hline 1 & 0.273844 & 0.309341 & 0.299199 & 0.8852 \\
\hline 2 & 0.069292 & 0.082271 & 0.077570 & 0.8422 \\
\hline 3 & 0.017376 & 0.022761 & 0.019574 & 0.7634 \\
\hline 4 & 0.004347 & 0.005861 & 0.004905 & 0.7417 \\
\hline 5 & 0.001087 & 0.001477 & 0.001227 & 0.7361 \\
\hline 6 & 0.000272 & 0.000370 & 0.000307 & 0.7347 \\
\hline 7 & 0.000068 & 0.000093 & 0.000077 & 0.7343 \\
\hline 8 & 0.000017 & 0.000023 & 0.000019 & 0.7342 \\
\hline
\end{tabular}

Tabela 2.3: Para cada refinamento de malha icosaédrica, apresentamos a área mínima, máxima e média, dos hexágonos ou pentágonos. Consideramos a esfera unitária.

Na Figura 2.10 mostramos a distribuição das áreas para malhas malhas hexagonais/pentagonais. Há uma concentração de células computacionais de áreas menores em torno dos 12 vértices iniciais do icosaedro, que são também os locais onde se formam os 12 pentágonos no caso das malhas de Voronoi. Para essa figura consideramos uma malha com 10242 nós (nível de malha 5) para que fosse possível ainda visualizarmos as células computacionais, mas o padrão se estende para malhas mais finas e também para malhas de triângulos. Para a normalização da medida de área, dividimos a área de cada célula pela maior delas. 


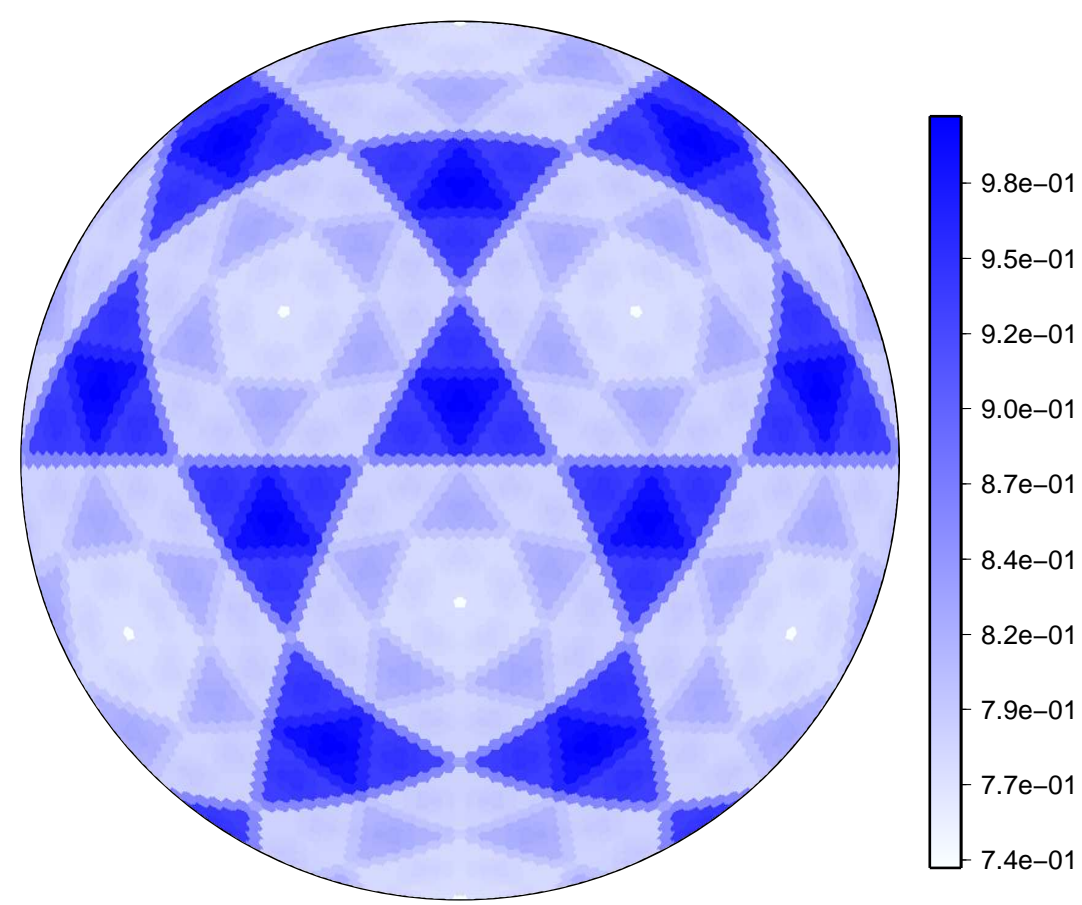

Figura 2.10: Distribuição das áreas dos hexágonos/pentágonos na esfera para uma malha com 10242 nós. As áreas foram normalizadas dividindo-as pela área máxima. 


\subsubsection{Distorções}

As distâncias entre os nós e as áreas provêm uma noção de homogeneidade dos tamanhos das células da malha, mas não dão informações sobre o formato das células computacionais. Para análise do formato das células as métricas mais comuns na literatura são aquelas que avaliam distorções. Há varias formas de se medir distorção e adotaremos uma medida semelhante à proposta em Tomita et al. [2001]. Considere uma célula computacional com $n$ arestas de comprimentos $l_{i}$, $i=1, \ldots, n$, então a distorção dessa célula será dada por

$$
S=\frac{\sqrt{\frac{1}{n} \sum_{i=1}^{n}\left(l_{i}-\bar{l}\right)^{2}}}{\bar{l}},
$$

onde estimamos o comprimento médio das arestas como $\bar{l}=\sqrt{\frac{1}{n} \sum_{i=1}^{n} l_{i}^{2}}$.

A distorção mede o quanto os comprimentos das arestas se afastam de seu valor médio. Uma célula regular não tem distorção. O ideal seria termos células computacionais próximas de regulares, com distorções mínimas. Na Tabela 2.4 mostramos os índices máximos e médios de distorções das células computacionais para malhas triangulares e hexagonais/pentagonais. Os índices de distorções mínimos para cada malha são nulos, pois em cada malha há sempre algumas células regulares. O grau de distorção parece estabilizar com o aumento do número de nós, convergindo em média para cerca de $8 \%$ de distorção nas células triangulares e 15\% para células de Voronoi. Isso indica que as células hexagonais/pentagonais são mais distorcidas que as triangulares.

Mostramos na Figura 2.11 a distribuição da distorção em uma malha icosaédrica com 10242 células hexagonais/pentagonais. As células mais distorcidas tendem a se concentrar próximas aos vértices do icosaedro original, ou seja, dos pentágonos. Isso ocorre também na malha formada por triângulos.

\begin{tabular}{|c|c|c|c|c|c|c|}
\hline Distorções & \multicolumn{3}{|c|}{ Triângulos } & \multicolumn{3}{c|}{ Hexágonos/Pentágonos } \\
\hline Nível & Máx & Média & Méd/Máx & Máx & Média & Méd/Máx \\
\hline 1 & 0.105496 & 0.079122 & 0.750000 & 0.106601 & 0.076144 & 0.714285 \\
\hline 2 & 0.128188 & 0.083643 & 0.652505 & 0.205656 & 0.119277 & 0.579985 \\
\hline 3 & 0.133632 & 0.083508 & 0.624907 & 0.245241 & 0.137627 & 0.561193 \\
\hline 4 & 0.134979 & 0.083379 & 0.617717 & 0.255423 & 0.146141 & 0.572155 \\
\hline 5 & 0.135315 & 0.083340 & 0.615896 & 0.257981 & 0.150248 & 0.582400 \\
\hline 6 & 0.135399 & 0.083330 & 0.615439 & 0.258622 & 0.152269 & 0.588771 \\
\hline 7 & 0.135420 & 0.083327 & 0.615324 & 0.258782 & 0.153272 & 0.592282 \\
\hline 8 & 0.135425 & 0.083327 & 0.615296 & 0.258822 & 0.153772 & 0.594122 \\
\hline
\end{tabular}

Tabela 2.4: Para cada refinamento de malha icosaédrica, apresentamos a distorção máxima, média e a razão entre elas para malhas formadas por triângulos e também malhas formadas por hexágonos ou pentágonos. 


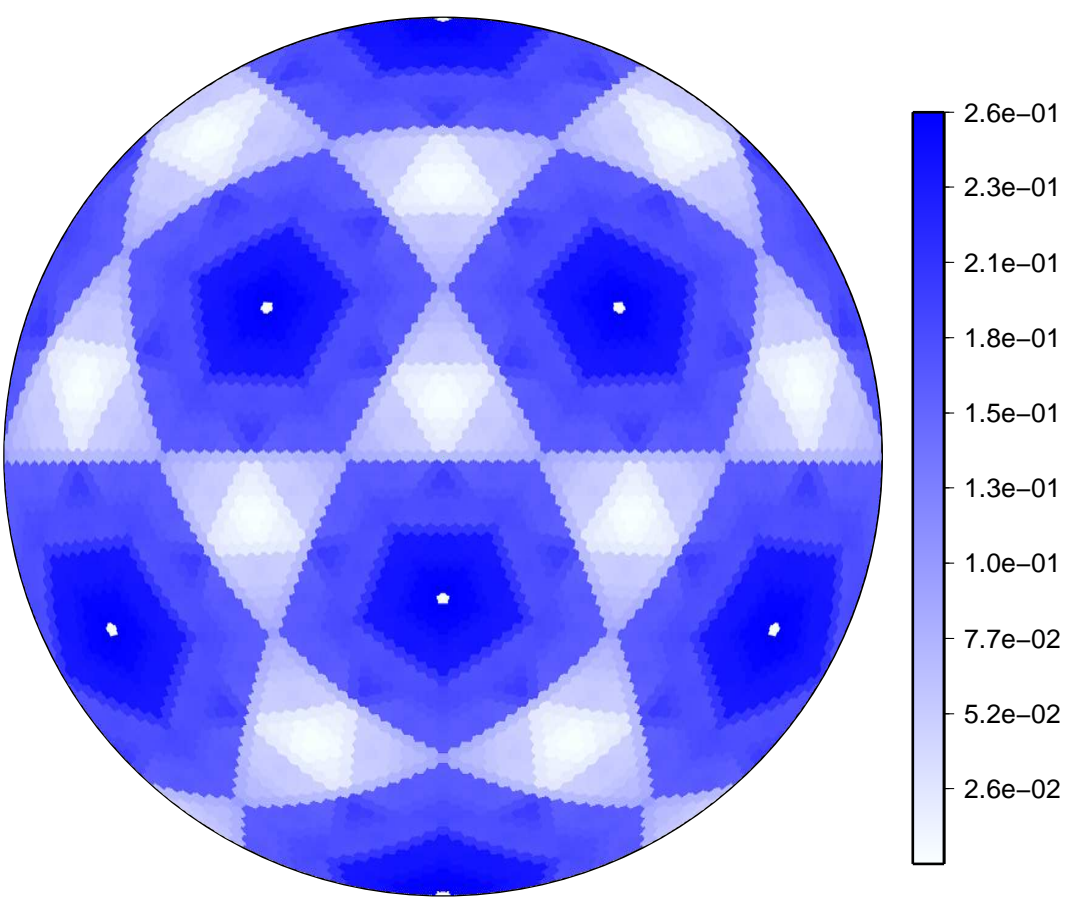

Figura 2.11: Distribuição das distorções dos hexágonos/pentágonos na esfera para uma malha com 10242 nós (nível 5). 


\subsubsection{Centros de massa}

Dado um triângulo esférico, vamos analisar a distância geodésica entre o centro de massa (baricentro) e o circuncentro. Essa também é uma medida de distorção do triângulo, pois um triângulo regular possui baricentro coincidente com o seu circuncentro. Para uma célula de Voronoi esférica definimos por centro geométrico o ponto gerador dessa, isto é, um vértice de um triângulo da malha de Delaunay. Esse ponto não necessariamente coincide com o seu centro de massa, assim é interessante analisarmos a distância geodésica entre o centro geométrico e o centro de massa do polígono.

O centro de massa usual em $\mathbb{R}^{3}$ de um polígono esférico $\Omega$ pode ser calculado como

$$
p^{*}=\int_{\Omega} p d \Omega
$$

que não estará na superfície da esfera, mas sim dentro dela. Gostaríamos de ter uma noção de centro de massa restrita a esfera, ou seja, com o centro de massa contido no interior do polígono esférico. Vamos considerar o conceito de centro de massa restrito, descrito em Du et al. [2003], que é válido para um conjunto amplo de variedades, mas que vamos adotar apenas para a esfera.

Definição 2.4.1 (Centro de massa esférico). Dado um polígono esférico $\Omega$, o centro de massa esférico $p^{s} \in \mathbb{R}^{3}$ é o ponto tal que $F\left(p^{s}\right) \leq F(q), \forall q \in \Omega$, onde

$$
F(p)=\int_{\Omega}\|p-q\|_{2}^{2} d \Omega(q) .
$$

e $\|\cdot\|_{2}$ é a norma euclidiana.

Caso o polígono seja plano, essa definição de $p^{s}$ coincide com $p^{*}$. Com base nessa definição, é mostrado em Du et al. [2003] que o centro de massa esférico pode ser obtido a partir do centro de massa geral em $\mathbb{R}^{3}$ como

$$
p^{s}=\frac{p^{*}}{\left\|p^{*}\right\|_{2}}
$$

onde supomos que a esfera está centrada na origem do sistema cartesiano, logo $p^{*} \neq 0$.

Com isso, mostra-se ainda que os centros de massa em $\mathbb{R}^{3}$ para triângulos esféricos podem ser calculados em coordenadas cartesianas como

$$
p^{s}=\frac{\frac{1}{3} \sum_{i=1}^{3} p_{i}}{\left\|\frac{1}{3} \sum_{i=1}^{3} p_{i}\right\|_{2}},
$$

onde consideramos os vértices do triângulo definidos pelos pontos $p_{i} \in \mathcal{S}^{2}$, com $i=1,2,3$.

Para polígonos esféricos convexos, como os hexágonos e pentágonos, podemos obter o centro de massa dividindo-os em triângulos (vide Miura e Kimoto [2005]). Considere um polígono esférico convexo de $m$ lados formado pelos pontos $q_{i}, i=1, \ldots, m$, dados no sentido anti-horário. Seja $p$ um ponto no seu interior. Considere o triângulo esférico $T_{i}$ formado pelos pontos $\left\{p, q_{i}, q_{i+1}\right\}$. Então o seu centro de massa esférico será dado por

$$
p^{s}=\frac{\sum_{i=1}^{m} T_{i}\left(p+q_{i}+q_{i+1}\right)}{\left\|\sum_{i=1}^{m} T_{i}\left(p+q_{i}+q_{i+1}\right)\right\|_{2}},
$$

onde assumimos que $q_{m+1}=q_{1}$ e $T_{i}$ é a área do triângulo esférico formado por $\left\{p, q_{i}, q_{i+1}\right\}$. No caso de malhas de Voronoi os pontos $q_{i}$ serão os circuncentros dos triângulos de Delaunay e o ponto $p$ será um ponto da malha triangular (vértice de um triângulo). No que segue, ao nos referirmos ao centro de massa, vamos estar nos referindo sempre ao centro de massa esférico.

$\mathrm{Na}$ Tabela 2.5 mostramos as relações entre os centros de massa (esféricos) e os centros geométricos (no caso de células de Voronoi) ou circuncentros (no caso de triângulos). Para as malhas hexagonais/pentagonais, percebe-se que o máximo das distâncias cai por um fator de ordem 2 , já a 
média cai com um fator de ordem maior. Isso evidencia nesse caso que as distâncias entre os nós e o centros de massa das células são reduzidas de formas diferentes entre as células ao refinar a malha.

\begin{tabular}{|c|c|c|c|c|c|c|}
\hline Centro de Massa & \multicolumn{3}{|c|}{ Triângulos } & \multicolumn{3}{c|}{ Voronoi } \\
\hline Nível & Máxima & Média & Med/Máx & Máxima & Média & Med/Máx \\
\hline 0 & $4.21 \mathrm{E}-08$ & $1.30 \mathrm{E}-08$ & 1.000000 & $2.98 \mathrm{E}-08$ & $9.51 \mathrm{E}-09$ & 1.000000 \\
\hline 1 & $3.26 \mathrm{E}-02$ & $2.45 \mathrm{E}-02$ & 0.750000 & $2.98 \mathrm{E}-08$ & $6.35 \mathrm{E}-09$ & 0.213107 \\
\hline 2 & $2.04 \mathrm{E}-02$ & $1.29 \mathrm{E}-02$ & 0.633291 & $1.11 \mathrm{E}-02$ & $5.43 \mathrm{E}-03$ & 0.488322 \\
\hline 3 & $1.07 \mathrm{E}-02$ & $6.46 \mathrm{E}-03$ & 0.602463 & $5.56 \mathrm{E}-03$ & $2.55 \mathrm{E}-03$ & 0.458683 \\
\hline 4 & $5.42 \mathrm{E}-03$ & $3.22 \mathrm{E}-03$ & 0.594578 & $2.78 \mathrm{E}-03$ & $8.53 \mathrm{E}-04$ & 0.306480 \\
\hline 5 & $2.72 \mathrm{E}-03$ & $1.61 \mathrm{E}-03$ & 0.592590 & $1.39 \mathrm{E}-03$ & $2.48 \mathrm{E}-04$ & 0.178465 \\
\hline 6 & $1.36 \mathrm{E}-03$ & $8.06 \mathrm{E}-04$ & 0.592091 & $6.96 \mathrm{E}-04$ & $6.75 \mathrm{E}-05$ & 0.097037 \\
\hline 7 & $6.81 \mathrm{E}-04$ & $4.03 \mathrm{E}-04$ & 0.591967 & $3.48 \mathrm{E}-04$ & $1.77 \mathrm{E}-05$ & 0.050847 \\
\hline 8 & $3.40 \mathrm{E}-04$ & $2.01 \mathrm{E}-04$ & 0.591935 & $1.74 \mathrm{E}-04$ & $4.54 \mathrm{E}-06$ & 0.026099 \\
\hline
\end{tabular}

Tabela 2.5: Máximo, média e razão média/máximo das distâncias (em radianos) entre os centros de massas e os centros geométricos.

Nas figuras 2.12 e 2.13 mostramos as distribuições das distâncias entre os centros de massa e os centros geométricos respectivamente para uma malha triangular e uma malha hexagonal/pentagonal com 10242 nós geradores. No caso da malha triangular nota-se o mesmo observado no estudo de distorções anterior, que as regiões em torno dos vértices originados do icosaedro primário tendem a ter triângulos menos equiláteros, ou seja, com mais distorções. Na malha hexagonal/pentagonal percebem-se maiores distâncias entre centros de massa e centros geométricos em todo um conjunto de arestas pertencentes às malhas mais grossas. Ficam em destaque os hexágonos que coincidem com arestas das malhas de níveis 0 e 1. Vamos analisar o motivo disso a seguir.

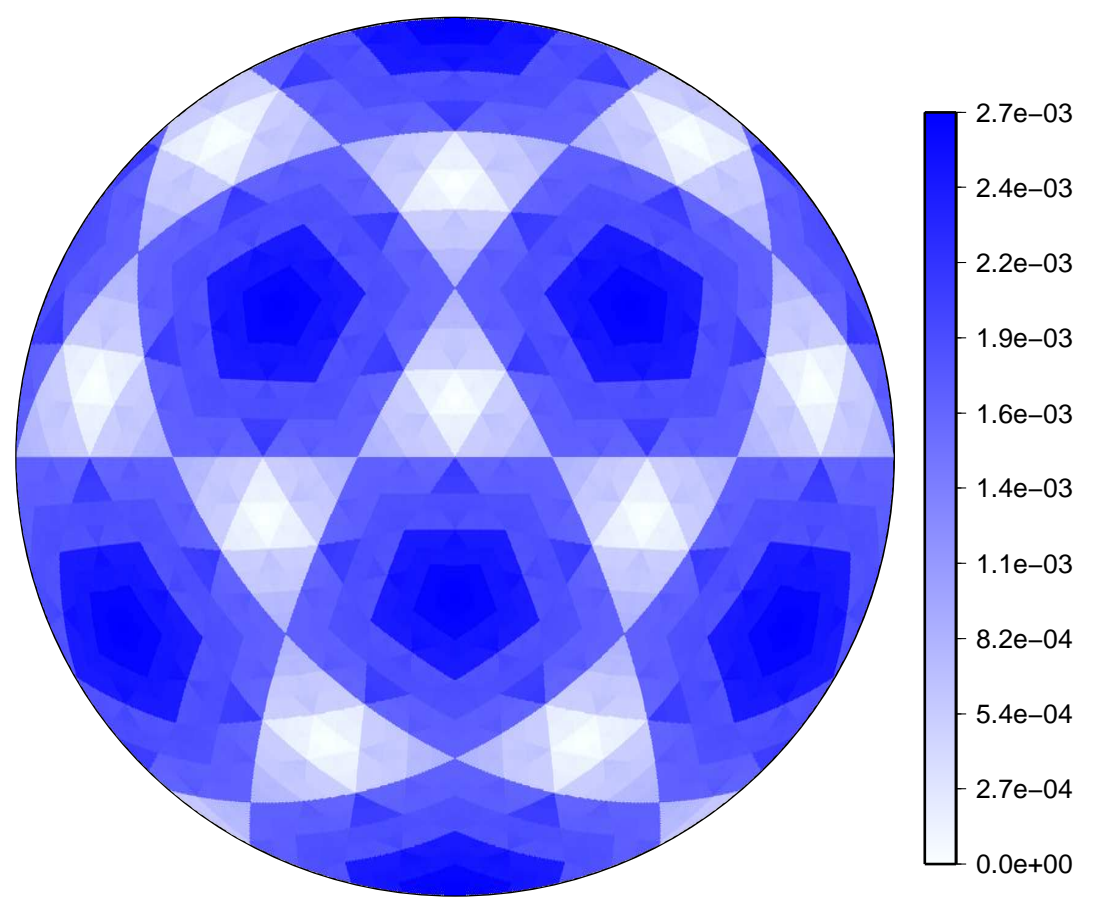

Figura 2.12: Distribuição das distâncias entre circuncentros e centros de massa de triângulos na esfera para uma malha icosaédrica de nível 5 (10242 nós). Distâncias geodésicas em radianos.

Considere a malha originada pelo icosaedro primário, com 12 nós. Nessa malha há uma subdivisão da esfera em 20 regiões triangulares, como visto anteriormente e ilustrado na Figura 2.6. 


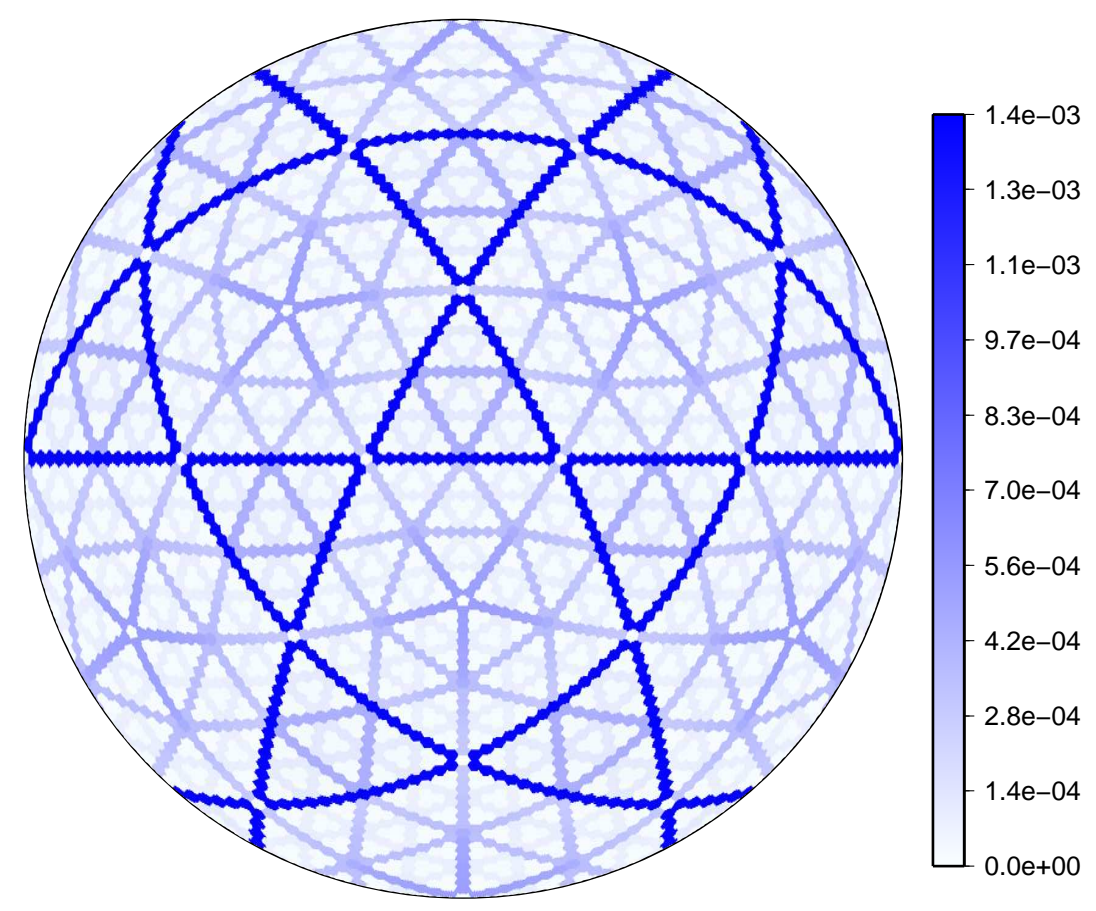

Figura 2.13: Distribuição das distâncias entre centros de massa e os pontos geradores de hexágonos ou pentágonos na esfera para uma malha icosaédrica de nível 5 (10242 nós). Distâncias geodésicas em radianos.

Ao realizarmos as subdivisões sucessivas de cada um desses triângulos iremos gerar novas regiões triangulares. Os hexágonos formados dentro de cada nova região tendem a ficar mais regulares, já aqueles que são formados em regiões de interface ficam menos regulares. Isso ocorre pois os novos triângulos gerados em sub-regiões triangulares têm um melhor alinhamento das suas arestas. Na Figura 2.14 ilustramos esse fato, onde nota-se que ao cruzar de uma sub-região para outra há um desalinhamento na configuração dos triângulos. O hexágono na parte de cima, em vermelho, está entre sub-regiões do icosaedro primário e, portanto, tende a ser mais irregular. O círculo preenchido em laranja ilustra seu centro de massa aproximado e vemos que este dista levemente do centro geométrico. O hexágono na parte inferior, em verde, está completamente dentro de uma sub-região do icosaedro primário. Porém, ele está em uma região de transição entre duas outras sub-regiões do icosaedro de nível 1, isto é, está em uma aresta da malha com 42 nós. Como a transição de regiões nesse caso é mais suave, o seu centro de massa está praticamente junto do centro geométrico, por isso foi representado como um único círculo verde. Essa é uma representação apenas ilustrativa, em proporções aumentadas, do que ocorre na esfera. Na Figura 2.15 mostramos essa situação em perspectiva esférica. Percebe-se que os hexágonos formados na borda do triângulo maior em verde, originado do icosaedro primário, tendem a serem mais desalinhados e, assim, possuem centro de massa mais afastado do centro geométrico. Mais adiante vamos analisar a questão de alinhamento das células computacionais com mais detalhes. 


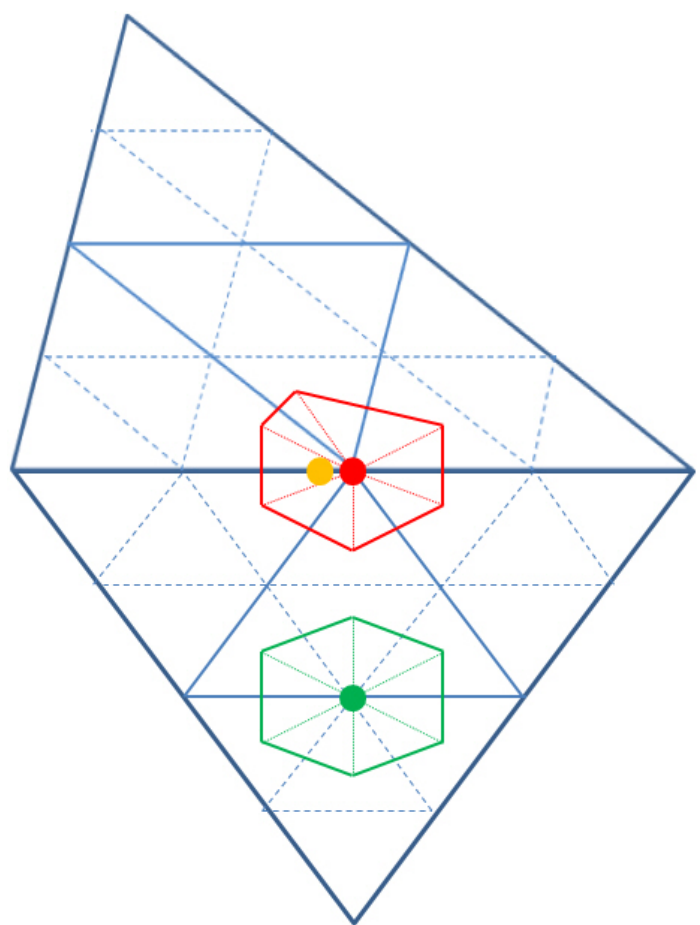

Figura 2.14: Alinhamento entre triângulos e hexágonos no plano. Hexágono central, em vermelho, está entre sub-regiões originadas do icosaedro primário. O círculo preenchido em laranja ilustra seu centro de massa aproximado. O hexágono na parte inferior, em verde, está completamente dentro de uma sub-região do icosaedro primário e seu centro de massa coincide com o centro geométrico.

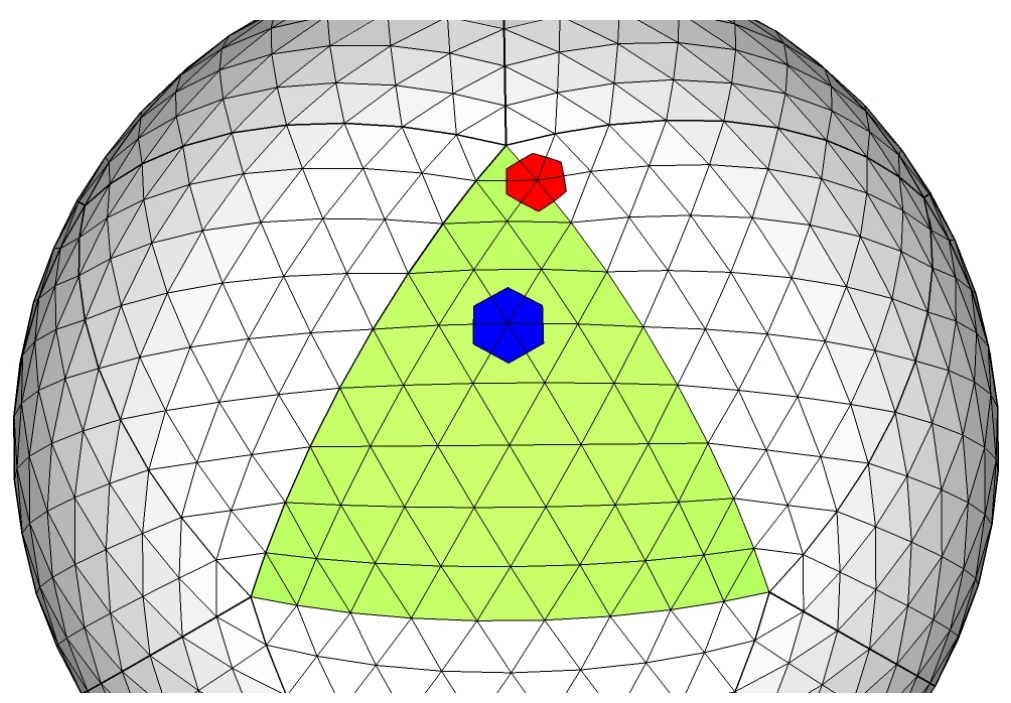

Figura 2.15: Alinhamento entre triângulos e hexágonos representado em perspectiva. O hexágono na parte superior, em vermelho, está entre sub-regiões originadas do icosaedro primário. O hexágono na parte inferior, em azul, está completamente dentro de uma sub-região do icosaedro primário. 


\subsubsection{Relação entre arestas da malha primal e dual}

O ponto de interseç̧ão das arestas de Voronoi e dos triângulos não necessariamente resultam no ponto médio da aresta de Voronoi. Vemos esse fato na Figura 2.16, onde mostramos os pontos médios das arestas das duas malhas, primal e dual. Essa característica de malha pode ser um agravante na discretização de alguns operadores diferenciais, em particular o laplaciano (Heikes e Randall [1995a]). Uma medida para avaliar essa propriedade na malha é considerar a distância entre os pontos médios das arestas, dividida pelo respectivo comprimento da aresta da célula de Voronoi. Na Tabela 2.6 mostramos estatísticas dessa métrica, onde percebe-se que as distâncias normalizadas máximas não são reduzidas com o refinamento da malha. Por outro lado, note que a média dessa métrica cai com o refinamento da malha, indicando que essa propriedade reage de forma diferente em diferentes locais da malha com o refinamento. Na Figura 2.17 vemos que as células com maiores distâncias entre pontos médios de arestas primais e duais estão em regiões onde originalmente se encontravam arestas das malhas mais grossas. Vimos que as regiões oriundas de arestas de malhas mais grossas apresentam a propriedade de terem centro de massa mais distante do nó, agora temos que elas também não possuem uma boa relação entre as arestas primais e duais, portanto, mais adiante nos dedicaremos a entender o que ocorre com essas células no contexto de resolução numérica de equações diferenciais.

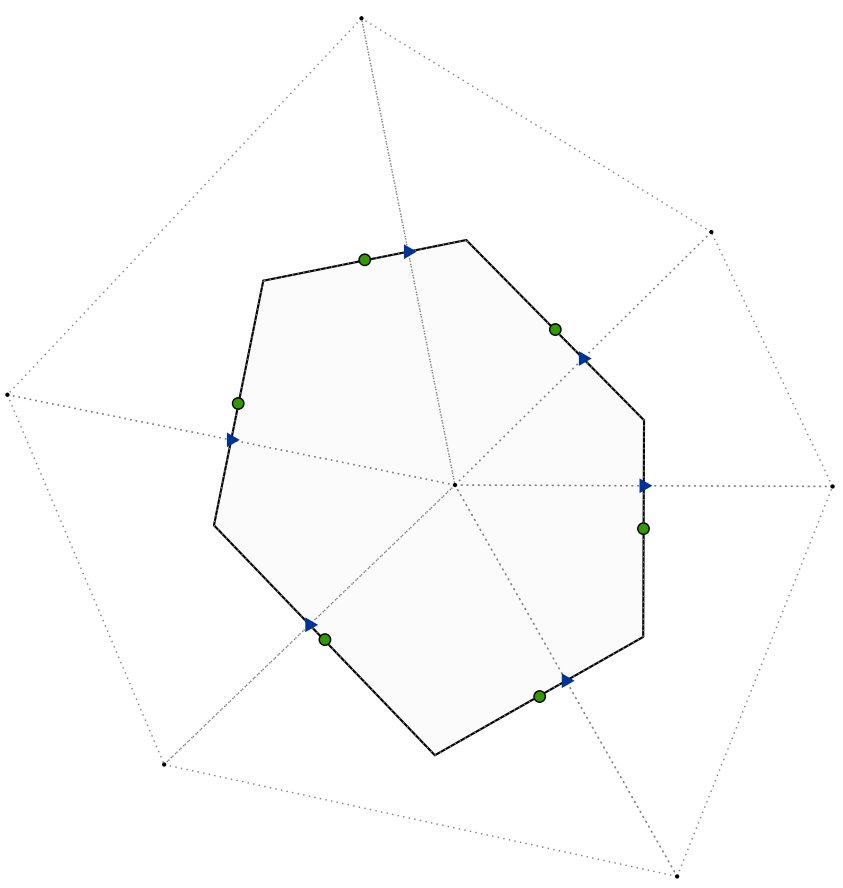

Figura 2.16: Pontos médios de arestas da malha de Delaunay (destacados em triângulos azuis) e pontos médios das arestas das células de Voronoi (destacados com círculos verdes). 


\begin{tabular}{|c|c|c|c|}
\hline \multicolumn{5}{|c|}{ Distâncias entre arestas primal e dual } \\
\hline Nível & Máx & Média & Mín/Máx \\
\hline 1 & $9.97 \mathrm{E}-02$ & $7.12 \mathrm{E}-02$ & 0.714286 \\
\hline 2 & $9.74 \mathrm{E}-02$ & $6.78 \mathrm{E}-02$ & 0.695515 \\
\hline 3 & $9.69 \mathrm{E}-02$ & $4.61 \mathrm{E}-02$ & 0.475848 \\
\hline 4 & $9.68 \mathrm{E}-02$ & $2.77 \mathrm{E}-02$ & 0.286261 \\
\hline 5 & $9.67 \mathrm{E}-02$ & $1.55 \mathrm{E}-02$ & 0.160061 \\
\hline 6 & $9.67 \mathrm{E}-02$ & $8.28 \mathrm{E}-03$ & 0.085578 \\
\hline 7 & $9.67 \mathrm{E}-02$ & $4.31 \mathrm{E}-03$ & 0.044518 \\
\hline 8 & $9.67 \mathrm{E}-02$ & $2.20 \mathrm{E}-03$ & 0.022781 \\
\hline
\end{tabular}

Tabela 2.6: Distâncias máximas e médias entre os pontos médios das arestas da malha triangular e de Voronoi normalizadas pelos respectivos comprimentos das arestas das células de Voronoi.

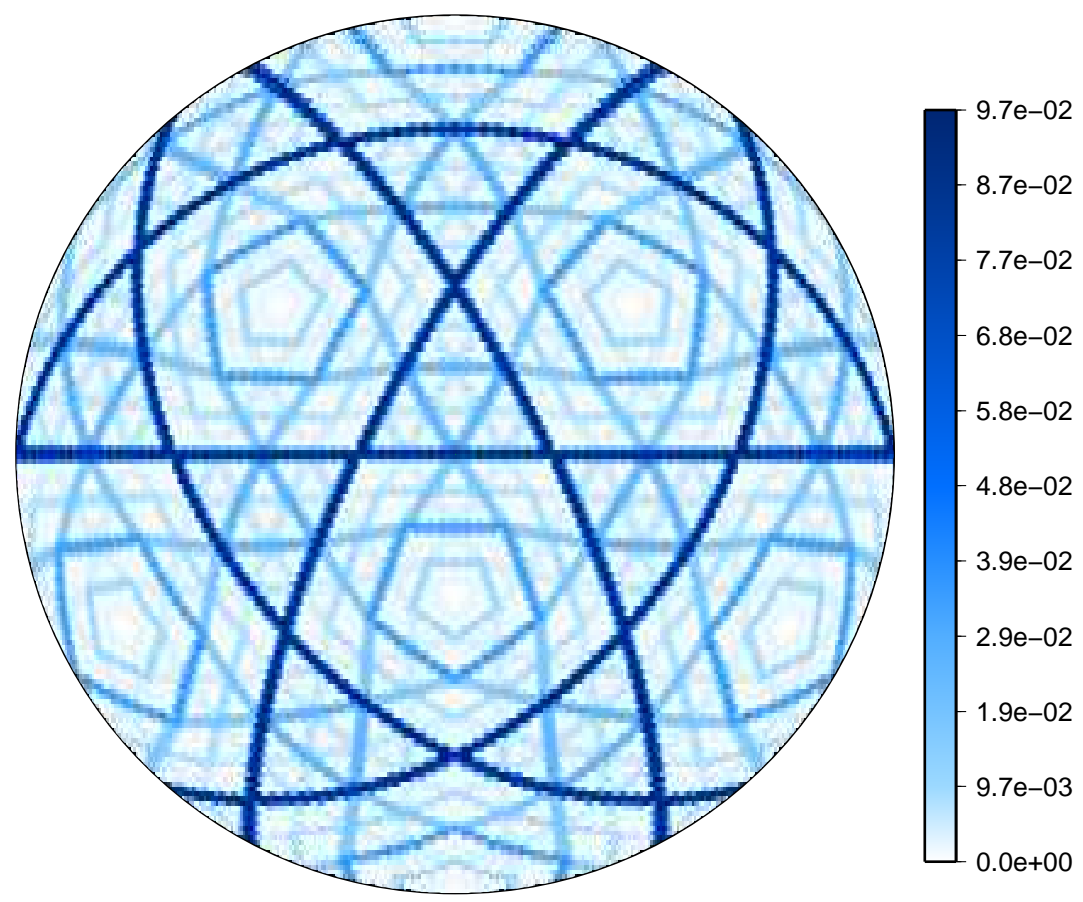

Figura 2.17: Distribuição das distâncias entre os pontos médios das arestas dos triângulos e os pontos médios das arestas das células de Voronoi normalizadas pelos respectivos comprimentos das arestas das células de Voronoi. Para cada célula de Voronoi apresentamos o máximo da distância entre arestas dessa célula. Foi usada uma malha icosaédrica de nível 5 (10242 nós). 


\subsection{Posicionamento de campos}

Há diversas formas de posicionar os campos escalares e vetoriais em malhas icosaédricas. Nesta seção vamos descrever as existentes e algumas outras variações possíveis. Mais adiante, vamos analisar seus comportamentos.

Em malhas icosaédricas há dois tipos de células computacionais que são interessantes: a triangular, que é gerada pela triangulação de Delaunay, e a hexagonal/pentagonal, que é gerada pela construção do dual da malha, conhecida coma malha de Voronoi. Denotaremos as malhas triangulares com o prefixo " $\mathrm{T}$ "e as hexagonais/pentagonais com o prefixo " $\mathrm{H}$ ".

Dada uma célula numérica, podemos associar tipos de colocação dos campos na malha de forma análoga ao que é feito em malhas retangulares, usando a classificação de Arakawa de A até E (Mesinger e Arakawa [1976]). Destacamos de forma genérica as principais diferenças entre elas a seguir.

- Tipo A : Escalares e vetores nos centros da célula. Como tanto escalares como vetores ficam na mesma posição, esse tipo de malha é chamada de colocada.

- Tipo B : Escalares nos centros das células e vetores nos cantos das células. Como escalares e vetores ficam em posições distintas, esse tipo de malha é descrita como deslocada.

- Tipo C : Escalares nos centros das células e vetores perpendiculares as arestas/faces das células no centro das arestas. Deslocada.

- Tipo D : Escalares nos centros das células e vetores tangentes às arestas/faces das células no centro das arestas. Deslocada.

Não consideramos a malha do tipo E, por se tratar apenas de uma variação (rotação) da malha tipo B, sendo também conhecida como B/E (Randall [1994]).

A

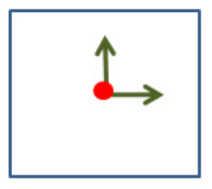

$\mathrm{HA}$

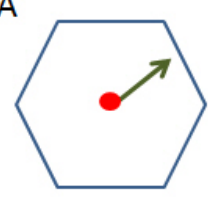

TA

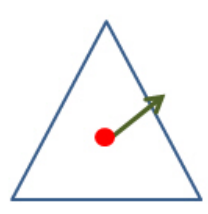

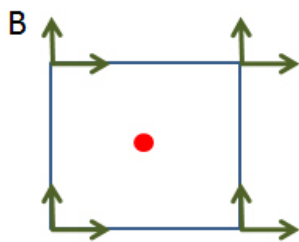

HB

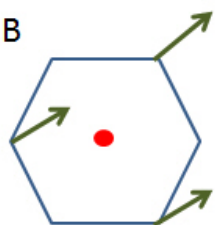

TB

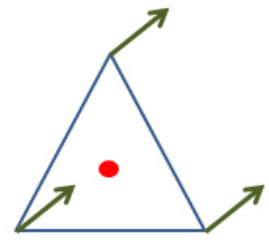

C
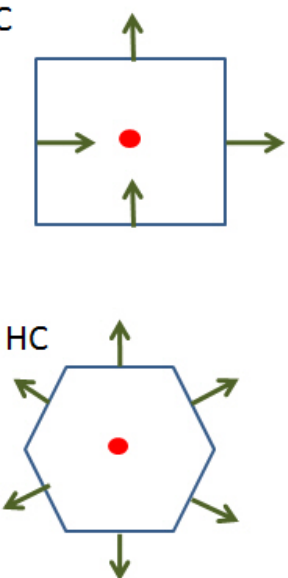

TC

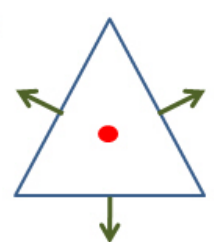

D

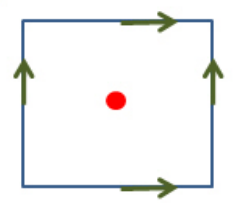

HD

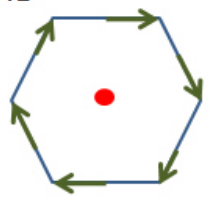

TD

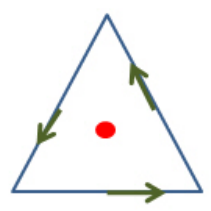

Figura 2.18: Tipos de grades numéricas. Os círculos representam campos escalares e os vetores velocidades.

Na Figura 2.18 destacamos diversos tipos de malhas, tanto retangulares, quanto triangulares e hexagonais. No que diz respeito aos tipos de grade A, deve-se lembrar da relação triângulo/hexágono dado pela formulação Delaunay/Voronoi. Dessa forma os centros dos hexágonos são os vértices dos triângulos, como apresentado na Figura 2.19. Analogamente, os centros dos triângulos são os vértices 
dos hexágonos, como mostrado na Figura 2.20. Nestes casos, e também nos casos das malhas do tipo B, pode ser necessário que o campo vetorial tenha uma base de referência. Por exemplo, podese decompor o vetor de velocidade nas direções leste-norte ( $u$ e $v$ ), como feito nas figuras 2.19 e 2.20. Mostramos na Figura 2.21 o alinhamento com as linhas de latitude e longitude desse tipo de referenciamento. Outra possibilidade é armazenar o vetor em coordenadas cartesianas do $\mathbb{R}^{3}$.

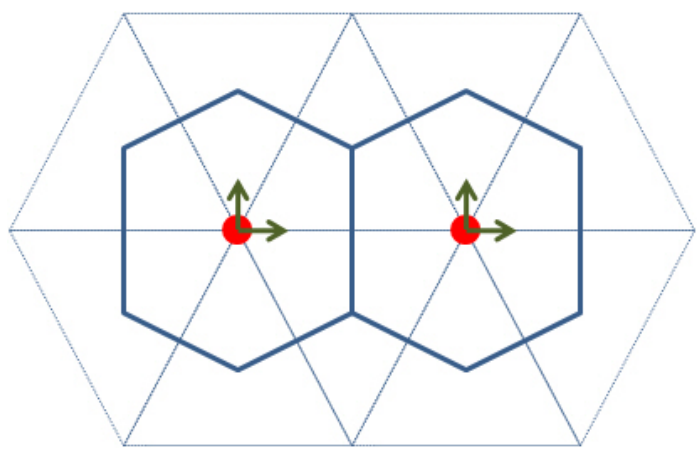

Figura 2.19: Escalares e vetores nos vértices dos triângulos ou centros dos hexágonos. Os círculos preenchidos nos vértices dos triângulos indicam locais para escalares, os vetores mostram a base para os vetores.

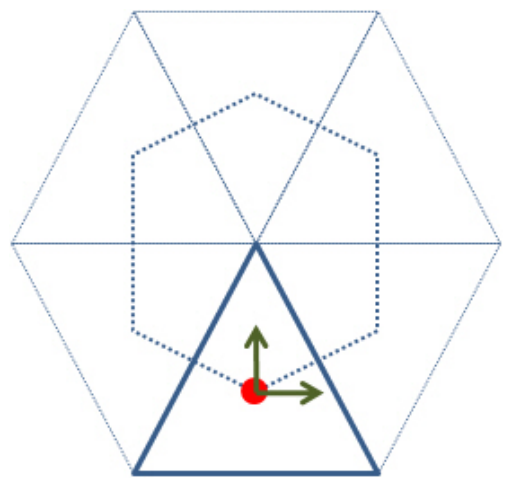

Figura 2.20: Escalares e vetores nos vértices dos hexágonos ou centros dos triângulos. O círculo preenchido no centro do triângulo indica o local para escalares, os vetores mostram a base para os vetores.

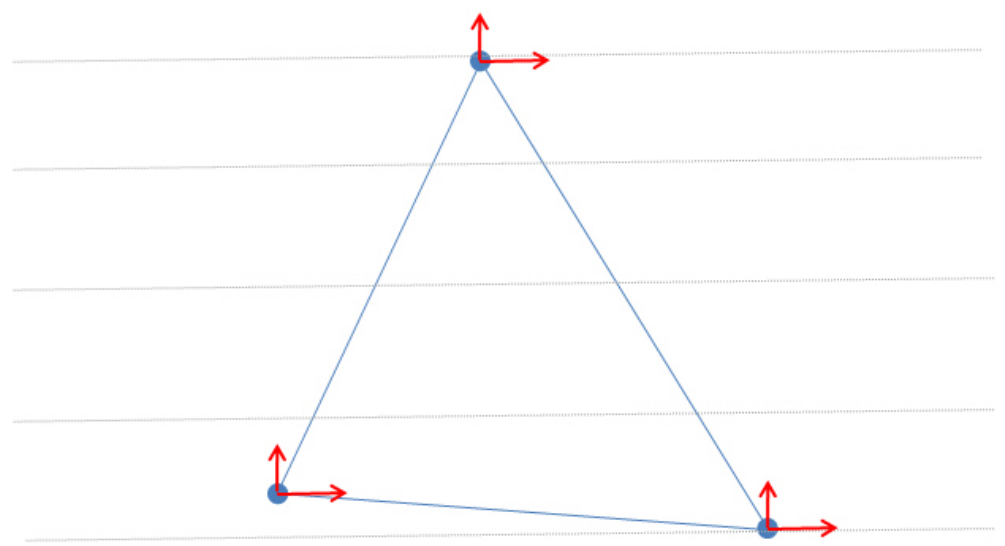

Figura 2.21: Escalares e vetores nos vértices dos triângulos. Os círculos preenchidos nos vértices dos triângulos indicam locais para escalares, os vetores mostram a base para os vetores e as linhas tracejadas indicam paralelos (linhas de latitude constantes) da esfera.

As posições deslocadas dos tipos C e D para os campos vetoriais em malhas retangulares costumam separar as velocidades zonais $(u)$ das meridionais $(v)$, mas os vetores permanecem perpendiculares ou tangentes às arestas. Porém, nas malhas hexagonais a situação pode ser um pouco 
diferente, pois ao considerarmos vetores perpendiculares ou tangentes não necessariamente garantimos um sistema de referência comum para todos os vetores. O mais natural parece ser considerar os vetores na sua forma cartesiana, em coordenadas do $\mathbb{R}^{3}$ restritas ao plano tangente da esfera no ponto de origem do vetor. Outra forma é considerar para cada ponto de malha contendo vetores uma base local definida por sua componente normal e tangente à aresta, nesse caso fica simples calcular fluxos e rotacionais, como veremos em capítulos mais adiantes. Exemplificamos essa possibilidade na Figura 2.22.

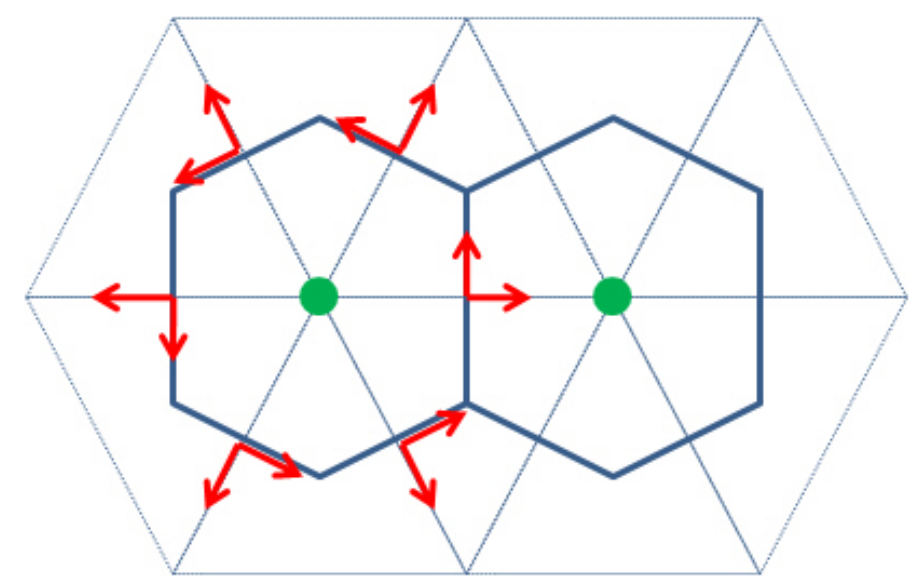

Figura 2.22: Células hexagonais com fluxos nas arestas. As setas indicam as posições dos vetores, normais as arestas dos hexágonos, ou tangentes as arestas dos triângulos e o círculo preenchido representa a posição dos escalares, nos centros dos hexágonos, ou vértices dos triângulos.

Nas malhas C e D os vetores normais/tangentes seguem uma certa orientação dada pela célula em questão, por exemplo, de dentro para fora, no caso da malha $\mathrm{C}$, e seguindo o sentido antihorário, no caso da malha D. Os fluxos entre células, bem como os divergentes, são calculadas com os vetores normais às arestas hexagonais, apontando sempre na direção de dentro para fora da célula. Os rotacionais são calculados com os vetores tangentes às arestas hexagonais sempre em um mesmo sentido, por exemplo, anti-horário. Logo, um problema desse método é que as orientações dos vetores tangentes podem não serem evidentes, pois a sua orientação depende do referencial, conforme ilustramos na Figura 2.23. Logo, computacionalmente, é preciso armazenar as componentes normais e tangentes a uma aresta e ainda suas relações de direções (de dentro para fora no caso de vetores normais, ou anti-horário no caso de vetores tangentes) com as células hexagonais ou triangulares. Nas malhas triangulares do tipo TC o problema persiste, mostramos na Figura 2.24 a disposição dos campos.

A questão de escolha do tipo de colocação de variáveis envolve muitos fatores. A escolha é naturalmente dependente do conjunto de equações que se deseja resolver e do método de discretização desejado. Nas equações para modelagem atmosférica geralmente há necessidade de se conhecer ventos e variáveis escalares em um mesmo ponto. Isso faz com que a malha colocada (tipo A) seja atraente, para evitar a necessidade de métodos de interpolações. Porém, esse tipo de colocação resulta em modos computacionais espúrios no campo de pressão, que podem levar a instabilidades em modelos tridimensionais. O cuidado que temos que ter ao propor alternativas é manter o balanço entre o número de informações a respeito do vento e escalares coerente. Numa malha do tipo A temos 2 componentes de vento para cada escalar. Na malha tipo $\mathrm{C}$ em retângulos esse balanço é mantido, porém em triângulos (TC) temos $3 / 2$ componentes de vento para cada escalar, o que pode gerar modos computacionais no campo de divergência, e na hexagonal (HC) temos 3 componentes de vento para cada escalar, que pode gerar modos computacionais no campo do rotacional. De todos os problemas relatados, de acordo com Weller et al. [2012], o menos grave, em termos de impacto nos resultados do modelo atmosférico, é a colocação do tipo HC.

As malhas do tipo C são interessantes pois permitem uma representação mais precisa das ondas mais rápidas, como as ondas acústicas e de gravidade. Esses tipos de ondas fornecem mecanismos de ajuste do balanço geostrófico, que consiste nos movimentos devidos ao equilíbrio entre força de 


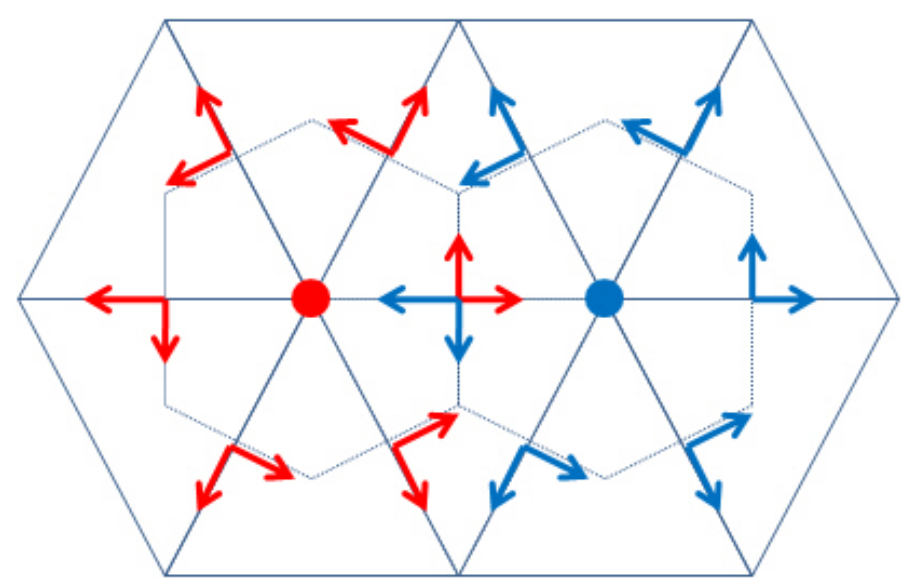

Figura 2.23: Células hexagonais com fluxos nas arestas com fluxos nas arestas dados pelos triângulos. As setas indicam as posições dos vetores, normais e tangentes às arestas dos hexágonos e o círculo preenchido representa a posição dos escalares, nos centros dos hexágonos, ou vértices dos triângulos. A cor vermelha refere-se ao hexágono à esquerda e a azul refere-se ao da direita.

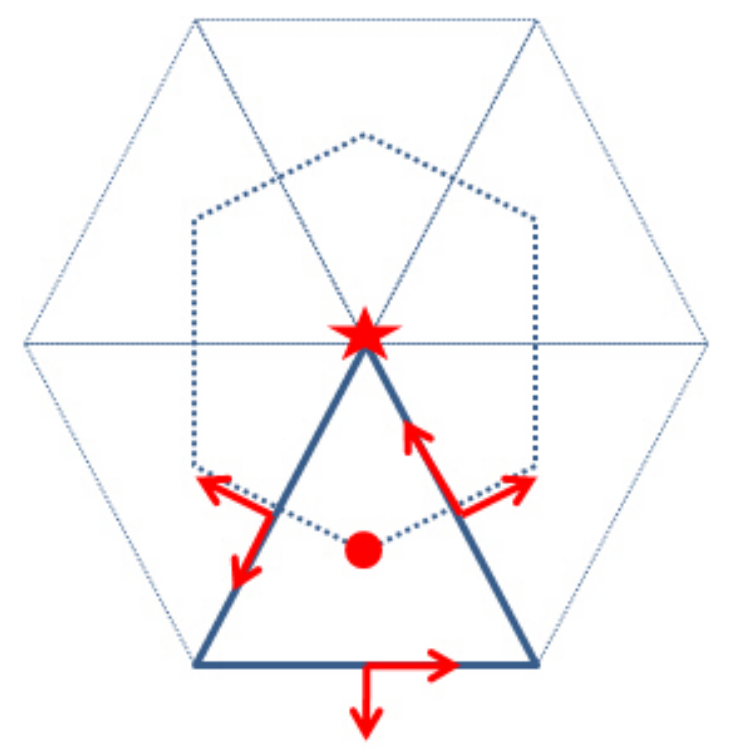

Figura 2.24: Células triangulares com fluxos nas arestas. As setas indicam as posições dos vetores, normais e tangentes às arestas dos triângulos, o círculo preenchido representa a posição dos escalares, nos centros dos triângulos, ou vértices dos hexágonos, e a estrela indica o ponto de vorticidade.

Coriolis e gradientes de pressão. Um estudo sobre a representação numérica e colocação dos campos em malhas retangulares no ajuste geostrófico pode ser visto em Randall [1994]. Para malhas hexagonais, Nickovic et al. [2002] analisaram o ajuste geostrófico com diversas colocações de escalares e vetores e, mais recentemente, para malhas do tipo $\mathrm{C}$ em polígonos quaisquer, temos o estudo de Thuburn et al. [2009] que propõe metodologias para preservar o balanço geostrófico. De acordo com o estudo de Nickovic et al. [2002], a colocação do tipo HC parece ser uma das formas mais adequadas de colocação das variáveis na malha e é a metodologia que vem sendo adotada pelos grupos de pesquisa que usam malhas hexagonais Bonaventura e Ringler [2005], Ringler et al. [2010], Skamarock et al. [2012]. Neste estudo chegamos a fazer testes com várias formas de colocação de variáveis na malha (TA, TB, TC, HA, HB, HC), mas usamos principalmente o tipo HC.

Na Tabela 2.7 destacamos as malhas usadas em modelos existentes na literatura. A malha do tipo HA é usada no modelo japonês NICAM, porém, nesse caso, os pontos onde as variáveis são armazenadas são os centros de massa dos hexágonos, que não necessariamente coincidem com o vértice dos triângulos. Além disso também usam um método de otimização da malha, conhecido 


\begin{tabular}{|c|c|c|c|}
\hline Modelo & Tipo de Malha & Vetores & Artigo de referência \\
\hline GME & HA & $(u, v)$ & Majewski et al. $[2002]$ \\
\hline FIM & HA & $(u, v)$ & Bao et al. $[2011]$ \\
\hline NICAM & HA & $\mathbb{R}^{3}$ & Satoh et al. $[2008]$ \\
\hline OLAM & TC & $\mathbb{R}^{3}$ & Walko e Avissar $[2008 \mathrm{a}]$ \\
\hline OMEGA & TC & $(u, v)$ & Bacon et al. $[2000]$ \\
\hline ICONSWM & TC & $\vec{n}, \vec{t}$ & Rípodas et al. $[2009]$ \\
\hline MPAS & HC & $\mathbb{R}^{3}$ & Skamarock et al. $[2012]$ \\
\hline
\end{tabular}

Tabela 2.7: Tipos de malhas usadas em diversos modelos existentes na literatura. Os tipo de base para os vetores usados são: $\mathbb{R}^{3}$, onde usam-se os vetores em coordenadas cartesianas; $(u, v)$, onde os vetores são nas direções de linhas de longitudes e latitudes; e $(\vec{n}, \vec{t})$, onde os vetores são normais e tangentes à arestas.

por spring dynamics, para melhorar a regularidade dos hexágonos. Mais detalhes sobre as malhas usadas em cada modelo estão no apêndice A.

Nas malhas triangulares, a distância do circuncentro de um triângulo até o ponto médio de uma aresta pode ser diferente da distância entre o ponto médio dessa mesma aresta e o circuncentro do triângulo vizinho. É possível melhorar essa descentralização utilizando, por exemplo, o algoritmo de Heikes e Randall [1995a]. Isso pode impactar na ordem de discretização dos fluxos do modelo. Ilustramos essa descentralização na Figura 2.25. Quanto mais regulares forem os triângulos, menor será esse problema. As distâncias dos vértices até o ponto de interseç̧ão com o arco que conecta os centros de massa dos triângulos são as mesmas. Isso deve-se às propriedades de construção da malha de Voronoi. Por outro lado, se os escalares forem armazenados nos baricentros dos triângulos, então a reta que conecta dois centros de triângulos vizinhos não é necessariamente perpendicular à aresta do triângulo. Essa ortogonalidade também é uma propriedade desejável para as discretizações.

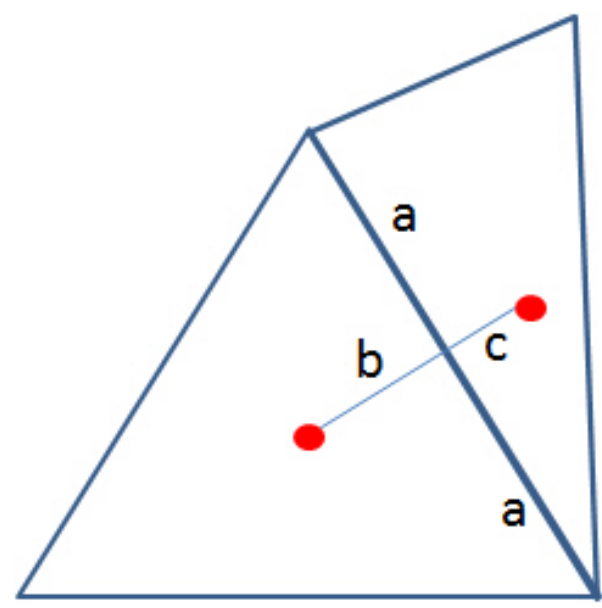

Figura 2.25: Descentralização dos pontos de centro de massa em triângulos. O arco que conecta os centros de massa tem distâncias até a aresta não necessariamente iguais $(b \neq c)$. Porém, as distâncias dos vértices até o ponto em que ocorre essa intersecção é igual (a).

O modelo OLAM (Walko e Avissar [2008a], Walko e Avissar [2008b]) usa uma colocação de pontos do tipo TC com escalares nos baricentros. O fato de termos células triangulares, apesar dos problemas relatados anteriormente, permite maior flexibilidade na geração da malha, possibilitando, por exemplo, refinamentos locais. Para discretizações de ordem mais alta é possível usar pontos dados em triângulos vizinhos. Mostramos na Figura 2.26 a colocação das variáveis no modelo OLAM.

No caso de malhas que utilizam células de Voronoi, o campo escalar pode ser colocado tanto nos vértices dos triângulos quanto nos centros de massa das células. $\mathrm{O}$ uso dos vértices dos triângulos garante ortogonalidade entre arestas da malha primal (de Delaunay) e dual (de Voronoi), mas, assim como nos triângulos, o ponto de intersecção entre as arestas primal e dual não coincide necessariamente com o ponto médio das arestas da malha dual. O uso do centro de massa garante 

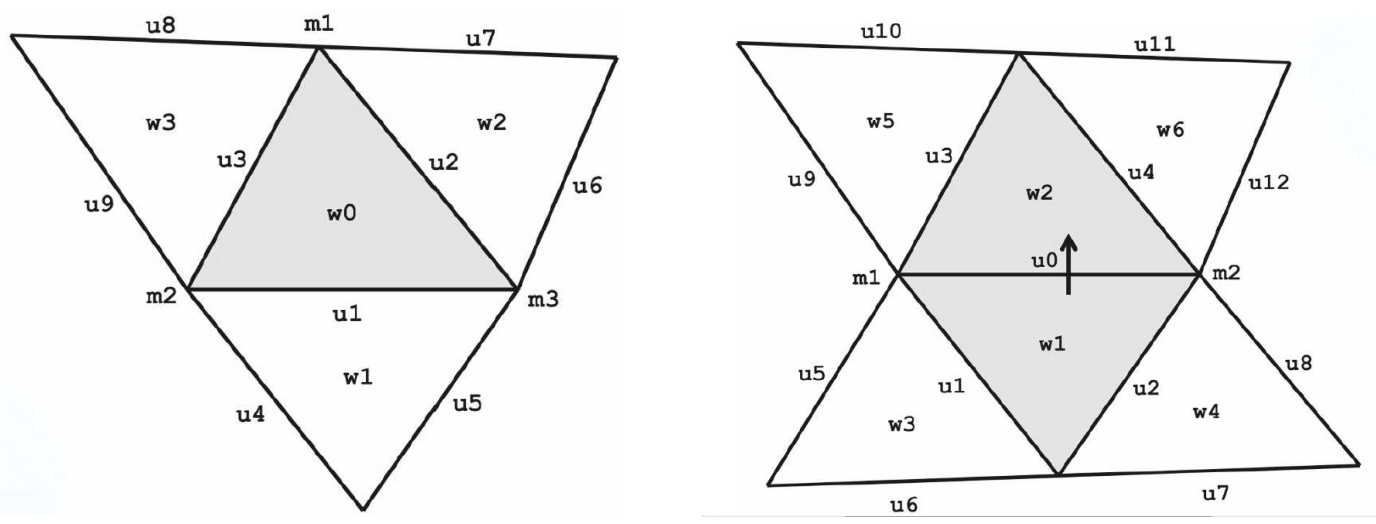

Figura 2.26: Colocação de variáveis do OLAM. Os pontos $u_{i}, i=1,2, \ldots, 12$ indicam pontos de vetores $e$ os $w_{i}, i=1,2, \ldots, 6$, de escalares. Fonte: Walko e Avissar [2008a], (c)2013 American Meteorological Society. Permissão para uso de figura em trabalho acadêmico sob as condições de uso aceitável ou razoável ("fair use").

boas aproximações para algumas discretizações de operadores diferenciais, mas a perda da ortogonalidade prejudica as discretizações de outros operadores. Uma forma de resolver esse impasse é utilizando uma otimização de malha que force com que os centros de massa coincidam com os vértices dos triângulos. Veremos mais detalhes a respeito mais adiante.

Há ainda outras possibilidades de colocação dos valores na malha. Uma alternativa é a malha do tipo Z, para o qual as equações são resolvidas na forma de vorticidade-divergente e todos os campos são escalares, sendo estes colocados nos centros das células (Randall [1994]). Ou ainda, pode ser considerada uma malha do tipo ZM, que é uma malha muito similar à malha do tipo B, mas que considera vetores em todos os cantos da célula (Ringler e Randall [2002]). Isso resulta em muito mais pontos do campo vetorial do que dos campos escalares. Ilustramos esses dois tipos de colocação na Figura 2.27.
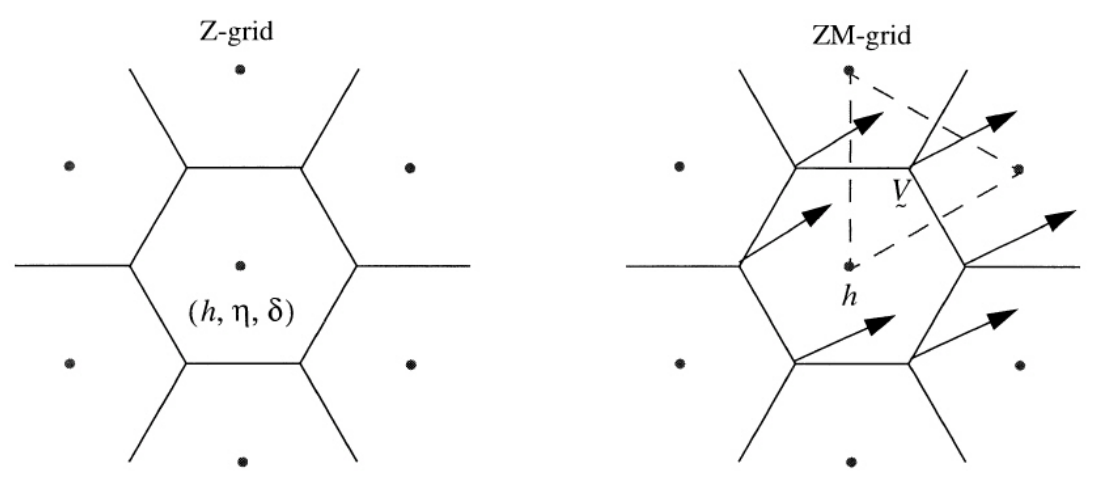

Figura 2.27: Malhas do tipo $Z$ e ZM. h é um ponto de massa, $\delta$ o divergente, $\eta$ a vorticidade e $V$ um vetor, como por exemplo a velocidade. Fonte: Ringler e Randall [2002], (c)2013 American Meteorological Society. Permissão para uso de figura em trabalho acadêmico sob as condições de uso aceitável ou razoável ("fair use").

Neste estudo, vamos analisar os métodos de colocação descritos anteriormente, mas daremos mais enfoque na malha com colocação de valores do tipo HC. 


\subsection{Estrutura computacional}

A malha icosaédrica carrega uma certa regularidade na sua estrutura, que pode ser usada na estrutura de dados. A malha icosaédrica primária é constituída de 20 triângulos que agrupados dois a dois geram 10 losangos, ou diamantes. Nesse caso, podemos usar uma estrutura de dados do tipo $(i, j)$ para varrer as células, como ilustrado na Figura 2.28.

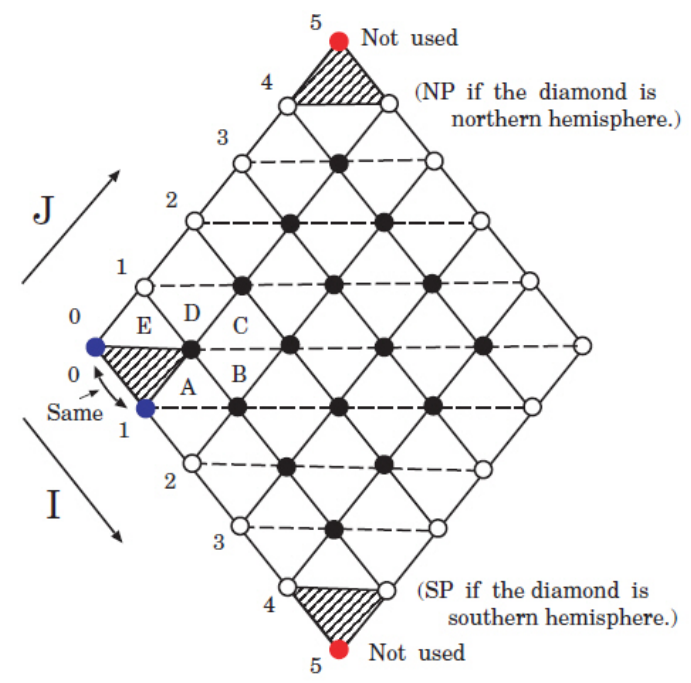

Figura 2.28: Indexação da malha icosaédrica em losangos, ou diamantes. NP indica polo norte, SP polo sul. Fonte: Tomita et al. [2008], (C)2013 Society for Industrial and Applied Mathematics. Permissão para uso de figura em trabalho acadêmico sob as condições de uso aceitável ou razoável ("fair use").

Apesar dessa estruturação permitir um acesso mais rápido e fácil aos pontos de malhas, ela pode se tornar inviável no caso de malhas otimizadas (que veremos mais adiante) ou alguns tipos de malhas com refinamentos locais. Queremos neste estudo usar uma estrutura de malha robusta, que permita uma fácil incorporação de outros tipos de malhas geodésicas. Por isso vamos armazenar as malhas de forma não estruturada, com base em listas de nós, triângulos e arestas. Construímos uma hierarquia de tipos em Fortran para a estruturação da malha. Essa hierarquia usa índices inteiros para nós, triângulos e arestas, e listas de índices para descrever as relações entre os elementos. A estrutura é muito similar à estrutura de malhas não estruturadas triangulares do tipo Half-Edge, porém, não usamos listas ligadas com ponteiros, a fim de facilitar otimizações do compilador e paralelismo.

A estrutura que usamos é formada basicamente por três listas: de nós, de arestas e de triângulos. Descrevemos a seguir as propriedades armazenadas de cada elemento para as três listas.

- Nó:

- coordenadas;

- nós vizinhos;

- arestas que possuem o nó;

- triângulos que possuem o nó.

- Aresta:

- coordenadas do ponto médio;

- nós que a formam;

- triângulos que a compartilham;

- comprimento. 
- Triângulo:

- ângulos internos;

- coordenadas do circuncentro e baricentro;

- nós geradores;

- arestas geradoras;

- triângulos vizinhos;

- área.

Nota-se que essa estrutura proposta carrega redundâncias, por exemplo, contendo tanto as arestas que conectam os nós, como os nós que formam uma aresta. Apesar disso implicar em maior uso de memória, há benefícios no desempenho computacional. Toda a construção dessa estrutura é pré-computada e armazenada em arquivos binários em disco para acessos futuros. Com essa abordagem, qualquer tipo de malha geodésica pode ser armazenada e, de fato, chegamos a investigar com essa estrutura outros tipos de malhas que não as icosaédricas, por exemplo as octaédricas, centroidais de Voronoi com refinamento local (Ju et al. [2011]), ou ainda malhas geradas com pontos aleatoriamente. 


\subsection{Otimizações}

Muitos métodos de discretizações de equações diferenciais do tipo volumes ou diferenças finitas são sensíveis ao formato da célula computacional. Com isso, as irregularidades da malha icosaédrica que descrevemos anteriormente podem afetar o esquema de discretização usado. Para minimizar as irregularidades da malha é possível aplicar otimizações, isto é, deslocar os nós para obtermos melhores propriedades. Algumas otimizações são passíveis de serem feitas na malha icosaédrica e em outras malhas geodésicas. Neste capítulo vamos mostrar algumas otimizações existentes e comparálas entre si e com a malha sem otimização, para ajudar na identificação da melhor abordagem para o desenvolvimento de um modelo atmosférico.

Uma boa referência sobre otimizações de malhas geodésicas é o trabalho de Miura e Kimoto [2005], onde diversos métodos de otimizações são comparados. Nós vamos focar apenas nas otimizações consideradas mais relevantes na literatura.

Heikes e Randall [1995a] propuseram um reajuste dos nós para garantir consistência de uma discretização por diferenças finitas do laplaciano. Esse ajuste é feito minimizando uma função objetivo com um método quase-Newton e métodos de gradientes por diferenças finitas. A função objetivo ajusta os nós no sentido de fazer com que o ponto de intersecção das arestas da malha primal e dual (da malha triangular com a malha hexagonal/pentagonal) seja o mais perto possível do ponto médio da aresta que liga vértices dos hexágonos/pentágonos.

Um outro método de otimização, proposto na área de meteorologia por Tomita et al. [2001], usa uma técnica baseada na dinâmica de molas (spring dynamics) para ajustar os nós da malha e gerar malhas com mais uniformidade na distribuição dos nós, isto é, com menos variação de distâncias entre os nós.

Uma abordagem que é mais antiga no plano, porém mais recente na esfera, é o uso de malha centroidais de Voronoi (Du et al. [2003]). Nesse tipo de malha os nós geradores das células de Voronoi são também os centros de massas das células. Tendo-se como base a malha icosaédrica pode-se perturbar os nós no sentido de gerar uma malha com essa propriedade. Vamos analisar em detalhes esse tipo de malha na próxima seção.

Apesar das otimizações originarem malhas diferentes da icosaédrica, como usualmente são geradas a partir delas, vamos continuar denotando as malhas otimizadas como malhas icosaédricas, mas nesse caso adicionaremos o termo "otimizadas".

\subsubsection{Malhas centroidais de Voronoi}

Considerando a malha dual, os nós geradores das células de Voronoi não são necessariamente os centros de massa (esféricos) da célula. A ideia da otimização do tipo centroidal de Voronoi é ajustar a malha para que os nós geradores sejam justamente os centros de massa das células de Voronoi. Uma forma de ajuste é usando o algoritmo iterativo de Loyde (Du et al. [2003], Miura e Kimoto [2005]). Esse algoritmo, no qual a cada iteração movem-se os nós da malha para os centros de massa da célula de Voronoi, leva assintoticamente a uma malha cujos nós são centros de massa das células. Na literatura esse tipo de malha é denominada malha esférica centroidal de Voronoi, do inglês, Spherical Centroidal Voronoi Tesselation (SCVT).

$\mathrm{Na}$ nossa implementação do método de Loyde usamos como critério de parada um número máximo de iterações de 50000, de distância máxima entre o nó e o centro de massa menor que $h \times 10^{-9}$ ou variação entre as distâncias até o centro de massa de duas iterações menor que $h \times 10^{-10}$, onde $h$ é o espaçamento médio entre dois pontos da malha. A convergência desse método é bem lenta, porém podemos armazenar a malha resultante da otimização para uso futuro, rodando o algoritmo uma única vez. Na Figura 2.29 mostramos um comparativo entre a malha icosaédrica usual e a otimizada, apenas para indicar que a mudança é sutil e a estrutura básica da malha icosaédrica se mantem preservada. Apesar de sutil, veremos mais adiante que as otimizações de malha podem ter grandes impactos na discretização de operadores diferenciais.

Vamos analisar algumas propriedades desse tipo de malha. Na Tabela 2.8 vemos que a razão entre as distâncias mínimas e máximas entre os nós decresce com o refinamento da malha. Isso 


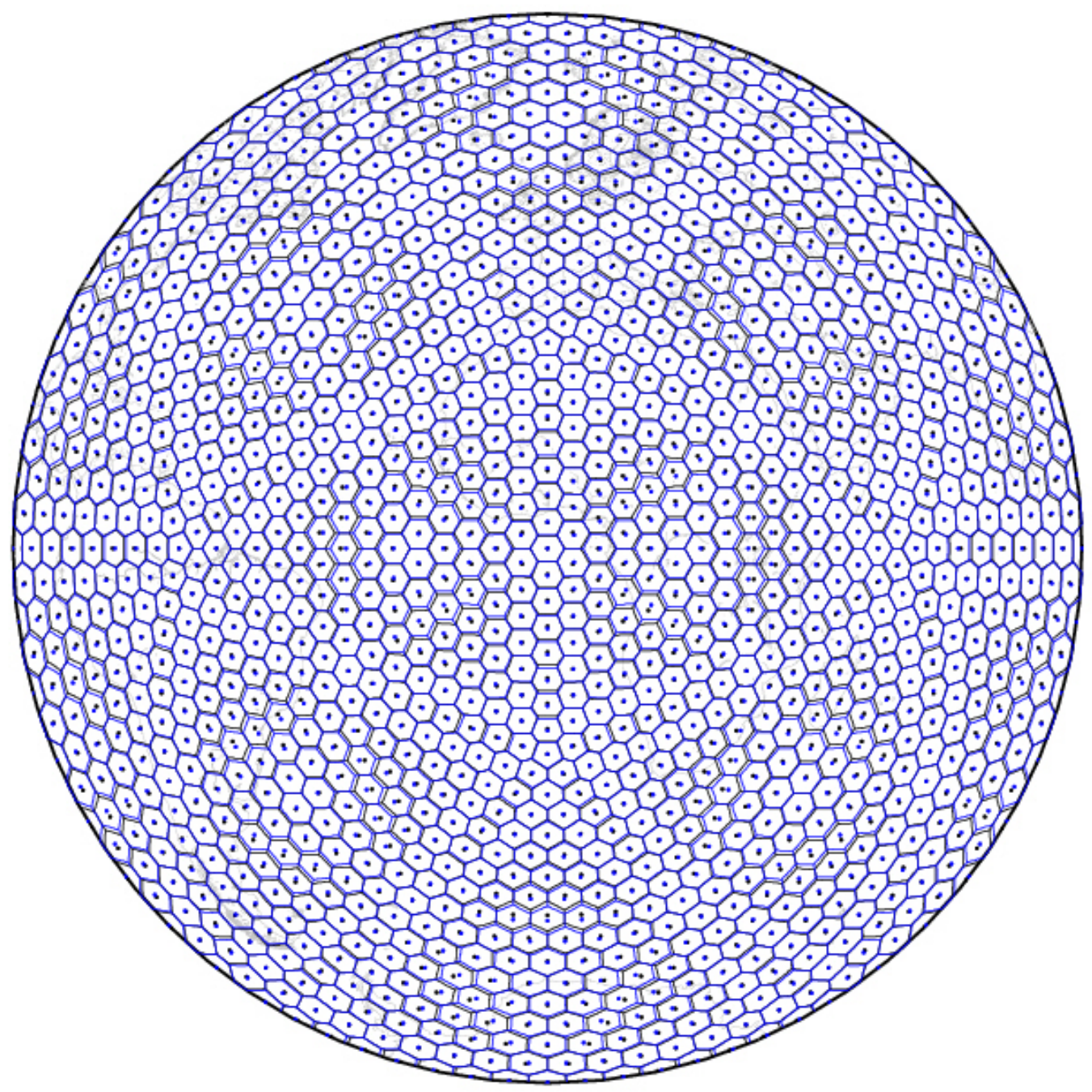

Figura 2.29: Células de Voronoi para icosaedro otimizado com SCVT (em azul) e em preto o icosaedro regular. Os pontos indicam os nós geradores das células. Malhas com 2562 nós.

indica que quanto mais fina a malha, menos homogênea em termos de distâncias entre nós ela será. Note que as malhas SCVT são menos homogêneas nesse sentido que as icosaédricas sem otimizações (compare a Tabela 2.8 com a 2.1). O mesmo ocorre com as áreas das células computacionais (veja a Tabela 2.9), mas por outro lado, a distribuição das áreas parece ser mais suave como vemos na Figura 2.30, apesar das menores áreas continuarem se concentrando em torno dos 12 pentágonos.

\begin{tabular}{|c|c|c|c|c|c|c|c|}
\hline \multicolumn{4}{|c|}{ Estrutura da Malha } & \multicolumn{3}{c|}{ Distâncias entre nós em graus (km) - SCVT } \\
\hline Nível & Nós & Triângulos & Arestas & Mínima & Máxima & Média & Mín/Máx \\
\hline 0 & 12 & 20 & 30 & $63.43(7054)$ & $63.43(7054)$ & $63.43(7054)$ & 1.0000 \\
\hline 1 & 42 & 80 & 120 & $31.72(3527)$ & $36.00(4003)$ & $33.86(3765)$ & 0.8810 \\
\hline 2 & 162 & 320 & 480 & $15.63(1738)$ & $18.22(2026)$ & $17.2(1913)$ & 0.8577 \\
\hline 3 & 642 & 1280 & 1920 & $7.63(849)$ & $9.13(1016)$ & $8.63(960)$ & 0.8355 \\
\hline 4 & 2562 & 5120 & 7680 & $3.71(412)$ & $4.57(509)$ & $4.32(480)$ & 0.8106 \\
\hline 5 & 10242 & 20480 & 30720 & $1.80(200)$ & $2.29(254)$ & $2.16(240)$ & 0.7868 \\
\hline 6 & 40962 & 81920 & 122880 & $0.87(97)$ & $1.14(127)$ & $1.08(120)$ & 0.7633 \\
\hline 7 & 163842 & 327680 & 491520 & $0.42(47)$ & $0.57(64)$ & $0.54(60)$ & 0.7405 \\
\hline 8 & 655362 & 1310720 & 1966080 & $0.21(23)$ & $0.29(32)$ & $0.27(30)$ & 0.7183 \\
\hline
\end{tabular}

Tabela 2.8: Análogo à Tabela 2.1 mas para a malhas otimizadas com SCVT. 


\begin{tabular}{|c|c|c|c|c|}
\hline \multicolumn{5}{|c|}{ Áreas das células de Voronoi - SCVT } \\
\hline Nível & Mín & Máx & Média & Mín/Máx \\
\hline 0 & 1.047198 & 1.047198 & 1.047198 & 1.0000 \\
\hline 1 & 0.273844 & 0.309341 & 0.299199 & 0.8852 \\
\hline 2 & 0.067315 & 0.080267 & 0.077570 & 0.8386 \\
\hline 3 & 0.016095 & 0.020224 & 0.019574 & 0.7958 \\
\hline 4 & 0.003802 & 0.005064 & 0.004905 & 0.7508 \\
\hline 5 & 0.000896 & 0.001267 & 0.001227 & 0.7070 \\
\hline 6 & 0.000211 & 0.000317 & 0.000307 & 0.6654 \\
\hline 7 & 0.000050 & 0.000079 & 0.000077 & 0.6262 \\
\hline 8 & 0.000012 & 0.000020 & 0.000019 & 0.5892 \\
\hline
\end{tabular}

Tabela 2.9: Análogo à Tabela 2.3 mas para a malhas otimizadas com SCVT.

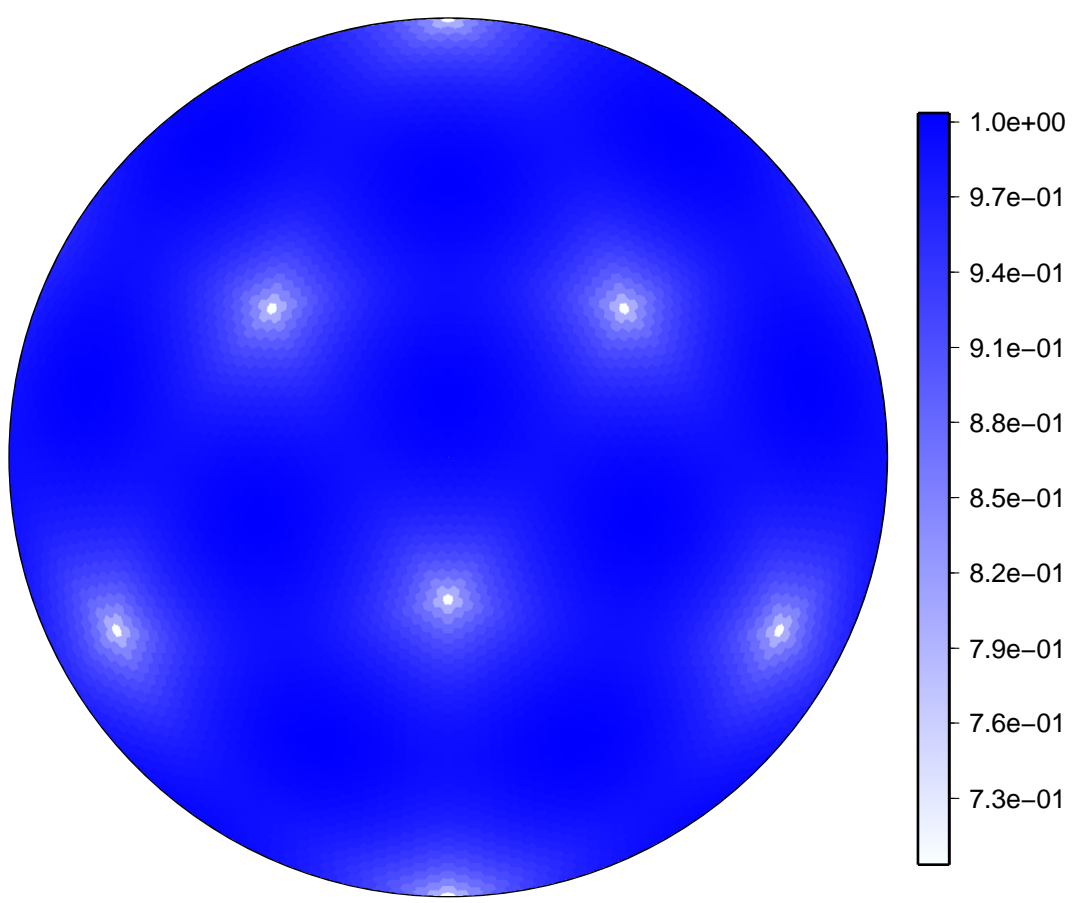

Figura 2.30: Razão entre a área da célula de Voronoi e o maior área de célula de Voronoi da malha (análogo à Figura 2.10 mas para a malha otimizada com SCVT).

Do ponto de vista de distorções começamos a ver vantagens da malha SCVT em relação à icosaédrica original. Na Tabela 2.10 mostramos a métrica de distorção, descrita anteriormente, agora para malhas SCVT, onde é possível perceber que temos uma malha com menores distorções máximas e médias das células de Voronoi que a malha icosaédrica sem otimizações (compare com a Tabela 2.4). A distribuição da distorção na malha também é mais suave, como podemos observar na Figura 2.31, mas nota-se que as células em torno dos pentágonos continuam a ter maiores distorções. Esse tipo de padrão de distribuição também pode ser percebido na análise das distâncias entre pontos médios das arestas das malhas primal e dual (Figura 2.36). Vemos ainda que o problema de não decaimento da distância máxima entre arestas primal e dual com o refinamento permanece semelhante a malha original, como pode ser visto na Tabela 2.11. Porém, as células responsáveis pelas maiores distâncias entre pontos médios de arestas primais e duais não são as originadas de arestas de malhas icosaédricas mais grossas, mas as mais próximas aos 12 pentágonos. 


\begin{tabular}{|c|c|c|c|c|c|c|}
\hline Distorções - SCVT & \multicolumn{3}{|c|}{ Triângulos } & \multicolumn{3}{c|}{ Hexágonos/Pentágonos } \\
\hline Nível & Máx & Média & Méd/Máx & Máx & Média & Méd/Máx \\
\hline 1 & 0.105496 & 0.079122 & 0.750000 & 0.106601 & 0.076144 & 0.714285 \\
\hline 2 & 0.128397 & 0.069989 & 0.545101 & 0.162290 & 0.106686 & 0.657379 \\
\hline 3 & 0.133765 & 0.066390 & 0.496316 & 0.185692 & 0.111204 & 0.598864 \\
\hline 4 & 0.135036 & 0.064623 & 0.478565 & 0.190140 & 0.110346 & 0.580339 \\
\hline 5 & 0.135335 & 0.064012 & 0.472987 & 0.191035 & 0.109641 & 0.573932 \\
\hline 6 & 0.135405 & 0.063794 & 0.471135 & 0.191239 & 0.109301 & 0.571541 \\
\hline 7 & 0.135422 & 0.063728 & 0.470587 & 0.191287 & 0.109181 & 0.570771 \\
\hline 8 & 0.135426 & 0.063708 & 0.470423 & 0.191299 & 0.109141 & 0.570525 \\
\hline
\end{tabular}

Tabela 2.10: Análogo à Tabela 2.4 mas para a malha otimizada com SCVT.

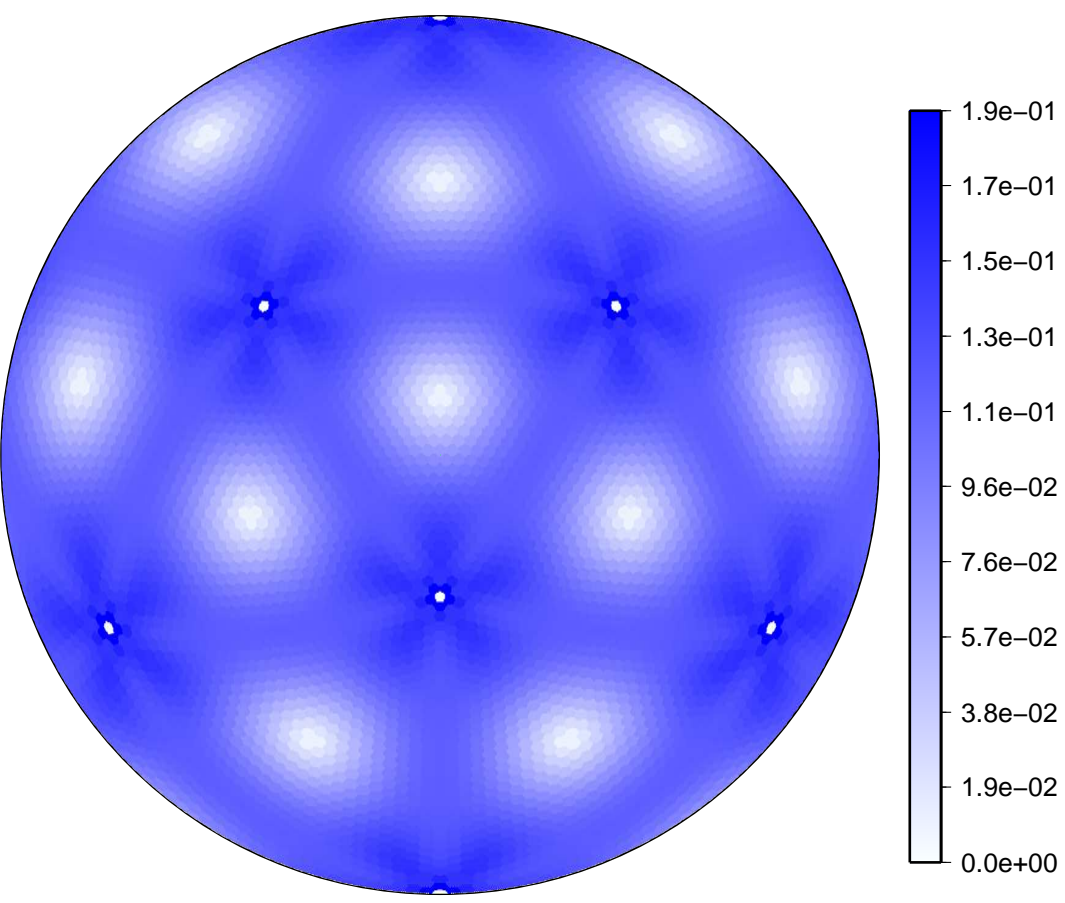

Figura 2.31: Distorção das células de Voronoi (análogo à Figura 2.11 mas para a malha otimizada com SCVT).

\begin{tabular}{|c|c|c|c|}
\hline \multicolumn{5}{|c|}{ Distâncias entre arestas primal e dual (SCVT) } \\
\hline Nível & Máx & Média & Mín/Máx \\
\hline 1 & $9.97 \mathrm{E}-02$ & $7.12 \mathrm{E}-02$ & 0.714286 \\
\hline 2 & $9.13 \mathrm{E}-02$ & $5.72 \mathrm{E}-02$ & 0.626127 \\
\hline 3 & $8.71 \mathrm{E}-02$ & $3.25 \mathrm{E}-02$ & 0.373203 \\
\hline 4 & $8.77 \mathrm{E}-02$ & $1.67 \mathrm{E}-02$ & 0.190999 \\
\hline 5 & $8.80 \mathrm{E}-02$ & $8.28 \mathrm{E}-03$ & 0.094046 \\
\hline 6 & $8.81 \mathrm{E}-02$ & $4.05 \mathrm{E}-03$ & 0.045963 \\
\hline 7 & $8.81 \mathrm{E}-02$ & $1.98 \mathrm{E}-03$ & 0.022525 \\
\hline 8 & $8.81 \mathrm{E}-02$ & $9.78 \mathrm{E}-04$ & 0.011099 \\
\hline
\end{tabular}

Tabela 2.11: Distâncias máximas e médias entre os pontos médios das arestas da malha triangular e de Voronoi normalizadas pelos respectivos comprimentos das arestas das células de Voronoi para malhas otimizadas com SCVT. 


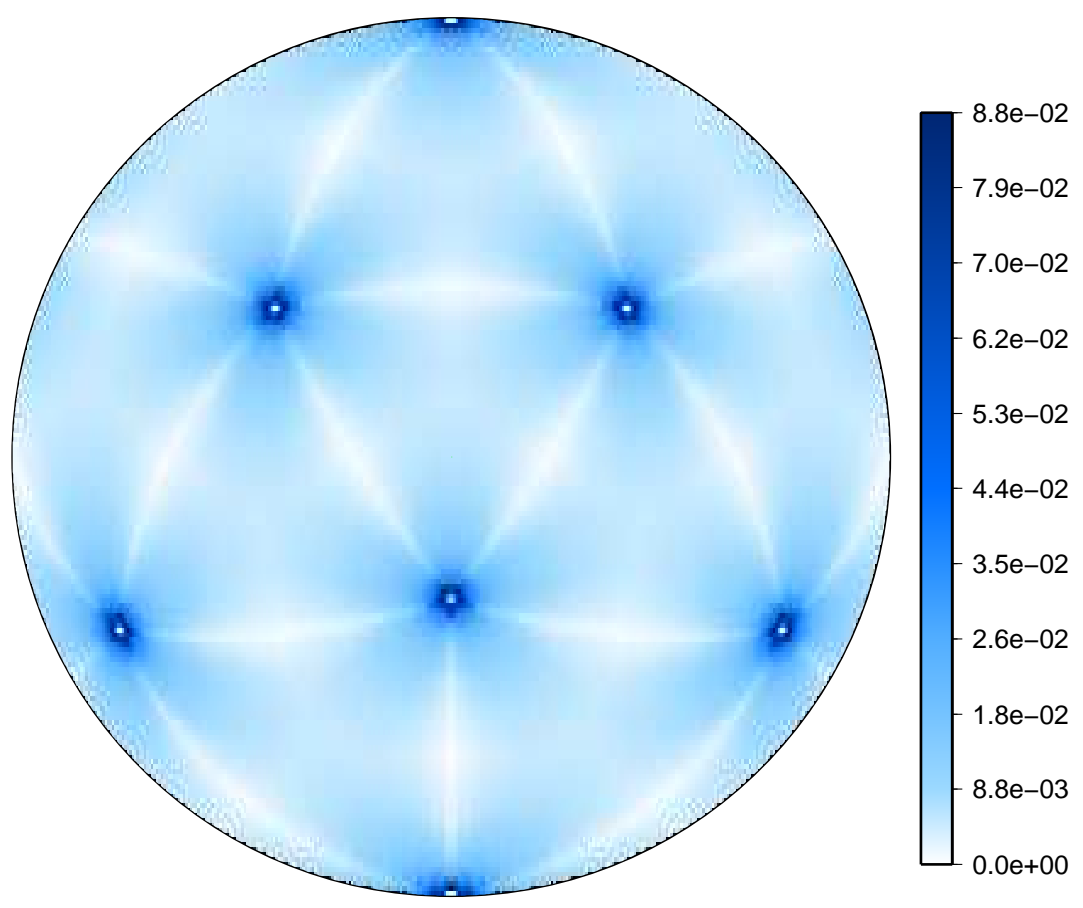

Figura 2.32: Distribuição das distâncias entre os pontos médios das arestas dos triângulos e os pontos médios das arestas das células de Voronoi normalizadas pelos respectivos comprimentos das arestas das células de Voronoi. Para cada célula de Voronoi mostramos o máximo da distância entre arestas dessa célula. Foi usada uma malha icosaédrica de nível 5 (10242 nós) otimizada com SCVT. 


\subsubsection{Malhas otimizadas com spring dynamics}

Técnicas de suavização de malhas triangulares são comuns na área de Desenho Assistido por Computador (CAD - Computer-Aided design) e consistem basicamente em mover os pontos de malha sem alterar a conectividade (Thompson et al. [1999]). Uma forma de se fazer isso é considerar que as arestas são molas e que os nós da malha fazem parte de um sistema de molas. Assim, a malha suavizada é obtida por relaxações até encontrar o equilíbrio do sistema.

Essa técnica foi inicialmente proposta para malhas icosaédricas em modelos atmosféricos por Tomita et al. [2002], que batizou a otimização de spring dynamics. O objetivo é deslocar os nós para minimizar uma função de energia e em Tomita et al. [2002] o método foi desenvolvido no sentido de minimizar as distorções das células. O método original resolve um sistema de equações diferenciais ordinárias por diferenças finitas para o conjunto de molas que conectam os pontos. No nosso trabalho usamos o algoritmo descrito em Miura e Kimoto [2005], que é interativo e desloca cada nó para minimizar a métrica de energia do sistema de spring dynamics, e representa um caso particular do método proposto em Tomita et al. [2002].

Podemos analisar a distribuição das distâncias em relação aos vizinhos de um nó com base na diferença em relação ao comprimento médio das arestas

$$
\bar{L}_{i}=\frac{1}{m_{i}} \sum_{j=1}^{m_{i}} L_{i j},
$$

onde $L_{i j}$ é a distância geodésica do i-ésimo ponto de malha até o seu j-ésimo vizinho e $m_{i}$ é o número de vizinhos ao i-ésimo ponto da malha. No método de spring dynamics, o objetivo é minimizar uma métrica de energia que tem como base o conceito de distribuição de distâncias, mas com um parâmetro de forçante do sistema. A energia minimizada é dada por,

$$
E_{S P R G}=\sum_{i=1}^{n} \sum_{j=1}^{m_{i}} \frac{1}{2}\left(L_{i j}-\bar{L}^{s}\right)^{2},
$$

onde $n$ é o número de nós da malha e $\bar{L}^{s}$ é o comprimento natural da mola, dado por

$$
\bar{L}^{s}=\beta \lambda,
$$

onde

$$
\lambda=\frac{2 \pi}{10 \times 2^{\text {glevel }-1}},
$$

é o comprimento característico entre dois nós no equador e $\beta$ é um parâmetro de forçante, que neste estudo adotamos como $\beta=1.2$ (recomendado em Tomita et al. [2002]). Note que, como $\beta>1$, definimos uma mola que em sua posição natural força os pontos a se repelirem.

Há uma questão problemática quanto ao critério de parada a ser usado nesse método. No método iterativo implementado definimos como critério de parada um número máximo de iterações de 20000, que na verdade não é atingido em nenhum dos casos testados (malhas com até 655362 nós). Para as malhas até o nível 6 o critério de parada sugerido em Miura e Kimoto [2005], de esperar o sistema estabilizar, funcionou e paramos quando a variação de energia entre iteradas foi menor que $\lambda \times 10^{-9}$. Porém, nas malhas mais finas, de níveis 7 e 8, a função de energia decresce indefinidamente, até um ponto em que a estrutura de vizinhança da malha precisaria ser alterada, portanto esse critério de parada deixa de ser coerente. Nestes casos usamos como critério de parada o ponto de distorção mínima. Usamos em todos os casos um parâmetro de relaxação $\alpha=0.09$ (vide Miura e Kimoto [2005]).

Na Figura 2.33 mostramos o tipo de efeito gerado pela otimização na malha icosaédrica, onde percebe-se que a otimização pode afetar mais algumas regiões que outras. Diferentemente das malhas SCVT, as malhas otimizadas com spring dynamics tendem a gerar malhas com o mesmo tipo de uniformidade em relação às icosaédricas do ponto de vista de distâncias entre os nós (veja a Tabela 


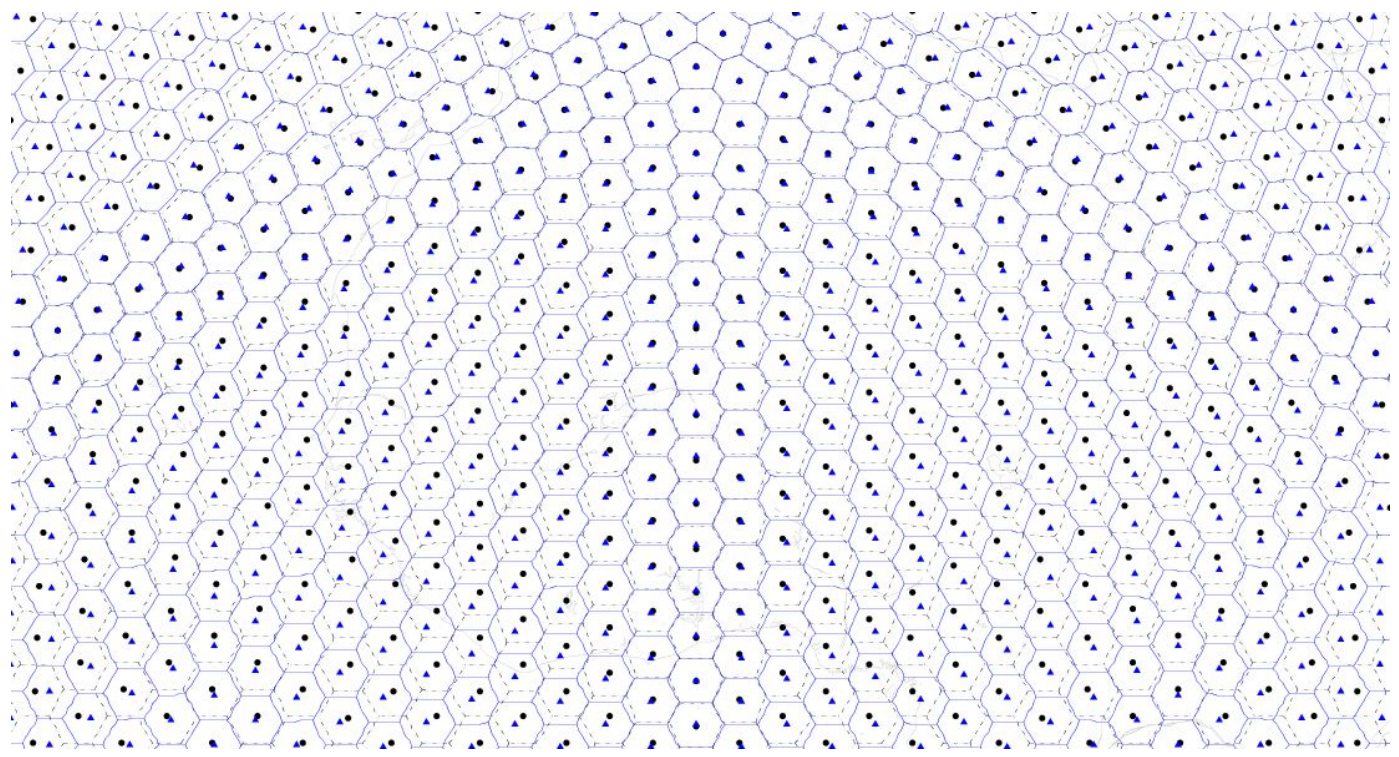

Figura 2.33: Células de Voronoi para icosaedro otimizado com spring dynamics, em azul, com pontos marcados com triângulos. Em preto, com nós marcados com círculos, está o icosaedro regular. Malha com 2562 nós.

2.12), e mais uniformes no que diz respeito à áreas (veja a Tabela 2.13). A distribuição das áreas é mais suave do que na malha icosaédrica, porém continuamos tendo células menores próximas aos pentágonos, como pode ser visto na Figura 2.34.

\begin{tabular}{|c|c|c|c|c|c|c|c|}
\hline \multicolumn{4}{|c|}{ Estrutura da Malha } & \multicolumn{3}{c|}{ Distâncias entre nós em graus (km) - SPRG } \\
\hline Nível & Nós & Triângulos & Arestas & Mínima & Máxima & Média & Mín/Máx \\
\hline 0 & 12 & 20 & 30 & $63.43(7054)$ & $63.43(7054)$ & $63.43(7054)$ & 1.0000 \\
\hline 1 & 42 & 80 & 120 & $31.72(3527)$ & $36(4003)$ & $33.86(3765)$ & 0.8810 \\
\hline 2 & 162 & 320 & 480 & $15.85(1762)$ & $18.5(2057)$ & $17.21(1914)$ & 0.8566 \\
\hline 3 & 642 & 1280 & 1920 & $7.9(879)$ & $9.3(1034)$ & $8.64(961)$ & 0.8495 \\
\hline 4 & 2562 & 5120 & 7680 & $3.92(436)$ & $4.64(516)$ & $4.33(481)$ & 0.8455 \\
\hline 5 & 10242 & 20480 & 30720 & $1.95(217)$ & $2.32(258)$ & $2.16(241)$ & 0.8400 \\
\hline 6 & 40962 & 81920 & 122880 & $0.97(108)$ & $1.16(129)$ & $1.08(120)$ & 0.8353 \\
\hline 7 & 163842 & 327680 & 491520 & $0.48(54)$ & $0.58(65)$ & $0.54(60)$ & 0.8326 \\
\hline 8 & 655362 & 1310720 & 1966080 & $0.24(27)$ & $0.29(32)$ & $0.27(30)$ & 0.8312 \\
\hline
\end{tabular}

Tabela 2.12: Análogo à Tabela 2.1 mas para a malha otimizada com spring dynamics.

\begin{tabular}{|c|c|c|c|c|}
\hline \multicolumn{5}{|c|}{ Áreas das células de Voronoi - SPRG } \\
\hline Nível & Mín & Máx & Média & Mín/Máx \\
\hline 0 & 1.047198 & 1.047198 & 1.047198 & 1.0000 \\
\hline 1 & 0.273844 & 0.309342 & 0.299199 & 0.8852 \\
\hline 2 & 0.069396 & 0.079854 & 0.077570 & 0.8690 \\
\hline 3 & 0.017371 & 0.020032 & 0.019574 & 0.8672 \\
\hline 4 & 0.004311 & 0.005012 & 0.004905 & 0.8601 \\
\hline 5 & 0.001069 & 0.001253 & 0.001227 & 0.8534 \\
\hline 6 & 0.000266 & 0.000313 & 0.000307 & 0.8491 \\
\hline 7 & 0.000066 & 0.000078 & 0.000077 & 0.8477 \\
\hline 8 & 0.000017 & 0.000020 & 0.000019 & 0.8521 \\
\hline
\end{tabular}

Tabela 2.13: Análogo à Tabela 2.3 mas para a malha otimizada com spring dynamics. 


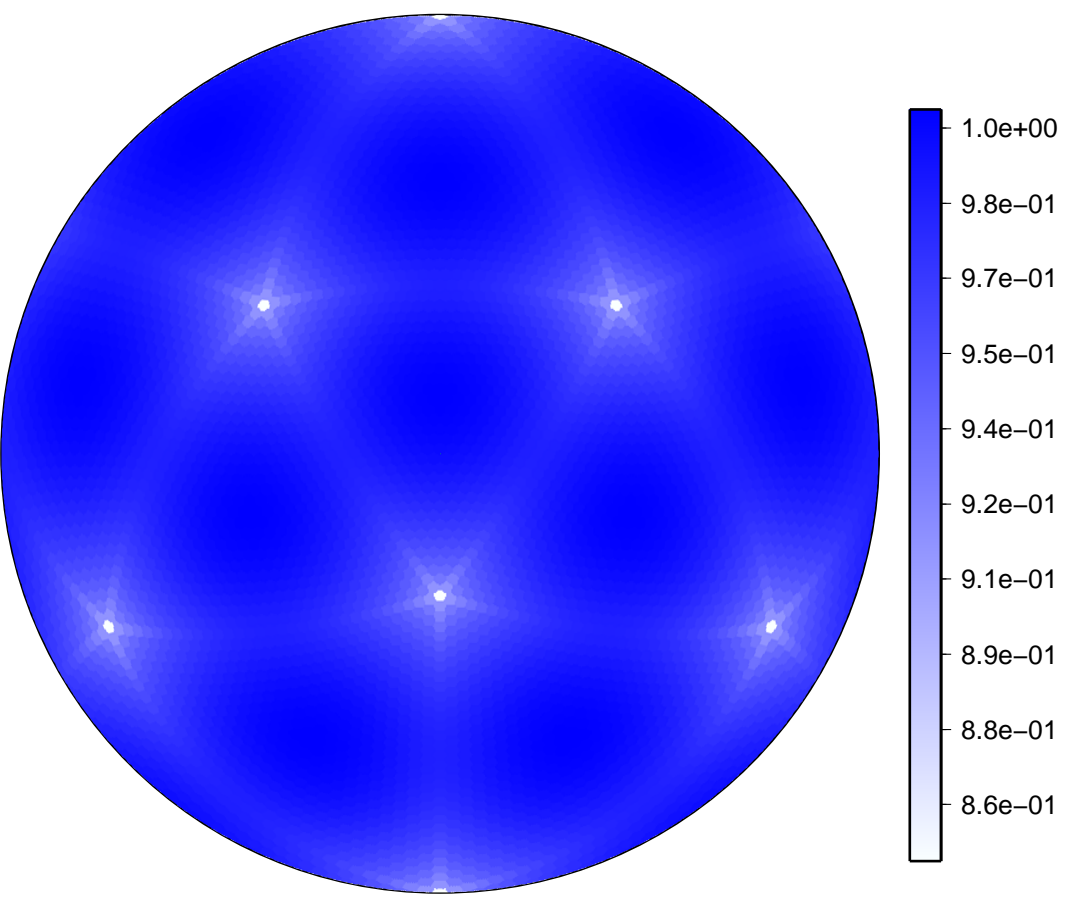

Figura 2.34: Razão entre a área da célula de Voronoi e o maior área de célula de Voronoi da malha (análogo à Figura 2.10 mas para a malha otimizada com spring dynamics).

Apesar do método ter sido desenvolvido para minimizar as distorções das células hexagonais, observamos que as malhas otimizadas com spring dynamics tem distorções maiores que as SCVT, porém, em média, menores que na malha icosaédrica (veja a Tabela 2.14). A distribuição da distorção na malha apresenta um padrão semelhante ao observado na malha SCVT (veja a Figura 2.35). Ao analisarmos o problema da distância entre os pontos médios das malhas primal e dual, observamos agora convergência da métrica máxima, como pode ser visto na Tabela 2.15. Isso indica que esse tipo de malha pode oferecer boas bases para discretizações de operadores que necessitam de proximidade dos pontos médios das malhas primal e dual. As células problemáticas nesse sentido são semelhantes as observadas com as malhas SCVT, as próximas aos pentágonos (veja a Figura 2.36).

\begin{tabular}{|c|c|c|c|c|c|c|}
\hline Distorções - SPRG & \multicolumn{3}{|c|}{ Triângulos } & \multicolumn{3}{c|}{ Hexágonos/Pentágonos } \\
\hline Nível & Máx & Média & Méd/Máx & Máx & Média & Méd/Máx \\
\hline 0 & 0.000000 & 0.000000 & 1.000000 & 0.000000 & 0.000000 & 1.000000 \\
\hline 1 & 0.105504 & 0.079122 & 0.749945 & 0.106606 & 0.076144 & 0.714258 \\
\hline 2 & 0.128185 & 0.077621 & 0.605544 & 0.174367 & 0.117227 & 0.672298 \\
\hline 3 & 0.133639 & 0.076949 & 0.575798 & 0.209900 & 0.129031 & 0.614725 \\
\hline 4 & 0.134988 & 0.075945 & 0.562603 & 0.222096 & 0.130277 & 0.586580 \\
\hline 5 & 0.135325 & 0.075433 & 0.557416 & 0.228592 & 0.129890 & 0.568220 \\
\hline 6 & 0.135441 & 0.075222 & 0.555383 & 0.234854 & 0.129583 & 0.551758 \\
\hline 7 & 0.135797 & 0.075148 & 0.553385 & 0.242543 & 0.129455 & 0.533740 \\
\hline 8 & 0.135999 & 0.075136 & 0.552476 & 0.255534 & 0.129444 & 0.506563 \\
\hline
\end{tabular}

Tabela 2.14: Análogo à Tabela 2.4 mas para a malha otimizada com spring dynamics. 


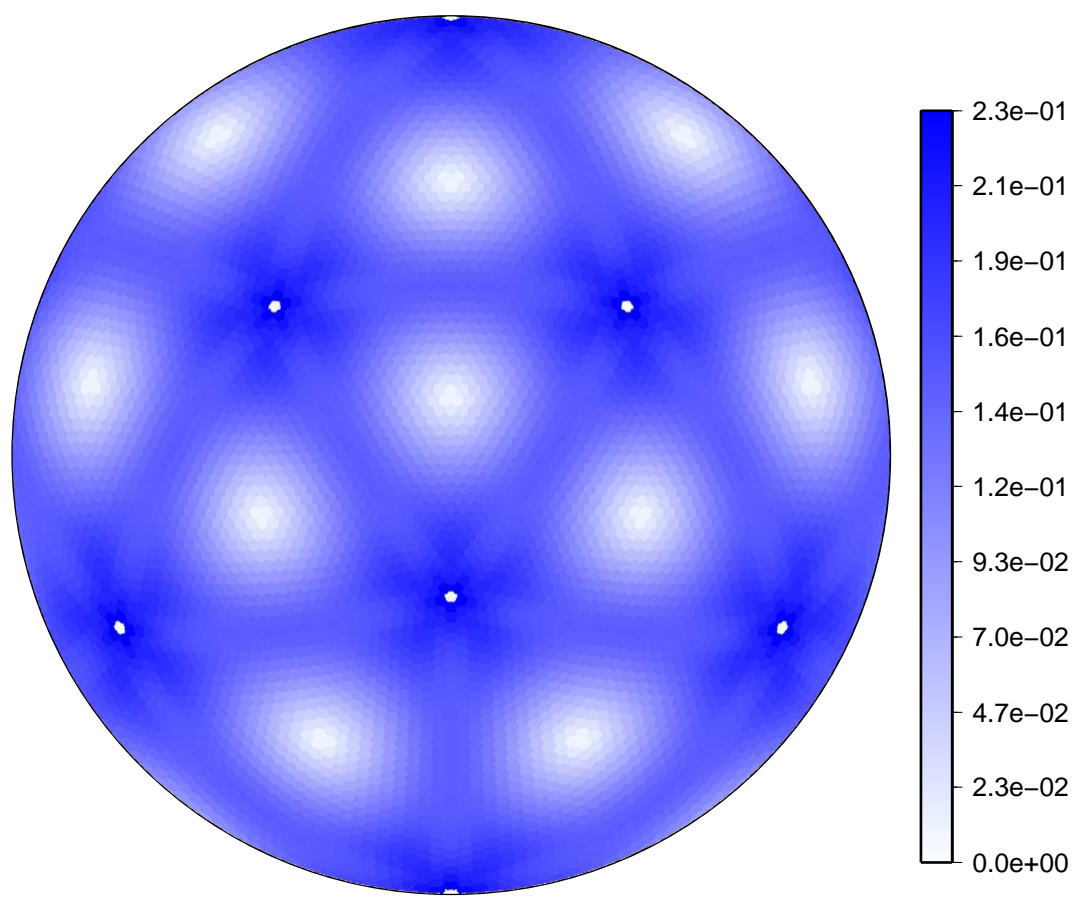

Figura 2.35: Distorção das células de Voronoi (análogo à Figura 2.11 mas para a malha otimizada com spring dynamics).

\begin{tabular}{|c|c|c|c|}
\hline \multicolumn{4}{|c|}{ Distâncias entre arestas primal e dual (SPRG) } \\
\hline Nível & Máx & Média & Mín/Máx \\
\hline 1 & $9.97 \mathrm{E}-02$ & $7.12 \mathrm{E}-02$ & 0.714254 \\
\hline 2 & $7.67 \mathrm{E}-02$ & $5.49 \mathrm{E}-02$ & 0.716213 \\
\hline 3 & $5.61 \mathrm{E}-02$ & $3.03 \mathrm{E}-02$ & 0.539285 \\
\hline 4 & $4.67 \mathrm{E}-02$ & $1.56 \mathrm{E}-02$ & 0.334822 \\
\hline 5 & $3.97 \mathrm{E}-02$ & $7.79 \mathrm{E}-03$ & 0.196407 \\
\hline 6 & $3.18 \mathrm{E}-02$ & $3.85 \mathrm{E}-03$ & 0.120930 \\
\hline 7 & $2.24 \mathrm{E}-02$ & $1.90 \mathrm{E}-03$ & 0.084866 \\
\hline 8 & $1.35 \mathrm{E}-02$ & $9.43 \mathrm{E}-04$ & 0.070003 \\
\hline
\end{tabular}

Tabela 2.15: Distâncias máximas e médias entre os pontos médios das arestas da malha triangular e de Voronoi normalizadas pelos respectivos comprimentos das arestas das células de Voronoi para malhas otimizadas com spring dynamics. 


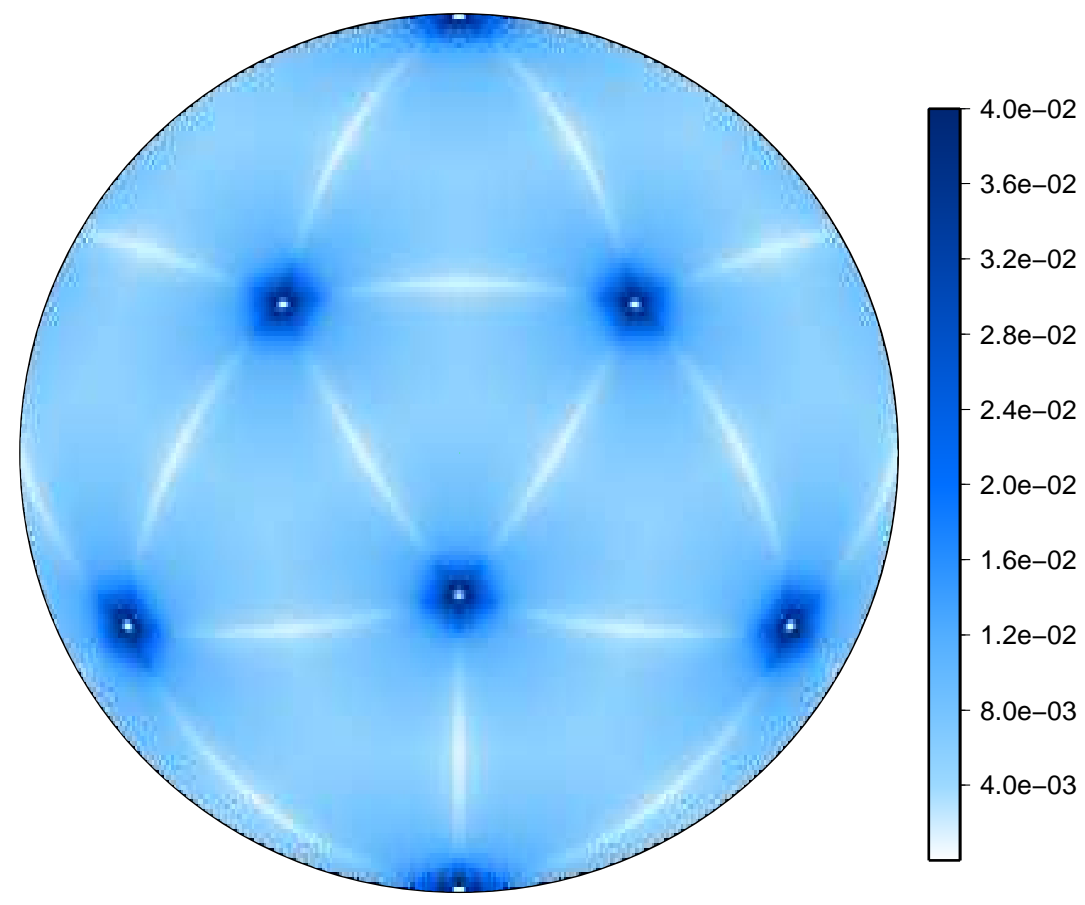

Figura 2.36: Distribuição das distâncias entre os pontos médios das arestas dos triângulos e os pontos médios das arestas das células de Voronoi normalizadas pelos respectivos comprimentos das arestas das células de Voronoi. Para cada célula de Voronoi apresentamos o máximo da distância entre arestas dessa célula. Foi usada uma malha icosaédrica de nível 5 (10242 nós) otimizada com spring dynamics. 


\subsubsection{Malhas de Heikes and Randall (1995)}

Vimos na seção 2.4.5 que os pontos médios das arestas das malhas primal e dual não necessariamente coincidem. Heikes e Randall [1995a] propuseram um método para minimizar globalmente essas distâncias entre os pontos médios das arestas. O método proposto consiste em escrever o problema como um conjunto de restrições e uma função objetivo a ser minimizada. Dessa forma, aplicando um algoritmo de otimização não linear, podemos obter uma distribuição de pontos que satisfazem a propriedade desejada. Miura e Kimoto [2005] propuseram um método iterativo para imitar a otimização de Heikes e Randall [1995a], deslocando gradativamente cada nó no sentido de reduzir a distância entre pontos médios das arestas que se intersectam. Tentamos reproduzir esse método, mas os resultados não foram tão bons quanto os descritos por Heikes e Randall [1995a]. Neste trabalho usamos o método implementado por J. Thuburn (não publicado), que utiliza um método bidimensional de direção conjugada de Powell para achar o mínimo local da função objetivo. As malhas obtidas com o otimizador de J. Thuburn se mostraram muito semelhantes às malhas obtidas por Heikes e Randall [1995a] (o pesquisador R. Heikes nos forneceu alguns exemplares de malhas deles).

Esse tipo de malha apresenta uma homogeneidade semelhante a icosaédrica básica no que diz respeito às distâncias entre nós (veja a Tabela 2.16), mas uma homogeneidade maior do ponto de vista de áreas (veja a Tabela 2.17), que agora apresenta distribuição mais suave (Figura 2.37).

\begin{tabular}{|c|c|c|c|c|c|c|c|}
\hline \multicolumn{4}{|c|}{ Estrutura da Malha } & \multicolumn{3}{c|}{ Distâncias entre nós em graus (km) - HR95 } \\
\hline Nível & Nós & Triângulos & Arestas & Mínima & Máxima & Média & Mín/Máx \\
\hline 0 & 12 & 20 & 30 & $63.43(7054)$ & $63.43(7054)$ & $63.43(7054)$ & 1.0000 \\
\hline 1 & 42 & 80 & 120 & $31.72(3527)$ & $36(4003)$ & $33.86(3765)$ & 0.8810 \\
\hline 2 & 162 & 320 & 480 & $15.49(1722)$ & $18.98(2110)$ & $17.23(1916)$ & 0.8160 \\
\hline 3 & 642 & 1280 & 1920 & $7.7(856)$ & $9.68(1076)$ & $8.65(962)$ & 0.7955 \\
\hline 4 & 2562 & 5120 & 7680 & $3.84(427)$ & $4.88(542)$ & $4.33(482)$ & 0.7885 \\
\hline 5 & 10242 & 20480 & 30720 & $1.92(213)$ & $2.44(272)$ & $2.17(241)$ & 0.7857 \\
\hline 6 & 40962 & 81920 & 122880 & $0.96(107)$ & $1.22(136)$ & $1.08(120)$ & 0.7859 \\
\hline 7 & 163842 & 327680 & 491520 & $0.48(0)$ & $0.61(0)$ & $0.54(0)$ & 0.7871 \\
\hline 8 & 655362 & 1310720 & 1966080 & $0.24(0)$ & $0.31(0)$ & $0.27(0)$ & 0.7874 \\
\hline
\end{tabular}

Tabela 2.16: Análogo à Tabela 2.1 mas para a malha otimizada com HR95.

\begin{tabular}{|c|c|c|c|c|}
\hline \multicolumn{5}{|c|}{ Áreas das células de Voronoi - HR95 } \\
\hline Nível & Mín & Máx & Média & Mín/Máx \\
\hline 0 & 1.047198 & 1.047198 & 1.047198 & 1.0000 \\
\hline 1 & 0.273844 & 0.309341 & 0.299199 & 0.8852 \\
\hline 2 & 0.072425 & 0.079109 & 0.077570 & 0.9155 \\
\hline 3 & 0.018650 & 0.019858 & 0.019574 & 0.9392 \\
\hline 4 & 0.004722 & 0.004999 & 0.004905 & 0.9446 \\
\hline 5 & 0.001186 & 0.001252 & 0.001227 & 0.9472 \\
\hline 6 & 0.000297 & 0.000313 & 0.000307 & 0.9478 \\
\hline 7 & 0.000074 & 0.000078 & 0.000077 & 0.9482 \\
\hline 8 & 0.000019 & 0.000020 & 0.000019 & 0.9491 \\
\hline
\end{tabular}

Tabela 2.17: Análogo à Tabela 2.3 mas para a malha otimizada com HR95.

Os indicadores de distorções também são semelhantes aos da malha icosaédrica básica (tabela 2.18), mas com distribuição um pouco mais suave (Figura 2.38). O grande diferencial desse tipo de malha é em relação ao problema de distância entre ponto médio de arestas da malha primal e dual. Vemos na Tabela 2.19 que há convergência linear da métrica máxima, essencial para termos 


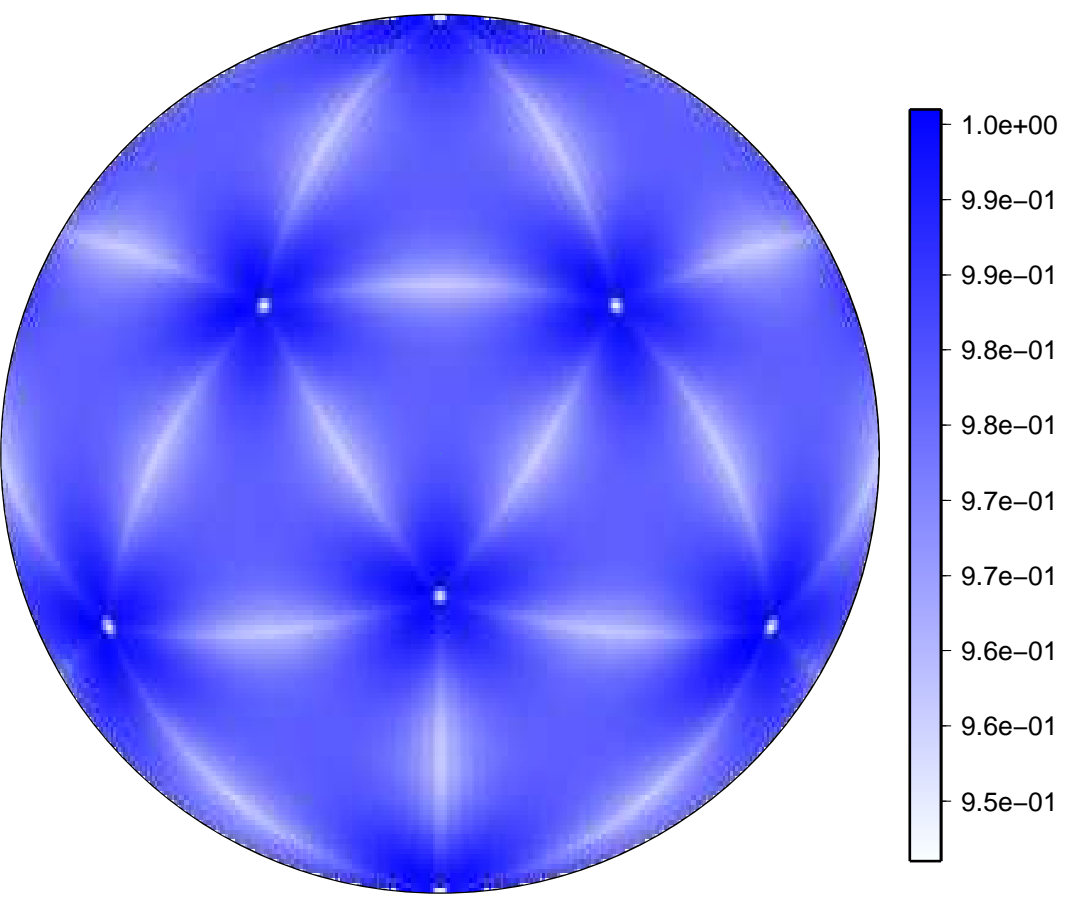

Figura 2.37: Razão entre a área da célula de Voronoi e o maior área de célula de Voronoi da malha (análogo à Figura 2.10 mas para a malha otimizada com HR95).

convergência da discretização do laplaciano, conforme descrito em Heikes e Randall [1995a].

\begin{tabular}{|c|c|c|c|c|c|c|}
\hline Distorções - HR95 & \multicolumn{3}{|c|}{ Triângulos } & \multicolumn{3}{c|}{ Hexágonos/Pentágonos } \\
\hline Nível & Máx & Média & Méd/Máx & Máx & Média & Méd/Máx \\
\hline 0 & 0.000000 & 0.000000 & 1.000000 & 0.000000 & 0.000000 & 1.000000 \\
\hline 1 & 0.105496 & 0.079122 & 0.750000 & 0.106601 & 0.076144 & 0.714286 \\
\hline 2 & 0.131209 & 0.089662 & 0.683358 & 0.194115 & 0.132687 & 0.683546 \\
\hline 3 & 0.136710 & 0.089940 & 0.657891 & 0.232189 & 0.150342 & 0.647500 \\
\hline 4 & 0.137819 & 0.089796 & 0.651549 & 0.248960 & 0.154885 & 0.622130 \\
\hline 5 & 0.137950 & 0.089699 & 0.650228 & 0.256254 & 0.155983 & 0.608706 \\
\hline 6 & 0.137545 & 0.089635 & 0.651679 & 0.259126 & 0.156196 & 0.602778 \\
\hline 7 & 0.136608 & 0.089485 & 0.655049 & 0.259952 & 0.156213 & 0.600929 \\
\hline 8 & 0.136122 & 0.089523 & 0.657668 & 0.259945 & 0.156318 & 0.601352 \\
\hline
\end{tabular}

Tabela 2.18: Análogo à Tabela 2.4 mas para a malha otimizada com HR95. 


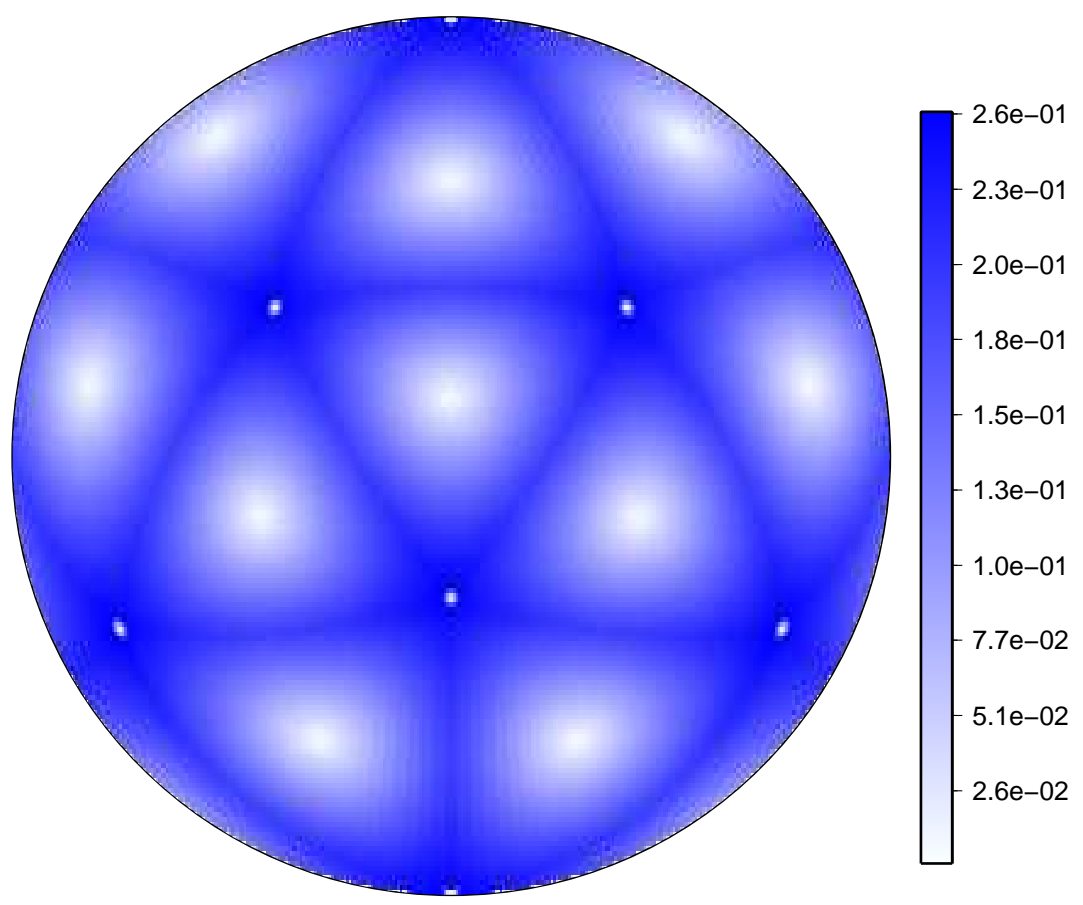

Figura 2.38: Distorção das células de Voronoi (análogo à Figura 2.11 mas para a malha otimizada com HR95).

\begin{tabular}{|c|c|c|c|}
\hline \multicolumn{5}{|c|}{ Distâncias entre arestas primal e dual (HR95) } \\
\hline Nível & Máx & Média & Mín/Máx \\
\hline 1 & $9.97 \mathrm{E}-02$ & $7.12 \mathrm{E}-02$ & 0.714286 \\
\hline 2 & $5.83 \mathrm{E}-02$ & $5.03 \mathrm{E}-02$ & 0.862595 \\
\hline 3 & $3.13 \mathrm{E}-02$ & $2.70 \mathrm{E}-02$ & 0.863417 \\
\hline 4 & $1.62 \mathrm{E}-02$ & $1.37 \mathrm{E}-02$ & 0.846550 \\
\hline 5 & $8.30 \mathrm{E}-03$ & $6.89 \mathrm{E}-03$ & 0.830282 \\
\hline 6 & $4.24 \mathrm{E}-03$ & $3.45 \mathrm{E}-03$ & 0.814804 \\
\hline 7 & $2.17 \mathrm{E}-03$ & $1.74 \mathrm{E}-03$ & 0.799330 \\
\hline 8 & $1.08 \mathrm{E}-03$ & $8.68 \mathrm{E}-04$ & 0.802373 \\
\hline
\end{tabular}

Tabela 2.19: Distâncias máximas e médias entre os pontos médios das arestas da malha triangular e de Voronoi normalizadas pelos respectivos comprimentos das arestas das células de Voronoi para malhas otimizadas com HR95. 


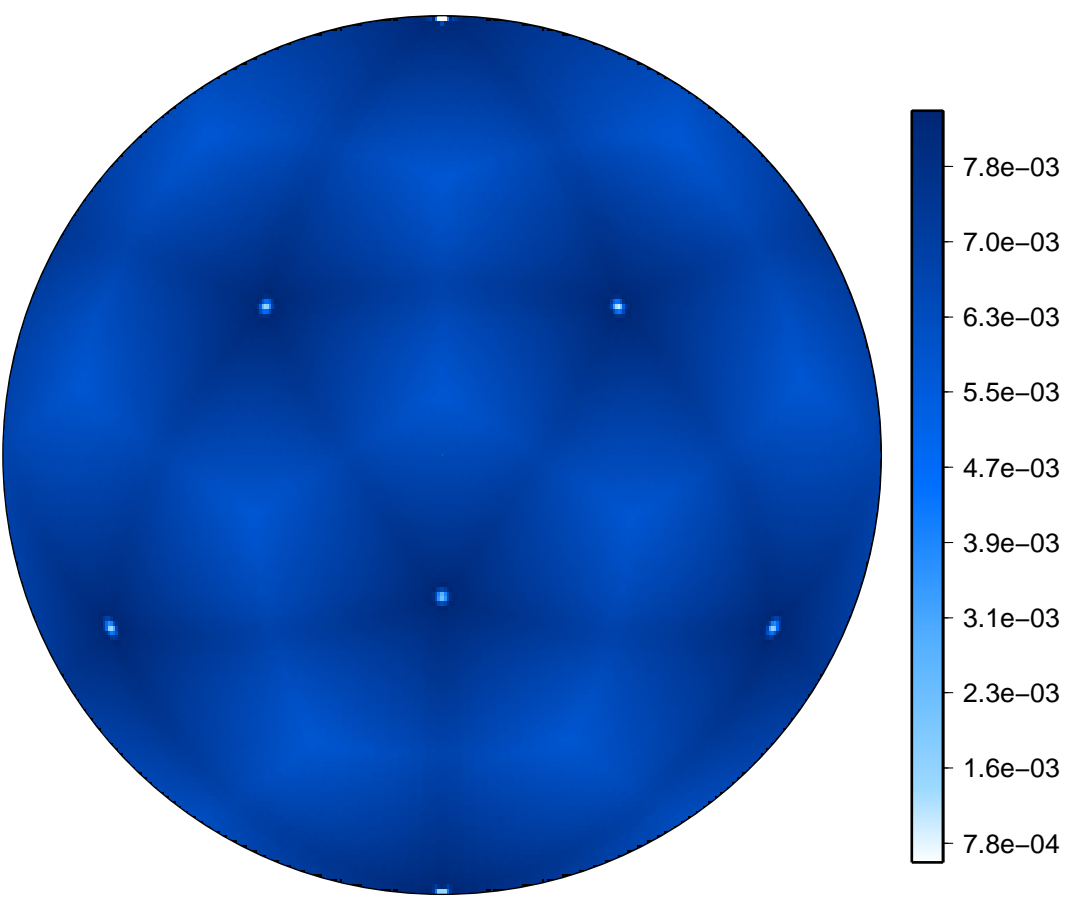

Figura 2.39: Distribuição das distâncias entre os pontos médios das arestas dos triângulos e os pontos médios das arestas das células de Voronoi normalizadas pelos respectivos comprimentos das arestas das células de Voronoi. Para cada célula de Voronoi apresentamos o máximo da distância entre arestas dessa célula. Foi usada uma malha icosaédrica de nível 5 (10242 nós) otimizada com HR95. 


\section{Capítulo 3}

\section{Análise de interferência de malha na discretização do divergente}

$\mathrm{Na}$ literatura o operador divergente é geralmente discretizado com base nos fluxos nos pontos médios das arestas das células computacionais, com auxílio do Teorema da Divergência. Ao longo da evolução do uso de malhas icosaédricas na modelagem atmosférica, constatou-se um curioso padrão entre o erro de discretização do operador divergente e a estrutura geométrica da malha. De acordo com a revisão que fizemos, esse problema é relatado explicitamente pela primeira vez em Tomita et al. [2001], mas aparentemente estaria presente em trabalhos mais antigos. No trabalho de Tomita et al. [2001] o padrão de interferência de malha no erro de discretização do divergente é atribuído a um problema de distorção das células computacionais. Eles verificaram que o padrão encontrado estava correlacionado com regiões de grandes variações na distribuição de área e distorção das células. Para contornar o problema propuseram uma otimização de spring dynamics, descrita no capítulo anterior.

Veremos neste capítulo que a distorção das células computacionais não é a causadora do padrão de interferência do erro de discretização do divergente, mas sim um outro fator ligado ao alinhamento das arestas da célula. Analisamos detalhadamente essa relação entre a geometria da malha icosaédrica e o erro de discretização do divergente pelo método mais usado na literatura. Provamos condições suficientes para obtermos ordem 2 de convergência de discretização do divergente usual na esfera. Por fim, mostramos diversos resultados numéricos da discretização do divergente e suas relações com a geometria da malha. Os resultados apresentados neste capítulo foram publicados em Peixoto e Barros [2013].

Começaremos a análise de discretização do divergente em polígonos no plano, para em seguida estendê-la à esfera. Depois, analisamos os resultados no contexto de malhas icosaédricas e apresentamos resultados numéricos.

\subsection{Análise no plano}

\subsubsection{Geometria}

Começamos com algumas notações, definições e resultados de geometria. Seja $\Omega$ um polígono convexo no plano com $n$ lados, formado pelos pontos $P_{i}, i=1, \ldots, n$. Para facilitar a notação consideramos os pontos ordenados no sentido anti-horário, e ainda que $P_{n+k}=P_{k}$, para $1 \leq k<n$. Seja $P_{0}$ o baricentro, ou centro de massa, de $\Omega$. Seja $Q_{i}$ o ponto médio da aresta $\gamma_{i}$, que conecta $P_{i}$ e $P_{i+1}$. Considere que a aresta $\gamma_{i}$ tenha comprimento $l_{i}=\left\|P_{i+1}-P_{i}\right\|$. Representamos esses elementos na Figura 3.1, onde também apresentamos os vetores normais às arestas $\left(\vec{n}_{i}\right)$.

Definição 3.1.1 (Polígono com lados opostos paralelos). Denominaremos por um polígono com lados opostos paralelos um polígono convexo com um número par de arestas $n$ tal que cada aresta $i$ seja paralela a sua aresta oposta $i+n / 2$. 


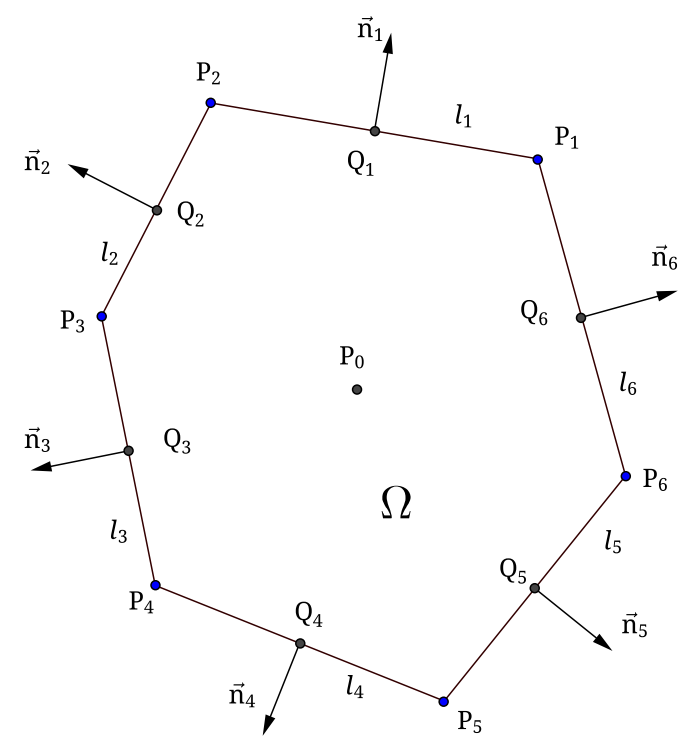

Figura 3.1: Notações para o polígono $\Omega$ no plano.

Definição 3.1.2 (Polígono alinhado). Diremos que um polígono é alinhado se tiver lados opostos paralelos e o comprimento das arestas opostas for igual.

Uma outra nomenclatura possível, existente na literatura para hexágonos, é de polígono centroidal (Villiers [2007]), mas esta nomenclatura pode gerar confusão com outros termos deste trabalho, portanto não vamos usá-la. Exemplos de polígonos alinhados são os paralelogramos, ou ainda os hexágonos com arestas 2 a 2 paralelas e de mesmo tamanho, ou qualquer polígono regular com número par de lados.

Proposição 3.1.3. Em um polígono com 4 ou 6 lados opostos paralelos, as retas que conectam os pontos médios das arestas opostas se intersectam em único ponto no interior do polígono.

Para o caso em que $n=4$ temos um paralelogramo, logo é simples verificar que o resultado é válido. Para o hexágono, o resultado da intersecção das retas em um único ponto está mostrado nos trabalhos de Villiers [2006] e Villiers [2007]. Esse ponto de intersecção não é necessariamente o centro de massa (veja na Figura 3.2 o caso de um hexágono). Além disso, esse resultado não é passível de ser estendido para polígonos com lados opostos paralelos com mais lados do que 6. Veja por exemplo o caso de um octógono com lados opostos paralelos na Figura 3.3, com 4 pontos de intersecção.

Proposição 3.1.4. Em um polígono alinhado com 4 ou 6 lados as retas que conectam os pontos médios das arestas opostas se intersectam no centro de massa do polígono.

Demonstração. Por definição, o centro de massa é a intersecção de todas as linhas retas que dividem o polígono em regiões de mesma área. Para $n=4$ temos um paralelogramo, logo é simples verificar que o resultado é valido. Para o hexágono alinhado, como o polígono tem lados opostos paralelos e de mesmo tamanho, uma reta que conecta os pontos médios opostos divide o polígono em 2 subpolígonos de mesma área. As 3 retas que conectam os pontos médios das arestas dividem o polígono em elementos de mesma área, logo, o seu ponto de encontro deve ser o centro de massa.

Uma consequência direta da proposição anterior é que as diagonais de um polígono alinhado também irão se encontrar em único ponto, que é o centro de massa. Além disso, o ponto de encontro será o ponto médio tanto das diagonais quanto das retas que conectam os pontos médios das arestas. Logo a distância de $P_{i}$ a $P_{0}$ será a mesma de $P_{i+n / 2}$ e $P_{0}$, assim como a distância de $Q_{i}$ a $P_{0}$ será a mesma de $Q_{i+n / 2}$ e $P_{0}$, onde $Q_{i}$ é o ponto médio da aresta $i$. 


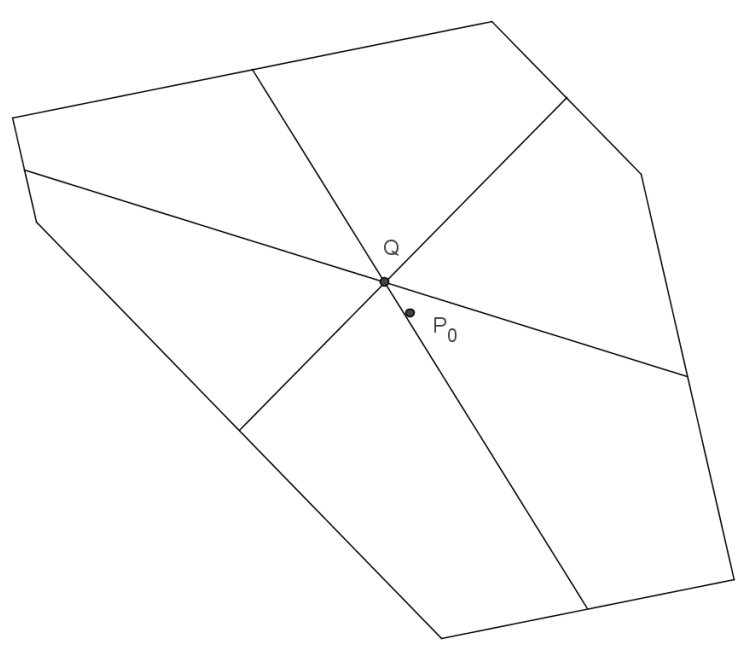

Figura 3.2: Hexágono com lados opostos paralelos. $Q$ é o ponto de encontro das retas que conectam os pontos médios das arestas e $P_{0}$ o centro de massa do polígono.

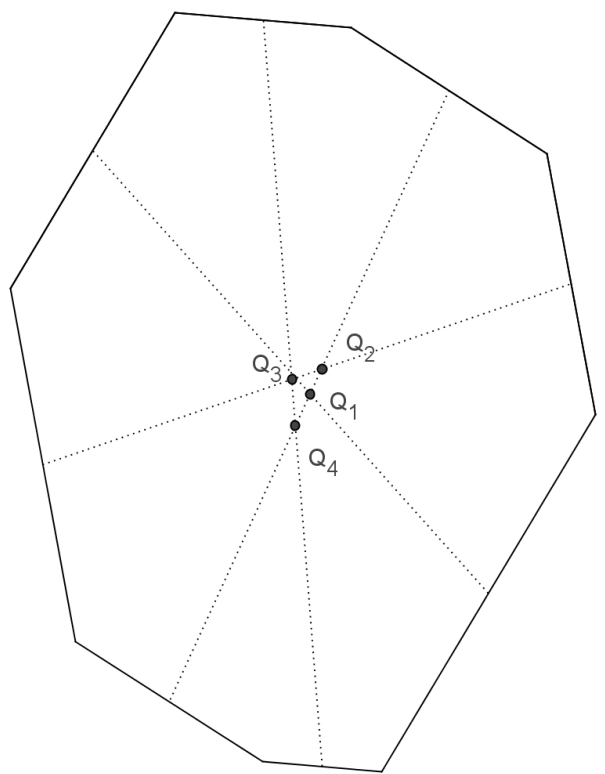

Figura 3.3: Octógono com lados opostos paralelos. $Q_{i}$ são o pontos de encontros das retas que conectam os pontos médios das arestas. 
Proposição 3.1.5. Um polígono convexo com pontos $P_{i}, i=1, \ldots, n$, onde $n$ é par, é alinhado se, e somente se, satisfizer $\Xi=0$, onde

$$
\Xi=\frac{1}{\bar{d} n} \sum_{i=1}^{n / 2}\left|d\left(P_{i+1+n / 2}, P_{i}\right)-d\left(P_{i+n / 2}, P_{i+1}\right)\right|+\left|d\left(P_{i+1}, P_{i}\right)-d\left(P_{i+n / 2+1}, P_{i+n / 2}\right)\right|,
$$

$d\left(P_{i}, P_{j}\right)=\left\|P_{i}-P_{j}\right\|, \bar{d}=\frac{1}{n} \sum_{i=1}^{n} d\left(P_{i+1}, P_{i}\right)$ e identificamos $P_{n+1}=P_{1}$.

Demonstração. Temos que

$$
\Xi=0 \Leftrightarrow\left\{\begin{array}{l}
d\left(P_{i+1+n / 2}, P_{i}\right)=d\left(P_{i+n / 2}, P_{i+1}\right) \\
d\left(P_{i+1}, P_{i}\right)=d\left(P_{i+n / 2+1}, P_{i+n / 2}\right)
\end{array}\right\}
$$

e portanto, se $\Xi=0$, o polígono tem lados opostos paralelos e de mesmo tamanho e vale a recíproca.

\subsubsection{Discretização do divergente}

O divergente de um campo vetorial $\vec{v}: \mathbb{R}^{2} \rightarrow \mathbb{R}^{2}$, com $\vec{v}=(u, v)$, em um ponto $\left(x_{0}, y_{0}\right)$ no plano é dado por

$$
\operatorname{div}(\vec{v})\left(x_{0}, y_{0}\right)=\nabla \cdot \vec{v}\left(x_{0}, y_{0}\right)=\frac{\partial u}{\partial x}\left(x_{0}, y_{0}\right)+\frac{\partial v}{\partial y}\left(x_{0}, y_{0}\right)
$$

Como consequência do Teorema da Divergência de Gauss, ele também pode ser expresso como

$$
\operatorname{div}(\vec{v})\left(x_{0}, y_{0}\right)=\lim _{\Omega \rightarrow\left\{\left(x_{0}, y_{0}\right)\right\}} \frac{1}{|\Omega|} \int_{\partial \Omega} \vec{v} \cdot \vec{n} d \partial \Omega,
$$

onde cada $\Omega$ é uma região do plano compacta contendo o ponto $\left(x_{0}, y_{0}\right)$ com fronteira $\partial \Omega$ suave por pedaços. $|\Omega|$ é a área de $\Omega, \vec{n}$ o vetor normal à fronteira e $d \partial \Omega$ o elemento de linha para a fronteira da célula. Definimos $\vec{v} \cdot \vec{n} d \partial \Omega$ como o fluxo por um elemento de linha $d \partial \Omega$. Sendo assim, o divergente nada mais é do que uma medida de fluxo por um elemento de linha.

Suponha que conhecemos vetores normais às arestas em seus pontos médios de uma célula poligonal $\Omega$ para um campo vetorial $\vec{v}$ e que queremos estimar o divergente em $P_{0}$, o centro de massa de $\Omega$. O método mais usual para tanto é tomarmos os fluxos nos pontos médios das arestas de uma célula computacional $\Omega$ (veja a Figura 3.1), isto é,

$$
\begin{aligned}
\operatorname{div}(\vec{v})\left(P_{0}\right) & \approx \frac{1}{|\Omega|} \int_{\Omega} \operatorname{div}(\vec{v}) d \Omega \\
& =\frac{1}{|\Omega|} \int_{\partial \Omega} \vec{v} \cdot \vec{n} d \partial \Omega \\
& \approx \frac{1}{|\Omega|} \sum_{i=1}^{n} \vec{v}\left(Q_{i}\right) \cdot \vec{n}_{i} l_{i} .
\end{aligned}
$$

Note que há duas aproximações na discretização descrita, uma devida à aproximação do valor do divergente no centro de massa pela média do divergente na célula, e outra devida à aproximação da integral de linha pela regra do ponto médio.

Vamos estimar a ordem do erro associado a esse método em relação a uma medida de tamanho de uma célula computacional poligonal. Tomaremos como métrica de comprimento da célula $\Omega$ o seu diâmetro $d=\sup _{p, q \in \Omega}\|p-q\|$. Seja $h_{i}=\left\|P_{i}-P_{0}\right\|$, então temos que $\max _{i=1, \ldots, n} h_{i} \leq d$, assim como os comprimentos das arestas também estão delimitados por $d$, isto é, $\max _{i=1, \ldots, n} l_{i} \leq d$.

Proposição 3.1.6. Seja $\vec{v}: \mathbb{R}^{2} \rightarrow \mathbb{R}^{2}$ um campo vetorial $\mathcal{C}^{4}$ e $\Omega$ um polígono convexo em $\mathbb{R}^{2}$ com diâmetro d. Então existe uma constante $C$ que independe do diâmetro d, tal que, para d pequeno, 
temos

$$
\left|\frac{1}{|\Omega|} \int_{\Omega} \operatorname{div}(\vec{v}) d \Omega-\operatorname{div}(\vec{v})\left(P_{0}\right)\right| \leq C d^{2},
$$

onde $P_{0}$ é o centro de massa de $\Omega$. Em outras palavras, a aproximação do divergente no centro de massa do polígono pela média do divergente no polígono é uma aproximação de ordem 2 em relação ao diâmetro do polígono.

Demonstração. Para facilitar a notação, seja $\delta=\operatorname{div}(\vec{v})$ o divergente do campo vetorial $\vec{v}$. O campo escalar $\delta$ será pelo menos $\mathcal{C}^{3}$, logo podemos considerar a expansão em Taylor de $\delta$ ao redor do ponto $P_{0}$ até ordem 3 e integral em relação a $\Omega$, obtendo

$$
\begin{aligned}
\frac{1}{|\Omega|} \int_{\Omega} \delta d \Omega=\delta\left(P_{0}\right)+\nabla \delta\left(P_{0}\right) \cdot \frac{1}{|\Omega|} \int_{\Omega}(P- & \left.P_{0}\right) d \Omega \\
& +\frac{1}{|\Omega|} \int_{\Omega}\left(P-P_{0}\right) \cdot\left(\nabla^{2} \delta\left(P_{0}\right)\left(P-P_{0}\right)\right) d \Omega+\ldots
\end{aligned}
$$

onde as integrais devem ser calculadas em relação à variável $P$. Usando o fato de que $P_{0}$ é o centro de massa, teremos que o segundo termo do lado direito da equação se anula. Majorando os termos das integrais temos o desejado, onde a constante $C$ irá depender dos elementos da hessiana de $\delta$ em $P_{0}$.

Proposição 3.1.7. Seja $\vec{v}: \mathbb{R}^{2} \rightarrow \mathbb{R}^{2}$ um campo vetorial $\mathcal{C}^{4}$ e $\Omega$ um polígono convexo em $\mathbb{R}^{2}$ com área satisfazendo $\alpha d^{2} \leq|\Omega| \leq d^{2}$, onde d é o diâmetro do polígono e $\alpha>0$. Então existe uma constante $C$ que independe do diâmetro $d$, tal que, para d pequeno, temos

$$
\left|\frac{1}{|\Omega|} \int_{\Omega} \delta d \Omega-\frac{1}{|\Omega|} \sum_{i=1}^{n} \vec{v}\left(Q_{i}\right) \cdot \vec{n}_{i} l_{i}\right| \leq C d .
$$

onde $P_{0}$ é o centro de massa de $\Omega$ e $Q_{i}, \vec{n}_{i}$ e $l_{i}$ são respectivamente o ponto médio, o vetor normal e o comprimento da aresta $i$ de $\Omega$. Em outras palavras, a aproximação do divergente médio em $\Omega$ pelo fluxo médio no centro das arestas é uma aproximação de ordem 1 em relação ao tamanho do polígono.

Demonstração. Utilizando o Teorema da Divergência (Teorema de Gauss), temos que

$$
\frac{1}{|\Omega|} \int_{\Omega} \delta d \Omega=\frac{1}{|\Omega|} \int_{\partial \Omega} \vec{v} \cdot \vec{n} d \partial \Omega
$$

onde temos que $\partial \Omega$ é o bordo de $\Omega$ e $\vec{n}$ é o vetor unitário normal ao bordo de $\Omega$, que é poligonal. Agora considere a seguinte parametrização das arestas,

$$
\gamma_{i}(l)=l \vec{t}_{i}+Q_{i}, \quad l \in\left[-l_{i} / 2, l_{i} / 2\right]
$$

onde $\vec{t}_{i}$ é o vetor unitário tangente à aresta $i$ no sentido anti-horário (de $P_{i}$ para $P_{i+1}$ ). Note que $\gamma_{i}\left(-l_{i} / 2\right)=P_{i}, \gamma_{i}\left(l_{i} / 2\right)=P_{i+1}, \gamma_{i}(0)=Q_{i}$ e que $\gamma_{i}^{\prime}(l)=\vec{t}_{i}$ independe de $l$. Além disso $\left\|\gamma^{\prime}(t)\right\|=\left\|\vec{t}_{i}\right\|=1$, então,

$$
\frac{1}{|\Omega|} \int_{\partial \Omega} \vec{v} \cdot \vec{n} d \partial \Omega=\frac{1}{|\Omega|} \sum_{i=1}^{n} \int_{\gamma_{i}} \vec{v} \cdot \vec{n} d \gamma_{i}=\frac{1}{|\Omega|} \sum_{i=1}^{n} \int_{-l_{i} / 2}^{l_{i} / 2} \vec{v}\left(\gamma_{i}(l)\right) \cdot \vec{n}_{i} d l,
$$

onde o vetor $\vec{n}_{i}$ é normal à aresta $\gamma_{i}$.

Considere a velocidade normal em relação à aresta $\gamma_{i}$ como sendo $w_{i}(l)=\vec{v}\left(\gamma_{i}(l)\right) \cdot \vec{n}_{i}$. Expan- 
dindo em série de Taylor ao redor de $l=0$ temos

$$
\int_{-l_{i} / 2}^{l_{i} / 2} \vec{v}\left(\gamma_{i}(l)\right) \cdot \vec{n}_{i} d l=w_{i}(0) l_{i}+w_{i}^{\prime \prime}(0) \frac{l_{i}^{3}}{24}+O\left(l_{i}^{5}\right)
$$

onde as integrais de ordens ímpares anulam-se por conta da paridade. Note que $w_{i}(0)=\vec{v}\left(Q_{i}\right) \cdot \vec{n}_{i}$ e $w_{i}^{\prime \prime}(0)$ é a derivada segunda da componente normal de $\vec{v}$ na direção tangente à aresta em $Q_{i}$, isto é, $w_{i}^{\prime \prime}(0)=\vec{t}_{i} \cdot \nabla^{2}\left(\vec{v}\left(Q_{i}\right) \cdot \vec{n}_{i}\right) \vec{t}_{i}$, onde $\nabla^{2}\left(\vec{v}\left(Q_{i}\right) \cdot \vec{n}_{i}\right)$ é a hessiana de $\vec{v} \cdot \vec{n}_{i}$ calculado em $Q_{i}$. Portanto obtemos

$$
\begin{aligned}
\frac{1}{|\Omega|} \int_{\partial \Omega} \vec{v} \cdot \vec{n} d \partial \Omega= & \frac{1}{|\Omega|} \sum_{i=1}^{n} \vec{v}\left(Q_{i}\right) \cdot \vec{n}_{i} l_{i}+ \\
& \frac{1}{|\Omega|} \sum_{i=1}^{n} \frac{l_{i}^{3}}{24} \vec{t}_{i} \cdot \nabla^{2}\left(\vec{v}\left(Q_{i}\right) \cdot \vec{n}_{i}\right) \vec{t}_{i}+\frac{1}{|\Omega|} \sum_{i=1}^{n} O\left(l_{i}^{5}\right) .
\end{aligned}
$$

Considerando que existe uma constante $\alpha>0$ tal que $\alpha d^{2} \leq|\Omega|$, isto é, $\Omega$ não é muito distorcido, então $1 /|\Omega| \leq 1 /\left(\alpha d^{2}\right)$. Usando ainda que $l_{i} \leq d$, temos que existe uma constante $C$ que depende somente da geometria do polígono e das derivadas segundas do campo vetorial nos pontos médios das arestas, tal que,

$$
\left|\frac{1}{|\Omega|} \int_{\partial \Omega} \vec{v} \cdot \vec{n} d \partial \Omega-\frac{1}{|\Omega|} \sum_{i=1}^{n} \vec{v}\left(Q_{i}\right) \cdot \vec{n}_{i} l_{i},\right| \leq C \frac{1}{d^{2}} d^{3} \leq C d .
$$

Teorema 3.1.8. Seja $\vec{v}: \mathbb{R}^{2} \rightarrow \mathbb{R}^{2}$ um campo vetorial $\mathcal{C}^{4}$ e $\Omega$ um polígono convexo em $\mathbb{R}^{2}$ com área satisfazendo $\alpha d^{2} \leq|\Omega| \leq d^{2}$, onde d é o diâmetro do polígono. Então existe uma constante $C$ que independe do diâmetro $d$, tal que, para d pequeno, temos

$$
\left|\operatorname{div}(\vec{v})\left(P_{0}\right)-\frac{1}{|\Omega|} \sum_{i=1}^{n} \vec{v}\left(Q_{i}\right) \cdot \vec{n}_{i} l_{i}\right| \leq C d,
$$

onde $P_{0}$ é o centro de massa de $\Omega, d=\sup _{p, q \in \Omega}\|p-q\| e Q_{i}, \vec{n}_{i}$ e $l_{i}$ são respectivamente o ponto médio, o vetor normal e o comprimento da aresta $i$ de $\Omega$. Em outras palavras, o erro de aproximação do método de estimativa do divergente com base nos fluxos nos pontos médio tem erro de pelo menos ordem um em relação ao tamanho da célula.

Demonstração. Consequência direta das proposições 3.1.6 e 3.1.7 anteriores, bastando aplicar a desigualdade triangular.

Observação 3.1.1. Na Proposição 3.1.7 foi usada uma aproximação da integral ao longo de uma aresta com base apenas no valor da função no ponto médio da aresta, que é um método de ordem $3 \mathrm{em}$ relação ao comprimento da aresta. Métodos de integração de ordem mais alta poderiam ser usados, assim a ordem do erro de aproximação resultante (Teorema 3.1.8) fica restrito a ordem de aproximação dada pela Proposição 3.1.6, ou seja, ordem 2. Não parece ser interessante usar métodos de integração com ordens maiores que 4, pois aumentaríamos o custo computacional sem ganho na ordem de discretização resultante.

Embora no caso geral podemos mostrar ordem um de discretização do divergente pela regra do ponto médio, há alguns casos especiais onde é possível verificarmos ordem 2 na discretização, mesmo usando o método de integração com base no ponto médio das arestas. Esses casos ocorrem quando o polígono $\Omega$ for alinhado. Vamos verificar essa proposição a seguir e detalhar as condições para termos segunda ordem de discretização. 
Proposição 3.1.9. Seja $\vec{v}: \mathbb{R}^{2} \rightarrow \mathbb{R}^{2}$ um campo vetorial $\mathcal{C}^{4}$ e $\Omega$ um polígono alinhado em $\mathbb{R}^{2}$, com área satisfazendo $\alpha d^{2} \leq|\Omega| \leq d^{2}$, onde $d$ é o diâmetro do polígono e $\alpha>0$. Então existe uma constante $C$ que independe do diâmetro $d$, tal que, para d pequeno, temos

$$
\left|\frac{1}{|\Omega|} \int_{\Omega} \delta d \Omega-\frac{1}{|\Omega|} \sum_{i=1}^{n} \vec{v}\left(Q_{i}\right) \cdot \vec{n}_{i} l_{i}\right| \leq C d^{2} .
$$

onde $Q_{i}, \vec{n}_{i}$ e $l_{i}$ são respectivamente o ponto médio, o vetor normal e o comprimento da aresta $i$ de $\Omega, d=\sup _{p, q \in \Omega}\|p-q\|$ e $P_{0}$ é o centro de massa de $\Omega$. Em outras palavras, a aproximação do divergente médio em $\Omega$ pelo fluxo médio no centro das arestas é uma aproximação de ordem $2 \mathrm{em}$ relação ao tamanho do polígono, se esse for alinhado.

Demonstração. A demonstração é a mesma da Proposição 3.1 .7 até a equação (3.10), porém vamos mostrar que, no caso de polígonos alinhados, os termos relativos às derivadas segundas do campo vetorial tem ordem um em relação a $d$ e com isso seguirá o resultado.

Primeiro note que para polígonos alinhados temos $n$ par, $l_{i}=l_{i+\frac{n}{2}}, \vec{n}_{i}=-\vec{n}_{i+\frac{n}{2}}$ e $\vec{t}_{i}=-\vec{t}_{i+\frac{n}{2}}$ para $i=1, . ., \frac{n}{2}$. Considerando essas relações na equação (3.10) temos que

$$
\begin{aligned}
\frac{1}{|\Omega|} \int_{\partial \Omega} \vec{v} \cdot \vec{n} d \partial \Omega= & \frac{1}{|\Omega|} \sum_{i=1}^{n} \vec{v}\left(Q_{i}\right) \cdot \vec{n}_{i} l_{i}+ \\
& \frac{1}{|\Omega|} \sum_{i=1}^{n / 2} \frac{l_{i}^{3}}{24} \vec{t}_{i} \cdot\left(\nabla^{2}\left(\vec{v}\left(Q_{i}\right) \cdot \vec{n}_{i}\right)-\nabla^{2}\left(\vec{v}\left(Q_{i+n / 2}\right) \cdot \vec{n}_{i}\right)\right) \vec{t}_{i}+\frac{1}{|\Omega|} \sum_{i=1}^{n} O\left(l_{i}^{5}\right) .
\end{aligned}
$$

Agora observe que os termos das hessianas $\nabla^{2}\left(\vec{v}\left(Q_{i}\right) \cdot \vec{n}_{i}\right)$ e $\nabla^{2}\left(\vec{v}\left(Q_{i+n / 2}\right) \cdot \vec{n}_{i}\right)$ diferem por $O(d)$ e, como, $l_{i}=O(d)$ para todo $i$, segue que

$$
\frac{1}{|\Omega|} \int_{\partial \Omega} \vec{v} \cdot \vec{n} d \partial \Omega=\frac{1}{|\Omega|} \sum_{i=1}^{n} \vec{v}\left(Q_{i}\right) \cdot \vec{n}_{i} l_{i}+\frac{O\left(d^{4}\right)}{|\Omega|} .
$$

Usando que $\frac{1}{|\Omega|} \leq \frac{1}{\alpha d^{2}}$ temos o resultado.

Teorema 3.1.10. Seja $\vec{v}: \mathbb{R}^{2} \rightarrow \mathbb{R}^{2}$ um campo vetorial $\mathcal{C}^{4}$ e $\Omega$ um polígono alinhado em $\mathbb{R}^{2}$ com área satisfazendo $\alpha d^{2} \leq|\Omega| \leq d^{2}$, onde d é o diâmetro do polígono. Então existe uma constante $C$ que independe do diâmetro $d$, tal que, para d pequeno, temos

$$
\left|\operatorname{div}(\vec{v})\left(x_{0}, y_{0}\right)-\frac{1}{|\Omega|} \sum_{i=1}^{n} \vec{v}\left(Q_{i}\right) \cdot \vec{n}_{i} h_{i}\right| \leq C d^{2},
$$

onde $P_{0}=\left(x_{0}, y_{0}\right)$ é o centro de massa de $\Omega, d=\sup _{p, q \in \Omega}\|p-q\|$ e $Q_{i}, \vec{n}_{i}$ e $l_{i}$ são respectivamente o ponto médio, o vetor normal e o comprimento da aresta $i$ de $\Omega$. Em outras palavras, o erro de aproximação do método de estimativa do divergente com base nos fluxos nos pontos médio tem erro de pelos menos ordem dois em relação ao tamanho da célula, para células alinhadas.

Demonstração. Consequência direta das proposições 3.1.6 e 3.1.9 anteriores, bastando-se aplicar a desigualdade triangular.

Observação 3.1.2. No caso de polígonos com número ímpar de lados, mesmo se os mesmos forem regulares, a segunda ordem na discretização do divergente pode não ser atingida. Considere o triângulo equilátero com vértices $P_{1}=l\left(-\frac{\sqrt{3}}{6}, \frac{1}{2}\right), P_{2}=l\left(-\frac{\sqrt{3}}{6},-\frac{1}{2}\right)$ e $P_{3}=l\left(\frac{\sqrt{3}}{3}, 0\right)$, que possui o centro de massa na origem do plano cartesiano e diâmetro $d=l>0$ (ver Figura 3.4). Para um campo 


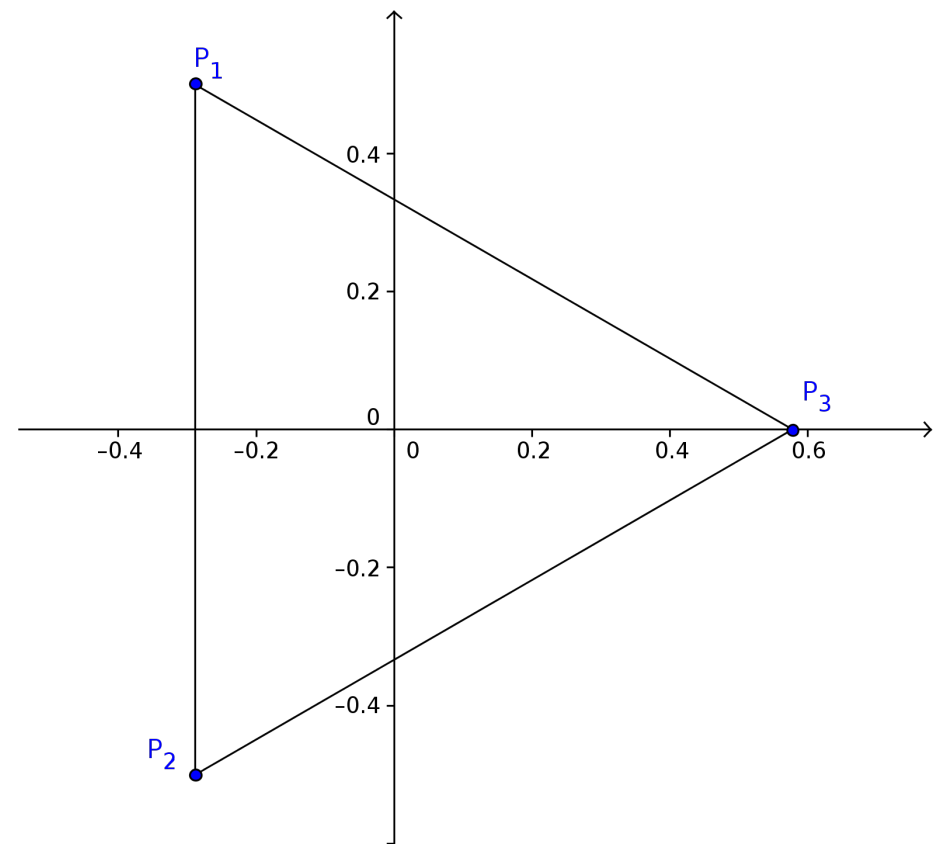

Figura 3.4: Exemplo de triângulo equilátero.

vetorial dado por

$$
\vec{v}=\left[\begin{array}{c}
u_{0}+u_{1} x+u_{2} x^{2} \\
0
\end{array}\right]
$$

o divergente exato é $\delta=u_{1}$, enquanto a discretização resulta em $\delta_{d}=u_{1}-l \frac{u_{2}}{4 \sqrt{3}}$, com erro de primeira ordem. Não é difícil estender o exemplo para pentágonos regulares.

\subsection{Análise na esfera}

Começamos com conceitos de geometria esférica, definições, notações e resultados de relações geométricas.

\subsubsection{Projeção radial de um polígono}

Definição 3.2.1 (Projeção Radial). Denotamos por projeção radial (azimutal ou gnomônica) de um ponto $Q$ da esfera sobre um plano tangente à esfera em um certo ponto $P$, o ponto de intersecção entre o plano tangente e a semireta que parte do centro da esfera e passa pelo ponto $Q$. Veja a Figura 3.5.

Definição 3.2.2 (Polígono Esférico Alinhado). Denominaremos por um polígono esférico alinhado um polígono esférico tal que sua projeção radial no plano tangente à esfera no seu centro de massa seja um polígono alinhado neste plano.

Na Figura 3.6 mostramos a projeção de um quadrilátero esférico no plano tangente. Nesta figura podemos ver como as arestas do quadrilátero, que são geodésicas, são projetadas como retas no plano tangente. Se o quadrilátero definido no plano tangente for alinhado, então diremos que o quadrilátero esférico também será.

Vamos definir notações e apresentar resultados que podem ser obtidos puramente a partir de relações trigonométricas entre os elementos usados na construção de polígonos esféricos projetados radialmente. Denotaremos por $\Omega$ um polígono esférico formado pelos vértices $P_{i}, i=1, \ldots, n$. Sem perda de generalidade, considere o sistema de coordenadas cartesianas definido tal que o centro de massa (conforme a definição 2.4.1) de $\Omega, P_{0}$, seja o polo norte, isto é, $P_{0}=(0,0,1)$ e seja 


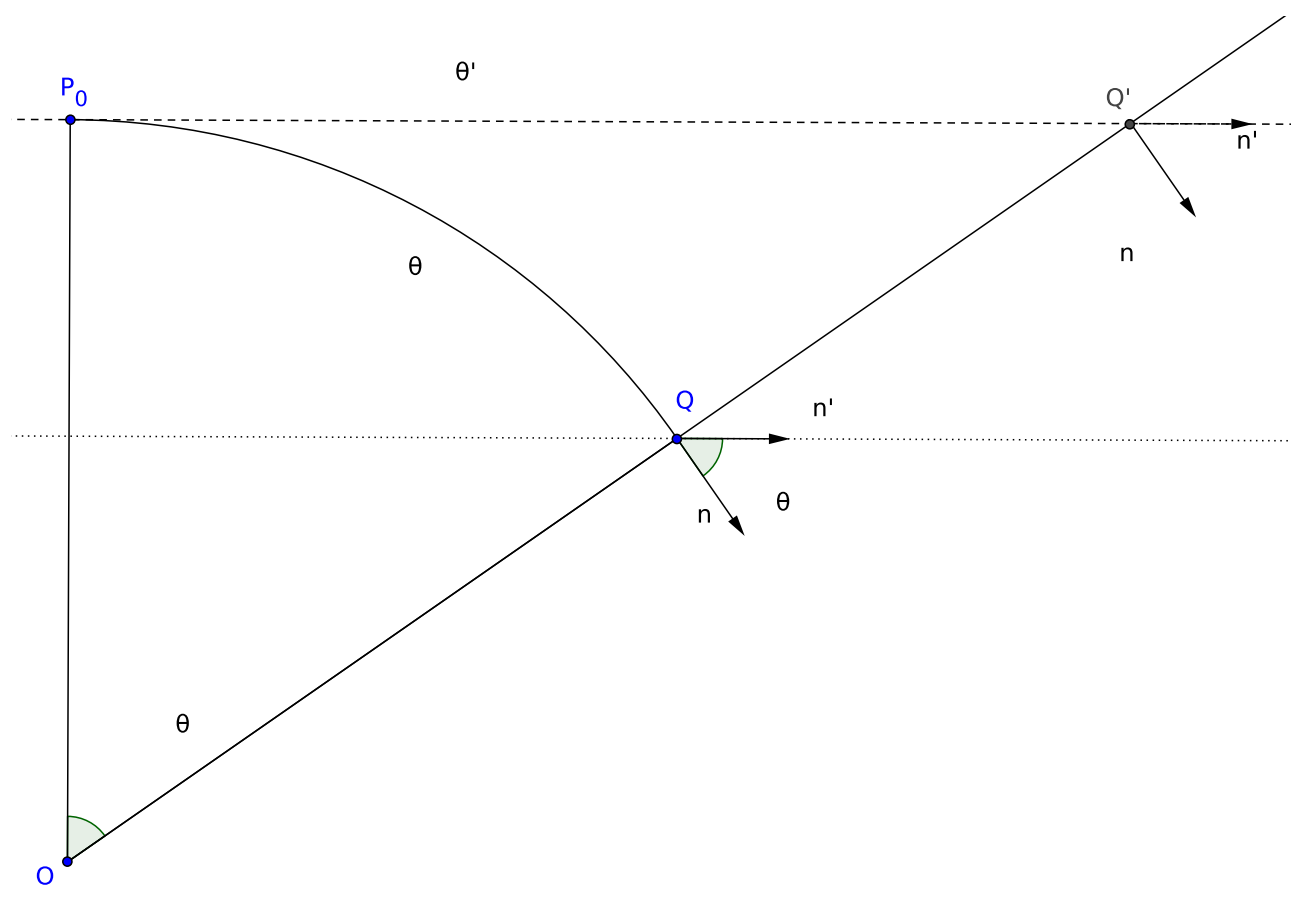

Figura 3.5: Notações para projeção radial.

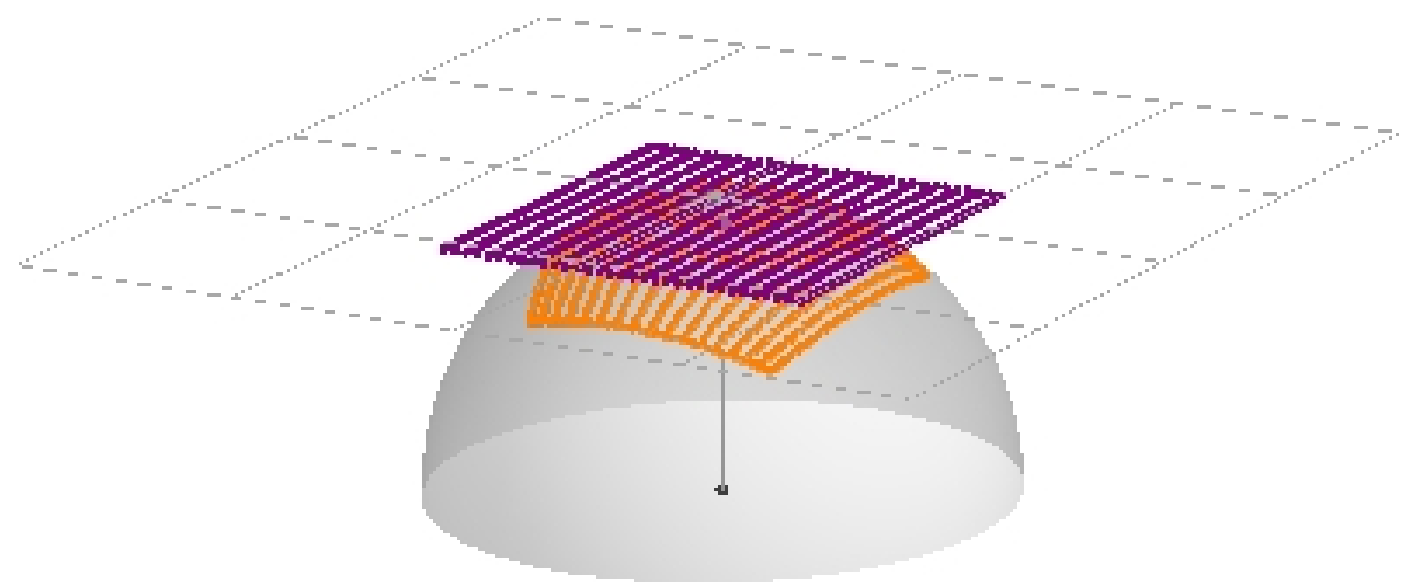

Figura 3.6: Projeção radial (azimutal ou gnomônica) de um quadrilátero esférico. Em laranja aparecem pontos do quadrilátero esférico e em azul suas projeções radiais no plano tangente ao centro de massa do polígono esférico. 
$O=(0,0,0)$ o centro (zero) do sistema. Seja $\Omega^{\prime}$ a projeção radial de $\Omega$ no plano tangente $\Gamma$ à esfera em $P_{0}$. Todos os elementos projetados serão representados com um sobre-escrito "linha" dos respectivos elementos da esfera. Definimos, para o polígono esférico, que:

- $\gamma_{i}$ é uma aresta geodésica de $\Omega$, formada pelos pontos $\left(P_{i}, P_{i+1}\right)$, com ponto médio $Q_{i}$;

- $l_{i}=\operatorname{acos}\left\langle P_{i+1}, P_{i}\right\rangle$ é o comprimento (em ângulo) da aresta $\gamma_{i}$;

- $l=\max _{i=1, \ldots, n} l_{i}$ é o máximo comprimento das arestas;

- $h_{i}=\operatorname{acos}\left\langle P_{i}, P_{0}\right\rangle$ é a distância (em ângulo) do centro de massa a um vértice $P_{i}$;

- $h=\max _{i=1, \ldots, n} h_{i}$ é o raio do polígono esférico;

- $\theta_{i}=\operatorname{acos}\left\langle Q_{i}, P_{0}\right\rangle$ é o ângulo entre o centro de massa e o ponto médio da aresta $\gamma_{i}$;

- $d=\sup _{p, q \in \Omega} \operatorname{acos}(\langle p, q\rangle)$ é o diâmetro de $\Omega$.

Agora para o polígono projetado $\left(\Omega^{\prime}\right)$, definimos que:

- $\Omega^{\prime}$ é formado pelo vértices $P_{i}^{\prime}, i=1, \ldots, n$, no plano $\Gamma$;

- $P_{i}^{\prime}=\frac{P_{i}}{\left\langle P_{i}, P_{0}\right\rangle}=\frac{P_{i}}{\cos \left(h_{i}\right)}$ é a projeção de $P_{i}$ em $\Gamma$;

- $Q_{i}^{\prime}=\frac{Q_{i}}{\left\langle Q_{i}, P_{0}\right\rangle}=\frac{Q_{i}}{\cos \left(\theta_{i}\right)}$ é a projeção de $Q_{i}$ em $\Gamma$;

- $h_{i}^{\prime}=\left\|P_{i}^{\prime}-P_{0}\right\|$ é a distância do centro de massa $P_{0}$ a um vértice $P_{i}^{\prime}$ de $\Omega^{\prime}$;

- $h^{\prime}=\max _{i=1, \ldots, n} h_{i}^{\prime}$ é o raio do polígono projetado;

- $l_{i}^{\prime}=\left\|P_{i+1}^{\prime}-P_{i}^{\prime}\right\|$ é o comprimento da aresta $i$ de $\Omega^{\prime}$;

- $l^{\prime}=\max _{i=1, \ldots, n} l_{i}^{\prime}$ é o máximo comprimento das arestas de $\Omega^{\prime}$;

- $\theta_{i}^{\prime}=\left\|Q_{i}^{\prime}-P_{0}\right\|$ é o distância do centro de massa até o ponto médio da aresta $i$ de $\Omega^{\prime}$;

- $\theta^{\prime}=\max _{i=1, \ldots, n} \theta_{i}^{\prime}$ é o máximo das distâncias do centro de massa até os pontos médios das arestas;

- $d^{\prime}=\sup _{p, q \in \Omega^{\prime}}\|p-q\|$ é o diâmetro de $\Omega^{\prime}$.

Representamos a maioria desses elementos na Figura 3.7, para um hexágono esférico ou plano. Apresentamos a seguir algumas relações que serão úteis mais adiante.

As arestas geodésicas podem ser parametrizadas como

$$
\gamma_{i}(t)=P_{i} \cos (t)+\tilde{P}_{i, i+1} \sin (t),
$$

onde $\tilde{P}_{i, i+1}$ é um vetor ortogonal a $P_{i}$ contido no plano gerado por $P_{i}, P_{i+1}$ dado por

$$
\tilde{P}_{i, i+1}=\frac{P_{i+1}-P_{i}\left\langle P_{i}, P_{i+1}\right\rangle}{\left\|P_{i+1}-P_{i}\left\langle P_{i}, P_{i+1}\right\rangle\right\|}
$$

e $t \in[0, \phi]$, $\operatorname{com} \phi=\arccos \left(\left\langle P_{i}, P_{i+1}\right\rangle\right)=\arcsin \left(\left\|P_{i+1} \times P_{i}\right\|\right)$ sendo o ângulo entre os dois pontos da esfera e o centro da mesma. Note que, com essa parametrização, $\left\|\gamma_{i}^{\prime}(t)\right\|=1$.

Podemos relacionar as distâncias esféricas com as distâncias projetadas no plano da seguinte forma:

$$
\begin{aligned}
h_{i}^{\prime} & =\tan \left(h_{i}\right), \\
\theta_{i}^{\prime} & =\tan \left(\theta_{i}\right), \\
d^{\prime} & =\tan (d) .
\end{aligned}
$$




$$
\begin{aligned}
l_{i}^{\prime} & =\sqrt{\left\langle P_{i+1}^{\prime}-P_{i}^{\prime}, P_{i+1}^{\prime}-P_{i}^{\prime}\right\rangle} \\
& =\sqrt{\left\langle\frac{P_{i+1}}{\left\langle P_{i+1}, P_{0}\right\rangle}-\frac{P_{i}}{\left\langle P_{i}, P_{0}\right\rangle}, \frac{P_{i+1}}{\left\langle P_{i+1}, P_{0}\right\rangle}-\frac{P_{i}}{\left\langle P_{i}, P_{0}\right\rangle}\right\rangle} \\
& =\sqrt{\frac{1}{\cos ^{2}\left(h_{i}\right)}+\frac{1}{\cos ^{2}\left(h_{i+1}\right)}-2 \frac{\cos \left(l_{i}\right)}{\cos \left(h_{i+1}\right) \cos \left(h_{i}\right)}}
\end{aligned}
$$

Para $l_{i}$ pequeno, expandindo a expressão de $l_{i}^{\prime}$ em série de Taylor em função de $l_{i}, h_{i}$ e $h_{i+1}$ em torno de zero temos que,

$$
l_{i}^{\prime}=l_{i}-\frac{1}{24} l_{i}{ }^{3}+\frac{1}{4} h_{i+1}{ }^{2} l_{i}+\frac{1}{4} h_{i}{ }^{2} l_{i}-\frac{1}{4} \frac{h_{i}{ }^{2} h_{i+1}{ }^{2}}{l_{i}}+\frac{1}{8} \frac{h_{i}{ }^{4}}{l_{i}}+\frac{1}{8} \frac{h_{i+1}{ }^{4}}{l_{i}}+\ldots=l_{i}+r_{d^{3}}^{l_{i}},
$$

onde $r_{d^{3}}^{l_{i}}$ é o resto da expansão em Taylor que possui ordem de $d^{3}$.

Se $\Omega$ for convexo, então $\Omega^{\prime}$ também será. Teremos ainda que existem $j$ e $k$ tais que $d^{\prime}=\left\|P_{j}-P_{k}\right\|$ e $d=\operatorname{acos}\left\langle P_{j}, P_{k}\right\rangle$. A relação entre os diâmetros do polígono esférico e projetado será dada por

$$
\begin{aligned}
d^{\prime} & =\sqrt{\left\langle P_{j}^{\prime}-P_{k}^{\prime}, P_{j}^{\prime}-P_{k}^{\prime}\right\rangle} \\
& =\sqrt{\frac{1}{\cos ^{2}\left(h_{j}\right)}+\frac{1}{\cos ^{2}\left(h_{k}\right)}-2 \frac{\cos (d)}{\cos \left(h_{j}\right) \cos \left(h_{k}\right)}},
\end{aligned}
$$

expandindo $d^{\prime}$ como função de $h_{j}, h_{k}$ e $d$ em torno de zero, temos que

$$
d^{\prime}=d\left(1-\frac{1}{24} d^{2}+\frac{1}{4} h_{j}^{2}+\frac{1}{4} h_{k}^{2}-\frac{1}{4} \frac{h_{k}{ }^{2} h_{j}^{2}}{d^{2}}+\frac{1}{8} \frac{h_{j}{ }^{4}}{d^{2}}+\frac{1}{8} \frac{h_{k}{ }^{4}}{d^{2}}+O\left(d^{3}\right)\right),
$$

logo, para $d$ pequeno temos que existem constantes $\beta_{1}$ e $\beta_{2}$, tais que $\beta_{1} d \leq d^{\prime} \leq \beta_{2} d$, e portanto $d^{\prime}=d+O\left(d^{3}\right)$.

Podemos também relacionar as áreas do polígono esférico com a do polígono projetado radialmente. Considere a aplicação $\vec{\psi}: \Omega^{\prime} \in \Gamma \rightarrow \Omega \in S^{2}$, onde

$$
\begin{gathered}
\vec{\psi}(s, t)=\frac{1}{\sqrt{1+s^{2}+t^{2}}}(s, t, 1), \\
\left\|\frac{\partial \vec{\psi}}{\partial s} \times \frac{\partial \vec{\psi}}{\partial t}\right\|=\frac{1}{\left(s^{2}+t^{2}+1\right)^{\frac{3}{2}}}=1-\frac{3}{2} s^{2}-\frac{3}{2} t^{2}+\frac{15}{8} t^{4}+\frac{15}{4} t^{2} s^{2}+\frac{15}{8} s^{4}+\ldots
\end{gathered}
$$

onde usamos a expansão em série de Taylor na última igualdade. Logo

$$
\begin{aligned}
|\Omega|= & \int_{\Omega} d \Omega \\
= & \int_{\Omega^{\prime}}\left\|\frac{\partial \vec{\psi}}{\partial s} \times \frac{\partial \vec{\psi}}{\partial t}\right\| d \Omega^{\prime} \\
= & \int_{\Omega^{\prime}}\left(1-\frac{3}{2} s^{2}-\frac{3}{2} t^{2}+\frac{15}{8} t^{4}+\frac{15}{4} t^{2} s^{2}+\frac{15}{8} s^{4}+\ldots\right) d \Omega^{\prime} \\
& \left|\Omega^{\prime}\right|+\int_{\Omega^{\prime}}\left(-\frac{3}{2} s^{2}-\frac{3}{2} t^{2}+\frac{15}{8} t^{4}+\frac{15}{4} t^{2} s^{2}+\frac{15}{8} s^{4}+\ldots\right) d \Omega^{\prime},
\end{aligned}
$$

e portanto

$$
\frac{|\Omega|}{\left|\Omega^{\prime}\right|}=1+r_{d^{2}}^{\Omega}
$$

onde $r_{d^{2}}^{\Omega}$ é o resto da expansão de Taylor envolvendo as integrais de $s^{2 k}$ e $t^{2 k}$, para $k=1,2, .$. em 

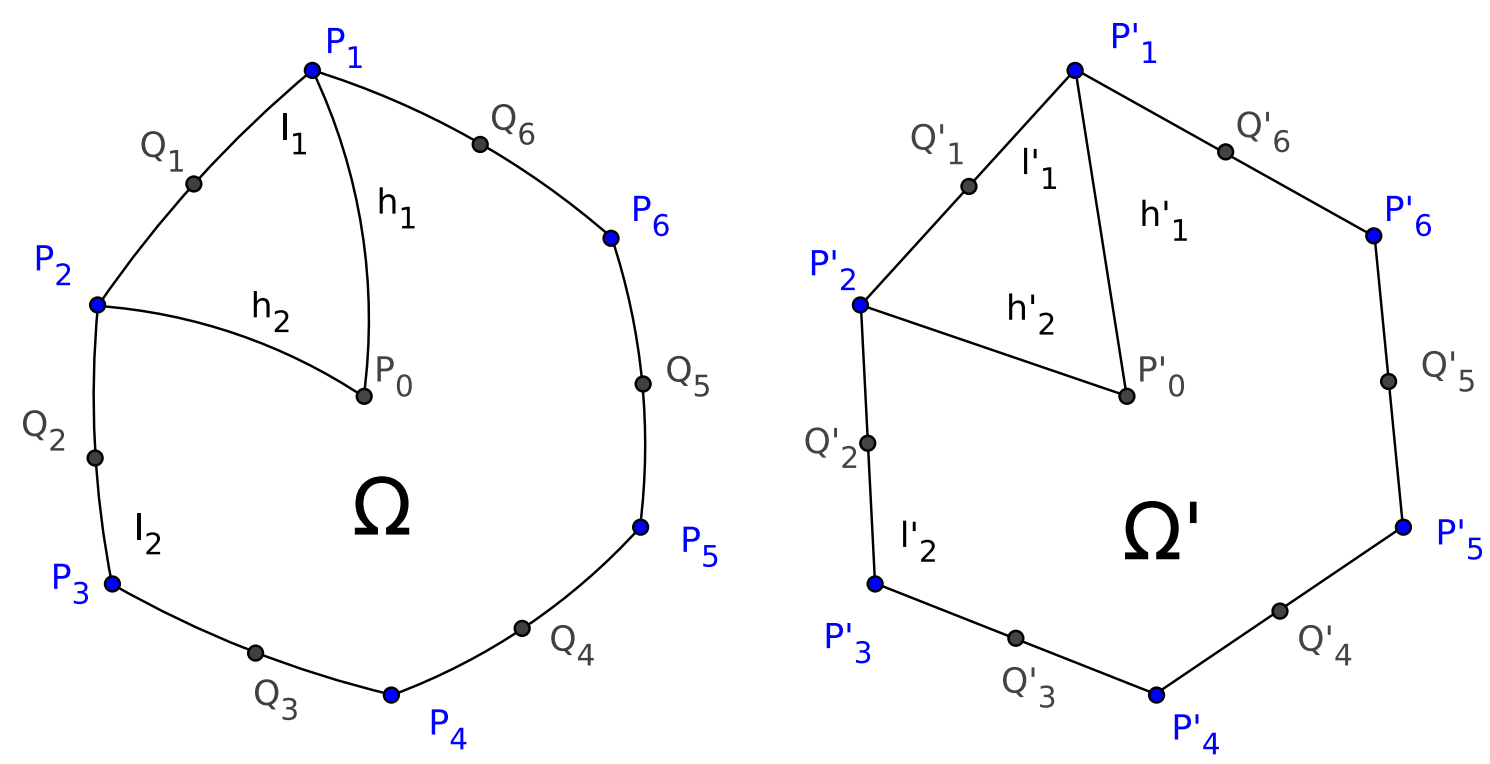

Figura 3.7: Indexação do polígono esférico e plano.

$\Omega^{\prime}$, dividido por $\left|\Omega^{\prime}\right|$, e possui ordem de $\left(d^{\prime}\right)^{2}$, que por sua vez, pelas relação entre $d$ e $d^{\prime}$ anteriores, também possui ordem de $d^{2}$.

Usando a projeção radial, o centro de massa esférico, $P_{0}$, que também pertence ao plano $\Gamma$, não será necessariamente o centro de massa de $\Omega^{\prime}$. Porém vamos mostrar que $P_{0}=\bar{P}_{0}+O\left(d^{2}\right)$, onde $\bar{P}_{0}$ é o centro de massa do polígono $\Omega^{\prime}$.

Primeiro note que o centro de massa (não restrito à esfera) de $\Omega$ terá a forma $P_{0}^{*}=\left(0,0, z^{*}\right)$ (veja a definição na seção 2.4.4), com

$$
\begin{aligned}
z^{*} & =\frac{1}{|\Omega|} \int_{\Omega} z d \Omega=\frac{1}{|\Omega|} \int_{\Omega^{\prime}} \frac{1}{\sqrt{1+s^{2}+t^{2}}}\left\|\frac{\partial \vec{\psi}}{\partial s} \times \frac{\partial \vec{\psi}}{\partial t}\right\| d \Omega^{\prime} \\
& =\frac{1}{|\Omega|} \int_{\Omega^{\prime}}\left(1-2 s^{2}-2 t^{2}+3 t^{4}+6 s^{2} t^{2}+3 s^{4}+\cdots\right) d \Omega^{\prime} \\
& =\frac{\left|\Omega^{\prime}\right|}{|\Omega|}+O\left(d^{2}\right)=1+O\left(d^{2}\right)
\end{aligned}
$$

e consequentemente $\left\|P_{0}^{*}-P_{0}\right\| \leq C d^{2}$, para alguma constante $C$.

Agora, comparando o centro de massa esférico $P_{0}$ com o centro de massa $\bar{P}_{0}$ do polígono plano $\Omega^{\prime}$, teremos que ambos possuem coordenada $z$ igual a 1 . Calculando a coordenada $\bar{x}$ de $\bar{P}_{0}$ temos que

$$
\begin{aligned}
0 & =\frac{1}{z^{*}|\Omega|} \int_{\Omega} x d \Omega \\
& =\frac{\left|\Omega^{\prime}\right|}{z^{*}|\Omega|} \frac{1}{\left|\Omega^{\prime}\right|} \int_{\Omega^{\prime}} s \frac{1}{\sqrt{1+s^{2}+t^{2}}}\left\|\frac{\partial \vec{\psi}}{\partial s} \times \frac{\partial \vec{\psi}}{\partial t}\right\| d \Omega^{\prime} \\
& =\frac{\left|\Omega^{\prime}\right|}{z^{*}|\Omega|} \frac{1}{\left|\Omega^{\prime}\right|} \int_{\Omega^{\prime}} s\left(1-2 s^{2}-2 t^{2}+3 t^{4}+6 s^{2} t^{2}+3 s^{4}+\cdots\right) d \Omega^{\prime} \\
& =\frac{\left|\Omega^{\prime}\right|}{z^{*}|\Omega|} \bar{x}-\frac{1}{z^{*}|\Omega|} \int_{\Omega^{\prime}} s\left(2 s^{2}+2 t^{2}-3 t^{4}-6 s^{2} t^{2}-3 s^{4}+\cdots\right) d \Omega^{\prime} \\
& =\bar{x}+O\left(d^{2}\right) .
\end{aligned}
$$


De forma similar obtemos que $\bar{y}=O\left(d^{2}\right)$, logo $\bar{P}_{0}=P_{0}+O\left(d^{2}\right)$.

Vejamos agora a generalização da proposição (3.1.5), referente ao índice de alinhamento, para a esfera.

Proposição 3.2.3. Um polígono esférico com um número par de arestas é alinhado se, e somente se, $\Xi=0$, onde

$$
\Xi=\frac{1}{\bar{d} n} \sum_{i=1}^{n / 2}\left|d\left(P_{i+1+n / 2}, P_{i}\right)-d\left(P_{i+n / 2}, P_{i+1}\right)\right|+\left|d\left(P_{i+1}, P_{i}\right)-d\left(P_{i+n / 2+1}, P_{i+n / 2}\right)\right|,
$$

$P_{i}, i=1, \ldots, n$, são os pontos do polígono esférico em coordenadas cartesianas, $d\left(P_{i}, P_{j}\right)$ é a distância em ângulo entre os pontos $P_{i}$ e $P_{j}, \bar{d}=\frac{1}{n} \sum_{i=1}^{n} d\left(P_{i}, P_{i+1}\right)$ e consideramos $P_{n+i}=P_{i}$.

Demonstração. Seja $d_{i, j}=\operatorname{acos}\left(\left\langle P_{i}, P_{j}\right\rangle\right)$, então podemos escrever $\Xi$ como

$$
\Xi=\frac{1}{\bar{d} n} \sum_{i=1}^{n / 2}\left[\left|d_{i+1+n / 2, i}-d_{i+n / 2, i+1}\right|+\left|l_{i}-l_{i+n / 2}\right|\right] .
$$

Assim,

$$
\Xi=0 \Leftrightarrow\left\{\begin{array}{l}
l_{i}=l_{i+n / 2} \\
d_{i+1+n / 2, i}=d_{i+n / 2, i+1}
\end{array}\right\}_{i=1, \ldots, n / 2}
$$

Usando as equações que relacionam comprimentos no polígono esférico em relação ao projetado, teremos que,

$$
\begin{array}{rll}
h_{i}^{\prime}=h_{i+n / 2}^{\prime} & \Leftrightarrow & h_{i}=h_{i+n / 2}, \\
l_{i}^{\prime}=l_{i+n / 2}^{\prime} & \Leftrightarrow \quad l_{i}=l_{i+n / 2} .
\end{array}
$$

Além disso, a distância no plano $d_{i, i+n / 2+1}^{\prime}=\left\|P_{i+n / 2+1}^{\prime}-P_{i}^{\prime}\right\|$ será igual a distância $d_{i+1, i+n / 2}^{\prime}=$ $\left\|P_{i+n / 2}^{\prime}-P_{i+1}^{\prime}\right\|$ se, e somente se, a distância na esfera $d_{i, i+n / 2+1}=\operatorname{acos}\left(\left\langle P_{i+n / 2+1}, P_{i}\right\rangle\right)$ for igual a $d_{i+1, i+n / 2}=\operatorname{acos}\left(\left\langle P_{i+n / 2}, P_{i+1}\right\rangle\right)$, pois

$$
\begin{aligned}
d_{i, i+n / 2+1}^{\prime}, & =\sqrt{\left\langle P_{i+n / 2+1}^{\prime}-P_{i}^{\prime}, P_{i+n / 2+1}^{\prime}-P_{i}^{\prime}\right\rangle} \\
& =\sqrt{\left\langle\frac{P_{i+n / 2+1}}{\left\langle P_{i+n / 2+1}, P_{0}\right\rangle}-\frac{P_{i}}{\left\langle P_{i}, P_{0}\right\rangle}, \frac{P_{i+n / 2+1}}{\left\langle P_{i+n / 2+1}, P_{0}\right\rangle}-\frac{P_{i}}{\left\langle P_{i}, P_{0}\right\rangle}\right\rangle} \\
& =\sqrt{\frac{1}{\cos \left(h_{i+n / 2+1}\right)^{2}}+\frac{1}{\cos \left(h_{i}\right)^{2}}-2 \frac{\cos \left(d_{i, i+n / 2+1}\right)}{\cos \left(h_{i+n / 2+1}\right) \cos \left(h_{i}\right)}}
\end{aligned}
$$

e

$$
\begin{aligned}
d_{i+1, i+n / 2}^{\prime}, & =\sqrt{\left\langle P_{i+n / 2}^{\prime}-P_{i+1}^{\prime}, P_{i+n / 2}^{\prime}-P_{i+1}^{\prime}\right\rangle} \\
& =\sqrt{\frac{1}{\cos \left(h_{i+n / 2}\right)^{2}}+\frac{1}{\cos \left(h_{i+1}\right)^{2}}-2 \frac{\cos \left(d_{i+1, i+n / 2}\right)}{\cos \left(h_{i+n / 2}\right) \cos \left(h_{i+1}\right)}} \\
& =\sqrt{\frac{1}{\cos \left(h_{i}\right)^{2}}+\frac{1}{\cos \left(h_{i+n / 2+1}\right)^{2}}-2 \frac{\cos \left(d_{i+1, i+n / 2}\right)}{\cos \left(h_{i}\right) \cos \left(h_{i+n / 2+1}\right)}}
\end{aligned}
$$


Logo teremos que

$$
\begin{gathered}
\sum_{i=1}^{n / 2}\left[\left|d_{i+1+n / 2, i}-d_{i+n / 2, i+1}\right|+\left|l_{i}-l_{i+n / 2}\right|\right]=0 \\
\Longleftrightarrow \\
\sum_{i=1}^{n / 2}\left[\left|d_{i+1+n / 2, i}^{\prime}-d_{i+n / 2, i+1}^{\prime}\right|+\left|l_{i}^{\prime}-l_{i+n / 2}^{\prime}\right|\right]=0
\end{gathered}
$$

Agora usando a proposição (3.1.5) temos o resultado desejado.

\subsubsection{Projeção radial de campo vetorial}

Para transferirmos a análise de discretização do divergente da esfera para o plano tangente $\Gamma$ precisamos definir uma noção de projeção de um campo vetorial da esfera para $\Gamma$. Iremos definir essa projeção vetorial de tal forma que os fluxos através das arestas de polígonos sejam localmente preservados.

Considere um plano $\Lambda$ tangente à esfera em um ponto qualquer $P$ de um polígono esférico $\Omega$. Seja $\Gamma_{P}$ o plano paralelo a $\Gamma$ que passa pelo ponto $P$. A interseç̧ão destes dois planos, $\Lambda$ e $\Gamma_{P}$, é uma reta que define um ângulo $\phi_{p}<\pi / 2$ entre eles. A projeção de um vetor $\vec{v}(P)$ será definida por $\vec{v}^{\prime}\left(P^{\prime}\right)$, onde $P^{\prime}$ é a projeção radial de $P$, obtido pela rotação de $\vec{v}(P)$ ao redor de $\zeta$ pelo ângulo $\phi_{p}$. Isto é,

$$
\vec{v}^{\prime}\left(P^{\prime}\right)=R_{P} \vec{v}(P)
$$

onde $R_{P}$ é a matriz de rotação que, para $\Gamma$ fixo, depende apenas de $P$, mas não de $\vec{v}$. Ilustramos os elementos evolvidos nesta projeção nas figuras 3.8 e 3.9 .

A projeção vetorial definida corresponde a uma projeção ortogonal do vetor $\vec{v}$ em $\Gamma$, seguido de uma restauração de sua magnitude. Como $\left(R_{p}\right)$ varia suavemente em relação a $P$, o campo vetorial projetado $\vec{v}^{\prime}$ tem o mesmo grau de diferenciabilidade que $\vec{v}$.

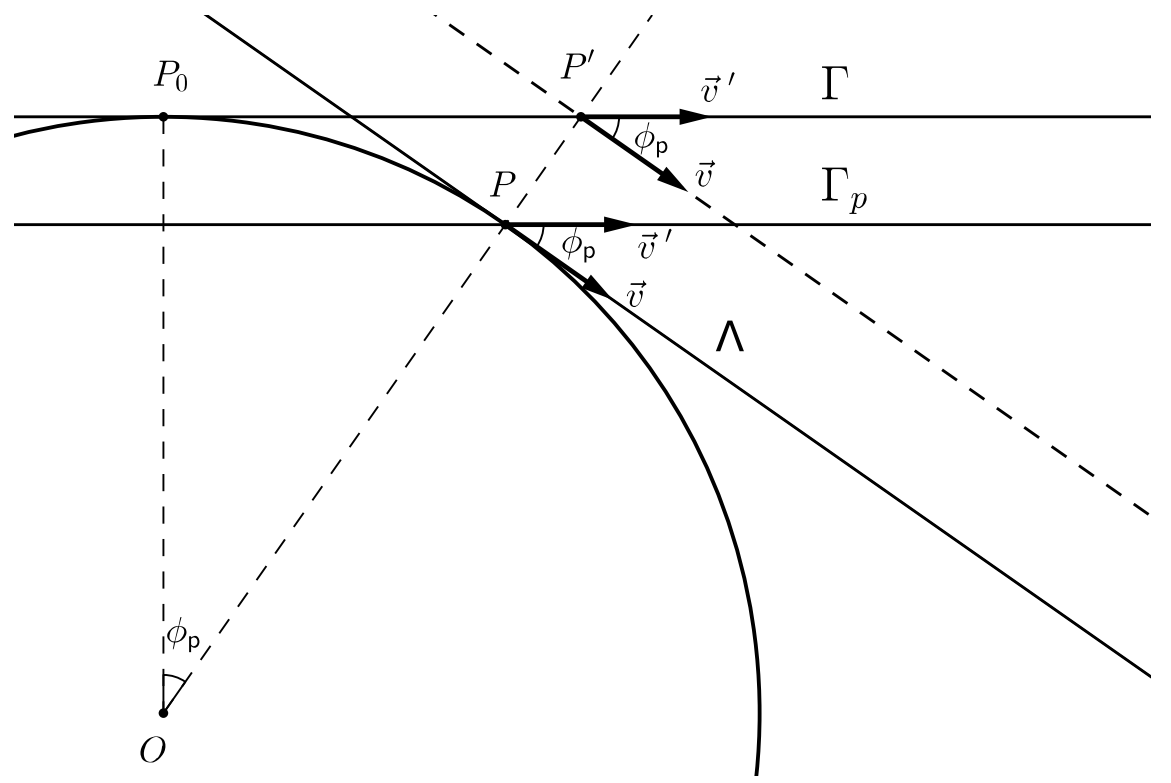

Figura 3.8: Elementos envolvidos na projeção de vetores. 


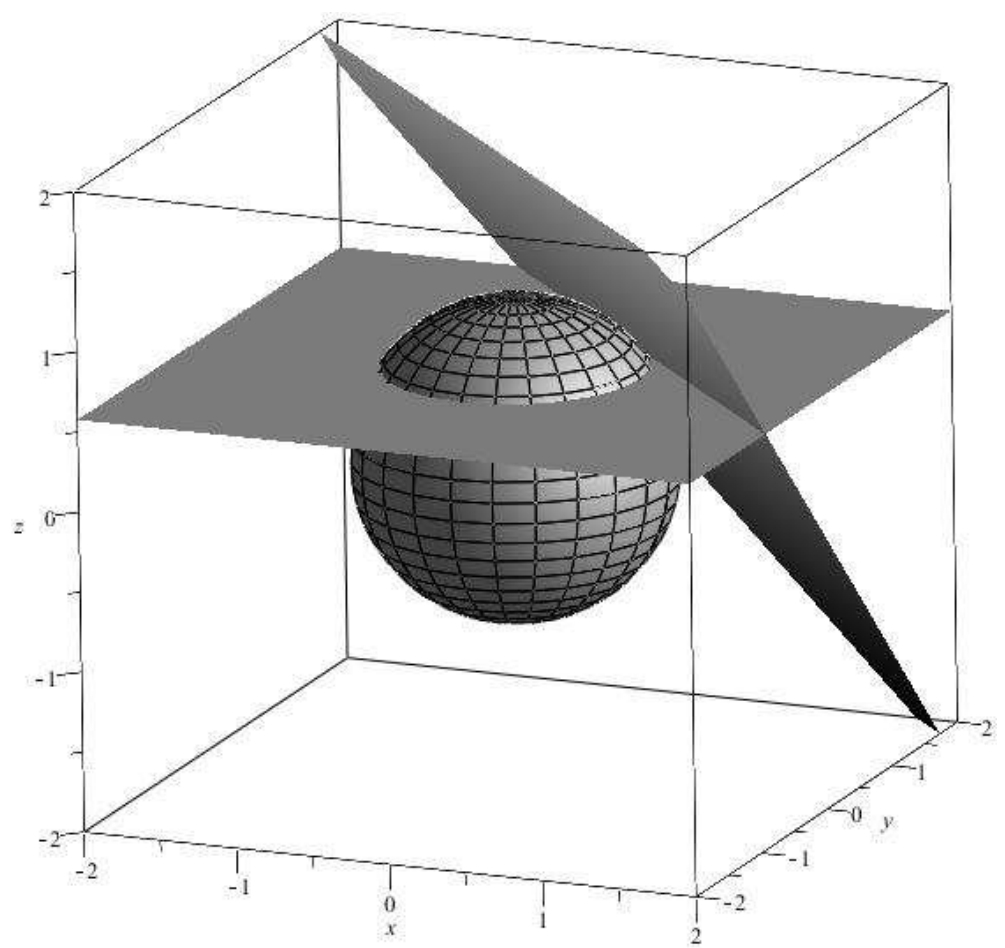

Figura 3.9: Representação geométrica entre os planos tangente à esfera $\Lambda$ e $\Gamma_{P}$, paralelo ao plano tangente ao polo norte $\Gamma$.

\subsubsection{Discretização do divergente}

Assim como feito para o plano, usando o Teorema da Divergência, podemos expressar o divergente de um campo vetorial $\vec{v}: \mathcal{S}^{2} \rightarrow T \mathcal{S}^{2}(p)$ em um ponto $\left(P_{0}\right)$ da esfera como

$$
\operatorname{div}(\vec{v})\left(P_{0}\right)=\lim _{\Omega \rightarrow\left\{\left(P_{0}\right)\right\}} \frac{1}{|\Omega|} \int_{\partial \Omega} \vec{v} \cdot \vec{n} d \partial \Omega,
$$

onde cada $\Omega$ é uma região da esfera compacta contendo o ponto $\left(x_{0}, y_{0}, z_{0}\right)$ com fronteira $\partial \Omega$ suave por pedaços. $|\Omega|$ o valor da área da região $\Omega, \vec{n}$ o vetor normal à fronteira e $d \partial \Omega$ o elemento de linha para a fronteira da célula. Definimos $\vec{v} \cdot \vec{n} d \partial \Omega$ com o fluxo por um elemento de linha $d \partial \Omega$.

Se quisermos calcular a integral do divergente do campo vetorial em uma certa região da esfera $\Omega$, compacta com fronteira $\partial \Omega$ suave por pedaços, podemos utilizar o Teorema da Divergência para obtermos

$$
\int_{\Omega} \operatorname{div}(\vec{v}) d \Omega=\int_{\partial \Omega} \vec{v} \cdot \vec{n} d \partial \Omega
$$

onde $\vec{n}$ o vetor normal ao contorno (tangente à esfera).

Se $\Omega$ for um polígono esférico, com $k$ arcos geodésicos, então, usando as definições de integral de linha, obtemos a relação,

$$
\int_{\partial \Omega} \vec{v} \cdot \vec{n} d \partial \Omega=\sum_{i=1}^{k} \int_{0}^{l_{i}} \vec{v}\left(\gamma_{i}(t)\right) \cdot \vec{n}_{i}\left\|\gamma_{i}^{\prime}(t)\right\| d t,
$$

onde $\gamma_{i}(t), \vec{n}_{i},\left\|\gamma_{i}^{\prime}(t)\right\|$ e $l_{i}$ representam respectivamente o i-ésimo arco geodésico (que pode ser parametrizado como na equação (3.17)), seu vetor normal (tangente à esfera), a norma de sua derivada e o ângulo formado pelos pontos que definem este arco e o centro da esfera.

Usando a regra do ponto médio para a integral de linha da equação (3.32), obtemos o método usual para cálculo do divergente na esfera, que é análogo ao plano, mas agora considerando fluxos médios tangentes a esfera. Suponha que $P_{0}$ seja o centro de massa (esférico) de um polígono esférico 
$\Omega$ com $n$ lados, então essa aproximação para o divergente em $P_{0}$ pode ser escrita como

$$
\operatorname{div}(\vec{v})\left(P_{0}\right) \approx \frac{1}{|\Omega|} \sum_{i=1}^{n} \vec{v}\left(Q_{i}\right) \cdot \vec{n}_{i} l_{i},
$$

onde $Q_{i}$ é o ponto médio da aresta $\gamma_{i}$ e $l_{i}$ o comprimento desta aresta.

Usando projeção radial para o plano tangente à esfera no centro de massa de um polígono esférico $\Omega$, podemos chegar a resultados análogos aos obtidos para o plano agora para a esfera.

Proposição 3.2.4. Seja $\vec{v}: p \in \mathcal{S}^{2} \rightarrow T \mathcal{S}^{2}(p)$ um campo vetorial $\mathcal{C}^{4}$ e $\Omega$ um polígono esférico em $\mathcal{S}^{2}$ com diâmetro d. Então existe uma constante $C$ que independe do diâmetro d, tal que, para d pequeno, temos

$$
\left|\frac{1}{|\Omega|} \int_{\Omega} \operatorname{div}(\vec{v}) d \Omega-\operatorname{div}(\vec{v})\left(P_{0}\right)\right| \leq C d^{2},
$$

onde $P_{0}$ é o centro de massa de $\Omega$. Em outras palavras, a aproximação do divergente no centro de massa do polígono pela média do divergente no polígono é uma aproximação de ordem 2 em relação ao diâmetro do polígono.

Demonstração. Seja $F: \mathbb{R}^{3} \rightarrow \mathbb{R}$ uma função suficientemente suave. Então temos que

$$
\frac{1}{|\Omega|} \int_{\Omega} F d \Omega=F\left(P_{0}^{*}\right)+\nabla F\left(P_{0}^{*}\right) \cdot \frac{1}{|\Omega|} \int_{\Omega}\left(P-P_{0}^{*}\right) d \Omega+O\left(d^{2}\right),
$$

onde $P_{0}^{*}$ é o centro de massa (não restrito à esfera) de $\Omega$. Por definição de centro de massa, o segundo termo do lado direito da equação anterior se anula. Para o divergente $\delta=\operatorname{div}(\vec{v})$ definido na esfera, podemos obter o seguinte campo suave, definido para $P \in \mathbb{R}^{3}, P \neq 0$,

$$
F(P)=\delta\left(\frac{P}{\|P\|}\right) .
$$

Como $F$ coincide com $\delta$ em $\Omega$ e $F\left(P_{0}^{*}\right)=\delta\left(P_{0}\right)$, temos que

$$
\frac{1}{|\Omega|} \int_{\Omega} \delta d \Omega=\delta\left(P_{0}\right)+O\left(d^{2}\right)
$$

onde o termo $O\left(d^{2}\right)$ depende apenas da hessiana de $\delta$ numa vizinhança compacta $\Omega$.

Teorema 3.2.5. Seja $\vec{v}: p \in \mathcal{S}^{2} \rightarrow T \mathcal{S}^{2}(p)$ um campo vetorial $\mathcal{C}^{4}$ e $\Omega$ um polígono esférico em $\mathcal{S}^{2}$ com $n$ arestas geodésicas. Suponha que $\Omega$ seja tal que $\alpha d^{2} \leq|\Omega|$, onde d é o diâmetro de $\Omega$ e $\alpha \in(0,1)$. Então existe uma constante $C$ que independe do diâmetro de $\Omega$, tal que,

$$
\left|\operatorname{div}(\vec{v})\left(P_{0}\right)-\frac{1}{|\Omega|} \sum_{i=1}^{n} \vec{v}\left(Q_{i}\right) \cdot \vec{n}_{i} l_{i}\right| \leq C d,
$$

onde $P_{0}$ é o centro de massa (esférico) de $\Omega, Q_{i}, \vec{n}_{i}$ e $l_{i}$ são respectivamente o ponto médio, o vetor normal e o comprimento da aresta $i$ de $\Omega$. Em outras palavras, o erro de aproximação do método de estimativa do divergente com base nos fluxos nos pontos médios é pelo menos de ordem um em relação ao tamanho da célula.

Demonstração. Para a demonstração vamos projetar radialmente o polígono e o campo no plano tangente ao centro de massa e usar os resultados que temos para o plano. Porém, alguns cuidados são necessários.

Primeiro vamos mostrar que $\operatorname{div}\left(\vec{v}^{\prime}\right)\left(P_{0}\right)=\operatorname{div}(\vec{v})\left(P_{0}\right)$, onde vamos usar a projeção vetorial definida anteriormente. Seja $Q$ um ponto do bordo de $\Omega$ e $Q^{\prime}$ sua projeção radial em $\Gamma$, sejam $f(Q)=\vec{v}(Q) \cdot \vec{n}_{Q}$ e $f^{\prime}\left(Q^{\prime}\right)=\vec{v}^{\prime}\left(Q^{\prime}\right) \cdot \vec{n}_{Q^{\prime}}^{\prime}$ os fluxos normais nos pontos $Q$ e $Q^{\prime}$ das arestas esférica 
e projetada, respectivamente. Então, usando o fato de que a matriz de rotação é ortogonal (i.e. $\left.\left(R_{p}\right)^{t} R_{p}=I\right)$, temos que

$$
\begin{aligned}
f^{\prime}\left(Q^{\prime}\right) & =\vec{v}^{\prime}\left(Q^{\prime}\right) \cdot \vec{n}_{Q^{\prime}}^{\prime}=\left(R_{Q} \vec{v}(Q)\right)^{t} R_{Q} \vec{n}_{Q} \\
& =(\vec{v}(Q))^{t}\left(R_{Q}\right)^{t} R_{Q} \vec{n}_{Q}=\vec{v}(Q) \cdot \vec{n}_{Q} \\
& =f(Q),
\end{aligned}
$$

logo a projeção de campos vetoriais preserva fluxos nas arestas dos polígonos. Note ainda que esse resultado pode ser estendido para outras regiões que não poligonais. Agora podemos mostrar que a projeção vetorial preserva o divergente em $P_{0}$.

Seja $\Theta$ uma calota esférica circular centrada em $P_{0}$ com raio geodésico $r$. Sua projeção radial $\left(\Theta^{\prime}\right)$ é um círculo em $\Gamma$, que também possui centro em $P_{0}$, mas raio $r^{\prime}=\tan (r)$.

Podemos parametrizar a borda de $\Theta^{\prime}$ como

$$
\zeta^{\prime}(t)=\left(r^{\prime} \cos (t), r^{\prime} \sin (t), 1\right)
$$

onde $t \in[0,2 \pi]$ (lembre-se que $P_{0}$ está no polo norte). Com essa parametrização temos que

$$
\left\|\frac{d \zeta^{\prime}(t)}{d t}\right\|=r^{\prime}
$$

Agora podemos parametrizar a borda de $\Theta$, um círculo na esfera, como

$$
\zeta(t)=\frac{\zeta^{\prime}(t)}{\left\|\zeta^{\prime}(t)\right\|}=\frac{1}{\sqrt{1+\left(r^{\prime}\right)^{2}}}\left(r^{\prime} \cos (t), r^{\prime} \sin (t), 1\right)
$$

tal que

$$
\left\|\frac{d \zeta(t)}{d t}\right\|=\frac{r^{\prime}}{\sqrt{1+\left(r^{\prime}\right)^{2}}} .
$$

Usando ambas parametrizações temos que

$$
\begin{aligned}
\operatorname{div}(\vec{v})\left(P_{0}\right) & =\lim _{\Theta \rightarrow\left\{P_{0}\right\}} \int_{\partial \Theta} \vec{v} \cdot \vec{n} d \partial \Theta \\
& =\lim _{\Theta \rightarrow\left\{P_{0}\right\}} \int_{0}^{2 \pi} \vec{v} \cdot \vec{n}(\zeta(t))\left\|\frac{d \zeta(t)}{d t}\right\| d t \\
& =\lim _{\Theta \rightarrow\left\{P_{0}\right\}} \int_{0}^{2 \pi} \vec{v} \cdot \vec{n}(\zeta(t)) \frac{r^{\prime}}{\sqrt{1+\left(r^{\prime}\right)^{2}}} d t \\
& =\lim _{\Theta \rightarrow\left\{P_{0}\right\}} \frac{1}{\sqrt{1+\left(r^{\prime}\right)^{2}}} \int_{0}^{2 \pi} \vec{v}^{\prime} \cdot \vec{n}^{\prime}\left(\zeta^{\prime}(t)\right) r^{\prime} d t \\
& =\lim _{\Theta \rightarrow\left\{P_{0}\right\}} \frac{1}{\sqrt{1+\left(r^{\prime}\right)^{2}}} \int_{0}^{2 \pi} \vec{v}^{\prime} \cdot \vec{n}^{\prime}\left(\zeta^{\prime}(t)\right)\left\|\frac{d \zeta^{\prime}(t)}{d t}\right\| d t \\
& =\lim _{\Theta \rightarrow\left\{P_{0}\right\}} \frac{1}{\sqrt{1+\left(r^{\prime}\right)^{2}}} \int_{\partial \Theta^{\prime}} \vec{v}^{\prime} \cdot \vec{n}^{\prime} d \partial \Theta^{\prime} \\
& =\lim _{\Theta \rightarrow\left\{P_{0}\right\}} \int_{\partial \Theta^{\prime}} \vec{v}^{\prime} \cdot \vec{n}^{\prime} d \partial \Theta^{\prime} \\
& =\operatorname{div}_{\left.\vec{v}^{\prime}\right)\left(P_{0}\right),}
\end{aligned}
$$

onde usamos que a projeção vetorial preserva fluxo no bordo, isto é, $\vec{v} \cdot \vec{n}(\zeta(t))=\vec{v}^{\prime} \cdot \vec{n}^{\prime}\left(\zeta^{\prime}(t)\right)$, e também que $\lim _{\Theta \rightarrow\left\{P_{0}\right\}} \frac{1}{\sqrt{1+\left(r^{\prime}\right)^{2}}}=1$.

Enfim, usando a relação entre o centro de massa do polígono esférico $P_{0}$ e do centro de massa de sua projeção $\bar{P}_{0}$, dada por $\bar{P}_{0}=P_{0}+O\left(d^{2}\right)$, temos que $\delta=\operatorname{div}(\vec{v})\left(P_{0}\right)=\operatorname{div}\left(\vec{v}^{\prime}\right)\left(P_{0}\right)=\operatorname{div}\left(\vec{v}^{\prime}\right)(\bar{P})+$ 
$O\left(d^{2}\right)$.

Agora podemos somar e subtrair a estimativa do divergente para o centro de massa $\bar{P}_{0}$ de forma a obter

$$
\begin{aligned}
&\left|\delta-\frac{1}{|\Omega|} \sum_{i=1}^{n} \vec{v}\left(Q_{i}\right) \cdot \vec{n}_{i} l_{i}\right|= \\
& \quad=\left|\delta-\frac{1}{\left|\Omega^{\prime}\right|} \sum_{i=1}^{n} \vec{v}^{\prime}\left(Q_{i}^{\prime}\right) \cdot \vec{n}_{i}^{\prime} l_{i}^{\prime}+\frac{1}{\left|\Omega^{\prime}\right|} \sum_{i=1}^{n} \vec{v}^{\prime}\left(Q_{i}^{\prime}\right) \cdot \vec{n}_{i}^{\prime} l_{i}^{\prime}-\frac{1}{|\Omega|} \sum_{i=1}^{n} \vec{v}\left(Q_{i}\right) \cdot \vec{n}_{i} l_{i}\right| \\
& \leq\left|\delta-\frac{1}{\left|\Omega^{\prime}\right|} \sum_{i=1}^{n} \vec{v}^{\prime}\left(Q_{i}^{\prime}\right) \cdot \vec{n}_{i}^{\prime} l_{i}^{\prime}\right|+\left|\frac{1}{\left|\Omega^{\prime}\right|} \sum_{i=1}^{n} \vec{v}^{\prime}\left(Q_{i}^{\prime}\right) \cdot \vec{n}_{i}^{\prime} l_{i}^{\prime}-\frac{1}{|\Omega|} \sum_{i=1}^{n} \vec{v}\left(Q_{i}\right) \cdot \vec{n}_{i} l_{i}\right| \\
&=D+E .
\end{aligned}
$$

onde $D$ será dado por

$$
\begin{aligned}
D & =\left|\delta-\frac{1}{\left|\Omega^{\prime}\right|} \sum_{i=1}^{n} \vec{v}^{\prime}\left(Q_{i}^{\prime}\right) \cdot \vec{n}_{i}^{\prime} l_{i}^{\prime}\right| \\
& \leq\left|\delta-\operatorname{div}\left(\vec{v}^{\prime}\right)(\bar{P})\right|+\left|\operatorname{div}\left(\vec{v}^{\prime}\right)(\bar{P})-\frac{1}{\left|\Omega^{\prime}\right|} \sum_{i=1}^{n} \vec{v}^{\prime}\left(Q_{i}^{\prime}\right) \cdot \vec{n}_{i}^{\prime} l_{i}^{\prime}\right| \leq O\left(d^{2}\right)+C_{D} d
\end{aligned}
$$

onde usamos as estimativas anteriores do divergente na esfera em relação ao projetado e tomamos $C_{D}$ como a constante resultante do Teorema 3.1.8 referente ao erro da discretização do divergente para o plano. O outro termo da equação, $E$, pode ser escrito como

$$
\begin{aligned}
E & =\left|\frac{1}{\left|\Omega^{\prime}\right|} \sum_{i=1}^{n} \vec{v}^{\prime}\left(Q_{i}^{\prime}\right) \cdot \vec{n}_{i}^{\prime} l_{i}^{\prime}-\frac{1}{|\Omega|} \sum_{i=1}^{n} \vec{v}\left(Q_{i}\right) \cdot \vec{n}_{i} l_{i}\right| \\
& =\frac{1}{|\Omega|}\left|\frac{|\Omega|}{\left|\Omega^{\prime}\right|} \sum_{i=1}^{n} \vec{v}^{\prime}\left(Q_{i}^{\prime}\right) \cdot \vec{n}_{i}^{\prime} l_{i}^{\prime}-\sum_{i=1}^{n} \vec{v}^{\prime}\left(Q_{i}^{\prime}\right) \cdot \vec{n}_{i}^{\prime} l_{i}\right| \\
& =\frac{1}{|\Omega|}\left|\sum_{i=1}^{n} \vec{v}^{\prime}\left(Q_{i}^{\prime}\right) \cdot \vec{n}_{i}^{\prime} \cdot\left(\frac{|\Omega|}{\left|\Omega^{\prime}\right|} l_{i}^{\prime}-l_{i}\right)\right| .
\end{aligned}
$$

Para $l_{i}$ pequeno, usando o resultado da equação (3.23), a relação entre as áreas do polígono esférico e projetado (equação (3.28)) e denominando $f_{i}=\vec{v}_{i}\left(Q_{i}\right) \cdot \vec{n}_{i}=\vec{v}^{\prime}\left(Q_{i}^{\prime}\right) \cdot \vec{n}_{i}^{\prime}=f_{i}^{\prime}$, temos que

$$
\begin{aligned}
E & =\frac{1}{|\Omega|}\left|\sum_{i=1}^{n} f_{i} \cdot\left(\frac{|\Omega|}{\left|\Omega^{\prime}\right|} l_{i}^{\prime}-l_{i}\right)\right| \\
& =\frac{1}{|\Omega|}\left|\sum_{i=1}^{n} f_{i} \cdot\left(\frac{|\Omega|}{\left|\Omega^{\prime}\right|}\left(l_{i}+r_{d^{3}}^{l_{i}}\right)-l_{i}\right)\right| \\
& =\frac{1}{|\Omega|}\left|\sum_{i=1}^{n} f_{i} \cdot\left(l_{i}\left(\frac{|\Omega|}{\left|\Omega^{\prime}\right|}-1\right)+\frac{|\Omega|}{\left|\Omega^{\prime}\right|} r_{d^{3}}^{l_{i}}\right)\right| \\
& =\frac{1}{|\Omega|}\left|\sum_{i=1}^{n} f_{i} \cdot\left(l_{i}\left(r_{d^{2}}^{\Omega}\right)+\left(1+r_{d^{2}}^{\Omega}\right) r_{d^{3}}^{l_{i}}\right)\right| \\
& =\frac{1}{|\Omega|}\left|\sum_{i=1}^{n} f_{i} \cdot\left(l_{i} r_{d^{2}}^{\Omega}+r_{d^{3}}^{l_{i}}+r_{d^{2}}^{\Omega} r_{d^{3}}^{l_{i}}\right)\right| .
\end{aligned}
$$


Agora usando a hipótese de que $\alpha d^{2} \leq|\Omega|$, que $l_{i} \leq d, r_{d^{2}}^{\Omega} \leq c_{1} d^{2}$ e que $r_{d^{3}}^{l_{i}} \leq c_{2} d^{3}$, temos

$$
\begin{aligned}
E & \leq \frac{1}{|\Omega|}\left|\sum_{i=1}^{n} f_{i} l_{i} r_{d^{2}}^{\Omega}\right|+\frac{1}{|\Omega|}\left|\sum_{i=1}^{n} f_{i} r_{d^{3}}^{l_{i}}\right|+\frac{1}{|\Omega|}\left|\sum_{i=1}^{n} f_{i} r_{d^{2}}^{\Omega} l_{d^{3}}^{l_{i}}\right| \\
& \leq \frac{1}{|\Omega|} c_{3} d^{3}+\frac{1}{|\Omega|} c_{4} d^{3}+\frac{1}{|\Omega|} c_{5} d^{3} \\
& \leq C_{2} d
\end{aligned}
$$

onde $c_{j}, j=1, \ldots, 5$ e $C_{2}$ são constantes.

Portanto, no caso geral, para quaisquer polígonos esféricos, temos pelo menos ordem 1 de aproximação do divergente pelo método dos fluxos nos pontos médios das arestas. Porém, assim como vimos para o plano, a condição geométrica de alinhamento da célula, faz com que a discretização fique de ordem 2 , como veremos a seguir.

Teorema 3.2.6. Seja $\vec{v}: p \in \mathcal{S}^{2} \rightarrow T \mathcal{S}^{2}(p)$ um campo vetorial $\mathcal{C}^{4}$ e $\Omega$ um polígono esférico alinhado em $\mathcal{S}^{2}$ com $n$ arestas geodésicas. Suponha que $\Omega$ seja tal que $\alpha d^{2} \leq|\Omega|$, onde d é o diâmetro de $\Omega$ e $\alpha \in(0,1)$. Então existe uma constante $C$ que independe do diâmetro de $\Omega$, tal que,

$$
\left|\operatorname{div}(\vec{v})\left(P_{0}\right)-\frac{1}{|\Omega|} \sum_{i=1}^{n} \vec{v}\left(Q_{i}\right) \cdot \vec{n}_{i} l_{i}\right| \leq C d^{2},
$$

onde $P_{0}$ é o centro de massa de $\Omega, Q_{i}, \vec{n}_{i}$ e $l_{i}$ são respectivamente o ponto médio, o vetor normal e o comprimento da aresta $i$ de $\Omega$. Em outras palavras, o erro de aproximação do método de estimativa do divergente com base nos fluxos nos pontos médio tem erro de pelo menos ordem dois em relação ao tamanho da célula, se esse for um polígono esférico alinhado.

Demonstração. A demonstração segue análoga ao do teorema anterior, porém agora vamos analisar a equação (3.43) sob as condições de alinhamento do polígono. O termo $D$ agora terá ordem 2 , pois podemos usar o Teorema 3.1.10, referente a ordem de discretização no plano para células alinhadas. Basta, portanto, mostrar que o termo $E$ também fica de ordem 2 para polígonos alinhados.

Usando a igualdade de arestas opostas temos que

$$
\begin{aligned}
E & =\frac{1}{|\Omega|}\left|\sum_{i=1}^{n} \vec{v}^{\prime}\left(Q_{i}^{\prime}\right) \cdot \vec{n}_{i}^{\prime} \cdot\left(\frac{|\Omega|}{\left|\Omega^{\prime}\right|} l_{i}^{\prime}-l_{i}\right)\right| \\
& =\frac{1}{|\Omega|}\left|\sum_{i=1}^{n / 2}\left(\vec{v}^{\prime}\left(Q_{i}^{\prime}\right)-\vec{v}^{\prime}\left(Q_{i+n / 2}^{\prime}\right)\right) \cdot \vec{n}_{i}^{\prime} \cdot\left(\frac{|\Omega|}{\left|\Omega^{\prime}\right|} l_{i}^{\prime}-l_{i}\right)\right|,
\end{aligned}
$$

onde usamos ainda que no polígono alinhado plano os vetores normais de lado opostos são o mesmo com sinais trocados. Agora usando a relação de que $l_{i}=l_{i}^{\prime}+O\left(d^{3}\right),|\Omega| /\left|\Omega^{\prime}\right|=1+O\left(d^{2}\right)$ e que $l_{i}=O(d)$ temos que

$$
E=\frac{O\left(d^{3}\right)}{|\Omega|}\left|\sum_{i=1}^{n / 2}\left(\vec{v}^{\prime}\left(Q_{i}^{\prime}\right)-\vec{v}^{\prime}\left(Q_{i+n / 2}^{\prime}\right)\right) \cdot \vec{n}_{i}^{\prime}\right|
$$

Finalmente note que $\vec{v}^{\prime}\left(Q_{i}^{\prime}\right)=\vec{v}^{\prime}\left(P_{0}\right)+O(d)$ e $\vec{v}^{\prime}\left(Q_{i+n / 2}^{\prime}\right)=\vec{v}^{\prime}\left(P_{0}\right)+O(d)$, logo,

$$
E=\frac{O\left(d^{3}\right)}{|\Omega|}\left|\sum_{i=1}^{n / 2} O(d)\right|=O\left(d^{2}\right)
$$

já que $|\Omega|=O\left(d^{2}\right)$. 
Observação 3.2.1 (Rotacional). Se supusermos conhecidos os vetores tangentes às arestas do polígono nos seus pontos médios, então todos os argumentos usados nas proposições, teoremas $e$ demonstrações anteriores podem ser facilmente estendidos para o operador diferencial rotacional (curl), que pode ser expresso por

$$
\operatorname{rot}(\vec{v})(p)=(\nabla \times \vec{v}) \cdot \vec{p}=\lim _{\Omega \rightarrow\{p\}} \frac{1}{|\Omega|} \int_{\partial \Omega} \vec{v} \cdot \vec{t} d \partial \Omega,
$$

onde $\vec{t}$ é o vetor tangente ao contorno do polígono. Note que bastará trocar os vetores normais por vetores tangentes ao polígono nas demonstrações que obteremos os mesmos resultados para o operador rotacional. Portanto, podemos esperar ordem 2 de discretização do rotacional em polígonos alinhados, e pelo menos ordem 1 caso contrário.

Observação 3.2.2 (Difusão). O operador diferencial de difusão, ou de Laplace, também pode ser expresso na forma de divergente. Dado um campo escalar $f$ e seu campo gradiente $\vec{v}=\nabla f$, o operador de Laplace pode ser expresso como

$$
\Delta f=\nabla \cdot \nabla f=\nabla \cdot \vec{v}=\operatorname{div}(\vec{v}) .
$$

Portanto, supondo que temos $\vec{v}=\nabla f$ nos pontos médios das arestas, então a discretização do laplaciano pelo método do ponto médio será de ordem 2 para polígonos alinhados.

\subsection{Alinhamento em malhas icosaédricas}

Conforme vimos, no caso geral, não há garantias de discretização de ordem 2 em triângulos, mesmo se forem regulares. Supondo que estamos usando como células computacionais o conjunto de triângulos, então, se tivermos 2 triângulos que compartilham uma aresta e sejam congruentes, como na Figura 3.10, eles irão formar um paralelogramo, que é um polígono alinhado. Dessa forma, podemos esperar ordem 2 na discretização do divergente para esta célula composta. Como a integral do divergente no paralelogramo deve ser igual à soma das integrais dos divergentes em cada triângulo, então podemos esperar que um dos triângulos estará subestimando o divergente exato e o outro superestimando. Em uma malha com muitos triângulos que formam dois a dois paralelogramos, podemos esperar um padrão de "xadrez" na distribuição do erro, com sub e super estimativas do divergente. Veremos um exemplo desse fenômeno mais adiante.

Na discretização em hexágonos, o Teorema 3.2.6, garante que, se o hexágono for alinhado teremos ordem 2, senão, pelo menos ordem 1. Mostramos na Figura 3.11 uma malha icosaédrica e indicamos casos de um hexágono alinhado e outro não alinhados. No hexágono no centro da região destacada em verde há alinhamento das arestas. Colorimos os triângulos 2 a 2 congruentes que formam paralelogramos. O hexágono na zona de transição da área verde não possui alinhamento de arestas, e os triângulos também não formam paralelogramos.

Na Figura 3.12 mostramos os formatos das células tanto triangulares, quando de Voronoi, para uma região de uma malha icosaédrica com 10242 nós. Podemos perceber visualmente diversos hexágonos alinhados e alguns não alinhados.

Pela Proposição 3.2.3 vemos que uma boa métrica para avaliar se um polígono é alinhado ou não é o valor de $\Xi$, que será zero no caso de polígonos alinhados, e positivo caso contrário. Quanto maior o $\Xi$, podemos pensar que temos polígonos mais desalinhados. Na Figura 3.13 apresentamos a distribuição dos valores de $\Xi$ em diversas malhas icosaédrica. Polígonos com número ímpar de lados (12 pentágonos) tiveram valor de $\Xi$ atribuído como nulo, apenas para poderem ser incluídos na representação gráfica. Pelas figuras, verifica-se que as regiões de maiores desalinhamentos ocorrem em regiões próximas às 32 arestas do icosaedro primário, de nível zero, e também das arestas originadas de malhas mais grossas, de níveis mais baixos. Na Figura 3.13 apresentamos o índice de alinhamento $\Xi$ em diversas malhas.

À medida que temos malhas mais finas, isto é, com mais pontos, a tendência é termos uma proporção de células alinhadas maior. Tomemos um parâmetro de corte para delimitar quais células 


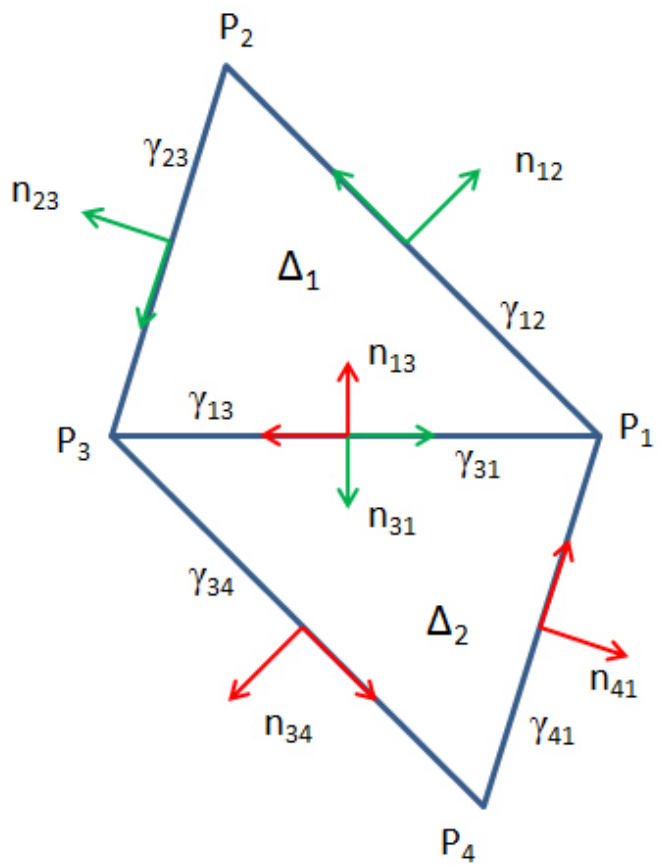

Figura 3.10: Triângulos semelhantes com simetria espelhada com uma aresta em comum.

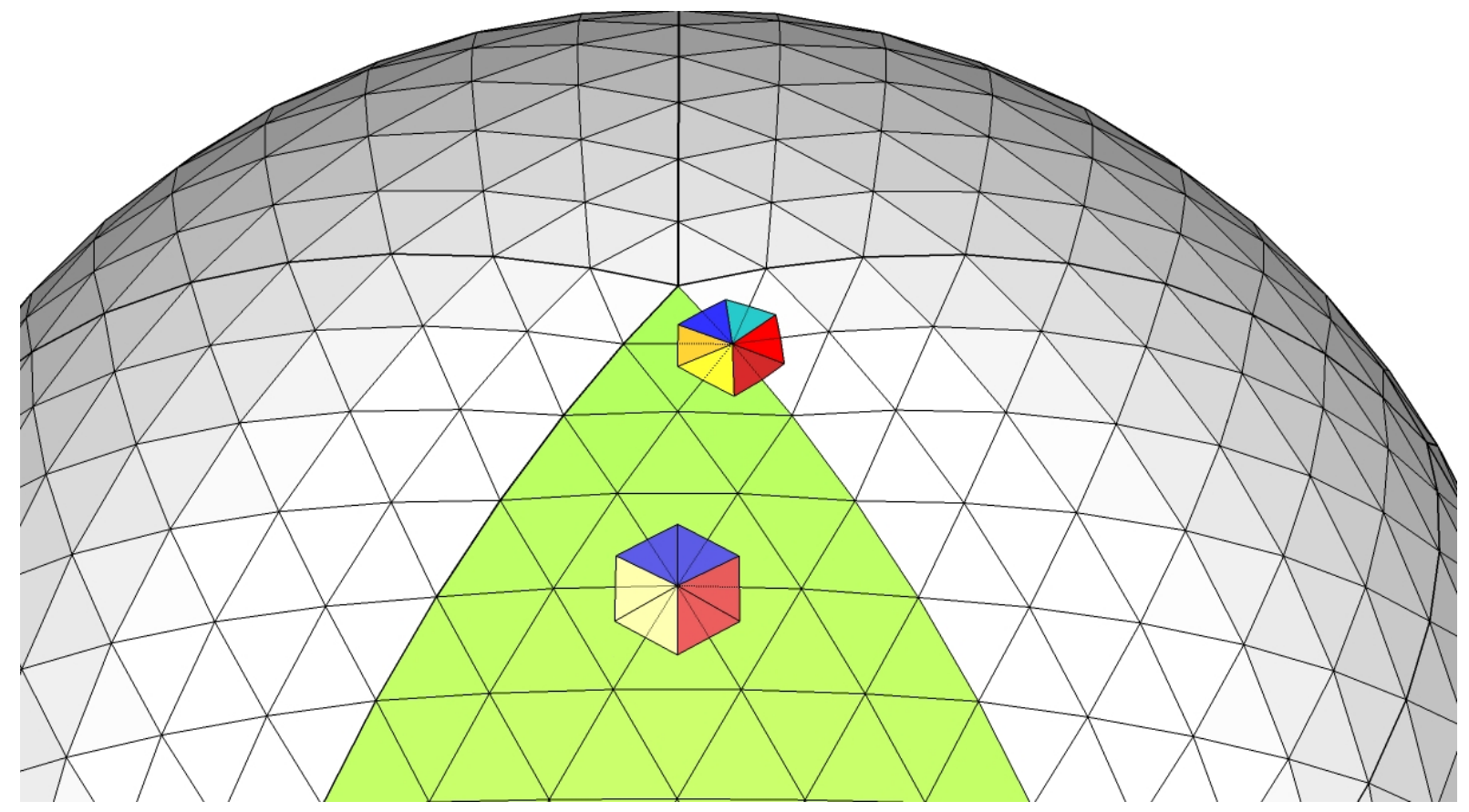

Figura 3.11: Alinhamentos em hexágonos esféricos.

são alinhadas como sendo $\epsilon=1 / 100$. Consideraremos alinhados os polígonos com $\Xi<\epsilon$. Mostramos na Tabela 3.1 os percentuais de células alinhadas para algumas malhas icosaédricas. Na figura 3.14 mostramos a evolução do índice de alinhamento máximo e médio para diversos níveis de malhas icosaédricas. Percebe-se que o alinhamento médio decresce com o refinamento, porém o máximo não. Isso mostra que as células alinhadas tendem a dominar nas malhas mais finas, porém, contendo sempre algumas células muito mal alinhadas. 


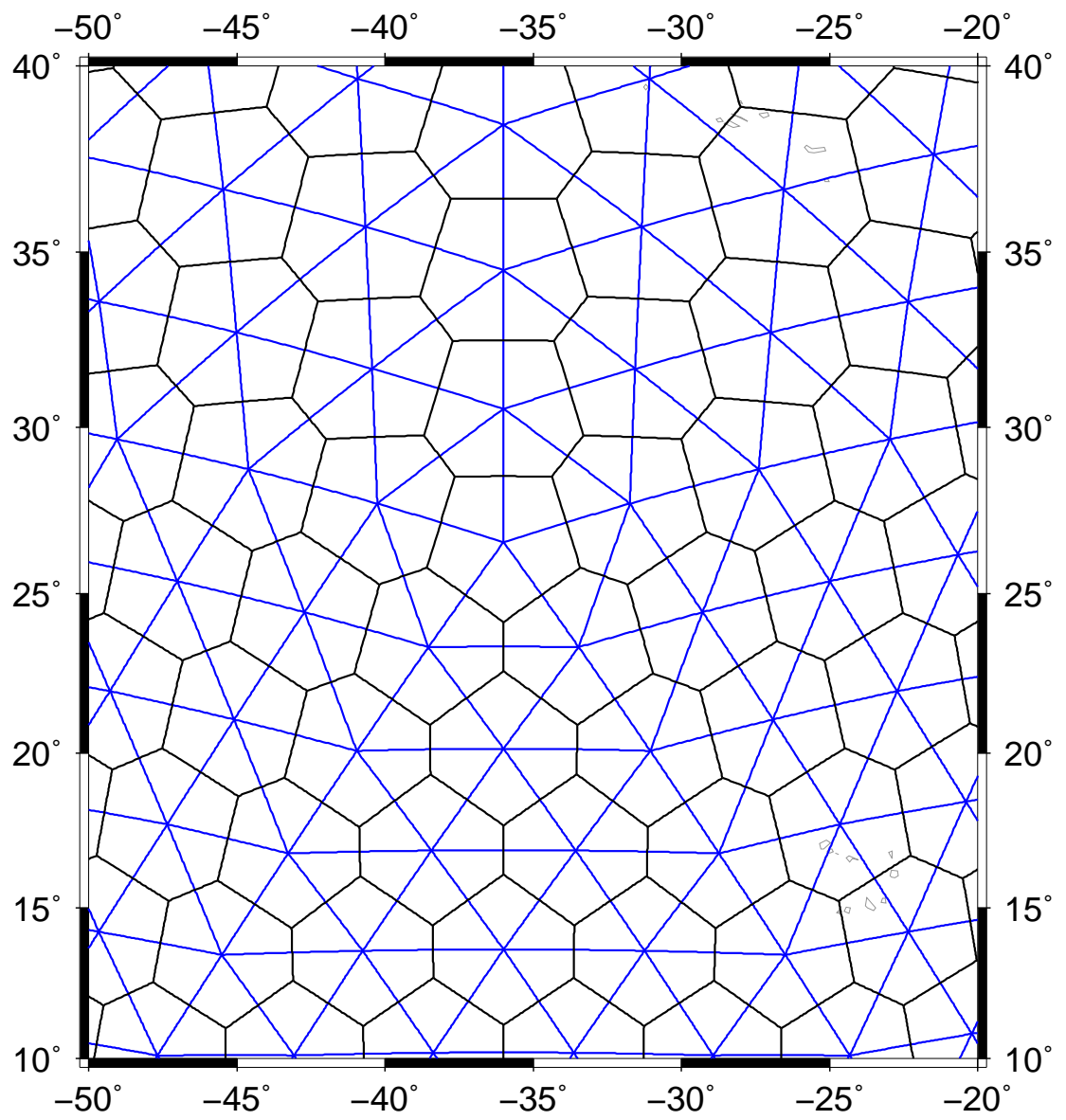

Figura 3.12: Malha triangular e seu dual de Voronoi com 10242 geradores

\begin{tabular}{|c|c|}
\hline Nós & \%Alinhados \\
\hline 10242 & $49.4 \%$ \\
\hline 40962 & $70.0 \%$ \\
\hline 163842 & $84.2 \%$ \\
\hline 655362 & $91.8 \%$ \\
\hline
\end{tabular}

Tabela 3.1: Percentuais de células consideradas alinhadas $(\Xi<1 / 100)$ para cada nível de malha icosaédrica. 
4

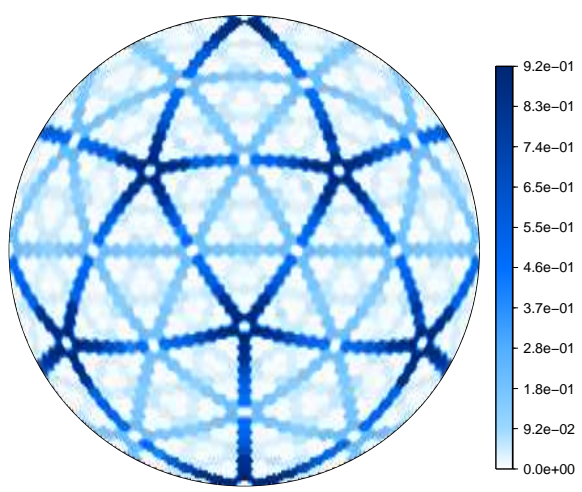

6

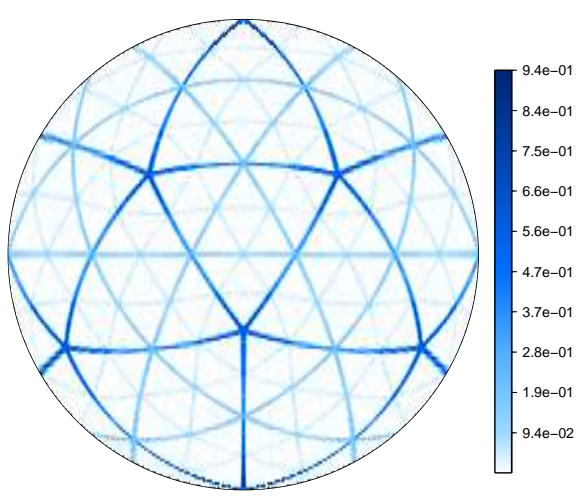

5

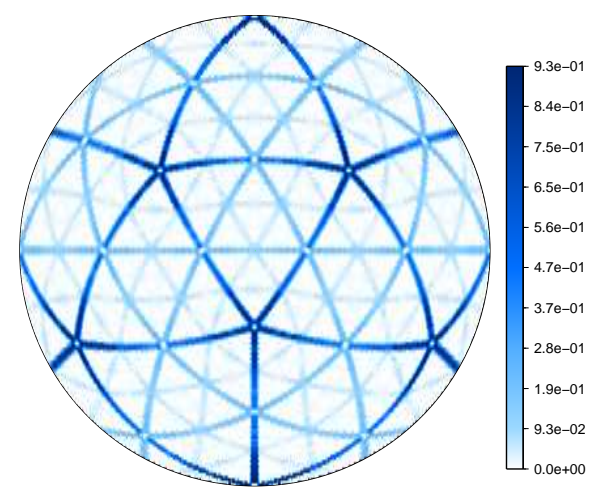

7

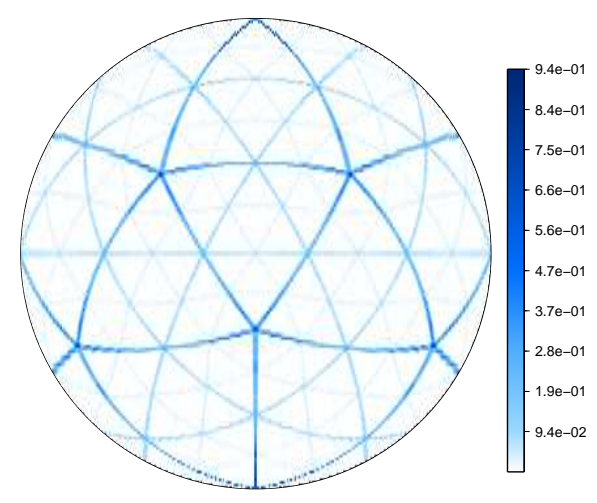

Figura 3.13: Índice de alinhamento $\Xi$ em malhas icosaédricas de níveis 4, 5, 6 e 7 .

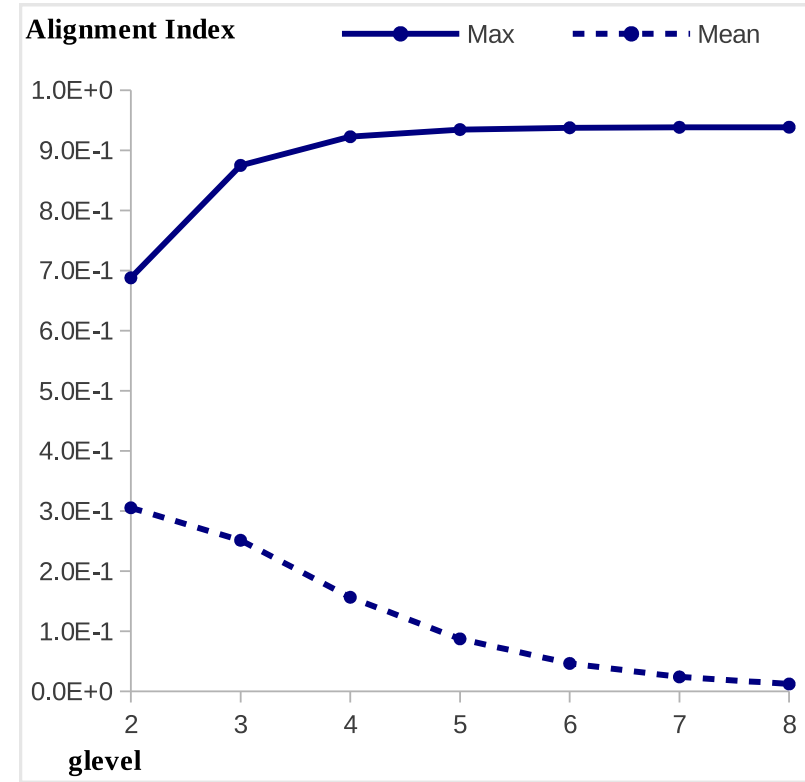

Figura 3.14: Índice de alinhamento $\Xi$ máximo e médio em malhas icosaédricas. 


\subsection{Resultados numéricos}

Iremos mostrar alguns resultados numéricos sobre a discretização do divergente com o método baseado nos fluxos nos pontos médios das arestas das células computacionais. Usaremos como métricas de erros entre um campo escalar estimado $\tilde{f}$ e o valor verdadeiro $f$, o erro quadrático médio $E_{2}$ e o máximo $E_{\infty}$, definidos como

$$
\begin{gathered}
E_{L_{2}}=\|f-\tilde{f}\|_{2}=\sqrt{\frac{\sum_{i=1}^{n}\left(f_{i}-\tilde{f}_{i}\right)^{2}}{n}}, \\
E_{L_{\infty}}=\|f-\tilde{f}\|_{\infty}=\max _{i=1, \ldots, n}\left|f_{i}-\tilde{f}_{i}\right| .
\end{gathered}
$$

\subsubsection{Campo de rotação}

Considere agora um campo de rotação sobre o eixo cartesiano $z$, que pode ser escrito como

$$
\vec{F}(x, y, z)=(-y, x, 0)
$$

onde $(x, y, z)$ é um ponto da esfera $\left(x^{2}+y^{2}+z^{2}=1\right)$. O campo é representado na Figura 3.15. Note que esse campo é não divergente.

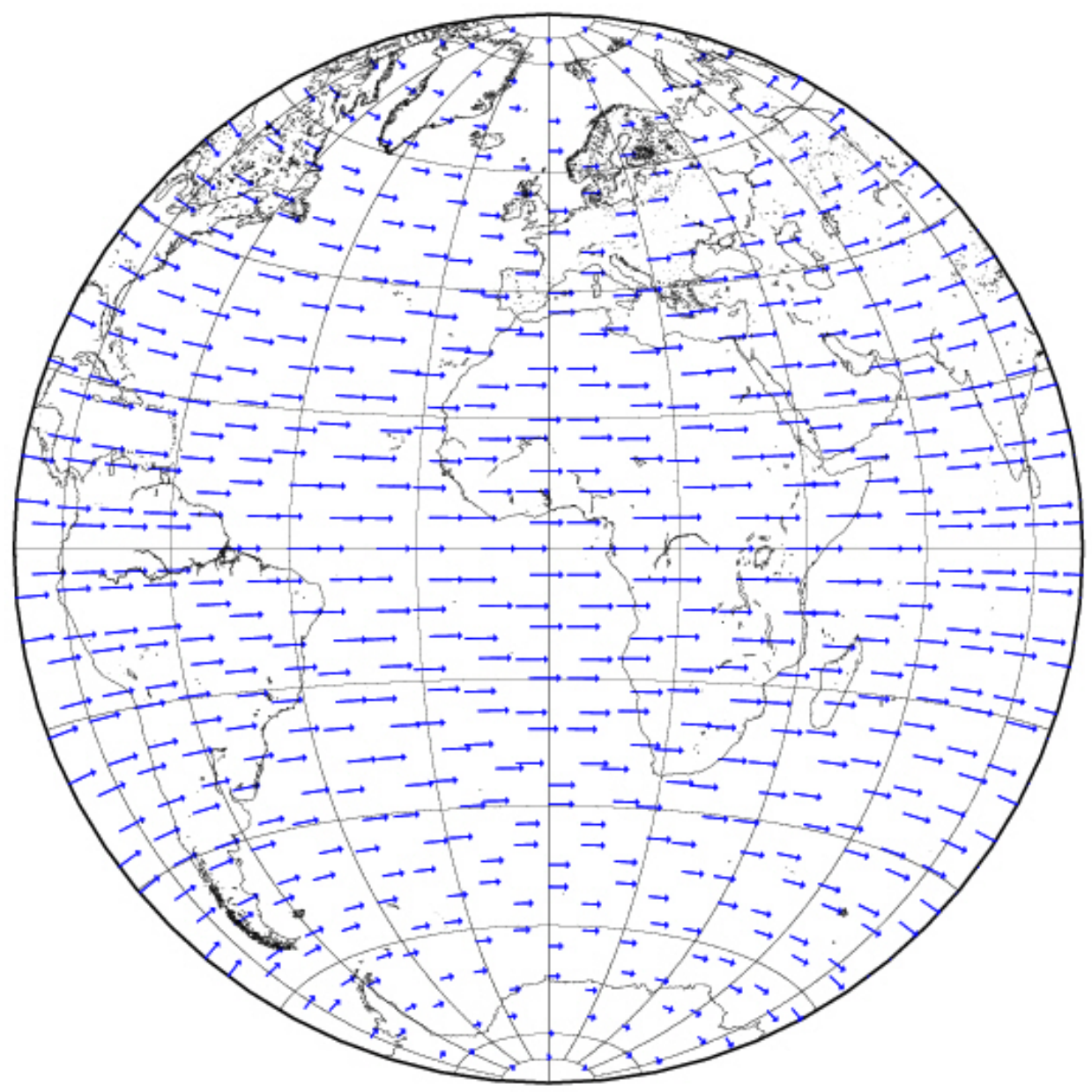

Figura 3.15: Campo vetorial de rotação. 


\section{Em triângulos}

Supondo o campo vetorial conhecido nos pontos médios das arestas dos triângulos, e usando o método de discretização do divergente com base nos fluxos nos pontos médios das arestas, teremos a distribuição de erros apresentada na Figura 3.16. Analisando essa figura é possível tirarmos algumas conclusões. Os triângulos em regiões onde o índice de alinhamento $\Xi$ é mais próximo de zero (veja a Figura 3.12) tendem a formar, 2 a 2, paralelogramos, e portanto ocorre uma superestimativa ao lado de uma subestimativa. Como o campo é simétrico em relação aos hemisférios, e a malha também, temos essa simetria de hemisférios. Por outro lado, a malha é simétrica em relação ao meridiano de Greenwich, mas o campo é anti-simétrico, logo temos uma mudança no padrão de cor (aonde era vermelho fica azul e vice versa). Na Tabela 3.2 apresentamos os erros associados ao método de discretização para divergente em triângulos, aonde fica clara a convergência de primeira ordem.

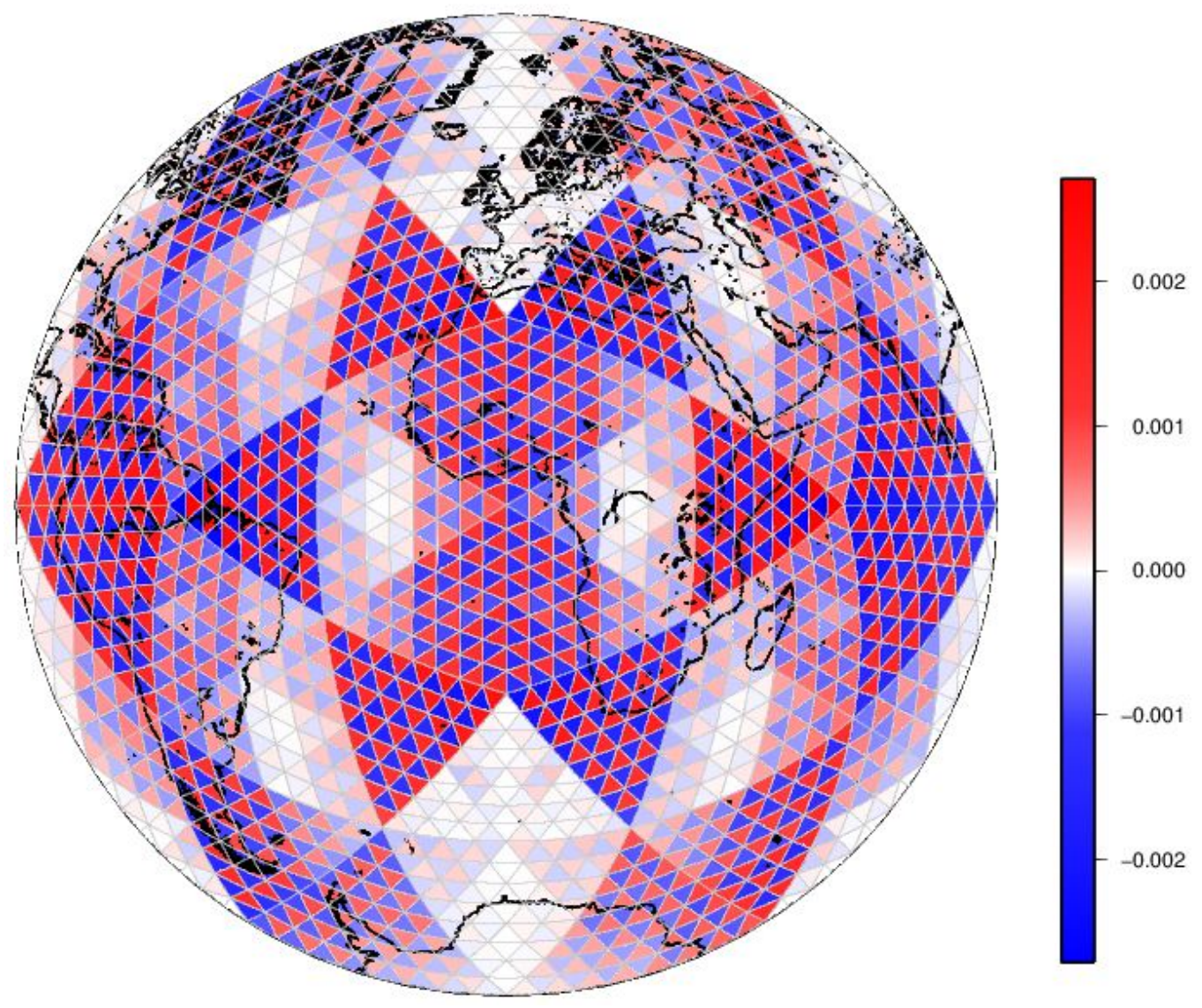

Figura 3.16: Divergente calculado pelo método do ponto médio para um campo vetorial de rotação. Malha icosaédrica com 5120 triângulos (2562 nós).

\begin{tabular}{|c|c|c|c|c|c|}
\hline Nós & Distância & Erro Máx & Razão Máx & Erro 2 & Razão 2 \\
\hline 162 & $17.22^{\circ}$ & $1.01 \mathrm{E}-02$ & 0.00 & $4.05 \mathrm{E}-03$ & 0.00 \\
\hline 642 & $8.64^{\circ}$ & $5.34 \mathrm{E}-03$ & 1.89 & $2.04 \mathrm{E}-03$ & 1.99 \\
\hline 2562 & $4.33^{\circ}$ & $2.71 \mathrm{E}-03$ & 1.97 & $1.02 \mathrm{E}-03$ & 2.00 \\
\hline 10242 & $2.16^{\circ}$ & $1.36 \mathrm{E}-03$ & 1.99 & $5.09 \mathrm{E}-04$ & 2.00 \\
\hline 40962 & $1.08^{\circ}$ & $6.80 \mathrm{E}-04$ & 2.00 & $2.55 \mathrm{E}-04$ & 2.00 \\
\hline 163842 & $0.54^{\circ}$ & $3.40 \mathrm{E}-04$ & 2.00 & $1.27 \mathrm{E}-04$ & 2.00 \\
\hline 655362 & $0.27^{\circ}$ & $1.70 \mathrm{E}-04$ & 2.00 & $6.37 \mathrm{E}-05$ & 2.00 \\
\hline
\end{tabular}

Tabela 3.2: Erro na estimativa do divergente de campo de rotação em malha triangular. São apresentados os erros máximos e quadrático médios, além das razões entre erros de malhas de nível $n-1$ e $n$. 


\section{Em células de Voronoi}

Consideramos agora o método de discretização do divergente em células hexágono-pentagonais supondo conhecidos os vetores nos pontos médios das arestas das células computacionais. Para o campo de rotação obtivemos a distribuição de erros apresentado na Figura 3.17. A distribuição de erro parece claramente ligada à distribuição do índice de alinhamento $\Xi$, indicando maiores erros aonde os polígonos não são alinhados. Na Tabela 3.3 apresentamos os erros associados para cada nível de malha. Percebe-se uma convergência de primeira ordem na norma do máximo, mas ordem um pouco maior na norma quadrática, indicando 2 padrões de erros. Na Figura 3.18 mostramos a correlação entre o erro, em valor absoluto, e o índice de alinhamento $\Xi$. Dependendo do campo vetorial é possível que tenhamos células onde o índice de alinhamento é alto, mas o erro é pequeno devido a cancelamentos fortuitos. Dependendo do campo vetorial o contrário também é possível, termos erros altos em regiões de baixo índice de alinhamento, mas menos provável, já que ordem de convergência nestas regiões é maior e logo pode se esperar um erro menor que nas demais. Os erros também guardam uma relação com a magnitude do próprio campo.

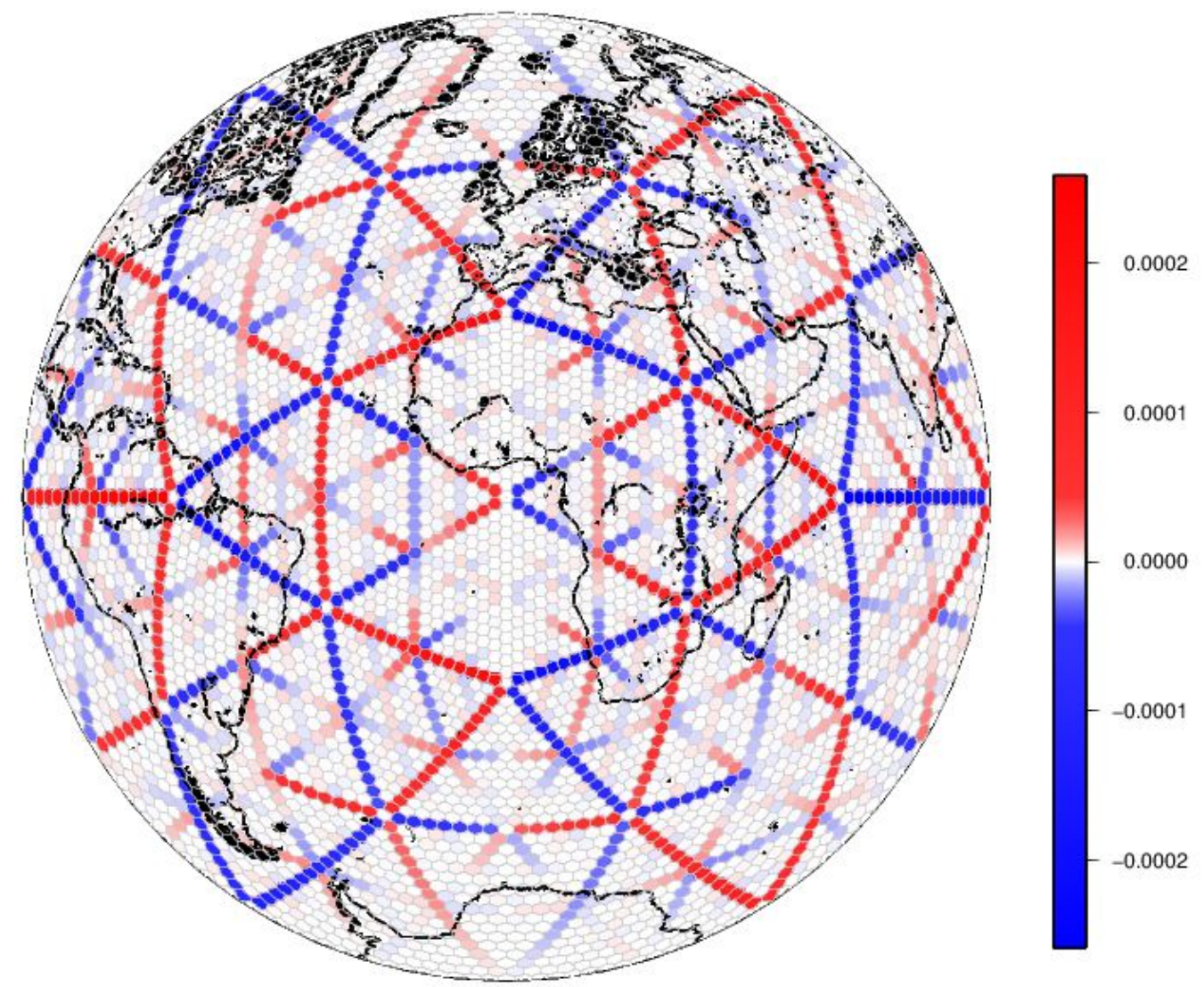

Figura 3.17: Divergente calculado pelo método do ponto médio para um campo vetorial de rotação em malha icosaédrica de Voronoi com 10242 nós. 


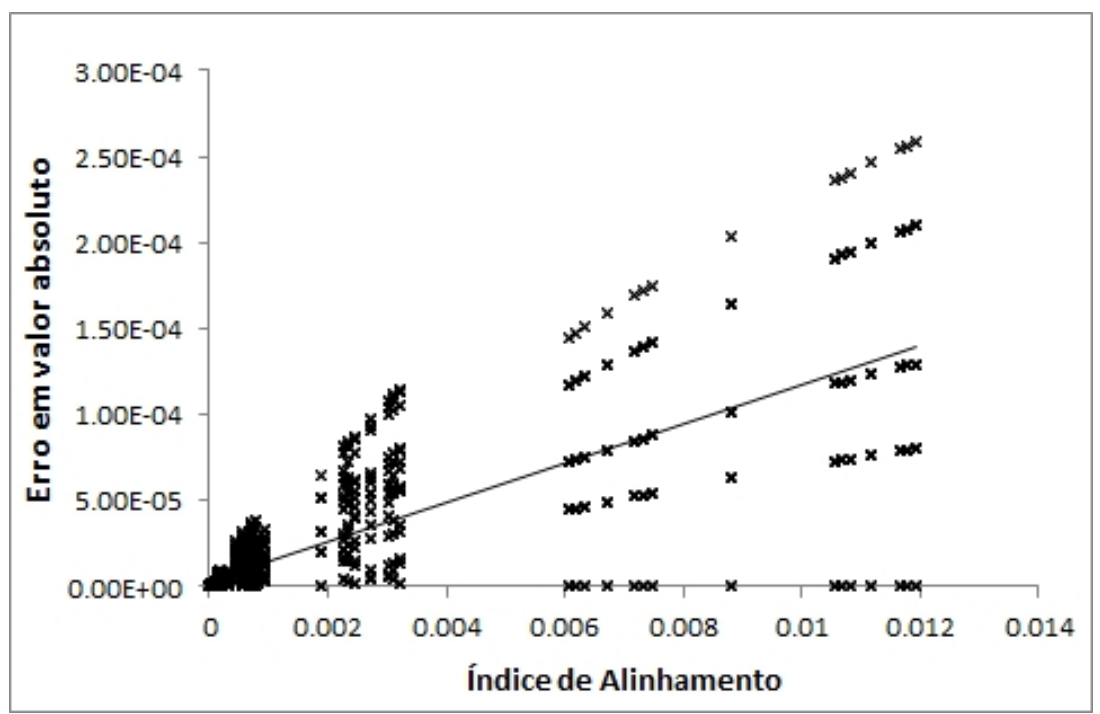

Figura 3.18: Erro do divergente do campo de rotação, em valor absoluto, em relação ao índice de alinhamento $\Xi$. Malha com 10242 nós.

\begin{tabular}{|c|c|c|c|c|c|}
\hline Nós & Distância & Erro Máx & Razão Máx & Erro 2 & Razão 2 \\
\hline 162 & $17.22^{\circ}$ & $1.58 \mathrm{E}-03$ & 0.00 & $5.86 \mathrm{E}-04$ & 0.00 \\
\hline 642 & $8.64^{\circ}$ & $9.79 \mathrm{E}-04$ & 1.61 & $2.75 \mathrm{E}-04$ & 2.13 \\
\hline 2562 & $4.33^{\circ}$ & $5.12 \mathrm{E}-04$ & 1.91 & $1.08 \mathrm{E}-04$ & 2.54 \\
\hline 10242 & $2.16^{\circ}$ & $2.59 \mathrm{E}-04$ & 1.98 & $4.02 \mathrm{E}-05$ & 2.70 \\
\hline 40962 & $1.08^{\circ}$ & $1.30 \mathrm{E}-04$ & 1.99 & $1.45 \mathrm{E}-05$ & 2.77 \\
\hline 163842 & $0.54^{\circ}$ & $6.50 \mathrm{E}-05$ & 2.00 & $5.19 \mathrm{E}-06$ & 2.80 \\
\hline 655362 & $0.27^{\circ}$ & $3.25 \mathrm{E}-05$ & 2.00 & $1.84 \mathrm{E}-06$ & 2.81 \\
\hline
\end{tabular}

Tabela 3.3: Erro na estimativa do divergente de campo de rotação para malha de Voronoi. São apresentados os erros máximos e quadrático médios, além das razões entre erros de malhas de nível $n-1$ e $n$. 


\subsubsection{Campo com divergência}

No próximo exemplo, usaremos um campo vetorial usado em Heikes e Randall [1995a] e também em Tomita et al. [2001], dado em coordenadas de longitude - latitude como

$$
\begin{aligned}
& u=-(\cos (\theta))^{3}(\sin (\lambda))^{2}, \\
& v=-4(\sin (\lambda))^{2} \cos (\lambda)(\cos (\theta))^{3},
\end{aligned}
$$

cujo divergente pode ser expresso como

$$
\operatorname{div}(u, v)=\frac{-2(\cos (\theta))^{3} \sin (\lambda) \cos (\lambda)+16(\sin (\lambda))^{2} \cos (\lambda)(\cos (\theta))^{3} \sin (\theta)}{\cos (\theta)},
$$

e é representado na Figura 3.19.

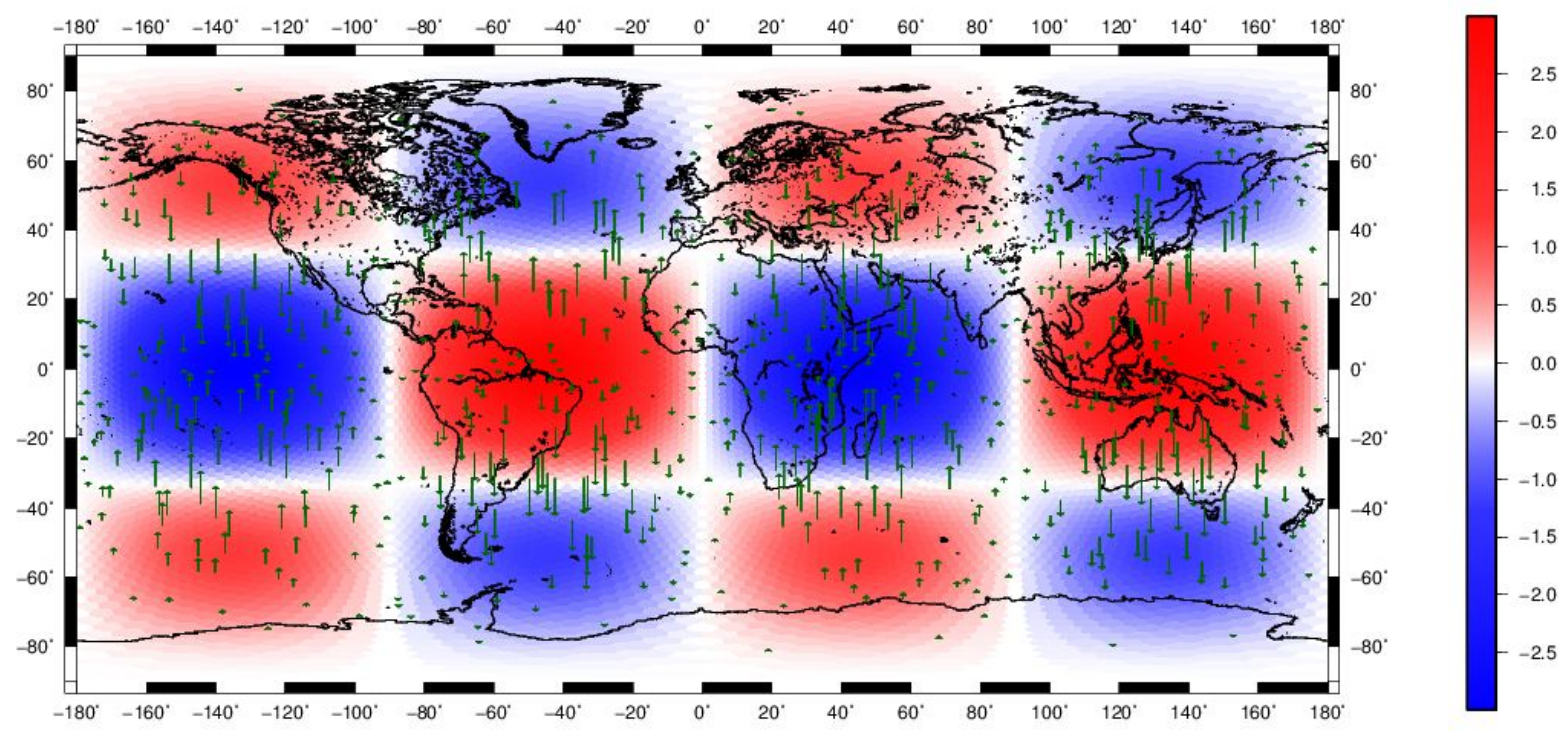

Figura 3.19: Divergente exato do campo trigonométrico. O campo vetorial é representado por vetores.

Na Figura 3.20 apresentamos a distribuição do erro relativo ao divergente calculado pelo método do ponto médio das arestas em uma malha icosaédrica usando células de Voronoi. Novamente verificamos a presença de malhas mais grossas aparecendo com erros elevados. Apresentamos na Tabela 3.4 os erros associados à cada malha icosaédrica. Nota-se convergência de ordem 1 na norma do máximo, mas um pouco acima de ordem 1 na norma quadrática. Considerando como sendo uma célula alinhada aquela tal que $\Xi<\epsilon$, onde $\epsilon=1 / 100$, observamos na Figura 3.21 que os erros nestas células decaem com segunda ordem, mas que em geral, somente primeira ordem é observado. 


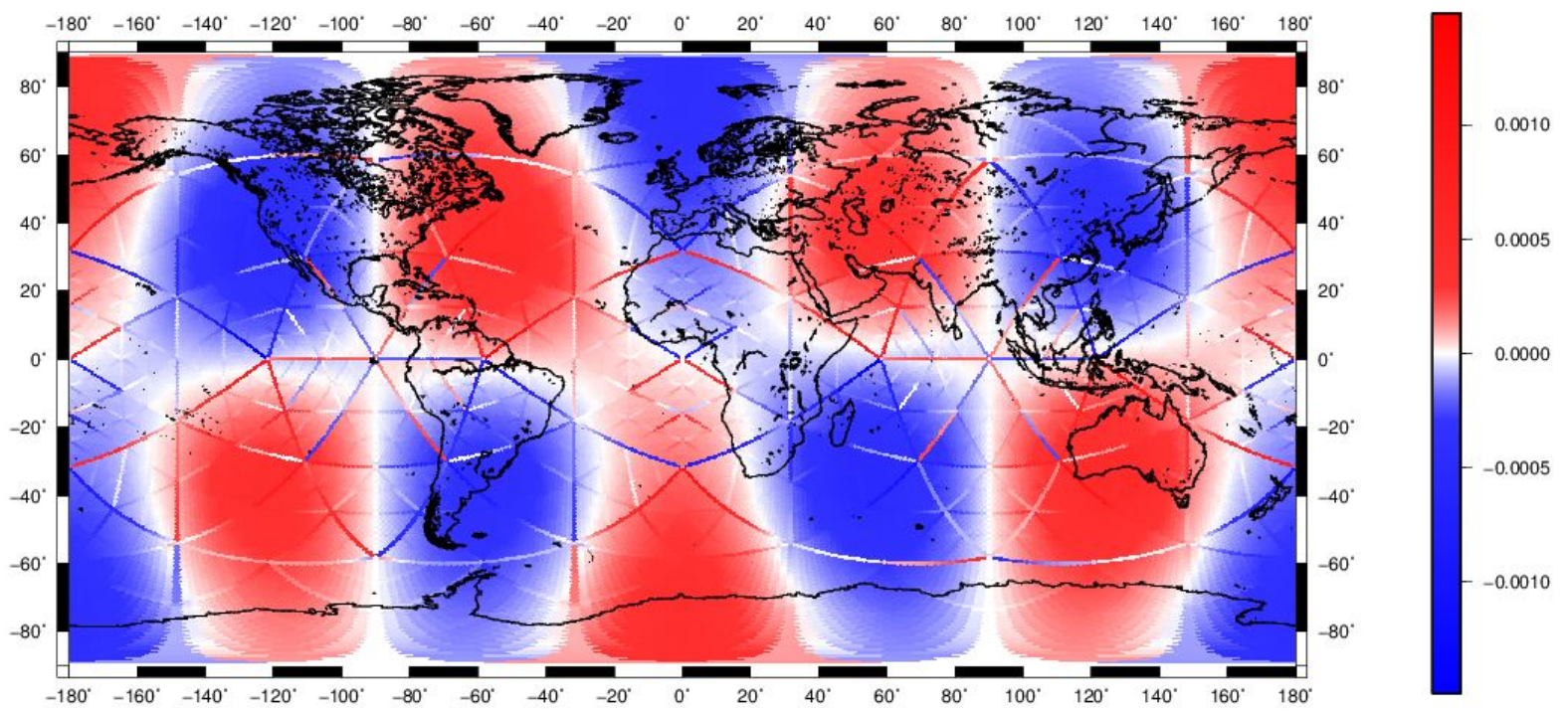

Figura 3.20: Erros no divergente do campo trigonométrico. Malha com 40962 nós.

\begin{tabular}{|c|c|c|c|c|c|}
\hline Nós & Distância & Erro Máx & Razão Máx & Erro 2 & Razão 2 \\
\hline 162 & $17.22^{\circ}$ & $1.17 \mathrm{E}-01$ & 0.00 & $4.93 \mathrm{E}-02$ & 0.00 \\
\hline 642 & $8.64^{\circ}$ & $3.30 \mathrm{E}-02$ & 3.56 & $1.31 \mathrm{E}-02$ & 3.76 \\
\hline 2562 & $4.33^{\circ}$ & $9.29 \mathrm{E}-03$ & 3.55 & $3.38 \mathrm{E}-03$ & 3.88 \\
\hline 10242 & $2.16^{\circ}$ & $3.12 \mathrm{E}-03$ & 2.98 & $8.77 \mathrm{E}-04$ & 3.86 \\
\hline 40962 & $1.08^{\circ}$ & $1.49 \mathrm{E}-03$ & 2.10 & $2.33 \mathrm{E}-04$ & 3.76 \\
\hline 163842 & $0.54^{\circ}$ & $7.29 \mathrm{E}-04$ & 2.04 & $6.45 \mathrm{E}-05$ & 3.61 \\
\hline 655362 & $0.27^{\circ}$ & $3.61 \mathrm{E}-04$ & 2.02 & $1.88 \mathrm{E}-05$ & 3.42 \\
\hline
\end{tabular}

Tabela 3.4: Erros na estimativa do divergente do campo trigonométrico para malha de Voronoi. São apresentados os erros máximos e quadrático médios, além das razões entre erros de malhas de nível n-1 e $n$.

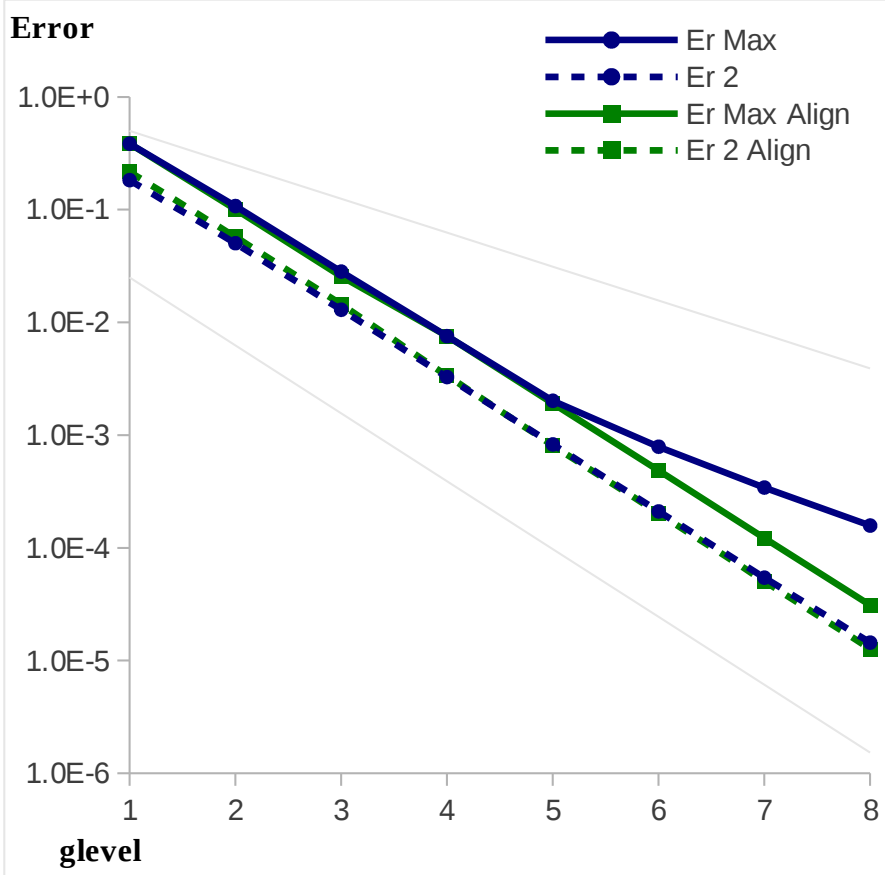

Figura 3.21: Erros no divergente do campo trigonométrico em diversos níveis de malhas icosaédricas com células de Voronoi (linhas marcadas com círculos). As linhas marcadas com quadrados indicam os erros calculados apenas nas células bem alinhadas $(\Xi<0.01)$. 


\subsubsection{Em malhas otimizadas}

O comportamento similar ao observado para as malhas icosaédricas ocorre também em malhas icosaédricas otimizadas. Porém, em malhas otimizadas, o padrão de interferência de malha é mais sutil. Na Figura 3.22 apresentamos os índices de alinhamento e erros na estimativa do divergente para as otimização HR95, spring dynamics e SCVT para o campo vetorial trigonométrico descrito anteriormente. O padrão de alinhamento da malha HR95 é similar ao da malha sem otimização. Por outro lado, nota-se bastante diferença na distribuição do índice de alinhamento das malhas SPRG e SCVT em relação à malha sem otimização. Percebe-se que a interferência de malha é reduzida, mas não desaparece, principalmente próximo aos pentágonos. Em todos os casos, o índice de alinhamento apresenta boa correlação com o erro. Além disso, todas as otimizações reduziram o erro na estimativa do divergente.
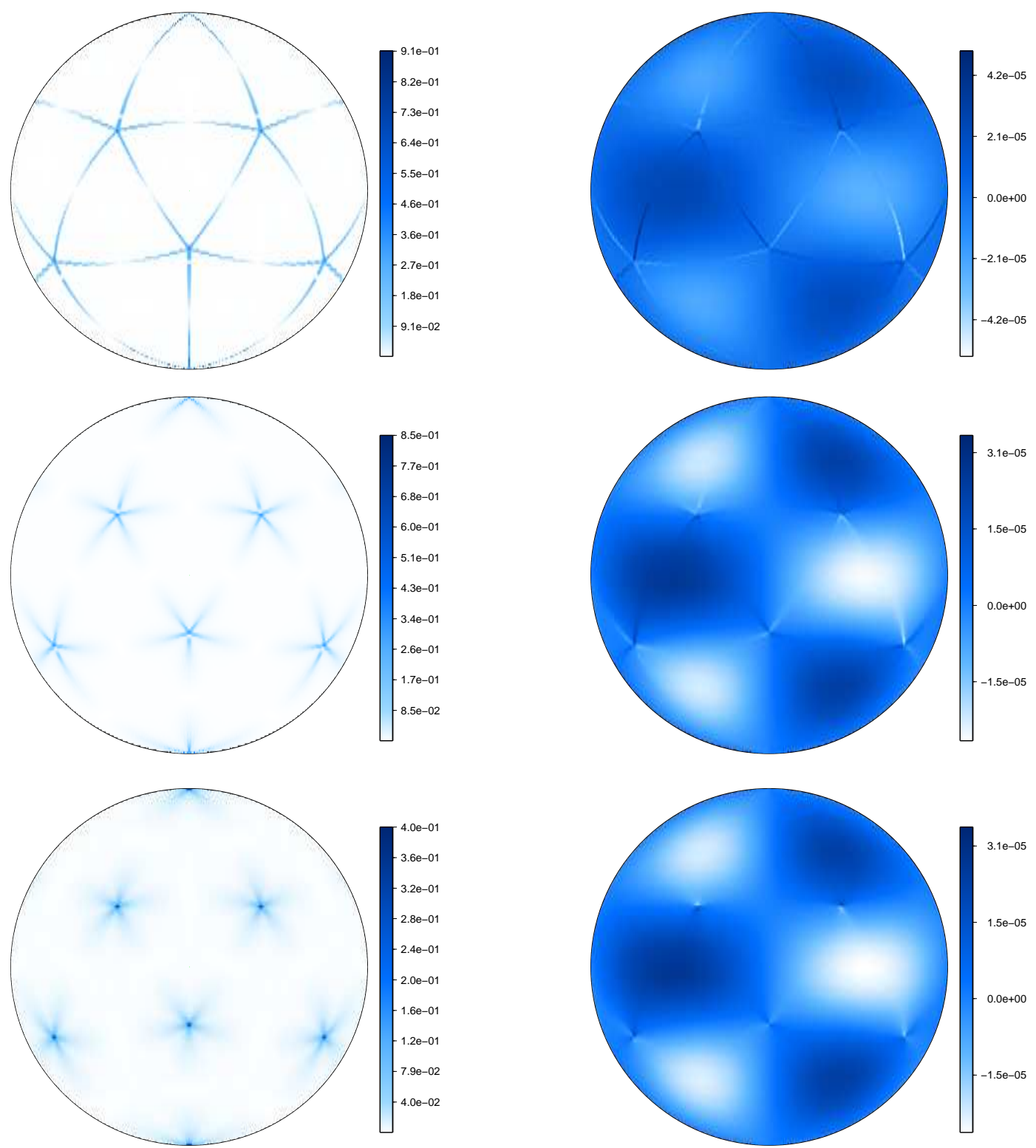

Figura 3.22: Índices de alinhamento (esquerda) e erro na estimativa do divergente (direita) para o campo vetorial trigonométrico com $m=1$ e $n=1$ em malhas icosaédricas de nivel 8 otimizadas com HR95 (acima), spring dynamics (meio) e SCVT (em baixo).

No que diz respeito à convergência, o padrão é muito similar ao da malha sem otimização. Vemos na Figura 3.23 que o erro máximo tende a ter primeira ordem nas malhas mais finas em 
todos os casos. Por outro lado, na mesmo figura, percebemos que restrito às células alinhadas o erro apresenta convergência de segunda ordem.

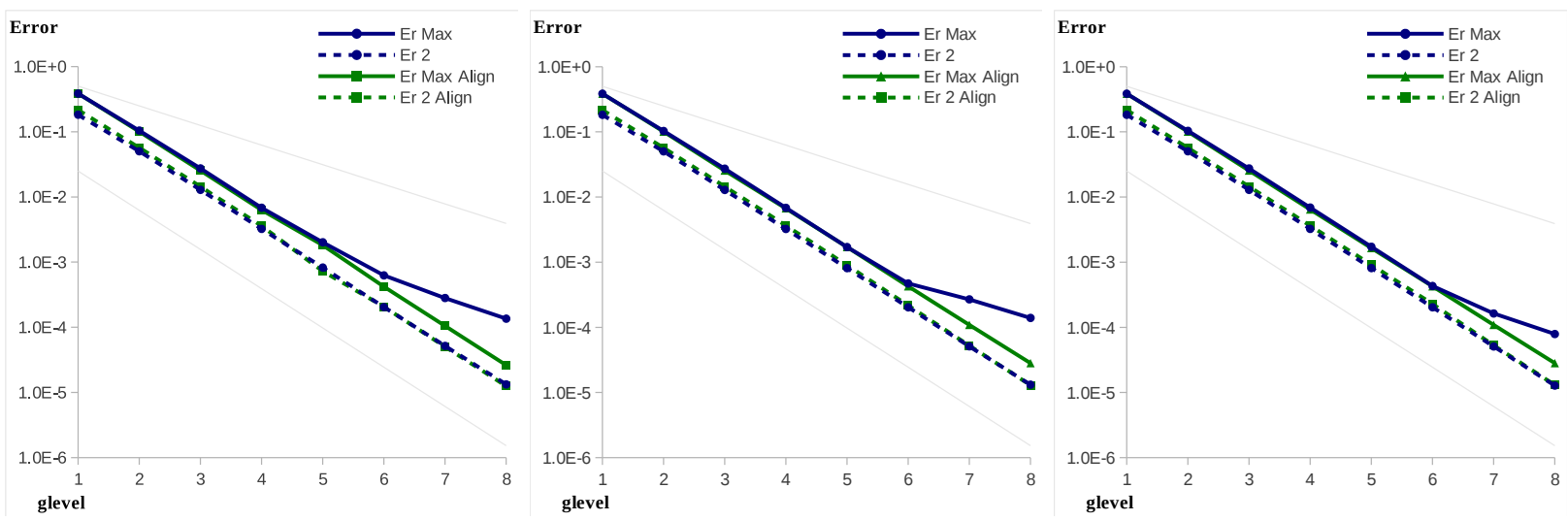

Figura 3.23: O mesmo que a Figura 3.21 mas agora considerando malhas otimizadas com HR95 (esquerda), spring dynamics (meio) e SCVT (direita). 


\subsection{Comentários}

A percepção desse padrão de malha na distribuição de erros na estimativa do divergente está presente no trabalho de Tomita et al. [2001], onde são apresentadas figuras nas quais percebese claramente a estrutura da malha no erro do divergente. Porém, a justificativa dada para tal distribuição refere-se a variações nas distorções e áreas da malha presentes nas regiões com maiores erros. Ao observarmos a Figura 2.11 vemos que há regiões com grandes distorções, mas com células bem alinhadas e erro na estimativa do divergente menor que em outras regiões. Como vimos com a questão do alinhamento dos polígonos, mesmo que tenhamos um polígono distorcido (com lados de tamanhos diferentes), se esses forem alinhados, teremos convergência de segunda ordem. Logo, a distorção não é o principal motivo de termos esse tipo de distribuição de erro na estimativa do divergente, mas sim o alinhamento das células. Por outro lado, não é razoável termos malhas com muitas distorções, pois nos teoremas demonstrados para garantir convergência quadrática em células alinhadas, utilizamos a hipótese de que área deve ser maior ou igual uma constante vezes o diâmetro, que por sua vez impõe um limite para o grau de distorção.

No trabalho de Wan [2009] o problema é relatado como ruído de malha na discretização do divergente, a algumas análises são feitas para casos particulares no plano, mostrando o fato de que as discretizações em triângulos levam geralmente a convergência de ordem um. O padrão de subestimativas e superestimativas para triângulos vizinhos aparecem nos resultados do trabalho de Wan [2009], mas não são analisados os motivos desse padrão. Como solução para aumentar a ordem de discretização do divergente é sugerido uma integração de alta ordem na aresta da célula computacional, mas como vimos, se estivermos usando um ponto como referência para o divergente médio da célula, estaremos ainda restritos a um erro de segunda ordem.

Nos diversos trabalhos sobre o assunto, as métricas mais importantes para avaliar a qualidade de uma malha são as distribuições de áreas e distorções (Miura e Kimoto [2005]). Destacamos com esse capítulo a importância de também se olhar para o alinhamento entre as arestas das células da malha, já que essa propriedade impacta na discretização do divergente. Além disso, os resultados são facilmente estendidos para o operador rotacional ou de difusão, tornando a teoria apresentada mais geral.

Os métodos de otimização de malhas atenuam os erros, mas o método de discretização do divergente continuará de primeira ordem. Pode ser possível a construção de método de otimização que melhore o alinhamento das células, porém, por conta dos pentágonos, a discretização do divergente irá continuar sendo de primeira ordem.

A teoria descrita e avaliada neste capítulo não está restrita a malhas icosaédricas. Ela aplica-se diretamente a qualquer malha geodésica, como as esferas cubadas e octaédricas. Tanto a esfera cubada quanto a malha octaédrica são interessantes de serem analisadas do ponto de vista de alinhamento, pois possuem somente células com número par de lados. Infelizmente, as células próximas ao vértices do cubo são bastante desalinhadas, assim como as células hexagonais em tornos dos 6 quadrados na malha octaédrica. Essa é uma análise a ser desenvolvida futuramente. 


\section{Capítulo 4}

\section{Análise de interpolações escalares e reconstruções vetoriais}

Na modelagem da dinâmica meteorológica diversas vezes precisamos fazer interpolações de campos escalares ou vetoriais. Em uma malha tradicional, de latitude e longitude, dada a sua ortogonalidade e estrutura, é mais simples obtermos métodos de interpolações derivados de métodos bidimensionais de malhas retangulares. Sendo assim, é possível usarmos, por exemplo, interpolações bi-cúbicas ou splines. No entanto, em malhas não estruturadas triangulares, ou hexagonais/pentagonais, não é tão simples obtermos interpolações com ordem maior que um e boas propriedades. De fato, esse tema ainda tem muitos pontos de pesquisa em aberto. O trabalho de Carfora [2007a] faz uma revisão simplificada de alguns métodos que foram propostos a respeito de interpolações para malhas geodésicas icosaédricas, e o trabalho de Fasshauer e Schumaker [1998] apresenta uma revisão mais completa de métodos de interpolação de escalares na esfera.

Muitos métodos de interpolações são dependentes do posicionamento dos dados em um malha. Vimos na seção 2.5 algumas formas possíveis de posicionarmos campos escalares e vetoriais, e vamos focar em métodos que sejam aplicáveis para malhas do tipo HC, com escalares nos vértices dos triângulos e componentes normais dos vetores nos pontos médios das arestas das células de Voronoi. No caso do campo escalar podemos usar a estrutura da triangulação de Delaunay no método de interpolação. Por outro lado, no caso do campo vetorial, como conhecemos somente as componentes normais, uma reconstrução vetorial deve ser aplicada. Apesar de focarmos em malhas $\mathrm{HC}$, alguns métodos que vamos analisar são mais gerais e se aplicam a outras malhas. Destacaremos isso ao longo do texto.

Um método simples de interpolação para dados escalares conhecidos em qualquer conjunto de pontos da esfera é adotar o valor escalar no ponto mais próximo ao ponto de interpolação. A região em torno de um ponto de malha que contempla os pontos mais próximos a si é justamente uma região de Voronoi. Logo, esse método definirá uma função interpoladora constante por células de Voronoi, e poderá apresentar descontinuidades entre as células. Apesar de possuir apenas primeira ordem de aproximação em relação ao espaçamento entre os pontos de malha, é um método de baixo custo interessante, por exemplo, para visualização de propriedades da malha.

É frequente o uso de coordenadas triangulares ou baricêntricas em malhas triangulares. Esse sistema de coordenadas pode ser usado para definir um plano em relação aos valores dados nos vértices do triângulo e gera um método de interpolação de segunda ordem. O método está fundamentado no cálculo de pesos para os vértices do triângulo com base em áreas de triângulos definidos entre o ponto de interpolação e os vértices. Para malhas poligonais, como a dual de Voronoi, o sistema de coordenadas baricêntricas pode ser generalizado para obtermos um método de interpolação também de segunda ordem. A generalização conhecida como coordenadas de Wachspress (Wachspress [1975]) usa as áreas de triângulos definidos pelos vértices do polígono e o ponto de interpolação para construir um polinômio que representa exatamente funções lineares. Há ainda os métodos de coordenadas baricêntricas generalizadas médias (Floater [2003]) e as de vizinhos naturais (Bobach et al. [2006]). As definições de coordenadas baricêntricas são geralmente dadas somente para o plano e 
seu uso na esfera envolve algumas peculiaridades que iremos analisar neste capítulo.

O desenvolvimento de métodos de interpolação de ordens mais altas para malhas não estruturadas, que são adequados a malhas icosaédricas, começou nos trabalhos de Lawson [1984] e Renka [1984], com métodos de interpolação do tipo Hermite. Com o tempo, outros métodos foram sendo propostos, sendo que hoje há diversos métodos aplicáveis a malhas não estruturadas. Porém, não há consenso quanto a quais métodos são melhores para malhas icosaédricas. Basicamente temos 2 tipos de métodos: aqueles que usam a estrutura da triangulação e outros baseados em distâncias.

Entre os métodos baseados em distâncias, os mais simples consideram uma função de base radial como função peso, onde entendemos por função de base radial aquela que é função somente da distância dos pontos de malha ao ponto de interpolação. Nesse tipo de método é realizada uma média ponderada com pontos vizinhos ao ponto de interpolação usando a função de base radial como peso nas ponderações. O trabalho de Franke [1982] relata diversos métodos desse tipo para o plano. Entre os métodos que usam função peso com base radial, o mais usado é o método local de Shepard modificado. Uma boa descrição desse método encontra-se em Renka [1988a] e, mais recentemente, em Thacker et al. [2010], onde são descritas algumas variações do método.

Outros métodos que também usam funções de bases radiais são conhecidos por métodos de funções da bases radiais (Radial Basis Functions - RBF). Nesse caso, constrói-se uma função interpoladora usando como base as funções radiais. Nessa metodologia é necessário resolver um sistema linear para obter a função interpoladora (Buhmann [2003]), mas este nem sempre será bem condicionado (Pottmann e Eck [1990], Cavoretto e De Rossi [2010], Tran e Gia [2008]). Essa abordagem pode apresentar globalmente convergência de alta ordem, mas como veremos, localmente eles podem simplesmente não convergir ou serem muito mal condicionados. Tais métodos vêm sendo usados na reconstrução de campos vetoriais em modelos que usam malhas com deslocamentos (tipo C).

Diversos métodos usam a estrutura de triangulação e, em geral, permitem interpolações de ordens mais altas. Dentre eles, os métodos de interpolação cúbica se caracterizam por interpolarem os valores nos pontos por uma função $C^{1}$. Uma primeira possível abordagem é a do tipo de Hermite (Renka [1997]), que envolve estimativas preliminares dos gradientes nos pontos de malha. Um outro método cúbico é baseado em polinômios de Bernstein-Bezier, ou splines esféricos (Alfeld et al. [1996a], Neamtu e Schumaker [2004]).

Já o método bi-quadrático consiste em usar a fórmula de interpolação bi-quadrática, comumente usada em métodos de elementos finitos (Zienkiewicz e Taylor [2005]). Essa interpolação usa além dos três vértices do triângulo, valores interpolados nos pontos médios das arestas do triângulo. A partir desses seis valores interpola-se uma função bi-quadrática. Nesse método é preciso primeiro interpolar o valor nos pontos médios das arestas. Esse procedimento pode ser feito usando uma interpolação cúbica de Hermite com os pontos dos finais das arestas (vértices do triângulo). Nesse caso, serão necessárias estimativas dos gradientes da função nos vértices do triângulo, assim como no caso do método de interpolação cúbica que usa interpolação de Hermite. Esse método é usado no modelo GME para cálculos de adveç̧ão semi-lagrangiana de nuvens e vapor d'água (Majewski et al. [2002]).

Em malhas deslocadas, onde conhecemos apenas uma componente do campo vetorial em certos pontos de malha, o trabalho de interpolação vetorial passa primeiro por um trabalho de reconstrução do campo de vetores. Para triângulos o mais natural é considerarmos bases vetoriais comuns em elementos finitos, por exemplo com o elemento de Raviart-Thomas (Raviart e Thomas [1977]), ou o elemento de Whitney/Nedelec (Whitney [1957], Nedelec [1980]). Porém, esses não são simples de ser estendidos para polígonos em geral, como no caso de malhas HC, com hexágonos e pentágonos. Em Klausen et al. [2012] foi proposto um método que pode ser visto como uma generalização do elemento de Raviart-Thomas para polígonos planos. Vamos analisar esse método e propor uma modificação para que fique definido na esfera.

Um método popular para reconstrução vetorial é devido a Perot [2000], que usa o Teorema da Divergência para deduzir o método. Esse método é, a princípio, de primeira ordem, mas, dependendo do formato da célula computacional, pode se tornar de segunda ordem. Esse método servirá de base para a construção de um método híbrido que usa a teoria de alinhamentos de células computacionais 
discutida no capítulo anterior.

Neste capítulo vamos descrever métodos de interpolações escalares e reconstruções vetoriais interessantes para serem usados em métodos semi-lagrangianos. Vamos comparar os métodos de interpolações escalares do ponto de vista de precisão e custo. Alguns métodos estão definidos somente para o plano e, por isso, vamos propor algumas generalizações para a esfera. O maior desafio está no desenvolvimento de um bom método de interpolação vetorial para malhas do tipo HC. Apresentaremos um método híbrido, original deste trabalho, de segunda ordem e baixo custo para esse fim.

Vamos começar descrevendo métodos de localização do ponto de interpolação em relação a uma malha geodésica. Em seguida analisaremos métodos de interpolação de campos escalares e depois vamos analisar métodos para interpolações/reconstruções vetoriais.

\subsection{Localização de ponto em malha}

O primeiro passo para se considerar uma interpolação em malhas triangulares é localizar o ponto que se deseja interpolar em relação à malha numérica. Isso é simples em malhas retangulares do tipo latitude/longitude, pois a indexação é estruturada e podemos usar as coordenadas do ponto para identificar a qual retângulo ele pertence. É possível considerarmos uma estrutura regular para malhas icosaédricas também, conforme descrito na seção 2.6, porém isso ainda não resolve trivialmente a forma de encontrarmos um ponto em relação à malha. Uma possibilidade é primeiro identificar a qual losango o ponto pertence e, depois, identificar seu posicionamento em relação a sub-losangos, sucessivamente. Destacamos esses passos na Figura 4.1, onde aparecem diversos níveis de divisões em diamantes. Esse método se caracteriza por uma busca binária do ponto na malha e é utilizado em alguns modelos icosaédricos como em Majewski et al. [2002]. O fato de termos que fazer uma busca binária nos leva a uma complexidade computacional de busca em média da ordem de $\log (N)$, onde $N$ é o número de pontos de malha.
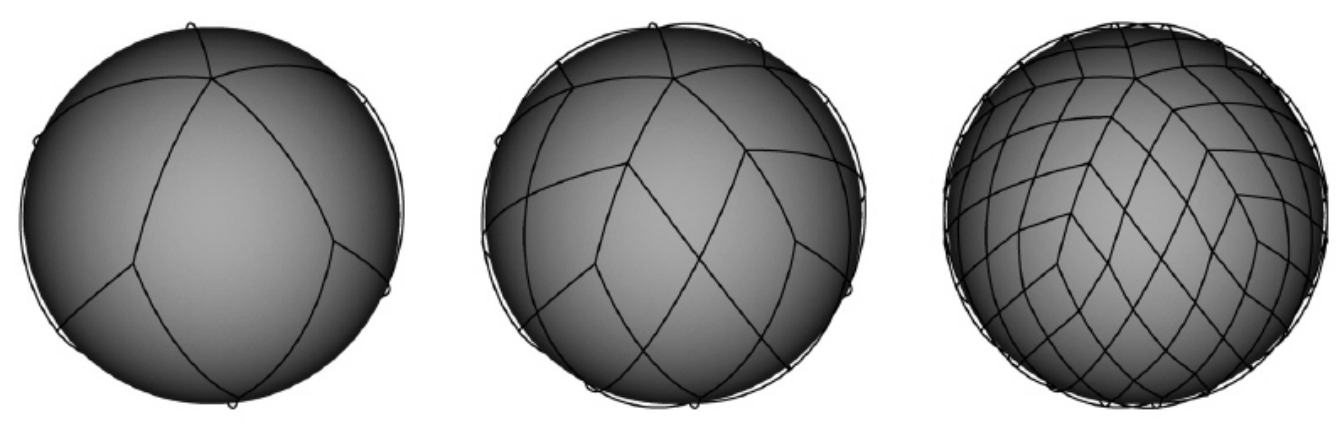

Figura 4.1: Subdivisões da malha icosaédrica em losangos ou diamantes. Fonte: Tomita et al. [2008], (C)2013 Society for Industrial and Applied Mathematics. Permissão para uso de figura em trabalho acadêmico sob as condições de uso aceitável ou razoável ("fair use").

Outra alternativa é usar uma busca linear. Uma forma de se realizar essa busca linear é a seguinte. Dado um ponto de malha inicial, de partida do algoritmo, percorrem-se os seus vizinhos analisando a posição do ponto de interpolação em relação aos grandes círculos formados pelo ponto de partida e seus vizinhos. O ponto de interpolação pode estar à direita ou esquerda de cada grande círculo, tendo como referência o ponto de partida. Percorrendo os vizinhos de forma anti-horária, no momento que detectarmos uma troca de posição (de direita para esquerda ou vice-versa), temos que o ponto de interpolação estará na direção dos dois últimos vizinhos analisados (veja a Figura 4.2). Com esses dois pontos vizinhos e mais o ponto de partida, define-se um triângulo. Testa-se se o ponto está nesse triângulo e, se estiver, temos o triângulo desejado. Caso contrário, adota-se um novo ponto de partida como sendo o ponto vizinho aos dois pontos recém encontrados na direção do ponto de chegada. Desta forma, recomeça-se o algoritmo até que o ponto que se deseja interpolar esteja contido em um triângulo formado no algoritmo. Ilustramos esse procedimento na Figura 4.2. 
Supondo $N$ pontos de malha, a busca linear tem um custo computacional médio da ordem de $\sqrt{N}$. Apesar de para $N$ grande isso incorrer em um custo maior do que a busca binária, a busca linear pode ser usada em qualquer malha geodésica, mesmo que não tenham estrutura binária. Além disso, se conhecermos informações de uma interpolação previamente feita para a próxima interpolação, reduzimos o custo da busca. Nesse caso, pressupõe-se que em geral as interpolações são feitas em sequências de pontos próximos, logo se temos o triângulo ao qual pertence um ponto interpolado, o próximo ponto a ser interpolado deve estar contido em um triângulo próximo ao anterior. Esse método é usado no pacote SSRFPACK de Renka [1997] para interpolações na esfera. Nele um ponto do triângulo obtido na última interpolação é um argumento de entrada e é usado como ponto de partida para buscar o triângulo da próxima interpolação. Quando não for dado um triângulo de partida, o método escolhe arbitrariamente um ponto de malha qualquer e a busca parte dele.

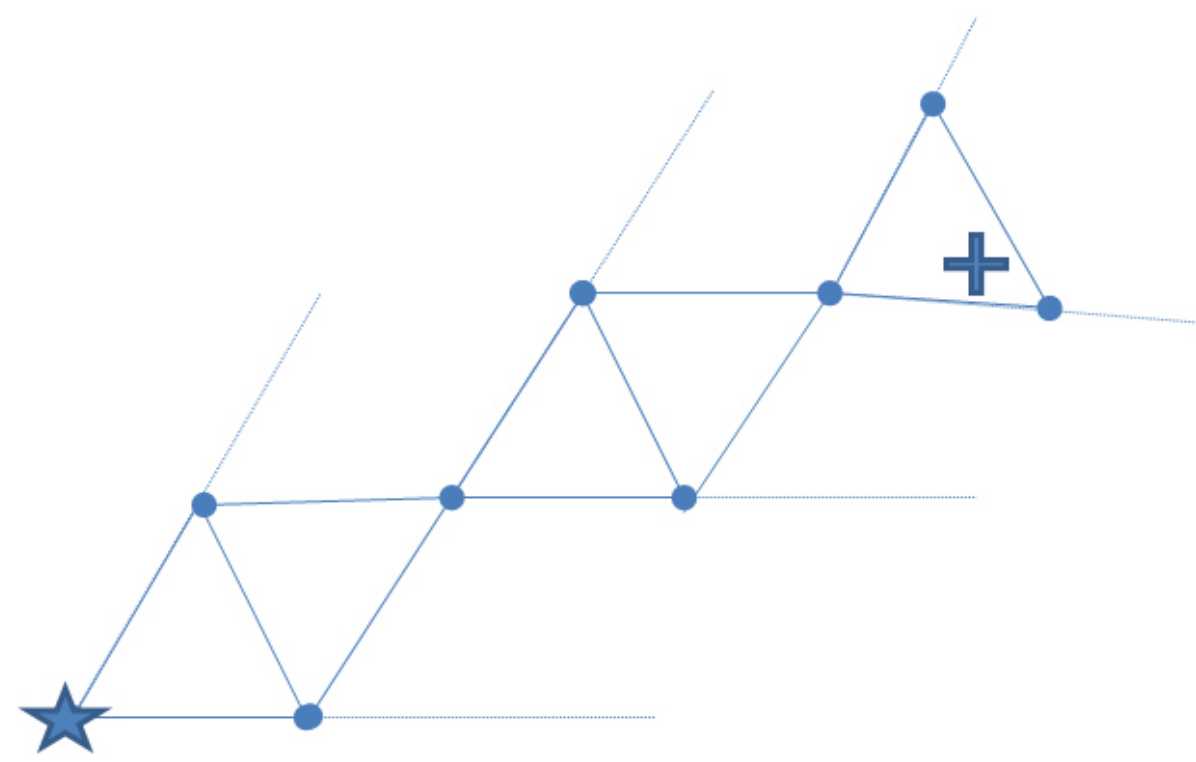

Figura 4.2: Ilustração do método de busca utilizada no pacote SSRFPACK de Renka [1997]. A estrela representa o ponto de partida e a cruz, o ponto que desejamos localizar em relação a malha. Os demais pontos, círculos preenchidos, representam pontos da malha conectados por arestas para formar a triangulação. As linhas tracejadas representam arcos geodésicos.

No presente trabalho propomos uma alternativa para o problema de busca cujo o custo computacional independe do número de pontos da malha. Para tanto, associamos os triângulos a uma malha do tipo latitude e longitude. Vamos detalhar o algoritmo a seguir.

Para cada malha icosaédrica definimos $\delta$ como a menor distância entre 2 pontos da malha icosaédrica. Definimos uma malha uniforme de latitude e longitude com espaçamento de grade menor que $\delta$. Dessa forma, a malha de latitude e longitude será sempre mais fina que a malha icosaédrica e, como veremos mais adiante, isso minimizará o custo das buscas. Seja $\delta_{1}$ a distância entre duas latitudes e $\delta_{2}$ das longitudes, tais que $\delta_{1}$ e $\delta_{2}$ são valores positivos fixados e menores que $\delta / 2$. Para cada latitude $(\theta)$ e longitude $(\lambda)$ da malha regular, associamos um retângulo, que será sempre formado pelos pontos: $(\theta, \lambda),\left(\theta+\delta_{1}, \lambda\right),\left(\theta, \lambda+\delta_{2}\right),\left(\theta+\delta_{1}, \lambda+\delta_{2}\right)$. Apresentamos na Figura 4.3 um exemplo das relações entre as malha icosaédricas e a do tipo latitude-longitude.

Para cada retângulo da malha regular geramos uma lista de triângulos que o intersectam. Como os retângulos serão sempre bem menores que os triângulos, então cada retângulo terá intersecção com no máximo 6 triângulos, para o caso da malha icosaédrica. Isso deve-se ao fato de que cada ponto da malha icosaédrica possui no máximo 6 vizinhos, logo um retângulo terá uma lista com número máximo de triângulos quando contiver um ponto da malha icosaédrica. Com isso criamos uma tabela onde para cada latitude e longitude da malha regular temos uma lista de triângulos. Desta forma, dado um ponto qualquer da esfera, trivialmente encontra-se a qual retângulo pertence. Depois é necessário testar a qual dos, no máximo 6, triângulos da lista o ponto pertence. 
A construção da lista relacionando retângulos e triângulos é custosa, porém pode ser préprocessada uma única vez e armazenada para uso futuro. Para cada retângulo usa-se o método de busca linear descrita anteriormente para obter o ponto mais próximo ao centro do retângulo. Em seguida, precorrem-se os seus vizinhos em busca de triângulos que intersectem o retângulo.

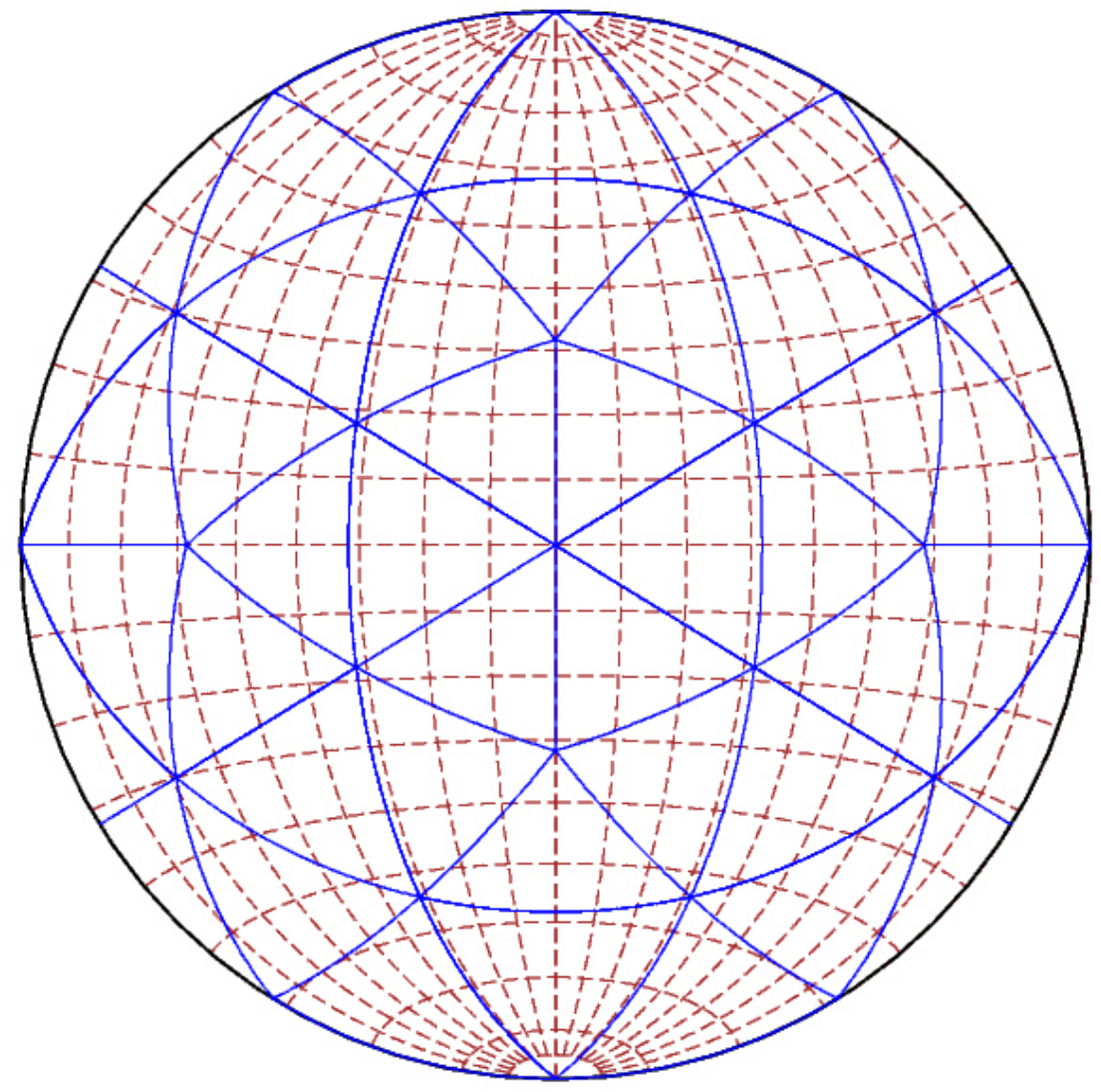

Figura 4.3: Malha icosaédrica com 42 pontos em azul e linha contínua. Malha latitude, longitude com intervalo de $10^{\circ}$ em marrom e linha pontilhada

Cada retângulo da malha regular, latitude-longitude, pode ter de 1 a 6 triângulos interceptandoo. Os retângulos totalmente inseridos em um único triângulo terão somente um elemento de intersecção. Logo, cada retângulo pode ter um número diferente de triângulos o interceptando e, por isso, utilizamos uma estrutura de matriz esparsa para armazenar essas informações.

A desvantagem dessa abordagem é o maior uso de memória. O custo extra de armazenamento desse método será dado por algo da ordem de $6 n^{2}$ inteiros, onde $n$ é o número de divisões na latitude. Por exemplo, no caso de uma malha icosaédrica com 40962 pontos, com malha regular contendo 460 latitudes e 910 longitudes, seriam necessários um pouco mais 7 MBytes, considerando um inteiro com 4 bytes. Portanto o custo de armazenamento é irrisório em relação às capacidades de armazenamento voláteis atuais. 


\subsection{Interpolações escalares}

Sejam $f_{i} \in \mathbb{R}$, com $i=1, \ldots n$, valores reais definidos em um conjunto de pontos de malha $\Pi=\left\{p_{i}\right\}_{i=1, \ldots, n}$ no plano $\mathbb{R}^{2}$ ou na esfera $\mathcal{S}^{2}$. O problema de interpolação escalar consiste em encontrar uma função $f$, com certas condições de regularidade, que satisfaça

$$
f\left(p_{i}\right)=f_{i}, i=1, \ldots, n .
$$

No plano, seja $U \subset \mathbb{R}^{2}$ o casco convexo de $\Pi$, ou, na esfera, $U=\mathcal{S}^{2}$. Estamos interessados em calcular $f$ em pontos $p$ de $U$.

Iremos validar os métodos usando a seguinte função escalar, dada, em coordenadas geográficas, por

$$
f(\lambda, \theta)=(\cos (\theta))^{3}(\sin (\lambda))^{2},
$$

onde $-\pi \leq \lambda \leq \pi$ é a longitude e $-\pi / 2 \leq \theta \leq \pi / 2$ é a latitude. Ilustramos essa função na Figura 4.4 .

O teste de interpolação será feito considerando um remapeamento da malha icosaédrica para uma malha do tipo longitude-latitude com $180 \times 360$ pontos. Assim, para cada ponto da malha de longitude/latitude será preciso realizar uma interpolação escalar com base em valores dados na malha icosaédrica. Vamos usar as mesmas métricas de erros usadas no capítulo anterior, sendo o erro máximo dado pela expressão (3.52) e o erro quadrático médio pela equação (3.51), mas agora considerando os diversos pontos da malha de longitude/latitude.

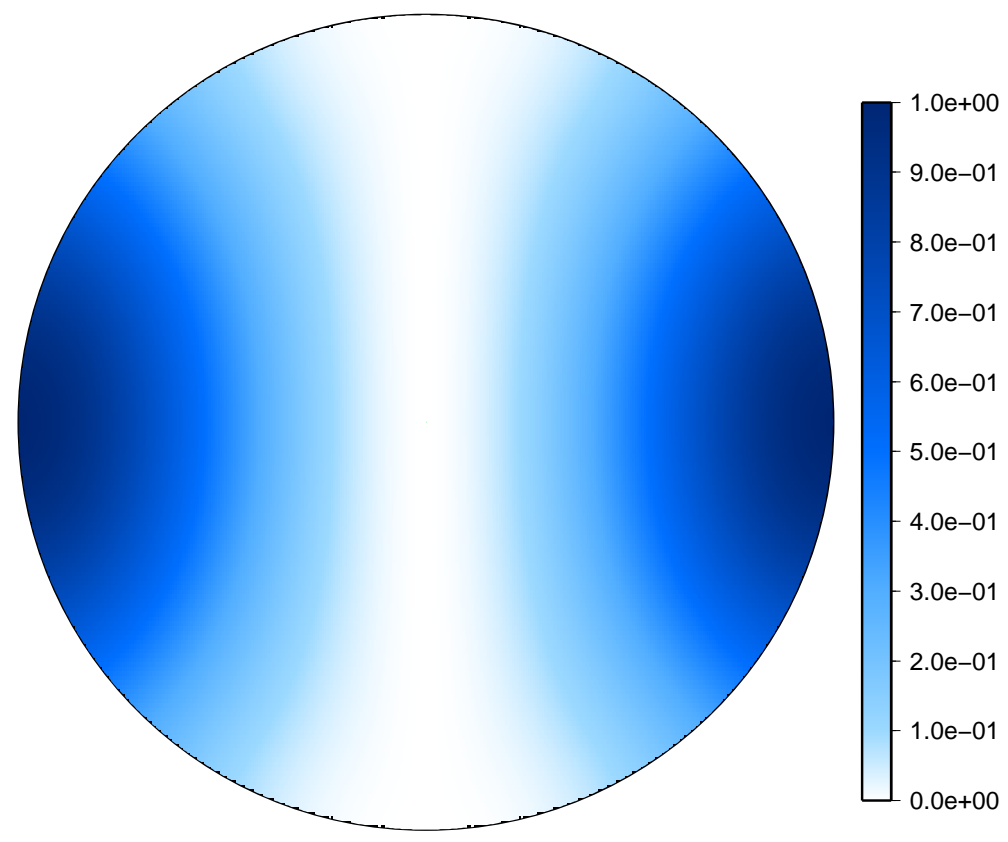

Figura 4.4: Função trigonométrica dada em (4.2) .

\subsubsection{Coordenadas baricêntricas}

As coordenadas baricêntricas são um conjunto de coordenadas relativas a um conjunto de pontos que podem ser usadas como pesos em uma combinação linear dos valores dos pontos. Veremos primeiro o caso plano e em seguida discutiremos o caso esférico.

Definimos por um sistema de coordenadas baricêntricas de $U \subset \mathbb{R}^{2}$, no plano, associado ao conjunto de pontos $\Pi$, como sendo o conjunto de funções $w_{i}: U \rightarrow \mathbb{R}, i=1, \ldots, n$, tal que para todo $p \in U$,

(i) $p=\sum_{i=1}^{n} w_{i}(p) p_{i}$ (linearidade), 
(ii) $w_{i}\left(p_{j}\right)=\delta_{i j}($ interpolação),

(iii) $\sum_{i=1}^{n} w_{i}(p)=1$ (partição de unidade),

onde $\delta_{i j}$ é o símbolo de Kronecker e assume valor um se $i=j$ e zero caso contrário. Se $w_{i}$ for não nulo apenas em uma vizinhança de $p$ e nulo para os demais pontos de malha, dizemos que (i) define a propriedade de coordenada local (Boissonnat e Flototto [2002]).

Nos métodos que usam coordenadas baricêntricas para interpolações, define-se a função interpoladora $\tilde{f}$ como

$$
\tilde{f}(p)=\sum_{i=1}^{n} w_{i}(p) f_{i} .
$$

A generalização de um sistema de coordenadas desse tipo para a esfera esbarra em alguns problemas (Boissonnat e Flototto [2002]). O primeiro consiste no fato de que se os pontos são dados na esfera, combinações convexas destes pontos não resultam em pontos necessariamente na esfera. Uma possível solução, adotada por alguns autores (por exemplo em Alfeld et al. [1996b]), é relaxar a terceira propriedade, permitindo com que a soma dos pesos seja maior que um (no caso da esfera), e, além disso, alguns autores propõem analisar o sistema de coordenadas usando o conceito de centro de massa Riemanniano (Rustamov [2010]). Neste estudo, como o propósito consiste em usar o sistema de coordenadas como pesos para métodos de interpolação, não podemos abrir mão das propriedades (ii) e (iii), logo vamos relaxar somente a propriedade (i). Assim a combinação dos valores não será linear, mas sim acompanhará a superfície esférica. Cada método terá suas peculiaridades no que diz respeito à generalização para a esfera e vamos descrevê-las à medida que formos apresentando os métodos. Não encontramos nenhum trabalho abordando o problema dessa forma, porém, como veremos, o análogo do método plano para a esfera relaxando a propriedade (i) aparece de forma bem natural nos métodos.

Estamos interessados no caso onde temos a propriedade de coordenada local, pois assim a interpolação irá depender apenas de pontos vizinhos ao ponto de interpolação. O caso mais simples é o do triângulo. Considerando que $p$ esteja contido num triângulo plano com vértices $\left(p_{1}, p_{2}, p_{3}\right)$, as coordenadas baricêntricas são unicamente definidas por:

$$
w_{k}(p)=\frac{A_{k}(p)}{A}, \quad k=1,2,3
$$

onde $A_{k}$ é a área definida pelo sub-triângulo $\left(p, p_{i}, p_{j}\right)$, com $i \neq j \neq k$, e $A$ é a área total do triângulo plano. Não é difícil ver que $w_{k} \in[0,1]$ e que $w_{k}=1 \Leftrightarrow p=p_{k}$. Como estamos no plano, a propriedade (i), de linearidade, decorre diretamente da definição de $w_{k}$.

As coordenadas baricêntricas em triângulos na esfera podem ser obtidas de duas formas, ambas relaxando a propriedade de linearidade. A primeira é considerando as coordenadas para o triângulo plano formado por 3 pontos na esfera. Se $p$ for agora um ponto da esfera contido em um triângulo esférico formado pelos vértices $\left(p_{1}, p_{2}, p_{3}\right)$, dados no sentido anti-horário em coordenadas cartesianas, podemos obter as coordenadas baricêntricas para a projeção radial $q$, de $p$, no triângulo plano $T$, definido pelos vértices do triângulo esférico, tal que $\frac{q}{\|q\|}=p$. É possível calcularmos as coordenadas baricêntricas de $q$ sem obtê-lo explicitamente, usando que

$$
\begin{aligned}
w_{k}(q) & =\frac{A_{k}(q)}{A}=\frac{2 A_{k}(q)}{2 A} \\
& =\frac{\left\|\left(v_{i(k)}-q\right) \times\left(v_{j(k)}-q\right)\right\|}{\left\|\left(v_{2}-v_{1}\right) \times\left(v_{3}-v_{1}\right)\right\|} \\
& =\frac{\operatorname{det}\left(q, v_{i(k)}, v_{j(k)}\right)}{\operatorname{det}\left(q, v_{2}, v_{3}\right)+\operatorname{det}\left(v_{1}, q, v_{3}\right)+\operatorname{det}\left(v_{1}, v_{2}, q\right)} \\
& =\frac{\operatorname{det}\left(p, v_{i(k)}, v_{j(k)}\right)}{\operatorname{det}\left(p, v_{2}, v_{3}\right)+\operatorname{det}\left(v_{1}, p, v_{3}\right)+\operatorname{det}\left(v_{1}, v_{2}, p\right)}
\end{aligned}
$$


onde $k=1,2,3,(i(k), j(k))=\{(2,3),(3,1),(1,2)\}$, det $(\cdot)$ indica o determinante da matriz cujas colunas são as coordenadas cartesianas dos pontos e a operação $\times$ é o produto vetorial.

A outra abordagem possível seria considerar área geodésicas na equação (4.4), nesse caso estaríamos nos referindo a coordenadas para o triângulo esférico, sem precisar projetar o ponto da esfera para o plano formado pelos vértices do triângulo. O custo computacional do cálculo de áreas geodésicas de triângulos é um pouco maior que de áreas de triângulos planos e os resultados são muito similares. Por isso adotamos o método que usa as áreas dos triângulos planos.

Agora suponha que tenhamos valores dados nos vértices de uma célula de Voronoi, ou de um polígono qualquer na esfera, nesse caso poderíamos triangularizar o polígono e usar coordenadas baricêntricas para triângulos. Porém, geralmente, a triangulação de um polígono não é necessariamente única, por exemplo no caso de um hexágono regular (veja a Figura 4.5). Como alternativa, foram criadas diversas coordenadas para polígonos em geral, conhecidas como coordenadas baricêntricas generalizadas. Entre elas estão as coordenadas naturais, ou de Voronoi (Bobach et al. [2006]), coordenadas harmônicas Derose e Meyer [2006], coordenadas de Wachspress (Wachspress [1975]) e coordenadas de valor médio Floater [2003]. Esses métodos são geralmente descritos para o plano e estimativas de erros para alguns destes métodos podem ser encontrados em Gillette et al. [2012], onde um estudo comparativo é feito. Em Floater et al. [2006] foi proposta uma forma geral de construção de coordenadas baricêntricas generalizadas em polígonos convexos e foram analisados os impactos do formato do polígono nas propriedades das coordenadas. Implementamos e testamos alguns dos métodos baseados em coordenadas naturais, mas encontramos um custo muito alto quando comparado com outros métodos de coordenadas generalizadas. As coordenadas harmônicas também apresentam um custo alto para o cálculo dos pesos, pois deve-se resolver uma equação de Laplace para obtê-los. As coordenadas de valor médio são simples de serem calculadas e possuem boas propriedades. Elas são construídas usando ângulos internos do polígono e triângulos formados com o ponto de interpolação. As coordenadas de Wachspress são muito parecidas com as coordenadas de valores médios, mas são menos suaves. Estas coordenadas podem ser construídas usando áreas, o que facilita a generalização para a esfera e computacionalmente pode ser mais simples que o cálculo de ângulo. Além disso, as coordenadas de Wachspress são uma extensão natural das coordenadas baricêntricas para triângulos. Adotamos as coordenadas de Wachspress para serem analisadas em detalhes neste estudo, mas também vamos descrever brevemente alguns resultados sobre as coordenadas naturais.
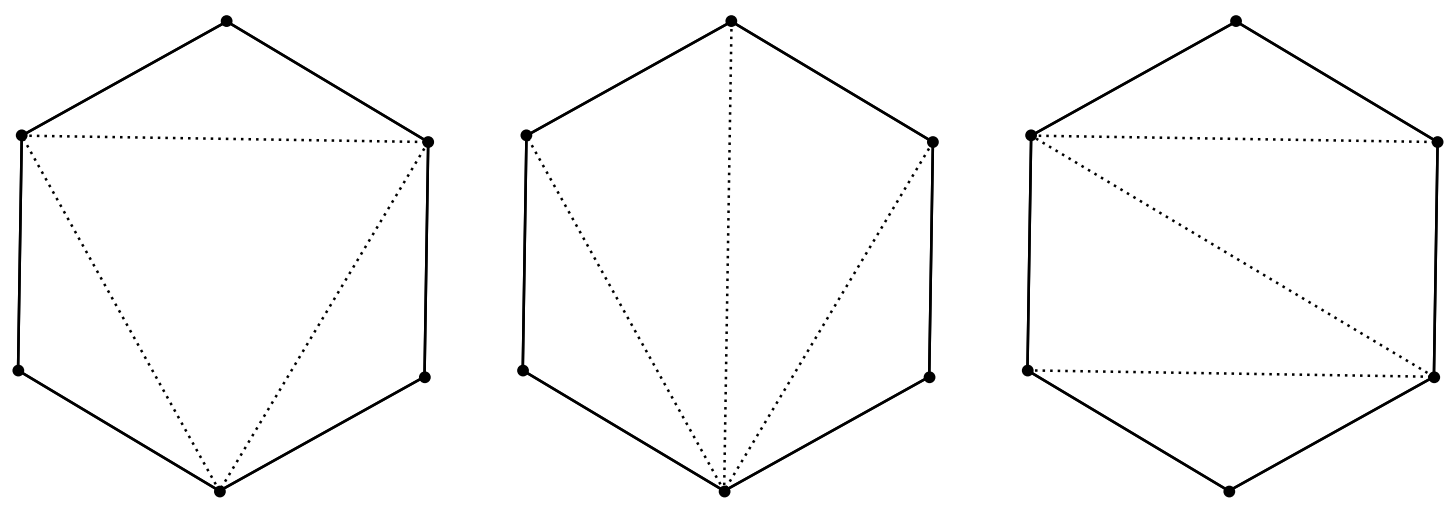

Figura 4.5: Triangulações diferentes de um hexágono regular.

\section{Coordenadas de Wachspress}

As coordenadas de Wachspress foram propostas inicialmente em 1975 (Wachspress [1975]) e têm sido usadas por alguns autores na área de geometria computacional (CAD - Computer Aided Geometry) como método de interpolação (Gillette et al. [2012], Ju et al. [2005], Lidberg [2011], Meyer et al. [2002]). Supondo um polígono convexo com um número arbitrário $n$ de vértices, $p_{i}$, $i=1, \ldots, n$, ordenados de forma anti-horária, as coordenadas de Wachspress são definidas pelas 
funções

$$
w_{i}(p)=\frac{\lambda_{i}(p)}{\sum_{j=1}^{n} \lambda_{j}(p)}
$$

onde

$$
\lambda_{i}(p)=B_{i} \prod_{j \neq i, i+1} A_{j}(p)
$$

$A_{i}(p)$ são as áreas dos triângulos formados pelo ponto $p$ e os vértices $p_{i-1}$ e $p_{i}$ do polígono, como por exemplo na Figura 4.6a para um polígono de 6 vértices, e $B_{i}$ são as áreas formada pelos vértices $p_{i-1}, p_{i}, p_{i+1}$, conforme o exemplo na Figura $4.6 \mathrm{~b}^{1}$.

(a)

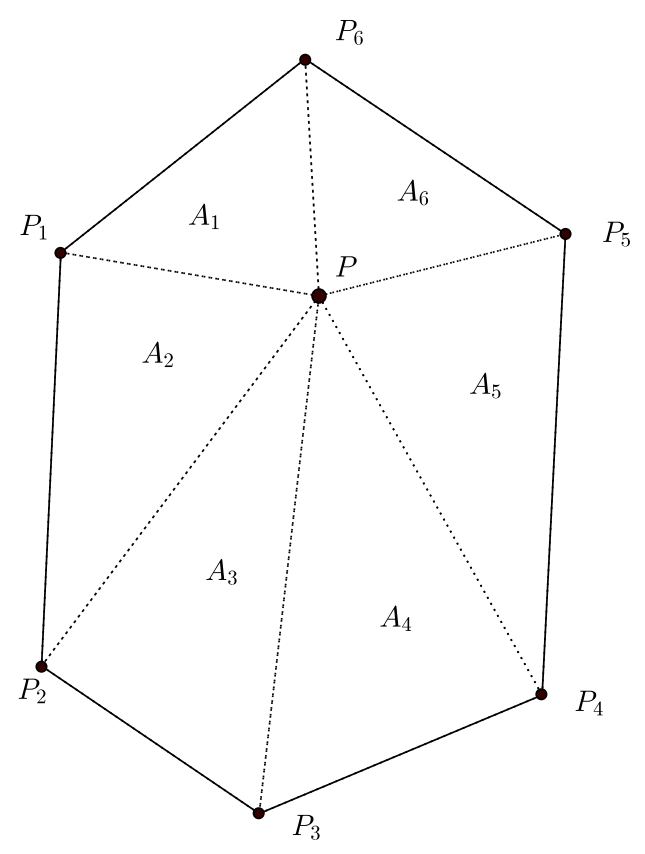

(b)

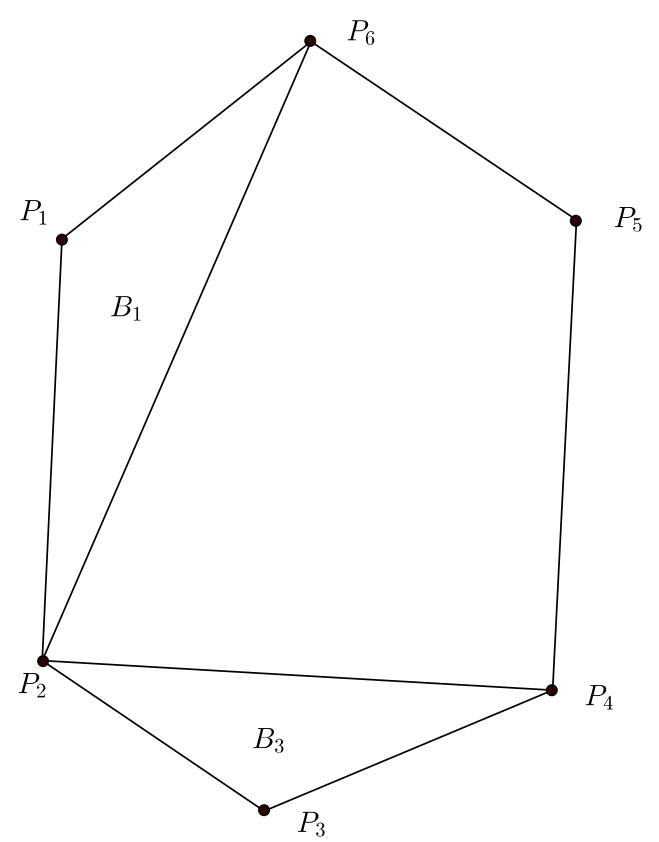

Figura 4.6: Notações para coordenadas de Wachspress.

Com isso podemos usar os pesos $w_{i}$ para interpolar o valor da função $f$ em $P$ com base nos pontos $P_{i}$. É simples verificar que as coordenadas de Wachspress para um polígono convexo com $n$ vértices definem um polinômio de grau $n-2$ no plano. Assim, no caso de um pentágono, temos um polinômio de grau 3 e, no caso de um hexágono, grau 4. Na Figura 4.7 apresentamos exemplos de funções interpoladoras para um pentágono e um hexágono, ambos regulares, aonde foi adotado o valor 1 no vértice superior e zero nos demais. As coordenadas são sensíveis ao formato do polígono e quando temos um ângulo muito obtuso em um dos vértices do polígono as coordenadas podem ter gradientes fortes, conforme ilustrado na Figura 4.8.

Como o método de construção se baseia somente nas áreas de elementos triangulares, a generalização para a esfera pode ser feita simplesmente adotando área geodésicas (esféricas) ao invés de planares. Porém, como comentado anteriormente, estaremos violando a propriedade de combinação convexa ou de coordenadas locais. Entendemos que isso não será um problema para o nosso propósito.

O método é usualmente proposto na literatura para interpolações no plano na forma como descrevemos acima. Porém percebemos que dessa forma estaremos sujeitos a problemas de precisão numérica. Isso ocorre para polígonos for relativamente pequenos, em que as áreas também serão, logo o produto destas áreas pode se tornar tão pequeno quanto a precisão de máquina, gerando grandes erros na hora do cálculo final de $w_{i}$. Para contornar esse problema vamos usar áreas relativas. Seja $A$ a área do polígono, redefinimos $A_{i}$ e $B_{i}$ como sendo os mesmos definidos anteriormente, mas agora divididos por $A$. Logo $A_{i}$ indicará um percentual de área do triângulo esférico formado por

\footnotetext{
${ }^{1}$ Para facilitar a notação consideramos que $p_{0}=p_{n}$ e $p_{n+1}=p_{1}$.
} 


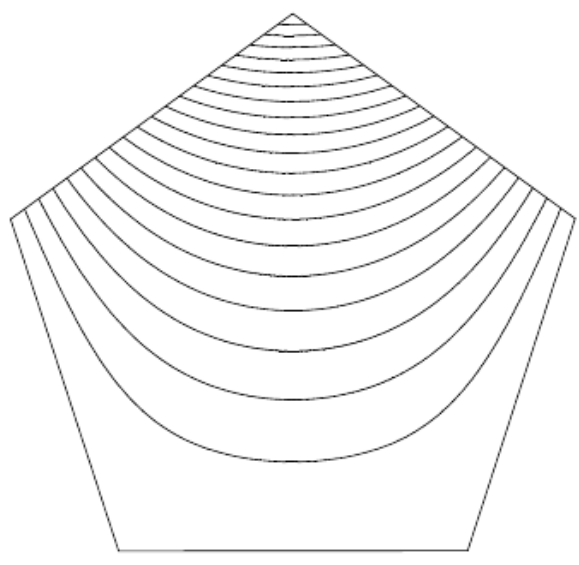

(a)

Figura 4.7: Curvas de nível de bases de Wachspress para um (a) pentágono e um (b) hexágono assumindo valor 1 no vértice superior e zero nos demais. Fonte: Floater et al. [2006], com licença para reuso. (a)

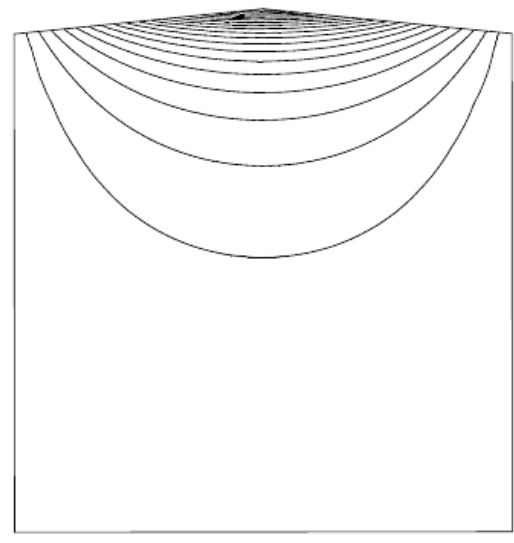

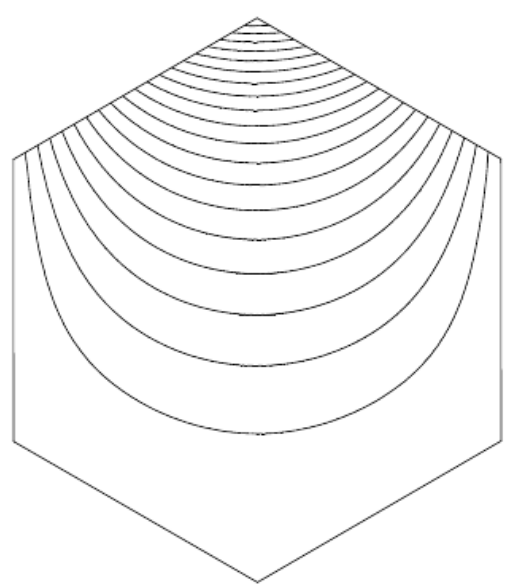

(b)

(b)

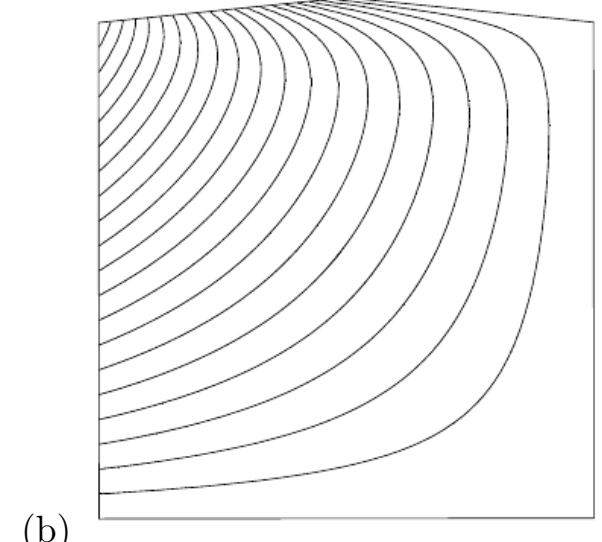

Figura 4.8: Curvas de nível de bases de Wachspress para um pentágono com um ângulo próximo a $180^{\circ}$. Em (a) foi assumido o valor 1 no vértice superior e zero nos demais. Em (b) foi assumido o valor 1 no vértice superior esquerdo e zero nos demais Fonte: Floater et al. [2006], com licença para reuso.

$p, p_{i-1}$ e $p_{i}$ em relação à área esférica total do polígono. Analogamente, $B_{i}$ será o percentual de área do triângulo esférico formado pelos vértices $p_{i-1}, p_{i}, p_{i+1}$ em relação à área esférica total do polígono. Note que se o polígono for um triângulo, o método de Wachspress coincide com o método de interpolação linear usando coordenadas baricêntricas em triângulos. A função de interpolação definida com as coordenadas de Wachspress irá reproduzir exatamente uma função linear no plano. No caso geral a função interpoladora será uma função de grau $n-2$, onde $n$ é o número de vértices, tal que, nas arestas, seja linear.

Suponha agora que os valores $f_{i}$ sejam dados nos pontos médios das arestas de uma malha de Voronoi, conforme destacado em quadrados (verdes) na Figura 4.9. Para essa disposição de valores podemos usar uma combinação de coordenadas de Wachspress para polígonos e triângulos na malha formada pelos pontos médios dos hexágonos destacada em verde tracejado na mesma figura. Essa malha é uma mistura única de triângulos, pentágonos e hexágonos. Assim (i) se o ponto de interpolação cair em um sub-triângulo em torno de um vértice da célula de Voronoi, então usamos interpolação linear nesse triângulo (Wachspress para o caso de polígono triangular), (ii) se o ponto cair em um hexágono ou pentágono na malha de arestas de Voronoi, então usamos a interpolação de Wachspress com base no polígono hexagonal ou pentagonal. Dessa forma garantimos que função interpoladora global seja pelo menos contínua.

Outro caso possível é termos os valores dados nos pontos médios de arestas de triângulos da 


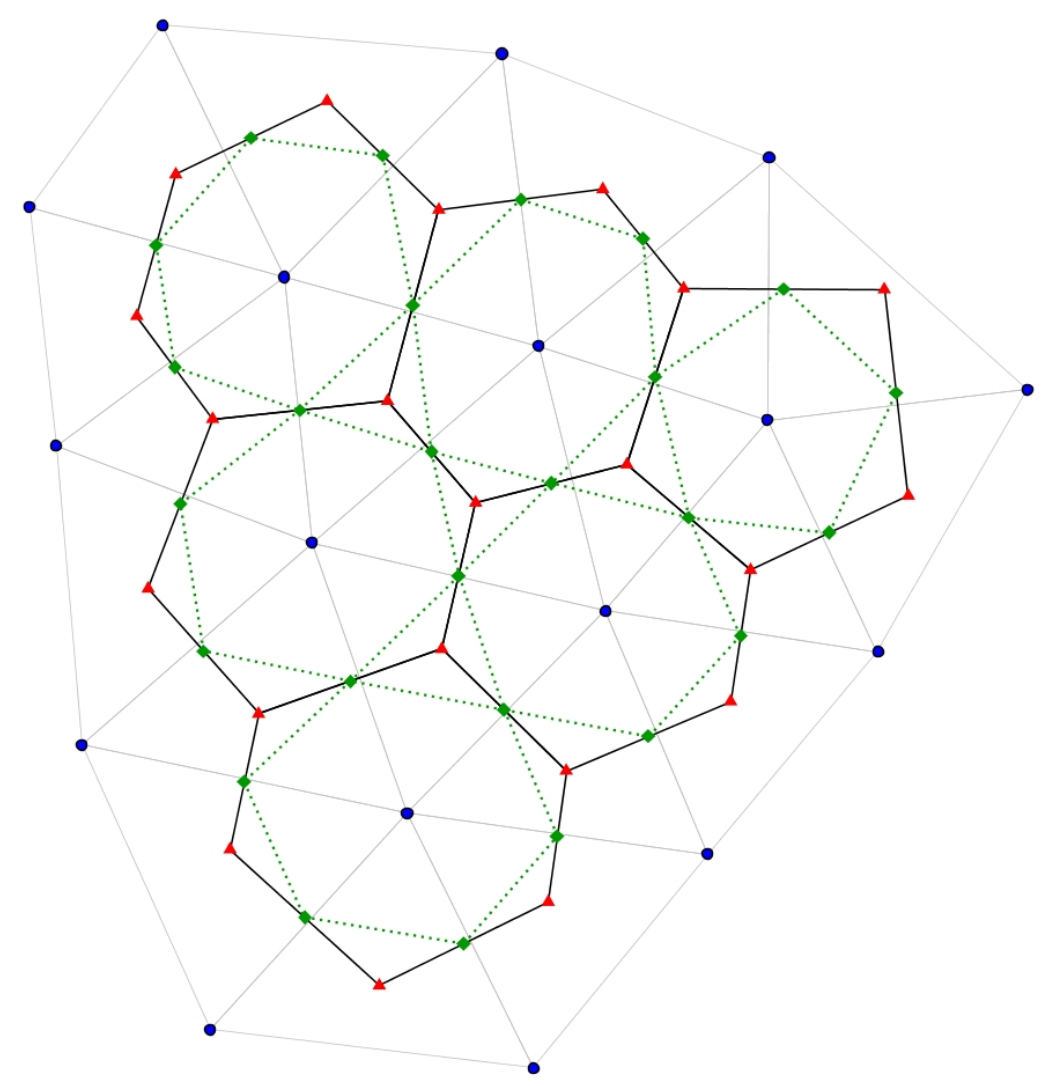

Figura 4.9: Malha considerando pontos nas arestas das células de Voronoi. Os círculos (azuis) indicam os nós da malha, ou vértices dos triângulos. As linhas conectam os nós para formar a malha de Delaunay. Os pontos indicados por pequenos triângulos (vermelhos) indicam os circuncentros dos triângulos da malha de Delaunay. Os circuncentros são conectados para formar as células de Voronoi. Os pontos médios das arestas das células de Voronoi estão marcados com um diamante (verde). Os pontos médios das arestas são conectados por linhas tracejadas verdes para cada célula de Voronoi.

malha de Delaunay. Esse caso pode ser resolvido de forma análoga à anterior.

\section{Coordenadas de vizinhos naturais}

As coordenadas de vizinhos naturais, também conhecidas por coordenadas de Sibson, usam diagramas de Voronoi em sua definição (Sibson [1980]). Dado um diagrama de Voronoi definido a partir de pontos de malha, como o ilustrado na Figura 4.10, considere o novo diagrama de Voronoi obtido incluindo o ponto para o qual queremos definir as coordenadas, ilustrado na Figura 4.11. As coordenadas de Sibson serão construídas relacionando as áreas do diagrama de Voronoi da malha com esse novo diagrama de Voronoi, incluindo o ponto de interpolação.

Seja $V$ o diagrama de Voronoi dos pontos de malha formados por $p_{i}, i=1, \ldots n$, onde cada ponto tem sua respectiva região de Voronoi $V_{p_{i}}$. Seja $D(p)$ a região de Voronoi de um ponto de interpolação $p$ relativo ao diagrama de Voronoi que inclui os pontos de malha e mais o ponto de interpolação. Seja $D_{j}(p)=D(p) \bigcap V_{p_{i}}$ a intersecção da região de Voronoi de $p$ com a de um ponto de malha $p_{i}$ e $C_{i}(p)$ a área de $D_{j}(p)$. Então as coordenadas de Sibson serão dadas por

$$
w_{i}(p)=\frac{C_{i}(p)}{\sum_{j=1}^{n} C_{j}(p)} .
$$

Note que apenas alguns pontos de malha terão $C_{i}$ não nulos, esses são os vizinhos naturais do ponto $p$.

A generalização desse tipo de sistema de coordenadas para a esfera pode ser feita diretamente usando arcos geodésicos, novamente perdendo a linearidade. A inclusão de pontos em di- 


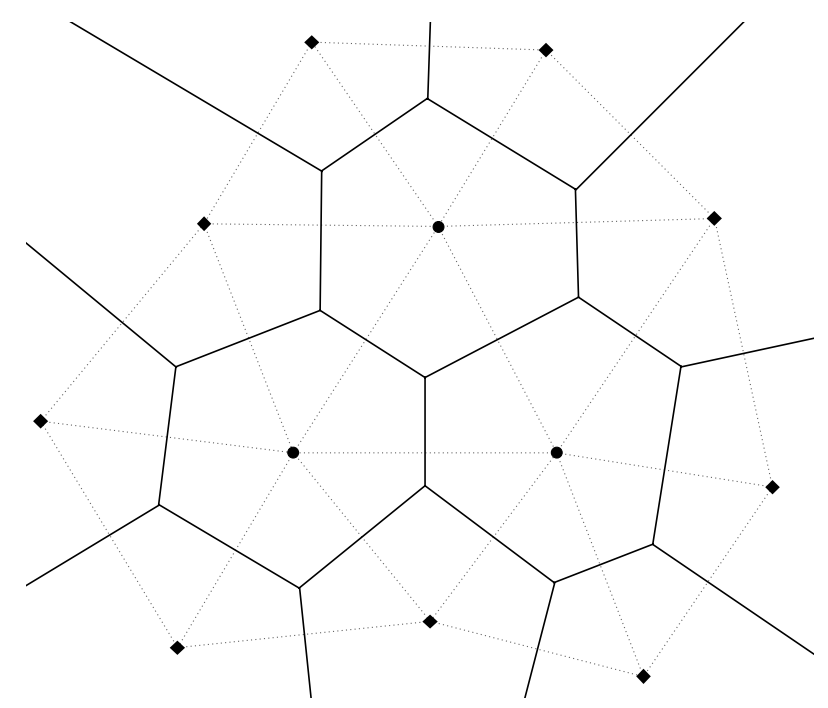

Figura 4.10: Diagrama de Voronoi para um conjunto de pontos no plano. Os nós são representados com círculos. As linhas tracejadas indicam a triangulação de Delaunay e a linha sólida o diagrama de Voronoi.

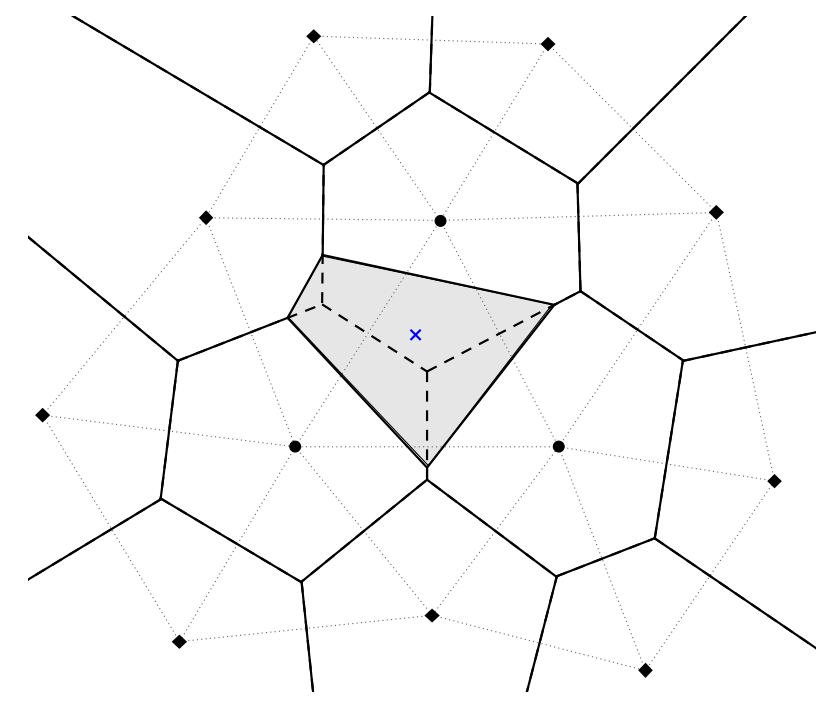

Figura 4.11: Diagrama de Voronoi para um conjunto de pontos no plano adicionando o ponto de interpolação (marcado com um $x$ ). A linha tracejada grossa indica a região de Voronoi da malha original e a linha sólida a do diagrama com o ponto de interpolação.

agramas de Voronoi é não trivial. Nós implementamos um método incremental, como descrito em Devadoss e O'Rourke [2011], mas generalizando para a esfera. Nesse caso, consideramos, para cada vizinho, o plano que divide o segmento entre o ponto de interpolação e o ponto de malha na metade. Em seguida encontramos os pontos de interseç̧ão desse plano com o diagrama de Voronoi original da malha. Repetindo esse procedimento para todos os pontos próximos ao ponto de interpolação teremos definido a região de Voronoi para o ponto de interpolação. A inclusão do ponto de interpolação em um diagrama de Voronoi faz com que esse tipo de coordenadas seja bastante custosa, como veremos mais adiante em avaliações numéricas.

Esse tipo de sistema de coordenadas define uma função $C^{1}$ no interior do conjunto de definição dos pontos de malha (ver Gillette et al. [2012] para detalhes), mas apenas $C^{0}$ globalmente. Farin [1990] propôs um aprimoramento para garantir uma função interpoladora $C^{1}$ globalmente. Porém esse método necessita, além do valor da função no ponto de malha, do seu gradiente. O gradiente pode ser estimado usando técnicas de mínimos quadrados, como veremos mais adiante, logo irá exigir o uso de outros pontos além dos vizinhos naturais. Uma boa descrição da implementação do método de Farin é dada em Hiyoshi e Sugihara [2004], onde apresenta-se ainda uma melhoria para 
se obter uma função interpoladora globalmente $C^{2}$.

\section{Testes numéricos}

Começamos analisando a questão de interpolação com coordenadas baricêntricas em triângulos. Na Tabela 4.1 mostramos os erros de interpolações da função trigonométrica descrita na equação (4.2) para esse método considerando a projeção radial do ponto de interpolação para o triângulo plano. Na Tabela 4.2 mostramos os erros associados ao método usando triângulos esféricos, que é equivalente ao método de Wachspress para triângulo na esfera. As diferenças são quase imperceptíveis, indicando que essa escolha não é relevante para a precisão da interpolação. Na Figura 4.12 mostramos a distribuição do erro para esse tipo de interpolação, onde se pode perceber que os maiores erros estão predominantemente nos interiores dos triângulos, longe dos vértices.

\begin{tabular}{|c|c|c|c|c|}
\hline Nível & Erro Máx CBTR & Erro 2 CBTR & Razão Máx & Razão 2 \\
\hline 0 & $3.8571 \mathrm{E}-01$ & $1.3430 \mathrm{E}-01$ & & \\
\hline 1 & $1.2084 \mathrm{E}-01$ & $3.8107 \mathrm{E}-02$ & 3.19 & 3.52 \\
\hline 2 & $3.9482 \mathrm{E}-02$ & $1.0076 \mathrm{E}-02$ & 3.06 & 3.78 \\
\hline 3 & $1.0540 \mathrm{E}-02$ & $2.5581 \mathrm{E}-03$ & 3.75 & 3.94 \\
\hline 4 & $2.6702 \mathrm{E}-03$ & $6.4251 \mathrm{E}-04$ & 3.95 & 3.98 \\
\hline 5 & $6.3105 \mathrm{E}-04$ & $1.6137 \mathrm{E}-04$ & 4.23 & 3.98 \\
\hline 6 & $1.6343 \mathrm{E}-04$ & $4.1975 \mathrm{E}-05$ & 3.86 & 3.84 \\
\hline 7 & $3.4850 \mathrm{E}-05$ & $9.7180 \mathrm{E}-06$ & 4.69 & 4.32 \\
\hline 8 & $9.3793 \mathrm{E}-06$ & $2.4757 \mathrm{E}-06$ & 3.72 & 3.93 \\
\hline
\end{tabular}

Tabela 4.1: Erros associados ao remapeamento da malha icosaédrica para uma malha do tipo longitudelatitude com $180 \times 360$ pontos considerando a função trigonométrica (equação (4.2)). Os dados foram fornecidos nos vértices dos triângulos, e o método usado foi o de coordenadas baricêntricas para triângulos projetando o ponto de interpolação no plano do triângulo (CBTR). Os erros apresentados são os do máximo e quadrático médio (2). Nas duas últimas colunas apresentamos as razóes entre os erros de dois níveis consecutivos de malha.

\begin{tabular}{|c|c|c|c|c|}
\hline Nível & Erro Máx WCTR & Erro 2 WCTR & Razão Máx & Razão 2 \\
\hline 0 & $3.8289 \mathrm{E}-01$ & $1.3302 \mathrm{E}-01$ & & \\
\hline 1 & $1.2054 \mathrm{E}-01$ & $3.8055 \mathrm{E}-02$ & 3.18 & 3.50 \\
\hline 2 & $3.9473 \mathrm{E}-02$ & $1.0072 \mathrm{E}-02$ & 3.05 & 3.78 \\
\hline 3 & $1.0541 \mathrm{E}-02$ & $2.5578 \mathrm{E}-03$ & 3.74 & 3.94 \\
\hline 4 & $2.6702 \mathrm{E}-03$ & $6.4250 \mathrm{E}-04$ & 3.95 & 3.98 \\
\hline 5 & $6.3111 \mathrm{E}-04$ & $1.6137 \mathrm{E}-04$ & 4.23 & 3.98 \\
\hline 6 & $1.6343 \mathrm{E}-04$ & $4.1976 \mathrm{E}-05$ & 3.86 & 3.84 \\
\hline 7 & $3.4850 \mathrm{E}-05$ & $9.7181 \mathrm{E}-06$ & 4.69 & 4.32 \\
\hline 8 & $9.3793 \mathrm{E}-06$ & $2.4757 \mathrm{E}-06$ & 3.72 & 3.93 \\
\hline
\end{tabular}

Tabela 4.2: Erros associados ao remapeamento da malha icosaédrica para uma malha do tipo longitudelatitude com $180 \times 360$ pontos considerando a função trigonométrica (equação (4.2)). Os dados foram fornecidos nos vértices dos triângulos, e o método usado foi o de coordenadas baricêntricas para triângulos esféricos, que equivale ao método de Wachspress na esfera para triângulos (WCTR). Os erros apresentados são os do máximo e quadrático médio (2). Nas duas últimas colunas apresentamos as razões entre os erros de dois niveis consecutivos de malha.

Na Tabela 4.3 mostramos os erros para o método de Wachspress, quando são dados os valores nos circuncentros dos triângulos, que são também os vértices das células de Voronoi. Os resultados são muito similares aos obtidos anteriormente, porém a distribuição do erro (veja a Figura 4.13) agora tem valores mais elevados nos centros das células de Voronoi, onde ficam os vértices dos triângulos. 


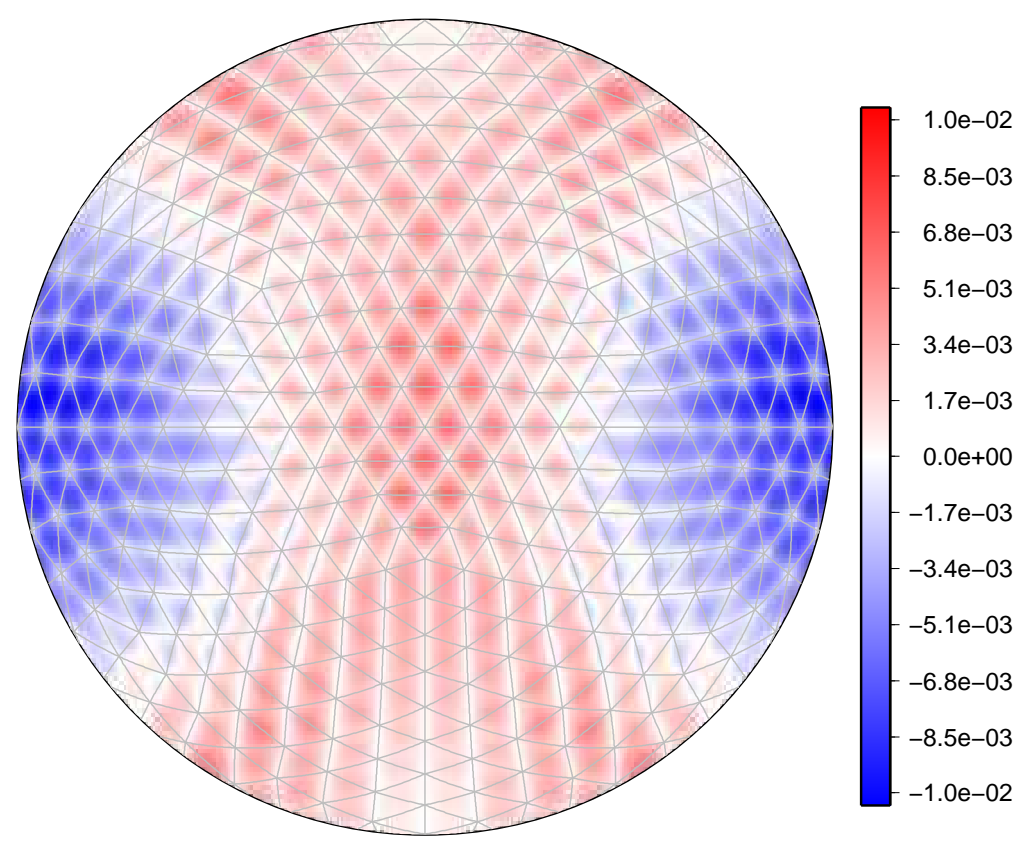

Figura 4.12: Re-mapeamento da função trigonométrica dada em (4.2) de uma malha icosaédrica de nível 3 para uma malha latitude longitude com $180 \times 360$ pontos. Os dados foram fornecidos nos vértices dos triângulos, e o método usado foi o de coordenadas baricêntricas para triângulos esféricos, que equivale ao método de Wachspress na esfera para triângulos (WCTR).

\begin{tabular}{|c|c|c|c|c|}
\hline Nível & Erro Máx WCHX & Erro 2 WCHX & Razão Máx & Razão 2 \\
\hline 0 & $2.3833 \mathrm{E}-01$ & $9.2601 \mathrm{E}-02$ & & \\
\hline 1 & $1.3953 \mathrm{E}-01$ & $2.9045 \mathrm{E}-02$ & 1.71 & 3.19 \\
\hline 2 & $3.6836 \mathrm{E}-02$ & $7.8603 \mathrm{E}-03$ & 3.79 & 3.70 \\
\hline 3 & $9.4085 \mathrm{E}-03$ & $2.0139 \mathrm{E}-03$ & 3.92 & 3.90 \\
\hline 4 & $2.5081 \mathrm{E}-03$ & $5.0805 \mathrm{E}-04$ & 3.75 & 3.96 \\
\hline 5 & $5.6256 \mathrm{E}-04$ & $1.2830 \mathrm{E}-04$ & 4.46 & 3.96 \\
\hline 6 & $1.3826 \mathrm{E}-04$ & $2.9283 \mathrm{E}-05$ & 4.07 & 4.38 \\
\hline 7 & $4.1626 \mathrm{E}-05$ & $8.3261 \mathrm{E}-06$ & 3.32 & 3.52 \\
\hline 8 & $1.0402 \mathrm{E}-05$ & $2.0282 \mathrm{E}-06$ & 4.00 & 4.11 \\
\hline
\end{tabular}

Tabela 4.3: Erros associados ao remapeamento da malha icosaédrica para uma malha do tipo longitudelatitude com $180 \times 360$ pontos considerando a função trigonométrica (equação (4.2)). Os dados foram fornecidos nos circuncentros dos triângulos (vértices das células de Voronoi), e o método usado foi o de coordenadas baricêntricas generalizadas de Wachspress (WCHX). Os erros apresentados são os do máximo e quadrático médio (2). Nas duas últimas colunas apresentamos as razões entre os erros de dois níveis consecutivos de malha.

Outra análise possível é considerando o método de Wachspress quando os valores são dados nos pontos médios das arestas das células de Voronoi. Mostramos os erros para essa abordagem na Tabela 4.4, e a distribuição do erro na Figura 4.14). Há uma pequena redução do erro, mas observamos que temos aproximadamente 3 vezes mais arestas que nós na malha, logo esse resultado é esperado. 


\begin{tabular}{|c|c|c|c|c|}
\hline Nível & Erro Máx WCHE & Erro 2 WCHE & Razão Máx & Razão 2 \\
\hline 0 & $1.6833 \mathrm{E}-01$ & $6.2366 \mathrm{E}-02$ & & \\
\hline 1 & $1.0812 \mathrm{E}-01$ & $1.9706 \mathrm{E}-02$ & 1.56 & 3.16 \\
\hline 2 & $2.7828 \mathrm{E}-02$ & $5.2292 \mathrm{E}-03$ & 3.89 & 3.77 \\
\hline 3 & $7.0682 \mathrm{E}-03$ & $1.3323 \mathrm{E}-03$ & 3.94 & 3.92 \\
\hline 4 & $1.8666 \mathrm{E}-03$ & $3.3578 \mathrm{E}-04$ & 3.79 & 3.97 \\
\hline 5 & $4.0176 \mathrm{E}-04$ & $8.4742 \mathrm{E}-05$ & 4.65 & 3.96 \\
\hline 6 & $1.0269 \mathrm{E}-04$ & $1.8766 \mathrm{E}-05$ & 3.91 & 4.52 \\
\hline 7 & $3.1285 \mathrm{E}-05$ & $5.5543 \mathrm{E}-06$ & 3.28 & 3.38 \\
\hline 8 & $7.8169 \mathrm{E}-06$ & $1.3379 \mathrm{E}-06$ & 4.00 & 4.15 \\
\hline
\end{tabular}

Tabela 4.4: Erros associados ao remapeamento da malha icosaédrica para uma malha do tipo longitudelatitude com $180 \times 360$ pontos considerando a função trigonométrica (equação (4.2)). Os dados foram fornecidos nos pontos médios das arestas das células de Voronoi, e o método usado foi o de coordenadas baricêntricas generalizadas de Wachspress (WCHE). Os erros apresentados são os do máximo e quadrático médio (2). Nas duas últimas colunas apresentamos as razões entre os erros de dois níveis consecutivos de malha.

\begin{tabular}{|c|c|c|c|c|}
\hline Nível & Erro Máx NATSIB & Erro 2 NATSIB & Razão Máx & Razão 2 \\
\hline 0 & $4.0542 \mathrm{E}-01$ & $1.3536 \mathrm{E}-01$ & & \\
\hline 1 & $1.2284 \mathrm{E}-01$ & $4.0370 \mathrm{E}-02$ & 3.30 & 3.35 \\
\hline 2 & $3.9901 \mathrm{E}-02$ & $1.0796 \mathrm{E}-02$ & 3.08 & 3.74 \\
\hline 3 & $1.0931 \mathrm{E}-02$ & $2.7487 \mathrm{E}-03$ & 3.65 & 3.93 \\
\hline 4 & $2.7413 \mathrm{E}-03$ & $6.9046 \mathrm{E}-04$ & 3.99 & 3.98 \\
\hline 5 & $6.5252 \mathrm{E}-04$ & $1.7263 \mathrm{E}-04$ & 4.20 & 4.00 \\
\hline 6 & $1.7663 \mathrm{E}-04$ & $4.5114 \mathrm{E}-05$ & 3.69 & 3.83 \\
\hline 7 & $3.8132 \mathrm{E}-05$ & $1.0508 \mathrm{E}-05$ & 4.63 & 4.29 \\
\hline 8 & $9.5699 \mathrm{E}-06$ & $2.6679 \mathrm{E}-06$ & 3.98 & 3.94 \\
\hline
\end{tabular}

Tabela 4.5: Erros associados ao remapeamento da malha icosaédrica para uma malha do tipo longitudelatitude com $180 \times 360$ pontos considerando a função trigonométrica (equação (4.2)). Os dados foram fornecidos nos vértices dos triângulos, e o método usado foi o de coordenadas de vizinhos naturais de Sibson (NATSIB). Os erros apresentados são os do máximo e quadrático médio (2). Nas duas últimas colunas apresentamos as razões entre os erros de dois niveis consecutivos de malha.

\begin{tabular}{|c|c|c|c|c|}
\hline Nível & Erro Máx NATFAR & Erro 2 NATFAR & Razão Máx & Razão 2 \\
\hline 0 & $3.0979 \mathrm{E}-01$ & $1.0301 \mathrm{E}-01$ & & \\
\hline 1 & $4.6952 \mathrm{E}-02$ & $1.3868 \mathrm{E}-02$ & 6.60 & 7.43 \\
\hline 2 & $4.9301 \mathrm{E}-03$ & $1.4720 \mathrm{E}-03$ & 9.52 & 9.42 \\
\hline 3 & $5.4393 \mathrm{E}-04$ & $1.4431 \mathrm{E}-04$ & 9.06 & 10.20 \\
\hline 4 & $6.8469 \mathrm{E}-05$ & $1.4901 \mathrm{E}-05$ & 7.94 & 9.68 \\
\hline 5 & $9.0166 \mathrm{E}-06$ & $1.6856 \mathrm{E}-06$ & 7.59 & 8.84 \\
\hline 6 & $9.1905 \mathrm{E}-07$ & $1.9132 \mathrm{E}-07$ & 9.81 & 8.81 \\
\hline 7 & $1.2033 \mathrm{E}-07$ & $2.4141 \mathrm{E}-08$ & 7.64 & 7.93 \\
\hline 8 & $3.9415 \mathrm{E}-08$ & $2.9092 \mathrm{E}-09$ & 3.05 & 8.30 \\
\hline
\end{tabular}

Tabela 4.6: Erros associados ao remapeamento da malha icosaédrica para uma malha do tipo longitudelatitude com $180 \times 360$ pontos considerando a função trigonométrica (equação (4.2)). Os dados foram fornecidos nos vértices dos triângulos, e o método usado foi o de coordenadas de vizinhos naturais de Farin (NATFAR). Os erros apresentados são os do máximo e quadrático médio (2). Nas duas últimas colunas apresentamos as razões entre os erros de dois niveis consecutivos de malha. 


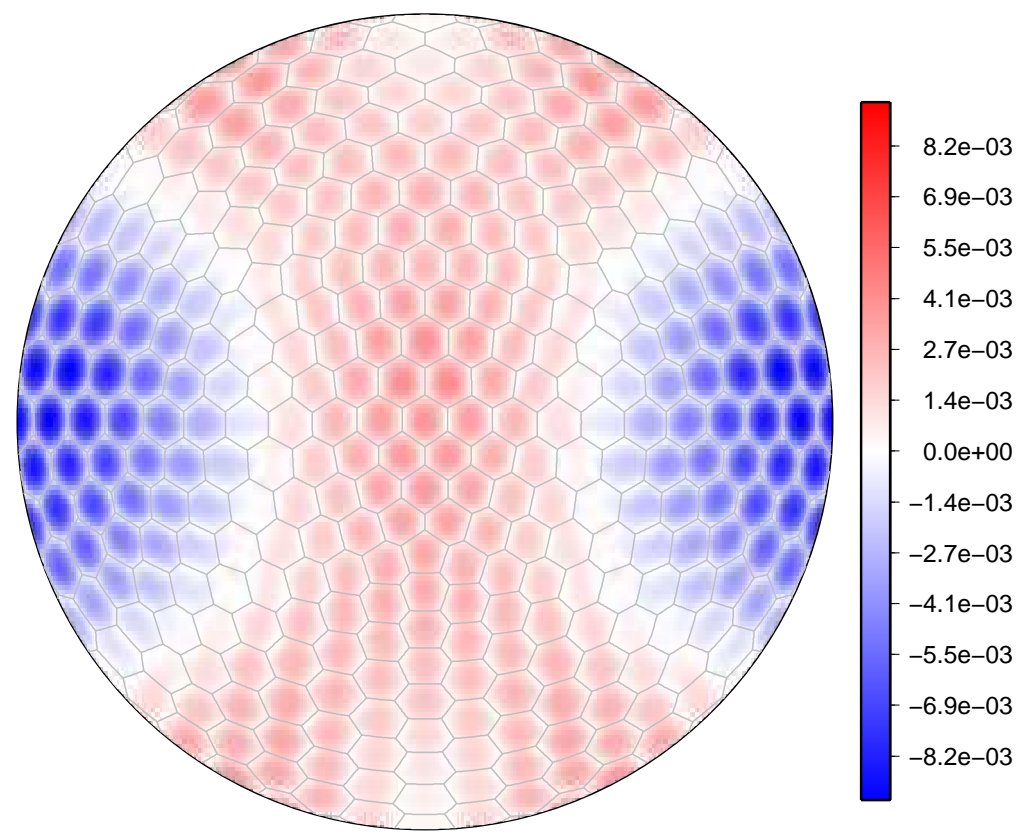

Figura 4.13: Erros associados ao remapeamento da função trigonométrica dada em (4.2) de uma malha icosaédrica de nível 3 para uma malha latitude longitude com $180 \times 360$ pontos. Os dados foram fornecidos nos circuncentros dos triângulos (vértices das células de Voronoi), e o método usado foi o de coordenadas baricêntricas generalizadas de Wachspress (WCHX).

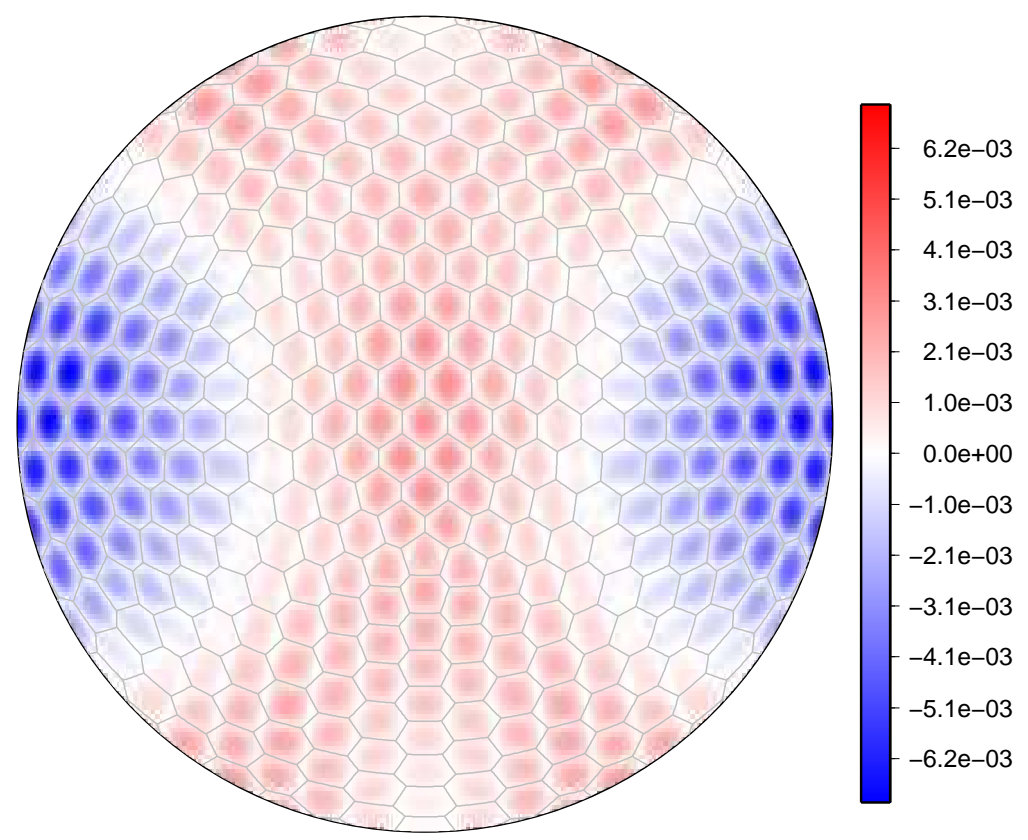

Figura 4.14: Erros associados ao remapeamento da função trigonométrica dada em (4.2) de uma malha icosaédrica de nivel 3 para uma malha latitude longitude com $180 \times 360$ pontos. Os dados foram fornecidos nos pontos médios das arestas das células de Voronoi, e o método usado foi o de coordenadas baricêntricas generalizadas de Wachspress (WCHE). 


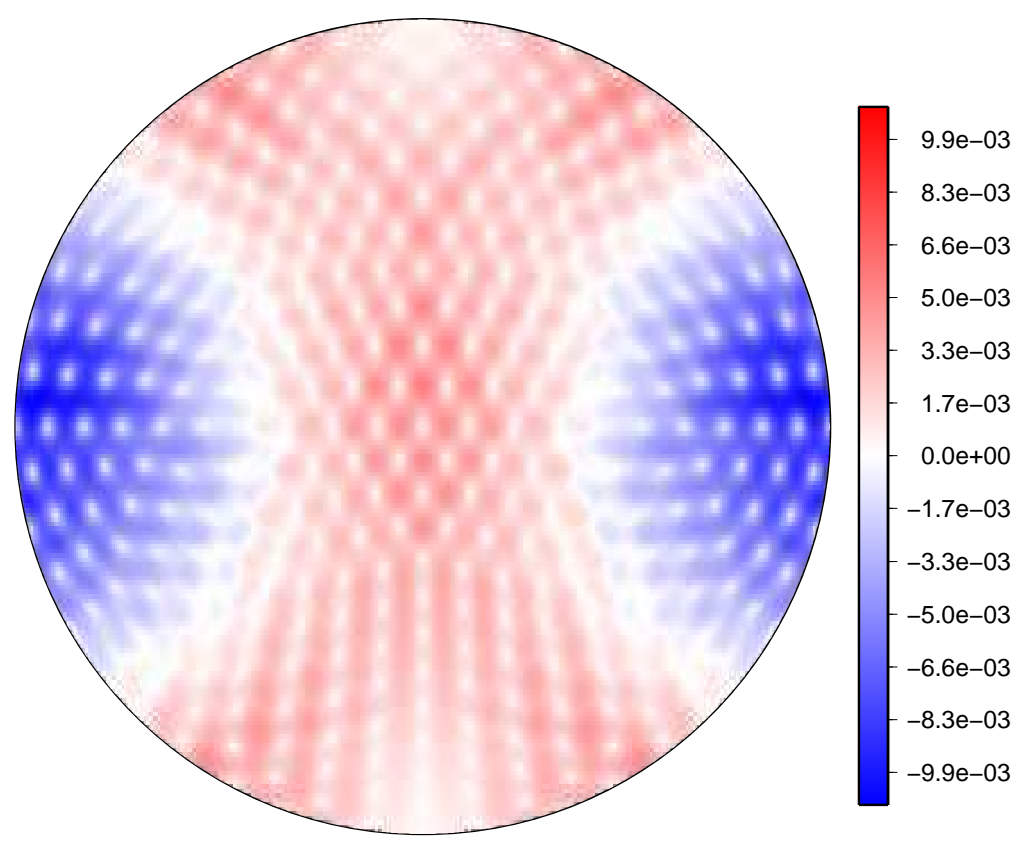

Figura 4.15: Erros associados ao remapeamento da função trigonométrica dada em (4.2) de uma malha icosaédrica de nivel 3 para uma malha latitude longitude com $180 \times 360$ pontos. Os dados foram fornecidos nos vértices dos triângulos, e o método usado foi o de coordenadas de vizinhos naturais de Sibson (NATSIB).

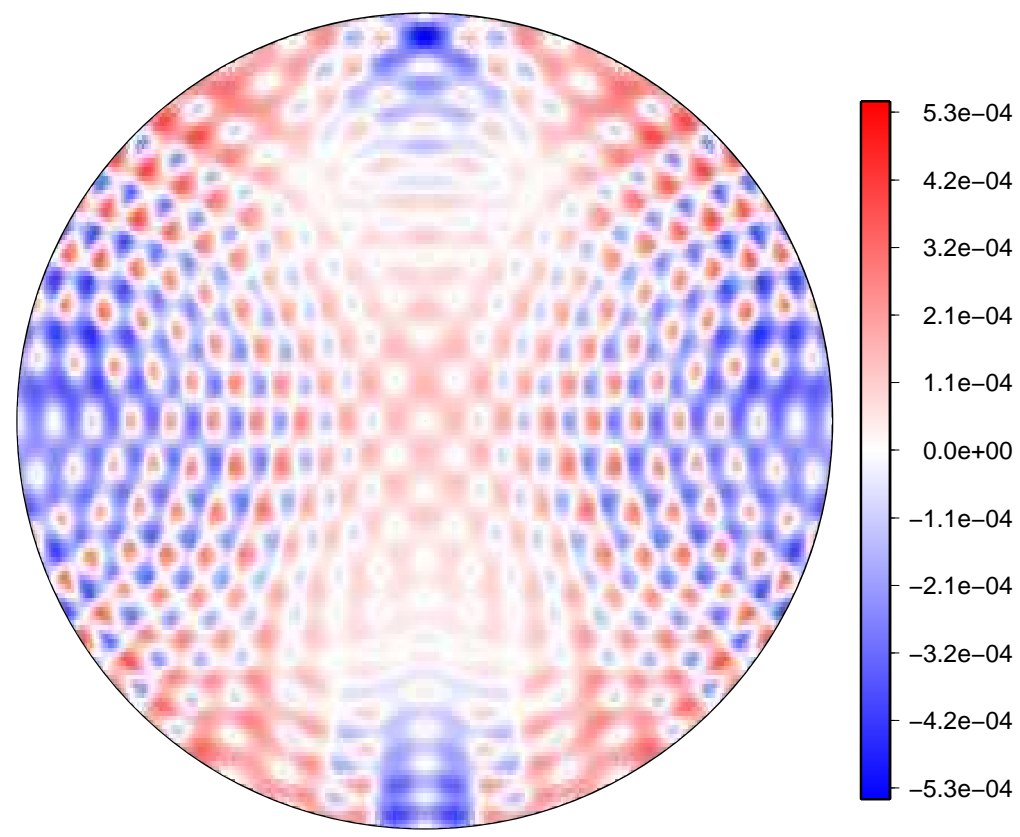

Figura 4.16: Erros associados ao remapeamento da função trigonométrica dada em (4.2) de uma malha icosaédrica de nivel 3 para uma malha latitude longitude com $180 \times 360$ pontos. Os dados foram fornecidos nos vértices dos triângulos, e o método usado foi o de coordenadas de vizinhos naturais de Farin (NATFAR). 


\subsubsection{Aproximação polinomial com MMQ}

Vamos descrever a seguir uma metodologia para construir localmente um polinômio quadrático para malhas icosaédricas na esfera usando a técnica de mínimos quadrados (MMQ). A metodologia é baseada nos trabalhos de Lawson [1984] e Renka [1984]. Essa metodologia poderá ser usada para interpolações escalares em geral, ou para estimar o gradiente de uma função, que é necessário em outros métodos de interpolações escalares, como o método de Farin [1990] descrito anteriormente.

Dado um ponto de malha na esfera $p$, seja $S_{n}=\left\{p_{1}, p_{2}, p_{3}, \ldots, p_{n}\right\}$ um conjunto com $n$ pontos de malha próximos ao ponto $p$. Sejam $f_{l}, l=1, \ldots, n$ valores reais associados aos pontos $p_{l}$, e seja $f_{p}$ o valor definido em $p$. O método consiste basicamente em projetar ortogonalmente os pontos de $S_{n}$ no o plano tangente à esfera em $p$ e, no plano, construir um polinômio que minimiza o erro quadrático médio em relação aos valores reais dados. Os pontos são projetados ortogonalmente no plano tangente. Uma forma simples de se fazer isso é rotacionando a esfera para que o $p$ fique no polo norte, $(0,0,1)$, assim a projeção pode ser obtida simplesmente tomando a coordenada $z$ como sendo 1. Para definirmos um polinômio de grau 2 no plano, são necessárias pelo menos 6 informações, portanto precisamos que $n \geq 5$, desta forma, contando o ponto $p$, temos o número de pontos necessário. Esse método não depende de uma triangulação, mas a distribuição dos pontos vizinhos $\left(S_{n}\right)$ não pode ser arbitrária. Mais adiante vamos discutir como escolher o conjunto $S_{n}$ em malhas icosaédricas. Por hora vamos simplesmente assumir que $n \geq 5$ e que o problema está bem posto (tem solução única).

No método que vamos descrever, vamos forçar que o polinômio aproximador $\tilde{f}$ seja interpolador em $p$, isto é, que $\tilde{f}(p)=f_{p}$. Além disso vamos considerar um peso para cada ponto $p_{l}$ no sistema de mínimos quadrados conforme sua distância ao ponto $p$, dando mais peso aos pontos mais próximos. O algoritmo para a construção do polinômio consiste nas seguintes etapas.

1. Rotacionar a esfera tal que o ponto de malha $p=(x, y, z)$ fique no polo norte, dado por $(0,0,1)$. Isto pode ser feito utilizando uma matriz de rotação $U=R_{y} R_{x}$, onde $R_{x}$ é uma rotação com relação ao eixo $\vec{x}$ e $R_{y}$ com relação ao eixo $\vec{y}$, dadas por,

$$
\begin{aligned}
& R_{x}=\left[\begin{array}{ccc}
1 & 0 & 0 \\
0 & c_{x} & -s_{x} \\
0 & s_{x} & c_{x}
\end{array}\right], \\
& R_{y}=\left[\begin{array}{ccc}
c_{y} & 0 & -s_{y} \\
0 & 1 & 0 \\
s_{y} & 0 & c_{y}
\end{array}\right],
\end{aligned}
$$

onde,

$$
\begin{aligned}
& s_{y}=x, \\
& c_{y}=y^{2}+z^{2}, \\
& s_{x}= \begin{cases}y / c_{y}, & \text { se } c_{y} \neq 0 \\
0, & \text { caso contrário. }\end{cases} \\
& c_{x}= \begin{cases}z / c_{y}, & \text { se } c_{y} \neq 0 ; \\
1, & \text { caso contrário. }\end{cases}
\end{aligned}
$$

Note que $U$ é ortogonal e, então, a rotação inversa fica definida por sua transposta, $U^{t}$. Dessa forma verifica-se que

$$
U p=\left[\begin{array}{l}
0 \\
0 \\
1
\end{array}\right] .
$$

2. Utilizando $U$ rotacionam-se os pontos do conjunto $S_{k}$ para próximo do polo, usaremos o símbolo $^{-}$para denotar os pontos rotacionados. Assim teremos um conjunto de pontos $\bar{S}_{n}=$ 
$\left\{\bar{p}_{1}, \bar{p}_{2}, \bar{p}_{3}, \ldots, \bar{p}_{n}\right\} \operatorname{com} \bar{p}_{l}=\left(x_{l}, y_{l}, z_{l}\right), l=1,2, \ldots, n$.

3. Considere a projeção ortogonal dos pontos de $\bar{S}_{n}$ no plano tangente ao polo norte. Na prática basta simplesmente considerar a coordenada $z$ como sendo 1, ou ignorá-la. Com isso temos o ponto $p$ e seus vizinhos definidos em um plano referido com um sistema cartesiano $X Y$. Ilustramos esse passo na Figura 4.17.

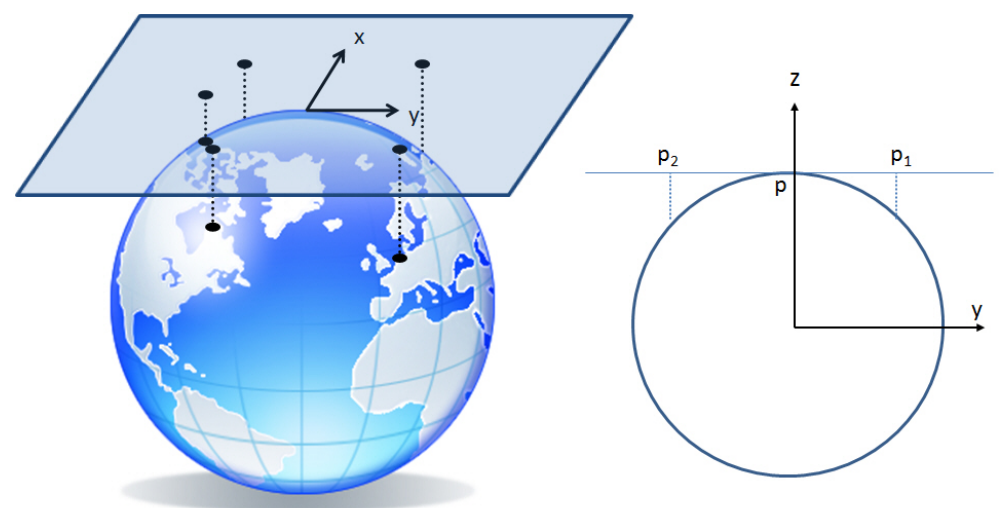

Figura 4.17: Ilustração indicando a projeção dos pontos vizinhos no plano tangente ao polo norte.

4. Considere para cada vizinho a distância euclidiana no plano até $p$, dada por

$$
d_{l}=\sqrt{x_{l}^{2}+y_{l}^{2}}
$$

Note que, como $\bar{p}_{l}$ está na esfera, teremos que $x_{l}^{2}+y_{l}^{2}+z_{l}^{2}=1$, e logo

$$
d_{l}=\sqrt{1-z_{l}^{2}} .
$$

Defina

$$
D_{l}=1-z_{l}
$$

e observe que $D_{l}$ é uma função crescente em relação a $d_{l}$ (escolhida por simplicidade computacional). Defina os pesos para o sistema de mínimos quadrados

$$
\omega_{l}=\frac{1}{D_{l}}-\frac{1}{R_{n}}
$$

onde $R_{n}$ é um parâmetro que depende de $S_{n}$ e $R_{n}>\max _{l=1,2, \ldots, n}\left\{D_{l}\right\}$. Essa escolha ajuda a dar mais peso a pontos mais próximos de $p$ caso os vizinhos estejam mal distribuídos.

5. Considere

$$
\gamma=\sqrt{\frac{\sum_{l=1}^{n} d_{l}^{2}}{n}}
$$

ou seja, $\gamma$ mede o desvio quadrático médio dos vizinhos em relação ao ponto $p$. $\gamma$ será usado para balancear as componentes quadráticas em relação às lineares para melhorar o condicionamento da matriz.

6. Em seguida, resolve-se o seguinte problema de mínimos quadrados: encontrar os valores $\left(\alpha_{i}\right)_{i=1, \ldots, 5}$ tal que

$$
\tilde{f}_{p}(x, y)=\alpha_{1} \frac{x^{2}}{\gamma^{2}}+\alpha_{2} \frac{x y}{\gamma^{2}}+\alpha_{3} \frac{x^{2}}{\gamma^{2}}+\alpha_{4} \frac{x}{\gamma}+\alpha_{5} \frac{y}{\gamma}+f_{p}
$$


minimize o erro quadrático médio em relação aos valores nos pontos de $\bar{S}_{n}$, considerando os pesos $\omega_{l}$ para cada ponto. Em outras palavras, queremos encontrar o vetor $\alpha$ tal que $r=A \alpha-b$ tenha norma euclidiana mínima, onde $A$ é a matriz $n \times 5$ com cada linha $a_{l}$ composta por

$$
a_{l}=\omega_{l}\left(\frac{x_{l}^{2}}{\gamma^{2}}, \frac{x_{l} y_{l}}{\gamma^{2}}, \frac{y_{l}^{2}}{\gamma^{2}}, \frac{x_{l}}{\gamma}, \frac{y_{l}}{\gamma}\right)
$$

e $b$ é formado por elementos $b_{l}$ dados por

$$
b_{l}=\left(f_{l}-f_{p}\right) \omega_{l}
$$

Se desejarmos aproximar a função em um ponto $q$ qualquer da esfera, usamos o polinômio obtido para o ponto de malha $p$ mais próximo a $q$. Para avaliar $\tilde{f}_{p}(q)$ aplicamos a rotação $(U)$ em $q$ para obter as coordenadas de $q$ no plano tangente, então avaliamos a função usando os valores de $\alpha$ encontrados para $\tilde{f}_{p}$.

Se quisermos estimar o gradiente no ponto de malha $p$, então calculamos o gradiente nas coordenadas rotacionadas

$$
\nabla \tilde{f}(\bar{p})=\nabla \tilde{f}(0,0)=\left(\frac{\alpha_{5}}{\gamma}, \frac{\alpha_{4}}{\gamma}\right) .
$$

e depois fazemos a rotação inversa dessa estimativa de gradiente para a posição original de $p$. Para tanto aplicamos a matriz de rotação inversa $U^{t}$ no vetor $\left(\frac{\alpha_{5}}{\gamma}, \frac{\alpha_{4}}{\gamma}, 0\right)$.

Para resolver o sistema $A^{t} A \alpha=A^{t} b$ de mínimos quadrados consideramos uma decomposição QR, com rotações de Givens e acumulação sequencial (Lawson e Hanson [1974]). Detalharemos a seguir o método.

Uma matriz de rotação de Givens é uma matriz identidade a menos de 4 pontos, que são elementos de rotação entre dois sub-vetores de dimensão dois. A aplicação de uma matriz de rotação de Givens em uma matriz como a usada no problema de mínimos quadrados acima, $A$, serve para zerar uma posição da matriz na parte triangular inferior. Com isso sucessivas aplicações de rotações de Givens transformam a matriz em triangular superior. Seja $G$ uma composição de matrizes de rotação de Givens tal que $A$, definida anteriormente, para um certo ponto, fique triangular superior. Como cada rotação de Givens é ortogonal, então $G$ é ortogonal, e admite inversa, $G^{t}$, como transposta de $G$. Além disso $\|G\|=1$. Aplicando $G$ ao problema de minimizar a norma do resíduo $r=A x-b$, temos que $G r=G A x-G b$, onde agora $G A$ é triangular superior e tem as $n-5$ linhas inferiores nulas, que denominaremos por $R=G A$. Denominaremos por $c=G b$, e $c=[c 1 ; c 2]$, onde $c 1$ tem dimensão $5 \times 1$, e $c 2$ tem dimensão $(n-5) \times 1$. Aplicando $G^{t}$ temos que $r=G^{t} R x-b$. Então para minimizar a norma de $r$ temos que

$$
\|r\|^{2}=\left\|G^{t} R x-b\right\|^{2}=\left\|G^{t}\right\|^{2}\|R x-G b\|^{2}=\|R x-c\|^{2} .
$$

Como $R$ é nula nas últimas $k-5$ linhas, então podemos usar o Teorema de Pitágoras para obtermos

$$
\|r\|^{2}=\|R x-c\|^{2}=\|\bar{R} x-c 1\|^{2}+\|c 2\|^{2},
$$

onde $\bar{R}$ é a restrição de $R$ a sua parte superior $5 \times 5$. Com isso temos que o problema de minimizar a norma do resíduo é equivalente a resolver

$$
\bar{R} x=c 1 .
$$

Note que, no caso em que tivermos exatamente 5 pontos em $S_{n}$, isto é, $n=5$, o problema de mínimos quadrados se transforma em um problema de interpolação. Esse é o mínimo necessário para construirmos um polinômio de grau 2 no plano.

Há uma forma elegante de se utilizar esse método, denominado por acumulação sequencial em decomposições QR. O interessante é podermos assumir que não conhecemos inicialmente o valor de $n$, e irmos construindo e resolvendo o problema à medida que vamos adicionando novos pontos 
ao sistema. Inicialmente, dados 2 pontos em $S_{n}, A$ terá as duas primeiras linhas preenchidas e podemos já aplicar a rotação de Givens para que $A$ contenha zeros abaixo da diagonal principal. Devemos tomar o cuidado de também aplicar as rotações no vetor $b$, ou aplicar as rotações no sistema aumentado $A: b$. Depois, adicionando um próximo ponto na próxima linha de $A$, aplicamos novas rotações para manter o sistema triangular superior. Fazemos isso até o quinto vizinho, onde teremos a matriz $A$ com sua parte superior de $5 \times 5$ triangularizada. O sistema nesse passo está pronto para resolver o problema de interpolação. Se adicionarmos mais vizinhos temos o problema de mínimos quadrados. Podemos usar a sexta linha da matriz $A$, e, ao aplicarmos novas rotações, esta irá ficar somente com elementos nulos, pois está inteiramente abaixo da diagonal principal. Com isso podemos usar a sexta linha da matriz novamente para os próximos elementos de $S_{n}$, até usarmos todos. Esse método permite economia de memória e, mais importante, não precisamos saber a priori quantos pontos vamos usar. Dessa forma, se depois de considerarmos $n$ pontos nos depararmos com um sistema mal condicionado, ou sem solução, podemos facilmente incluir mais um ponto de malha. Apesar do método ser custoso, com ordem $O\left(n 5^{2}\right)$ de operações, ele é bastante estável e faz um bom uso de memória.

A escolha de $S_{n}$ irá depender da estrutura da malha. É natural pensar que $S_{n}$ seja formado, por exemplo, em ordem de proximidade com o ponto de malha $p$ ao qual queremos aplicar o método. No trabalho de Renka [1984] é recomendado o uso dos 9 pontos mais próximos. Isso é condizente com malhas bastante irregulares, porém, em malhas icosaédricas, há um problema com a escolha de número de pontos. Na malha icosaédrica, cada ponto tem 5 ou 6 vizinhos mais próximos, dependendo se o ponto era um vértice original do icosaedro (nesse caso terá 5 vizinhos), ou se é fruto de refinamentos (nesse caso terá 6 vizinhos). As distâncias de um ponto até os seus vizinhos mais próximos é praticamente a mesma, não sendo relevante ordenar os pontos por distância. Da mesma forma, temos um segundo nível de vizinhança, com os vizinhos de cada vizinho. Na Figura 4.18 mostramos uma região típica de vizinhança em uma malha icosaédrica. Note que no primeiro nível de vizinhança temos 6 pontos, e no segundo nível de vizinhança temos 12 pontos. As distâncias de um ponto central com relação aos pontos de seu segundo nível de vizinhança são muito parecidas, o que torna a escolha de quais vizinhos de nível 2 serão considerados em $S_{n}$ praticamente arbitrária. Dessa forma teríamos que escolher 18 vizinhos (6 mais próximos e 12 de segundo nível), para mantermos simetria na escolha dos pontos.

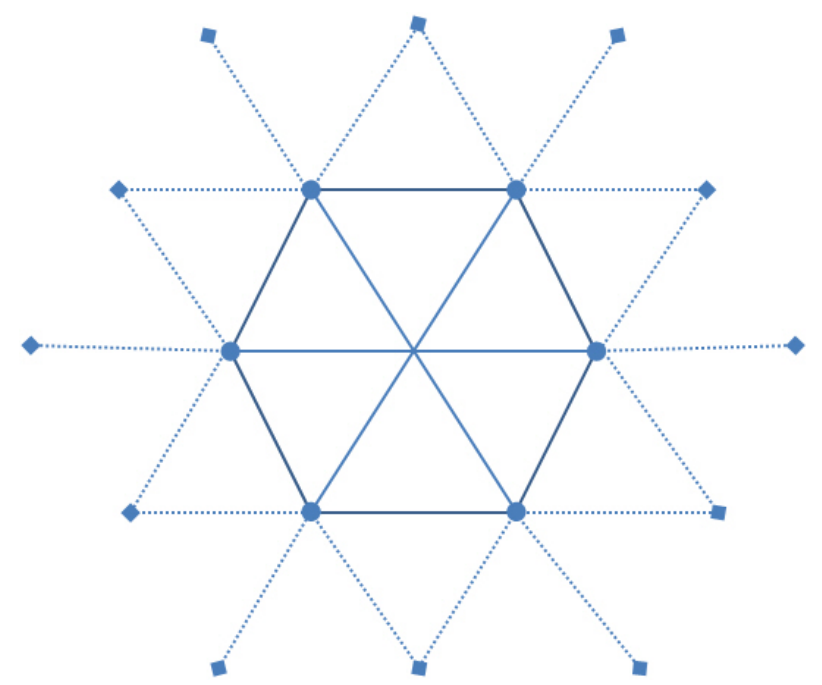

Figura 4.18: Ilustração indicando a região de vizinhança de um ponto em uma malha icosaédrica. Os vizinhos mais próximos, de nível 1, aparecem com círculos preenchidos e linhas cheias. O vizinhos de nível 2, vizinhos de vizinhos, aparecem com diamantes preenchidos e linha pontilhada.

A nossa implementação desse método seguiu a mesma linha da versão disponível no pacote SSRFPACK para interpolações de dados na superfície da esfera desenvolvido por Renka [1997]. Porém, estamos considerando apenas os vizinhos de primeiro nível. Com isso nos 12 pontos que 
derivam de vértices do icosaedro temos 5 vizinhos e, portanto, a quadrática é interpolada. Nos demais pontos de malha são usados os 6 vizinhos e a quadrática é ajustada por mínimos quadrados.

Esse método de aproximação por uma função quadrática em coordenadas rotacionadas (ou equivalentemente, coordenadas locais) é utilizado no modelo alemão GME para discretização dos operadores de diferenças finitas (Majewski et al. [2002]).

\section{Testes numéricos}

Começamos avaliando o erro relativo ao método de mínimos quadrados com polinômio de grau 2 para função teste dada em (4.2), que apresentamos na Tabela 4.7. A convergência resultante é de terceira ordem. Observa-se na distribuição do erro (Figura 4.19) que os maiores valores ocorrem nas bordas das células hexagonais, mas seguindo o padrão da função. Isso ocorre pois o polinômio é sempre construído centrado em algum ponto de malha (centro de hexágono). Nessa abordagem não há garantias de continuidade da função interpoladora.

\begin{tabular}{|c|c|c|c|c|}
\hline Nível & Erro Máx LSQHX & Erro 2 LSQHX & Razão Máx & Razão 2 \\
\hline 0 & $2.7500 \mathrm{E}-01$ & $9.9651 \mathrm{E}-02$ & & \\
\hline 1 & $7.0336 \mathrm{E}-02$ & $1.7357 \mathrm{E}-02$ & 3.91 & 5.74 \\
\hline 2 & $9.8791 \mathrm{E}-03$ & $2.6180 \mathrm{E}-03$ & 7.12 & 6.63 \\
\hline 3 & $1.2214 \mathrm{E}-03$ & $3.5486 \mathrm{E}-04$ & 8.09 & 7.38 \\
\hline 4 & $1.5670 \mathrm{E}-04$ & $4.6147 \mathrm{E}-05$ & 7.79 & 7.69 \\
\hline 5 & $1.9662 \mathrm{E}-05$ & $5.8483 \mathrm{E}-06$ & 7.97 & 7.89 \\
\hline 6 & $2.4934 \mathrm{E}-06$ & $7.3611 \mathrm{E}-07$ & 7.89 & 7.94 \\
\hline 7 & $3.0410 \mathrm{E}-07$ & $9.2797 \mathrm{E}-08$ & 8.20 & 7.93 \\
\hline 8 & $3.9040 \mathrm{E}-08$ & $1.1645 \mathrm{E}-08$ & 7.79 & 7.97 \\
\hline
\end{tabular}

Tabela 4.7: Erros associados ao remapeamento da malha icosaédrica para uma malha do tipo longitudelatitude com $180 \times 360$ pontos considerando a função trigonométrica (equação (4.2)). Os dados foram fornecidos nos vértices dos triângulos, e o método usado foi o de mínimos quadrados para um polinômio de grau 2 usando como referência o ponto de malha mais próximo ao ponto de interpolação (LSHX). Os erros apresentados são os do máximo e quadrático médio (2). Nas duas últimas colunas apresentamos as razões entre os erros de dois niveis consecutivos de malha.

O gradiente da função teste dada na equação (4.2) é dado em coordenadas geográficas por

$$
\nabla f=2(\cos (\theta))^{2} \sin (\lambda) \cos (\lambda) \vec{\lambda}-3(\cos (\theta))^{2}(\sin (\lambda))^{2} \sin (\theta) \vec{\theta} .
$$

Para avaliar o erro de estimativa do gradiente associado a cada ponto de malha usamos a norma euclidiana usual do $\mathbb{R}^{3}$, isto é, dado um gradiente analítico $g_{j}$ em um ponto de malha $j$ e a estimativa $\tilde{g}_{j}$ nesse ponto, o erro pontual $e_{j}$ é calculado como

$$
e_{j}=\left\|g_{j}-\tilde{g}_{j}\right\|=\sqrt{\sum_{i=1}^{3}\left(g_{j}(i)-\tilde{g}_{j}(i)\right)^{2}},
$$

onde $g_{j}(i)$ é a i-ésima componente do vetor gradiente $g_{j}$.

Mostramos na Tabela 4.8 os erros na estimativa do gradiente usando o método de mínimos quadrados, indicando uma aproximação de segunda ordem. Na Figura 4.20 mostramos a distribuição da norma do erro e erros vetoriais. 


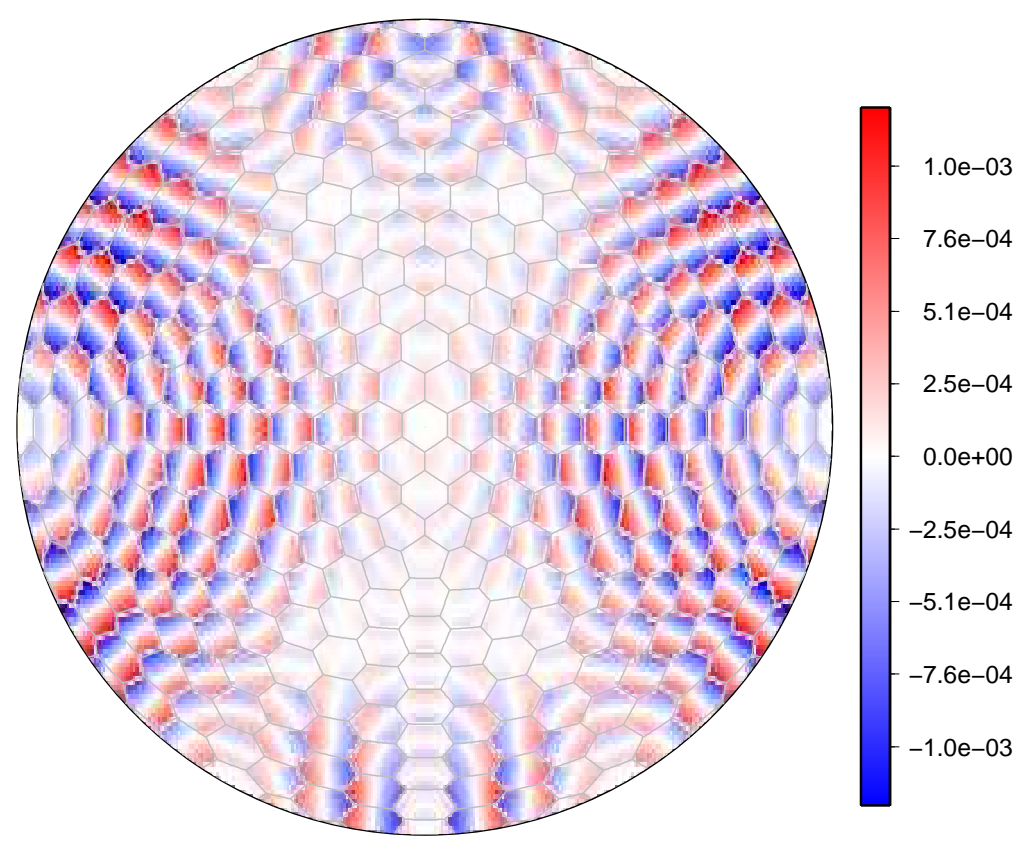

Figura 4.19: Erros associados ao remapeamento da função trigonométrica dada em (4.2) de uma malha icosaédrica de nível 3 para uma malha latitude longitude com $180 \times 360$ pontos. Os dados foram fornecidos nos vértices dos triângulos, e o método usado foi o de minimos quadrados para um polinômio de grau 2 usando como referência o ponto de malha mais próximo ao ponto de interpolação (LSHX).

\begin{tabular}{|c|c|c|c|c|}
\hline Nível & Erro Máx LSGD & Erro 2 LSGD & Razão Máx & Razão 2 \\
\hline 0 & $7.2928 \mathrm{E}-01$ & $5.0875 \mathrm{E}-01$ & & \\
\hline 1 & $3.0046 \mathrm{E}-01$ & $1.5440 \mathrm{E}-01$ & 2.43 & 3.30 \\
\hline 2 & $8.4603 \mathrm{E}-02$ & $4.3605 \mathrm{E}-02$ & 3.55 & 3.54 \\
\hline 3 & $2.1660 \mathrm{E}-02$ & $1.1334 \mathrm{E}-02$ & 3.91 & 3.85 \\
\hline 4 & $5.4532 \mathrm{E}-03$ & $2.8684 \mathrm{E}-03$ & 3.97 & 3.95 \\
\hline 5 & $1.3822 \mathrm{E}-03$ & $7.1998 \mathrm{E}-04$ & 3.95 & 3.98 \\
\hline 6 & $3.4824 \mathrm{E}-04$ & $1.8024 \mathrm{E}-04$ & 3.97 & 3.99 \\
\hline 7 & $8.7336 \mathrm{E}-05$ & $4.5084 \mathrm{E}-05$ & 3.99 & 4.00 \\
\hline 8 & $2.1851 \mathrm{E}-05$ & $1.1273 \mathrm{E}-05$ & 4.00 & 4.00 \\
\hline
\end{tabular}

Tabela 4.8: Erros associados cálculo do gradiente da função trigonométrica (equação (4.2)) nos nós de uma malha icosaédrica de nível 3. Os dados foram fornecidos nos vértices dos triângulos, e o método usado foi o de mínimos quadrados para um polinômio de grau 2 para cálculo do gradiente (LSGD). Os erros apresentados são os do máximo e quadrático médio (2). Nas duas últimas colunas apresentamos as razões entre os erros de dois niveis consecutivos de malha. 


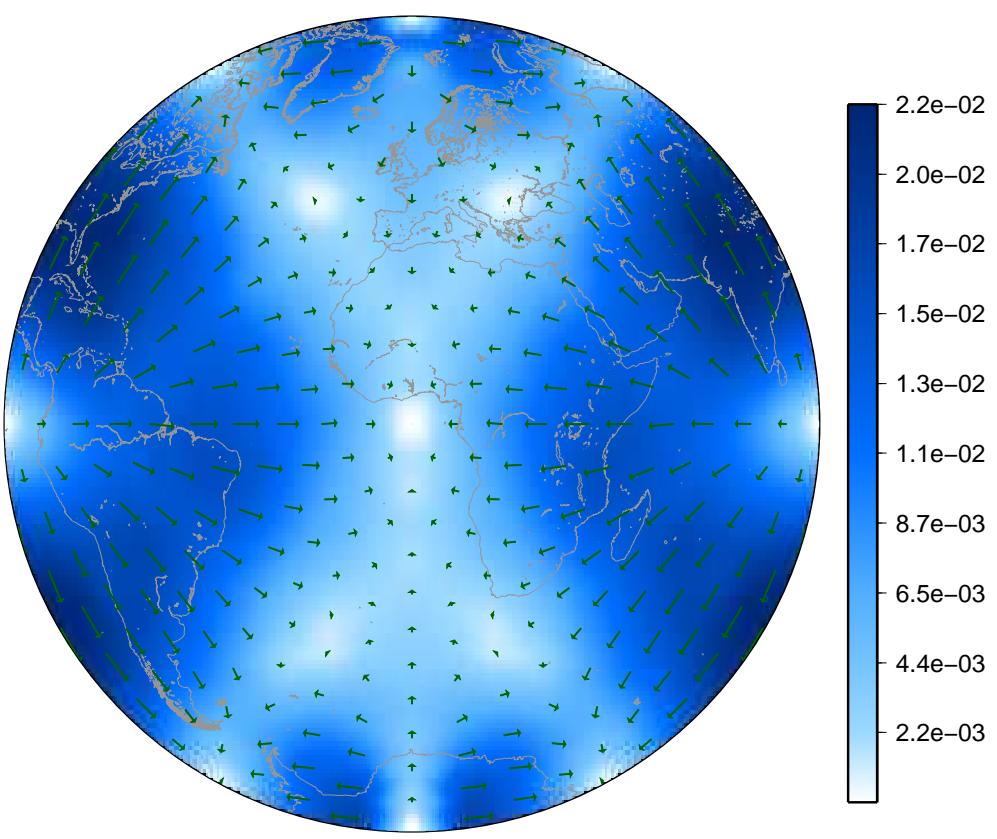

Figura 4.20: O campo escalar mostra a norma do erro na estimativa do gradiente da função (4.2) para uma malha icosaédrica de nível 3. O campo vetorial mostra a distribuição do erro vetorial (redimensionado para facilitar visualização). Os dados foram fornecidos nos vértices dos triângulos, e o método usado foi o de mínimos quadrados para um polinômio de grau 2 para cálculo do gradiente (LSGD). 


\subsubsection{Método C1 de Hermite}

Renka [1984] desenvolveu um método de interpolação $C^{1}$ para valores dados nos vértices de triângulos na esfera. Supondo que queremos interpolar valores de uma função para um ponto dentro de um triângulo, o método segue 2 passos de interpolações do tipo Hermite. No primeiro passo, interpola-se para pontos das arestas do triângulo e, no segundo, para o ponto de interpolação dentro do triângulo. Como o método é baseado em interpolação de Hermite, são necessárias estimativas do gradiente da função. Para tanto podemos usar o método descrito na seção anterior.

Vamos assumir conhecidos os valores $f_{v_{i}}$ e os gradientes $g_{v_{i}}$ da função nos 3 vértices $v_{i}$ de um triângulo esférico.

\section{Interpolação em geodésica da esfera}

A primeira etapa do método de Renka é uma interpolação de Hermite para pontos nas arestas do triângulo. Vamos descrever uma forma de fazer isso que garante posteriormente uma interpolação $C^{1}$ para a malha.

Sejam $p_{1}$ e $p_{2}$ os dois pontos finais do arco pertencentes a esfera unitária, com $f_{i}$ e $g_{i}$ respectivamente os valores e os gradientes nos ponto $p_{1}$ e $p_{2}$. Lembre-se que o gradiente é tangente à esfera, ou seja, $\left\langle g_{i}, p_{i}\right\rangle=0$. Primeiro vamos decompor os gradientes em suas componentes tangente e normal ao arco. Seja

$$
h=\frac{p_{1} \times p_{2}}{\left\|p_{1} \times p_{2}\right\|}=\frac{p_{1} \times p_{2}}{\sin (a)}
$$

um vetor normal ao plano que contém o arco, onde $a$ é o ângulo entre os pontos $p_{1}$ e $p_{2}$, e $\times$ indica o produto vetorial entre os vetores.

Sejam

$$
\begin{aligned}
& h_{1}=h \times p_{1}=\frac{\left(p_{2}-\left\langle p_{1}, p_{2}\right\rangle p_{1}\right)}{\sin (a)}, \\
& h_{2}=h \times p_{2}=\frac{\left(-p_{1}+\left\langle p_{1}, p_{2}\right\rangle p_{2}\right)}{\sin (a)},
\end{aligned}
$$

vetores unitários tangentes ao arco nos pontos $p_{1}$ e $p_{2}$, respectivamente. Então as componentes tangenciais, em relação ao arco, dos gradientes em $p_{1}$ e $p_{2}$ são dados respectivamente por,

$$
\begin{aligned}
& \tau_{1}=\left\langle g_{1}, h_{1}\right\rangle=\frac{\left\langle g_{1}, p_{2}\right\rangle}{\sin (a)}, \\
& \tau_{2}=\left\langle g_{2}, h_{2}\right\rangle=-\frac{\left\langle g_{2}, p_{1}\right\rangle}{\sin (a)},
\end{aligned}
$$

onde as simplificações são obtidas usando as propriedades de produto vetorial triplo em produtos escalares. As componentes normais ao plano do arco serão

$$
\begin{aligned}
& \nu_{1}=\left\langle g_{1}, h\right\rangle, \\
& \nu_{2}=\left\langle g_{2}, h\right\rangle .
\end{aligned}
$$

Agora seja $q$ um ponto intermediário do arco, entre $p_{1}$ e $p_{2}$. Seja $\alpha$ o ângulo entre $p_{1}$ e $q$. Defina

$$
\begin{aligned}
& s=\alpha / a, \\
& t=1-s .
\end{aligned}
$$

Então o valor interpolado no ponto $q$, usando o polinômio cúbico de Hermite, será dado por

$$
f_{q}=(2 s+1) t^{2} f_{1}+(3-2 s) s^{2} f_{2}+s t\left(\tau_{1} t-\tau_{2} s\right) a .
$$


A componente tangente do gradiente no ponto $q$ será dada por

$$
\tau_{q}=\frac{d f_{q}}{d \alpha}=\frac{6 s t\left(f_{2}-f_{1}\right)}{a}+(1-3 s) t \tau_{1}+(3 s-2) s \tau_{2},
$$

e a componente normal do gradiente será dada pela interpolação linear das componentes normais nos pontos finais do arco,

$$
\nu_{q}=t \nu_{1}+s \nu_{2}
$$

Ilustramos os vetores descritos acima na Figura 4.21.

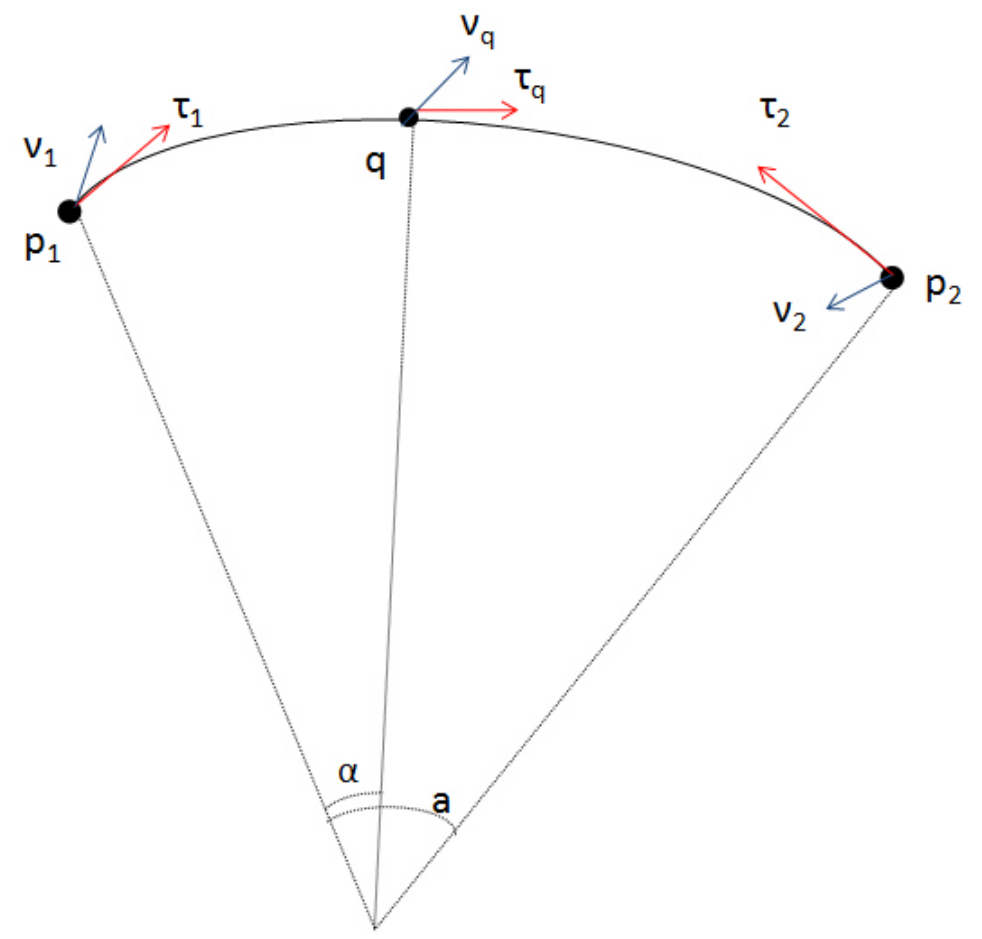

Figura 4.21: Ilustração dos vetores utilizados na interpolação em geodésica.

Seja

$$
h_{q}=h \times q
$$

o vetor unitário tangente ao arco no ponto $q$ e, lembrando que $h$ é normal ao plano do arco, temos que o gradiente em $q$ será dado por

$$
g_{q}=\tau_{q} h_{q}+\nu_{q} h
$$

Com isso, dado um ponto $q$ pertencente a um arco, ou geodésica, da esfera, podemos interpolar o valor e o gradiente nesse ponto, respectivamente $f_{q}$ e $g_{q}$, com base nos valores e gradientes dos pontos finais do arco.

\section{Projeção da esfera para o plano}

Vamos utilizar as relações de interpolação de Hermite em triângulos planos mais adiante, por isso precisamos projetar os elementos do triângulo esférico para o triângulo plano.

Dado um ponto $p$ contido no triângulo esférico, seja $p_{i}$ o ponto de intersecção do círculo geodésico que passa pelo vértice $v_{i}$ e pelo ponto $p$ com a aresta oposta a $v_{i}$, para $i=1,2,3$, conforme ilustrado na Figura 4.22.

A projeção do ponto $p$ e dos pontos $p_{i}$ para o triângulo plano será feita usando projeção radial, assim definimos $q$ tal que $p=\frac{q}{\|q\|}$ e $q_{i}$ tal que $p_{i}=\frac{q_{i}}{\left\|q_{i}\right\|}, i=1,2,3$, ilustrados na Figura 4.23.

Sejam $\left(b_{1}, b_{2}, b_{3}\right)$ as coordenadas baricêntricas planares de $q$ em relação ao triângulo. Então 


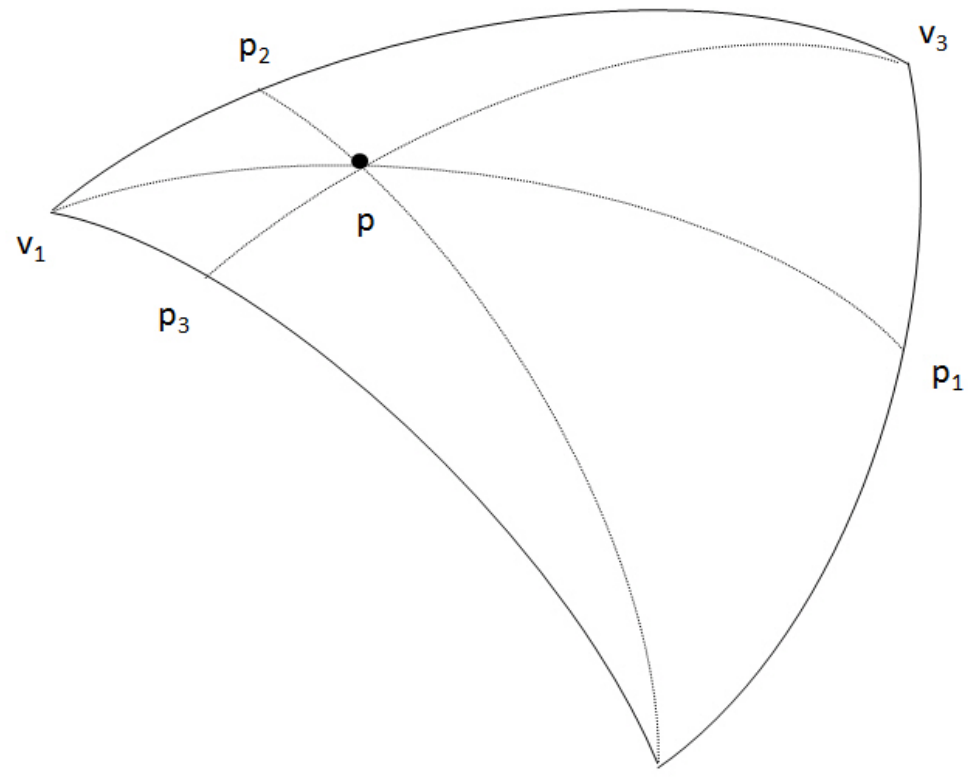

$\mathrm{v}_{2}$

Figura 4.22: Triângulo esférico e os arcos que conectam o ponto de interpolação p com os vértices do triângulo para gerar os pontos $p_{1}, p_{2}$ e $p_{3}$ nas arestas.

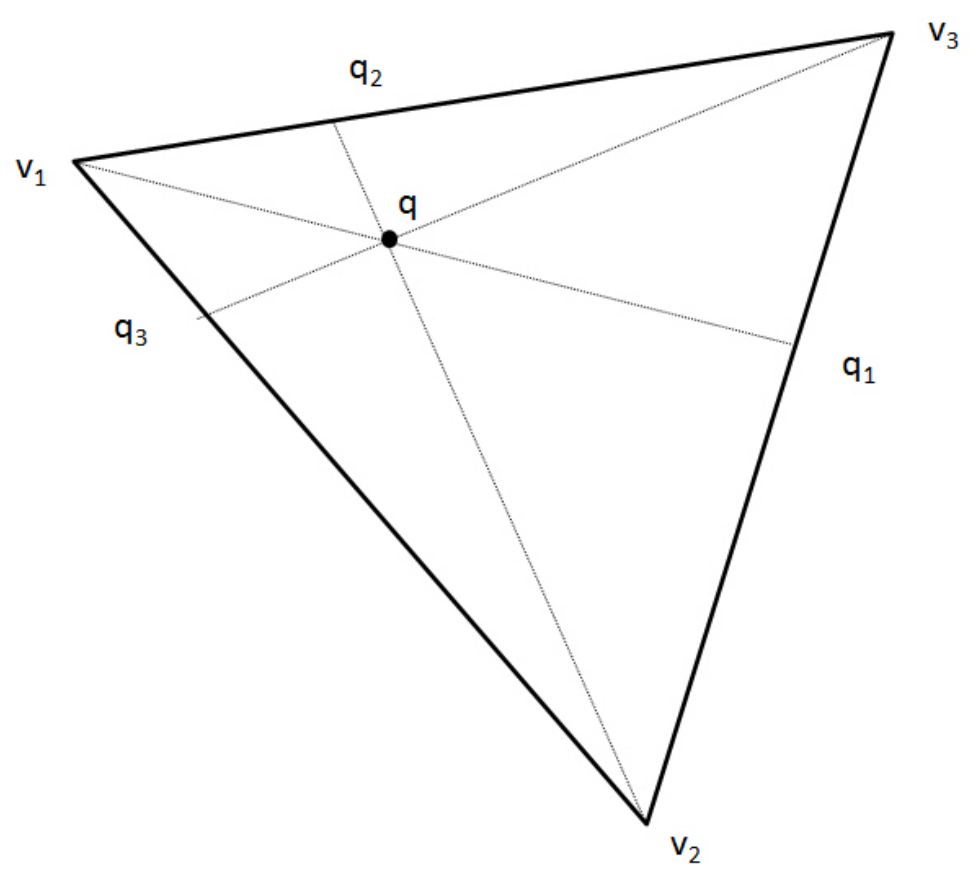

Figura 4.23: Triângulo plano e os arcos que conectam o ponto de interpolação p com os vértices do triângulo para gerar os pontos $p_{1}, p_{2}$ e $p_{3}$ nas arestas.

podemos calcular os pontos $q_{1}, q_{2}$ e $q_{3}$ como

$$
\begin{aligned}
& q_{1}=\frac{b_{2} v_{2}+b_{3} v_{3}}{b_{2}+b_{3}}, \\
& q_{2}=\frac{b_{1} v_{1}+b_{3} v_{3}}{b_{1}+b_{3}}, \\
& q_{3}=\frac{b_{1} v_{1}+b_{2} v_{2}}{b_{1}+b_{2}} .
\end{aligned}
$$


Os valores dados em $p_{i}$ são projetados por igualdade em $q_{i}$ diretamente, ou seja, assumimos que $f_{q_{i}}=f_{p_{i}}$. Os gradientes nos pontos $p_{i}$ são projetados utilizando projeções ortogonais em relação ao plano do triângulo, assim

$$
g_{q_{i}}=\left(I-\vec{n} \vec{n}^{t}\right) \frac{g_{p_{i}}}{\left\|q_{i}\right\|} .
$$

onde $I$ é a matriz identidade do $\mathbb{R}^{3} \mathrm{e}^{t}$ indica a transposta do vetor e $\vec{n}$ é o vetor normal unitário ao plano do triângulo.

\section{Interpolação de Hermite em triângulos planos}

Para o cálculo de interpolação em um ponto contido em um triângulo esférico vamos utilizar o triângulo plano formado pelos vértices do triângulo esférico, com valores das arestas projetados para o triângulo plano. É possível construir a interpolação de Hermite no triângulo esférico, estendendo o que iremos descrever para o triângulo plano. Porém, resultados numéricos mostram pouca diferença entre considerar a interpolação no triângulo plano ou esférico para esse método, conforme descrito por Renka [1984].

Considere o triângulo plano definido pelo pontos $v_{1}, v_{2}$ e $v_{3}$, e um ponto $q$ contido nele. Sejam $\left(b_{1}, b_{2}, b_{3}\right)$ as coordenadas baricêntricas de $q$ no triângulo plano e $q_{1}, q_{2}$ e $q_{3}$ conforme definidos anteriormente nas equações (4.45) a (4.47). Então o polinômio interpolador de Hermite pode ser dado por (Lawson [1984]):

$$
f(q)=\sum_{i=1}^{3} c_{i} h_{i}(q),
$$

onde,

$$
c_{i}=\frac{b_{j} b_{k}}{b_{1} b_{2}+b_{2} b_{3}+b_{3} b_{1}}, \quad \text { para } j \neq k \neq i, \text { e } i, j, k=1,2,3
$$

$\mathrm{e}$

$$
\begin{aligned}
h_{i}(q)= & f_{q_{i}}+b_{i}^{2}\left(3-2 b_{i}\right)\left(f_{v_{i}}-f_{q_{i}}\right)+ \\
& b_{i}\left(1-b_{i}\right)\left(b_{i}\left\langle g_{v_{i}}, q_{i}-v_{i}\right\rangle-\left(1-b_{i}\right)\left\langle g_{q_{i}}, q_{i}-v_{i}\right\rangle\right),
\end{aligned}
$$

onde $f_{q_{i}}$ e $g_{q_{i}}$ são estimados usando a interpolação de Hermite para arco geodésico e projetados no plano, como indicado anteriormente.

Esse método não garante algumas propriedades desejáveis em interpolações e alguns ajustes são possíveis. Para evitar over ou undershooting em regiões de gradientes fortes é possível considerar uma superfície sob tensão. Uma forma de fazer isso é usando interpolações lineares por partes nestas regiões, ou então, como proposto por Renka [1997], um método que é quase linear por partes mas que continua garantindo a diferenciabilidade e continuidade da diferencial.

Para garantir monotonicidade, pode-se forçar que os valores interpolados não sejam maiores, nem menores, que os valores dos vértices do triângulo (Majewski et al. [2002]). Para garantir que a interpolação seja positiva definida pode-se forçar que o valor interpolado seja sempre maior ou igual a zero (Majewski et al. [2002]).

\section{Testes numéricos}

Na Tabela 4.9 apresentamos os erros para o remapeamento, que indicam terceira ordem de convergência, e na Figura 4.24 mostramos a distribuição do erro para uma malha de nível 3. Note na distribuição do erro que não há descontinuidades, indicando que a função gerada é pelo menos contínua. 


\begin{tabular}{|c|c|c|c|c|}
\hline Nível & Erro Máx C1RK & Erro 2 C1RK & Razão Máx & Razão 2 \\
\hline 0 & $2.6442 \mathrm{E}-01$ & $9.4082 \mathrm{E}-02$ & & \\
\hline 1 & $4.3866 \mathrm{E}-02$ & $1.2107 \mathrm{E}-02$ & 6.03 & 7.77 \\
\hline 2 & $4.5324 \mathrm{E}-03$ & $1.3398 \mathrm{E}-03$ & 9.68 & 9.04 \\
\hline 3 & $6.4596 \mathrm{E}-04$ & $1.3906 \mathrm{E}-04$ & 7.02 & 9.63 \\
\hline 4 & $7.7220 \mathrm{E}-05$ & $1.5104 \mathrm{E}-05$ & 8.37 & 9.21 \\
\hline 5 & $1.0933 \mathrm{E}-05$ & $1.7879 \mathrm{E}-06$ & 7.06 & 8.45 \\
\hline 6 & $8.8772 \mathrm{E}-07$ & $2.0445 \mathrm{E}-07$ & 12.32 & 8.74 \\
\hline 7 & $1.2667 \mathrm{E}-07$ & $2.5581 \mathrm{E}-08$ & 7.01 & 7.99 \\
\hline 8 & $1.1819 \mathrm{E}-08$ & $3.1394 \mathrm{E}-09$ & 10.72 & 8.15 \\
\hline
\end{tabular}

Tabela 4.9: Erros associados ao remapeamento da malha icosaédrica para uma malha do tipo longitudelatitude com $180 \times 360$ pontos considerando a função trigonométrica (equação (4.2)). Os dados foram fornecidos nos vértices dos triângulos, e o método usado foi o de minimos quadrados para obter o gradiente nos pontos de malha seguido pelo método de $C^{1}$ de Hermite de Renka (C1RK). Os erros apresentados são os do máximo e quadrático médio (2). Nas duas últimas colunas apresentamos as razões entre os erros de dois niveis consecutivos de malha.

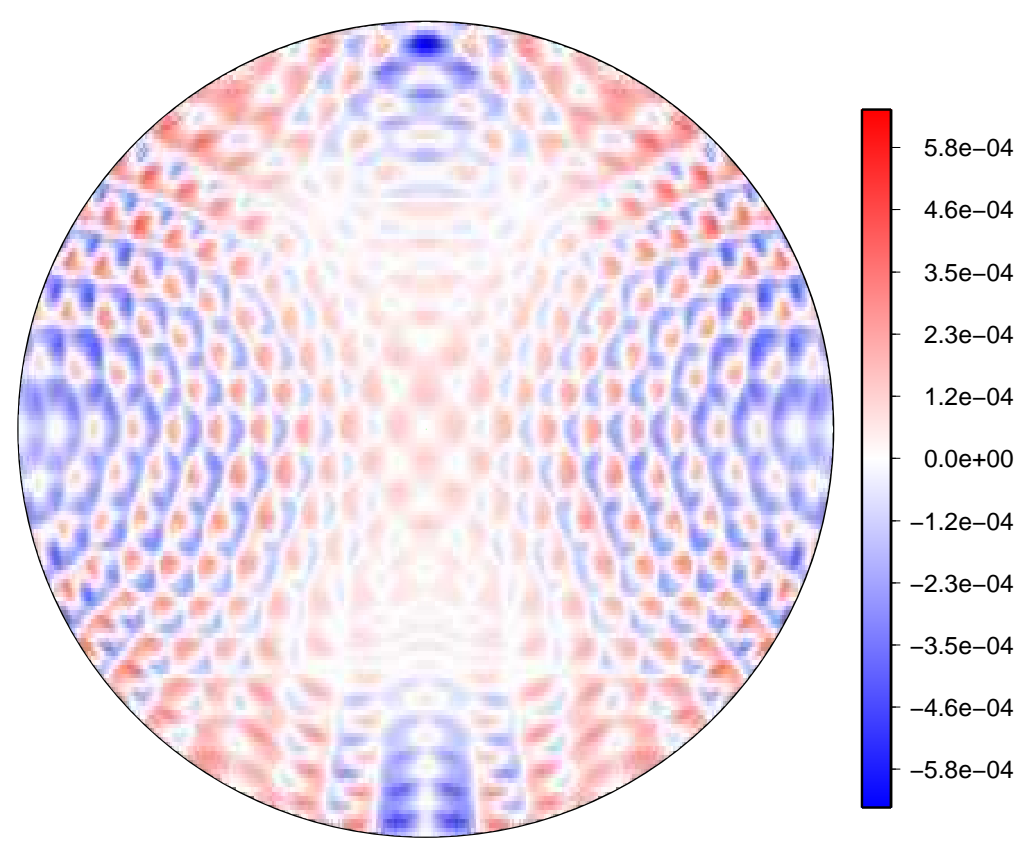

Figura 4.24: Erros associados ao remapeamento da função trigonométrica dada em (4.2) de uma malha icosaédrica de nível 3 para uma malha latitude longitude com $180 \times 360$ pontos. Os dados foram fornecidos nos vértices dos triângulos, e o método usado foi o de mínimos quadrados para obter o gradiente nos pontos de malha seguido pelo método de $C^{1}$ de Hermite de Renka (C1RK). 


\begin{tabular}{|c|c|c|}
\hline Função de Base Radial & \multicolumn{2}{|l|}{$\phi(r)$} \\
\hline Gaussiana & \multicolumn{2}{|l|}{$e^{-(\epsilon r)^{2}}$} \\
\hline Quadrática Inversa & \multicolumn{2}{|l|}{$\frac{1}{1+(\epsilon r)^{2}}$} \\
\hline Multiquadrática Inversa & \multicolumn{2}{|l|}{$\frac{1}{\sqrt{1+(\epsilon r)^{2}}}$} \\
\hline Spline Cúbico & $\left\{\begin{array}{l}\frac{1}{4}(2-(\epsilon r))^{3} \\
\frac{1}{4}\left(3(\epsilon r)^{3}-6(\epsilon r)^{2}+4\right) \\
0\end{array}\right.$ & $\begin{array}{c}1 \leq \epsilon r \leq 2 \\
0 \leq \epsilon r \leq 1 \\
2<\epsilon r\end{array}$ \\
\hline
\end{tabular}

Tabela 4.10: Funções de base radial com decaimento rápido.

\subsubsection{Funções de base radial}

Os métodos que usam funções de base radial (Radial Basis Functions - RBF) em geral não necessitam de qualquer estrutura de malha, o que os torna atraentes em malha não estruturadas. Há dois tipos de métodos que usam funções radiais: os que usam as funções radiais como base para construção de função interpoladora; e aqueles que usam as funções radiais apenas como pesos para a interpolação. Veremos a seguir detalhes desses dois tipos de métodos.

\section{RBF como base}

Os métodos que usam funções radiais como base para interpolação são comumente chamados simplesmente de métodos de funções de base radial (Radial Basis Function methods - RBF). O livro de Buhmann [2003] é uma referência completa para o assunto em $\mathbb{R}^{n}$. Há bastante informação sobre essa classe de métodos em Fasshauer [2011]. Há também diversos trabalhos que usam esse tipo de método para a esfera, como em Baxter e Hubbert [2001] ou em Hesse e Le Gia [2008]. Apesar do seu uso ter se tornado popular, veremos que o método possui claras limitações do ponto de vista numérico. Por outro lado, o método independe de qualquer tipo de estrutura de malha, podendo ser usado em interpolações para pontos dispersos (scattered data). A princípio vamos analisar o método no plano, mencionando as modificações necessárias para a esfera ao longo do texto.

Uma função de base radial, centrada em um ponto $q$, é uma função real do tipo

$$
\phi_{q}(p)=\phi(d(p, q))
$$

onde $d(p, q)$ é a distância de um ponto $p$ até o ponto $q$, isto é, uma RBF é uma função que só depende da distância (raio) do ponto $p$ até o centro da RBF. Na esfera unitária, quando a métrica usada é ângulo entre os vetores de posição central e do ponto de avaliação da função $(d(p, q)=$ $\arccos (\langle p, q\rangle))$, a função de base radial é denotada por função de base zonal (Baxter e Hubbert [2001]).

Dados $n$ pontos no plano (ou na esfera), $\left\{p_{i}\right\}_{i=1, \ldots, n}$, e seus respectivos valores nestes pontos $\left\{f_{i}\right\}_{i=1, \ldots, n}$, a função interpoladora usando RBF é dada por

$$
s(p)=\sum_{i=1}^{n} \lambda_{i} \phi\left(d\left(p, p_{i}\right)\right)
$$

onde os coeficientes $\lambda=\left(\lambda_{i}\right)_{i=1, \ldots, n}$ são determinados resolvendo-se o sistema linear $A \lambda=f$, onde as entradas de $A$ são dadas por $a_{i j}=\phi\left(d\left(p_{i}, p_{j}\right)\right)$, com $i=1, \ldots, n$ e $j=1, \ldots, n$, e $f=\left(f_{i}\right)_{i=1, \ldots, n}$.

Como nesta tese estamos interessados em interpolações com características locais, isso é, que utilizam apenas informações de uma vizinhança do ponto de interpolação, vamos focar apenas em funções radiais com suporte concentrado em uma vizinhança do centro da função. Na Tabela 4.10 mostramos algumas das principais funções de base radial com essa propriedade. O parâmetro $\epsilon$ é um indicador de largura da função. Quanto menor ele for, mais perto da função constante a função radial será. 


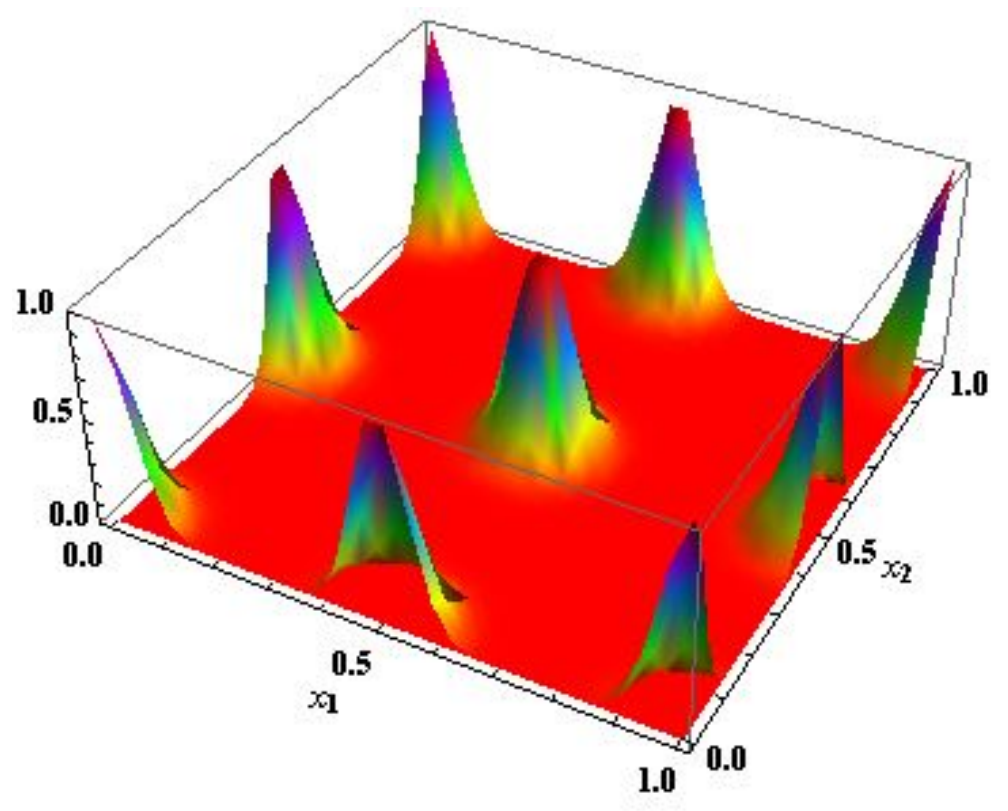

Figura 4.25: Base para polinômio interpolador com função de base radial gaussiana e parâmetro $\epsilon=15$. Gerado usando o aplicativo de Fasshauer [2012].

As matrizes geradas com as funções de base radial são sempre simétricas. As funções descritas na Tabela 4.10 geram sistemas cujas soluções estão garantidas desde que tenhamos pelo menos 2 pontos de malha distintos e $\epsilon>0$ (Buhmann [2003], Baxter e Hubbert [2001]). Além disso, as funções apresentadas acima definem sempre matrizes positivas definidas, isto é, são núcleos positivos definidos (ver Fasshauer [2011]).

O parâmetro $\epsilon$ tem um papel importante nesse tipo de interpolação. Para ilustrar os seus efeitos na interpolação Fasshauer desenvolveu um aplicativo em Mathematica CFD que permite visualizar a interação entre $\epsilon$ e o polinômio interpolador (Fasshauer [2012]). Considere 9 pontos uniformemente espaçados no quadrado de lado 1 e a função de base radial gaussiana. Suponha que $\epsilon$ seja suficientemente grande, de forma a termos a função com valor um no seu centro e zero, ou bem próximo de zero, nos demais pontos de malha. Nesse caso, a matriz resultante seria a identidade, ou uma perturbação da identidade, e os coeficientes seriam dados pelos respectivos valores nos centros das funções. Ilustramos a base do polinômio interpolador tomando $\epsilon=15$ na Figura 4.25, onde verifica-se que há muitos pontos na região que terão valor interpolado nulo, e logo poderíamos ter um erro de interpolação considerável. Note por outro lado que, nesse caso, temos uma matriz com número de condição muito pequeno, igual ou próximo de 1 . Há diversas análises indicando que valores menores de $\epsilon$ reduzem o erro de interpolação (Wright [2003]), porém o preço que se paga é termos uma matriz com número de condição cada vez maior. Ilustramos isso na Figura 4.26, onde assumimos $\epsilon=1.5$ e o número de condição para a matriz obtida foi maior que 50 .

Há diversos trabalhos que estudam a convergência desse método de interpolação. No trabalho de Fasshauer e Schumaker [1998] são descritos os principais resultados. São descritas as ordens de convergência e os graus de condicionamento das matrizes esperados para o método. O fato mais importante a ser destacado é que, ao considerarmos mais pontos na interpolação, a ordem do método cresce, porém a ordem de crescimento do mal condicionamento da matriz também aumenta. Em Fasshauer [2011] é descrito o seguinte fato:

"Usando as bases usuais de RBF (como as da Tabela 4.10), não é possível obtermos alta precisão e estabilidade ao mesmo tempo."

Vamos analisar o caso onde temos um conjunto de pontos fixados e verificar o que ocorre ao alterarmos as distâncias relativas entre os pontos. Sejam $p_{i}, i=1, \ldots, n$, pontos distintos do plano, 


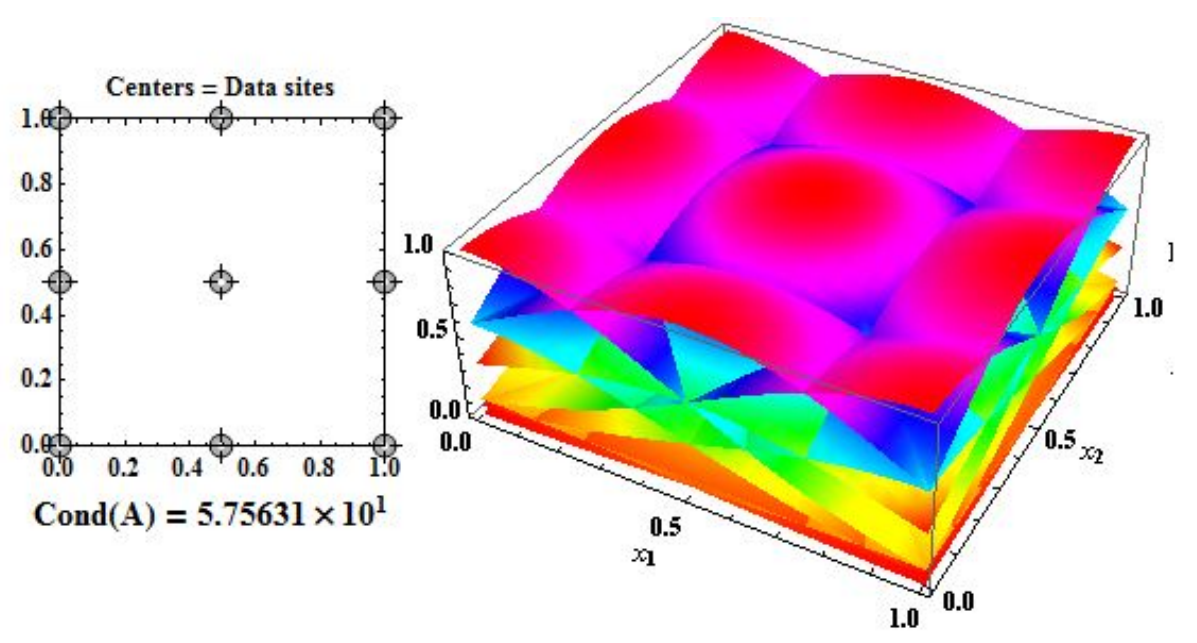

Figura 4.26: Base para polinômio interpolador com função de base radial gaussiana e parâmetro $\epsilon=1.5$. Gerado usando o aplicativo de Fasshauer [2012].

e $h_{\text {min }}=\min _{i, j=1, \ldots, n}\left\|p_{i}-p_{j}\right\|$, e $h_{\max }=\max _{i, j=1, \ldots, n}\left\|p_{i}-p_{j}\right\|$. Seja $\phi_{\epsilon}$ uma função de base radial com parâmetro $\epsilon$. Vamos analisar o método de interpolação por RBF tendo em vista diferentes valores de $h_{\min }$ e $h_{\max }$ para $n$ fixado.

$\mathrm{Na}$ literatura, as implementações de métodos de interpolações locais usando funções de base radial para a modelagem meteorológica adotam parâmetro de formato $\epsilon$ fixado (Skamarock et al. [2012], Bonaventura et al. [2004]). Isso irá garantir convergência para o método, mas ao custo de mal condicionamento da matriz para malhas mais finas. Para as malhas utilizadas na literatura, não observou-se impactos na precisão por problemas de instabilidade. Há dois motivos para isso. O primeiro é que sabemos que se refinarmos mais a malha o sistema se tornará irresolvível, logo os exemplos apresentados na literatura não atingiram malhas suficientemente finas para que problemas fossem observados para a escolha de $\epsilon$ adotada. O segundo é que o parâmetro $\epsilon$ pode ter sido aumentado para garantir resolubilidade para a malha mais fina testada.

Na prática, como sabemos que a matriz do sistema de interpolação por RBF terá um número de condição elevado quando $h_{\max }$ for muito pequeno, $h_{\max } \rightarrow 0$, para garantir convergência em malhas mais finas, será preciso exigir que $\epsilon \propto h_{\text {min }}$, de tal forma que a matriz do sistema tenha número de condição que viabilize a sua solução numérica.

Por um lado é interessante termos $\epsilon h_{\min }$ suficientemente grande para reduzir a instabilidade do sistema. Por outro lado, se $\epsilon h_{\text {min }}$ for muito grande, então as funções radiais terão suportes concentrados em regiões muito pequenas (veja a Figura 4.25), logo teremos erros maiores. Portanto, é natural que adotemos $\epsilon=c / h_{\text {min }}$, para alguma constante $c>0$ escolhida convenientemente. Isso fará com que a matriz do sistema tenha número de condição sob controle. O ideal é escolhermos $c$ o menor possível, para garantir boas aproximações, mas que ainda mantenha o sistema resolvível do ponto de vista numérico. Isso nos leva a um sistema cuja matriz independe de $h_{\min }, h_{\max }$ ou $\epsilon$, e logo independe de quão perto ou longe estão os pontos, mas somente de como são suas distâncias relativas $d\left(p_{i}, p_{j}\right) / h_{\text {min }}$. A consequência disso é que a função interpoladora irá gerar um erro da mesma ordem de grandeza, independentemente do refinamento da malha. Isso ocorre pois uma função de base radial com $\epsilon=c / h_{\min }$ é equivalente à mesma função com parâmetro $c$ mas com argumento $r / h_{\text {min }}$, logo

$$
s(p)=\sum_{i=1}^{n} \lambda_{i} \phi_{\epsilon}\left(d\left(p, p_{i}\right)\right)=\sum_{i=1}^{n} \lambda_{i} \phi_{c}\left(d\left(p, p_{i}\right) / h_{m i n}\right) .
$$

Como $d\left(p, p_{i}\right) \propto h_{\text {min }}, s(p)$ terá um erro que não dependerá do nível de refinamento da malha, não haverá convergência do método se $\epsilon \propto h_{\min }$.

As análises anteriores revelam que o método de interpolação que usa funções de base radial 
não é apropriado para interpolações locais, considerando um número fixo de pontos, a menos que consideremos $\epsilon$ fixado, mas escolhido de tal forma a conservar estabilidade numérica.

Para compreendermos melhor o problema da dualidade entre estabilidade numérica e precisão realizamos uma bateria de testes numéricos utilizando a função de base radial gaussiana, usando o teste de remapeamento. Vamos usar um função de base radial gaussiana. Vamos considerar 3 conjuntos de pontos para definir a vizinhança do ponto de interpolação que servirão de base para o problema de interpolação:

- TR - Verifica-se em qual triângulo o ponto de interpolação está e usam-se os vértices desse triângulo como centros das funções radiais -3 pontos,

- HX - Verifica-se qual o nó mais próximo do ponto de interpolação e usa-se este e os seus vizinhos diretos - 6 ou 7 pontos,

- ETR - O mesmo que o caso TR, mas estendendo para os vizinhos dos vértices do triângulo (Figura 4.27) - 11 ou 12 pontos.

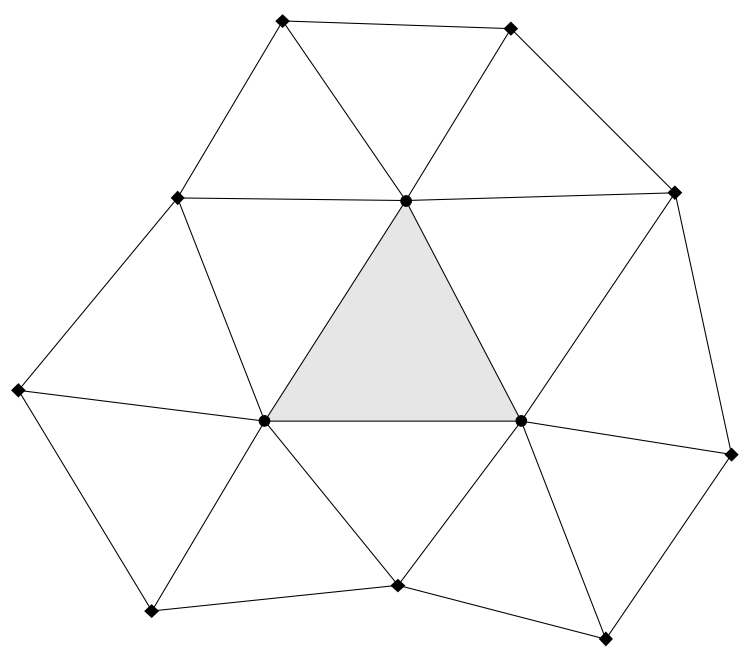

Figura 4.27: Ilustração indicando a região de vizinhança de um triângulo (hachurado) em uma malha icosaédrica. Os vizinhos mais próximos, de nivel 1, aparecem com círculos preenchidos. Os vizinhos de nível 2, vizinhos de vizinhos, aparecem com diamantes preenchidos.

Para resolver os sistemas lineares gerados pelo método de funções de base radial estamos usando um método de Cholesky com decomposição do tipo $L D L^{t}$, isto é, com $L$ matriz triangular inferior e $D$ diagonal. Aqui estamos usando o fato de que as bases usadas geram sistemas com matrizes simétricas positivas definidas. Para termos uma ideia do condicionamento da matriz, calculamos a razão entre o maior elemento de $D$ e o menor elemento. Essa decomposição só depende da malha, logo, pode ser pré-calculada e armazenada para uso futuro, barateando o custo computacional do método mas aumentando o uso de memória.

O primeiro teste é com o conjunto de pontos $T R$, para o qual adotamos o parâmetro de largura $\epsilon=1$. Apresentamos os erros na Tabela 4.11, onde é possível perceber uma aproximação de segunda ordem, mas também uma piora no condicionamento da matriz com ordem dois. Mostramos na Figura 4.28 a distribuição do erro para uma malha de nível 3, onde nota-se uma marcação dos triângulos envolvidos na interpolação.

Para o conjunto de pontos HX, com 6 ou 7 pontos, realizamos os testes de remapeamento com parâmetro de formato $\epsilon=0.5$. Os resultados estão na Tabela 4.12. Observa-se uma ordem de convergência cúbica, porém, o condicionamento da matriz piora muito com o refinamento de malha, indicando ordem 6 . Na malha de nível 8 a resolução do sistema ficou prejudicada por conta de instabilidades numéricas e o erro cresceu. Isso mostra que o parâmetro $\epsilon$ escolhido não foi adequado para esse conjunto de malhas e precisaria ser maior para usarmos o método na malha de nível 8. 


\begin{tabular}{|c|c|c|c|c|c|c|}
\hline Nível & ErroMáx RBFTR & Erro2 RBFTR & CondSis & RazMáx & Raz2 & RazCond \\
\hline 0 & $2.7818 \mathrm{E}-01$ & $1.3388 \mathrm{E}-01$ & $1.15 \mathrm{E}+00$ & & & \\
\hline 1 & $1.0098 \mathrm{E}-01$ & $3.4801 \mathrm{E}-02$ & $2.38 \mathrm{E}+00$ & 2.75 & 3.85 & 2.06 \\
\hline 2 & $2.6934 \mathrm{E}-02$ & $8.8202 \mathrm{E}-03$ & $9.57 \mathrm{E}+00$ & 3.75 & 3.95 & 4.02 \\
\hline 3 & $6.7979 \mathrm{E}-03$ & $2.2130 \mathrm{E}-03$ & $3.94 \mathrm{E}+01$ & 3.96 & 3.99 & 4.12 \\
\hline 4 & $1.7061 \mathrm{E}-03$ & $5.5335 \mathrm{E}-04$ & $1.59 \mathrm{E}+02$ & 3.98 & 4.00 & 4.04 \\
\hline 5 & $4.1412 \mathrm{E}-04$ & $1.3800 \mathrm{E}-04$ & $6.38 \mathrm{E}+02$ & 4.12 & 4.01 & 4.01 \\
\hline 6 & $1.0476 \mathrm{E}-04$ & $3.4465 \mathrm{E}-05$ & $2.55 \mathrm{E}+03$ & 3.95 & 4.00 & 4.00 \\
\hline 7 & $2.6079 \mathrm{E}-05$ & $8.8077 \mathrm{E}-06$ & $1.02 \mathrm{E}+04$ & 4.02 & 3.91 & 4.00 \\
\hline 8 & $6.5894 \mathrm{E}-06$ & $2.1857 \mathrm{E}-06$ & $4.08 \mathrm{E}+04$ & 3.96 & 4.03 & 4.00 \\
\hline
\end{tabular}

Tabela 4.11: Erros associados ao remapeamento da malha icosaédrica para uma malha do tipo longitudelatitude com $180 \times 360$ pontos considerando a função trigonométrica (equação (4.2)). Os dados foram fornecidos nos vértices dos triângulos, e o método usado foi o de funções da base radiais considerando uma gaussiana com $\epsilon=1$ e conjunto de pontos TR (RBFTR-e1). Os erros apresentados são os do máximo e quadrático médio (2). Na coluna CondSis são apresentadas estimativas do número de condição com base na decomposição de Cholesky.

\begin{tabular}{|c|c|c|c|c|c|c|}
\hline Nível & ErMáx RBFHX-e0.5 & Er2 RBFHX-e0.5 & CondSis & Razão Máx & Razão 2 & Razão Cond. \\
\hline 0 & $2.5290 \mathrm{E}-01$ & $9.8155 \mathrm{E}-02$ & $1.48 \mathrm{E}+01$ & & & \\
\hline 1 & $6.2914 \mathrm{E}-02$ & $1.7043 \mathrm{E}-02$ & $1.54 \mathrm{E}+03$ & 4.02 & 5.76 & 103.91 \\
\hline 2 & $8.7326 \mathrm{E}-03$ & $2.5700 \mathrm{E}-03$ & $1.72 \mathrm{E}+05$ & 7.20 & 6.63 & 111.77 \\
\hline 3 & $1.2291 \mathrm{E}-03$ & $3.5758 \mathrm{E}-04$ & $1.23 \mathrm{E}+07$ & 7.10 & 7.19 & 71.46 \\
\hline 4 & $1.7180 \mathrm{E}-04$ & $4.7370 \mathrm{E}-05$ & $8.09 \mathrm{E}+08$ & 7.15 & 7.55 & 65.63 \\
\hline 5 & $2.1867 \mathrm{E}-05$ & $6.0668 \mathrm{E}-06$ & $5.21 \mathrm{E}+10$ & 7.86 & 7.81 & 64.40 \\
\hline 6 & $2.7594 \mathrm{E}-06$ & $7.7648 \mathrm{E}-07$ & $3.36 \mathrm{E}+12$ & 7.92 & 7.81 & 64.42 \\
\hline 7 & $4.0037 \mathrm{E}-07$ & $9.8068 \mathrm{E}-08$ & $3.11 \mathrm{E}+14$ & 6.89 & 7.92 & 92.53 \\
\hline 8 & $9.4765 \mathrm{E}-04$ & $5.8163 \mathrm{E}-06$ & $2.66 \mathrm{E}+20$ & 0.00 & 0.02 & - \\
\hline
\end{tabular}

Tabela 4.12: Erros associados ao remapeamento da malha icosaédrica para uma malha do tipo longitudelatitude com $180 \times 360$ pontos considerando a função trigonométrica (equação (4.2)). Os dados foram fornecidos nos vértices dos triângulos, e o método usado foi o de funções da base radiais considerando uma gaussiana com $\epsilon=0.5$ e conjunto de pontos $H X$ (RBFHX-e0.5). Os erros apresentados são os do máximo e quadrático médio (2). Na coluna CondSis são apresentadas estimativas do número de condição com base na decomposição de Cholesky. 


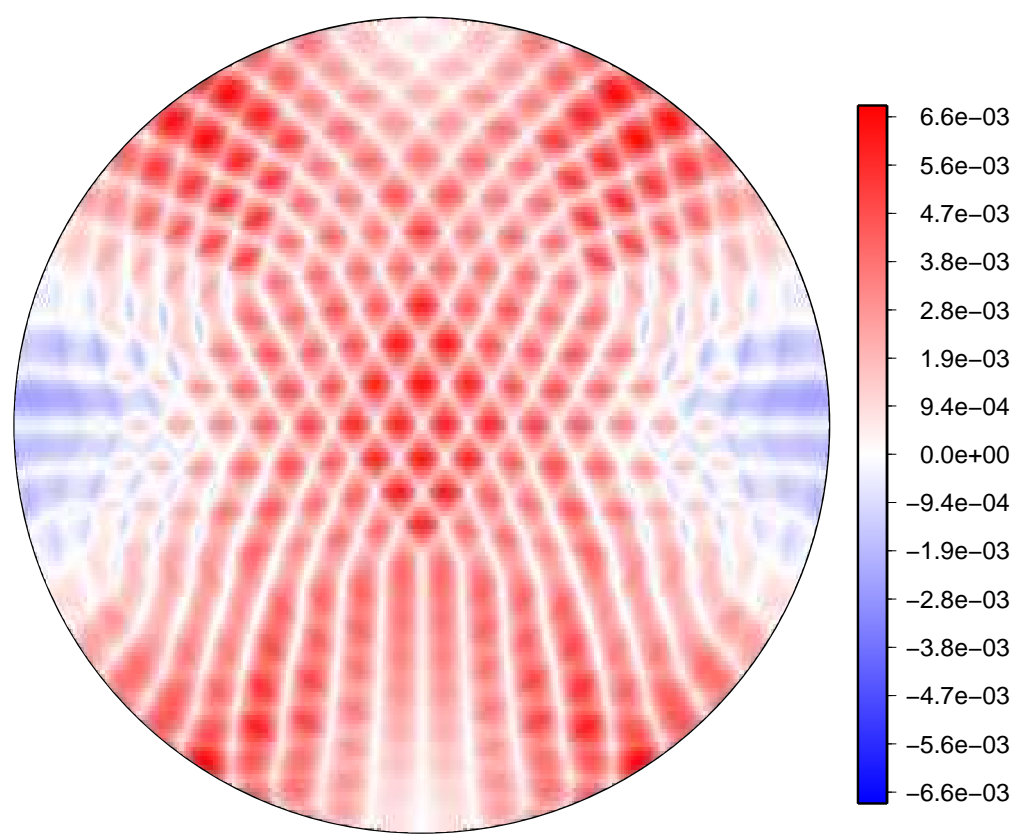

Figura 4.28: Erros associados ao remapeamento da função trigonométrica dada em (4.2) de uma malha icosaédrica de nível 3 para uma malha latitude longitude com $180 \times 360$ pontos. Os dados foram fornecidos nos vértices dos triângulos, e o método usado foi o de funções da base radiais considerando uma gaussiana com $\epsilon=1$ e conjunto de pontos TR (RBFTR-e1).

Consideramos o mesmo teste agora com parâmetro $\epsilon=5$ e apresentamos os resultados na Tabela 4.13. Percebe-se agora que não houve impactos de problemas de instabilidade numérica na precisão, e obtivemos convergência cúbica até para a malha de nível 8. Porém, ao compararmos os erros do método com esse novo parâmetro em relação ao primeiro, vemos que o erro aumentou significativamente, principalmente na norma quadrática. Isso evidencia que o método é computacionalmente inviável do ponto de vista assintótico, pois se refinarmos mais a malha teremos que alterar o parâmetro $\epsilon$ para manter estabilidade, mas com isso não vamos observar convergência do erro para o método.

\begin{tabular}{|c|c|c|c|c|c|c|}
\hline Nível & ErroMáx RBFHX-e5 & Erro2 RBFHX-e5 & CondSis & RazMáx & Raz2 & RazCond \\
\hline 0 & $9.9920 \mathrm{E}-01$ & $3.1240 \mathrm{E}-01$ & $1.00 \mathrm{E}+00$ & & & \\
\hline 1 & $7.8610 \mathrm{E}-01$ & $2.2021 \mathrm{E}-01$ & $1.00 \mathrm{E}+00$ & 1.27 & 1.42 & 1.00 \\
\hline 2 & $7.6101 \mathrm{E}-02$ & $1.6226 \mathrm{E}-02$ & $1.07 \mathrm{E}+00$ & 10.33 & 13.57 & 1.07 \\
\hline 3 & $5.0258 \mathrm{E}-02$ & $1.0834 \mathrm{E}-02$ & $4.19 \mathrm{E}+00$ & 1.51 & 1.50 & 3.93 \\
\hline 4 & $5.9045 \mathrm{E}-03$ & $1.4572 \mathrm{E}-03$ & $1.04 \mathrm{E}+02$ & 8.51 & 7.43 & 24.80 \\
\hline 5 & $6.7882 \mathrm{E}-04$ & $1.8203 \mathrm{E}-04$ & $5.18 \mathrm{E}+03$ & 8.70 & 8.01 & 49.81 \\
\hline 6 & $7.9572 \mathrm{E}-05$ & $2.2102 \mathrm{E}-05$ & $3.11 \mathrm{E}+05$ & 8.53 & 8.24 & 60.07 \\
\hline 7 & $9.6350 \mathrm{E}-06$ & $2.8697 \mathrm{E}-06$ & $1.96 \mathrm{E}+07$ & 8.26 & 7.70 & 62.99 \\
\hline 8 & $1.1799 \mathrm{E}-06$ & $3.5612 \mathrm{E}-07$ & $1.25 \mathrm{E}+09$ & 8.17 & 8.06 & 63.76 \\
\hline
\end{tabular}

Tabela 4.13: Erros associados ao remapeamento da malha icosaédrica para uma malha do tipo longitudelatitude com $180 \times 360$ pontos considerando a função trigonométrica (equação (4.2)). Os dados foram fornecidos nos vértices dos triângulos, e o método usado foi o de funções da base radiais considerando uma gaussiana com $\epsilon=5$ e conjunto de pontos $H X$ (RBFHX-e5). Os erros apresentados são os do máximo e quadrático médio (2). Na coluna CondSis são apresentadas estimativas do número de condição com base na decomposição de Cholesky.

O método de funções de base radial para hexágonos (com o conjunto de pontos HX) não irá garantir continuidade global, pois um ponto na aresta pode estar associado arbitrariamente a 2 conjuntos de pontos distintos e não há restrições de continuidade no método. Apresentamos a 
distribuição do erro para o conjunto de pontos HX com parâmetro $\epsilon=1$ na Figura 4.29, onde percebe-se claramente as descontinuidades.

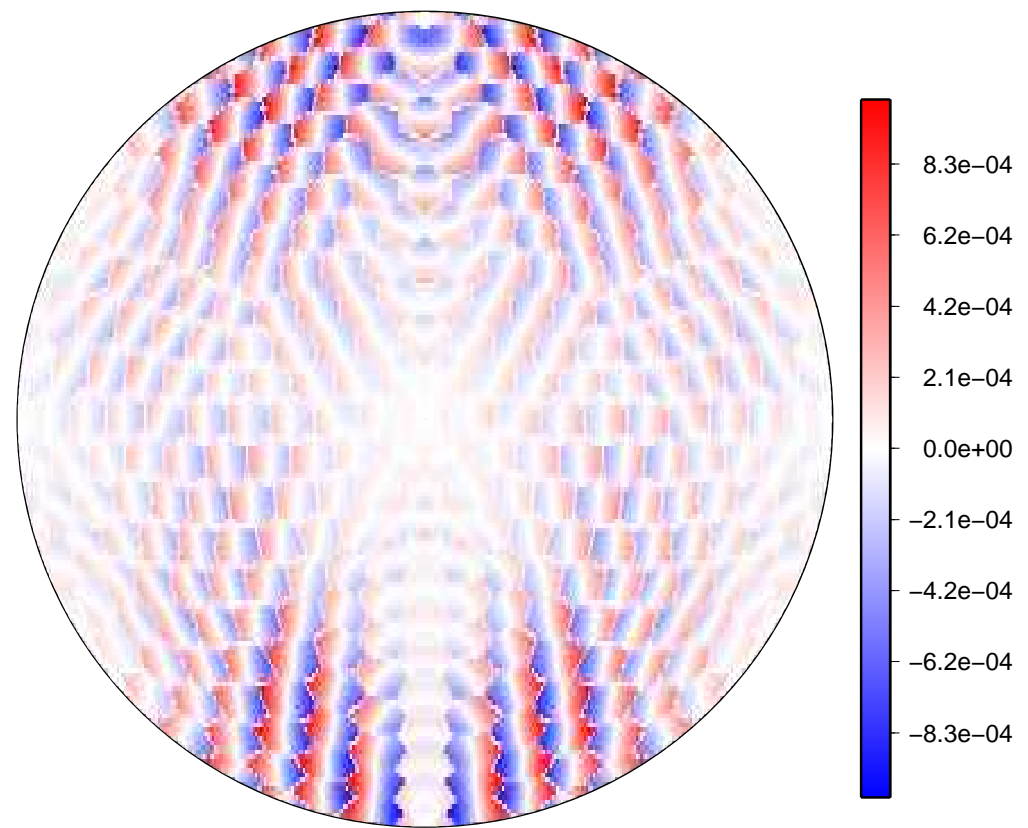

Figura 4.29: Erros associados ao remapeamento da função trigonométrica dada em (4.2) de uma malha icosaédrica de nivel 3 para uma malha latitude longitude com $180 \times 360$ pontos. Os dados foram fornecidos nos vértices dos triângulos, e o método usado foi o de funções da base radiais considerando uma gaussiana com $\epsilon=1$ e conjunto de pontos $H X$ (RBFHX-e1).

Se tentarmos usar o parâmetro $\epsilon=1$ para o conjunto de pontos $E T R$, o sistema fica instável a ponto de não ser possível resolvê-lo para níveis de malha maiores que 6. Aumentando o parâmetro para $\epsilon=5$ o sistema fica resolvível, e os resultados são apresentados na Tabela 4.14. A ordem de convergência aumentou para 4, por outro lado, o condicionamento da matriz revela taxas de crescimento proibitivas do ponto de vista computacional. Por outro lado, a distribuição do erro, apresentado na Figura 4.30 indica continuidade na função interpoladora.

\begin{tabular}{|c|c|c|c|c|c|c|}
\hline Nível & ErroMáx RBFETR & Erro2 RBFETR & CondSis & RazMáx & Raz2 & RazãoCond \\
\hline 0 & $9.9920 \mathrm{E}-01$ & $3.1240 \mathrm{E}-01$ & $1.00 \mathrm{E}+00$ & & & \\
\hline 1 & $7.8610 \mathrm{E}-01$ & $2.2021 \mathrm{E}-01$ & $1.00 \mathrm{E}+00$ & 1.27 & 1.42 & 1.00 \\
\hline 2 & $1.2789 \mathrm{E}-01$ & $2.0173 \mathrm{E}-02$ & $1.07 \mathrm{E}+00$ & 6.15 & 10.92 & 1.07 \\
\hline 3 & $6.8163 \mathrm{E}-02$ & $1.7391 \mathrm{E}-02$ & $5.15 \mathrm{E}+00$ & 1.88 & 1.16 & 4.83 \\
\hline 4 & $7.6110 \mathrm{E}-03$ & $1.7525 \mathrm{E}-03$ & $3.45 \mathrm{E}+02$ & 8.96 & 9.92 & 67.04 \\
\hline 5 & $5.2357 \mathrm{E}-04$ & $1.1894 \mathrm{E}-04$ & $6.34 \mathrm{E}+04$ & 14.54 & 14.73 & 183.85 \\
\hline 6 & $3.2823 \mathrm{E}-05$ & $7.8655 \mathrm{E}-06$ & $1.50 \mathrm{E}+07$ & 15.95 & 15.12 & 235.88 \\
\hline 7 & $1.9781 \mathrm{E}-06$ & $4.5446 \mathrm{E}-07$ & $3.75 \mathrm{E}+09$ & 16.59 & 17.31 & 251.00 \\
\hline 8 & $1.2913 \mathrm{E}-07$ & $2.9156 \mathrm{E}-08$ & $1.34 \mathrm{E}+12$ & 15.32 & 15.59 & 358.03 \\
\hline
\end{tabular}

Tabela 4.14: Erros associados ao remapeamento da malha icosaédrica para uma malha do tipo longitudelatitude com $180 \times 360$ pontos considerando a função trigonométrica (equação (4.2)). Os dados foram fornecidos nos vértices dos triângulos, e o método usado foi o de funções da base radiais considerando uma gaussiana com $\epsilon=5$ e conjunto de pontos ETR (RBFETR-e5). Os erros apresentados são os do máximo e quadrático médio (2). Na coluna CondSis são apresentadas estimativas do número de condição com base na decomposição de Cholesky.

Esses resultados numéricos ilustram a problemática de instabilidade numérica ao trabalharmos com funções de base radial usando um número fixado de pontos. Apesar disso, esse método é usado no projeto ICON para a reconstrução de campos vetoriais. Nos trabalhos de Ruppert [2007] e 
Wan [2009] é discutida a questão de mal condicionamento da matriz e, com base nisto, são escolhido parâmetros $\epsilon$ de formato da base que garantam convergência dentro de escopo de malhas estudadas. Uma otimização proposta em Ruppert [2007] evolve adicionar uma correção polinomial na função interpoladora para que se garanta convergência sempre. Foram propostas na literatura algumas formas de se estabilizar o sistema (Fornberg e Piret [2008], Fasshauer e McCourt [2012]), mas os métodos, além de computacionalmente muito caros, são aplicáveis somente para a esfera toda.

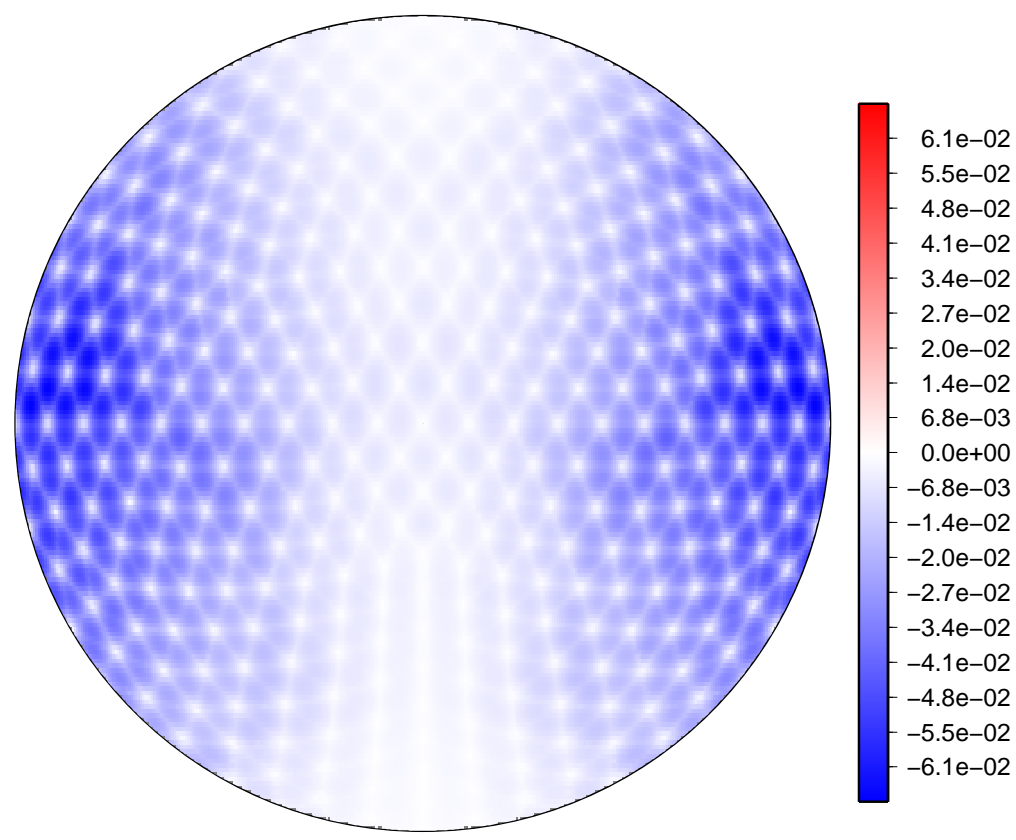

Figura 4.30: Erros associados ao remapeamento da função trigonométrica dada em (4.2) de uma malha icosaédrica de nível 3 para uma malha latitude longitude com $180 \times 360$ pontos. Os dados foram fornecidos nos vértices dos triângulos, e o método usado foi o de funções da base radiais considerando uma gaussiana com $\epsilon=5$ e conjunto de pontos ETR (RBFETR-e5).

\section{RBF como peso}

A ideia de um método de função de base radial como peso é simplesmente usar a função de base radial como ponderação para a combinação linear de valores dados em pontos de malha. Nesse tipo de método, o ideal é o uso de funções de base radial com decaimento dado pelo inverso da distância, em relação ao ponto central, a alguma potência. O essencial é dar mais peso a pontos próximos ao de interpolação e menos peso aos mais distantes.

Dado um ponto de interpolação $p$, um conjunto de pontos $\left\{p_{i}\right\}_{i=1, \ldots, n}$, com seus valores dados por $\left\{f_{i}\right\}_{i=1, \ldots, n}$, e uma função de base radial $\phi$, definimos a função aproximadora por

$$
\tilde{f}(p)=\frac{\sum_{i=1}^{n} \phi\left(d\left(p, p_{i}\right)\right) f_{i}}{\sum_{i=1}^{n} \phi\left(d\left(p, p_{i}\right)\right)}
$$

onde $d(\cdot, \cdot)$ é uma métrica de distância entre dois pontos.

Em Shepard [1968] é proposto um método, que ficou conhecido como método de Shepard, que usa o inverso do quadrado da distância, onde $\phi(r)=1 / r^{2}$. Esse tipo de função não estará bem definida nos pontos de malha, logo é preciso adicionar uma condição que defina que $\tilde{f}\left(p_{i}\right)=f_{i}$ caso a distância de $d\left(p, p_{i}\right)$ seja menor que uma tolerância numérica. O suporte da função, apesar de cair rapidamente, não é compacto. Isso faz com que o custo computacional desse método seja elevado. Para aprimorar o método de Shepard, Franke e Nielson [1980] propuseram o que ficou conhecido como método de Shepard local modificado, onde eles propõe uma função peso com suporte limitado, 
dada por

$$
\phi(r)=\left[\frac{(R-r)_{+}}{R r}\right]^{2}
$$

onde $R>0$ é uma constante que define o raio máximo de vizinhança da função de base radial e $(\cdot)_{+}$é uma função que vale zero se a variável for negativa e o próprio valor se for positiva. Além disso, eles propõe que a aproximação seja feita usando um aproximação polinomial dos valores $f_{i}$, isto é,

$$
\tilde{f}(p)=\frac{\sum_{i=1}^{n} \phi\left(d\left(p, p_{i}\right)\right) P_{i}(p)}{\sum_{i=1}^{n} \phi\left(d\left(p, p_{i}\right)\right)},
$$

onde $P_{i}(p)$ é um polinômio em torno do ponto $p_{i}$, tal que $P_{i}\left(p_{i}\right)=f_{i}$.

Renka [1988a] descreve uma implementação desse método e disponibiliza códigos para o caso de polinômios quadráticos (Renka [1988b]) e cúbicos (Renka [1988c]). Para a estimativa dos polinômios $P_{i}$ o método proposto é o descrito na seção de método de mínimos quadrados anterior (seção 4.2.2). Sendo assim, o método de Shepard modificado basicamente pondera, com base em distâncias, polinômios obtidos por mínimos quadrados nos pontos de malha. Vimos anteriormente que o método de aproximação polinomial quadrática usando mínimos quadrados, quando usado em interpolações considerando simplesmente o ponto de malha mais próximo, não gera uma função globalmente contínua. Por outro lado, com a abordagem de ponderações por funções radiais (Shepard modificado) obtemos uma função globalmente contínua.

A definição do raio $R$ deve depender da malha considerada, de maneira que ele defina vizinhanças de cada ponto de malha que cubram a esfera toda, mas, por outro lado, que sejam pequenas o suficiente para deixar o método eficiente. Na nossa implementação do método de Shepard modificado consideramos $R$ como sendo $105 \%$ da máxima distância entre os nós, desta forma garantimos a cobertura de todos os triângulos, logo de toda a esfera. Além disso, com essa parametrização, estaremos em geral usando no máximo 7 pontos na interpolação, definidos por um ponto de malha e os seus vizinhos de primeiro nível. Com essa abordagem a função interpoladora será globalmente contínua, a menos do pequeno salto próximo aos pontos de malha, que podemos limitar ao erro de máquina.

O método é robusto no sentido de não necessitar de nenhum tipo de estrutura de malha. Porém, é necessário fazer uma varredura da intersecção das vizinhanças dos pontos de malha com o ponto de interpolação. Mesmo em uma malha como a icosaédrica isso gera um custo adicional considerável, pois não é possível definir os conjuntos de pontos que serão usados a priori, mas somente depois de conhecido o ponto de interpolação. Na nossa implementação geramos para cada ponto de interpolação uma lista de pontos de malha que distam $R$, ou menos, em ordem de distâncias. O custo disso é da ordem do número de pontos contidos em uma vizinhança ao quadrado (em geral uma vizinhança contém no máximo 7 pontos). Como isso é feito para cada interpolação, esse método se mostra mais caro que os demais (mostraremos um comparativo de custo computacional mais adiante).

Ao testarmos o método local modificado de Shepard, sem uso de polinômio, isso é, $P_{i}(p)=f_{i}$, verificamos que o método é apenas de ordem um (veja a Tabela 4.15). Por outro lado, quando consideramos um polinômio quadrático, estimado com a metodologia descrita em seções anteriores, obtivemos ordem 3 de convergência (ver Tabela 4.16). Na distribuição do erro tanto do método sem polinômio (Figura 4.31), quando do método com polinômio quadrático (Figura 4.32), observa-se continuidade. Ao compararmos o método de mínimos quadrados utilizando o ponto de malha mais próximo ao de interpolação, descrito anteriormente (ver Figura 4.19), com o quadrático de Shepard, percebemos que além da continuidade da função os erros são um pouco menores, mas tem a mesma ordem de convergência. 


\begin{tabular}{|c|c|c|c|c|}
\hline Nível & Erro Máx LMSP & Erro 2 LMSP & Razão Máx & Razão 2 \\
\hline 0 & $3.7603 \mathrm{E}-01$ & $1.4263 \mathrm{E}-01$ & & \\
\hline 1 & $1.9395 \mathrm{E}-01$ & $5.8784 \mathrm{E}-02$ & 1.94 & 2.43 \\
\hline 2 & $9.0500 \mathrm{E}-02$ & $2.6199 \mathrm{E}-02$ & 2.14 & 2.24 \\
\hline 3 & $4.4459 \mathrm{E}-02$ & $1.2583 \mathrm{E}-02$ & 2.04 & 2.08 \\
\hline 4 & $2.1948 \mathrm{E}-02$ & $6.2191 \mathrm{E}-03$ & 2.03 & 2.02 \\
\hline 5 & $1.0784 \mathrm{E}-02$ & $3.1595 \mathrm{E}-03$ & 2.04 & 1.97 \\
\hline 6 & $5.4739 \mathrm{E}-03$ & $1.4990 \mathrm{E}-03$ & 1.97 & 2.11 \\
\hline 7 & $2.7360 \mathrm{E}-03$ & $8.0037 \mathrm{E}-04$ & 2.00 & 1.87 \\
\hline 8 & $1.3370 \mathrm{E}-03$ & $3.9360 \mathrm{E}-04$ & 2.05 & 2.03 \\
\hline
\end{tabular}

Tabela 4.15: Erros associados ao remapeamento da malha icosaédrica para uma malha do tipo longitudelatitude com $180 \times 360$ pontos considerando a função trigonométrica (equação (4.2)). Os dados foram fornecidos nos vértices dos triângulos, e o método usado foi o local modificado de Shepard (LMSP). Os erros apresentados são os do máximo e quadrático médio (2).

\begin{tabular}{|c|c|c|c|c|}
\hline Nível & Erro Máx QDSP & Erro 2 QDSP & Razão Máx & Razão 2 \\
\hline 0 & $2.7322 \mathrm{E}-01$ & $9.5147 \mathrm{E}-02$ & & \\
\hline 1 & $5.2851 \mathrm{E}-02$ & $1.3883 \mathrm{E}-02$ & 5.17 & 6.85 \\
\hline 2 & $6.6079 \mathrm{E}-03$ & $1.7805 \mathrm{E}-03$ & 8.00 & 7.80 \\
\hline 3 & $8.1308 \mathrm{E}-04$ & $2.2155 \mathrm{E}-04$ & 8.13 & 8.04 \\
\hline 4 & $1.0318 \mathrm{E}-04$ & $2.7709 \mathrm{E}-05$ & 7.88 & 8.00 \\
\hline 5 & $1.2372 \mathrm{E}-05$ & $3.5840 \mathrm{E}-06$ & 8.34 & 7.73 \\
\hline 6 & $1.5859 \mathrm{E}-06$ & $4.2212 \mathrm{E}-07$ & 7.80 & 8.49 \\
\hline 7 & $1.9193 \mathrm{E}-07$ & $5.5440 \mathrm{E}-08$ & 8.26 & 7.61 \\
\hline 8 & $2.4980 \mathrm{E}-08$ & $6.9013 \mathrm{E}-09$ & 7.68 & 8.03 \\
\hline
\end{tabular}

Tabela 4.16: Erros associados ao remapeamento da malha icosaédrica para uma malha do tipo longitudelatitude com $180 \times 360$ pontos considerando a função trigonométrica (equação (4.2)). Os dados foram fornecidos nos vértices dos triângulos, e o método usado foi o local modificado de Shepard quadrático (QDSP). Os erros apresentados são os do máximo e quadrático médio (2). 


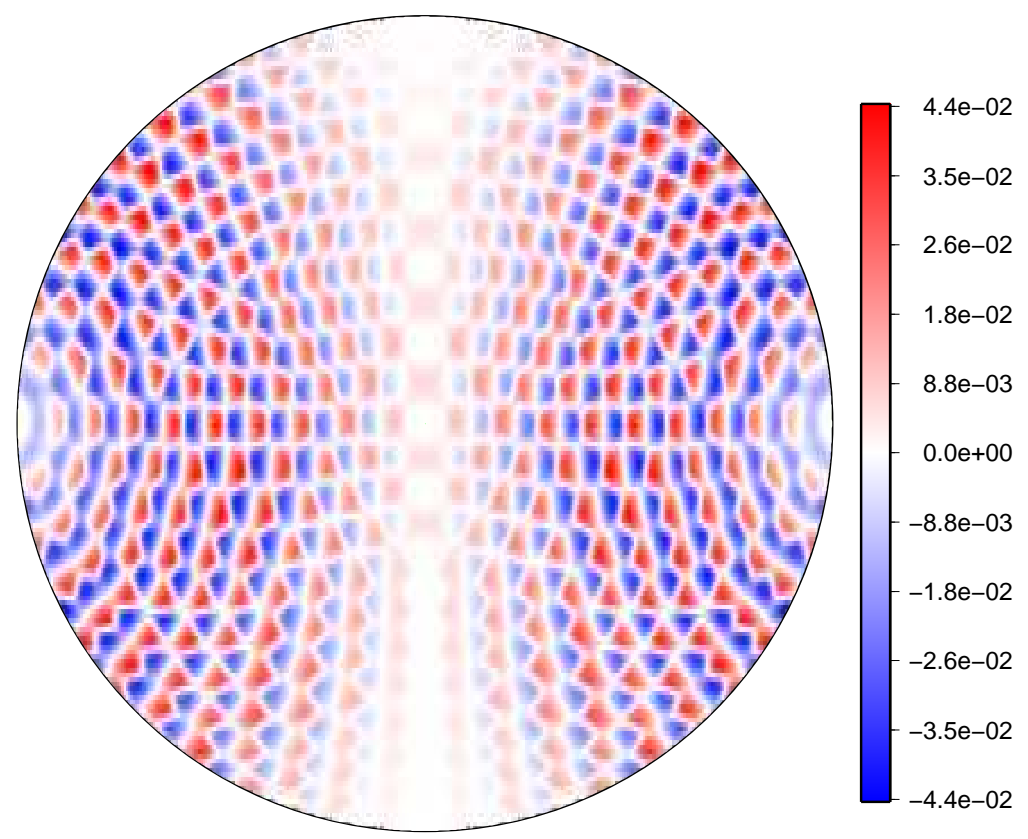

Figura 4.31: Erros associados ao remapeamento da função trigonométrica dada em (4.2) de uma malha icosaédrica de nível 3 para uma malha latitude longitude com $180 \times 360$ pontos. Os dados foram fornecidos nos vértices dos triângulos, e o método usado foi o local modificado de Shepard (LMSP).

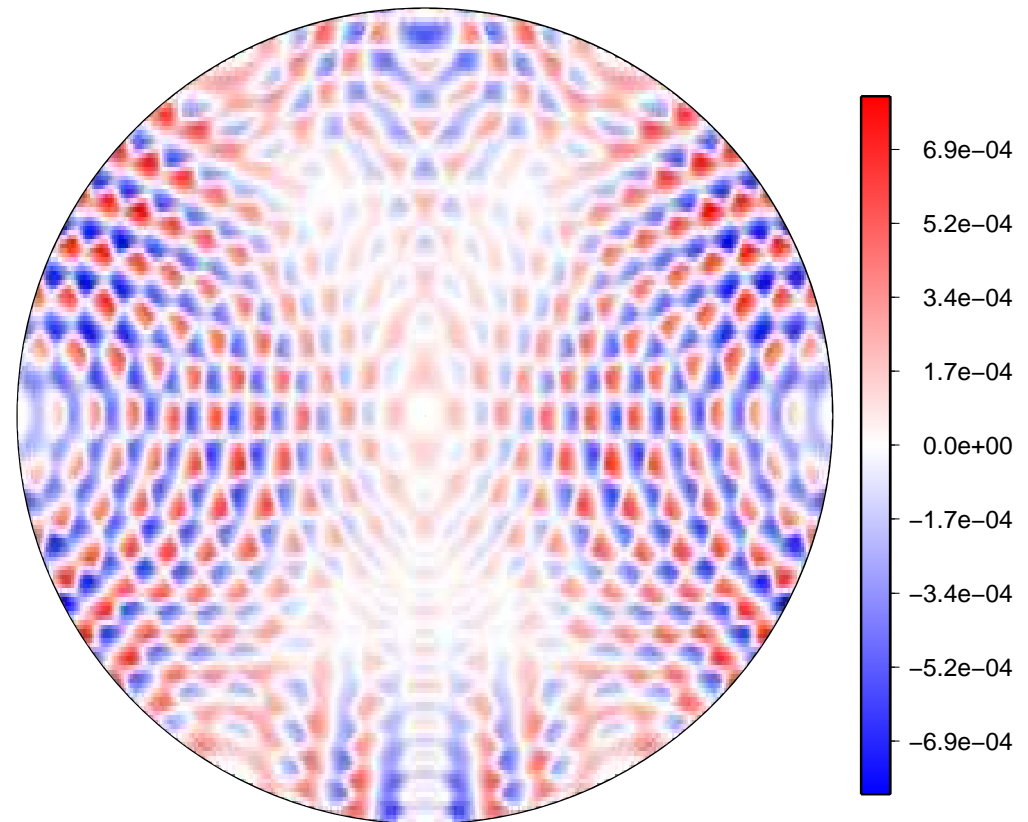

Figura 4.32: Erros associados ao remapeamento da função trigonométrica dada em (4.2) de uma malha icosaédrica de nivel 3 para uma malha latitude longitude com $180 \times 360$ pontos. Os dados foram fornecidos nos vértices dos triângulos, e o método usado foi o local modificado de Shepard quadrático (QDSP). 


\subsubsection{Comparativos}

A seguir vamos comparar os métodos descritos do ponto de vista de precisão e custo computacional. Os experimentos para medir custos computacionais foram realizados da seguinte forma. Supusemos que os valores reais são dados nos vértices dos triângulos, e vamos realizamos dois experimentos envolvendo interpolações. No primeiro interpolamos valores para os circuncentros de cada triângulo (indicamos esse experimento por TRC). No segundo fizemos um remapeamento da malha icosaédrica para uma malha regular com 1440 longitudes e 720 latitudes (indicado por RLL). Medimos os tempos de execução 15 vezes para cada experimento e cada método de interpolação e, ao final, consideramos para análises as médias dos tempos. Como todos os métodos usam o mesmo mecanismo de busca do ponto de interpolação na malha, medimos também o tempo só de busca, para servir de controle. Indicamos nas tabelas como tempo total o tempo incluindo a busca e parcial, subtraindo o tempo de busca.

Alguns métodos possuem uma etapa preliminar de cálculo com base apenas nos pontos de malha (como o cálculo do gradiente) e, por isso, quando vamos realizar um número de interpolações maior que o número de pontos da malha, o custo da etapa preliminar pode ser diluído. Para avaliarmos esse grau dessa diluição comparamos as razões entre os tempos parciais do experimento de remapeamento com o experimento de interpolações para os circuncentros.

Na Tabela 4.17 apresentamos um comparativo dos erros máximos entre alguns dos métodos de segunda de ordem. Desses métodos, aquele que possui menores erros é o de funções de base radial (RBFTR). Porém, há que se lembrar que esse método está sujeito a instabilidades numéricas em malhas mais finas. Além disso, o custo computacional desse método é muito maior que os demais métodos de segunda ordem (veja a Tabela 4.18). Há pouca diferença entre os demais métodos de segunda ordem no que diz respeito ao erro máximo. Por outro lado, como pode ser visto na Tabela 4.18, do ponto de vista de custo computacional, o método de coordenadas naturais (NATSIB) é muito mais caro que os demais métodos. Isso ocorre pois há um custo alto na inclusão de pontos em um diagrama de Voronoi. Os métodos de coordenadas baricêntricas em triângulos (CBTR) mostrou ter o melhor custo-benefício como método de segunda ordem quando os dados são fornecidos nos vértices dos triângulos. O método de Wachspress para hexágonos (WCHX), que tem precisão e custo semelhante ao método CBTR, mostrou-se o mais adequado quando os dados são fornecidos nos circuncentros dos triângulos.

\begin{tabular}{|c|c|c|c|c|}
\hline \multicolumn{5}{|c|}{ Métodos de ordem 2 } \\
\hline Nível & RBFTR & CBTR & WCHX & NATSIB \\
\hline 0 & $2.78 \mathrm{E}-1$ & $3.86 \mathrm{E}-1$ & $2.38 \mathrm{E}-1$ & $4.05 \mathrm{E}-1$ \\
\hline 1 & $1.01 \mathrm{E}-1$ & $1.21 \mathrm{E}-1$ & $1.40 \mathrm{E}-1$ & $1.23 \mathrm{E}-1$ \\
\hline 2 & $2.69 \mathrm{E}-2$ & $3.95 \mathrm{E}-2$ & $3.68 \mathrm{E}-2$ & $3.99 \mathrm{E}-2$ \\
\hline 3 & $6.80 \mathrm{E}-3$ & $1.05 \mathrm{E}-2$ & $9.41 \mathrm{E}-3$ & $1.09 \mathrm{E}-2$ \\
\hline 4 & $1.71 \mathrm{E}-3$ & $2.67 \mathrm{E}-3$ & $2.51 \mathrm{E}-3$ & $2.74 \mathrm{E}-3$ \\
\hline 5 & $4.14 \mathrm{E}-4$ & $6.31 \mathrm{E}-4$ & $5.63 \mathrm{E}-4$ & $6.53 \mathrm{E}-4$ \\
\hline 6 & $1.05 \mathrm{E}-4$ & $1.63 \mathrm{E}-4$ & $1.38 \mathrm{E}-4$ & $1.77 \mathrm{E}-4$ \\
\hline 7 & $2.61 \mathrm{E}-5$ & $3.49 \mathrm{E}-5$ & $4.16 \mathrm{E}-5$ & $3.81 \mathrm{E}-5$ \\
\hline 8 & $6.59 \mathrm{E}-6$ & $9.38 \mathrm{E}-6$ & $1.04 \mathrm{E}-5$ & $9.57 \mathrm{E}-6$ \\
\hline
\end{tabular}

Tabela 4.17: Erros na norma do máximo associados ao remapeamento da malha icosaédrica para uma malha do tipo longitude-latitude com $180 \times 360$ pontos considerando a função trigonométrica (equação (4.2)) para diversos métodos de interpolação escalar de segunda ordem. As siglas para os métodos seguem o mesmo padrão das tabelas anteriores apresentadas em cada método, e em todos os métodos os dados foram fornecidos nos vértices dos triângulos, com exceção do método de Wachspress HX (WCHX), cujos dados foram fornecidos nos circuncentros dos triângulos.

Vamos comparar agora os métodos de ordem 3. Os métodos de coordenadas naturais de Farin, apresentam um custo computacional proibitivo (veja NATFAR na Tabela 4.18). Apesar de ser possível otimizar o método que implementamos para inclusão de ponto em diagrama de Voronoi, 


\begin{tabular}{|c|c|c|c|c|c|}
\hline \multicolumn{7}{|c|}{ Tempos de execução - Dados nos vértices dos triângulos } \\
\hline \hline Método & TRC Total & TRC Parcial & RLL Total & RLL Parcial & RLL/TRC Parcial \\
\hline Só Busca & 0.139 & 0.000 & 0.732 & 0.000 & - \\
\hline Nó mais próximo & 0.144 & 0.006 & 0.770 & 0.038 & 6.8 \\
\hline CBTR (3) & 0.147 & 0.008 & 0.795 & 0.062 & 7.5 \\
\hline C1RK (3) & 0.233 & 0.094 & 1.337 & 0.605 & 6.4 \\
\hline LSQHX (3) & 0.163 & 0.024 & 0.837 & 0.105 & 4.4 \\
\hline RBFTR (2) & 0.205 & 0.066 & 1.166 & 0.433 & 6.6 \\
\hline RBFETR (4) & 0.359 & 0.220 & 1.973 & 1.240 & 5.6 \\
\hline RBFHX (3) & 0.289 & 0.150 & 1.536 & 0.804 & 5.4 \\
\hline NATSIB (2) & 1.259 & 1.120 & 8.141 & 7.409 & 6.6 \\
\hline NATFAR (3) & 1.407 & 1.268 & 9.567 & 8.835 & 7.0 \\
\hline LMSHEP (1) & 0.421 & 0.282 & 2.935 & 2.202 & 7.8 \\
\hline QDSHEP (3) & 0.452 & 0.313 & 3.050 & 2.318 & 7.4 \\
\hline
\end{tabular}

Tabela 4.18: Tempos médios de execução, em segundos, para diversos métodos de interpolações quando os valores são dados nos vértices dos triângulos (malha HA). As siglas usadas para os métodos são as mesmas usadas ao longo do capítulo, e o número entre parênteses indica a ordem do método. As colunas indicadas com TRC indicam que foram feitas interpolações dos vértices dos triângulos para os circuncentros. As colunas indicadas por RLL indicam que foi feito um remapeamento da malha icosaédrica para uma malha do tipo longitude-latitude com resolução de $1440 \times 720$. Total refere-se ao tempo incluindo a busca do triângulo ao qual pertence o ponto de interpolação e parcial indica que o tempo de busca foi subtraído. A última coluna (RLL/TRC Parcial) indica a razão entre os tempos parciais. A malha icosaédrica usada foi a de nível \%. Os tempos representam médias de 15 repetições dos experimentos.

\begin{tabular}{|c|c|c|c|c|c|}
\hline \multicolumn{7}{|c|}{ Métodos de ordem 3} \\
\hline Nível & RBF-HX & QDSP & LSQHX & C1RK & NATFAR \\
\hline 0 & $2.40 \mathrm{E}-1$ & $2.73 \mathrm{E}-1$ & $2.75 \mathrm{E}-1$ & $2.64 \mathrm{E}-1$ & $3.10 \mathrm{E}-1$ \\
\hline 1 & $4.76 \mathrm{E}-2$ & $5.29 \mathrm{E}-2$ & $7.03 \mathrm{E}-2$ & $4.39 \mathrm{E}-2$ & $4.70 \mathrm{E}-2$ \\
\hline 2 & $7.52 \mathrm{E}-3$ & $6.61 \mathrm{E}-3$ & $9.88 \mathrm{E}-3$ & $4.53 \mathrm{E}-3$ & $4.93 \mathrm{E}-3$ \\
\hline 3 & $1.02 \mathrm{E}-3$ & $8.13 \mathrm{E}-4$ & $1.22 \mathrm{E}-3$ & $6.46 \mathrm{E}-4$ & $5.44 \mathrm{E}-4$ \\
\hline 4 & $1.34 \mathrm{E}-4$ & $1.03 \mathrm{E}-4$ & $1.57 \mathrm{E}-4$ & $7.72 \mathrm{E}-5$ & $6.85 \mathrm{E}-5$ \\
\hline 5 & $1.72 \mathrm{E}-5$ & $1.24 \mathrm{E}-5$ & $1.97 \mathrm{E}-5$ & $1.09 \mathrm{E}-5$ & $9.02 \mathrm{E}-6$ \\
\hline 6 & $2.14 \mathrm{E}-6$ & $1.59 \mathrm{E}-6$ & $2.49 \mathrm{E}-6$ & $8.88 \mathrm{E}-7$ & $9.19 \mathrm{E}-7$ \\
\hline 7 & $2.72 \mathrm{E}-7$ & $1.92 \mathrm{E}-7$ & $3.04 \mathrm{E}-7$ & $1.27 \mathrm{E}-7$ & $1.20 \mathrm{E}-7$ \\
\hline 8 & $3.39 \mathrm{E}-8$ & $2.50 \mathrm{E}-8$ & $3.90 \mathrm{E}-8$ & $1.18 \mathrm{E}-8$ & $3.94 \mathrm{E}-8$ \\
\hline
\end{tabular}

Tabela 4.19: Erros na norma do máximo associados ao remapeamento da malha icosaédrica para uma malha do tipo longitude-latitude com $180 \times 360$ pontos considerando a função trigonométrica (equação (4.2)) para diversos métodos de interpolação escalar de terceira ordem. As siglas para os métodos seguem o mesmo padrão das tabelas anteriores apresentadas em cada método, e em todos os métodos os dados foram fornecidos nos vértices dos triângulos. 
parte dominante do custo para esse tipo de interpolação, acreditamos que ainda assim o método teria um custo maior que os demais métodos testados. Além disso, o método gera a pior aproximação quando observada a norma do máximo, como pode ser visto na Tabela 4.19.

O método de função de base radial de terceira ordem (RBFHX) apresenta erros comparáveis aos outros métodos e tem um custo aceitável. Nesse método a decomposição do tipo $L^{t} D L$, que depende somente dos pontos de malha, foi pré-processada. O problema do método é a dualidade entre estabilidade e precisão, que inibe seu uso em malha muito mais finas. O método que usa função radial apenas como peso, Shepard quadrático (QDSP), apresenta um custo elevado quando comparado aos método $C^{1}$ de Renka (C1RK) e de mínimos quadrados (LSQHX). Isso ocorre por não haver estêncil definido a priori e termos que realizar buscas por pontos próximos ao de interpolação a cada interpolação. A vantagem desse método em relação ao LSQHX é que temos uma função globalmente contínua, por isso possui melhores aproximações.

O método de mínimos quadrados (LSQHX) apresenta uma boa relação de custo-benefício. O seu custo é essencialmente concentrado na construção dos polinômios nos pontos de malha, uma vez que a interpolação é uma simples avaliação do polinômio. O custo da construção dos polinômios pode ficar bastante diluído quando realizamos interpolações em muito mais pontos do que os de malha. Note que ele possui a menor razão entre RLL/TRC parciais. Em contrapartida, como vimos anteriormente, o método pode gerar uma função globalmente descontínua nas arestas das células de Voronoi.

Com base nos métodos analisados, percebemos que os menores erros são os do método $C^{1}$ de Renka (C1RK) (veja a Tabela 4.19). Apesar do custo computacional desse método ser maior que o LSQHX, ele é aceitável, além disso garante boas propriedades de continuidade da função interpoladora. Esse método requer o cálculo dos gradientes nos pontos de malha, logo esperaríamos que esse custo fosse diluído ao realizarmos mais interpolações do que pontos de malha. Porém, observa-se que essa diluição é pequena, pois o custo de cômputo das interpolações de Hermite não são desprezíveis. Tanto esse método quanto o de mínimos quadrados podem ser otimizados. A matriz do sistema de mínimos quadrados $(A)$, que também é usada no cálculo dos gradientes, depende somente das posições dos pontos de malha. Portanto, a sua pseudo-inversa $\left(\left(A^{t} A\right)^{-1} A^{t}\right)$ poderia ser calculada e armazenada para uso em interpolações. Isso geraria um custo de armazenamento da ordem de $k \times 5 \times n$, sendo $n$ o número de nós da malha e $k$ o número médio de vizinhos dos nós (6 para malhas icosaédricas). Pretendemos investigar futuramente o custo-benefício dessa abordagem.

Quando os valores forem dados nos vértices dos triângulos, concluímos que o método de interpolação de coordenadas baricêntricas para triângulos (CBTR) parece ser o mais adequado como método de segunda ordem. Entre os métodos de terceira ordem, o método de $C^{1}$ de Renka (C1RK) parece ter um bom custo-benefício. Quando os valores forem dados nos circuncentros dos triângulos, ou nos pontos médios das arestas, então os métodos de Wachspress (WCHX e WCHE) são possibilidades de baixo custo para obter segunda ordem. 


\subsection{Reconstruções vetoriais}

Suponha que sejam fornecidas apenas as componentes normais, $u_{i}$, de um campo vetorial, em relação aos pontos médios das arestas de uma malha na esfera. O problema da reconstrução vetorial é encontrar um campo vetorial $\vec{u}$ que interpole, ou aproxime, o campo vetorial que define as componentes $u_{i}$. Supondo que as componentes normais sejam dadas nos pontos médios de arestas de células de Voronoi, $\vec{x}_{i}$, então o problema de interpolação é encontrar $\vec{u}$ tal que

$$
\vec{u}\left(\vec{x}_{i}\right) \cdot \vec{n}_{i}=u_{i}, \quad i=1, \ldots, n
$$

onde $\vec{n}_{i}$ é um vetor normal à aresta $i$ que é parte de um conjunto de $n$ arestas. Esse problema aparece naturalmente quando usamos malhas deslocadas, por exemplo do tipo $\mathrm{HC}$, onde conhecemos apenas as componentes normais do campo vetorial em relação às arestas de células de Voronoi. No trabalho de Wang et al. [2011] foram analisados diversos métodos de reconstruções vetoriais para malhas do tipo TC, onde são conhecidas as componentes normais das arestas dos triângulos. Nós vamos analisar diversos métodos para reconstruções vetoriais em malhas do tipo $\mathrm{HC}$ e, usando a teoria de alinhamento de células que discutida em capítulos anteriores, vamos propor uma abordagem híbrida entre os métodos.

O nosso interesse na reconstrução vetorial é também relacionado a métodos semi-lagrangianos de transporte em que, como veremos no capítulo que segue, vamos precisar reconstruir o campo de vetores para qualquer ponto da esfera. Além disso, estamos buscando preferencialmente métodos pelo menos de ordem 2. Veremos que alguns métodos de reconstrução vetorial permitem uma reconstrução direta para qualquer ponto da esfera, mas isso geralmente afetará sua ordem de precisão. Uma alternativa é dividir a reconstrução vetorial, com dados fornecidos como componentes normais de arestas, em 2 etapas: reconstrução vetorial a partir das componentes normais para ponto específicos da esfera e interpolação vetorial, usando métodos escalares, para qualquer ponto da esfera. Uma interpolação vetorial, usando os métodos de interpolações escalares para as componentes dos vetores em coordenadas cartesianas do $\mathbb{R}^{3}$, resulta em não necessariamente termos um vetor interpolado tangente à esfera. Portando, podemos precisar de uma etapa adicional de projetar o vetor no espaço tangente à esfera.

Os métodos que vamos analisar permitem reconstruções com boa precisão para os nós das células de Voronoi (vértices dos triângulos), que denominaremos por Reconstrução Vetorial para Nós (RVN), ou para os circuncentros dos triângulos (vértices das células de Voronoi), que denominaremos por Reconstrução Vetorial para Circuncentros (RVC). Para obtermos o campo vetorial em qualquer ponto da esfera podemos primeiro aplicar globalmente reconstruções do tipo RVN ou RVC e depois usar um método de coordenadas baricêntricas para obtermos a reconstrução para qualquer ponto da esfera. Isso irá garantir segunda ordem da segunda etapa do processo. Assim, uma vez realizada uma RVN, vamos usar o método de interpolação com coordenadas baricêntricas em triângulos para obtermos o campo vetorial em qualquer ponto da esfera. Quando realizarmos uma RVC, vamos usar o método de coordenadas baricêntricas generalizadas de Wachspress para obtermos o campo vetorial em qualquer ponto da esfera. Se a RVN ou RVC forem de segunda ordem, é de se esperar que tenhamos um método final de segunda ordem.

Para testar os métodos que iremos analisar usaremos o campo vetorial dado pelos ventos de uma onda de Rossby-Haurwitz estática com número de onda 4. Em coordenadas geográficas esse campo vetorial pode ser escrito como

$$
\begin{aligned}
& u=a \omega_{0} \cos (\theta)+a \omega_{m} \cos ^{m-1}(\theta)\left(m \sin ^{2}(\theta)-\cos ^{2}(\theta)\right) \cos (m \lambda) \\
& v=-a m \omega_{m} \cos ^{m-1}(\theta) \sin (\theta) \sin (m \lambda)
\end{aligned}
$$

onde $u$ e $v$ são respectivamente as componentes zonais e meridionais do campo, e os parâmetros que consideraremos foram obtidos de Williamson et al. [1992]: $m=4$, raio da terra $a=6.37122 \times 10^{6}$, $\omega_{m}=\omega_{0}=50 \mathrm{~ms}^{-1} / a=7.848 \times 10^{-6}$. Ilustramos esse campo vetorial na Figura 4.33.

As métricas de erros considerados são as mesmas de antes, mas agora relativas à norma euclidiana 


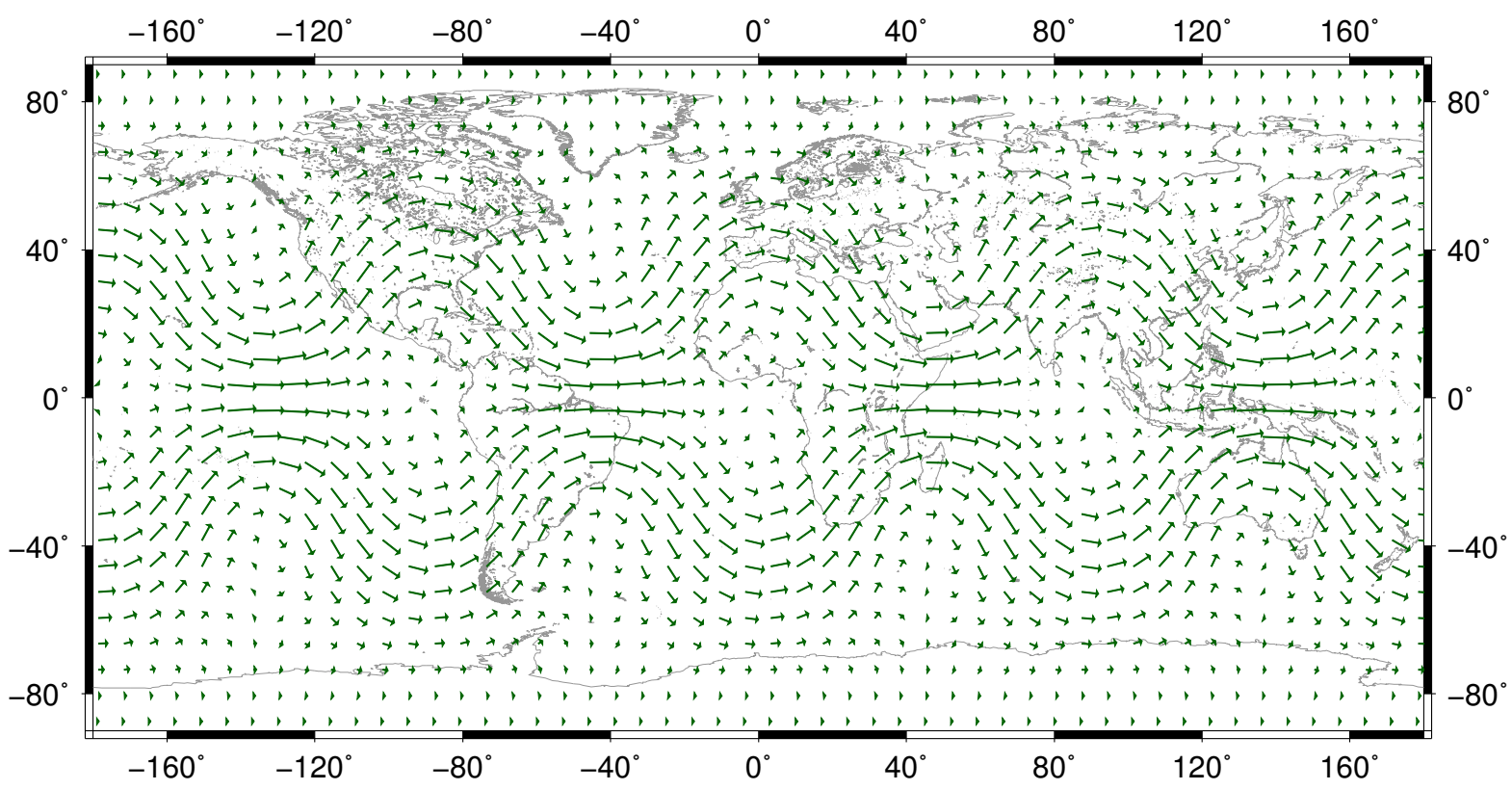

Figura 4.33: Onda de Rossby-Haurwitz de número 4.

do vetor diferença entre o estimado e o exato. Para os testes de reconstrução em qualquer ponto da esfera vamos considerar um remapeamento da malha icosaédrica para uma malha do tipo latitudelongitude de $1 \mathrm{grau}$, como feito nos testes de interpolações escalares. 


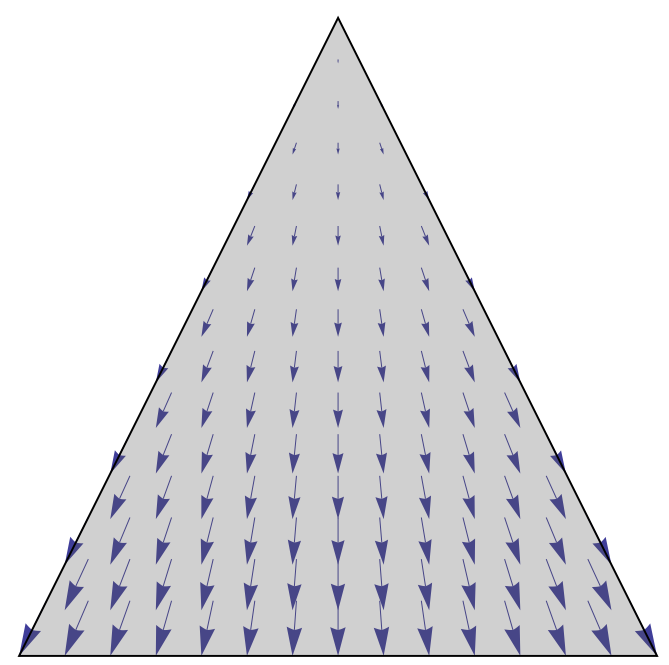

Figura 4.34: Exemplo para base vetorial triangular RTO.

\subsubsection{Bases vetoriais triangulares}

$\mathrm{Na}$ área de elementos finitos existem bases vetoriais que podem ser usadas em reconstruções vetoriais em triângulos. Veremos duas bases interessantes.

\section{Elemento de Raviart-Thomas de ordem 0}

Em Raviart e Thomas [1977] foi proposta uma base de elementos finitos que possui características muito apropriadas para reconstrução de vetores em triângulos, conhecida como elemento de Raviart-Thomas de ordem zero (RT0). A base é definida tomando como referência uma aresta do triângulo, tal que o campo vetorial seja linear, sendo que a componente normal do vetor na aresta de referência seja unitária e nas demais arestas seja nula. Considere um triângulo com vértices $\vec{c}_{i}$, $i=1,2,3$, e seja $\gamma_{i}$ a aresta oposta ao vértice $\vec{c}_{i}$. Então, com base em Walters et al. [2009], podemos definir o elemento vetorial para uma aresta $\gamma_{i}$ como sendo

$$
\vec{\psi}_{i}(\vec{x})^{r t}=\frac{l_{i}}{2 A}\left(\vec{x}-\vec{c}_{i}\right)
$$

onde $A$ é a área do triângulo e $l_{i}$ é o comprimento da aresta $\gamma_{i}$. Não é difícil ver que

$$
\vec{\psi}_{i}^{r t}\left(\vec{x}_{j}\right) \cdot \vec{n}_{j}=\delta_{i j}
$$

onde $\vec{n}_{j}$ é o vetor normal unitário à aresta $\gamma_{j}$, que aponta para fora do triângulo, $\vec{x}_{j}$ é um ponto qualquer de $\gamma_{j}$ e $\delta_{i j}=\{1$ se $i=j, 0$ se $i \neq j\}$. Ilustramos um caso particular desse tipo de base na Figura 4.34.

Sejam $u_{i}, i=1,2,3$, as componentes normais de um campo vetorial dadas nos pontos médios das arestas de um triângulo, então, dado um ponto $\vec{x}$ qualquer do triângulo, podemos reconstruir o campo vetorial nesse ponto como sendo

$$
\vec{u}^{r t}(\vec{x})=\sum_{i=1}^{3} u_{i} \vec{\psi}_{i}^{r t}(\vec{x}) .
$$

Esse tipo de base pode ser usado na reconstrução vetorial quando temos as componentes normais do campo vetorial definidas nas arestas dos triângulos. Essa abordagem é um dos casos discutidos para malha TC em Wang et al. [2011]. Para malhas HC ele não se aplica, mas veremos mais adiante como generalizar esse método para células de Voronoi. Esse método de reconstrução garante reprodução exata de campos vetoriais constantes e também de campos vetoriais lineares mas com 


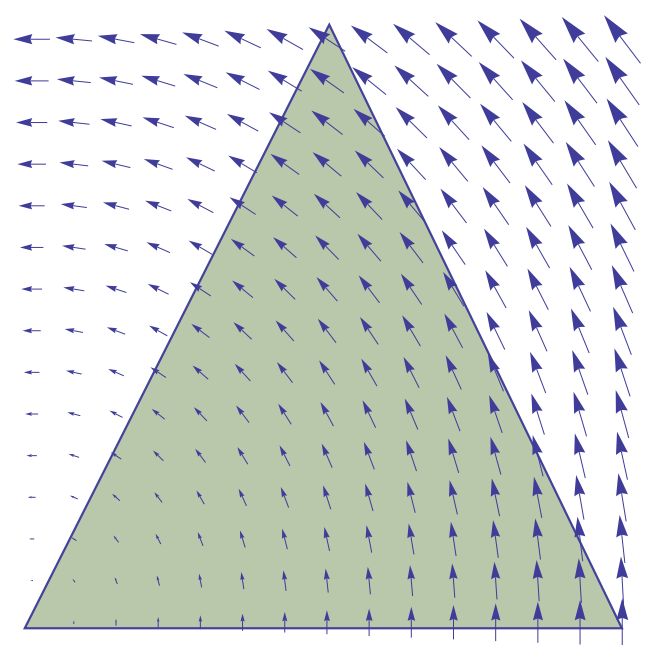

Figura 4.35: Exemplo para base vetorial triangular de Whitney

divergência nula. Porém, não garante reprodução exata de campos lineares em geral, portanto é de se esperar apenas primeira ordem de convergência. O método de Raviart-Thomas pode ser estendido para a esfera aplicando-o diretamente sobre os pontos escritos em coordenadas do $\mathbb{R}^{3}$ e depois projetando o vetor reconstruído para a esfera.

\section{Elemento de Whitney de ordem 0}

Suponha agora que conhecemos as componentes tangentes ao invés das componentes normais do campo vetorial. Portanto, agora vamos supor que $u_{i}$ é uma componente tangente à aresta $\gamma_{i}$ do triângulo. Nesse caso, é possível desenvolvermos uma base que satisfaça uma propriedade similar a de RT0, tal que o produto interno da base referente a uma aresta com o vetor tangente à aresta seja unitário na aresta que define a base e nulo nas demais. Esse elemento foi proposto originalmente por Whitney [1957]. Mais adiante foi generalizado para dimensões maiores (tetraedros) por Nedelec [1980], que acabou tendo esse tipo de elemento batizado pelo seu nome. De acordo com Solin [2005], a base pode ser expressa em coordenadas baricêntricas como

$$
\vec{\psi}_{i}^{w t}(\vec{x})=\frac{w_{i-1}(\vec{x}) \vec{n}_{i+1}}{\vec{n}_{i+1} \cdot \vec{t}_{i}}+\frac{w_{i+1}(\vec{x}) \vec{n}_{i-1}}{\vec{n}_{i-1} \cdot \vec{t}_{i}}
$$

onde $\vec{t}_{i}$ é o vetor tangente à aresta $i, w_{i}(\vec{x})$ é a coordenada baricêntrica do ponto $\vec{x}$ relativa ao vértice $i$, oposto a aresta $i$, e identificamos os vértices e arestas de forma cíclica (a aresta 4 é na verdade a aresta 1). Percebe-se facilmente que

$$
\vec{\psi}_{i}^{w t}\left(\vec{x}_{j}\right) \cdot \vec{t}_{j}=\delta_{i j}
$$

para $\vec{x}_{j}$ um ponto qualquer da aresta $j$. Note que $w_{i}\left(\vec{x}_{j}\right)=0$ se $i=j$. Ilustramos essa base na Figura 4.35. Assim como no método de Raviart-Thomas, esse método garante reprodução exata de campo vetoriais constantes, mas também de lineares com rotacional nulo. Porém não garante reprodução exata de campos lineares em geral, portanto novamente provê apenas primeira ordem de convergência.

Em uma malha icosaédrica deslocada do tipo HC, definida para células de Voronoi, conhecemos as componentes normais às arestas dos pentágonos/hexágonos. Porém, ao olharmos para a malha primal, triangular, vemos que por pouco não temos as componentes tangentes para as arestas dos triângulos. Isso ocorre pois, como os pontos médios das arestas dos triângulos não coincidem com os pontos médios das arestas das células de Voronoi, os vetores normais as células de Voronoi não coincidem com os vetores tangentes as arestas dos triângulos. Vemos esse fato na Figura 4.36, onde 


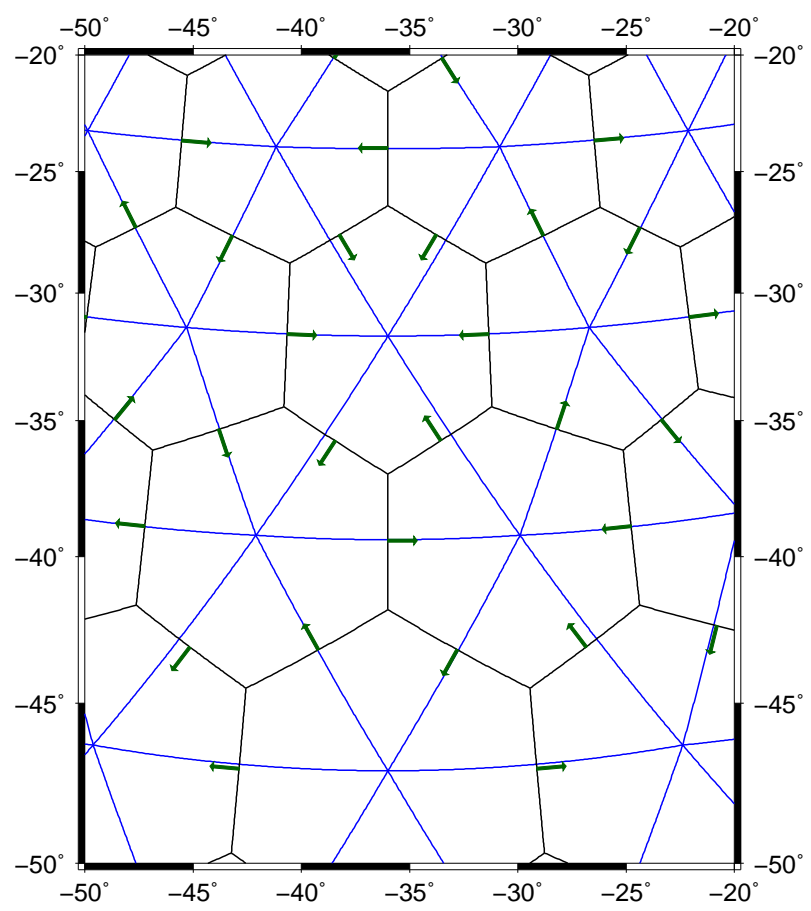

Figura 4.36: Parte de uma malha icosaédrica de nível 3 onde foram destacados os vetores normais as arestas das células de Voronoi nos seus pontos médios.

mostramos um pedaço da malha icosaédrica de nível 3 destacando os vetores normais as arestas das células de Voronoi. Por outro lado, os dados do campo vetorial de componentes normais das arestas de células de Voronoi são uma aproximação de primeira ordem para as componentes tangentes as arestas dos triângulos. Portanto, podemos usar o elemento de Whitney para fazer uma reconstrução dentro do triângulo, por exemplo para o seu circuncentro, ou baricentro. O método pode estendido para a esfera tomando as coordenadas baricêntricas para a esfera, como descritas anteriormente.

Na Tabela 4.20 mostramos os erros associados à reconstrução do campo vetorial de teste dos pontos médios das arestas das células de Voronoi (malha tipo HC) para os circuncentros dos triângulos (vértices das células de Voronoi). Fica clara a convergência de primeira ordem, como era de se esperar. Porém, temos três componentes do método que são de primeira ordem: o espaço de aproximação; o uso de ponto médio de aresta de célula de Voronoi aproximando o ponto médio de aresta de triângulo; e uma aproximação devido à escolha da posição do ponto de interpolação (no circuncentro). Na análise da distribuição do erro, mostrado na Figura 4.37, pode-se perceber uma interferência das malhas mais grossas, mas não é evidente que os erros maiores ocorrem aonde os pontos médios das arestas das malhas primal e dual distam mais (compare com a Figura 2.17). Em tese, uma reconstrução para o baricentro poderia ter erros menores, porém, não temos evidências de erros maiores concentrados em locais aonde o circuncentro dista mais do baricentro (ver Figura 2.12). Portanto o padrão de erro parece estar sendo dominado pelo espaço de aproximação da base adotada.

Ao fazermos o remapeamento para uma malha longitude-latitude, usando primeiro a reconstrução para os circuncentros dos triângulos (RVC) com o método de Whitney (WHT) e depois usando o método de Wachspress (WCHX) para obter o campo vetorial em qualquer ponto de malha, observamos que o método permanece de primeira ordem (ver Tabela 4.21), mas a distribuição do erro muda bastante (ver Figura 4.38). 


\begin{tabular}{|c|c|c|c|c|}
\hline \multicolumn{5}{|c|}{ Rec. vetorial para circuncentros - Método de Whitney } \\
\hline Nível & Erro Máx & Erro 2 & Razão Máx & Razão 2 \\
\hline 0 & $6.2016 \mathrm{E}+01$ & $6.2526 \mathrm{E}+01$ & & \\
\hline 1 & $3.2823 \mathrm{E}+01$ & $2.7529 \mathrm{E}+01$ & 1.89 & 2.27 \\
\hline 2 & $2.0049 \mathrm{E}+01$ & $1.3714 \mathrm{E}+01$ & 1.64 & 2.01 \\
\hline 3 & $1.0399 \mathrm{E}+01$ & $6.8480 \mathrm{E}+00$ & 1.93 & 2.00 \\
\hline 4 & $5.3044 \mathrm{E}+00$ & $3.4273 \mathrm{E}+00$ & 1.96 & 2.00 \\
\hline 5 & $2.6829 \mathrm{E}+00$ & $1.7153 \mathrm{E}+00$ & 1.98 & 2.00 \\
\hline 6 & $1.3529 \mathrm{E}+00$ & $8.5813 \mathrm{E}-01$ & 1.98 & 2.00 \\
\hline 7 & $6.8080 \mathrm{E}-01$ & $4.2920 \mathrm{E}-01$ & 1.99 & 2.00 \\
\hline 8 & $3.4142 \mathrm{E}-01$ & $2.1464 \mathrm{E}-01$ & 1.99 & 2.00 \\
\hline
\end{tabular}

Tabela 4.20: Erros associados à reconstrução vetorial (RVC) da onda de Rossby-Haurwitz de uma malha HC para os circuncentros dos triângulos usando o método de Whitney (WHT).

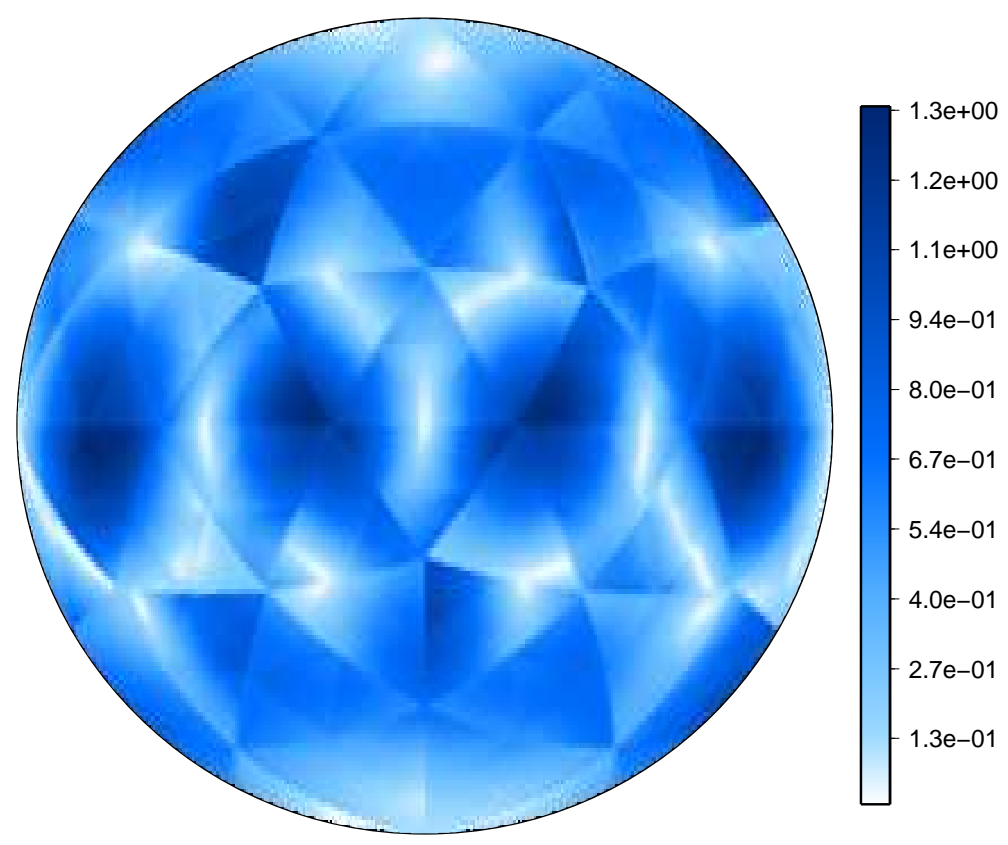

Figura 4.37: Distribuição do erro para a reconstrução vetorial (RVC) da onda de Rossby-Haurwitz de uma malha icosaédrica de nível 6 do tipo HC para os circuncentros dos triângulos usando o método de Whitney (WHT).

\begin{tabular}{|c|c|c|c|c|}
\hline \multicolumn{5}{|c|}{ Remap lon-lat - Método de Whitney / Wachspress } \\
\hline Nível & Erro Máx & Erro 2 & Razão Máx & Razão 2 \\
\hline 0 & $8.7052 \mathrm{E}+01$ & $3.8076 \mathrm{E}+01$ & & \\
\hline 1 & $5.2718 \mathrm{E}+01$ & $2.0654 \mathrm{E}+01$ & 1.65 & 1.84 \\
\hline 2 & $1.8255 \mathrm{E}+01$ & $7.0881 \mathrm{E}+00$ & 2.89 & 2.91 \\
\hline 3 & $8.8739 \mathrm{E}+00$ & $2.1894 \mathrm{E}+00$ & 2.06 & 3.24 \\
\hline 4 & $4.2595 \mathrm{E}+00$ & $7.7301 \mathrm{E}-01$ & 2.08 & 2.83 \\
\hline 5 & $2.0939 \mathrm{E}+00$ & $3.2321 \mathrm{E}-01$ & 2.03 & 2.39 \\
\hline 6 & $1.1307 \mathrm{E}+00$ & $1.5426 \mathrm{E}-01$ & 1.85 & 2.10 \\
\hline 7 & $5.7951 \mathrm{E}-01$ & $7.3138 \mathrm{E}-02$ & 1.95 & 2.11 \\
\hline 8 & $2.4119 \mathrm{E}-01$ & $3.6148 \mathrm{E}-02$ & 2.40 & 2.02 \\
\hline
\end{tabular}

Tabela 4.21: Erros associados à reconstrução vetorial da onda de Rossby-Haurwitz de uma malha HC para pontos de uma malha do tipo longitude latitude com 1 grau usando primeiro uma RVC com o método de Whitney (WHT) e depois o método de interpolação com coordenadas de Wachspress (WCHX). 


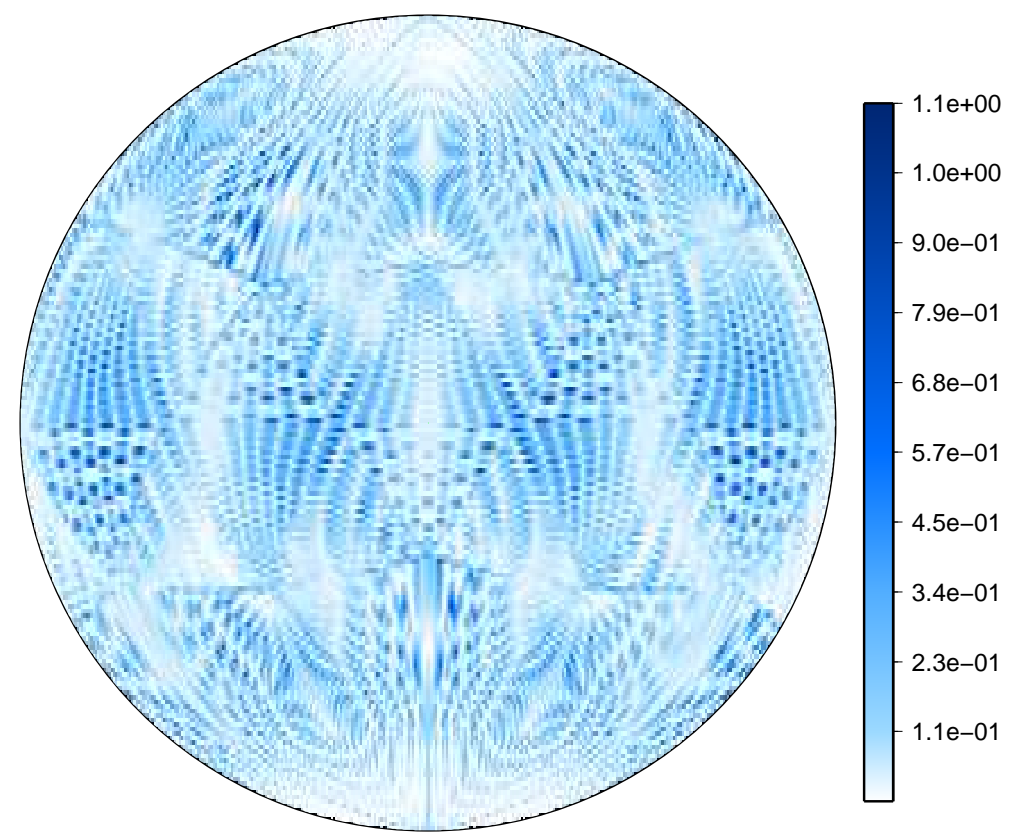

Figura 4.38: Distribuição do erro para a reconstrução vetorial da onda de Rossby-Haurwitz de uma malha icosaédrica $H C$ de nivel 6 para pontos de uma malha do tipo longitude latitude com 1 grau usando primeiro uma RVC com o método de Whitney (WHT) e depois o método de interpolação com coordenadas de Wachspress (WCHX). 


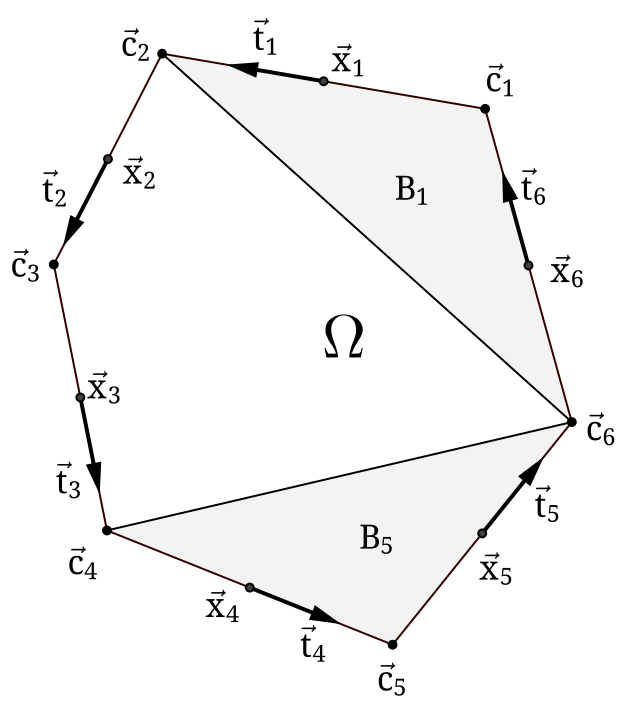

Figura 4.39: Notação para a reconstrução de base baseada em arestas (EBB).

\subsubsection{Bases vetoriais em coordenadas baricêntricas generalizadas}

O método que vamos analisar a seguir é uma forma direta de usar as coordenadas baricêntricas generalizadas em reconstruções vetoriais e também uma generalização para polígonos do método de reconstrução usando a base de Raviart-Thomas. O método foi proposto recentemente em Klausen et al. [2012] e usa uma base de funções definidas com base em arestas (Edge-based basis - EBB). Dada uma aresta $\gamma_{i}$ de um polígono plano $\Omega$, definimos a base vetorial de arestas como a função vetorial em relação ao um ponto $\vec{x}$ dada por

$$
\vec{\psi}_{i}^{e b}(\vec{x})=\frac{\vec{t}_{i-1}}{2 B_{i}} w_{i}(\vec{x})-\frac{\vec{t}_{i+1}}{2 B_{i+1}} w_{i+1}(\vec{x})
$$

onde $\vec{t}_{j}$ é o vetor unitário tangente à aresta $j$ no sentido anti-horário (ver Figura 4.39), $w_{j}$ é a coordenada baricêntrica generalizada relativa ao vértice $j$, e $B_{j}$ é a área do triângulo formado pelos vértices $\left\{\vec{c}_{j-1}, \vec{c}_{j}, \vec{c}_{j+1}\right\}$, como representado na Figura 4.6. Mostramos na Figura 4.40 um exemplo de base de arestas para um hexágono regular. Se o polígono for um triângulo, então é simples ver que a base é equivalente ao elemento de ordem 0 de Raviart-Thomas, e ainda satisfaz a propriedade

$$
\vec{\psi}_{i}^{e b}\left(\vec{x}_{j}\right) \cdot \vec{n}_{j}=\delta_{i j} .
$$

Dadas as componentes normais às arestas do polígono $\left(u_{i}\right)$ de um campo vetorial, a reconstrução pode ser obtida como

$$
\vec{u}^{e b}(\vec{x})=\sum_{i=1}^{n} u_{i} \vec{\psi}_{i}^{e b}(\vec{x})
$$

que irá reproduzir exatamente campos vetoriais constantes (veja Klausen et al. [2012] para mais detalhes).

Assim como no caso do método de Whitney, para estendermos esse método para a esfera basta tomarmos as coordenadas baricêntricas generalizadas na esfera, conforme descrito anteriormente, e usar as áreas $B_{i}$ como sendo geodésicas.

Mostramos na Tabela 4.22 os erros associados à reconstrução de malhas icosaédricas HC para os vértices dos triângulos (nós das células de Voronoi). Percebe-se que o método é de primeira ordem, mas com decaimento um pouco acima de 2 na norma quadrática média. Ao olharmos a distribuição do erro, na Figura 4.41, percebemos que as células com maiores erros são células desalinhadas (compare com a Figura 3.13). Isso indica que possivelmente em células alinhadas há uma maior 


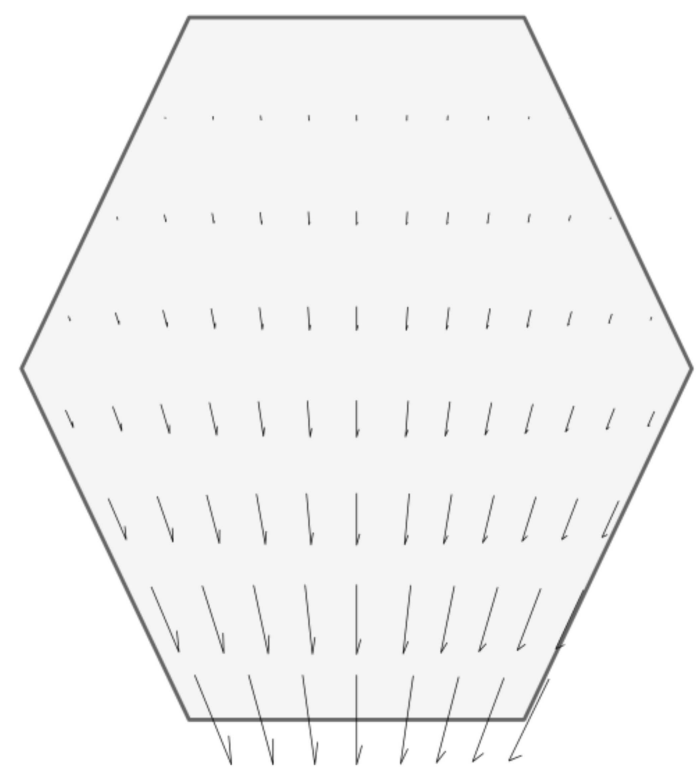

Figura 4.40: Exemplo de base de arestas para um hexágono regular.

precisão do método. Veremos mais adiante detalhes disso quando considerarmos métodos híbridos, aonde iremos usar métodos distintos para células alinhadas e não alinhadas. O mesmo ocorre com o remapeamento para malha do tipo longitude-latitude, onde um padrão de malha é visível (veja a Figura 4.42), mas agora o erro na norma quadrática parece ter uma ordem um pouco mais próxima de 2, conforme indicado na Tabela 4.23.

\begin{tabular}{|c|c|c|c|c|}
\hline \multicolumn{5}{|c|}{ Rec. vetorial para nós - Método EBB } \\
\hline Nível & Erro Máx & Erro 2 & Razão Máx & Razão 2 \\
\hline 0 & $3.46 \mathrm{E}+01$ & $2.64 \mathrm{E}+01$ & & \\
\hline 1 & $1.77 \mathrm{E}+01$ & $1.03 \mathrm{E}+01$ & 1.95 & 2.56 \\
\hline 2 & $5.10 \mathrm{E}+00$ & $2.90 \mathrm{E}+00$ & 3.47 & 3.57 \\
\hline 3 & $1.77 \mathrm{E}+00$ & $8.13 \mathrm{E}-01$ & 2.88 & 3.56 \\
\hline 4 & $6.88 \mathrm{E}-01$ & $2.36 \mathrm{E}-01$ & 2.58 & 3.44 \\
\hline 5 & $2.97 \mathrm{E}-01$ & $7.25 \mathrm{E}-02$ & 2.31 & 3.26 \\
\hline 6 & $1.42 \mathrm{E}-01$ & $2.34 \mathrm{E}-02$ & 2.09 & 3.10 \\
\hline 7 & $7.50 \mathrm{E}-02$ & $7.83 \mathrm{E}-03$ & 1.90 & 2.98 \\
\hline 8 & $3.84 \mathrm{E}-02$ & $2.69 \mathrm{E}-03$ & 1.95 & 2.91 \\
\hline
\end{tabular}

Tabela 4.22: Erros associados à reconstrução vetorial (RVN) da onda de Rossby-Haurwitz de uma malha HC para os vértices dos triângulos usando o método de Klausen et al. [2012] (EBB). 


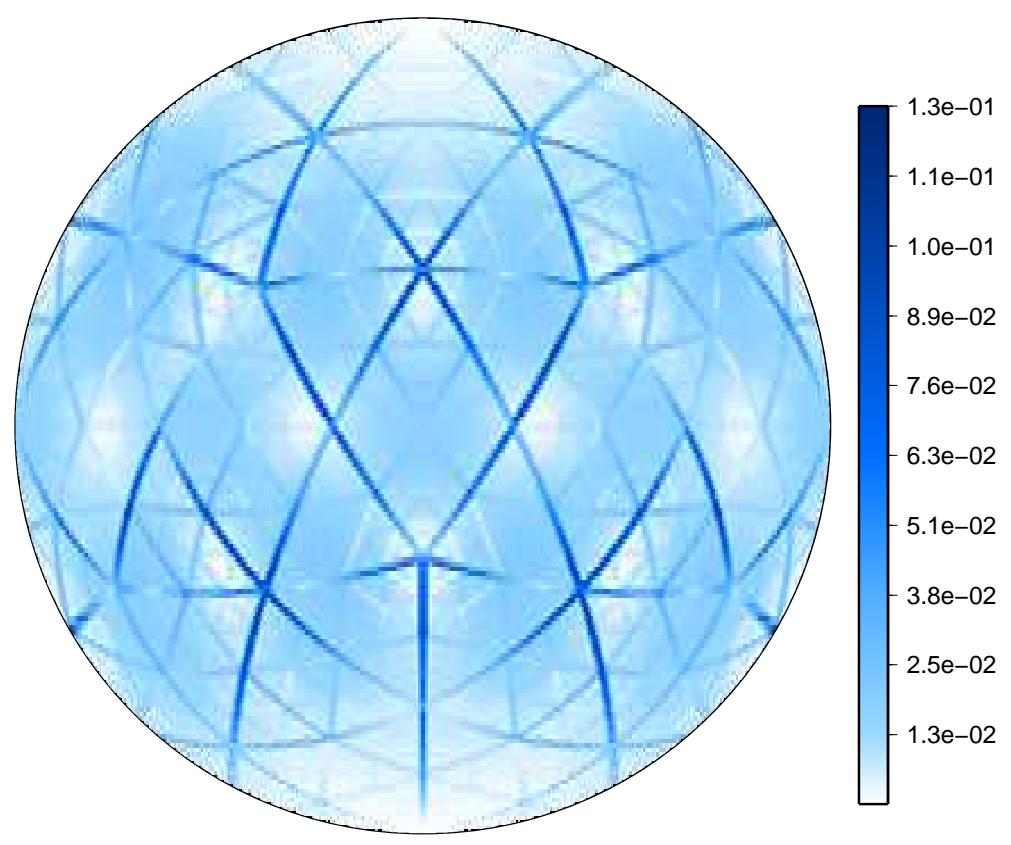

Figura 4.41: Distribuição do erro para a reconstrução vetorial da onda de Rossby-Haurwitz de uma malha icosaédrica de nível 6 do tipo HC para os vértices dos triângulos usando o método de Klausen et al. [2012] $(E B B)$.

\begin{tabular}{|c|c|c|c|c|}
\hline \multicolumn{5}{|c|}{ Remap lon-lat - Método EBB / CBTR } \\
\hline Nível & Erro Máx & Erro 2 & Razão Máx & Razão 2 \\
\hline 0 & $8.65 \mathrm{E}+01$ & $3.80 \mathrm{E}+01$ & & \\
\hline 1 & $4.97 \mathrm{E}+01$ & $2.21 \mathrm{E}+01$ & 1.74 & 1.72 \\
\hline 2 & $1.72 \mathrm{E}+01$ & $7.58 \mathrm{E}+00$ & 2.90 & 2.92 \\
\hline 3 & $5.10 \mathrm{E}+00$ & $2.07 \mathrm{E}+00$ & 3.36 & 3.65 \\
\hline 4 & $1.37 \mathrm{E}+00$ & $5.37 \mathrm{E}-01$ & 3.73 & 3.86 \\
\hline 5 & $3.87 \mathrm{E}-01$ & $1.39 \mathrm{E}-01$ & 3.53 & 3.88 \\
\hline 6 & $1.50 \mathrm{E}-01$ & $3.65 \mathrm{E}-02$ & 2.58 & 3.80 \\
\hline 7 & $6.50 \mathrm{E}-02$ & $9.65 \mathrm{E}-03$ & 2.30 & 3.78 \\
\hline 8 & $2.97 \mathrm{E}-02$ & $2.73 \mathrm{E}-03$ & 2.19 & 3.54 \\
\hline
\end{tabular}

Tabela 4.23: Erros associados à reconstrução vetorial da onda de Rossby-Haurwitz de uma malha HC para pontos de uma malha do tipo longitude latitude com 1 grau usando primeiro uma RVN com o método de Klausen et al. [2012] (EBB) e depois o método de interpolação com coordenadas baricêntricas para triângulos (CBTR). 


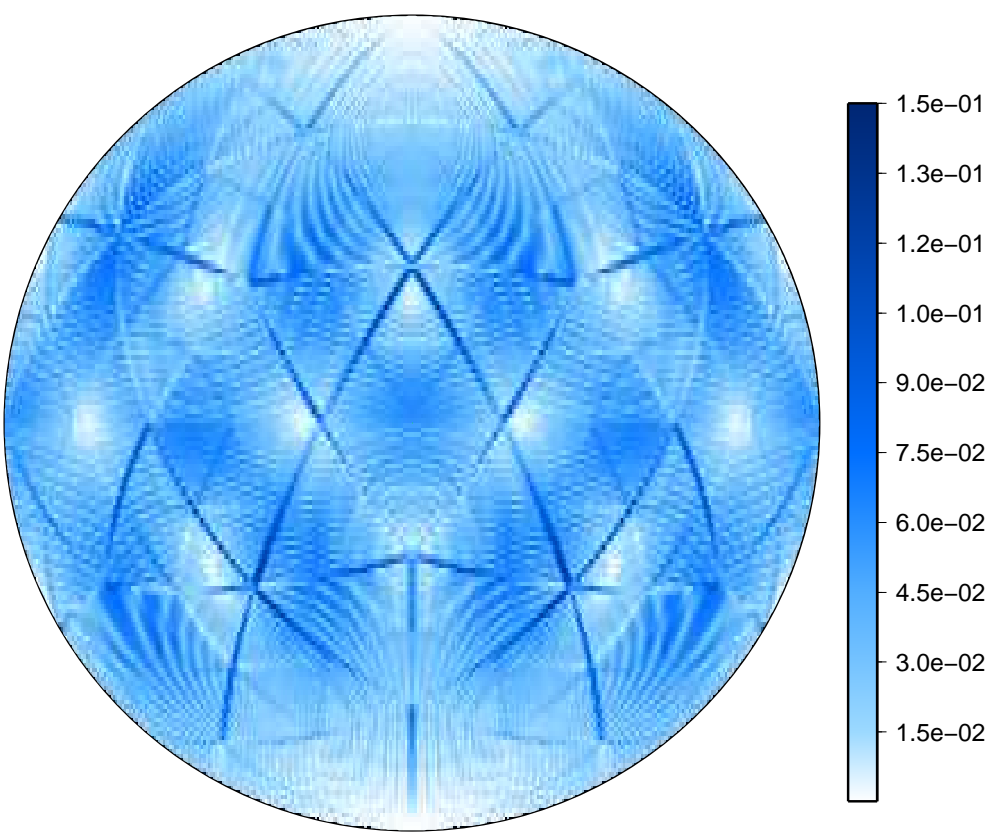

Figura 4.42: Distribuição do erro para a reconstrução vetorial da onda de Rossby-Haurwitz de uma malha icosaédrica $H C$ de nível 6 para pontos de uma malha do tipo longitude latitude com 1 grau usando primeiro uma RVN com o método de Klausen et al. [2012] (EBB) e depois o método de interpolação com coordenadas baricêntricas para triângulos (CBTR). 


\subsubsection{Método de Perot}

Em Perot [2000] foram propostos alguns métodos de reconstruções vetoriais que preservam, ou mimetizam, algumas propriedades de certos operadores diferenciais como o divergente ou o rotacional. Vamos descrever dois destes métodos: o primeiro para reconstrução vetorial quando conhecemos as componentes normais relativas às arestas de um polígono de um campo vetorial e, o segundo, quando conhecemos as componentes tangentes.

\section{Reconstrução a partir de componentes normais}

Seja $\Omega$ um polígono plano com $n$ lados, e considere um campo vetorial da forma $\vec{v}=(\vec{a} \cdot \vec{r}) \vec{u}$, onde $\vec{a}$ é um vetor constante arbitrário, $\vec{r}=\vec{x}-\overrightarrow{x_{0}}$, com $\vec{x}_{0}$ sendo o centro de massa, ou um outro ponto qualquer no interior do polígono $\Omega$, e $\vec{u}$ um campo vetorial, então temos, pelo Teorema da Divergência, que

$$
\begin{aligned}
\int_{\Omega} \operatorname{div}(\vec{v}) d A & =\int_{\partial \Omega} \vec{v} \cdot \vec{n} d l \\
\int_{\Omega} \operatorname{div}((\vec{a} \cdot \vec{r}) \vec{u}) d A & =\sum_{i=1}^{n} \int_{\gamma_{i}} \vec{v} \cdot \vec{n}_{i} d l \\
& \Longleftrightarrow \vec{a} \cdot\left(\sum_{i=1}^{n} \int_{\gamma_{i}} \vec{r}\left(\vec{u} \cdot \vec{n}_{i}\right) d l\right)
\end{aligned}
$$

onde $\gamma_{i}$ é a $i$-ésima aresta de $\Omega$ e $\vec{n}_{i}$ o seu vetor normal que aponta para fora do polígono. Agora suponha $\vec{u}=\vec{u}_{0}$, com $\vec{u}_{0}$ um vetor constante, então $\operatorname{div}(\vec{u})=0$ e temos que,

$$
\vec{u}_{0}=\frac{1}{|\Omega|} \sum_{i=1}^{n} \vec{r}_{i} u_{i} l_{i},
$$

onde $u_{i}=\vec{u}\left(\vec{x}_{i}\right) \cdot \vec{n}_{i}, \vec{r}_{i}=\vec{x}_{i}-\vec{x}_{0}$, com $\vec{x}_{i}$ o ponto médio da aresta $\gamma_{i}$ e $l_{i}$ o seu o comprimento. Representamos as notações usadas para um hexágono na Figura 4.43. Essa última equação define um método de reconstrução vetorial de primeira ordem para o ponto $\vec{x}_{0}$, quando conhecidas as componentes normais $\left(u_{i}\right)$ em relação às arestas do polígono de um campo vetorial.

Para estendermos o método para a esfera assumimos que $\Omega$ é um polígono esférico, com área geodésica $|\Omega|$ e o comprimento da aresta geodésica $\gamma_{i}$ dado por $l_{i}$. As definições de $u_{i}$ e $\vec{r}_{i}$ podem ser mantidas, assumindo que estamos usando coordenadas cartesianas em $\mathbb{R}^{3}$. $\vec{x}_{0}$ deve ser um ponto da esfera contido em $\Omega$. Como a combinação linear dos $\vec{r}_{i}$ não irá necessariamente gerar um vetor tangente à esfera, pode ser necessário projetá-lo no plano tangente à esfera em $\vec{x}_{0}$.

Testamos esse método para uma malha icosaédrica HC, reconstruindo o campo nos vértices dos triângulos (nós das células de Voronoi). A distribuição do erro associado à reconstrução, apresentada na Figura 4.44, possui uma forte correlação com a distribuição do índice de alinhamento (veja a Figura 3.13), assim como ocorreu com o método de Klausen et al. [2012] visto anteriormente. Na Tabela 4.24 mostramos os erros para diversas malhas, que indicam convergência de primeira ordem na norma do máximo e um pouco acima na norma quadrática, indicando que convergência pode variar entre as células de diferentes formatos.

Usando os mesmos argumentos contidos no capítulo de análise de interferência de malha (capítulo 3), podemos verificar que o método de Perot será de segunda ordem se o polígono for alinhado e o ponto de reconstrução for o centro de massa. Isso se deve ao fato de que o método foi construído com base no Teorema da Divergência. Usaremos esse fato mais adiante na construção de um método híbrido que usa o alinhamento das células como critério para definir o método a ser usado na célula.

$\mathrm{Na}$ análise de remapeamento para malha de longitude-latitude o padrão de interferência de malha persiste (veja a Figura 4.45) e, assim como ocorreu no método EBB, a ordem de convergência na 


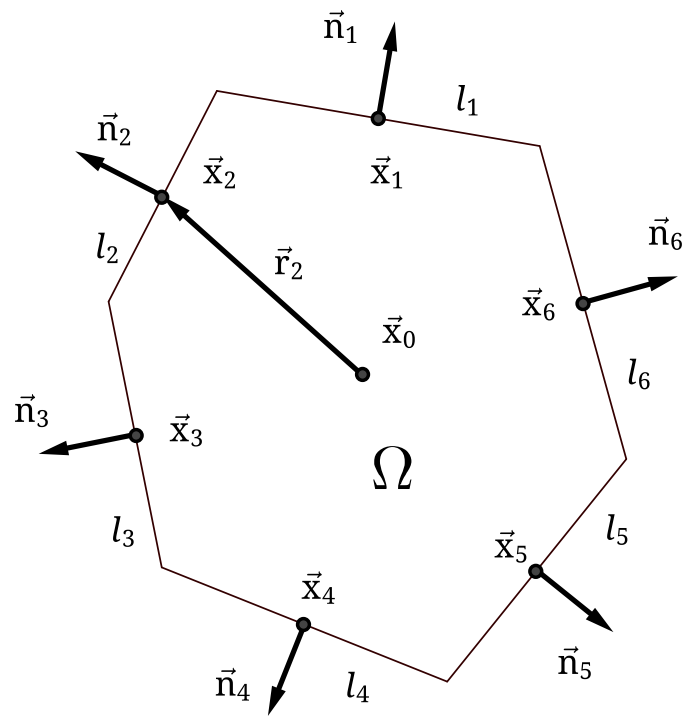

Figura 4.43: Notações para o método de Perot.

norma quadrática aumentou ligeiramente, se aproximando de dois (veja a Tabela 4.25). Isso é um indício de que há diferenças nas ordens de convergência entre as diferentes células computacionais.

\begin{tabular}{|c|c|c|c|c|}
\hline \multicolumn{5}{|c|}{ Rec. vetorial para nós - Método PERHX } \\
\hline Nível & Erro Máx & Erro 2 & Razão Máx & Razão 2 \\
\hline 0 & $3.7315 \mathrm{E}+01$ & $2.7559 \mathrm{E}+01$ & & \\
\hline 1 & $1.8988 \mathrm{E}+01$ & $1.0848 \mathrm{E}+01$ & 1.97 & 2.54 \\
\hline 2 & $5.2904 \mathrm{E}+00$ & $3.2095 \mathrm{E}+00$ & 3.59 & 3.38 \\
\hline 3 & $2.0956 \mathrm{E}+00$ & $9.2269 \mathrm{E}-01$ & 2.52 & 3.48 \\
\hline 4 & $8.5829 \mathrm{E}-01$ & $2.7405 \mathrm{E}-01$ & 2.44 & 3.37 \\
\hline 5 & $3.8394 \mathrm{E}-01$ & $8.5665 \mathrm{E}-02$ & 2.24 & 3.20 \\
\hline 6 & $1.8263 \mathrm{E}-01$ & $2.8053 \mathrm{E}-02$ & 2.10 & 3.05 \\
\hline 7 & $9.3421 \mathrm{E}-02$ & $9.4955 \mathrm{E}-03$ & 1.95 & 2.95 \\
\hline 8 & $4.7176 \mathrm{E}-02$ & $3.2796 \mathrm{E}-03$ & 1.98 & 2.90 \\
\hline
\end{tabular}

Tabela 4.24: Erros associados à reconstrução vetorial da onda de Rossby-Haurwitz de uma malha HC para os vértices dos triângulos (nós das células de Voronoi) usando o método de Perot (PERHX). 


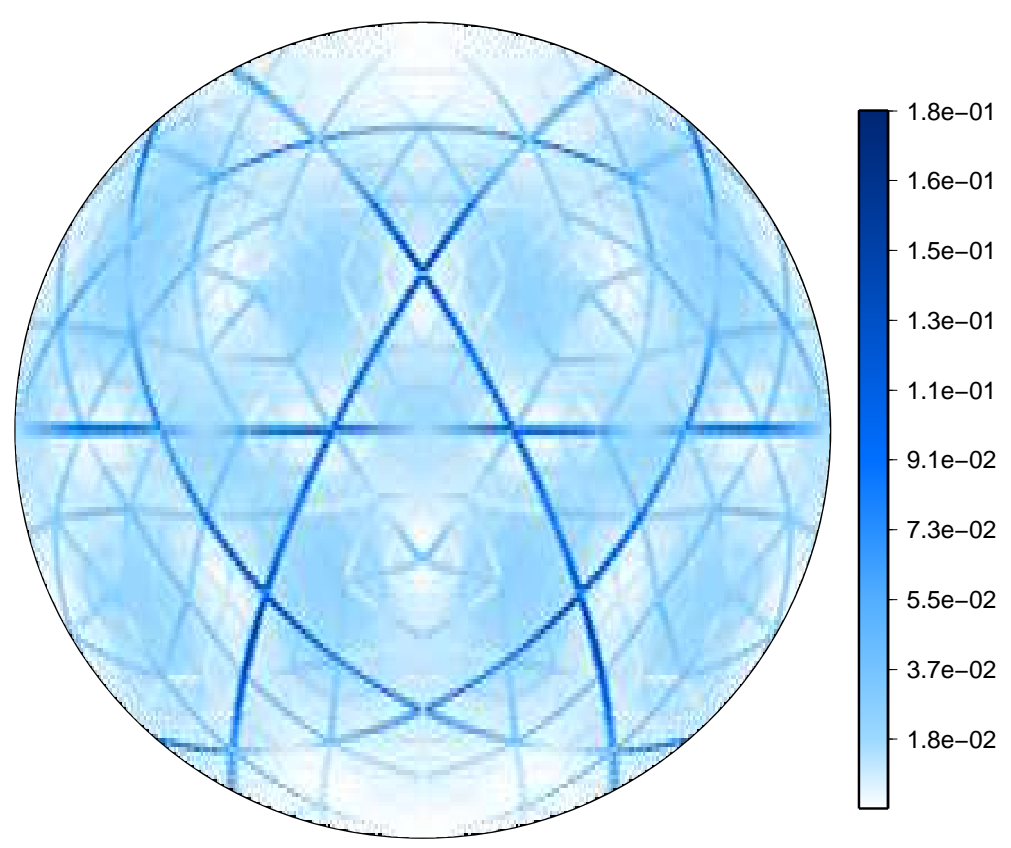

Figura 4.44: Distribuição do erro para a reconstrução vetorial da onda de Rossby-Haurwitz de uma malha icosaédrica de nível 6 do tipo HC para os vértices dos triângulos usando o método de Perot (PERHX).

\begin{tabular}{|c|c|c|c|c|}
\hline \multicolumn{5}{|c|}{ Remap lon-lat - Método PERHX / CBTR } \\
\hline Nível & Erro Máx & Erro 2 & Razão Máx & Razão 2 \\
\hline 0 & $8.4847 \mathrm{E}+01$ & $3.7637 \mathrm{E}+01$ & & \\
\hline 1 & $5.0219 \mathrm{E}+01$ & $2.2367 \mathrm{E}+01$ & 1.69 & 1.68 \\
\hline 2 & $1.7341 \mathrm{E}+01$ & $7.7709 \mathrm{E}+00$ & 2.90 & 2.88 \\
\hline 3 & $5.1144 \mathrm{E}+00$ & $2.1389 \mathrm{E}+00$ & 3.39 & 3.63 \\
\hline 4 & $1.4111 \mathrm{E}+00$ & $5.5812 \mathrm{E}-01$ & 3.62 & 3.83 \\
\hline 5 & $4.7464 \mathrm{E}-01$ & $1.4558 \mathrm{E}-01$ & 2.97 & 3.83 \\
\hline 6 & $1.8639 \mathrm{E}-01$ & $3.8828 \mathrm{E}-02$ & 2.55 & 3.75 \\
\hline 7 & $8.5582 \mathrm{E}-02$ & $1.0466 \mathrm{E}-02$ & 2.18 & 3.71 \\
\hline 8 & $3.8061 \mathrm{E}-02$ & $3.0452 \mathrm{E}-03$ & 2.25 & 3.44 \\
\hline
\end{tabular}

Tabela 4.25: Erros associados à reconstrução vetorial da onda de Rossby-Haurwitz de uma malha HC para pontos de uma malha do tipo longitude latitude com 1 grau usando primeiro uma RVN com o método de Perot usando componentes normais (PERHX) e depois o método de interpolação com coordenadas baricêntricas para triângulos (CBTR). 


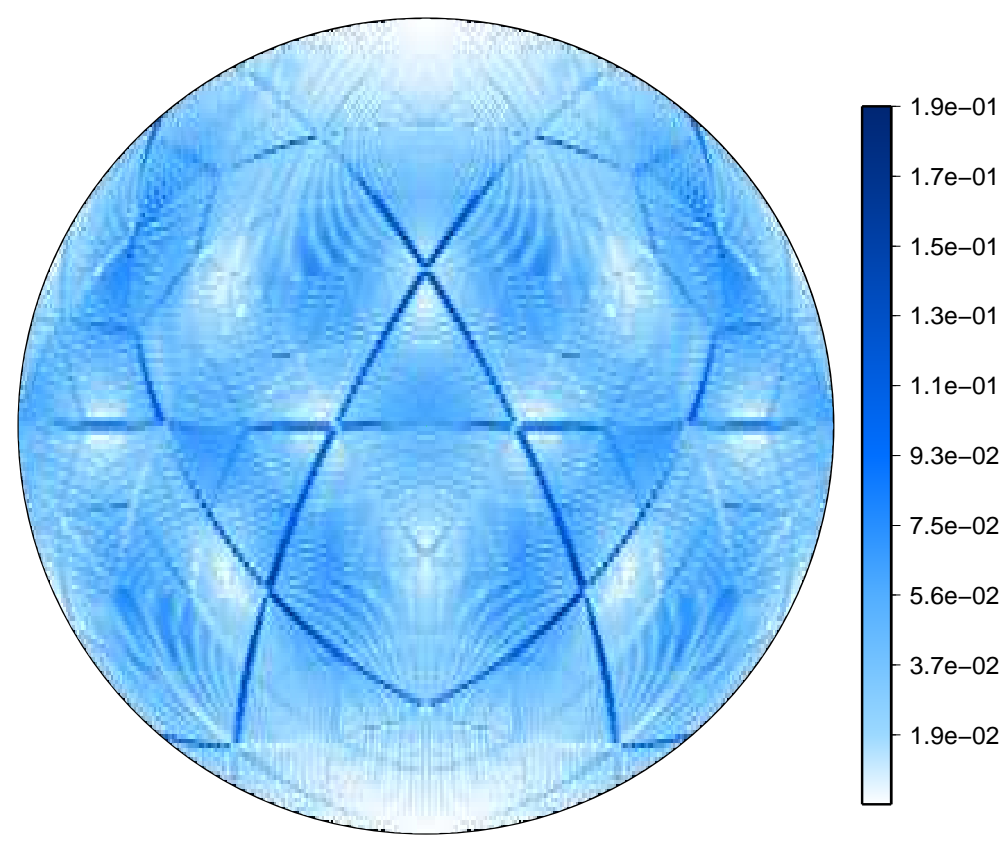

Figura 4.45: Distribuição do erro para a reconstrução vetorial da onda de Rossby-Haurwitz de uma malha icosaédrica $H C$ de nivel 6 para pontos de uma malha do tipo longitude latitude com 1 grau usando primeiro uma RVN com o método de Perot usando componentes normais (PERHX) e depois o método de interpolação com coordenadas baricêntricas para triângulos (CBTR). 


\section{Reconstrução a partir de componentes tangentes}

Perot também propôs um método de reconstrução quando são conhecidas as componentes tangentes às arestas do campo vetorial, mas agora usando resultados do Teorema da Divergência para o rotacional. Considere $\vec{v}=\left(\vec{a} \cdot \vec{r}^{t}\right) \vec{u}$, onde $\vec{r}^{t}=\vec{k} \times \vec{r}$, com $\vec{k}$ sendo um vetor unitário perpendicular ao plano do polígono e os demais elementos como anteriormente. Vamos supor que $u_{i}$ sejam as componentes tangentes às arestas do polígono $\Omega$ em relação ao campo vetorial $\vec{u}$, isto é $u_{i}=\vec{u}\left(\vec{x}_{i}\right) \cdot \vec{t}_{i}$, para $\overrightarrow{t_{i}}$ o vetor tangente à aresta $\gamma_{i}$ no sentido anti-horário (como indicado na Figura 4.39). Usando o Teorema da Divergência para o rotacional temos que

$$
\begin{aligned}
\int_{\Omega}(\nabla \times \vec{v}) \cdot \vec{k} d A & =\int_{\partial \Omega} \vec{v} \cdot \vec{t} d l \\
\int_{\Omega}\left(\nabla \times\left(\left(\vec{a} \cdot \vec{r}^{t}\right) \vec{u}\right)\right) \cdot \vec{k} d A & =\sum_{i=1}^{n} \int_{\gamma_{i}}\left(\left(\vec{a} \cdot \vec{r}^{t}\right) \vec{u}\right) \cdot \vec{t}_{i} d l \\
& \Longleftrightarrow \sum_{i=1}^{n} \int_{\gamma_{i}}((\vec{a} \cdot(\vec{k} \times \vec{r})) \vec{u}) \cdot \vec{t}_{i} d l \\
\int_{\Omega}\left(\left(\vec{a} \cdot \vec{r}^{t}\right)(\nabla \times \vec{u})+\nabla\left(\vec{a} \cdot \vec{r}^{t}\right) \times \vec{u}\right) \cdot \vec{k} d A & \Longleftrightarrow \sum_{i=1}^{n} \int_{\gamma_{i}}((\vec{a} \cdot(\vec{k} \times \vec{r})) \vec{u}) \cdot \vec{t}_{i} d l \\
\int_{\Omega}\left(\left(\vec{a} \cdot \vec{r}^{t}\right)(\nabla \times \vec{u})+(\vec{a} \times \vec{k}) \times \vec{u}\right) \cdot \vec{k} d A & \Longleftrightarrow \sum_{\Omega}^{n} \int_{\gamma_{i}} \vec{a} \cdot(\vec{k} \times \vec{r})\left(\vec{u} \cdot \vec{t}_{i}\right) d l \\
\int_{\left(\vec{a} \cdot \vec{r}^{t}\right) \omega+\vec{a} \cdot \vec{u} d A} & =\sum_{i=1}^{n} \int_{\gamma^{\prime}}(\vec{k} \times \vec{r})\left(\vec{u} \cdot \vec{t}_{i}\right) d l \\
\vec{a} \cdot \int_{\gamma_{i}} \omega+\vec{u} d A & =\vec{a} \cdot \sum_{\gamma_{i}} \int^{n}
\end{aligned}
$$

onde $\omega$ é a vorticidade de $\vec{u}$, dada por

$$
\omega=(\nabla \times \vec{u}) \cdot \vec{k}
$$

e usamos que

$$
\nabla\left(\vec{a} \cdot \vec{r}^{t}\right)=\vec{a} \times \vec{k}
$$

e que

$$
\vec{k} \cdot(\vec{a} \times \vec{k} \times \vec{u})=\vec{a} \cdot \vec{u} .
$$

Usando o fato de $\vec{a}$ ser uma constante arbitrária e, supondo $\vec{u}$ como sendo o campo constante $\vec{u}_{0}$ (portanto $\omega=0$ ), temos que

$$
\vec{u}_{0}=\frac{1}{|\Omega|} \vec{k} \times \sum_{i=1}^{n} \vec{r}_{i} u_{i} l_{i},
$$

onde $l_{i}$ é o comprimento da aresta $\gamma_{i}$ e $\vec{r}_{i}=\vec{x}_{i}-\vec{x}_{0}$. Esse é o método de Perot quando são conhecidas as componentes tangentes ao invés das normais, que pode ser estendido para a esfera da mesma forma que o método descrito anteriormente.

Em malhas icosaédricas do tipo HC podemos usar o método de Perot descrito na equação (4.73) para reconstruir o campo vetorial nos vértices das células de Voronoi (circuncentros dos triângulos), da mesma forma como fizemos com o método de Whitney. Mostramos na Tabela 4.26 os erros associados a essa abordagem e, na Figura 4.46, a distribuição do erro para uma malha icosaédrica de nível 6. Para a análise do remapeamento, percebemos um comportamento muito similar ao método de Whitney (veja a Tabela 4.27 e Figura 4.47). 


\begin{tabular}{|c|c|c|c|c|}
\hline \multicolumn{5}{|c|}{ Rec. vetorial para Circuncentros - Método PERTR } \\
\hline Nível & Erro Máx & Erro 2 & Razão Máx & Razão 2 \\
\hline 0 & $6.01 \mathrm{E}+01$ & $6.15 \mathrm{E}+01$ & & \\
\hline 1 & $3.36 \mathrm{E}+01$ & $2.92 \mathrm{E}+01$ & 1.79 & 2.11 \\
\hline 2 & $1.98 \mathrm{E}+01$ & $1.46 \mathrm{E}+01$ & 1.70 & 2.01 \\
\hline 3 & $1.03 \mathrm{E}+01$ & $7.30 \mathrm{E}+00$ & 1.92 & 1.99 \\
\hline 4 & $5.28 \mathrm{E}+00$ & $3.66 \mathrm{E}+00$ & 1.96 & 1.99 \\
\hline 5 & $2.67 \mathrm{E}+00$ & $1.83 \mathrm{E}+00$ & 1.98 & 2.00 \\
\hline 6 & $1.35 \mathrm{E}+00$ & $9.18 \mathrm{E}-01$ & 1.98 & 2.00 \\
\hline 7 & $6.78 \mathrm{E}-01$ & $4.60 \mathrm{E}-01$ & 1.99 & 2.00 \\
\hline 8 & $3.40 \mathrm{E}-01$ & $2.30 \mathrm{E}-01$ & 1.99 & 2.00 \\
\hline
\end{tabular}

Tabela 4.26: Erros associados à reconstrução vetorial da onda de Rossby-Haurwitz de uma malha HC para os circuncentros dos triângulos usando o método de Perot para componentes tangentes (PERTR).

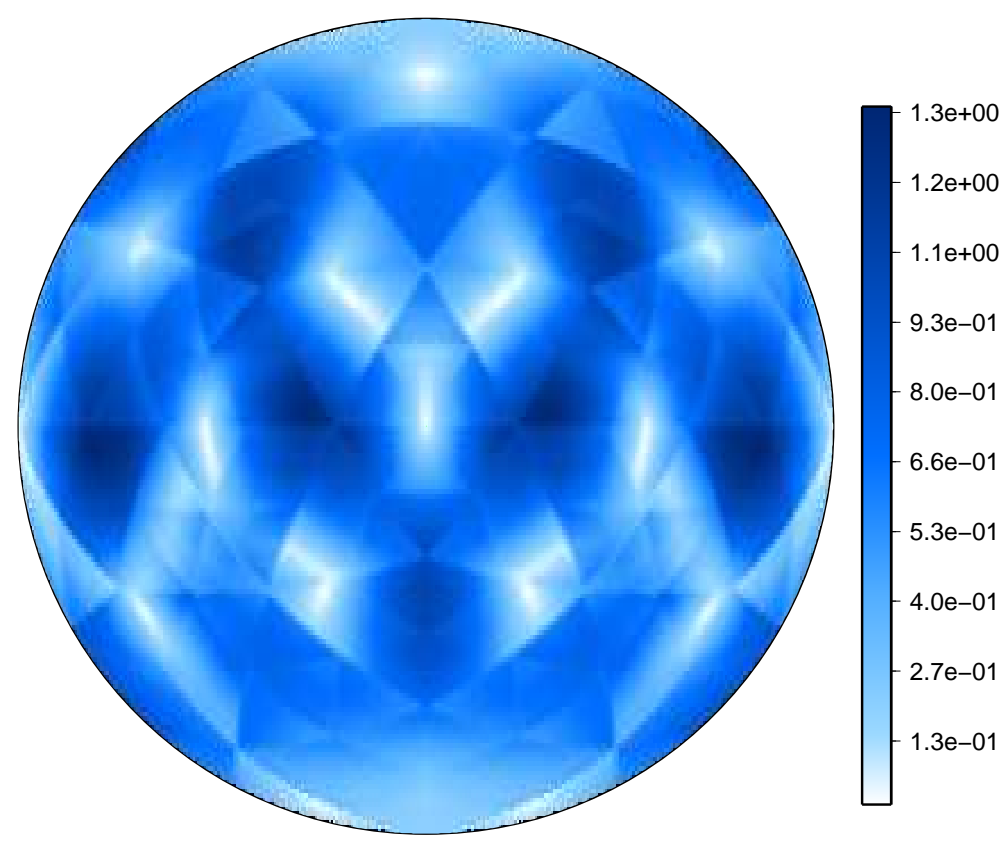

Figura 4.46: Distribuição do erro para a reconstrução vetorial da onda de Rossby-Haurwitz de uma malha icosaédrica de nível 6 do tipo HC para os vértices dos triângulos usando o método de Perot para componentes tangentes (PERTR).

\begin{tabular}{|c|c|c|c|c|}
\hline \multicolumn{5}{|c|}{ Remap lon-lat - Método PERTR / WCHX } \\
\hline Nível & Erro Máx & Erro 2 & Razão Máx & Razão 2 \\
\hline 0 & $8.59 \mathrm{E}+01$ & $3.79 \mathrm{E}+01$ & & \\
\hline 1 & $5.61 \mathrm{E}+01$ & $2.15 \mathrm{E}+01$ & 1.53 & 1.76 \\
\hline 2 & $1.94 \mathrm{E}+01$ & $7.43 \mathrm{E}+00$ & 2.89 & 2.89 \\
\hline 3 & $8.83 \mathrm{E}+00$ & $2.33 \mathrm{E}+00$ & 2.20 & 3.19 \\
\hline 4 & $4.26 \mathrm{E}+00$ & $8.32 \mathrm{E}-01$ & 2.07 & 2.80 \\
\hline 5 & $2.08 \mathrm{E}+00$ & $3.48 \mathrm{E}-01$ & 2.05 & 2.39 \\
\hline 6 & $1.11 \mathrm{E}+00$ & $1.66 \mathrm{E}-01$ & 1.87 & 2.09 \\
\hline 7 & $5.79 \mathrm{E}-01$ & $7.84 \mathrm{E}-02$ & 1.92 & 2.12 \\
\hline 8 & $2.39 \mathrm{E}-01$ & $3.88 \mathrm{E}-02$ & 2.43 & 2.02 \\
\hline
\end{tabular}

Tabela 4.27: Erros associados à reconstrução vetorial da onda de Rossby-Haurwitz de uma malha HC para pontos de uma malha do tipo longitude latitude com 1 grau usando primeiro uma RVN com o método de Perot usando componentes tangentes (PERTR) e depois o método de interpolação com coordenadas baricêntricas de Wachspress (WCHX). 


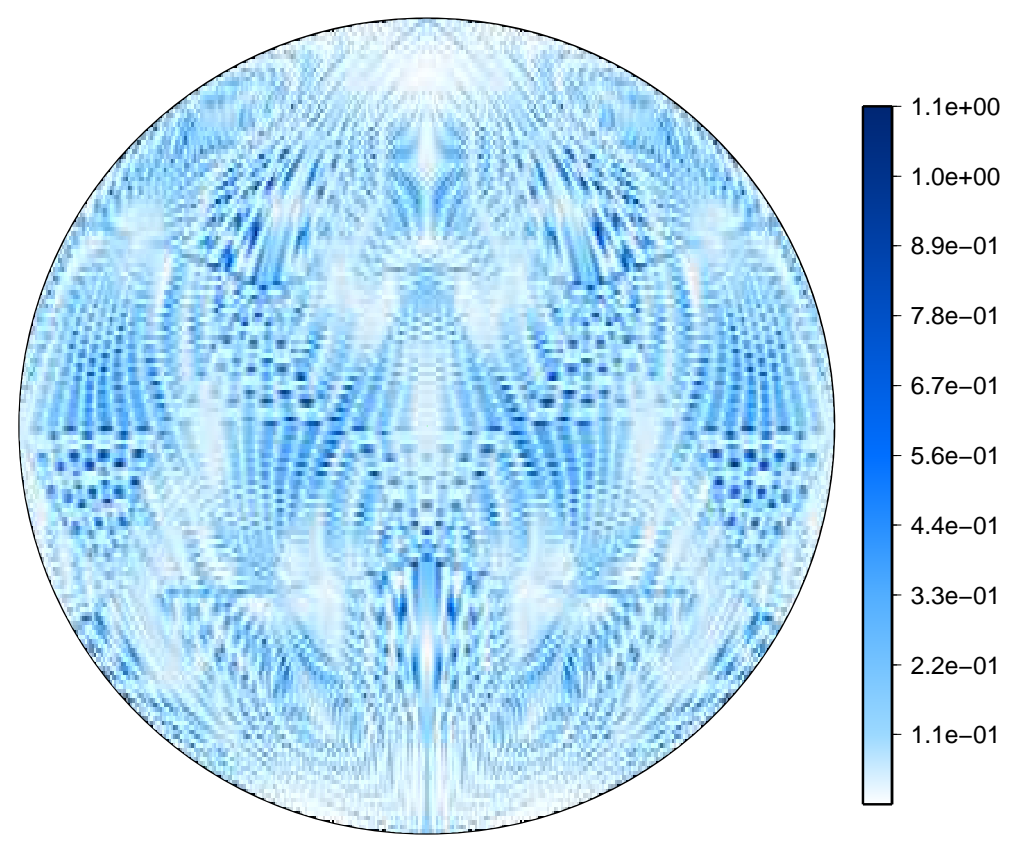

Figura 4.47: Distribuição do erro para a reconstrução vetorial da onda de Rossby-Haurwitz de uma malha icosaédrica $H C$ de nivel 6 para pontos de uma malha do tipo longitude latitude com 1 grau usando primeiro uma RVN com o método de Perot usando componentes tangentes (PERTR) e depois o método de interpolação com coordenadas baricêntricas de Wachspress (WCHX). 


\subsubsection{Funções de base radial}

Vimos os conceitos básicos do uso de funções radiais como base para interpolação escalar na seção 4.2.4, agora vamos estender essa teoria para a reconstrução vetorial. Esse método é usado em dois modelos meteorológicos construídos sobre malha icosaédricas, o ICON e o MPAS, e está descrito em Bonaventura et al. [2011], Ruppert [2007] e Wan [2009] para o ICON e em Skamarock et al. [2012] para o MPAS.

Dado um conjunto de arestas vizinhas a um ponto de reconstrução, queremos encontrar um campo vetorial da forma

$$
\vec{u}(\vec{x})=\sum_{i=1}^{n} \lambda_{i} \phi_{\vec{x}_{i}}(\vec{x}) \vec{n}_{i},
$$

onde estamos usando a mesma notação de função de base radial, sendo a função de base radial $\phi_{\vec{x}_{i}}$ centrada em $\vec{x}_{i}$, ponto médio da aresta $i$, e $\vec{n}_{i}$ é o vetor normal à aresta $i$. Então o problema de interpolação, considerando conhecidas as componentes normais $\left(u_{j}\right)$ do campo vetorial nos pontos médios de um conjunto de arestas vizinhas ao ponto de reconstrução, é encontrar os coeficientes $\lambda_{i}$, $i=1, \ldots, n$, que satisfaçam

$$
\sum_{i=1}^{n} \lambda_{i} \phi_{\vec{x}_{i}}\left(\vec{x}_{j}\right) \vec{n}_{i} \cdot \vec{n}_{j}=u_{j}, \quad j=1, . ., n .
$$

Obtém-se um sistema linear de equações com matriz definida pelas entradas $a_{i j}=\phi\left(d\left(\vec{x}_{j}, \vec{x}_{i}\right)\right) \vec{n}_{i} \cdot \vec{n}_{j}$. A matriz é claramente simétrica e, dependendo da base radial escolhida, pode ser definida positiva (veja Bonaventura et al. [2011]). Nós vamos usar a função de base radial gaussiana (ver Tabela 4.10) nos nossos experimentos, caso em que teremos um sistema com matriz simétrica positiva definida.

Assim como no problema de interpolação escalar, a escolha do parâmetro de formato da função radial é crucial e teremos os mesmos desafios do ponto de vista de instabilidades numéricas (Fasshauer [2011], Fuselier e Wright [2009]). Foram feitas algumas tentativas de contornar o problema de instabilidade numérica desse tipo de método, como em Fornberg e Piret [2008] e Fasshauer e McCourt [2012]. Infelizmente as propostas aumentam o custo computacional e, como por exemplo mostrado em Fornberg e Piret [2008], pode-se perder as propriedades de localidade.

Para a reconstrução em um nó de célula de Voronoi podemos usar os dados fornecidos no conjunto de arestas que se conectam a esse nó. Em malhas icosaédricas isso resulta em 5 ou 6 arestas (veja a Figura 4.50a). Para a reconstrução vetorial no circuncentro de um triângulo, podem ser usadas apenas as 3 arestas do triângulo de interesse, ou o conjunto de 9 pontos indicado na Figura 4.50b.

Analisamos o método para o conjunto de arestas mais próximas ao nó, como indicado na Figura 4.50a, que resulta em 6 arestas para hexágonos e 5 para pentágonos (RBFHX). Consideramos um parâmetro de formato para a função de base radial gaussiana de $\epsilon=1$. Resolvemos o sistema usando uma decomposição de Cholesky do tipo $L D L^{t}$, onde $D$ é diagonal e $L$ é triangular unitária. A razão entre o maior elemento de $D$ e o menor fornece uma estimativa para o condicionamento da matriz, apresentado na Tabela 4.28. Vemos que a estimativa para o número de condição da matriz cresce com ordem 4, muito maior que a ordem de decaimento do erro. Isso é um indicativo de que em malhas mais finas estaremos sujeitos a instabilidades numéricas. A distribuição do erro para a RVN com RBFHX, apresentada na Figura 4.48, mostra uma interferência de malha relativa a malhas mais grossas. Os mesmos padrões de convergência e distribuição do erro são observados na análise de remapeamento (tabela 4.29 e Figura 4.49).

Considerando a mesma função radial e o mesmo parâmetro de formato, analisamos a reconstrução para os circuncentros dos triângulos, usando dois conjuntos de pontos. Primeiro usando apenas as 3 arestas de célula de Voronoi que estão conectadas ao circuncentro (RBFTR). O segundo usando um conjunto de 9 arestas próximas ao circuncentro escolhidas conforme ilustrado na Figura 4.50b (RBFETR). O método RBFTR tem erros que caem com primeira ordem apenas, conforme a Tabela 4.30. O método RBFETR apresenta segunda ordem de convergência para o erro (tabela 4.31). 


\begin{tabular}{|c|c|c|c|c|c|c|}
\hline \multicolumn{7}{|c|}{ Rec. vetorial para nós - Método RBFHX } \\
\hline Nível & Erro Máx & Erro 2 & NúmCond & Razão Máx & Razão 2 & Razão NC \\
\hline 0 & $3.0884 \mathrm{E}+01$ & $2.5822 \mathrm{E}+01$ & $1.4500 \mathrm{E}+00$ & & & \\
\hline 1 & $1.3412 \mathrm{E}+01$ & $7.8558 \mathrm{E}+00$ & $1.2605 \mathrm{E}+01$ & 2.30 & 3.29 & 8.69 \\
\hline 2 & $3.5056 \mathrm{E}+00$ & $2.0868 \mathrm{E}+00$ & $2.4195 \mathrm{E}+02$ & 3.83 & 3.76 & 19.19 \\
\hline 3 & $1.3795 \mathrm{E}+00$ & $5.9307 \mathrm{E}-01$ & $4.1252 \mathrm{E}+03$ & 2.54 & 3.52 & 17.05 \\
\hline 4 & $5.3667 \mathrm{E}-01$ & $1.6789 \mathrm{E}-01$ & $6.7112 \mathrm{E}+04$ & 2.57 & 3.53 & 16.27 \\
\hline 5 & $1.6739 \mathrm{E}-01$ & $4.4294 \mathrm{E}-02$ & $1.0783 \mathrm{E}+06$ & 3.21 & 3.79 & 16.07 \\
\hline 6 & $4.6302 \mathrm{E}-02$ & $1.1105 \mathrm{E}-02$ & $1.7271 \mathrm{E}+07$ & 3.62 & 3.99 & 16.02 \\
\hline 7 & $1.3291 \mathrm{E}-02$ & $2.7223 \mathrm{E}-03$ & $2.7641 \mathrm{E}+08$ & 3.48 & 4.08 & 16.00 \\
\hline 8 & $3.4620 \mathrm{E}-03$ & $6.6546 \mathrm{E}-04$ & $4.4230 \mathrm{E}+09$ & 3.84 & 4.09 & 16.00 \\
\hline
\end{tabular}

Tabela 4.28: Erros associados à reconstrução vetorial da onda de Rossby-Haurwitz de uma malha HC para os vértices dos triângulos, nós das células de Voronoi, usando o método de funções de base radial com as 5 , ou 6, arestas mais próximas (RBFHX). Além dos erros são apresentadas estimativas para os máximos dos números de condição das matrizes envolvidas no método.

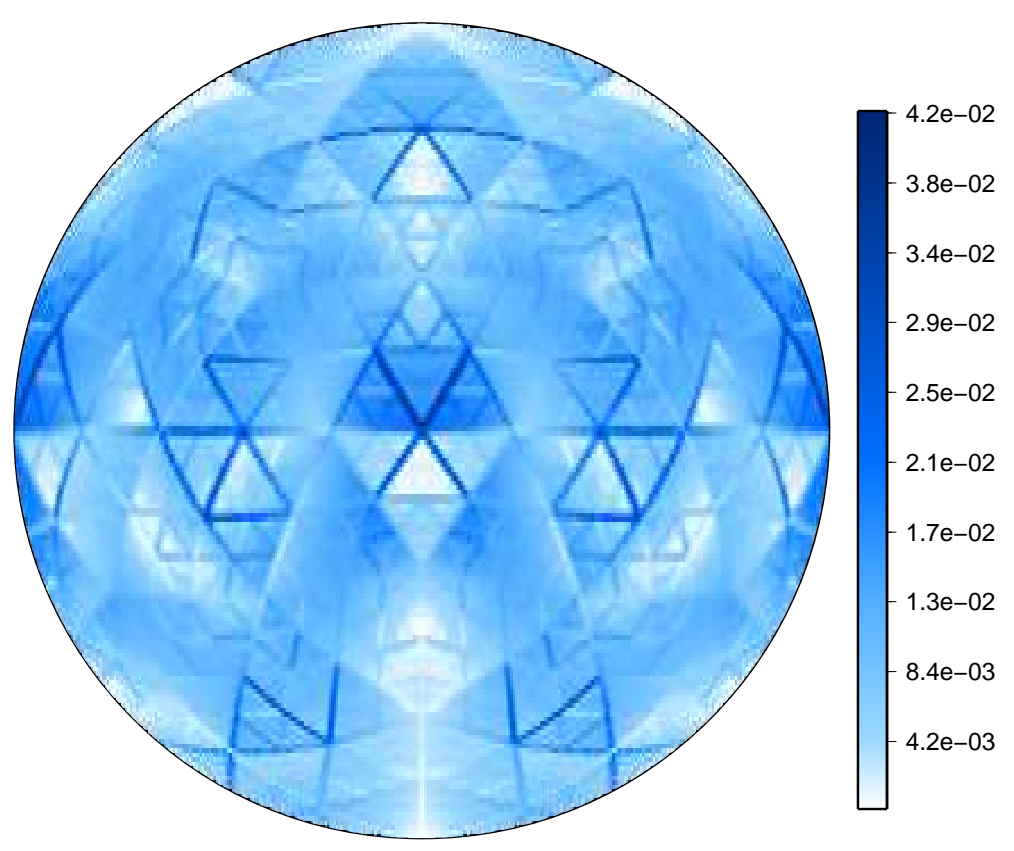

Figura 4.48: Distribuição do erro para a reconstrução vetorial da onda de Rossby-Haurwitz de uma malha icosaédrica de nível 6 do tipo HC para os vértices dos triângulos, nós das células de Voronoi, usando o método de funções de base radial com as 5, ou 6, arestas mais próximas (RBFHX). 


\begin{tabular}{|c|c|c|c|c|}
\hline \multicolumn{5}{|c|}{ Remap lon-lat - Método RBFHX / CBTR } \\
\hline Nível & Erro Máx & Erro 2 & Razão Máx & Razão 2 \\
\hline 0 & $8.9471 \mathrm{E}+01$ & $3.9027 \mathrm{E}+01$ & & \\
\hline 1 & $4.7935 \mathrm{E}+01$ & $2.1099 \mathrm{E}+01$ & 1.87 & 1.85 \\
\hline 2 & $1.5551 \mathrm{E}+01$ & $6.7439 \mathrm{E}+00$ & 3.08 & 3.13 \\
\hline 3 & $4.7111 \mathrm{E}+00$ & $1.7932 \mathrm{E}+00$ & 3.30 & 3.76 \\
\hline 4 & $1.2467 \mathrm{E}+00$ & $4.6020 \mathrm{E}-01$ & 3.78 & 3.90 \\
\hline 5 & $3.3205 \mathrm{E}-01$ & $1.1694 \mathrm{E}-01$ & 3.75 & 3.94 \\
\hline 6 & $8.3319 \mathrm{E}-02$ & $2.9598 \mathrm{E}-02$ & 3.99 & 3.95 \\
\hline 7 & $2.0795 \mathrm{E}-02$ & $7.2784 \mathrm{E}-03$ & 4.01 & 4.07 \\
\hline 8 & $5.0369 \mathrm{E}-03$ & $1.8419 \mathrm{E}-03$ & 4.13 & 3.95 \\
\hline
\end{tabular}

Tabela 4.29: Erros associados à reconstrução vetorial da onda de Rossby-Haurwitz de uma malha HC para pontos de uma malha do tipo longitude latitude com 1 grau usando primeiro uma RVN com o método de funções de base radial com as 5 ou 6 arestas mais próximas (RBFHX) e depois o método de interpolação com coordenadas baricêntricas para triângulos (CBTR).

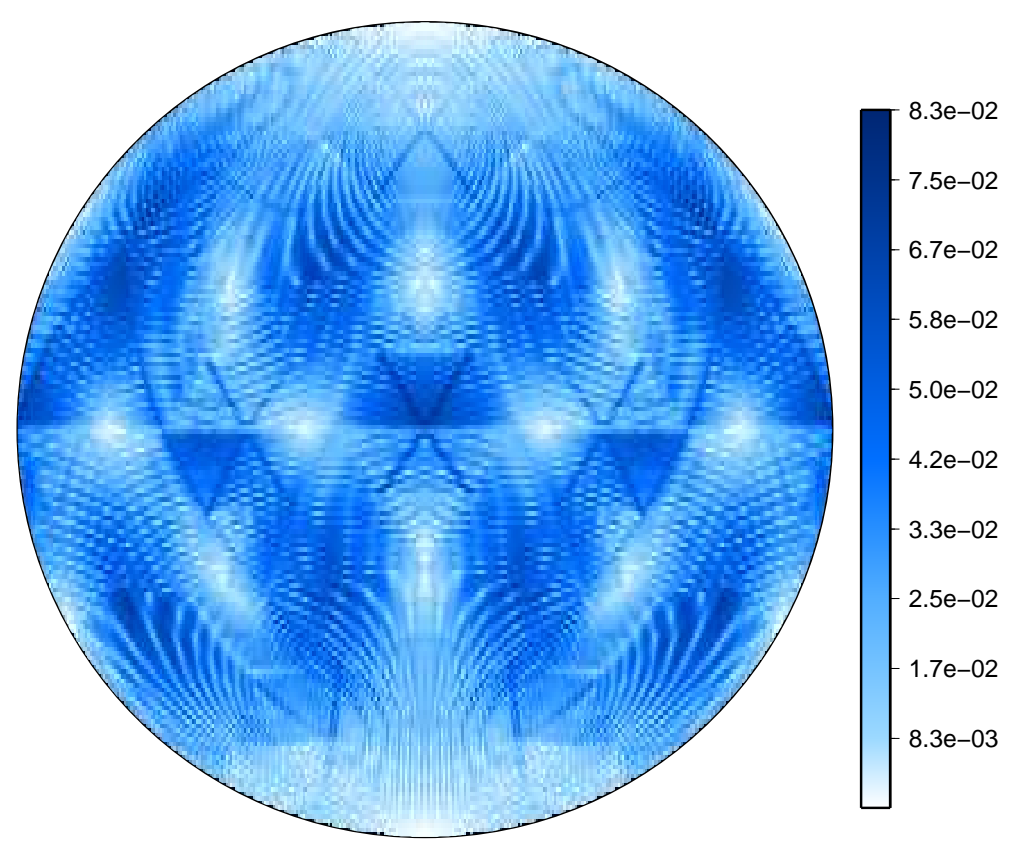

Figura 4.49: Distribuição do erro para a reconstrução vetorial da onda de Rossby-Haurwitz de uma malha icosaédrica $H C$ de nível 6 para pontos de uma malha do tipo longitude latitude com 1 grau usando primeiro uma RVN com o método de funções de base radial com as 5 ou 6 arestas mais próximas (RBFHX) e depois o método de interpolação com coordenadas baricêntricas para triângulos (CBTR). 
Repare que o número de condição cresce com ordem 2, no caso RBFTR, e 4 no caso RBFETR, logo, é de se esperar que venhamos a ter os mesmos problemas de instabilidades numéricas observadas no caso escalar também nas reconstruções vetoriais.

\begin{tabular}{|c|c|c|c|c|c|c|}
\hline \multicolumn{7}{|c|}{ Rec. vetorial para circuncentros - Método RBFTR } \\
\hline Nível & Erro Máx & Erro 2 & NúmCond & Razão Máx & Razão 2 & Razão NC \\
\hline 0 & $6.1408 \mathrm{E}+01$ & $6.2201 \mathrm{E}+01$ & $1.52 \mathrm{E}+00$ & & & \\
\hline 1 & $3.1352 \mathrm{E}+01$ & $2.6656 \mathrm{E}+01$ & $5.12 \mathrm{E}+00$ & 1.96 & 2.33 & 3.37 \\
\hline 2 & $1.9777 \mathrm{E}+01$ & $1.3236 \mathrm{E}+01$ & $1.97 \mathrm{E}+01$ & 1.59 & 2.01 & 3.85 \\
\hline 3 & $1.0360 \mathrm{E}+01$ & $6.5908 \mathrm{E}+00$ & $7.95 \mathrm{E}+01$ & 1.91 & 2.01 & 4.03 \\
\hline 4 & $5.2679 \mathrm{E}+00$ & $3.2931 \mathrm{E}+00$ & $3.19 \mathrm{E}+02$ & 1.97 & 2.00 & 4.01 \\
\hline 5 & $2.6628 \mathrm{E}+00$ & $1.6467 \mathrm{E}+00$ & $1.28 \mathrm{E}+03$ & 1.98 & 2.00 & 4.00 \\
\hline 6 & $1.3459 \mathrm{E}+00$ & $8.2353 \mathrm{E}-01$ & $5.11 \mathrm{E}+03$ & 1.98 & 2.00 & 4.00 \\
\hline 7 & $6.7798 \mathrm{E}-01$ & $4.1182 \mathrm{E}-01$ & $2.04 \mathrm{E}+04$ & 1.99 & 2.00 & 4.00 \\
\hline 8 & $3.4016 \mathrm{E}-01$ & $2.0592 \mathrm{E}-01$ & $8.17 \mathrm{E}+04$ & 1.99 & 2.00 & 4.00 \\
\hline
\end{tabular}

Tabela 4.30: Erros associados à reconstrução vetorial da onda de Rossby-Haurwitz de uma malha HC para os circuncentros dos triângulos usando o método de funções de base radial com as 3 arestas mais próximas (RBFTR). Além dos erros são apresentadas estimativas para os máximos dos números de condição das matrizes envolvidas no método.

\begin{tabular}{|c|c|c|c|c|c|c|}
\hline \multicolumn{7}{|c|}{ Rec. vetorial para circuncentros - Método RBFETR } \\
\hline Nível & Erro Máx & Erro 2 & NúmCond & Razão Máx & Razão 2 & Razão NC \\
\hline 0 & $6.7915 \mathrm{E}+01$ & $6.6985 \mathrm{E}+01$ & $2.30 \mathrm{E}+00$ & & & \\
\hline 1 & $2.6070 \mathrm{E}+01$ & $1.8377 \mathrm{E}+01$ & $3.67 \mathrm{E}+01$ & 2.61 & 3.65 & 15.96 \\
\hline 2 & $5.3970 \mathrm{E}+00$ & $3.9400 \mathrm{E}+00$ & $5.14 \mathrm{E}+02$ & 4.83 & 4.66 & 14.03 \\
\hline 3 & $1.3587 \mathrm{E}+00$ & $8.7175 \mathrm{E}-01$ & $8.87 \mathrm{E}+03$ & 3.97 & 4.52 & 17.23 \\
\hline 4 & $3.5525 \mathrm{E}-01$ & $2.0555 \mathrm{E}-01$ & $1.46 \mathrm{E}+05$ & 3.82 & 4.24 & 16.46 \\
\hline 5 & $9.0560 \mathrm{E}-02$ & $5.0374 \mathrm{E}-02$ & $2.35 \mathrm{E}+06$ & 3.92 & 4.08 & 16.12 \\
\hline 6 & $2.2769 \mathrm{E}-02$ & $1.2508 \mathrm{E}-02$ & $3.77 \mathrm{E}+07$ & 3.98 & 4.03 & 16.03 \\
\hline 7 & $5.7026 \mathrm{E}-03$ & $3.1188 \mathrm{E}-03$ & $6.04 \mathrm{E}+08$ & 3.99 & 4.01 & 16.01 \\
\hline 8 & $1.4266 \mathrm{E}-03$ & $7.7886 \mathrm{E}-04$ & $9.66 \mathrm{E}+09$ & 4.00 & 4.00 & 16.00 \\
\hline
\end{tabular}

Tabela 4.31: Erros associados à reconstrução vetorial da onda de Rossby-Haurwitz de uma malha HC para os circuncentros dos triângulos usando o método de funções de base radial com as 9 arestas mais próximas (RBFETR). Além dos erros são apresentadas estimativas para os máximos dos números de condição das matrizes envolvidas no método. 


\subsubsection{Método de mínimos quadrados}

Nesta seção vamos analisar um método de reconstrução vetorial polinomial usando mínimos quadrados. O caso planar é discutido no trabalho de Vidovic [2009]. Nós vamos mostrar como a metodologia funciona e como pode ser estendida para a esfera.

Suponha que queremos obter um campo vetorial linear da forma

$$
\vec{u}(\vec{x})=\overrightarrow{a_{0}}+A \vec{x}=\overrightarrow{a_{0}}+\vec{a}_{1} x+\vec{a}_{2} y,
$$

onde $\vec{x}=(x, y), \vec{a}_{0}=\left(a_{0}^{x}, a_{0}^{y}\right) \mathrm{e}$

$$
A=\left[\begin{array}{ll}
\vec{a}_{1} & \vec{a}_{2}
\end{array}\right]=\left[\begin{array}{ll}
a_{1}^{x} & a_{2}^{x} \\
a_{1}^{y} & a_{2}^{y}
\end{array}\right],
$$

dadas as componentes normais $\left(u_{i}\right)$, em relação às arestas de uma malha, de um campo vetorial. Então o problema de aproximação polinomial usando mínimos quadrados pode ser escrito como

$$
\vec{u}\left(\vec{x}_{i}\right) \cdot \vec{n}_{i}=\overrightarrow{a_{0}} \cdot \vec{n}_{i}+\left(A \vec{x}_{i}\right) \cdot \vec{n}_{i}=u_{i}, \quad i=1, \ldots, k,
$$

onde $k$ é o número de arestas a serem consideradas na aproximação e $\vec{n}_{i}$ é um vetor normal à $i$-ésima aresta. Na forma matricial podemos escrever que $M \vec{a}=\vec{b}$, onde $\vec{a}=\left[a_{0}^{x}, a_{0}^{y}, a_{1}^{x}, a_{1}^{y}, a_{2}^{x}, a_{2}^{y}\right]$, $\vec{b}=\left[u_{1}, \ldots, u_{n}\right], \mathrm{e}$

$$
M=\left[\begin{array}{cccccc}
n_{1}^{x} & n_{1}^{y} & n_{1}^{x} x_{1} & n_{1}^{y} x_{1} & n_{1}^{x} y_{1} & n_{1}^{y} y_{1} \\
n_{2}^{x} & n_{2}^{y} & n_{2}^{x} x_{2} & n_{2}^{y} x_{2} & n_{2}^{x} y_{2} & n_{2}^{y} y_{2} \\
\vdots & \vdots & \vdots & \vdots & \vdots & \vdots \\
n_{k}^{x} & n_{k}^{y} & n_{k}^{x} x_{k} & n_{k}^{y} x_{k} & n_{k}^{x} y_{k} & n_{k}^{y} y_{k}
\end{array}\right]
$$

Para o problema ser interpolatório, 6 arestas seriam em princípio necessárias para definir um campo vetorial linear, pois teremos 6 coeficientes desconhecidos no sistema $(\vec{a})$ e 6 equações. Nesse caso, um hexágono teria arestas suficientes para solução do problema interpolatório (veja a Figura 4.50a). Infelizmente, se o hexágono for regular, o posto da matriz $M$ é 5 (existe um autovalor nulo), assim seriam necessárias mais arestas para recuperar o campo vetorial (veja Vidovic [2009] para mais detalhes). Em uma malha icosaédrica, para reconstruirmos um campo vetorial linear em um nó (vértice de triangulo) vamos usar 2 níveis de vizinhança, para preservar simetria, o que resultará no uso de 12 arestas no caso dos hexágonos e 10 no caso dos pentágonos (veja a Figura 4.50c). Se a reconstrução for feita para um circuncentro de um triângulo, vértice de célula de Voronoi, então podemos usar 9 arestas, as 3 do triângulo e mais 6 dos triângulos vizinhos, como indicado na Figura 4.50b.

Para a esfera vamos usar uma ideia similar à descrita em Renka [1984], em que uma projeção ortográfica é feita para o plano tangente ao ponto de reconstrução. A implementação pode ser feita considerando uma rotação de uma certa vizinhança do ponto de reconstrução para o polo norte, que em coordenadas cartesianas será o ponto $(0,0,1)$. A projeção ortográfica é então obtida simplesmente ignorando as coordenadas $z$ dos pontos rotacionados. O método planar é então aplicado, e depois o vetor reconstruído é rotacionado de volta à posição original.

Nas Tabelas 4.32 e 4.34 mostramos os erros associados às reconstruções, respectivamente para os nós das células de Voronoi e circuncentros dos triângulos. Nas figuras 4.51 e 4.53 são apresentadas as distribuições do erro para os métodos analisados. Em ambos os casos nota-se uma convergência quadrática (ordem 2) e um padrão de erro similar. 
(a)

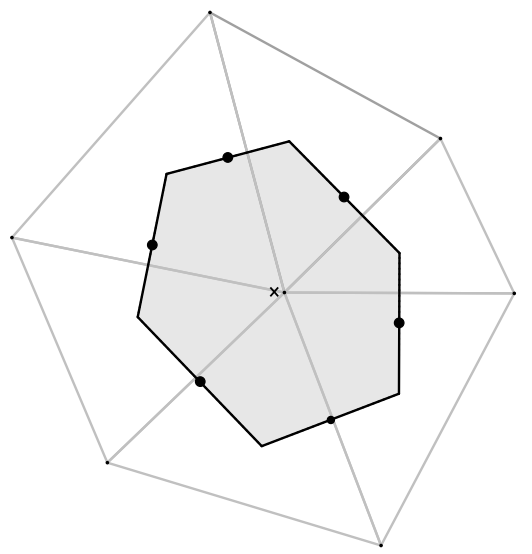

(b)
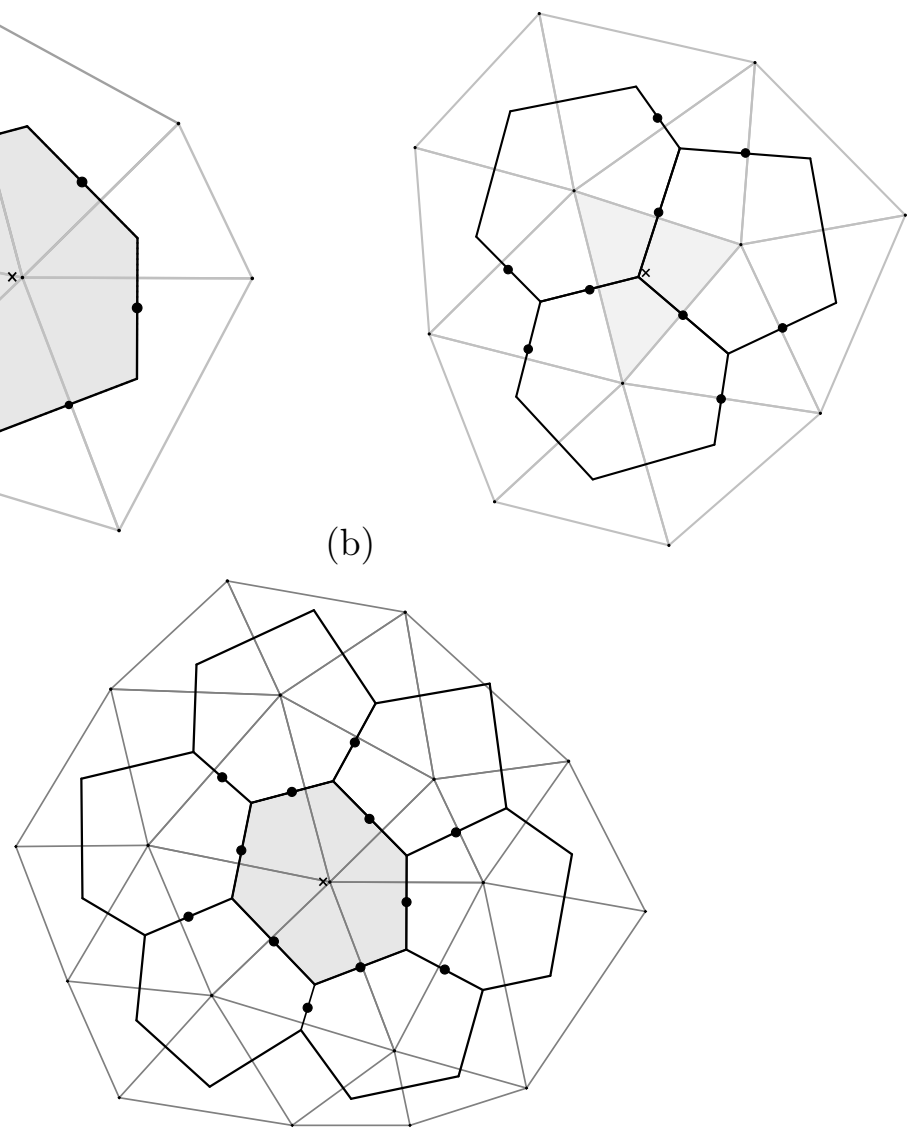

(c)

Figura 4.50: Exemplos de conjuntos de arestas usados em reconstruções vetoriais. (a) Conjunto de 6 arestas hexagonal, (b) conjunto de 9 arestas centradas em triângulo e (c) conjunto hexagonal estendido de 12 arestas. A linha cinza indica a triangulação de Delaunay e a preta o diagrama de Voronoi. Os círculos preenchidos pretos são os pontos médios das arestas de Voronoi, que são considerados nos conjuntos de arestas. A cruz indica o centro de massa da célula hachurada (ou uma célula de Voronoi (a) e (c) ou um triângulo (b)).

\begin{tabular}{|c|c|c|c|c|}
\hline \multicolumn{5}{|c|}{ Rec. vetorial para nós - Método LSQHXE } \\
\hline Nível & Erro Máx & Erro 2 & Razão Máx & Razão 2 \\
\hline 0 & $3.4732 \mathrm{E}+01$ & $2.6482 \mathrm{E}+01$ & & \\
\hline 1 & $2.3164 \mathrm{E}+01$ & $1.2602 \mathrm{E}+01$ & 1.50 & 2.10 \\
\hline 2 & $8.5246 \mathrm{E}+00$ & $4.6283 \mathrm{E}+00$ & 2.72 & 2.72 \\
\hline 3 & $2.4218 \mathrm{E}+00$ & $1.2997 \mathrm{E}+00$ & 3.52 & 3.56 \\
\hline 4 & $6.2549 \mathrm{E}-01$ & $3.3511 \mathrm{E}-01$ & 3.87 & 3.88 \\
\hline 5 & $1.5765 \mathrm{E}-01$ & $8.4454 \mathrm{E}-02$ & 3.97 & 3.97 \\
\hline 6 & $3.9494 \mathrm{E}-02$ & $2.1159 \mathrm{E}-02$ & 3.99 & 3.99 \\
\hline 7 & $9.8785 \mathrm{E}-03$ & $5.2928 \mathrm{E}-03$ & 4.00 & 4.00 \\
\hline 8 & $2.4699 \mathrm{E}-03$ & $1.3234 \mathrm{E}-03$ & 4.00 & 4.00 \\
\hline
\end{tabular}

Tabela 4.32: Erros associados à reconstrução vetorial da onda de Rossby-Haurwitz de uma malha HC para os vértices dos triângulos, nós das células de Voronoi, usando o método de aproximação polinomial com minimos quadrados com 10 ou 12 pontos (LSQHXE). 


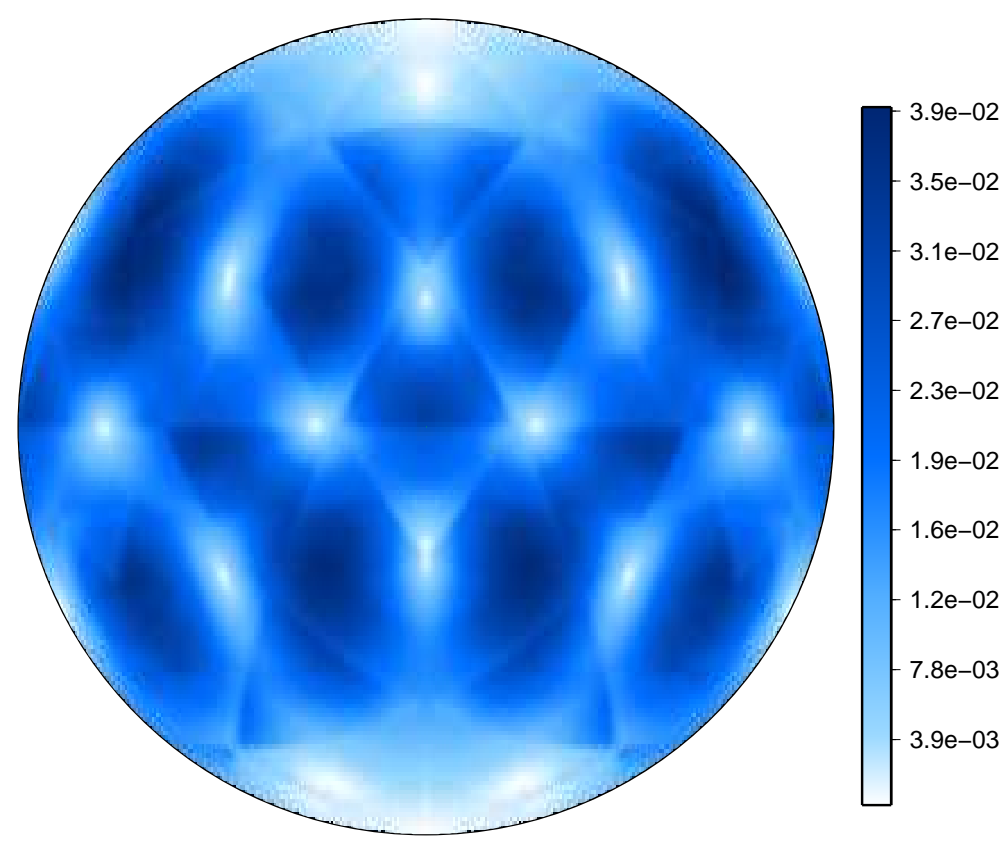

Figura 4.51: Distribuição do erro para a reconstrução vetorial da onda de Rossby-Haurwitz de uma malha icosaédrica de nível 6 do tipo HC para os vértices dos triângulos usando o método de aproximação polinomial com minimos quadrados com 10 ou 12 pontos (LSQHXE).

\begin{tabular}{|c|c|c|c|c|}
\hline \multicolumn{5}{|c|}{ Remap lon-lat - Método LSQHXE / CBTR } \\
\hline Nível & Erro Máx & Erro 2 & Razão Máx & Razão 2 \\
\hline 0 & $8.6392 \mathrm{E}+01$ & $3.7954 \mathrm{E}+01$ & & \\
\hline 1 & $5.1654 \mathrm{E}+01$ & $2.2983 \mathrm{E}+01$ & 1.67 & 1.65 \\
\hline 2 & $1.9397 \mathrm{E}+01$ & $8.8608 \mathrm{E}+00$ & 2.66 & 2.59 \\
\hline 3 & $6.2418 \mathrm{E}+00$ & $2.5336 \mathrm{E}+00$ & 3.11 & 3.50 \\
\hline 4 & $1.6589 \mathrm{E}+00$ & $6.5672 \mathrm{E}-01$ & 3.76 & 3.86 \\
\hline 5 & $4.3614 \mathrm{E}-01$ & $1.6589 \mathrm{E}-01$ & 3.80 & 3.96 \\
\hline 6 & $1.0930 \mathrm{E}-01$ & $4.1767 \mathrm{E}-02$ & 3.99 & 3.97 \\
\hline 7 & $2.7365 \mathrm{E}-02$ & $1.0313 \mathrm{E}-02$ & 3.99 & 4.05 \\
\hline 8 & $6.6850 \mathrm{E}-03$ & $2.6006 \mathrm{E}-03$ & 4.09 & 3.97 \\
\hline
\end{tabular}

Tabela 4.33: Erros associados à reconstrução vetorial da onda de Rossby-Haurwitz de uma malha HC para pontos de uma malha do tipo longitude latitude com 1 grau usando primeiro uma RVN com o método de aproximação polinomial linear com mínimos quadrados (LSQHXE) e depois o método de interpolação com coordenadas baricêntricas para triângulos (CBTR). 


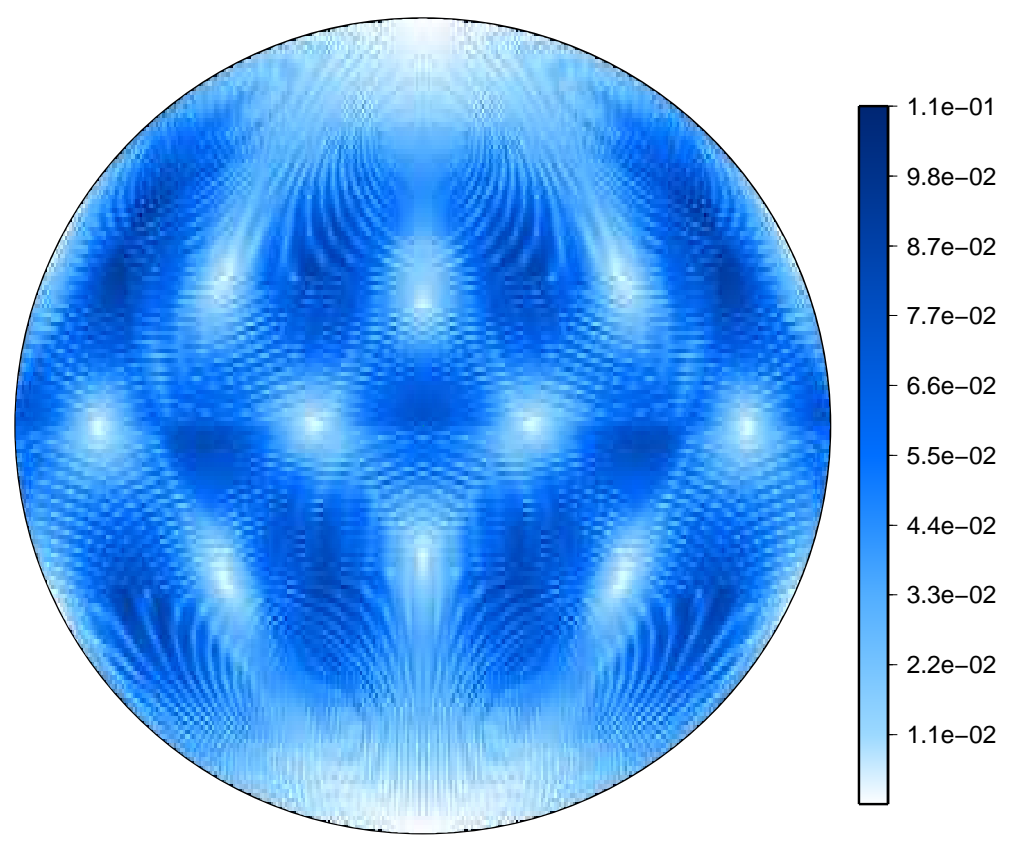

Figura 4.52: Distribuição do erro para a reconstrução vetorial da onda de Rossby-Haurwitz de uma malha icosaédrica $H C$ de nível 6 para pontos de uma malha do tipo longitude latitude com 1 grau usando primeiro uma RVN com o método de aproximação polinomial linear com minimos quadrados (LSQHXE) e depois o método de interpolação com coordenadas baricêntricas para triângulos (CBTR).

\begin{tabular}{|c|c|c|c|c|}
\hline \multicolumn{5}{|c|}{ Rec. vetorial para circuncentros - Método LSQTRC } \\
\hline Nível & Erro Máx & Erro 2 & Razão Máx & Razão 2 \\
\hline 0 & $6.1629 \mathrm{E}+01$ & $6.3210 \mathrm{E}+01$ & & \\
\hline 1 & $3.1184 \mathrm{E}+01$ & $2.4460 \mathrm{E}+01$ & 1.98 & 2.58 \\
\hline 2 & $9.1405 \mathrm{E}+00$ & $6.9986 \mathrm{E}+00$ & 3.41 & 3.49 \\
\hline 3 & $2.4593 \mathrm{E}+00$ & $1.8030 \mathrm{E}+00$ & 3.72 & 3.88 \\
\hline 4 & $6.4967 \mathrm{E}-01$ & $4.5484 \mathrm{E}-01$ & 3.79 & 3.96 \\
\hline 5 & $1.6501 \mathrm{E}-01$ & $1.1405 \mathrm{E}-01$ & 3.94 & 3.99 \\
\hline 6 & $4.1465 \mathrm{E}-02$ & $2.8545 \mathrm{E}-02$ & 3.98 & 4.00 \\
\hline 7 & $1.0386 \mathrm{E}-02$ & $7.1395 \mathrm{E}-03$ & 3.99 & 4.00 \\
\hline 8 & $2.5985 \mathrm{E}-03$ & $1.7852 \mathrm{E}-03$ & 4.00 & 4.00 \\
\hline
\end{tabular}

Tabela 4.34: Erros associados à reconstrução vetorial da onda de Rossby-Haurwitz de uma malha HC para os circuncentros dos triângulos usando o método de aproximação polinomial com minimos quadrados com 9 pontos (LSQTRC). 


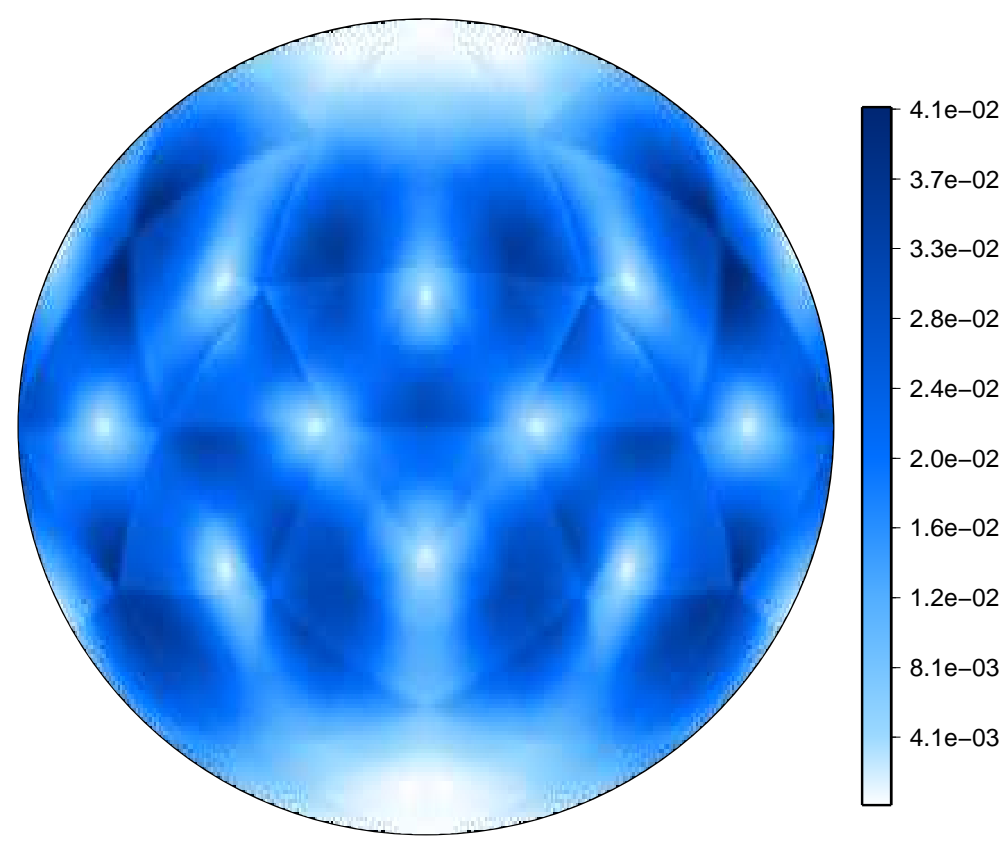

Figura 4.53: Distribuição do erro para a reconstrução vetorial da onda de Rossby-Haurwitz de uma malha icosaédrica de nível 6 do tipo HC para os circuncentros dos triângulos usando o método de aproximação polinomial com mínimos quadrados com 9 pontos (LSQTRC).

\begin{tabular}{|c|c|c|c|c|}
\hline \multicolumn{5}{|c|}{ Remap lon-lat - Método LSQTRC / WCHX } \\
\hline Nível & Erro Máx & Erro 2 & Razão Máx & Razão 2 \\
\hline 0 & $8.7231 \mathrm{E}+01$ & $3.8295 \mathrm{E}+01$ & & \\
\hline 1 & $5.3086 \mathrm{E}+01$ & $2.2698 \mathrm{E}+01$ & 1.64 & 1.69 \\
\hline 2 & $1.9259 \mathrm{E}+01$ & $7.9916 \mathrm{E}+00$ & 2.76 & 2.84 \\
\hline 3 & $5.5515 \mathrm{E}+00$ & $2.1995 \mathrm{E}+00$ & 3.47 & 3.63 \\
\hline 4 & $1.4766 \mathrm{E}+00$ & $5.6541 \mathrm{E}-01$ & 3.76 & 3.89 \\
\hline 5 & $3.9217 \mathrm{E}-01$ & $1.4305 \mathrm{E}-01$ & 3.77 & 3.95 \\
\hline 6 & $1.0060 \mathrm{E}-01$ & $3.5103 \mathrm{E}-02$ & 3.90 & 4.08 \\
\hline 7 & $2.5382 \mathrm{E}-02$ & $9.0336 \mathrm{E}-03$ & 3.96 & 3.89 \\
\hline 8 & $6.4052 \mathrm{E}-03$ & $2.2396 \mathrm{E}-03$ & 3.96 & 4.03 \\
\hline
\end{tabular}

Tabela 4.35: Erros associados à reconstrução vetorial da onda de Rossby-Haurwitz de uma malha HC para pontos de uma malha do tipo longitude latitude com 1 grau usando primeiro uma RVN com o método de aproximação polinomial linear com minimos quadrados (LSQTRC) e depois o método de interpolação com coordenadas baricêntricas de Wachspress (WCHX). 


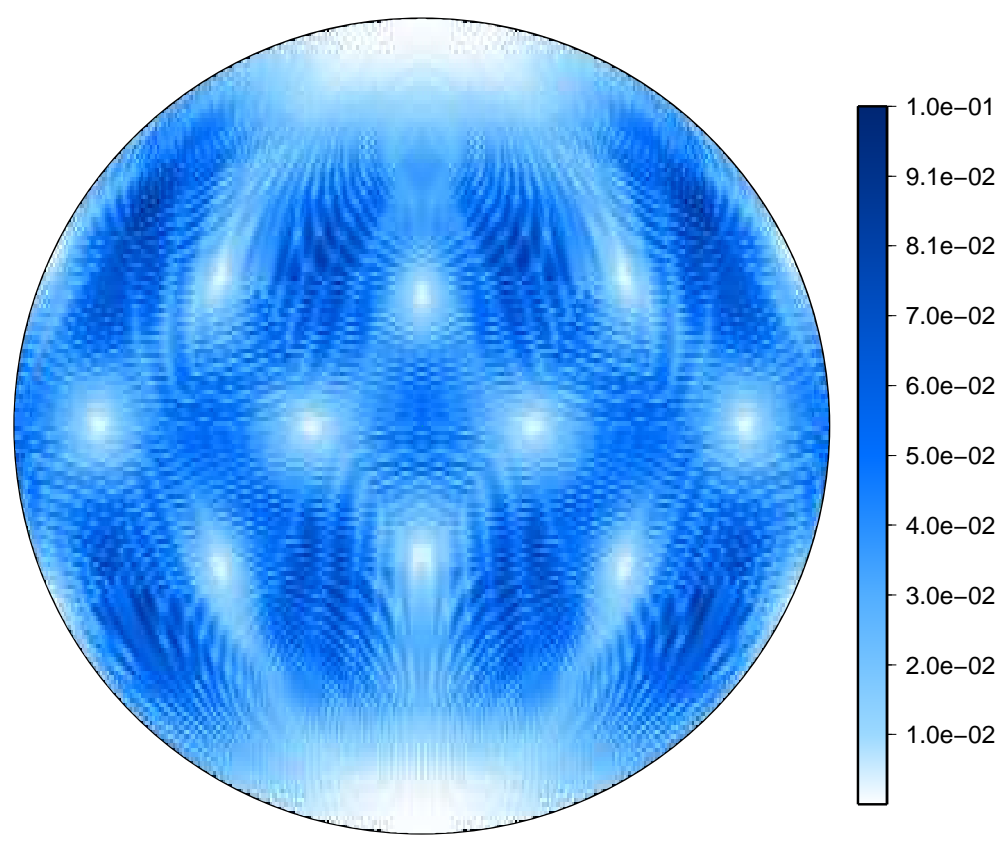

Figura 4.54: Distribuição do erro para a reconstrução vetorial da onda de Rossby-Haurwitz de uma malha icosaédrica $H C$ de nível 6 para pontos de uma malha do tipo longitude latitude com 1 grau usando primeiro uma RVN com o método de aproximação polinomial linear com minimos quadrados (LSQTRC) e depois o método de interpolação com coordenadas baricêntricas de Wachspress (WCHX). 


\subsubsection{Método híbrido}

Vimos que o método de Perot para células de Voronoi com componentes normais sofre de problemas de interferência de malha de mesma origem que a discretização do divergente analisado no capítulo 3. Os erros em células não alinhadas tendem a convergir com ordem menor que em células alinhadas, resultando em uma interferência de malha na distribuição do erro do método. Podemos fazer uso do índice de alinhamento para separar as células alinhadas das não alinhadas e usar métodos distintos nesses dois casos. Uma abordagem eficiente é considerar o método polinomial de mínimos quadrados para as células não alinhadas, garantindo segunda ordem nelas, e usar o método de Perot nas células alinhadas, aonde vamos obter segunda ordem. O resultado esperado é um método de segunda ordem, mas como as células não alinhadas são minoria em malhas icosaédricas, o custo computacional será da ordem do custo do método de Perot, que é menos custoso que o método de mínimos quadrados (apresentamos comparações mais adiante). O mesmo tipo de abordagem parece fazer sentido para o método de Klausen et al. [2012] (EBB), porém, neste caso não temos a prova de que de fato o método será de segunda ordem em células alinhadas. Portanto vamos adotar o método híbrido apenas com o método de Perot.

Testamos o método híbrido para um parâmetro de corte do índice de alinhamento de 0.01 , que resulta nos percentuais de células alinhadas descritos na Tabela 3.1. Apresentamos os erros na Tabela 4.36, onde nota-se o aumento da ordem de convergência quando comparamos com o método de Perot puro (ver Tabela 4.24). A distribuição do erro ainda revela padrões de malha, mas agora de malhas mais finas que antes. Naturalmente, se aumentarmos o limiar de corte do índice de alinhamento vamos eliminar cada vez mais o padrão de interferência de malha presente na distribuição do erro. Ao analisarmos os erros do teste de remapeamento, veja a Tabela 4.37, fica clara a convergência quadrática. Além disso, o padrão de interferência de malha fica mais sutil (Figura 4.56)

\begin{tabular}{|c|c|c|c|c|}
\hline \multicolumn{5}{|c|}{ Rec. vetorial para nós - Método Híbrido - PERHX+LSQHXE } \\
\hline Nível & Erro Máx & Erro 2 & Razão Máx & Razão 2 \\
\hline 0 & $3.4732 \mathrm{E}+01$ & $2.6482 \mathrm{E}+01$ & & \\
\hline 1 & $1.8988 \mathrm{E}+01$ & $1.1388 \mathrm{E}+01$ & 1.83 & 2.33 \\
\hline 2 & $7.6627 \mathrm{E}+00$ & $4.3632 \mathrm{E}+00$ & 2.48 & 2.61 \\
\hline 3 & $2.3142 \mathrm{E}+00$ & $1.2781 \mathrm{E}+00$ & 3.31 & 3.41 \\
\hline 4 & $6.1383 \mathrm{E}-01$ & $2.9991 \mathrm{E}-01$ & 3.77 & 4.26 \\
\hline 5 & $1.5348 \mathrm{E}-01$ & $6.9849 \mathrm{E}-02$ & 4.00 & 4.29 \\
\hline 6 & $3.8648 \mathrm{E}-02$ & $1.5727 \mathrm{E}-02$ & 3.97 & 4.44 \\
\hline 7 & $9.6758 \mathrm{E}-03$ & $3.6167 \mathrm{E}-03$ & 3.99 & 4.35 \\
\hline 8 & $3.4328 \mathrm{E}-03$ & $8.6646 \mathrm{E}-04$ & 2.82 & 4.17 \\
\hline
\end{tabular}

Tabela 4.36: Erros associados à reconstrução vetorial da onda de Rossby-Haurwitz de uma malha HC para os vértices dos triângulos, nós das células de Voronoi, usando o método híbrido com Perot (PERHX) e minimos quadrados (LSQHXE) com limiar de corte para o indice de alinhamento de 0.01. 


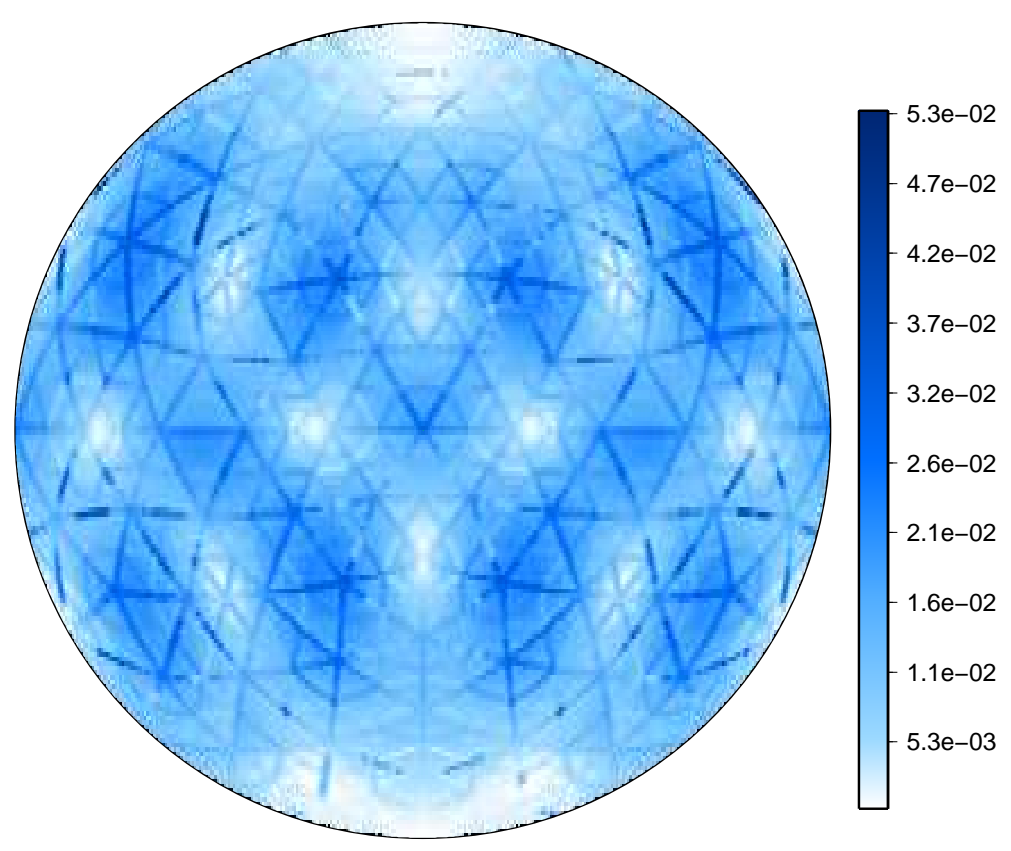

Figura 4.55: Distribuição do erro para a reconstrução vetorial da onda de Rossby-Haurwitz de uma malha icosaédrica de nível 6 do tipo HC para os vértices dos triângulos, nós das células de Voronoi, usando o método híbrido com Perot (PERHX) e mínimos quadrados (LSQHXE) com limiar de corte para o indice de alinhamento de 0.01 .

\begin{tabular}{|c|c|c|c|c|}
\hline \multicolumn{5}{|c|}{ Remap lon-lat - Método Híbrido - PERHX+LSQHXE / CBTR } \\
\hline Nível & Erro Máx & Erro 2 & Razão Máx & Razão 2 \\
\hline 0 & $8.6392 \mathrm{E}+01$ & $3.7954 \mathrm{E}+01$ & & \\
\hline 1 & $5.0176 \mathrm{E}+01$ & $2.2555 \mathrm{E}+01$ & 1.72 & 1.68 \\
\hline 2 & $1.8899 \mathrm{E}+01$ & $8.6629 \mathrm{E}+00$ & 2.65 & 2.60 \\
\hline 3 & $6.2158 \mathrm{E}+00$ & $2.5143 \mathrm{E}+00$ & 3.04 & 3.45 \\
\hline 4 & $1.6589 \mathrm{E}+00$ & $6.2250 \mathrm{E}-01$ & 3.75 & 4.04 \\
\hline 5 & $4.2003 \mathrm{E}-01$ & $1.5217 \mathrm{E}-01$ & 3.95 & 4.09 \\
\hline 6 & $1.0211 \mathrm{E}-01$ & $3.6824 \mathrm{E}-02$ & 4.11 & 4.13 \\
\hline 7 & $2.5428 \mathrm{E}-02$ & $8.8063 \mathrm{E}-03$ & 4.02 & 4.18 \\
\hline 8 & $6.1211 \mathrm{E}-03$ & $2.1882 \mathrm{E}-03$ & 4.15 & 4.02 \\
\hline
\end{tabular}

Tabela 4.37: Erros associados à reconstrução vetorial da onda de Rossby-Haurwitz de uma malha HC para pontos de uma malha do tipo longitude latitude com 1 grau usando primeiro uma RVN com o método híbrido, Perot (PERHX) e minimos quadrados (LSQHXE) com limiar de corte para o índice de alinhamento de 0.01, e depois o método de interpolação com coordenadas baricêntricas para triângulos (CBTR). 


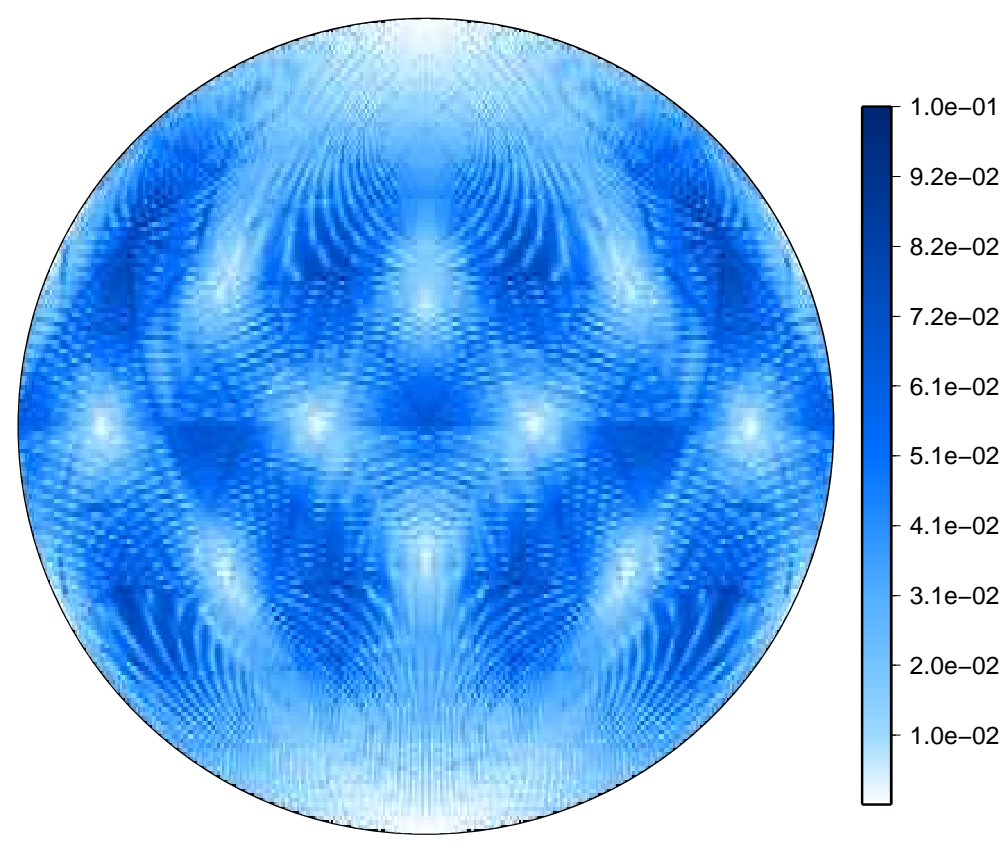

Figura 4.56: Distribuição do erro para a reconstrução vetorial da onda de Rossby-Haurwitz de uma malha icosaédrica $H C$ de nível 6 para pontos de uma malha do tipo longitude latitude com 1 grau usando primeiro uma RVN com o método híbrido, Perot (PERHX) e mínimos quadrados (LSQHXE) com limiar de corte para o indice de alinhamento de 0.01 , e depois o método de interpolação com coordenadas baricêntricas para triângulos (CBTR). 
O método híbrido proposto é aplicável não somente à malha icosaédrica, mas para qualquer malha geodésica, uma vez que a teoria de alinhamento é geral para malhas geodésicas. Testamos o método para uma malha icosaédrica otimizada com SCVT. Nesse caso, como a otimização melhora as propriedades de alinhamento da malha, o parâmetro de corte para o alinhamento de células precisa ser adaptado. Em malhas icosaédricas otimizadas com SCVT a proporção de células desalinhadas é bastante reduzida, sendo que, podemos assumir que $95 \%$ das células podem ser consideradas alinhadas, independente do nível de malha.

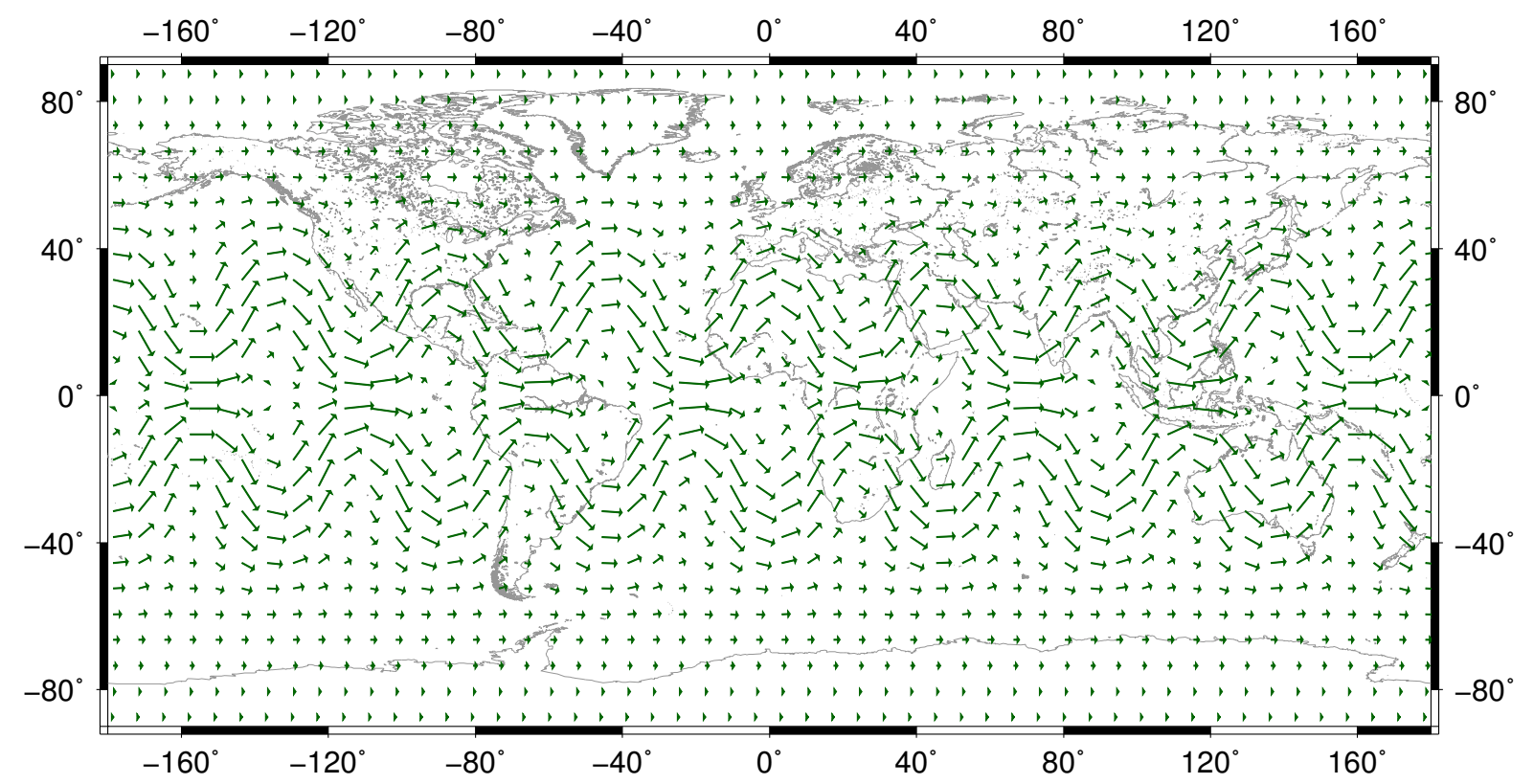

Figura 4.57: Onda de Rossby-Haurwitz de número 8.

Para captarmos melhor as diferenças entre os métodos envolvidos na reconstrução híbrida vamos usar uma onda de Rossby-Haurwitz de número 8 (ilustrada na Figura 4.57). Apresentamos na Tabela 4.38 os erros obtidos na reconstrução desse campo vetorial de uma malha HC para os vértice dos triângulos com o método de Perot (PERHX) e com o método híbrido. Verifica-se claramente a diferença na taxa de convergência.

\begin{tabular}{|c|c|c|c|c|c|c|c|c|}
\hline \multicolumn{7}{|c|}{ Rec. vetorial para nós - Método Híbrido - Malha SCVT } \\
\hline \multicolumn{3}{|c|}{ PERHX+LSQHXE (5\%) } & \multicolumn{5}{c|}{ PERHX } \\
\hline Nível & Erro Máx & Erro 2 & Raz Máx & Raz 2 & Erro Máx & Erro 2 & Raz Máx & Raz 2 \\
\hline 0 & $7.25 \mathrm{E}+01$ & $4.93 \mathrm{E}+01$ & & & $7.30 \mathrm{E}+01$ & $4.96 \mathrm{E}+01$ & & \\
\hline 1 & $5.17 \mathrm{E}+01$ & $2.70 \mathrm{E}+01$ & 1.40 & 1.82 & $4.88 \mathrm{E}+01$ & $2.62 \mathrm{E}+01$ & 1.49 & 1.89 \\
\hline 2 & $2.26 \mathrm{E}+01$ & $9.83 \mathrm{E}+00$ & 2.29 & 2.75 & $1.88 \mathrm{E}+01$ & $9.31 \mathrm{E}+00$ & 2.60 & 2.82 \\
\hline 3 & $8.08 \mathrm{E}+00$ & $2.87 \mathrm{E}+00$ & 2.80 & 3.42 & $5.38 \mathrm{E}+00$ & $2.55 \mathrm{E}+00$ & 3.49 & 3.64 \\
\hline 4 & $2.14 \mathrm{E}+00$ & $6.96 \mathrm{E}-01$ & 3.77 & 4.13 & $1.46 \mathrm{E}+00$ & $6.55 \mathrm{E}-01$ & 3.69 & 3.90 \\
\hline 5 & $5.94 \mathrm{E}-01$ & $1.76 \mathrm{E}-01$ & 3.61 & 3.96 & $3.66 \mathrm{E}-01$ & $1.65 \mathrm{E}-01$ & 3.98 & 3.97 \\
\hline 6 & $1.49 \mathrm{E}-01$ & $4.39 \mathrm{E}-02$ & 3.99 & 4.00 & $1.42 \mathrm{E}-01$ & $4.15 \mathrm{E}-02$ & 2.58 & 3.98 \\
\hline 7 & $3.71 \mathrm{E}-02$ & $1.10 \mathrm{E}-02$ & 4.01 & 4.00 & $6.50 \mathrm{E}-02$ & $1.04 \mathrm{E}-02$ & 2.18 & 3.98 \\
\hline 8 & $9.34 \mathrm{E}-03$ & $2.77 \mathrm{E}-03$ & 3.98 & 3.97 & $3.08 \mathrm{E}-02$ & $2.63 \mathrm{E}-03$ & 2.11 & 3.96 \\
\hline
\end{tabular}

Tabela 4.38: Erros associados à reconstrução vetorial da onda de Rossby-Haurwitz de número 8 de uma malha icosaédrica HC, otimizada com SCVT, para os vértices dos triângulos (RVN) usando o método híbrido com Perot (PERHX) e mínimos quadrados (LSQHXE) com limiar de corte para o indice de alinhamento tal que $5 \%$ das células sejam mal alinhadas. 


\subsubsection{Comparativo}

Vamos agora comparar os métodos de reconstruções do ponto de vista de custo computacional e precisão. Analisamos os tempos de execução dos diversos algoritmos em 3 situações:

- Tempo total - Medida de tempo que inclui tanto a reconstrução para os nós (RVN) ou circuncentros dos triângulos (RVC) quanto um remapeamento da malha icosaédrica para uma malha regular do tipo longitude-latitude com $360 \times 180$ pontos.

- Tempo de Reconstrução - Medida de tempo que inclui apenas o tempo de reconstrução (RVN ou RVC).

- Overhead na reconstrução - Medida de tempo comum a todos os métodos de reconstrução. Nesse caso, nenhuma reconstrução é feita. Considera-se o vetor reconstruído nulo. Essa medida só diz respeito à parte de reconstrução e não a parte de remapeamento para malha regular.

As análises de tempos computacionais são baseadas em médias de 15 repetições em cada experimento. A malha usada foi a icosaédrica de nível 7 em todos os casos. Nos remapeamentos com base em reconstruções para circuncentros (RVC) usamos sempre o método de interpolação vetorial de coordenadas baricêntricas generalizadas de Wachspress. No caso de remapeamentos com base em reconstruções para os nós (RVN) usamos sempre o método de interpolação vetorial com coordenadas baricêntricas para triângulos.

Os resultados estão dispostos nas Tabelas 4.39 e 4.40. O primeiro fato interessante a se observar é que, quando não executamos nenhuma reconstrução e medimos somente o tempo das partes comuns aos métodos, o tempo de execução total no caso RVN é menor que no caso RVC. Isso ocorre pois temos aproximadamente duas vezes mais triângulos do que nós na malha.

\begin{tabular}{|c|c|c|c|c|c|c|c|}
\hline & \multicolumn{3}{|c|}{ Tempo de execução } & \multicolumn{2}{c|}{ Erro RVN } & \multicolumn{2}{c|}{ Erro Remap LL } \\
\hline Método & RVN+RLL & RVN & RVN-OH & Máx & 2 & Máx & 2 \\
\hline Sem recon & 0.3526 & 0.2710 & 0.0000 & & & & \\
\hline EBB & 0.8606 & 0.7718 & 0.5008 & $7.50 \mathrm{E}-02$ & $7.83 \mathrm{E}-03$ & $6.50 \mathrm{E}-02$ & $9.65 \mathrm{E}-03$ \\
\hline PERHX & 0.4158 & 0.3283 & 0.0573 & $9.34 \mathrm{E}-02$ & $9.50 \mathrm{E}-03$ & $8.56 \mathrm{E}-02$ & $1.05 \mathrm{E}-02$ \\
\hline RBFHX-e1 & 0.5192 & 0.4310 & 0.1600 & $1.33 \mathrm{E}-02$ & $2.72 \mathrm{E}-03$ & $2.08 \mathrm{E}-02$ & $7.28 \mathrm{E}-03$ \\
\hline LSQHXE & 1.0129 & 0.9249 & 0.6539 & $9.88 \mathrm{E}-03$ & $5.29 \mathrm{E}-03$ & $2.74 \mathrm{E}-02$ & $1.03 \mathrm{E}-02$ \\
\hline Híbrido & 0.5216 & 0.4328 & 0.1619 & $9.68 \mathrm{E}-03$ & $3.62 \mathrm{E}-03$ & $2.54 \mathrm{E}-02$ & $8.81 \mathrm{E}-03$ \\
\hline
\end{tabular}

Tabela 4.39: Comparação dos tempos de execução e erros para diversos métodos de reconstruções vetoriais do tipo RVN (para os nós das células de Voronoi). A coluna $R V N+R L L$ indica o tempo de execução em segundos da reconstrução incluindo a reconstrução para os nós da malha e o remapeamento para uma malha longitude-latidude com um grau de espaçamento. A coluna RVN mostra o tempo total da parte de reconstrução para os nós da malha. A coluna $\mathrm{RVN}-\mathrm{OH}$ indica o tempo de reconstrução para os nós menos o tempo de overhead (OH), que é o tempo sem reconstrução alguma. As demais colunas indicam os erros máximo e quadráticos (2) para a reconstrução (RVN) e o remapeamento (RLL). Malha icosaédrica de nível $\%$.

Em todos os método do tipo RBF usamos um parâmetro de formato $\epsilon=1$. O método de reconstrução para nós por RBF com 5 ou 6 arestas (RBFHX) revelou uma relação custo-precisão boa, revelando o menor erro no remapeamento para malha regular. O mesmo ocorre no caso da reconstrução para circuncentros com 9 arestas (RBFETR). Apesar disso, há que se lembrar que o método está sujeito a possíveis problemas de instabilidades numéricas em malhas muitos finas, como vimos anteriormente. Por outro lado, os método de aproximações polinomiais por mínimos quadrados (LSQHXE e LSQTRC) apresentam excelentes aproximações sem o problema de instabilidade.

Nos métodos de funções radiais (RBFHX, RBFTR, RBFETR), como as matrizes dos sistemas lineares a serem resolvidos só dependem da malha, pré-calculamos as decomposições de Cholesky $\left(L^{t} D L\right)$, reduzindo o custo computacional na hora da reconstrução. No caso dos métodos de mínimos quadrados (LSQHXE e LSQTRC), os sistemas foram construídos e resolvidos na hora da reconstrução, apesar das matrizes dos sistemas de mínimos quadrados $(A)$ dependerem somente da 


\begin{tabular}{|c|c|c|c|c|c|c|c|}
\hline & \multicolumn{3}{|c|}{ Tempo de execução } & \multicolumn{2}{c|}{ Erro RVC } & \multicolumn{2}{c|}{ Erro Remap LL } \\
\hline Método & RVC+RLL & RVC & RVC-OH & Máx & 2 & Máx & 2 \\
\hline Sem recon & 0.4408 & 0.3584 & 0.0000 & - & - & - & - \\
\hline WHT & 0.7064 & 0.4472 & 0.0888 & $6.81 \mathrm{E}-01$ & $4.29 \mathrm{E}-01$ & $5.80 \mathrm{E}-01$ & $7.31 \mathrm{E}-02$ \\
\hline PERTR & 0.7003 & 0.4416 & 0.0832 & $6.78 \mathrm{E}-01$ & $4.60 \mathrm{E}-01$ & $5.79 \mathrm{E}-01$ & $7.84 \mathrm{E}-02$ \\
\hline RBFTR-e1 & 0.8078 & 0.5491 & 0.1907 & $6.78 \mathrm{E}-01$ & $4.12 \mathrm{E}-01$ & $5.79 \mathrm{E}-01$ & $7.00 \mathrm{E}-02$ \\
\hline RBFETR-e1 & 1.0016 & 0.7438 & 0.3854 & $5.70 \mathrm{E}-03$ & $3.12 \mathrm{E}-03$ & $1.96 \mathrm{E}-02$ & $6.45 \mathrm{E}-03$ \\
\hline LSQTRC & 1.4748 & 1.2158 & 0.8574 & $1.04 \mathrm{E}-02$ & $7.14 \mathrm{E}-03$ & $2.54 \mathrm{E}-02$ & $9.03 \mathrm{E}-03$ \\
\hline
\end{tabular}

Tabela 4.40: Comparação dos tempos de execução e erros para diversos métodos de reconstruções vetoriais do tipo RVC (para os circuncentros dos triângulos). A coluna $R V C+R L L$ indica o tempo de execução em segundos da reconstrução incluindo a reconstrução para os circuncentros dos triângulos e o remapeamento para uma malha longitude-latidude com um grau de espaçamento. A coluna RVN mostra o tempo total da parte de reconstrução para os nós da malha. A coluna $\mathrm{RVC}$-OH indica o tempo de reconstrução para os nós menos o tempo de overhead $(\mathrm{OH})$, que é o tempo sem reconstrução alguma. As demais colunas indicam os erros máximo e quadráticos (2) para a reconstrução (RVC) e o remapeamento (RLL).

malha. Por isso observamos tempos significativamente maiores em relação aos métodos de RBF. É possível pré-calcularmos e armazenarmos a pseudo-inversa $\left(\left(A^{t} A\right)^{-1} A^{t}\right)$ da matriz do sistema de mínimos quadrados, ou uma decomposição da matriz $A^{t} A$, para melhorarmos a performance do método. O custo-benefício desta abordagem é um tópico ainda a ser investigado.

Os métodos que usam somente as 3 arestas vizinhas para reconstrução nos circuncentros (WHT, PERTR e RBFTR) geram aproximações muito piores que os demais métodos. Nesse caso, o método de RBFTR revela um custo maior que outros dois métodos, mas uma precisão equivalente.

Os métodos de base de arestas (EBB) e de Perot para hexágonos (PERHX) indicam boas aproximações quando avaliamos o erro na norma quadrática, mas uma precisão pior quando usamos a norma do máximo. Ambos os métodos apresentam interferência de malha na distribuição do erro e, potencialmente, poderiam ser considerados em um método híbrido. Porém, o custo do método EBB é significativamente maior que o de Perot.

O método híbrido, considerando o método de Perot (PERHX) nas células melhor alinhadas e o método de mínimos quadrados (LSQHXE) nas células mal alinhadas, revelou um ótimo custobeneficio. Os erros obtidos são comparáveis aos dos métodos de maior precisão, porém o custo é bastante reduzido. No teste realizado usamos um parâmetro de corte para o índice de alinhamento de 0.01 , que na malha de nível 7 resulta em aproximadamente $15 \%$ de células mal alinhadas. 


\section{Capítulo 5}

\section{Transporte semi-lagrangiano em malhas icosaédricas}

Um método lagrangiano de integração numérica de equações de dinâmica dos fluidos considera a evolução de cada partícula de uma substância individualmente. Dessa forma, para o caso de modelos meteorológicos, um observador vê a evolução da atmosfera ao seu redor, enquanto é transportado por uma partícula do fluido. Em contraste, temos os métodos eulerianos, onde um observador vê a evolução da atmosfera de um ponto fixo. Em métodos do tipo lagrangianos, dada a posição de uma partícula em um certo instante de tempo, usam-se as características da trajetória da partícula no fluido para saber de onde a partícula partiu em um instante de tempo anterior, ou então para onde a partícula irá, em um momento futuro. Ao considerarmos um método lagrangiano em uma malha numérica, no qual temos um referencial fixado, o ponto de partida ou chegada pode não pertencer à malha. Um método semi-lagrangiano é aquele que mescla a malha com referencial fixado, comum para métodos eulerianos, com cálculos de trajetórias de partículas, comum em métodos lagrangianos, por isso a denominação semi. Uma vantagem de se usar um método semi-lagrangiano é poder usar passos de tempos maiores que no caso euleriano (explicito), por não estar restrito à condição de CFL. O trabalho de Staniforth e Côté [1991] faz uma revisão de métodos semi-lagrangianos até a década de 90. De 1990 até hoje diversos métodos semi-lagrangianos foram propostos, mas são essencialmente adaptações dos métodos descritos em Staniforth e Côté [1991]. O trabalho de Carfora [2007b] faz uma breve análise sobre a abordagem semi-lagrangiana para malhas geodésicas.

Entre os modelos existentes que usam malhas icosaédricas, o modelo alemão GME chegou a testar um método semi-lagrangiano no estilo do descrito por Ritchie [1987] apenas para advecção de vapor de água e de nuvens (Majewski et al. [2002]). Para as interpolações dos ventos são usadas interpolações bilineares, usando coordenadas locais. Para as interpolações do campo escalar são usadas aproximações bi-quadráticas. No método usado no modelo é necessário fazer uma busca para determinar em qual triângulo encontra-se o ponto de partida, para a qual é usada uma busca binária. Como há componentes do modelo discretizados de forma euleriana explícita, o passo de tempo do modelo está sujeito à restrição de CFL. Para passos de tempo pequenos o método semilagrangiano é menos eficiente que métodos eulerianos e, por isso, o método semi-lagrangiano não tem sido usado no modelo.

Mais recentemente alguns pesquisadores têm investido no desenvolvimento de modelos de transporte para malhas geodésicas, incluindo as icosaédricas, mas em geral são métodos eulerianos que estão restritos à condição de CFL, como em Lipscomb e Ringler [2005], Miura [2007], Joppich e Pott [2008], Skamarock e Menchaca [2010b], Skamarock e Gassmann [2011] e Chen et al. [2012]. Em Lauritzen et al. [2010] foi proposto um método semi-lagrangiano conservativo mas somente para malhas geodésicas cubadas.

No presente trabalho, adotamos a estratégia de calculo da trajetória semi-lagrangiana descrita em Ritchie [1987], adaptada para malhas geodésicas. No trabalho de Ritchie [1987] é descrito um método com 3 níveis temporais, porém não é difícil considerar o método para 2 níveis de tempo, conforme descrito em Garcia [2001], potencialmente reduzindo o erro pela metade. Na abordagem 
destas duas referências, como a malha usada é de longitude-latitude, é necessário fazer conversões dos pontos e velocidades para coordenadas cartesianas. Neste trabalho, como estamos trabalhando com malhas geodésicas, podemos resolver diretamente o cálculo de trajetória em coordenadas cartesianas, supondo que ambos os pontos e as velocidades sejam dados também em coordenadas cartesianas. Isso simplifica bastante os cálculos, como veremos adiante.

Para testar o método proposto usaremos um teste de rotação com velocidade variável e ainda casos de deformações descritos em Nair e Lauritzen [2010].

\subsection{Modelo de transporte}

Sejam $\rho(r, t)$ a densidade do fluido, $\phi(r, t)$ a concentração de uma substância (ou traçador) no fluido por unidade de massa do fluido e $\vec{v}(r, t)$ a velocidade do fluido em um ponto $r$ da esfera, em um instante $t$ do tempo. As equações do transporte na forma de fluxos para a conservação de massa do fluido e da substância são dadas por

$$
\begin{aligned}
\frac{\partial \rho}{\partial t}+\nabla \cdot(\rho \vec{v}) & =0 \\
\frac{\partial \rho \phi}{\partial t}+\nabla \cdot(\rho \phi \vec{v}) & =0 .
\end{aligned}
$$

Estamos assumindo que não há difusão, fontes ou sumidouros. Podemos representar (5.1) na forma lagrangiana como

$$
\begin{aligned}
& \frac{D \phi(r, t)}{D t}=0, \\
& \frac{D \rho(r, t)}{D t}=-\rho \nabla \cdot \vec{v},
\end{aligned}
$$

onde $p$ é a posição de uma partícula na esfera,

$$
\frac{D}{D t}=\frac{\partial}{\partial t}+\vec{v} \cdot \nabla
$$

é a derivada total, ou material, e $\vec{v}$ é o campo de velocidades do fluido tal que,

$$
\vec{v}=\frac{d r(t)}{d t}
$$

\subsection{Método semi-lagrangiano}

Vamos supor o campo de velocidades conhecido em qualquer instante de tempo em um conjunto de pontos de malha. Mais especificamente, vamos assumir que conhecemos as componentes normais das velocidades em relação às arestas das células de Voronoi em seus pontos médios (malha tipo $\mathrm{HC})$.

A concentração do composto $\phi$ não varia ao longo da trajetória da partícula e, portanto, podemos assumir a seguinte discretização para $\phi$,

$$
\phi_{c}^{t+\Delta t}=\phi_{p}^{t}
$$

onde $\phi_{c}^{t+\Delta t}=\phi\left(r_{c}, t+\Delta t\right)$ é a concentração no tempo $t+\Delta t$ em um ponto de chegada da partícula $r_{c}$, que deve ser um ponto de malha, e $\phi_{p}^{t}=\phi\left(r_{p}, t\right)$ é a concentração no tempo $t$ em um ponto de partida da partícula $r_{p}$, que não necessariamente é um ponto de malha. Dessa forma, para obtermos a concentração no ponto de malha $r_{c}$ no tempo $t+\Delta t$ precisamos estimar a trajetória para obter o 
ponto $r_{p}$ e interpolar o valor de $\phi$ neste ponto com base nos valores dados em pontos de malha no instante $t$.

Para a equação da densidade precisamos também discretizar o termo de divergência. Vamos estimar o termo de divergência como a média do divergente no ponto de partida e a do ponto de chegada no tempo intermediário $t+\Delta t / 2$, assim

$$
\rho_{c}^{t+\Delta t}=\rho_{p}^{t}-\frac{\Delta t}{2}\left[(\rho \nabla \cdot \vec{v})_{p}^{t+\Delta t / 2}+(\rho \nabla \cdot \vec{v})_{c}^{t+\Delta t / 2}\right] .
$$

Numericamente podemos estimar a densidade no ponto de chegada no tempo $t+\Delta t$ como sendo,

$$
\rho_{c}^{t+\Delta t}=\left(\rho^{t}-\frac{\Delta t}{2}(\rho \nabla \cdot \vec{v})^{t+\Delta t / 2}\right)_{p}-\frac{\Delta t}{2}(\rho \nabla \cdot \vec{v})_{c}^{t+\Delta t / 2},
$$

isto é, primeiro calculamos o campo escalar $\rho^{t}-\frac{\Delta t}{2}(\rho \nabla \cdot \vec{v})^{t+\Delta t / 2}$ nos pontos de malha e depois interpolamos o valor deste campo no ponto de partida. Com isso reduzimos o número de interpolações a serem realizadas. Neste caso estamos assumindo que o campo de velocidades é conhecido em qualquer instante de tempo nas arestas da malha, portanto esse será conhecido no tempo $t+\Delta t / 2$, porém não conhecemos $\rho$ nesse instante de tempo. Para estimarmos a densidade no tempo intermediário vamos usar uma extrapolação linear,

$$
\rho^{t+\Delta t / 2}=\frac{3 \rho^{t}}{2}-\frac{\rho^{t-\Delta t}}{2} .
$$

Para o passo de tempo inicial usaremos que $\rho^{\Delta t / 2}=\rho^{0}$.

No método semi-lagrangiano temos 3 fontes básicas de erros:

(i) Erro devido à interpolação do campo escalar, que ocorre pois em geral não conhecemos o valor do campo escalar no ponto de partida.

(ii) Erro devido ao cálculo do ponto de partida, que é um erro devido ao cálculo da trajetória. Esse erro pode ser dividido em duas partes: o erro na discretização temporal e os erros devido às interpolações/reconstruções vetoriais.

(iii) Erro na estimativa do divergente.

\subsection{Cálculo da trajetória}

Seja $r(t)$ a posição de uma partícula no instante de tempo $t$. Suponha que conhecemos a posição de chegada da partícula no tempo $t+\Delta t$ e queremos saber de onde se originou essa partícula, isto é, queremos achar o ponto de partida $r_{p}=r(t)$ dado o ponto de chegada $r_{c}=r(t+\Delta t)$. Como vamos assumir um método de 2 níveis no tempo, para preservarmos segunda ordem, vamos considerar primeiro uma estimativa para um ponto médio da trajetória e, posteriormente, vamos obter a estimativa para o ponto de partida. A aproximação em segunda ordem para a partícula $r$ no ponto médio da trajetória pode ser dada por

$$
r(t+\Delta t)=r\left(t+\frac{\Delta t}{2}\right)+\frac{\Delta t}{2} \dot{r}\left(t+\frac{\Delta t}{2}\right)+O\left((\Delta t)^{2}\right),
$$

e portanto,

$$
r\left(t+\frac{\Delta t}{2}\right)=r_{c}-\frac{\Delta t}{2} \dot{r}\left(t+\frac{\Delta t}{2}\right)+O\left((\Delta t)^{2}\right),
$$

que podemos corrigir para que permaneça na esfera, mantendo segunda ordem, tomando

$$
r\left(t+\frac{\Delta t}{2}\right)=\frac{r_{c}-\frac{\Delta t}{2} \dot{r}\left(t+\frac{\Delta t}{2}\right)}{\left\|r_{c}-\frac{\Delta t}{2} \dot{r}\left(t+\frac{\Delta t}{2}\right)\right\|} .
$$




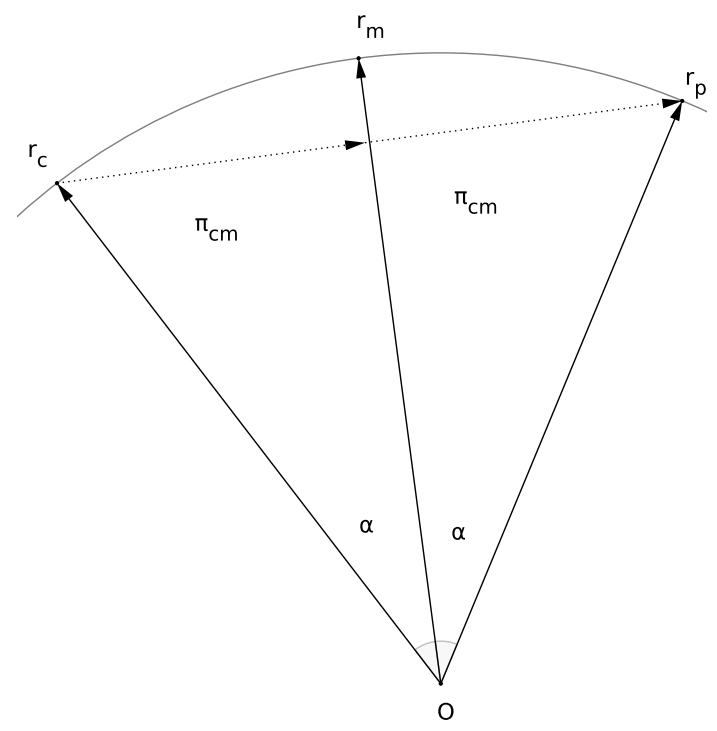

Figura 5.1: Relações entre os pontos de chegada, médio e de partida.

O valor de $\dot{r}\left(t+\frac{\Delta t}{2}\right)$ depende implicitamente da posição do ponto médio médio da trajetória, $r_{m}=r\left(t+\frac{\Delta t}{2}\right)$, logo, para achar o ponto médio da trajetória temos que resolver essa equação não linear. Usamos um método iterativo para isso, considerando a equação de iteração como sendo

$$
r_{m}^{k+1}=\frac{r_{c}-\frac{\Delta t}{2} \vec{v}_{m}^{k}}{\left\|r_{c}-\frac{\Delta t}{2} \vec{v}_{m}^{k}\right\|}
$$

onde $\vec{v}_{m}^{k}$ é a velocidade no tempo $t+\Delta t / 2$ no ponto médio $r_{m}^{k}$. Supondo o campo de velocidades conhecido nas arestas da malha (malha $\mathrm{HC}$ ), o valor de $\vec{v}_{m}^{k}$ pode ser reconstruído para o ponto $r_{m}$, uma vez que esse não será necessariamente um ponto de malha. Podemos tomar como posição inicial $r_{m}^{0}$ do ponto médio o ponto de chegada $r_{c}$. De acordo com Staniforth e Côté [1991], duas ou três iterações são suficientes para obter uma boa estimativa do ponto médio da trajetória.

Para obtermos o ponto de partida tomamos o vetor pertencente ao plano formado por $r_{m}$ e $r_{c}$ tal que o ângulo entre $r_{p}$ e $r_{m}$ seja o mesmo de $r_{c}$ e $r_{m}$. Assim podemos obter o ponto de partida $r_{p}$ como sendo,

$$
r_{p}=2\left\langle r_{m}, r_{c}\right\rangle r_{m}-r_{c},
$$

que apresentamos na Figura 5.1, onde $\pi_{c m}=\left\langle r_{m}, r_{c}\right\rangle r_{m}$ é a projeção ortogonal de $r_{c}$ em $r_{m}$. Essa última etapa faz com que os erros de segunda ordem se cancelem, caso seja conhecido o valor exato do campo vetorial em qualquer instante, resultando em um método de terceira ordem no tempo (veja o apêndice $\mathrm{C}$ para mais detalhes).

\subsection{Análise de convergência}

Um teste usual para modelos de transporte na esfera é a advecção passiva por rotação, como descrito em Williamson et al. [1992], o qual usaremos para validar os métodos implementados.

$\mathrm{Na}$ implementação do método semi-lagrangiano em uma malha do tipo HC, com escalares dados nos vértices dos triângulos e supondo conhecidas apenas as componentes normais das velocidades dadas nos pontos médios das arestas das células de Voronoi, há dois locais onde interpolações são importantes: no cálculo da trajetória, no qual iremos usar alguns métodos discutidos no capítulo de reconstruções vetoriais; e na estimativa de campos escalares ( $\rho$ e $\phi)$ no ponto de partida, em que vamos usar o método $C^{1}$ de Renka.

Para a reconstrução vetorial consideramos dois métodos: (i) o método de aproximação polinomial 
com mínimos quadrados na reconstrução para os circuncentros dos triângulos, seguido de uma interpolação usando coordenadas de Wachspress (LSQTRC/WCHX), (ii) o método híbrido, usando Perot para as células mais bem alinhadas e aproximação polinomial com mínimos quadrados para as mal alinhadas, seguido de uma interpolação usando coordenadas baricêntricas para triângulos (PERHX/LSQHXE/CBTR). Para as malhas icosaédricas sem otimização, adotaremos o parâmetro de corte para o índice de alinhamento no método híbrido de 0.01 . Ambos os métodos são de segunda ordem, mas como vimos anteriormente, o método híbrido tem um custo menor.

Para a análise de convergência vamos considerar uma rotação de uma Gaussiana ao redor do eixo $z$, isso é, em torno do equador. Nos trabalhos de Ritchie [1987] e Garcia [2001] eles consideram a rotação em torno de um outro eixo, para forçar com que a substância (traçador) passe por um polo. Como estamos usando uma malha isotrópica, isso não se faz necessário e usamos a rotação seguindo o equador.

A rotação ao redor do eixo $z$ define um campo com velocidades constantes no tempo. Apesar de ser um teste interessante para as interpolações, pode ser muito simples para analisar o método de cálculo da trajetória. Para deixar o método mais interessante incluímos um caso onde a rotação tem velocidade variável. Em coordenadas geográficas, definimos a trajetória lagrangiana de um ponto de partida na esfera $\left(\lambda_{0}, \theta_{0}\right)$, em coordenadas geográficas, no instante de tempo $t$ como sendo

$$
\begin{aligned}
\lambda(t) & =\lambda_{0}+a(t), \\
\theta(t) & =\theta_{0},
\end{aligned}
$$

onde $a(t)$ é uma função que depende só do tempo, dada por

$$
a(t)=\frac{2 \pi t}{T}+\delta t b(t)
$$

onde $T$ é o período total de uma revolução, que adotaremos como sendo $T=5, \delta$ é uma constante e $b(t)$ é função somente do tempo. $a(t)$ é tal que $\lambda(0)=\lambda_{0}$, e $b(t)$ deve ser tal que ao final de um ciclo completo $(\mathrm{T})$ retornemos à condição inicial. Assim, devemos forçar que

$$
a(T)=2 \pi+\delta T b(t)=0+2 k \pi, \quad k \in \mathbb{Z} .
$$

Definiremos $b(t)$ como uma onda senoidal, dada por

$$
b(t)=\sin \left(\frac{2 \pi t}{T}\right)
$$

e adotaremos

$$
\delta=\frac{2 \pi}{3 T}
$$

A velocidade da partícula lagrangiana terá componente meridional nula $(v=0)$, mas componente zonal não nula. A componente zonal da velocidade em um ponto $(\lambda, \theta)$ qualquer da esfera, no instante $t$, será dada por

$$
u(\lambda, \theta, t)=\lambda^{\prime}(t) \cos (\theta)=a^{\prime}(t) \cos (\theta)=\frac{2 \pi}{T} \cos (\theta)+\delta\left(b(t)+t b^{\prime}(t)\right) \cos (\theta),
$$

tal que o primeiro termo resultante define a rotação com velocidade constante, e o termo multiplicado pela constante $\delta$ irá definir a variação da velocidade. Se $\delta=0$, então temos o caso de velocidade constante. Mostramos na Figura 5.2 o gráfico de $a^{\prime}(t)$, que mostra a componente variável da velocidade no tempo para o caso onde $T=5$ e $\delta=\frac{2 \pi}{3 T}$. Observe-se que neste caso há um momento em que teremos velocidades negativas, indicando que a rotação terá sentido invertido.

Se quisermos encontrar o ponto de partida exato no tempo $(t-d t)$ de um ponto chegada $(\lambda(t), \theta(t))$, basta tomar

$$
\lambda(t-d t)=\lambda_{0}+a(t-d t)=\lambda(t)-a(t)+a(t-d t)
$$




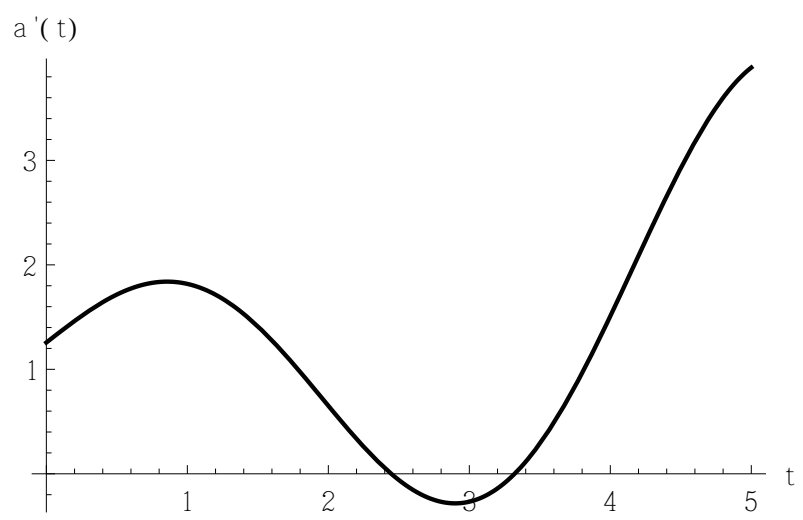

Figura 5.2: Gráfico da função de variação da velocidade no tempo $\left(a^{\prime}(t)\right)$.

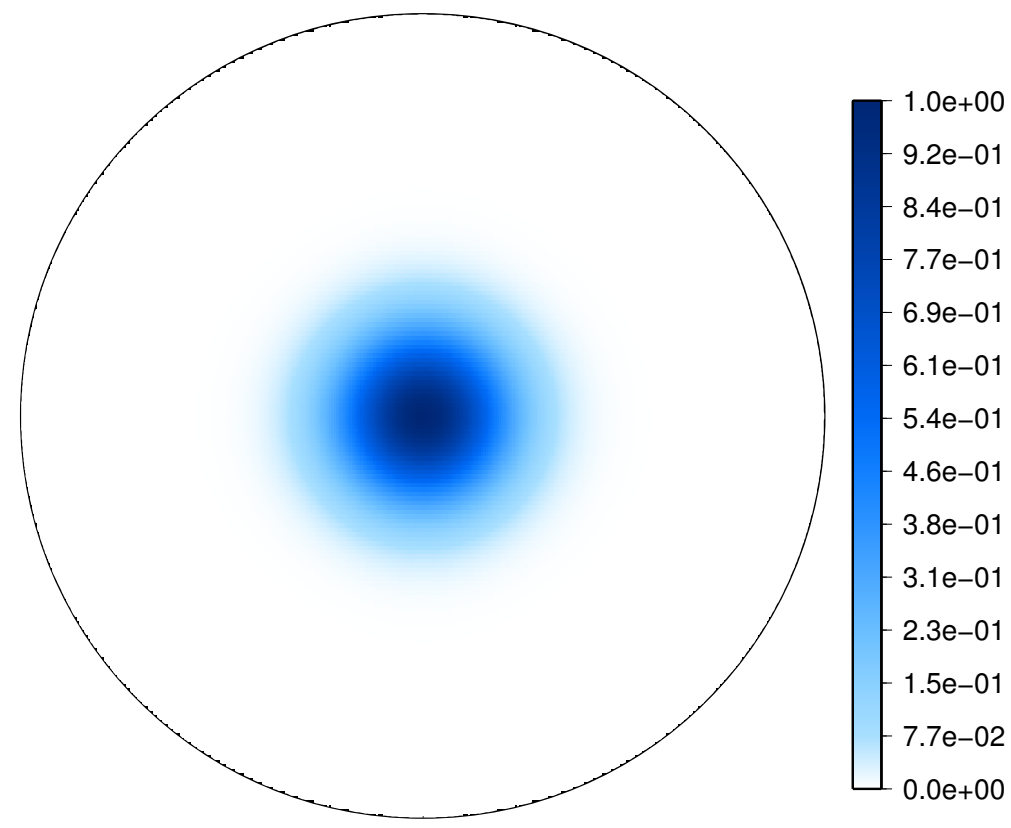

Figura 5.3: Condição inicial de $\phi$ para o teste de rotação.

e $\theta(t-d t)=\theta(t)$.

A condição inicial que utilizamos para o traçador é uma Gaussiana dada, em longitude-latitude, por

$$
\phi(\lambda, \theta)=\exp ^{-180 \frac{\lambda^{2}+\theta^{2}}{\pi L}},
$$

onde $L$ é um parâmetro que determina a largura (adotamos $L=5$ ). Ilustramos a condição inicial na Figura 5.3. Para avaliar o campo escalar exato em qualquer instante de tempo $t$ em um ponto $(\lambda, \theta)$, usamos

$$
\phi_{T}(\lambda, \theta, t)=\phi(\lambda-a(t), \theta) .
$$

Com isso definimos um teste de transporte com velocidade variável no tempo e solução não trivial que permite avaliar cada componente de discretização do modelo separadamente, considerando as demais exatas.

$\mathrm{Na}$ análise vamos usar o conceito de número de Courant, que vamos definir agora. O número de Courant (C) é um número adimensional que relaciona a discretização temporal e espacial. Ele pode ser estimado como

$$
C=u_{\max } \frac{d t}{h},
$$

onde $u_{\max }$ é a máxima velocidade de transporte, em valor absoluto, $h$ é o espaçamento médio entre dois pontos de malha, em radianos, e $d t=T / N T$, onde $N T$ é o número de passos no tempo para uma 


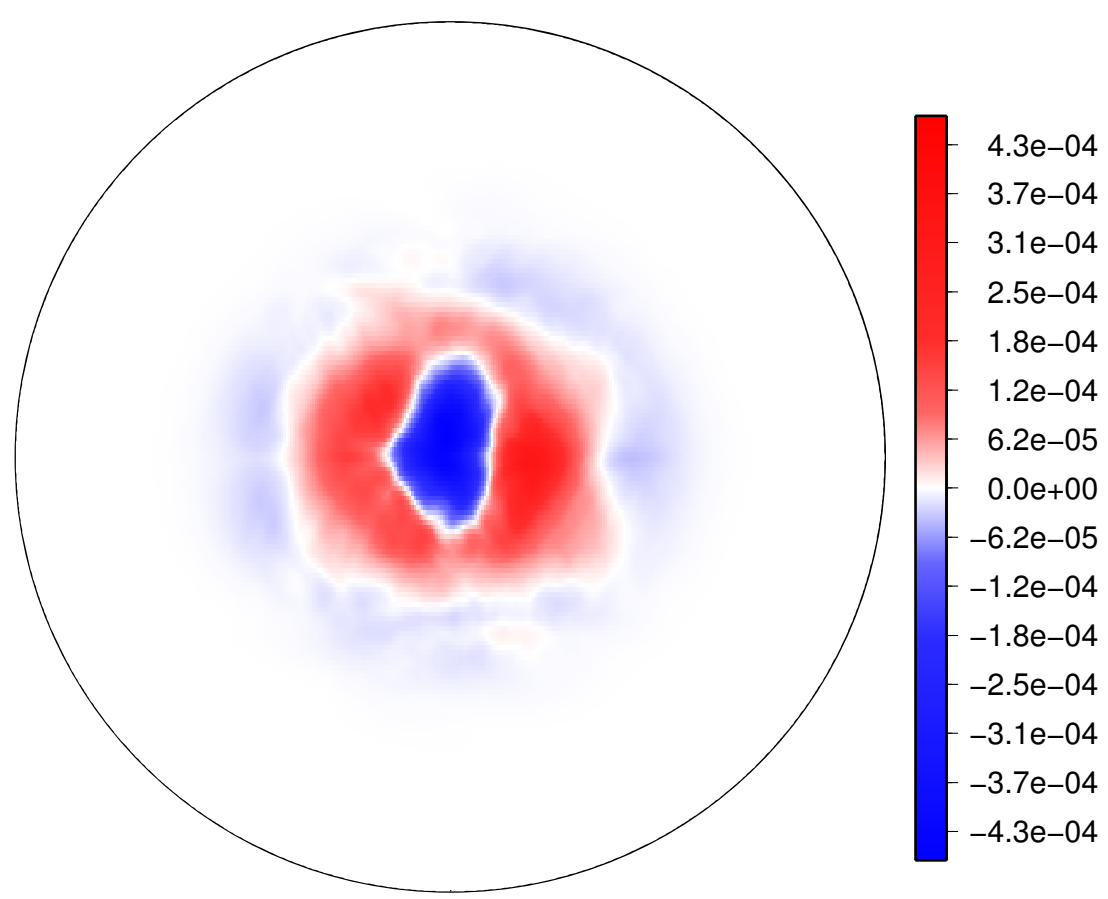

Figura 5.4: Erro na variável $\phi$ no tempo final do teste de rotação com velocidade variável com cálculos de trajetórias exatos e erros somente devido à interpolação escalar (C1RK). Malha icosaédrica de nível 6 e 128 passos de tempo.

revolução completa com período total $T$. Para o exemplo de rotação variável $u_{\max }^{v}=u(0,0, T) \approx$ 3.89 radianos por unidade de tempo. No caso de velocidade constante temos $u_{\max }^{c} \approx 1.25$. Logo, o número de Courant para o caso de velocidade variável será aproximadamente $u_{\max }^{v} / u_{\max }^{c} \approx 3.1$ vezes maior que o número de Courant com velocidade constante.

\subsubsection{Interpolação escalar}

A primeira validação possível é considerando a trajetória calculada exatamente e analisando apenas o erro devido a sucessivas interpolações escalares. Apresentamos os erros de $\phi$ para esse caso na Tabela 5.1, onde usamos 128 passos de tempo para obtermos uma revolução completa da rotação com velocidade variável. Apesar de observarmos oscilações na taxa de convergência, os resultados são condizentes com o método de interpolação escalar adotado (C1RK). Na Figura 5.4 mostramos o erro na variável $\phi$ ao final de uma revolução completa considerando 128 passos de tempo e uma malha de nível 6. Nota-se uma leve difusão da condição inicial.

\begin{tabular}{|c|c|c|c|c|}
\hline \multicolumn{5}{|c|}{ Rotação Variável - Erro de sucessivas interpolações escalares } \\
\hline Nível & Erro Máx & Erro 2 & Razão Máx & Razão 2 \\
\hline 3 & $3.30 \mathrm{E}-01$ & $3.21 \mathrm{E}-02$ & & \\
\hline 4 & $6.57 \mathrm{E}-02$ & $5.95 \mathrm{E}-03$ & 5.0301 & 5.3863 \\
\hline 5 & $7.36 \mathrm{E}-03$ & $5.96 \mathrm{E}-04$ & 8.9165 & 9.9856 \\
\hline 6 & $4.72 \mathrm{E}-04$ & $3.68 \mathrm{E}-05$ & 15.6073 & 16.2047 \\
\hline 7 & $3.67 \mathrm{E}-05$ & $2.61 \mathrm{E}-06$ & 12.8527 & 14.0727 \\
\hline 8 & $4.19 \mathrm{E}-06$ & $2.02 \mathrm{E}-07$ & 8.7607 & 12.9192 \\
\hline
\end{tabular}

Tabela 5.1: Erros obtidos para o campo escalar $\phi$ ao final de uma revolução da rotação com velocidade variável usando 128 passos de tempo e cálculo de trajetória exato. O método de interpolação escalar considerado é $C^{1}$ de Renka $(C 1 R K)$. 


\subsubsection{Trajetória}

Agora vamos analisar o cálculo da trajetória. Em um primeiro teste vamos assumir que o campo escalar e o vetorial foram obtidos exatamente, sendo que a única fonte de erro estará no cálculo da trajetória, com campo vetorial dado exatamente nos pontos em que for necessário. Como não temos erros devido às interpolações, a única fonte de erro encontra-se na discretização temporal. Fixando uma malha de nível 4, com 2562 pontos, verificamos que o erro de discretização temporal é de terceira ordem, como apresentado na Tabela 5.2. Isso é condizente com o método descrito na situação onde consideramos conhecido o campo de velocidade em qualquer instante de tempo e ponto da esfera.

Os erros para a variável $\phi$ são calculados comparando o campo obtido ao final de uma revolução completa com a distribuição inicial, nas normas do máximo (ErMáx) e quadrática média (Er2). Apresentamos dois tipos de erros no cálculo do ponto de partida (PP), o primeiro (ErMáx) é o máximo da distância entre o ponto de partida exato e calculado em todos os instantes de tempo. O segundo erro apresentado (Er2) é o máximo dos erros quadráticos médios a cada passo de tempo.

\begin{tabular}{|c|c|c|c|c|c|c|c|c|}
\hline \multicolumn{10}{|c|}{ Rotação Variável - Erro temporal no cálculo da trajetória } \\
\hline NT & ErMáx $\phi$ & Er2 $\phi$ & ErMáx PP & Er2 PP & RMáx $\phi$ & R2 $\phi$ & RMáx PP & R2 PP \\
\hline 8 & $9.65 \mathrm{E}-01$ & $1.98 \mathrm{E}-01$ & $5.91 \mathrm{E}-01$ & $5.11 \mathrm{E}-01$ & & & & \\
\hline 16 & $2.12 \mathrm{E}-01$ & $2.94 \mathrm{E}-02$ & $1.13 \mathrm{E}-01$ & $9.33 \mathrm{E}-02$ & 4.55 & 6.72 & 5.24 & 5.47 \\
\hline 32 & $2.76 \mathrm{E}-02$ & $3.62 \mathrm{E}-03$ & $1.58 \mathrm{E}-02$ & $1.28 \mathrm{E}-02$ & 7.69 & 8.12 & 7.13 & 7.31 \\
\hline 64 & $3.49 \mathrm{E}-03$ & $4.56 \mathrm{E}-04$ & $2.06 \mathrm{E}-03$ & $1.65 \mathrm{E}-03$ & 7.91 & 7.95 & 7.67 & 7.73 \\
\hline 128 & $4.41 \mathrm{E}-04$ & $5.75 \mathrm{E}-05$ & $2.62 \mathrm{E}-04$ & $2.10 \mathrm{E}-04$ & 7.92 & 7.93 & 7.86 & 7.87 \\
\hline 256 & $5.54 \mathrm{E}-05$ & $7.23 \mathrm{E}-06$ & $3.30 \mathrm{E}-05$ & $2.64 \mathrm{E}-05$ & 7.95 & 7.95 & 7.93 & 7.94 \\
\hline 512 & $6.96 \mathrm{E}-06$ & $9.07 \mathrm{E}-07$ & $4.15 \mathrm{E}-06$ & $3.32 \mathrm{E}-06$ & 7.97 & 7.97 & 7.97 & 7.97 \\
\hline 1024 & $8.71 \mathrm{E}-07$ & $1.14 \mathrm{E}-07$ & $5.19 \mathrm{E}-07$ & $4.15 \mathrm{E}-07$ & 7.98 & 7.99 & 7.98 & 7.98 \\
\hline 2048 & $1.09 \mathrm{E}-07$ & $1.42 \mathrm{E}-08$ & $6.50 \mathrm{E}-08$ & $5.20 \mathrm{E}-08$ & 7.99 & 7.99 & 7.99 & 7.99 \\
\hline
\end{tabular}

Tabela 5.2: Erros obtidos para o campo escalar $\phi$ ao final de uma revolução usando uma malha de nível 4 (com 2562 pontos de malha) e todas as interpolações exatas. NT indica o número de passos de tempo utilizados. Nas colunas indicada com PP (Ponto de Partida) mostramos os erros máximos (ErMáx) e máximos do quadrático médio (Er2) dos pontos de partidas estimados em relação aos exatos. As colunas marcadas com RMáx e R2 indicam as razões entre os respectivos erros ErMáx e Er2 entre dois espaçamentos de tempo consecutivos.

\subsubsection{Interpolação vetorial}

A seguir vamos analisar o erro no cálculo da trajetória incluindo a interpolação vetorial, que tem erros associados tanto ao espaçamento de malha quanto ao temporal. Se considerarmos uma malha fixada, então é de se esperar que ao reduzirmos gradativamente o espaçamento temporal, a partir de algum $d t$ o erro na discretização espacial deve dominar. Na Figura 5.5 apresentamos os erros máximos no cálculo do ponto de partida para o teste de rotação com velocidade variável, considerando o método de reconstrução vetorial LSQTRC. Na malha mais fina, de nível 8, observase convergência temporal de terceira ordem, pois o erro na reconstrução é muito pequeno. Porém nas malhas mais grossas, o erro de discretização espacial passa a dominar para algum refinamento do espaçamento temporal. Neste exemplo, o erro espacial domina o temporal quando a relação entre eles, levando em conta a velocidade máxima pelo número de Courant, fica menor que 1 (veja a Tabela 5.3).

Na Figura 5.6 mostramos os erros de $\phi$ após uma revolução completa fixando o número de passos de tempo em 2048 e também o erro no cálculo do ponto de partida (PP). Nesse caso, observa-se dominância do erro espacial, de segunda ordem, até a malha de nível 6, devido ao uso do método de segunda ordem de aproximação polinomial LSQTRC. Nas malhas de níveis 7 e 8, o erro espacial está em uma ordem semelhante ao erro temporal, por isso a convergência quadrática não é nítida. Na Figura 5.7 mostramos a distribuição do erro na variável $\phi$ ao final de uma revolução completa 


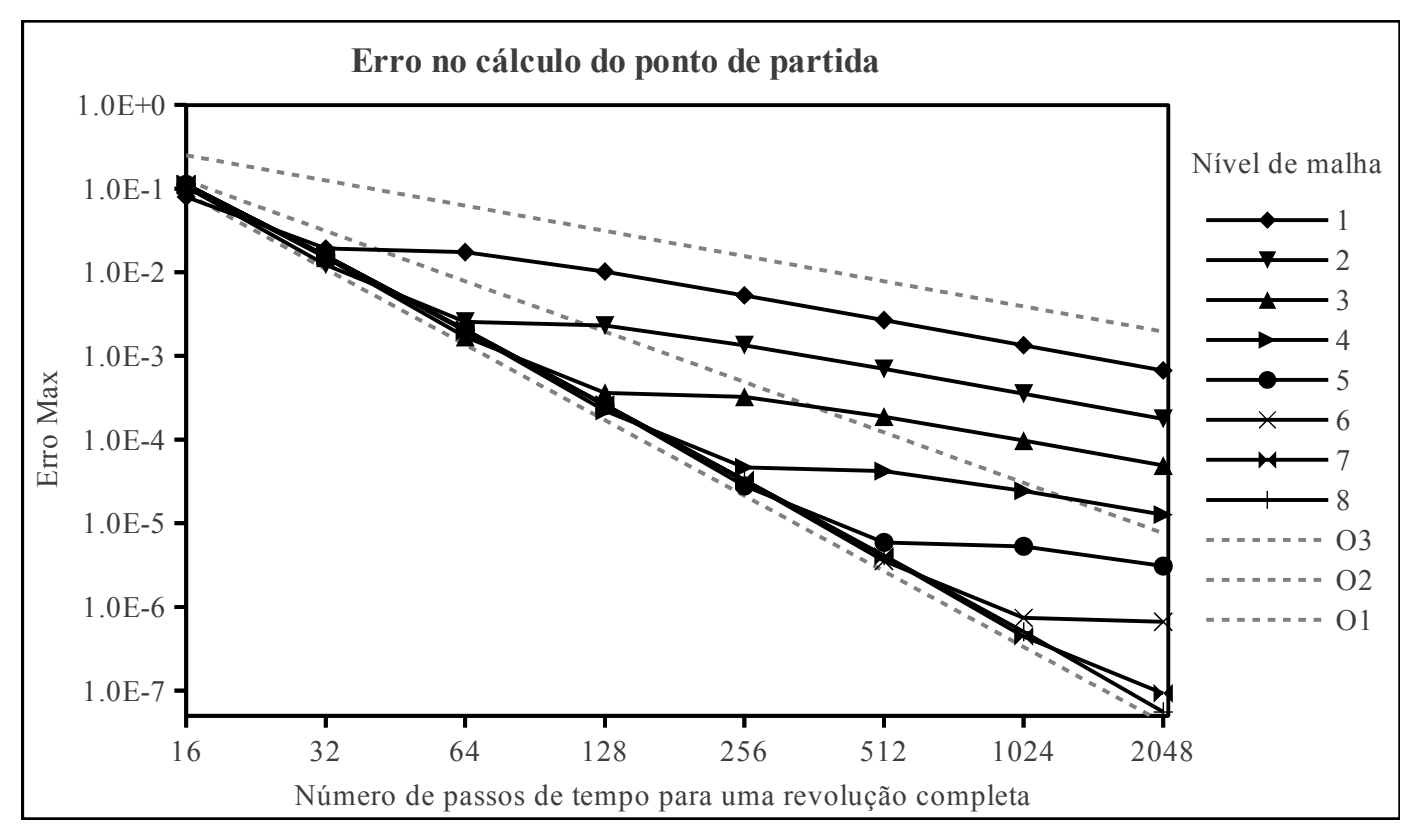

Figura 5.5: Erros máximos no cálculo do ponto de partida para o teste de rotação com velocidade variável em diversas malhas considerando espaçamentos de tempo diferentes. $O$ eixo $x$ indica quantos passos no tempo foram usados para uma revolução completa. O eixo y indica o maior erro no cálculo do ponto de partida em todos os instantes de tempo ao longo de uma revolução completa. As linhas tracejadas são referências para convergências de ordem 1, 2 e 3 no tempo. O método de reconstrução vetorial usado foi o LSQTRC.

\begin{tabular}{|c|c|c|c|c|c|c|c|c|c|}
\hline \multicolumn{10}{|c|}{ Número de Courant } \\
\hline Nível $\backslash \mathbf{N T}$ & $\mathbf{8}$ & $\mathbf{1 6}$ & $\mathbf{3 2}$ & $\mathbf{6 4}$ & $\mathbf{1 2 8}$ & $\mathbf{2 5 6}$ & $\mathbf{5 1 2}$ & $\mathbf{1 0 2 4}$ & $\mathbf{2 0 4 8}$ \\
\hline $\mathbf{0}$ & 2.20 & 1.10 & 0.55 & 0.27 & 0.14 & 0.07 & 0.03 & 0.02 & 0.01 \\
\hline $\mathbf{1}$ & 4.11 & 2.06 & 1.03 & 0.51 & 0.26 & 0.13 & 0.06 & 0.03 & 0.02 \\
\hline $\mathbf{2}$ & 8.09 & 4.04 & 2.02 & 1.01 & 0.51 & 0.25 & 0.13 & 0.06 & 0.03 \\
\hline $\mathbf{3}$ & 16.12 & 8.06 & 4.03 & 2.02 & 1.01 & 0.50 & 0.25 & 0.13 & 0.06 \\
\hline $\mathbf{4}$ & 32.17 & 16.09 & 8.04 & 4.02 & 2.01 & 1.01 & 0.50 & 0.25 & 0.13 \\
\hline $\mathbf{5}$ & 64.49 & 32.25 & 16.12 & 8.06 & 4.03 & 2.02 & 1.01 & 0.50 & 0.25 \\
\hline $\mathbf{6}$ & 128.98 & 64.49 & 32.25 & 16.12 & 8.06 & 4.03 & 2.02 & 1.01 & 0.50 \\
\hline $\mathbf{7}$ & 257.96 & 128.98 & 64.49 & 32.25 & 16.12 & 8.06 & 4.03 & 2.02 & 1.01 \\
\hline $\mathbf{8}$ & 515.93 & 257.96 & 128.98 & 64.49 & 32.25 & 16.12 & 8.06 & 4.03 & 2.02 \\
\hline
\end{tabular}

Tabela 5.3: Números de Courant para o teste de rotação com velocidade variável para diversos níveis de malha (linhas) e espaçamentos temporais (colunas). A velocidade máxima considerada para a rotação com velocidade variável foi de 3.89 . 
para uma malha de nível 6 considerando 2048 passos de tempo. A distribuição do erro revela que a trajetória calculada resultou em um leve atraso na rotação, pois temos um erro de fase.

Para o caso de velocidade de rotação constante, $\delta=0$, a velocidade máxima é menor que no caso com velocidade variável (3 vezes menor aproximadamente), por isso, com 2048 passos de tempo, o erro dominante será o espacial para os tempos analisados, até 2048 passos de tempo. Mostramos na Tabela 5.4 os erros obtidos para o caso de velocidade de rotação constante, na qual é possível ver a convergência quadrática.

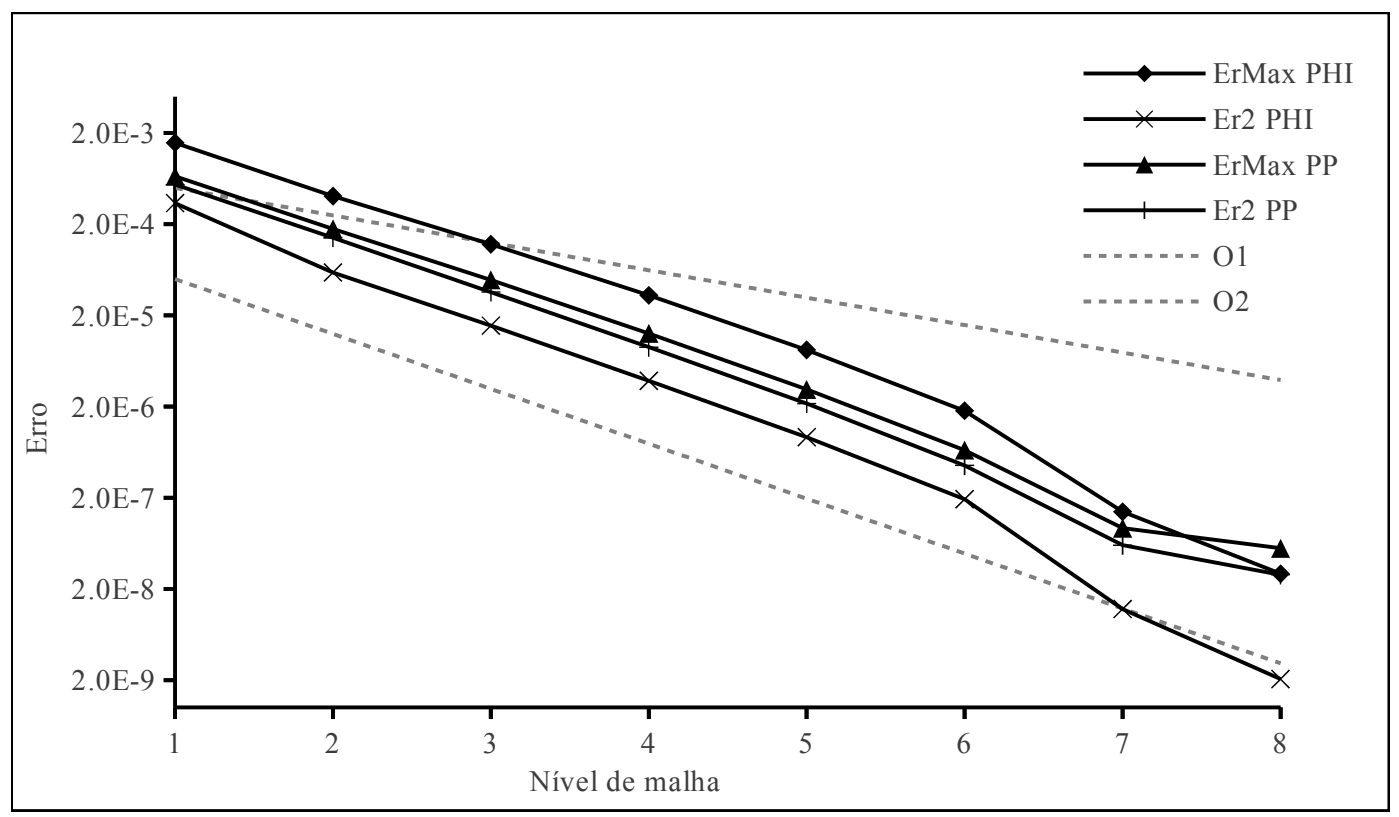

Figura 5.6: Erros na variável $\phi$ e no cálculo do ponto de partida (PP) para o teste de rotação com velocidade variável em diversas malhas considerando 2048 passos de tempo. As linhas tracejadas indicam referências de ordem 1, 2 no espaço. O método de reconstrução vetorial usado foi o LSQTRC. O campo escalar foi obtido de forma exata, portanto não há erros de interpolações escalares.

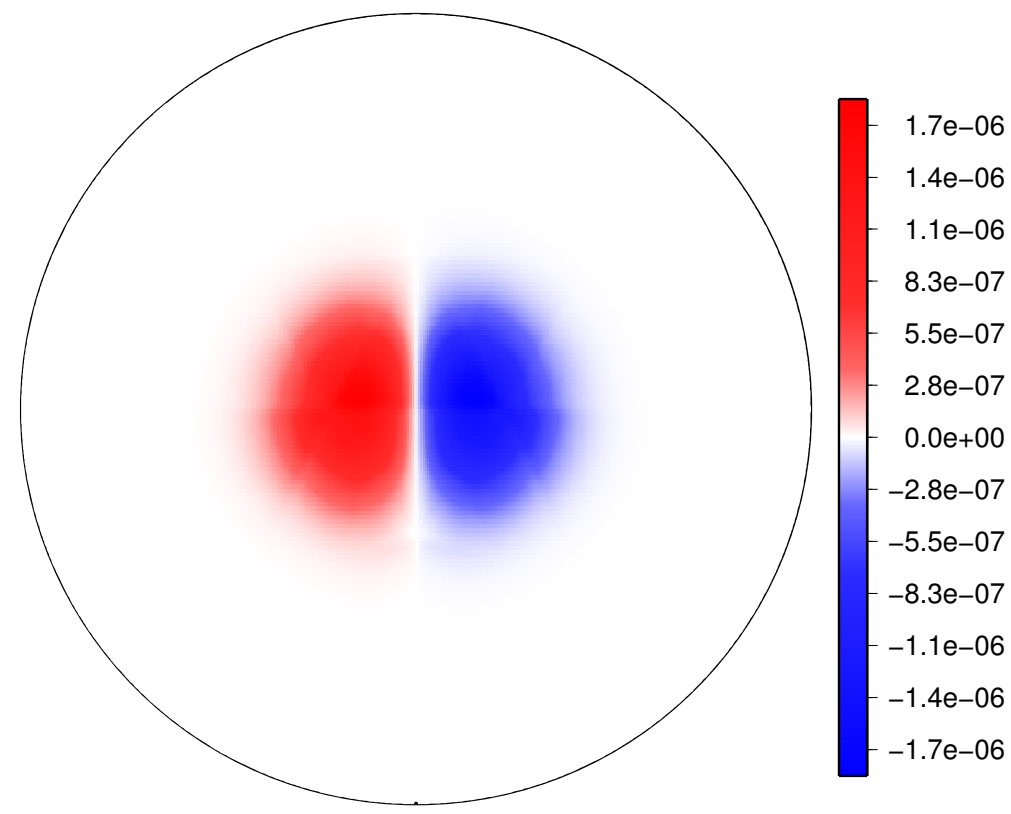

Figura 5.7: Erros na variável $\phi$ para o teste de rotação com velocidade variável ao final de uma revolução completa em uma malha de nivel 6 considerando 2048 passos de tempo. O campo escalar foi obtido de forma exata, portanto não há erros de interpolações escalares. 


\begin{tabular}{|c|c|c|c|c|c|c|}
\hline \multicolumn{6}{|c|}{ Rotação com velocidade constante - Erro no cálculo da trajetória - Interpv LSQTRC } \\
\hline Nós & Erro Máx $\phi$ & Erro $2 \phi$ & Erro Máx PP & Razão Máx & Razão 2 & Razão PP \\
\hline 2562 & $1.08 \mathrm{E}-05$ & $1.25 \mathrm{E}-06$ & $4.14 \mathrm{E}-06$ & & & \\
\hline 10242 & $2.82 \mathrm{E}-06$ & $3.13 \mathrm{E}-07$ & $1.04 \mathrm{E}-06$ & 3.84 & 4.01 & 3.99 \\
\hline 40962 & $7.03 \mathrm{E}-07$ & $7.70 \mathrm{E}-08$ & $2.57 \mathrm{E}-07$ & 4.01 & 4.06 & 4.04 \\
\hline 163842 & $1.67 \mathrm{E}-07$ & $1.80 \mathrm{E}-08$ & $6.08 \mathrm{E}-08$ & 4.21 & 4.28 & 4.23 \\
\hline 655362 & $3.14 \mathrm{E}-08$ & $3.25 \mathrm{E}-09$ & $1.16 \mathrm{E}-08$ & 5.32 & 5.55 & 5.22 \\
\hline
\end{tabular}

Tabela 5.4: Erros obtidos para o campo escalar $\phi$ e no cálculo do ponto de partida (PP) ao final de uma revolução para rotação com velocidade constante, $\delta=0$, usando 2048 passos de tempo e considerando uma reconstrução vetorial polinomial com mínimos quadrados de 9 pontos (LSQTRC). 


\subsubsection{Reconstrução híbrida}

Considerando agora o método híbrido de reconstrução, vamos fixar 2048 passos de tempo e analisar o erro no cálculo da trajetória. Usaremos sempre o parâmetro de corte para o índice de alinhamento do método híbrido com valor 0.01 , que para uma malha de nível 8 resulta em $15 \%$ de células não alinhadas. Mostramos na Figura 5.8 os erros no cálculo do ponto de partida para os métodos envolvidos na abordagem de reconstrução híbrida. Os erros máximos nos cálculos das trajetórias apresentados pelo método de Perot são muito maiores que os erros do método de reconstrução polinomial (LSQHXE). Por outro lado, os erros quadráticos médios do método de Perot estão mais próximos do método de aproximação polinomial, indicando que há uma minoria de células com erros elevados. O método híbrido tira vantagem disto, usando o método de aproximação polinomial apenas na minoria de células mal alinhadas, e o método de Perot, que é computacionalmente barato, nas demais.

É interessante analisarmos a distribuição do erro no cálculo da trajetória. Isso pode ser feito para um passo de tempo específico. Mostramos na Figura 5.9 as distribuições dos erros nos cálculos das trajetórias do primeiro passo de tempo do teste de rotação com velocidade variável para os 3 métodos envolvidos no método híbrido (PERHX, o LSQHXE e o híbrido). Vemos claramente a interferência de malha no método de Perot, que é reduzida no método híbrido. Note pelas escalas que o método híbrido e o polinomial com mínimos quadrados tem erros máximos mais de uma ordem de grandeza menores que o método de Perot.

Ao analisarmos o erro da variável $\phi$ ao final de um ciclo completo (veja a Figura 5.10) vemos que a interferência de malha ocorrido no cálculo da trajetória com o método Perot contamina também a variável $\phi$. O método híbrido reduz fortemente a interferência de malha.

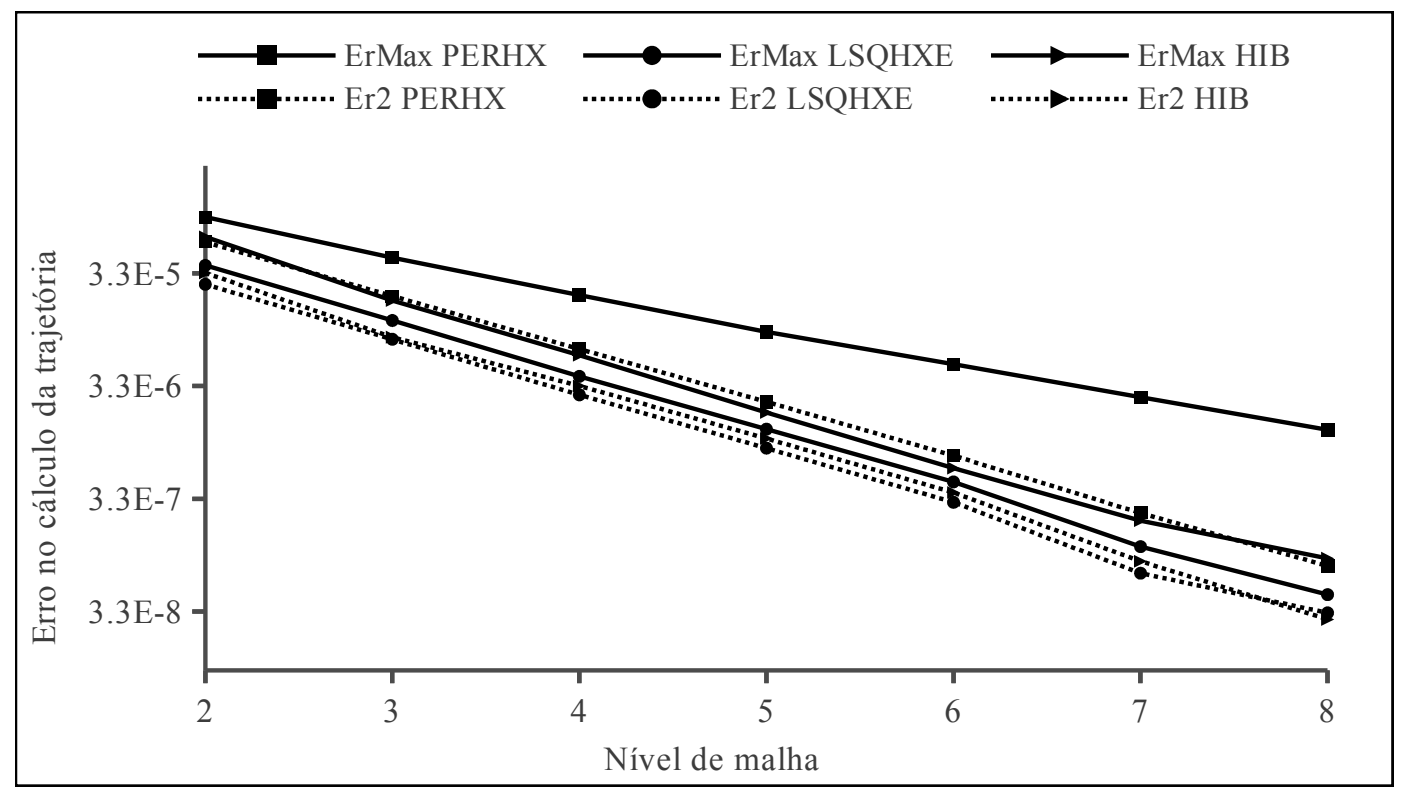

Figura 5.8: Erros no cálculo do ponto de partida para o teste de rotação com velocidade variável em diversas malhas considerando 2048 passos de tempo. As linhas tracejadas indicam os máximos das normas quadrático médias de todos os tempos. As linhas continuas indicam os erros máximos dentre os máximos para cada tempo. 

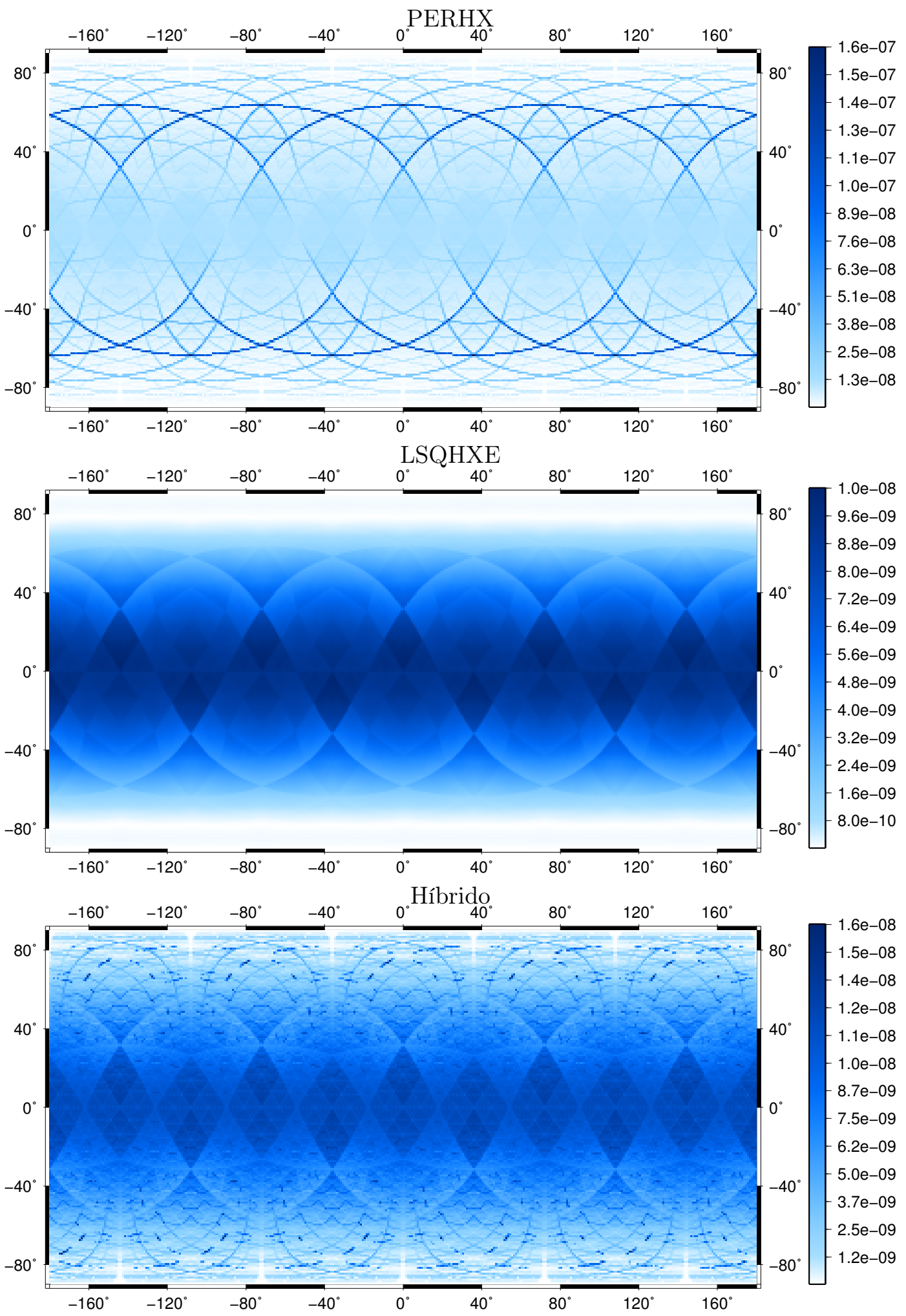

Figura 5.9: Distribuições dos erros no cálculo da trajetória da rotação com velocidade variável para o primeiro passo de tempo considerando os métodos envolvidos na reconstrução híbrida. O método híbrido usado considera como parâmetro de corte para o alinhamento das células 0.01 . Foi fixado um espaçamento de tempo relativo a 2048 passos para uma revolução completa e uma malha de nível 8. 


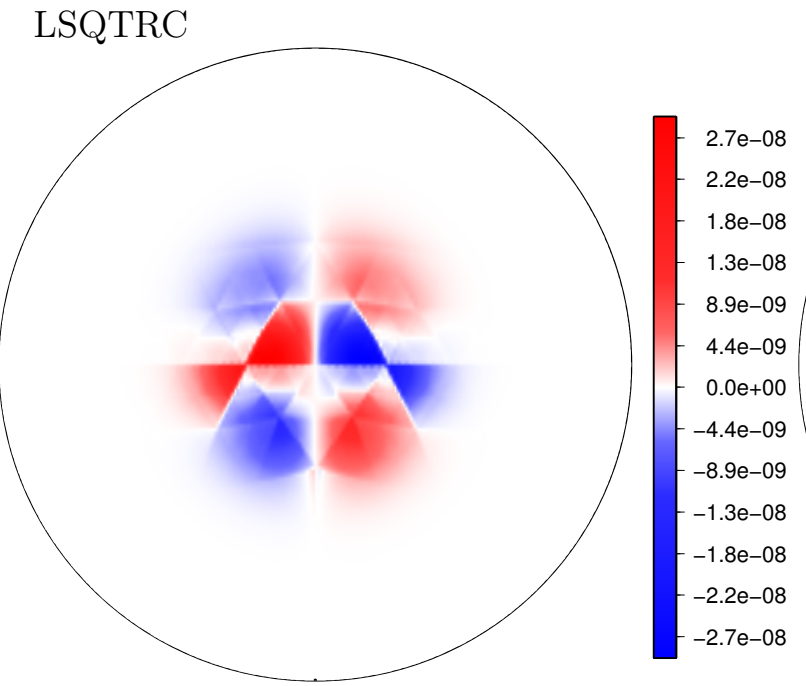

PERHX

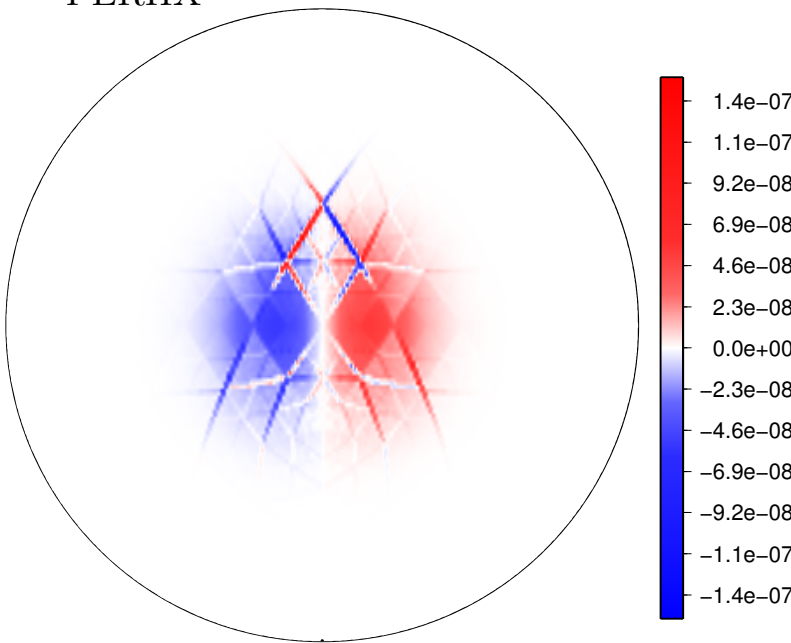

LSQHXE

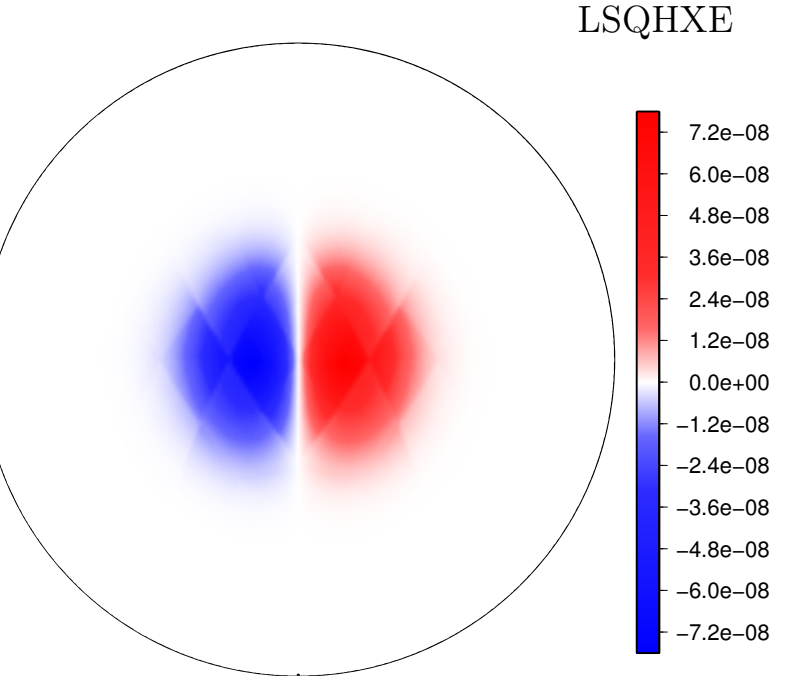

Híbrido

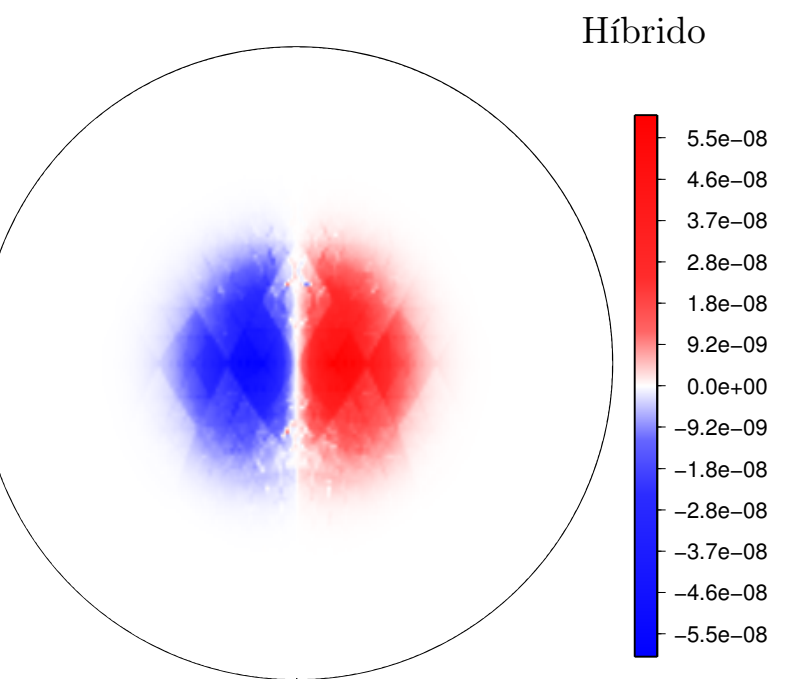

Figura 5.10: Distribuições dos erros na variável $\phi$ ao final de revolução completa para o teste de rotação com velocidade variável considerando alguns métodos de reconstruções vetoriais e erro somente devido ao cálculo da trajetória (função escalar obtida exatamente). O método híbrido usado considera como parâmetro de corte para o alinhamento das células 0.01 . Foi fixado um espaçamento de tempo relativo a 2048 passos para uma revolução completa e uma malha de nível 8. 


\subsubsection{Densidade}

Estamos considerando a variável de densidade $\rho$ sempre inicializada com valor constante igual a um. A rotação, mesmo com velocidade variável, é um campo vetorial não divergente. Portanto a densidade exata deve permanecer com valor constante ao logo da evolução do transporte. Porém, a discretização do divergente está sujeita a erros com interferências de malha. Os erros na estimativa do divergente são gerados a cada passo de tempo e ainda transportados com o fluido.

Para analisarmos o efeito isolado do erro no cálculo do divergente no modelo de transporte, vamos considerar a trajetória calculada exatamente. Nesse caso, o número de passos no tempo só influenciará na quantidade de acumulações dos erros nas estimativas do divergente e da interpolações escalares. Adotaremos 128 passos de tempo e usaremos a interpolação escalar C1RK. Mostramos na Tabela 5.5 os erros obtidos ao final de uma revolução completa para a densidade, onde percebe-se a convergência de primeira ordem, relacionada a discretização do divergente.

\begin{tabular}{|c|c|c|c|c|}
\hline \multicolumn{5}{|c|}{ Erro na densidade - Discretização do divergente } \\
\hline Nós & Erro Máx $\rho$ & Erro $2 \rho$ & Razão Máx & Razão 2 \\
\hline 162 & $6.71 \mathrm{E}-04$ & $3.21 \mathrm{E}-04$ & - & - \\
\hline 642 & $2.27 \mathrm{E}-04$ & $6.49 \mathrm{E}-05$ & 2.96 & 4.94 \\
\hline 2562 & $8.23 \mathrm{E}-05$ & $1.78 \mathrm{E}-05$ & 2.76 & 3.65 \\
\hline 10242 & $3.14 \mathrm{E}-05$ & $6.44 \mathrm{E}-06$ & 2.62 & 2.76 \\
\hline 40962 & $2.38 \mathrm{E}-05$ & $3.43 \mathrm{E}-06$ & 1.32 & 1.88 \\
\hline 163842 & $1.25 \mathrm{E}-05$ & $1.51 \mathrm{E}-06$ & 1.90 & 2.27 \\
\hline 655362 & $6.58 \mathrm{E}-06$ & $6.51 \mathrm{E}-07$ & 1.90 & 2.33 \\
\hline
\end{tabular}

Tabela 5.5: Erros obtidos para o campo escalar de densidade ( $\rho)$ ao final de uma revolução completa do teste de rotação com velocidade variável usando 128 passos de tempo, trajetória calculada exatamente e interpolação escala com o método C1RK.

Na Figura 5.11 mostramos a distribuição do erro da densidade no primeiro passo de tempo, onde fica evidente a interferência de malha. Na Figura 5.12 apresentamos a distribuição do erro no final de uma revolução completa, que revela uma mistura de erros na discretização do divergente gerados e transportados. Nessa figura, observa-se que a interferência de malha gerada a cada passo de tempo resulta, no final de uma revolução, em um ruído da ordem do espaçamento de malha.

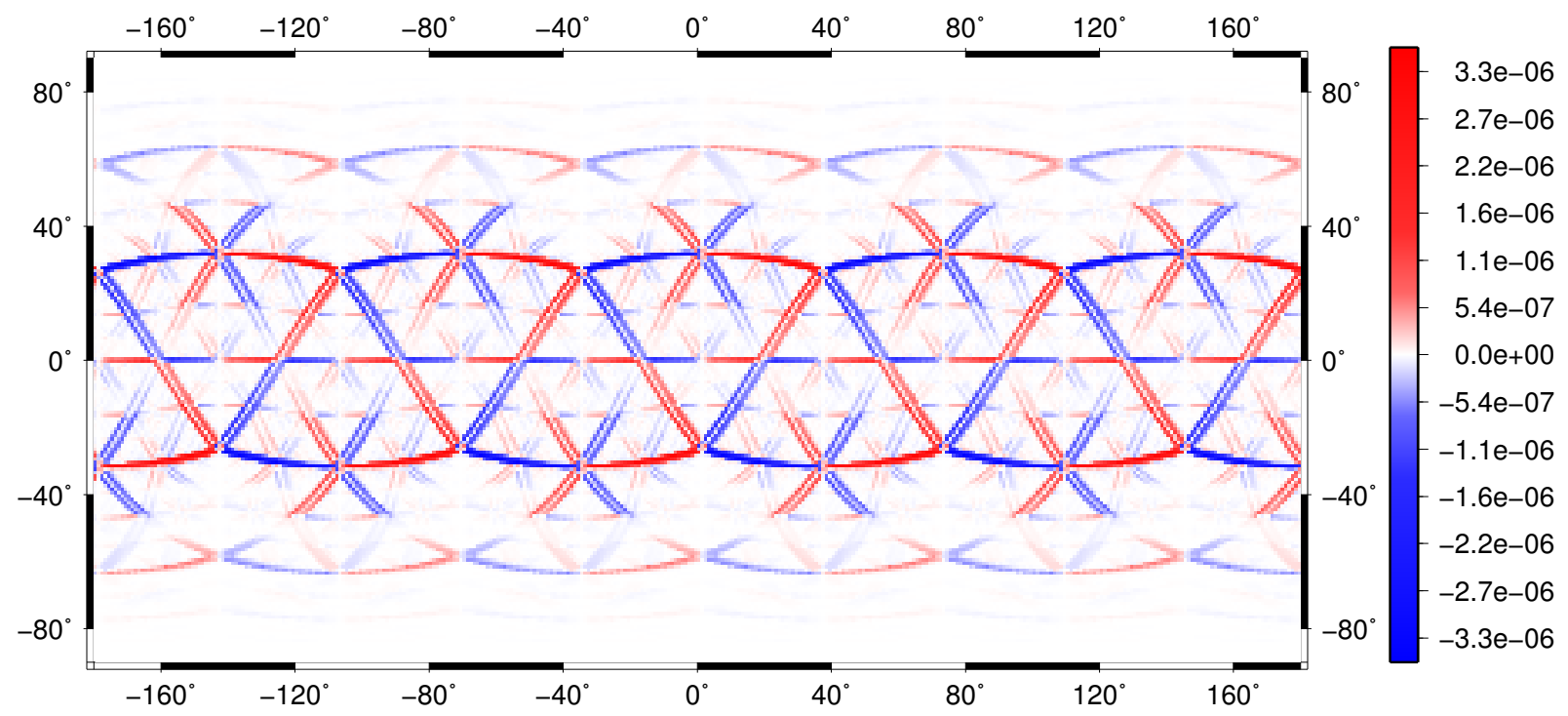

Figura 5.11: Erro no campo de densidade $\rho$ para no primeiro passo de tempo do teste de rotação com velocidade variável. O teste considera 128 passos para uma revolução completa e uma malha icosaédrica de nível 6. A trajetória foi calculada exatamente e os erros são somente devido à discretização do divergente e interpolações escalares (método C1RK). 


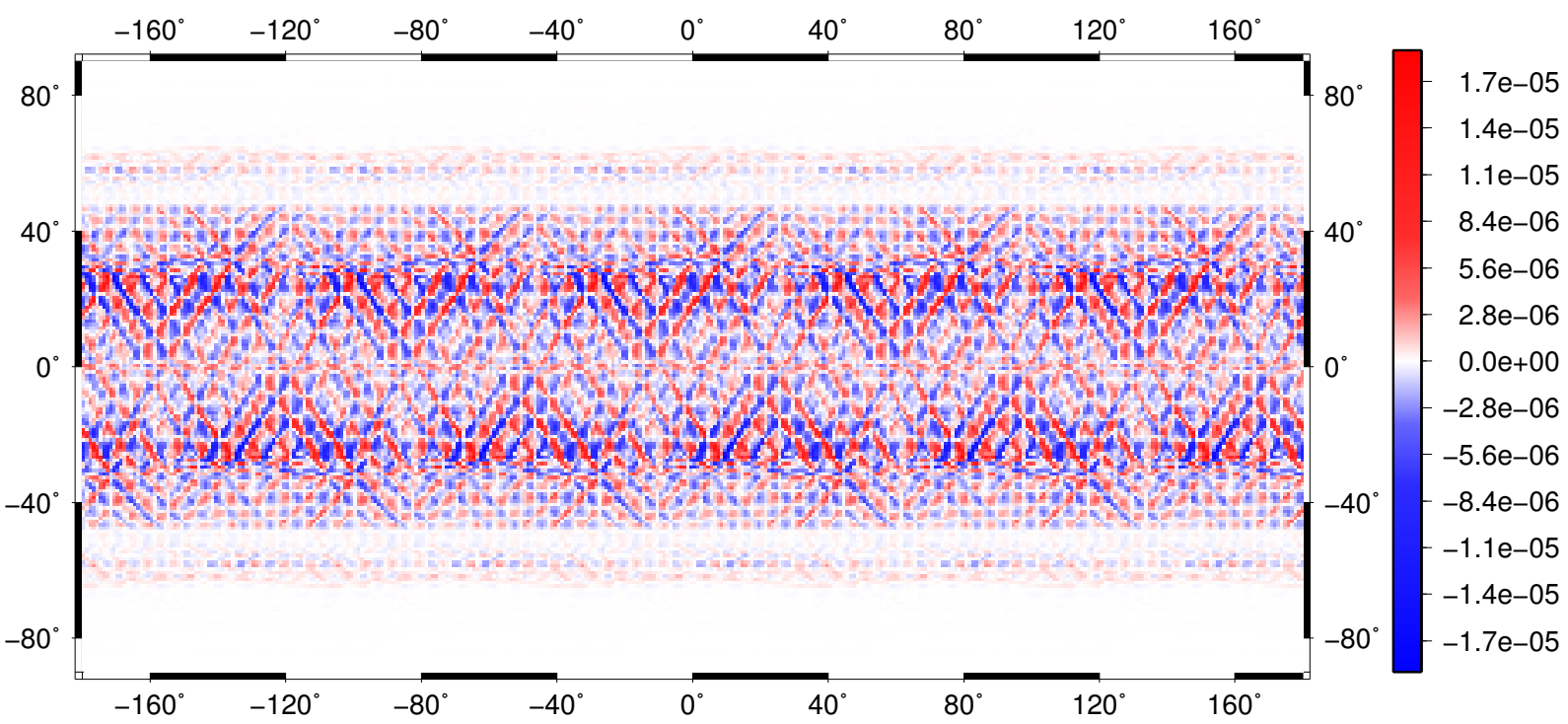

Figura 5.12: Erro no campo de densidade $\rho$ ao final de uma revolução do teste de rotação com velocidade variável. O teste considera 128 passos de tempo e uma malha icosaédrica de nível 6 . A trajetória foi calculada exatamente e os erros são somente devido à discretização do divergente e interpolações escalares (método $C 1 R K)$.

Vejamos agora um caso com mais passos de tempo, 1024, e também incluindo o cálculo de trajetória, com uma reconstrução vetorial LSQTRC. Mostramos na Figura 5.13 a distribuição do erro para a densidade ao final de uma revolução completa da rotação com velocidade variável. Percebe-se claramente um padrão de interferência de malha, com a presença de uma onda com número de onda 5. Nesse caso, o erro é devido a uma combinação de erros das diversas aproximações envolvidas, incluindo o erro na discretização do divergente, que é dominante.

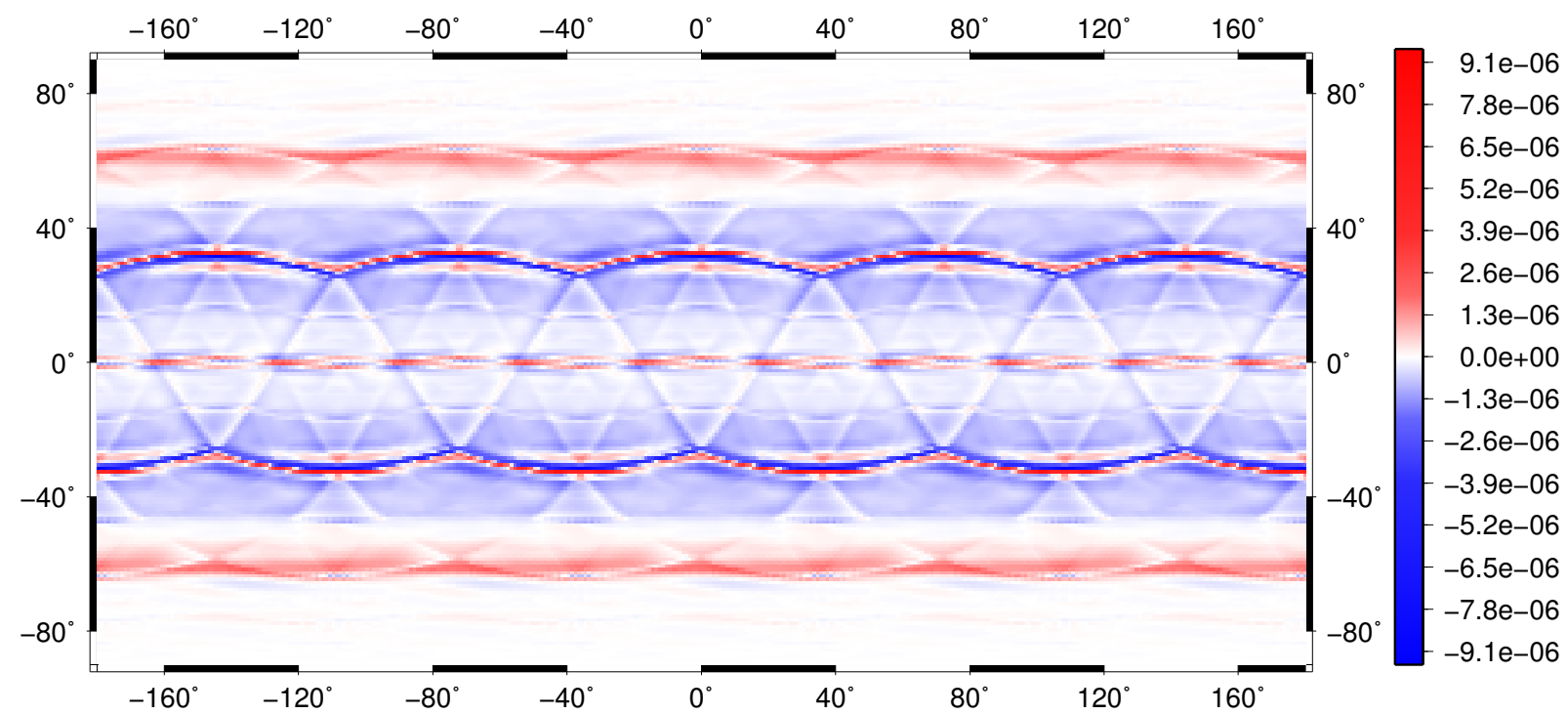

Figura 5.13: Erro no campo de densidade $\rho$ para uma revolução completa do teste de rotação com velocidade variável. Foram usados 1024 passos de tempo e uma malha icosaédrica de nível 6 . O método de reconstrução vetorial usado foi o polinomial com mínimos quadrados de 9 pontos (LSQTRC) e o método de interpolação escalar foi o C1RK. 


\subsection{Deformação com rotação}

O campo vetorial de rotação usado na análise de convergência é interessante para validação do método, mas o campo não deforma a condição inicial, que é uma característica presente em transporte de substâncias na atmosfera. Um conjunto de testes propostos em Nair e Lauritzen [2010] pode ser usado para testar o método de transporte em situações de deformações da condição inicial do traçador. Nesses testes definem-se campos de velocidades que irão deformar a condição inicial até um certo ponto e depois reconstruí-la. Com isso, ao final de um ciclo completo a solução obtida deve ser igual a condição inicial, possibilitando análises de erros. No teste de número 4 do artigo de Nair e Lauritzen [2010] é descrito um campo vetorial não divergente com deformação acrescido de uma rotação de fundo, o que elimina potenciais cancelamentos de erros. Esse teste é uma modificação do teste de número 2 do artigo, no qual é adicionado uma rotação com velocidade constante. Usaremos estes testes para analisar algumas características do método de transporte.

O problema teste 2 de Nair e Lauritzen [2010] tem campo de velocidades dado em coordenadas esféricas (geográficas) ao longo do tempo como

$$
\begin{aligned}
& \left.u(\lambda, \theta, t)=k \sin ^{2}(\lambda+\pi) \sin (2 \theta) \cos (\pi t / T)\right), \\
& v(\lambda, \theta, t)=k \sin (2(\lambda+\pi)) \cos (\theta) \cos (\pi t / T)),
\end{aligned}
$$

onde assumiremos o período total $T=5$ e $k=2$. Apresentamos o campo de velocidades inicial na Figura 5.14. Para este campo vetorial não conhecemos as trajetórias exatas para podermos comparar com a estimada pelo método semi-lagrangiano. Porém podemos estimá-las com alta ordem usando expansões em Taylor. Em Nair e Lauritzen [2010] é descrita uma aproximação de terceira ordem para o cálculo da trajetória que pode ser usada com espaçamento de tempo reduzido para obtermos uma referência.

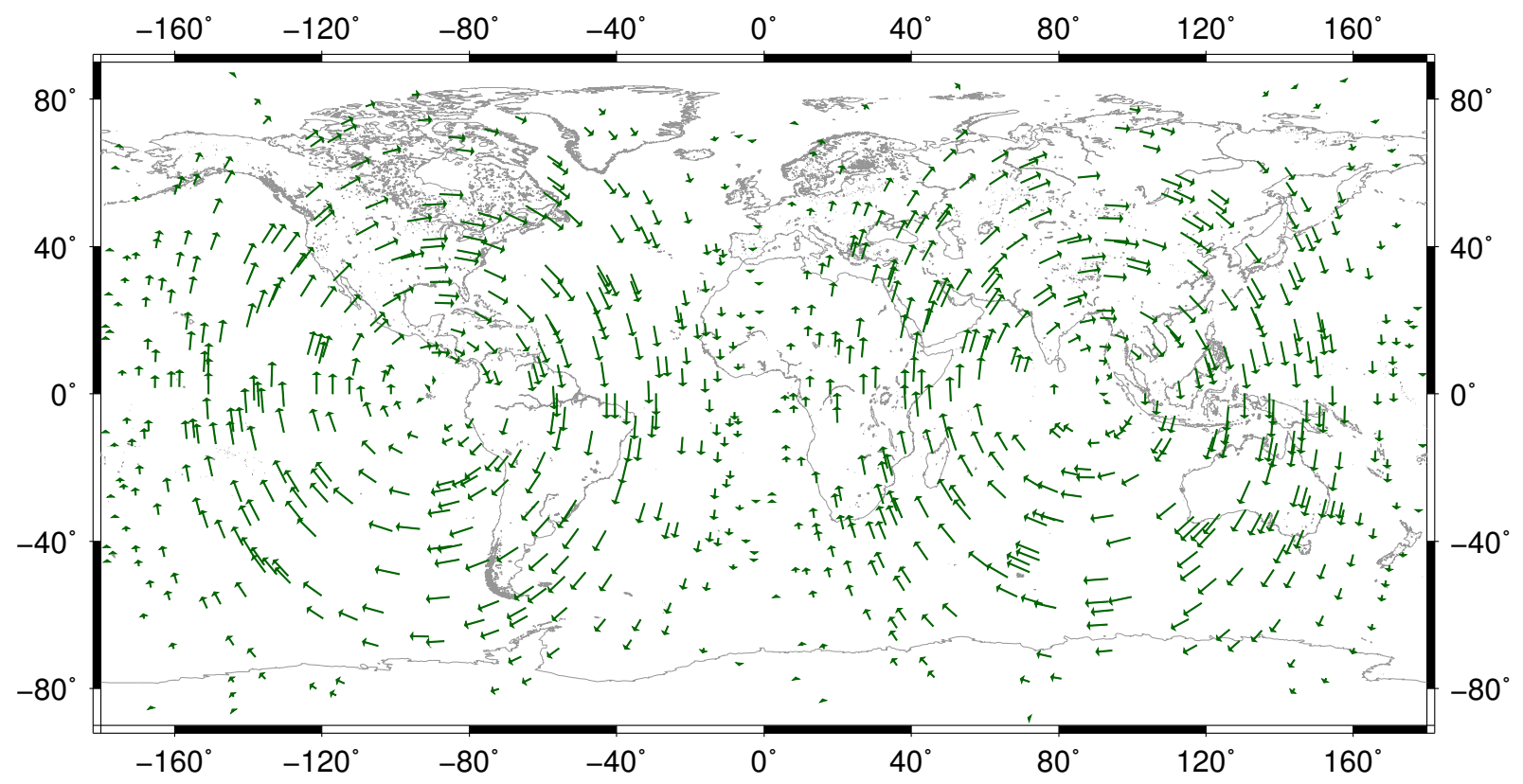

Figura 5.14: Campo de velocidades inicial para o caso 2

Para evitar cancelamentos de erros, foi proposto como teste 4 de Nair e Lauritzen [2010] esse mesmo campo vetorial mas adicionado de uma rotação. Isso pode ser feito adicionando o termo $-2 \pi t / T$ na componente zonal do campo de velocidades, resultando no campo de velocidades

$$
\begin{aligned}
& \left.u(\lambda, \theta, t)=k \sin ^{2}\left(\lambda^{\prime}+\pi\right) \sin (2 \theta) \cos (\pi t / T)\right)+2 \pi \cos (\theta) / T, \\
& \left.v(\lambda, \theta, t)=k \sin \left(2\left(\lambda^{\prime}+\pi\right)\right) \cos (\theta) \cos (\pi t / T)\right),
\end{aligned}
$$


onde $\lambda^{\prime}=\lambda-2 \pi t / T$. Apresentamos o instante inicial do campo modificado (teste número 4) na Figura 5.15. A velocidade máxima desse campo é aproximadamente 3.82.

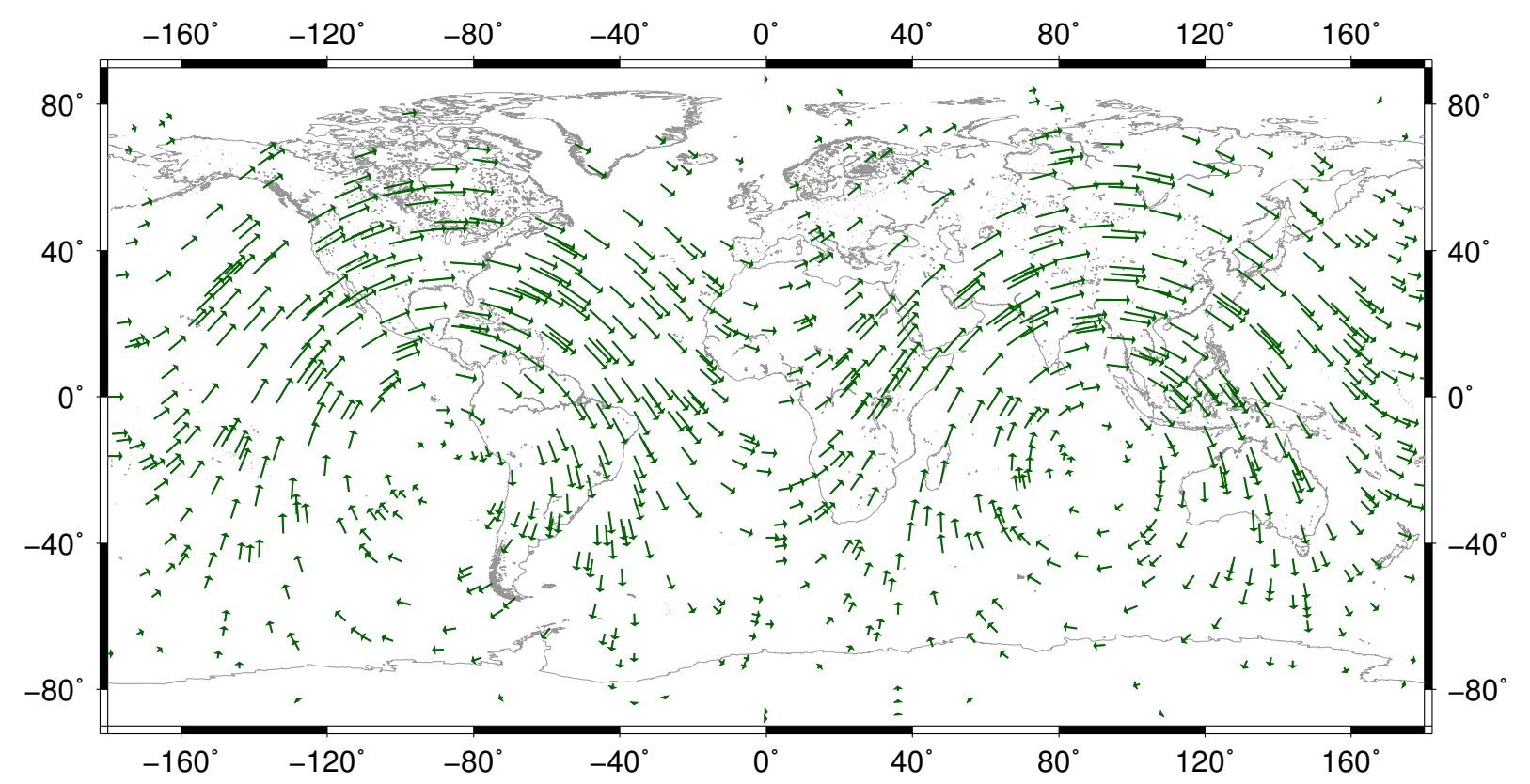

Figura 5.15: Campo de velocidades inicial para o teste número 4.

A primeira análise que vamos realizar com o teste de deformação com rotação é a respeito da evolução da densidade. Vamos considerar a distribuição inicial da densidade como constante igual a 1. Assim, o principal erro no transporte da densidade será a parte de discretização do divergente. Apesar do campo vetorial considerado neste experimento ser não divergente, a discretização usando o fluxo nos pontos médios das arestas de Voronoi, descrito no capítulo 3, não preserva divergência nula, portanto esperamos ver interferências de malha no modelo de transporte para a densidade. Na Figura 5.16 mostramos o erro para o campo escalar de densidade $\rho$ em alguns instantes de tempo. É possível perceber que a interferência de malha ocorre a cada passo de tempo, que, por sua vez, é transportada na esfera. Ao final observa-se que a interferência de malha gerou um ruido global na distribuição do erro da densidade. O teste foi realizado em uma malha de nível 6 (40962 nós) e 128 passos de tempo.

Uma condição inicial escalar proposta para $\phi$ é dada por duas gaussianas no equador, como ilustrado na Figura 5.17, e escrita como

$$
\phi(\lambda, \theta)=h_{1}(\lambda, \theta)+h_{2}(\lambda, \theta),
$$

onde cada $h_{i}$ é definido em coordenadas cartesianas como

$$
h_{i}(x, y, z)=\exp \left\{-5\left[\left(x-x_{i}\right)^{2}+\left(y-y_{i}\right)^{2}+\left(z-z_{i}\right)^{2}\right]\right\},
$$

e $p_{i}=\left(\lambda_{i}, \theta_{i}\right)$ são pontos fixados dados em coordenadas esféricas por

$$
\begin{aligned}
& \left(\lambda_{1}, \theta_{1}\right)=(-\pi / 6,0) \\
& \left(\lambda_{2}, \theta_{2}\right)=(\pi / 6,0)
\end{aligned}
$$

O teste descrito irá deformar as gaussianas até o instante $T / 2$, revertendo então a deformação até reconstruí-las nos seus locais de origem. Apresentamos a evolução desse teste na Figura 5.19, para o qual consideramos 128 passos de tempo e uma malha de nível 6. Isso nos fornece um número de Courant de aproximadamente 8. Apesar do número de passos de tempo ser pequeno, e o número de Courant ser alto, o método é capaz de descrever nitidamente o campo no máximo de deformação 

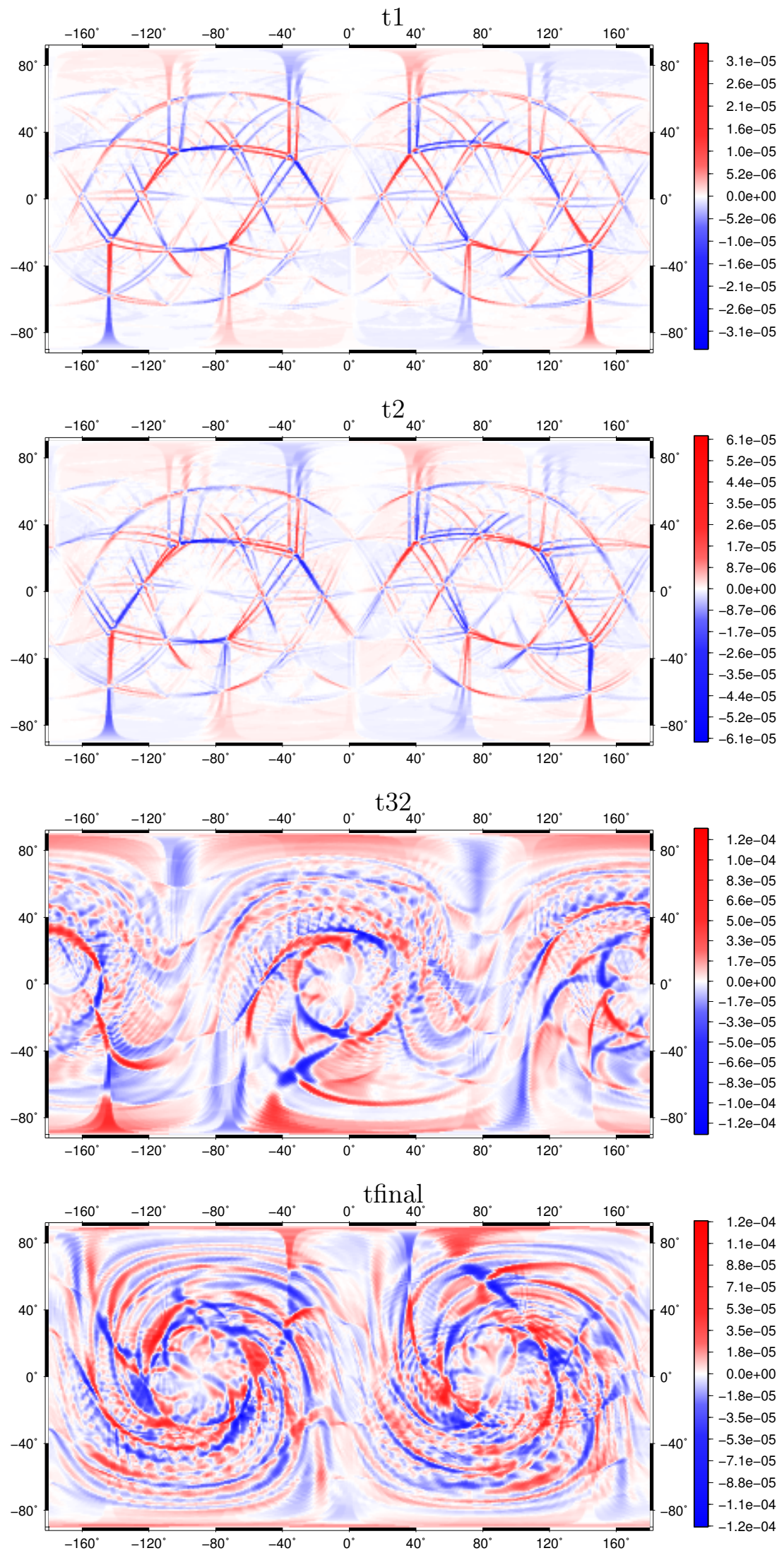

Figura 5.16: Teste de deformação com rotação para a densidade. Apresentamos a evolução do erro da densidade $(\rho)$ com 1, 2, 32, 128 passos de tempos. O método de reconstrução vetorial usado foi o polinomial com minimos quadrados de 9 pontos (LSQTRC). A malha usada é a icosaédrica de nível 6 e foram usados 128 passos de tempo. 


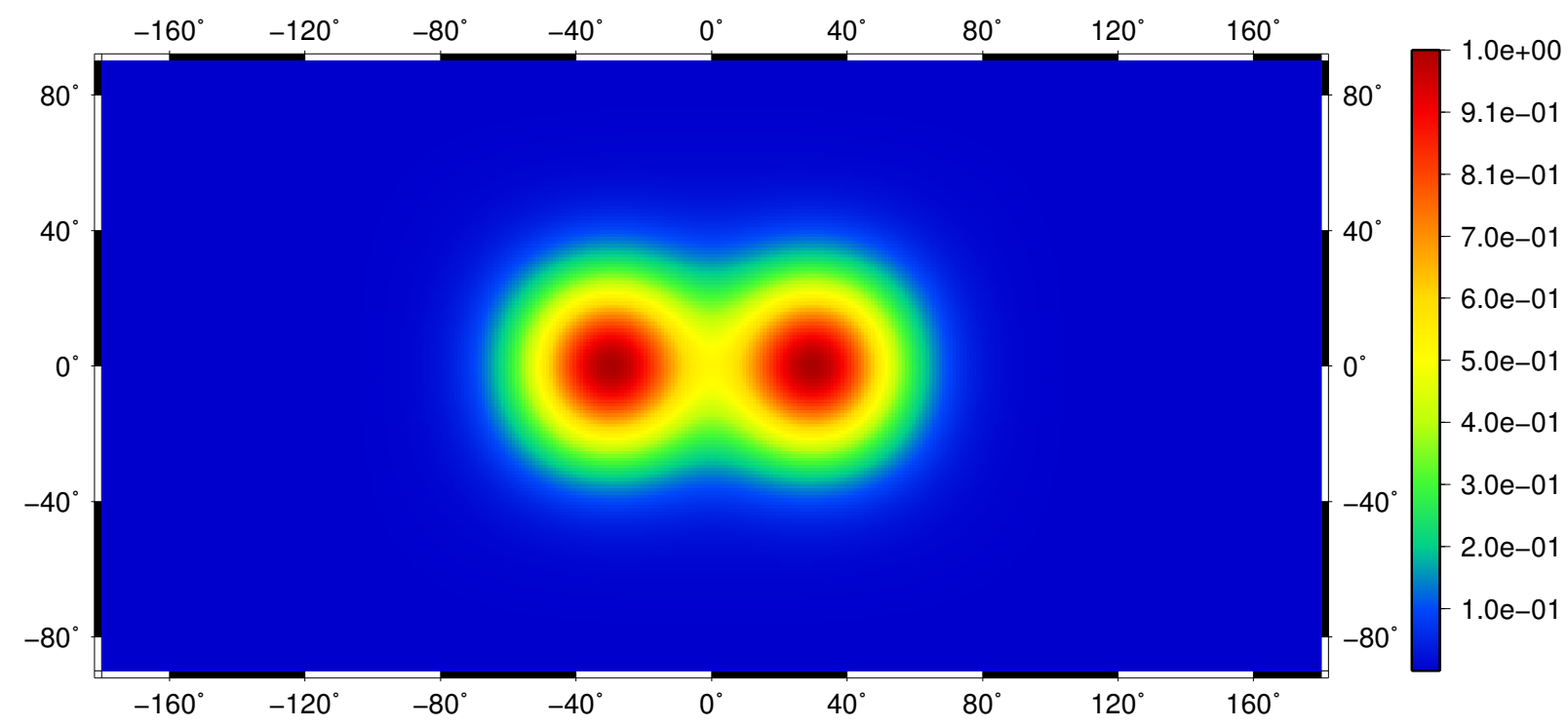

Figura 5.17: Condição inicial de duas gaussianas.

(passo de tempo 64). O erro ao final de um ciclo completo é apresentado na Figura 5.18.

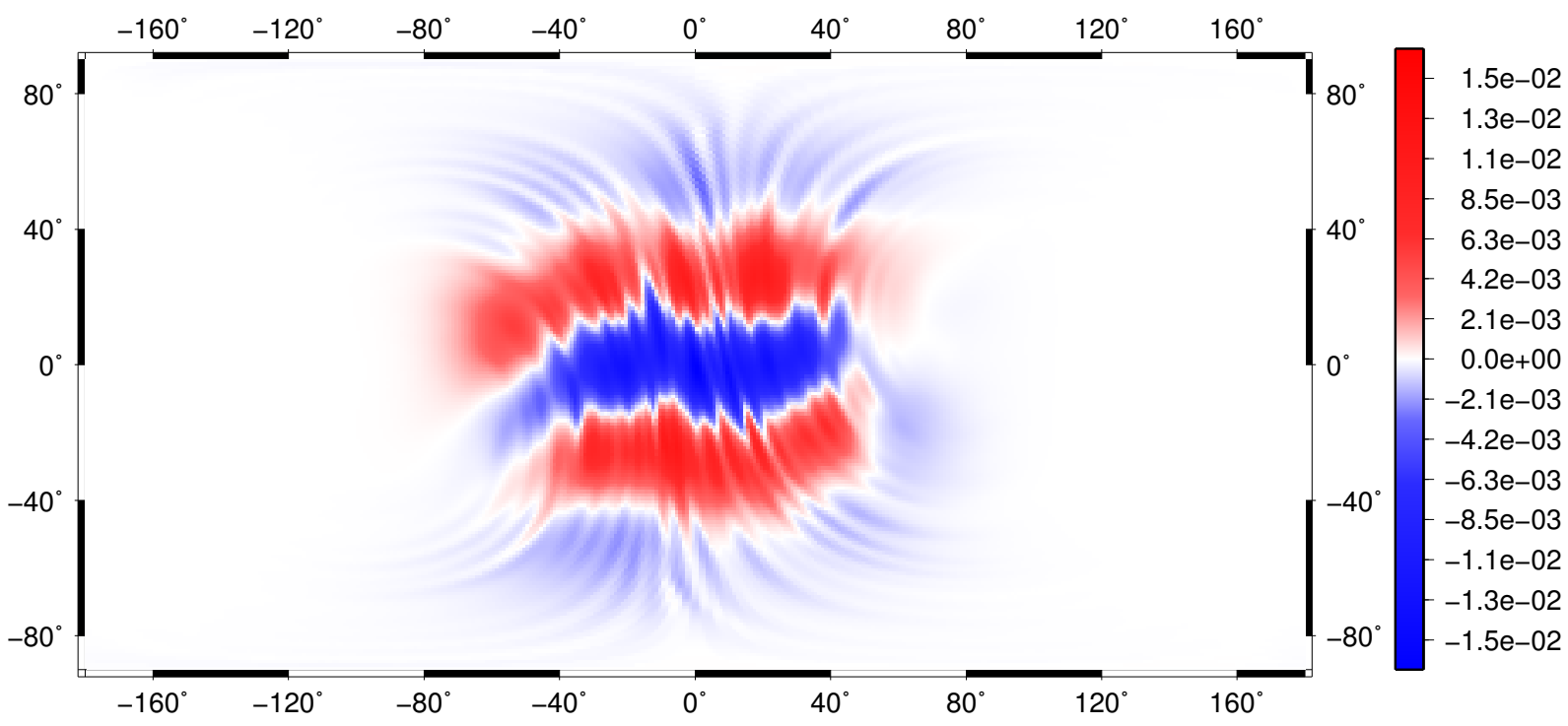

Figura 5.18: Erro final para o teste de deformação com rotação para o traçador para condição inicial de duas gaussianas. O método de reconstrução vetorial usado foi o polinomial com mínimos quadrados de 9 pontos (LSQTRC). A malha usada é a icosaédrica de nível 6 e foram usados 128 passos de tempo. 

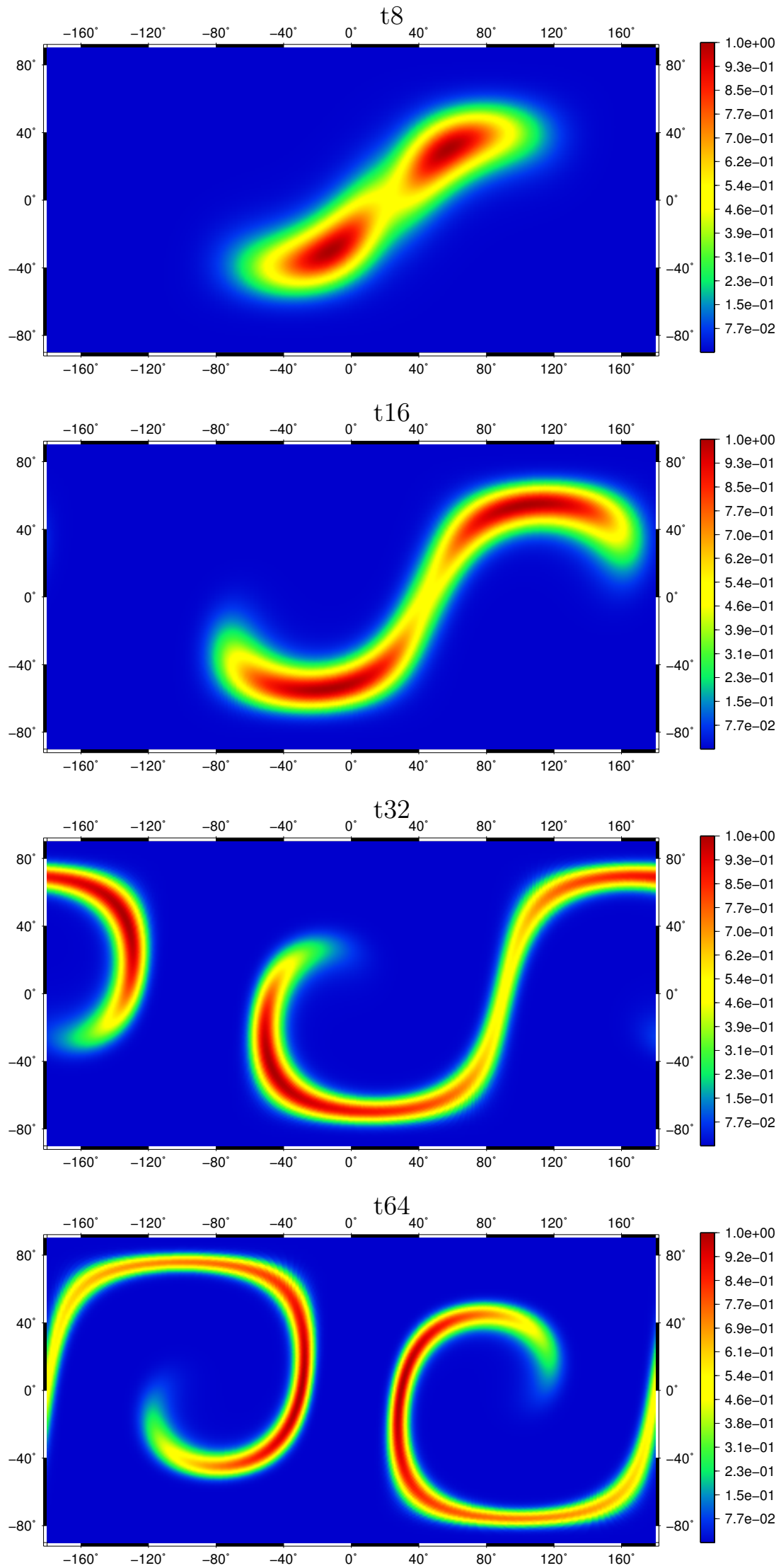

Figura 5.19: Teste de deformação com rotação para o traçador. Apresentamos a evolução do da concentração do traçador $(\phi)$ com 8, 16, 32 e 64 passos de tempos. O método de reconstrução vetorial usado foi o polinomial com minimos quadrados de 9 pontos (LSQTRC). A malha usada é a icosaédrica de nível 6 e foram usados 128 passos de tempo. 
Considerando a trajetória calculada usando série de Taylor de terceira ordem, usando 100 subintervalos de tempo a cada passo de tempo do modelo de transporte, temos uma referência para o cálculo dos pontos de partida. Usando essa referência, podemos avaliar o erro máximo obtido com os cálculos dos pontos de partida em todos os passos de tempo. Analisamos esse erro para diversos números de Courant e apresentamos os resultados na Figura 5.20. Percebe-se claramente a convergência de terceira ordem. Além disso, quanto menor o espaçamento temporal, mantendo constante o nível de malha, temos um erro menor. Os números de Courant apresentados nos gráficos são aproximações inteiras dos números exatos.

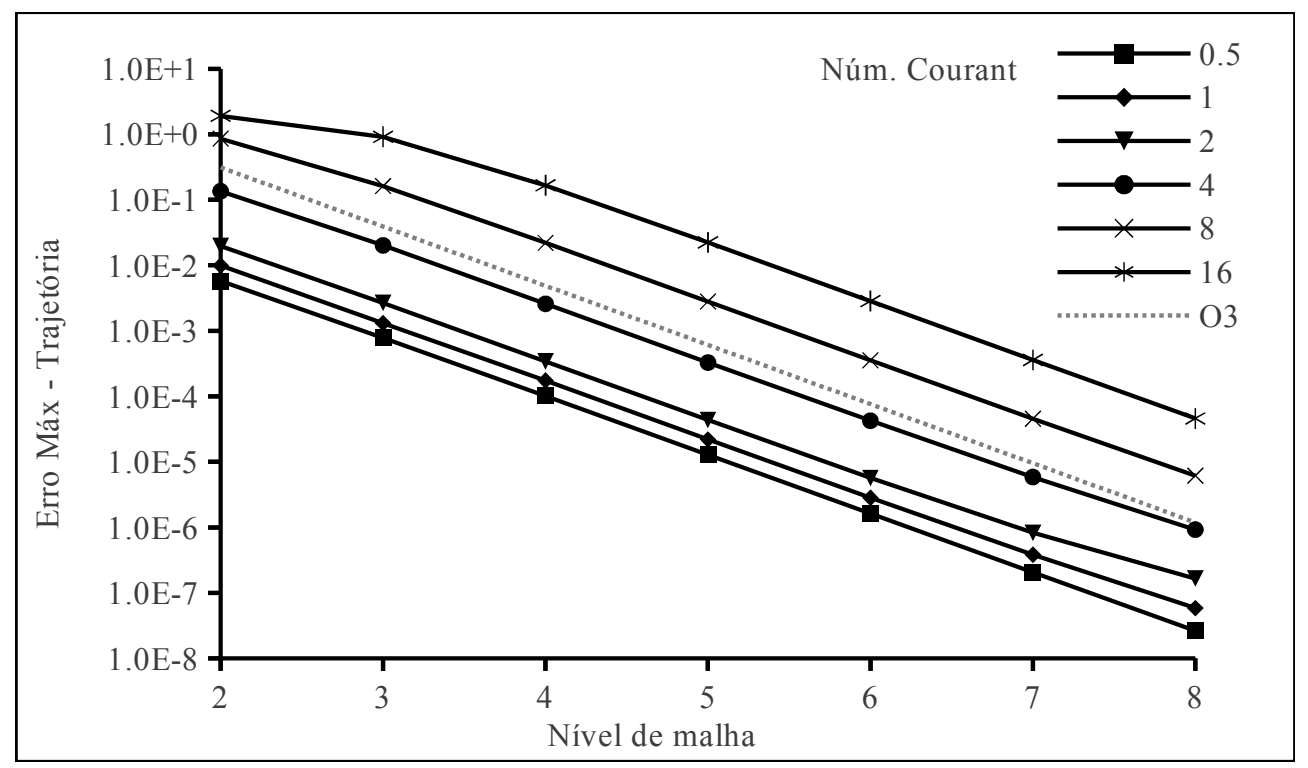

Figura 5.20: Erro máximo no cálculo dos pontos de partida para diversos números de Courant e níveis de malhas para o teste de deformação com rotação. A linha pontilhada (O3) é uma referência para convergência de terceira ordem. Os números de Courant são aproximações inteiras dos números de Courant exatos.

Representamos graficamente os erros obtidos ao final de uma revolução completa do traçador (variável $\phi$ ) para diversos números de Courant na Figura 5.21. Para um nível de malha fixado, o aumento do número de Courant, consequentemente aumento do espaçamento temporal, reduz o erro na variável $\phi$. Isso aparentemente ocorre pois o erro dominante é o da interpolação escalar, e ao realizamos menos interpolações, obtém-se erros menores. Porém, há um limite para isso. Percebe-se que ao consideramos um número de Courant de aproximadamente 16, temos um erro maior do que no caso com número de Courant 8 , indicando que o erro temporal passou a dominar o de interpolações escalares. Para um número de Courant fixado, percebe-se segunda ordem de convergência em relação ao refinamento de malha.

Nos testes feitos agora para o campo de deformação com rotação usamos o método de reconstrução vetorial por aproximação polinomial LSQTRC. Na Figura 5.22 comparamos o método LSQTRC com o método híbrido, usando limiar de corte de 0.01. Observa-se que a trajetória é calculada um pouco melhor no método de aproximação polinomial, mas com diferença muita pequena. Por outro lado, a estimativa da variável $\phi$ é essencialmente a mesma. 


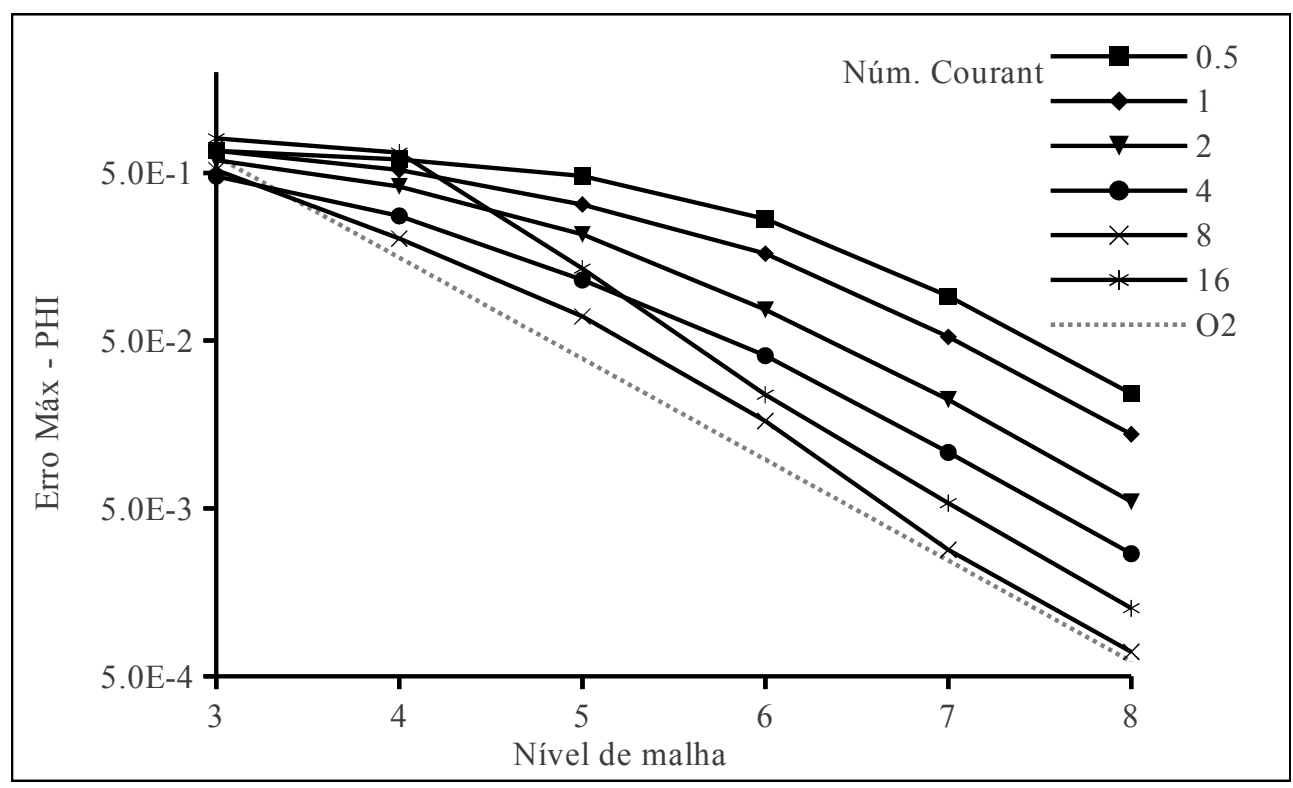

Figura 5.21: Erro máximo na variável $\phi$ ao final de uma revolução completa para diversos números de Courant e níveis de malhas considerando o teste de deformação com rotação. A linha pontilhada (O2) é uma referência para convergência de segunda ordem.

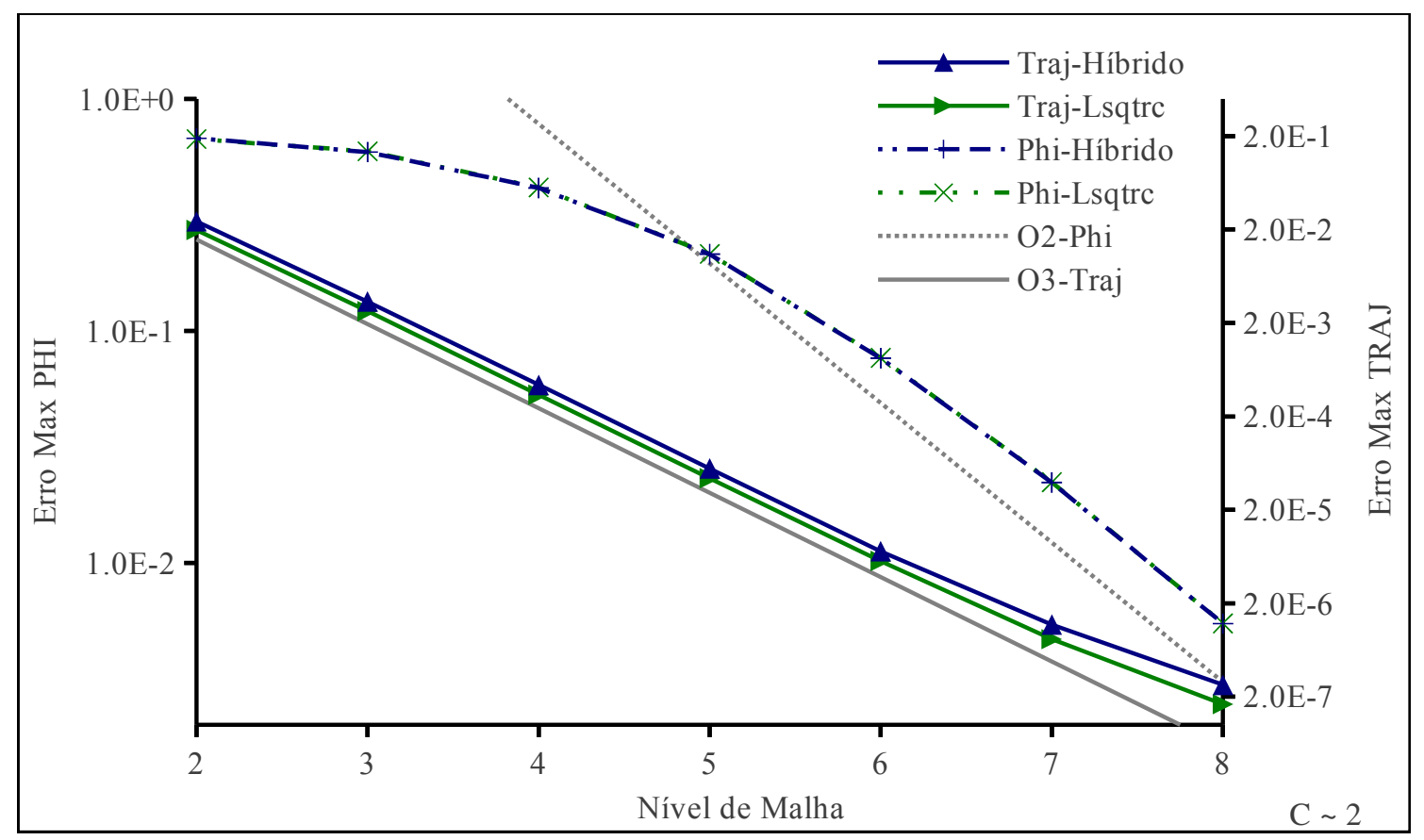

Figura 5.22: Erro máximo na variável no traçador (Phi) ao final de uma revolução completa e erro máximo no cálculo das trajetória (Traj) para dois métodos de reconstrução vetorial: LSQTRC e híbrido. Foi fixado um número de Courant de aproximadamente 2. A linha pontilhada indicada por O2-Phi é uma referência de segunda ordem para o erro no traçador. A linha sólida indicado por O3-Traj é uma referência de terceira ordem para o erro no cálculo da trajetória. 


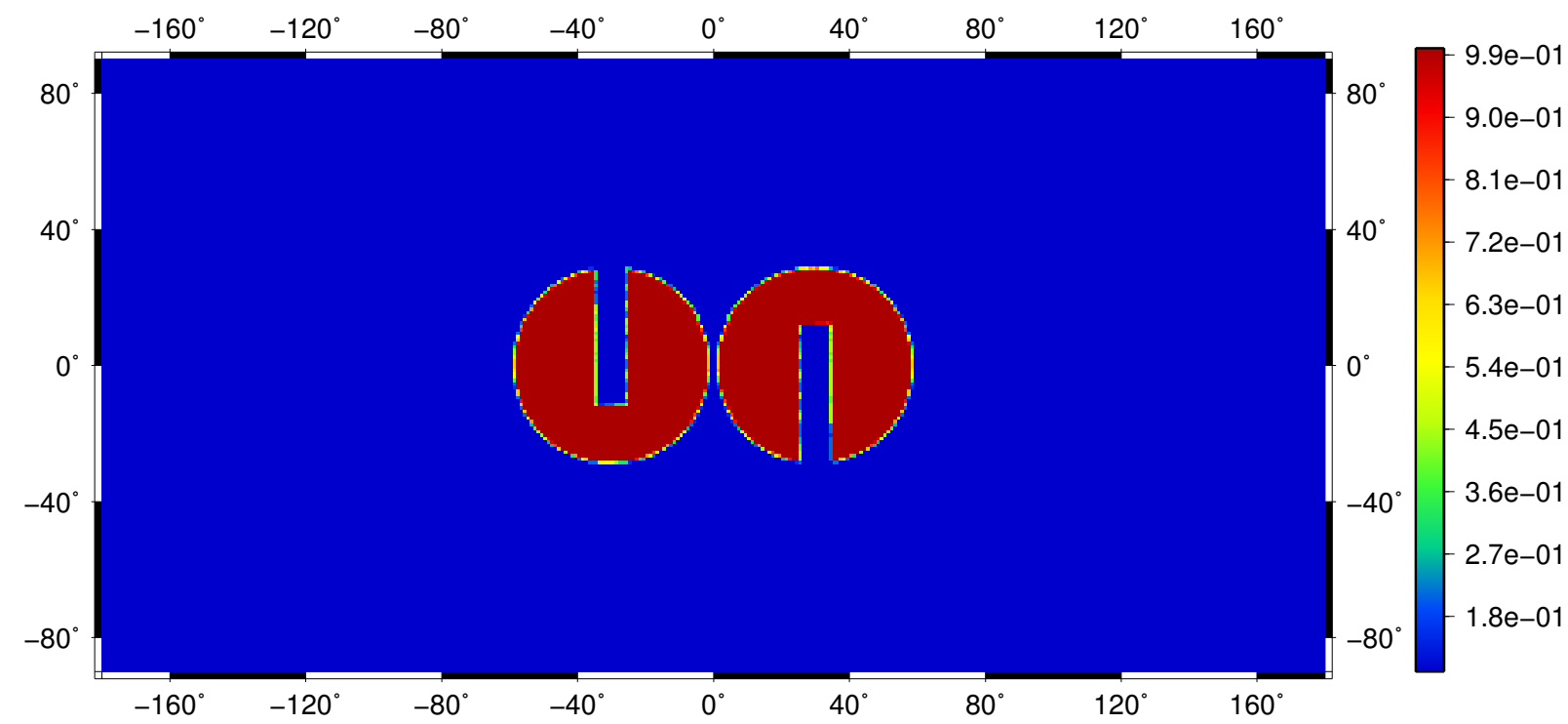

Figura 5.23: Condição inicial dos cilindros cortados (variável $\phi$ ). A malha usada é a icosaédrica de nível 6 .

\subsection{Monotonicidade}

Um esquema é monotônico se ele não cria novos máximos ou mínimos globais de razão de mistura. As interpolações de ordem maior que dois consideradas neste estudo não são intrinsecamente monotônicas. Isso significa, por exemplo, que ao realizarmos o transporte de uma substância (com concentrações inicialmente positivas) pode ser que observemos concentrações negativas da substância. Uma possível forma de assegurar monotonicidade é garantindo que o valor escalar interpolado esteja sempre entre o mínimo e o máximo dos valores considerados na interpolação. Isso poderá afetar a ordem do método, mas irá garantir uma propriedade desejável para o método de transporte.

Considerando o teste de deformação com rotação, conforme definido anteriormente, podemos usar uma outra condição inicial para $\phi$ mais interessante para análise de monotonicidade, considerando um campo escalar descontínuo, na forma de um cilindro cortado,

$$
\phi(\lambda, \theta)= \begin{cases}c & \text { se } r_{i} \leq r \text { e }\left|\lambda_{i}-\lambda\right| \geq r / 6 \\ c & \text { se } r_{1} \leq r \text { e }\left|\lambda_{1}-\lambda\right|<r / 6 \text { e } \theta-\theta_{1}<-\frac{5 r}{12} \\ c & \text { se } r_{2} \leq r \text { e }\left|\lambda_{2}-\lambda\right|<r / 6 \text { e } \theta-\theta_{2}>\frac{5 r}{12} \\ b & \text { caso contrário, }\end{cases}
$$

onde vamos tomar $c=1$ e $b=0.1$ e $\left(\lambda_{i}, \theta_{i}\right), i=1,2$, e os outros parâmetros iguais ao caso anterior. Esse campo escalar é apresentado na Figura 5.23. Vejamos primeiro a evolução para o caso sem controle de monotonicidade. Vamos usar o método híbrido de reconstrução vetorial (PERHX+LSQHXE) nestes testes, usando um parâmetro de corte de 0.01 para o índice de alinhamento. Para esse teste escolhemos uma malha de nível 6 e, para mantermos o erro no cálculo da trajetória pequeno e destacarmos o erro de interpolações escalares, escolhemos $d t$ tal que o número de Courant seja pequeno, aproximadamente 2, usando 512 passos de tempo. Mostramos na Figura 5.25 os primeiros passos de tempo, onde é possível ver claramente que ocorrem valores negativos de $\phi$, não físicos (repare nas mudanças nas escalas). Na Figura 5.26 mostramos mais passos de tempo, agora ilustrando o máximo de deformação e a solução final. A aproximação nos arredores da descontinuidade é ruim, como era de se esperar, mas o formato básico do cilindro é visível. Veja o erro no tempo final na Figura 5.24. Ao adicionarmos a restrição de monotonicidade não observamos mais oscilações e valores negativos, como podemos ver na sequência de gráficos da Figura 5.27, e o erro tem uma leve redução e fica mais concentrado em torno da descontinuidade (ver Figura 5.28). 


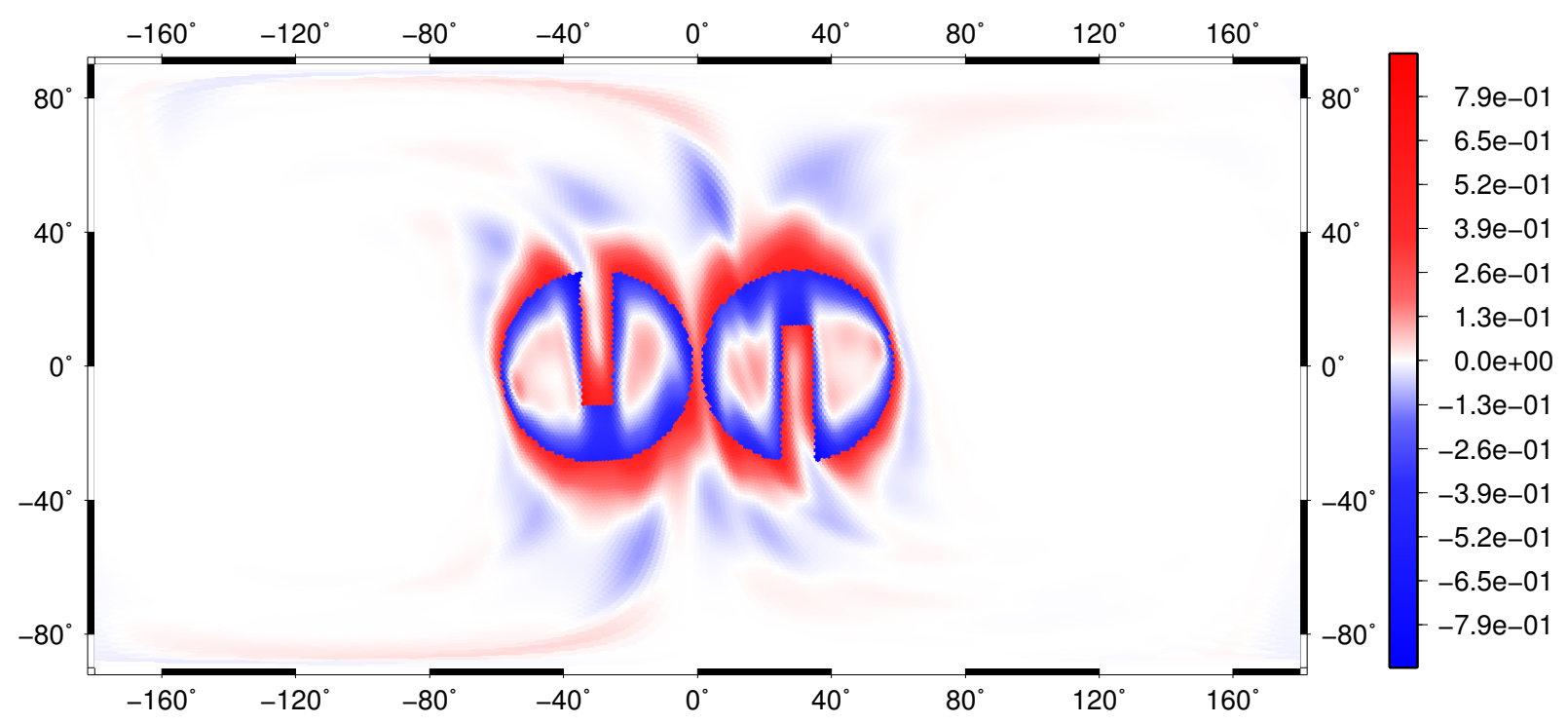

Figura 5.24: Erro final para o teste de deformação com rotação para o traçador com condição inicial de dois cilindros cortados. O método de reconstrução vetorial usado foi o híbrido (PERHX+LSQHXE). A malha usada é a icosaédrica de nivel 6 e foram considerados 512 passos de tempo. 

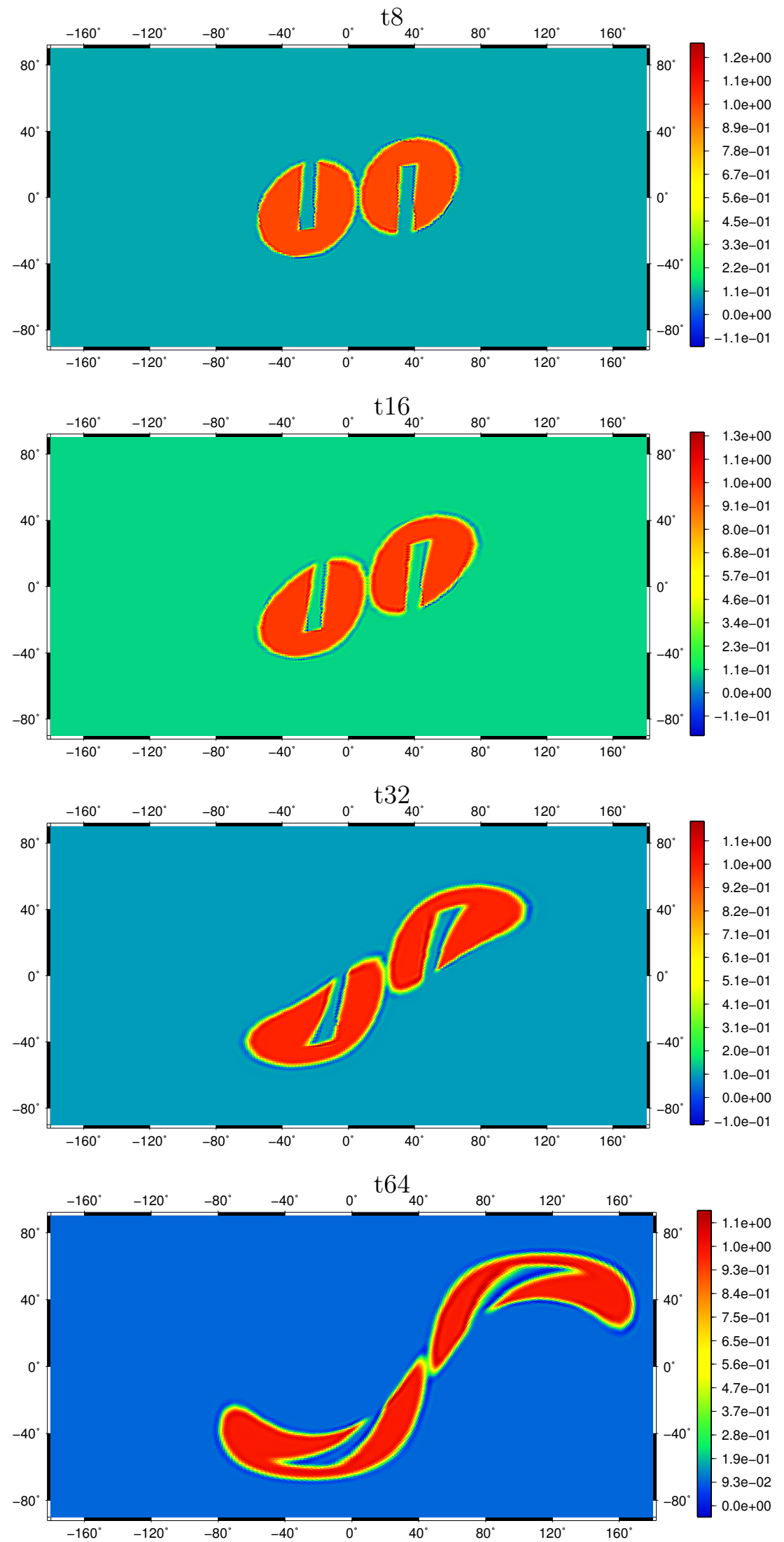

Figura 5.25: Teste de deformação com rotação para o traçador. Apresentamos a evolução do da concentração do traçador $(\phi)$ com 8, 16, 32, 64 passos de tempos. O método de reconstrução vetorial usado foi o híbrido (PERHX + LSQHXE). A malha usada é a icosaédrica de nivel 6 e foram considerados 512 passos de tempo. 

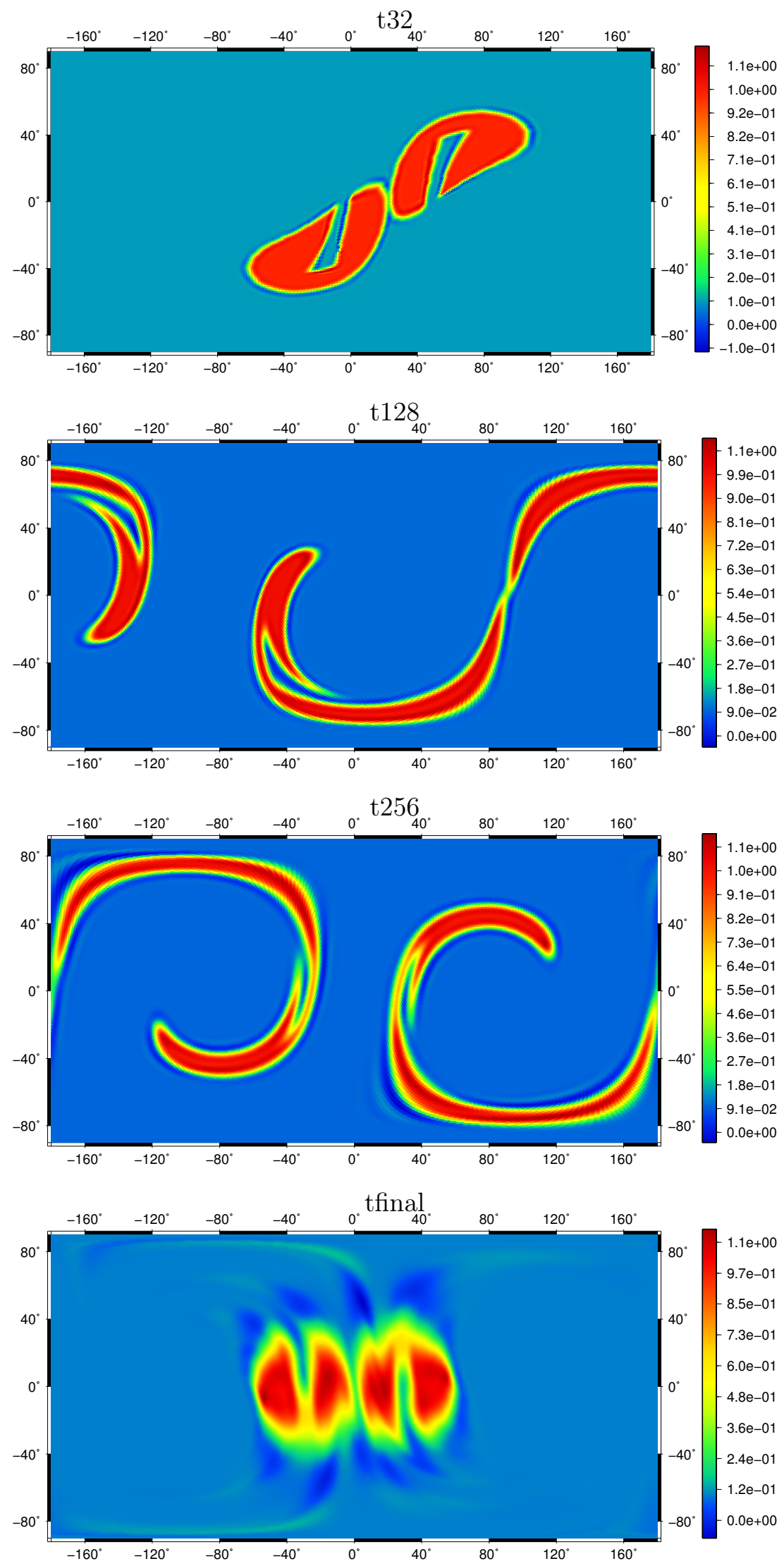

Figura 5.26: Teste de deformação com rotação para o traçador. Apresentamos a evolução do da concentração do traçador ( $\phi)$ com 128, 256, 512 passos de tempos. O método de reconstrução vetorial usado foi o híbrido (PERHX+LSQHXE). A malha usada é a icosaédrica de nível 6 e foram considerados 512 passos de tempo. 

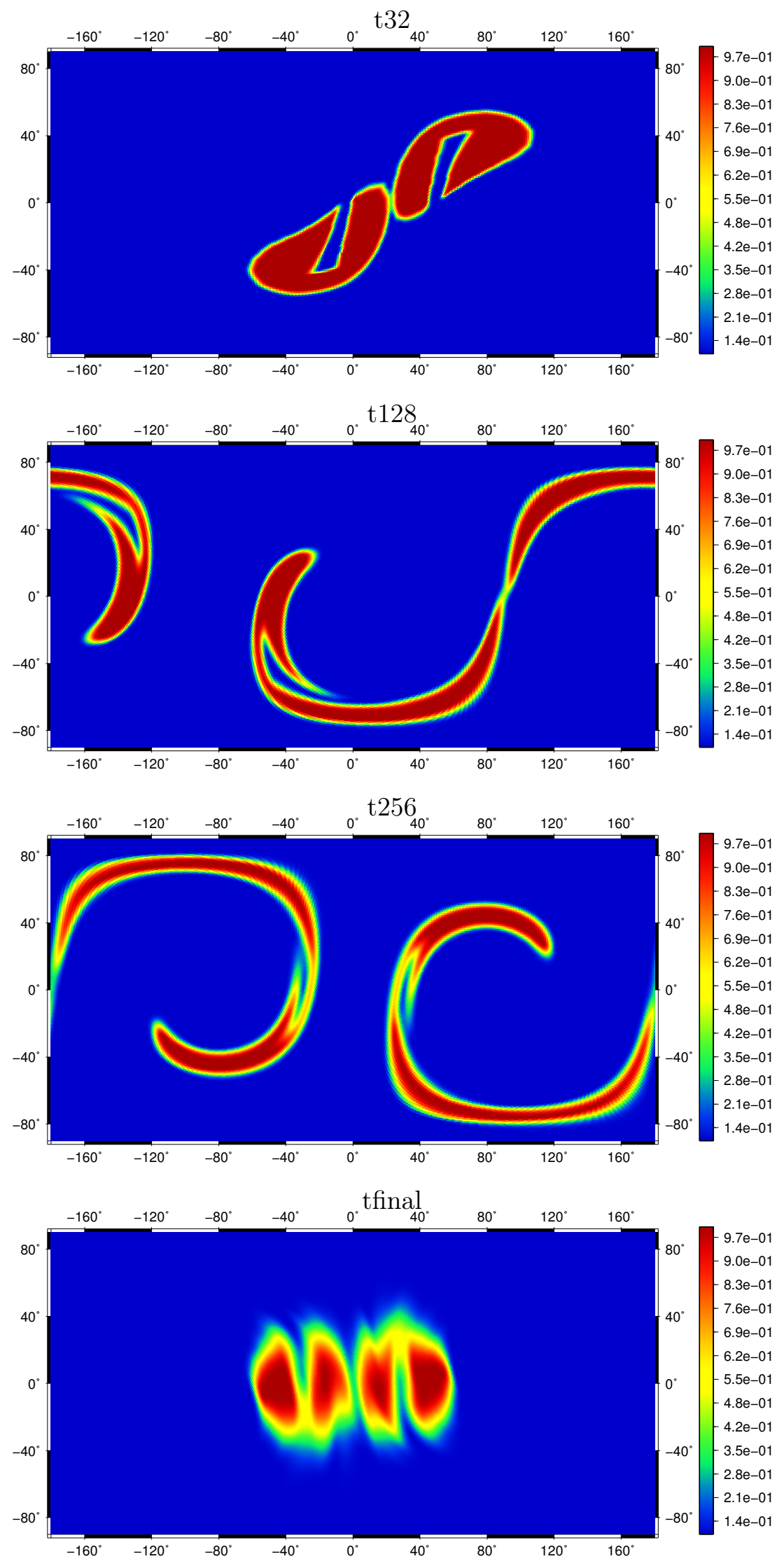

Figura 5.27: Teste de deformação com rotação para o traçador com controle de monotonicidade. Apresentamos a evolução do da concentração do traçador $(\phi)$ com 32, 128, 256 e 512 passos de tempos. O método de reconstruçấo vetorial usado foi o híbrido (PERHX+LSQHXE). A malha usada é a icosaédrica de nível 6 e foram considerados 512 passos de tempo. 


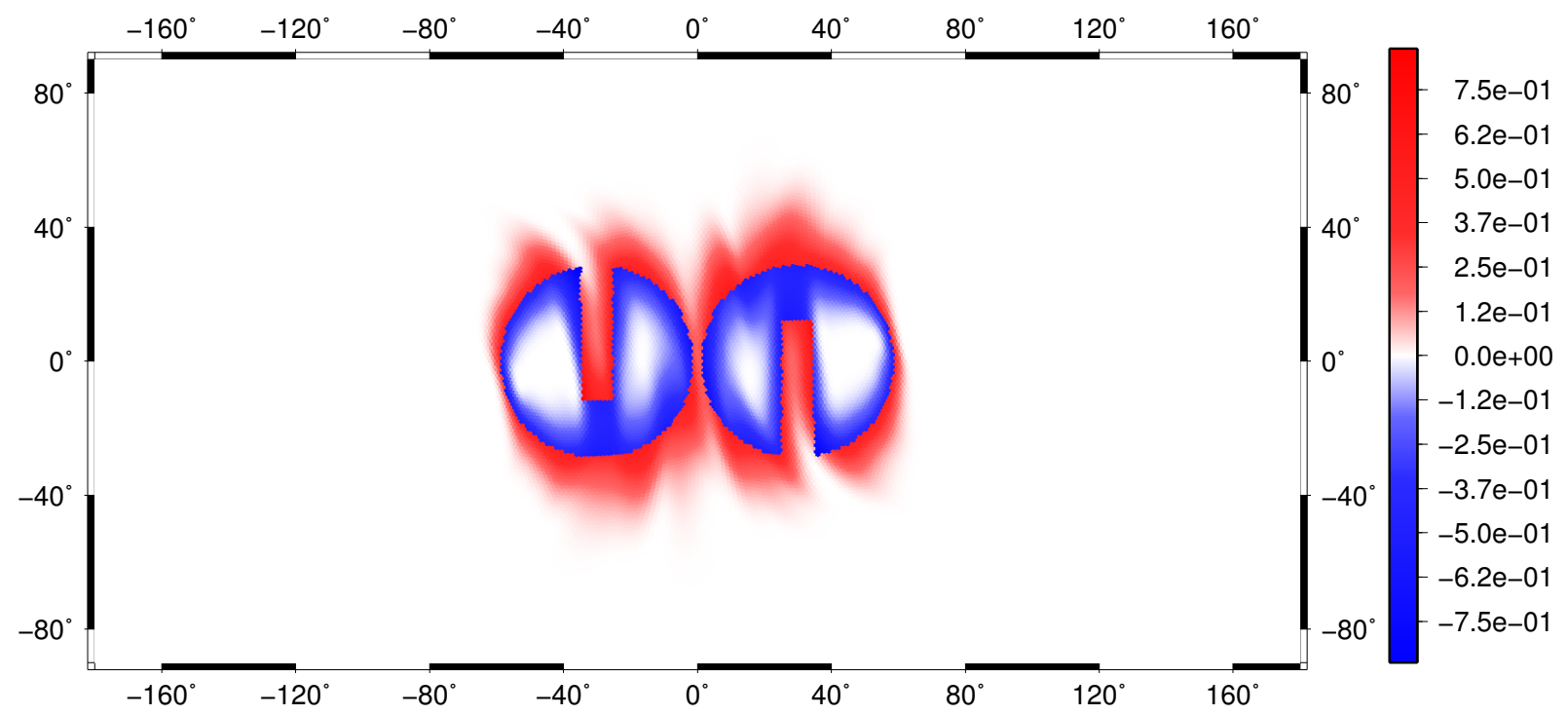

Figura 5.28: Erro final para o teste de deformação com rotação para o traçador com condição inicial de dois cilindros cortados impondo monotonicidade. O método de reconstrução vetorial usado foi o híbrido (PERHX+LSQHXE). A malha usada é a icosaédrica de nível 6 e foram considerados 512 passos de tempo. 


\subsection{Deformação com divergência}

O problema teste 3 de Nair e Lauritzen [2010] tem campo de velocidades com divergência não nula, dado em coordenadas esféricas (geográficas) ao longo do tempo como

$$
\begin{aligned}
& \left.u(\lambda, \theta, t)=-k \sin ^{2}((\lambda+\pi) / 2) \sin (2 \theta) \cos ^{2}(\theta) \cos (\pi t / T)\right), \\
& \left.v(\lambda, \theta, t)=\frac{k}{2} \sin (\lambda+\pi) \cos ^{3}(\theta) \cos (\pi t / T)\right),
\end{aligned}
$$

onde assumiremos o período total $T=5$ e $k=1$.

A condição inicial escalar será dada por dois sinos cossenoidais, que representam um campo escalar quase suave, da seguinte forma

$$
\phi(\lambda, \theta)= \begin{cases}b+\operatorname{ch}_{1}(\lambda, \theta) & \text { se } r_{1}<r \\ b+\operatorname{ch}_{2}(\lambda, \theta) & \text { se } r_{2}<r \\ b & \text { caso contrário }\end{cases}
$$

onde cada $h_{i}$ é definido como

$$
h_{i}(x, y, z)=\frac{1}{2}\left[1+\cos \left(\pi r_{i} / r\right)\right],
$$

$r=1 / 2, r_{i}=r_{i}(\lambda, \theta)$ é a distância geodésica entre $(\lambda, \theta)$ e $\left(\lambda_{i}, \theta_{i}\right)$, onde $\left(\lambda_{i}, \theta_{i}\right)$ são pontos fixados da esfera dados em coordenadas esféricas por

$$
\begin{aligned}
& \left(\lambda_{1}, \theta_{1}\right)=(-\pi / 3,0), \\
& \left(\lambda_{2}, \theta_{2}\right)=(\pi / 3,0) .
\end{aligned}
$$

Adotaremos $b=0.1$ e $c=1$.

A condição inicial e o campo de vetores são apresentados respectivamente nas figuras 5.29 e 5.30 .

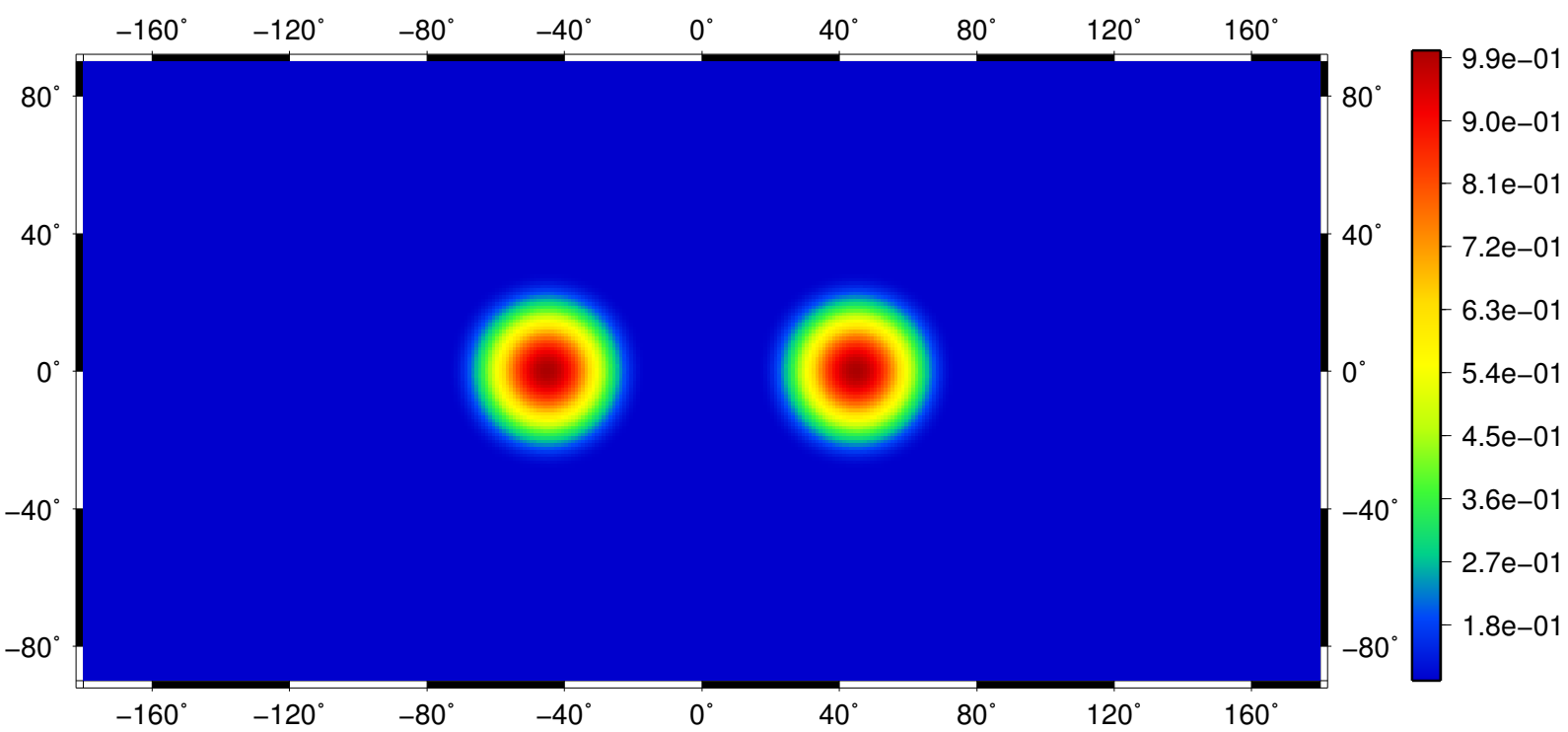

Figura 5.29: Condição inicial de sinos cossenoidais para o teste de deformação com divergência de número 3.

Resolvemos esse problema de transporte usando o método de reconstrução híbrido ( PERHX + LSQHXE ), com um parâmetro de corte de 0.01 para o índice de alinhamento. Adotamos uma malha de nível 6 e usamos 128 passos no tempo (resultando em um número de Courant de aproximadamente 2.3). Mostramos na Figura 5.31 alguns passos de tempo. Na Figura 5.32 mostramos os erros ao final 


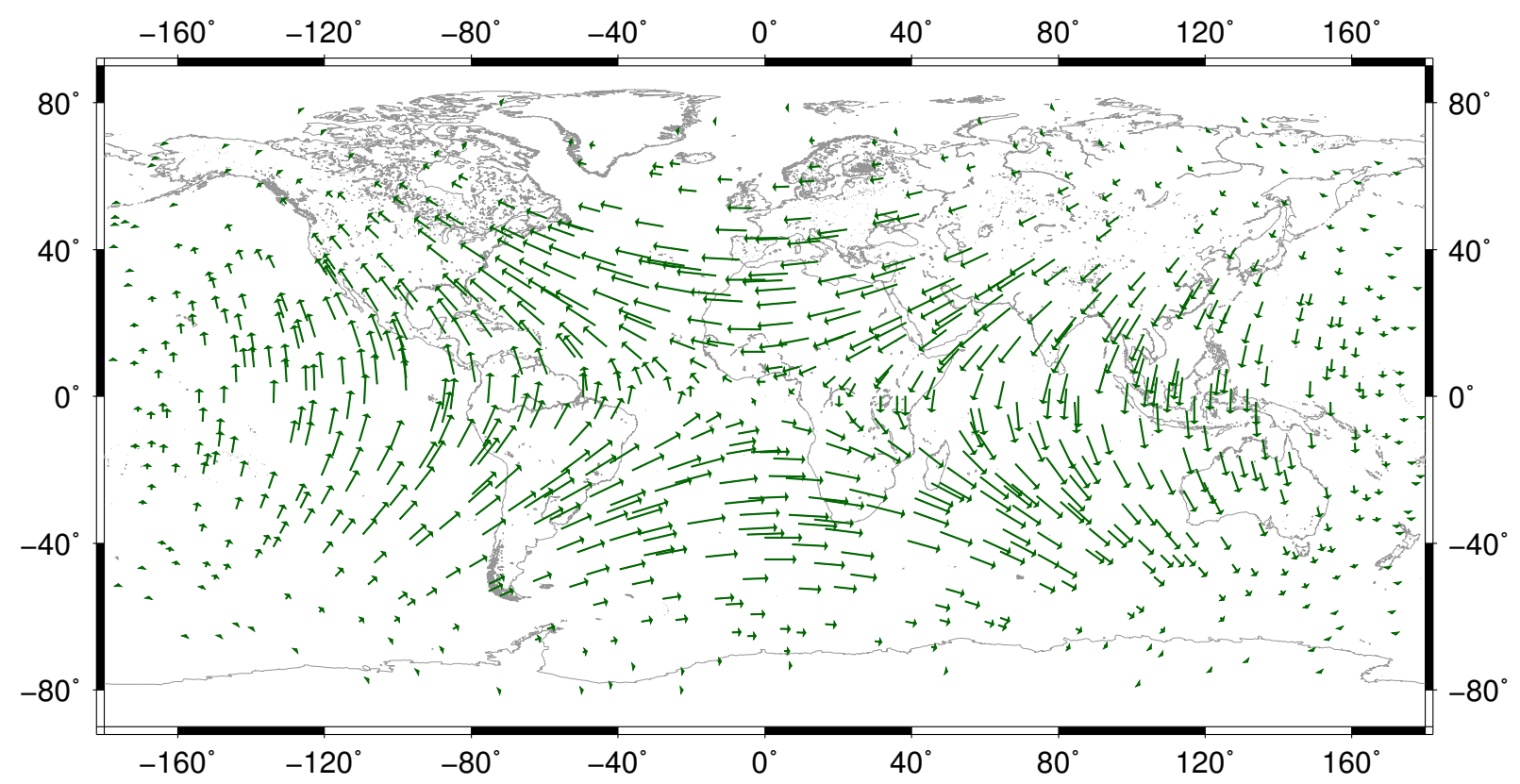

Figura 5.30: Campo de velocidade inicial para o teste de deformação com divergência de número 3.

do processo das variáveis $\phi, \rho$ e $\phi \rho$. Nos testes sem divergência, apresentados anteriormente, o erro no campo da densidade é significativamente menor que o erro no campo do traçador. Por isso, o erro predominante na densidade do traçador $(\phi \rho)$ originava-se do erro nos cálculos da evolução somente do traçador, e não da densidade. Nesse caso, observa-se que o erro ocorrido no campo da densidade impacta diretamente a densidade do traçador $(\phi \rho)$, pois temos um campo com divergência. Na Figura 5.32 percebe-se que o erro na densidade do traçador é uma combinação de erros ocorridos na evolução do traçador e da densidade, que agora são de ordens de grandeza comparáveis. 

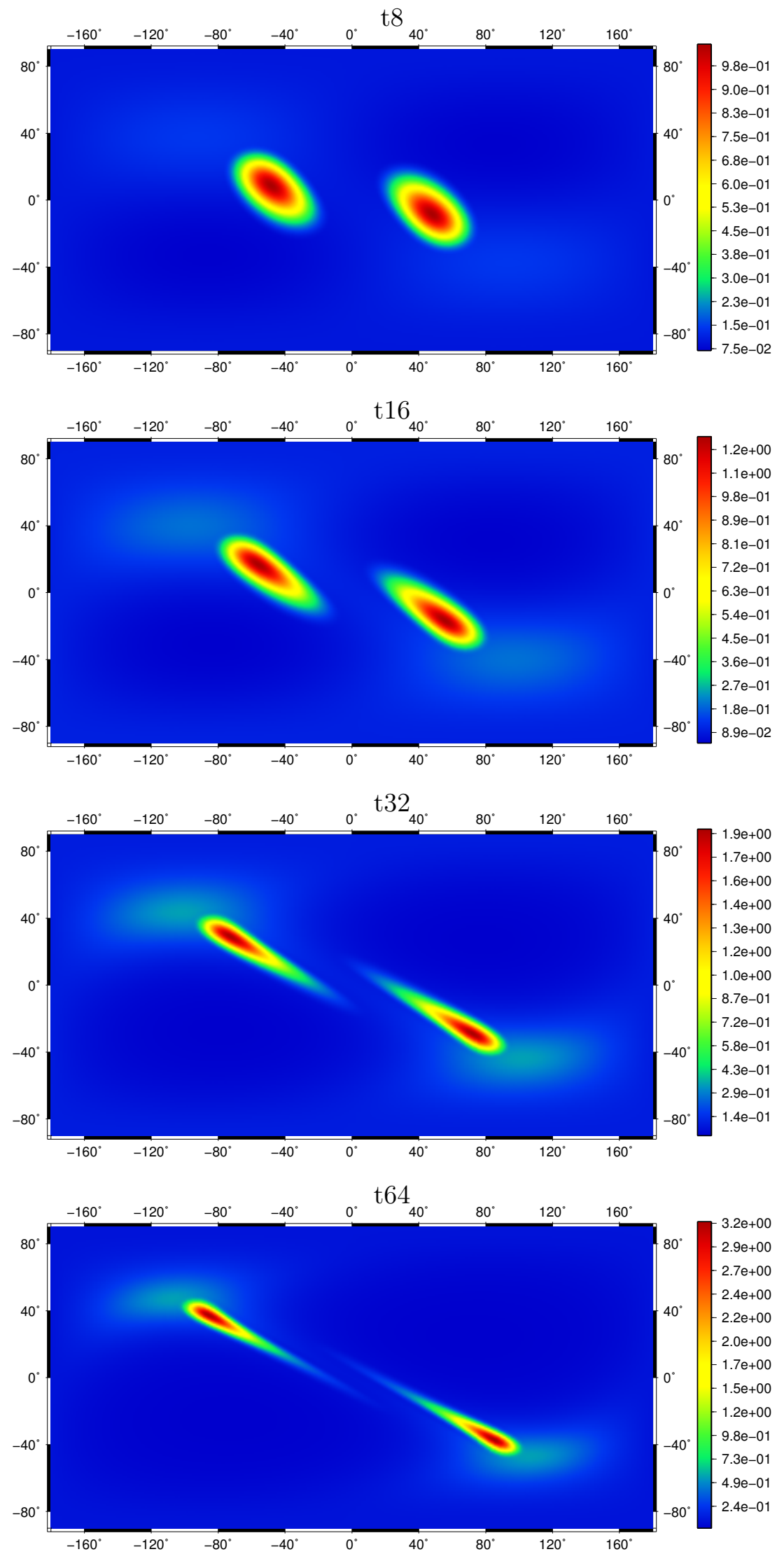

Figura 5.31: Teste de deformação com divergência para a densidade do traçador ( $\phi \rho)$ com condição inicial de sinos cossenoidais. Apresentamos a evolução a densidade do traçador com 8, 16, 32 e 64 passos de tempos. O método de reconstrução vetorial usado foi o híbrido. A malha usada é a icosaédrica de nível 6 e foram considerados 128 passos de tempo. 

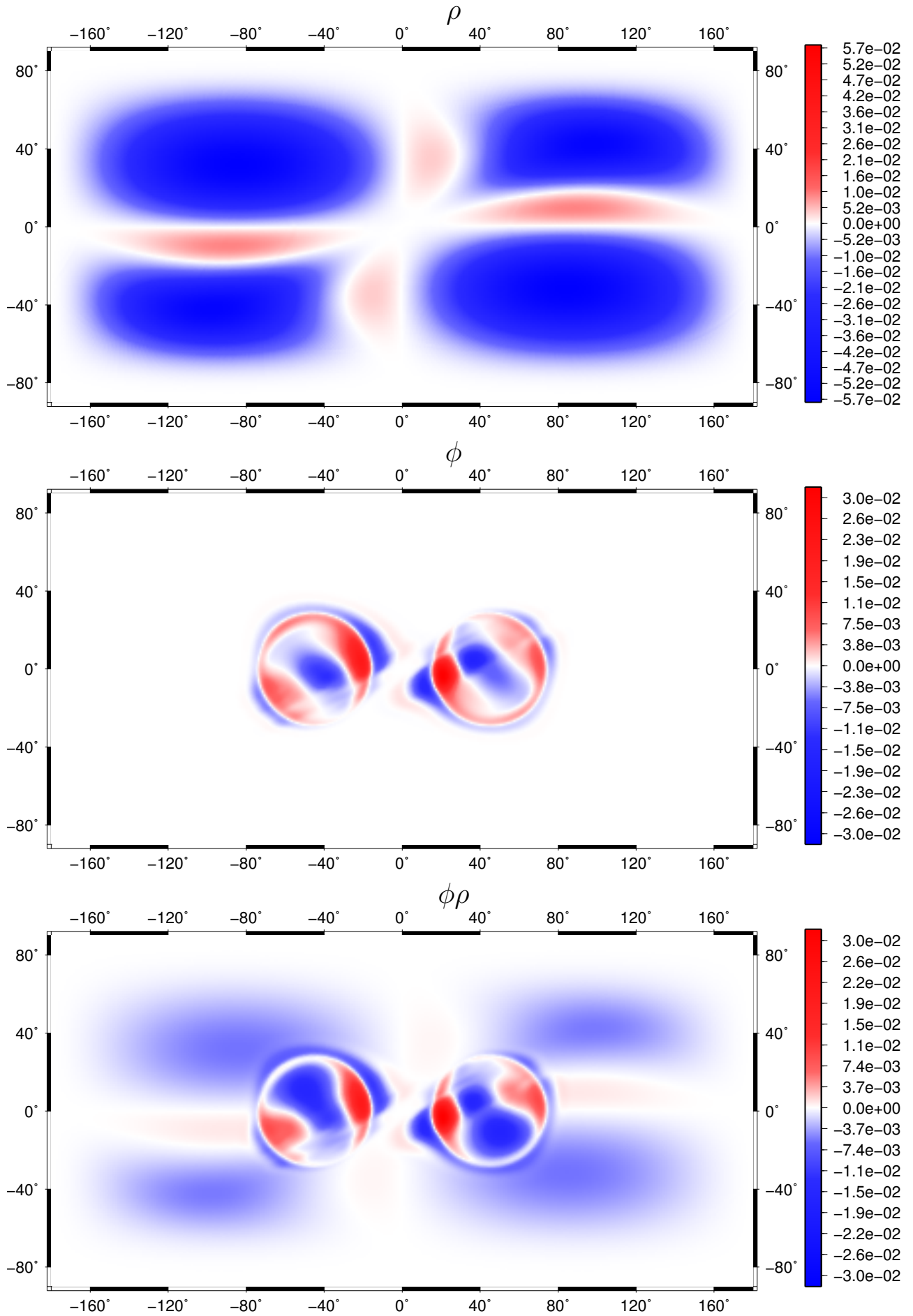

Figura 5.32: Erro final para o teste de deformação com divergência para a densidade $\rho$, a concentração do traçador $\phi$ e a densidade do traçador $\phi \rho$. A condição inicial usada foi a de sinos cossenoidais. O método de reconstrução vetorial usado foi o híbrido. A malha usada é a icosaédrica de nível 6 e foram considerados 128 passos de tempo. 


\subsection{Conservação de massa}

O método de transporte semi-lagrangiano em sua proposta inicial não garante conservação de massa ao longo do transporte. Podemos aplicar uma correção ao final de cada passo de tempo para mantermos a massa conservada. A massa total, supondo um traçador com razão de mistura, concentração, unitária, é dada por

$$
M_{\rho}(t)=\int_{\mathcal{S}^{2}} \rho(t) d A,
$$

que na malha discreta podemos estimar como

$$
M_{\rho}^{k}=\sum_{i=1}^{n} \rho_{i}^{k}\left|\Omega_{i}\right|,
$$

onde $k$ representa um instante de tempo discreto, $n$ é o número de células, $\Omega_{i}$ é uma célula e $\left|\Omega_{i}\right|$ é sua área. Uma forma simples de conservar a massa global é corrigindo ao final de cada passo de tempo a densidade por um fator da seguinte forma

$$
\tilde{\rho}_{i}^{k}=\frac{M_{\rho}^{0}}{M_{\rho}^{k}} \rho_{i}^{k} .
$$

A conservação de massa de um traçador em geral pode ser obtida realizando o mesmo procedimento para corrigir $\phi$ e conservar a massa relativa a $\rho \phi$.

Para analisar a conservação de massa vamos usar o teste com divergência descrito na seção anterior. Na Figura 5.33 apresentamos o erro de $\phi \rho$ no final de uma revolução impondo conservação de massa, onde vemos que o padrão de erro se alterou, principalmente na variável de densidade, quando comparado ao que vimos na Figura 5.32. Porém, os erros são de magnitudes similares.

Na Figura 5.34 mostramos a evolução da massa (em variação percentual) para o teste com divergência considerando 128 passos no tempo, sem o corretor de massa global. Vemos que a variação da massa total é pequena, não chegando a 1.5\%. Apesar disso, para o transporte em longos períodos, o ajuste para conservação de massa é indicado. Ao forçarmos a monotonicidade, há uma variação um pouco menor da massa do traçador. Realizamos o mesmo teste com mais passos de tempo (512), para reduzir o erro temporal, e verificamos um efeito positivo da monotonicidade na conservação de massa (veja a Figura 5.35). Por outro lado, isso não corre com a densidade (massa do fluido), possivelmente devido a suavidade do campo inicial de densidade e do campo vetorial. 

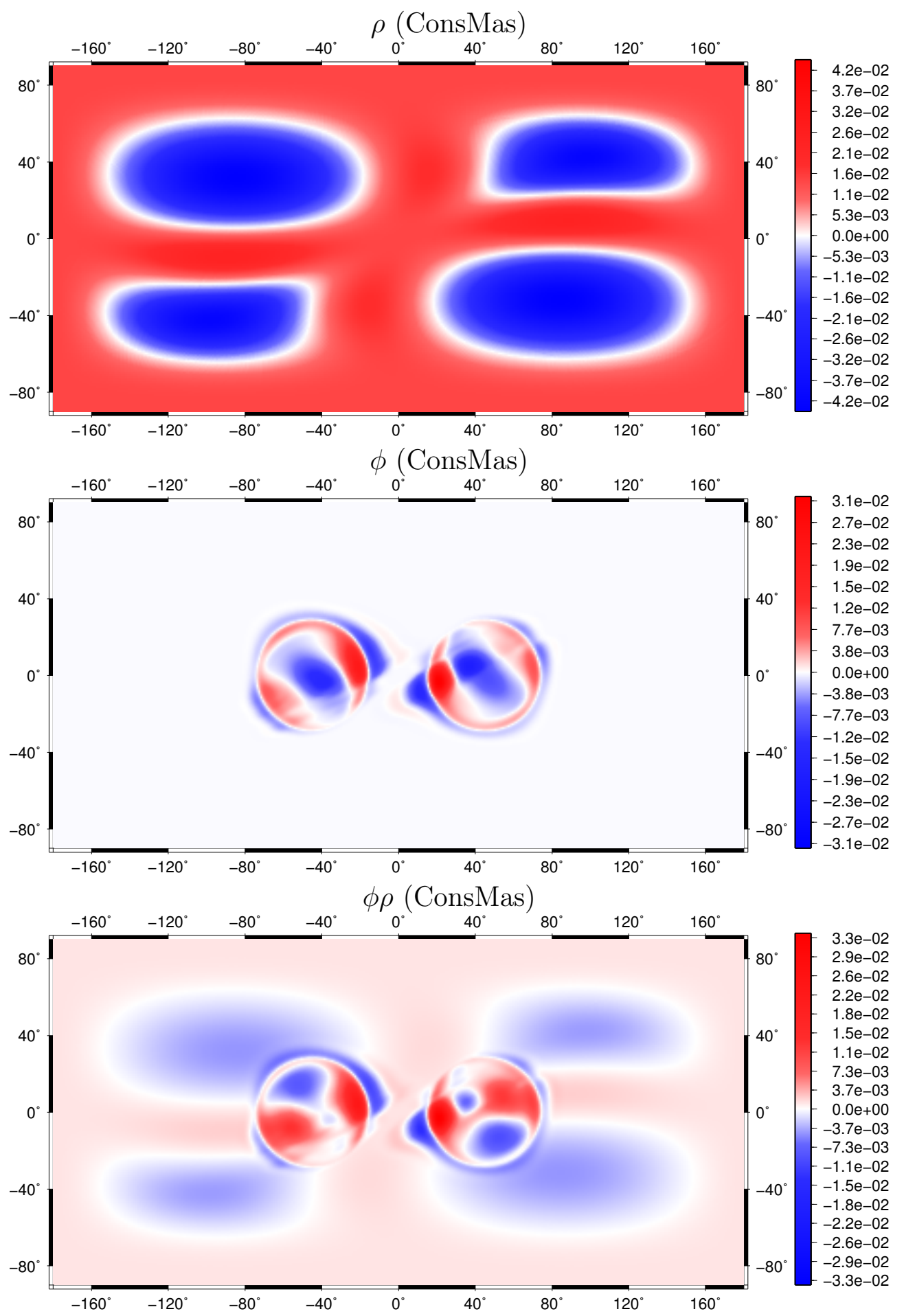

Figura 5.33: Erro final para o teste de deformação com divergência usando controle de massa global para a densidade $\rho$, a concentração do traçador $\phi$ e a densidade do traçador $\phi \rho$. A condição inicial usada foi a de sinos cossenoidais. O método de reconstrução vetorial usado foi o híbrido. A malha é a icosaédrica de nível 6 e foram considerados 128 passos de tempo. 


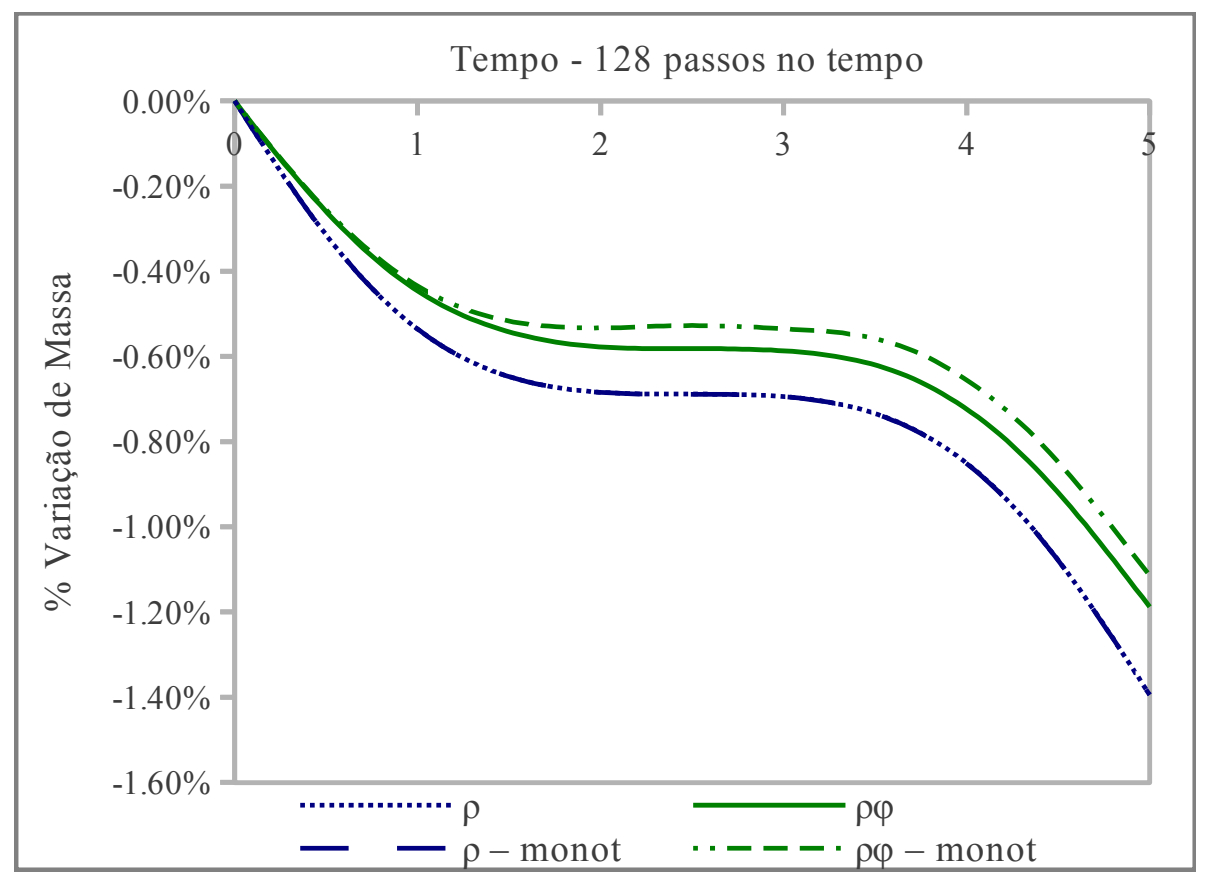

Figura 5.34: Evolução do percentual de variação de massa para o teste de transporte com divergência com condição inicial de sinos cossenoidais com e sem controle de monotonicidade. Foram usados 128 passos no tempo e uma malha de nível 6.

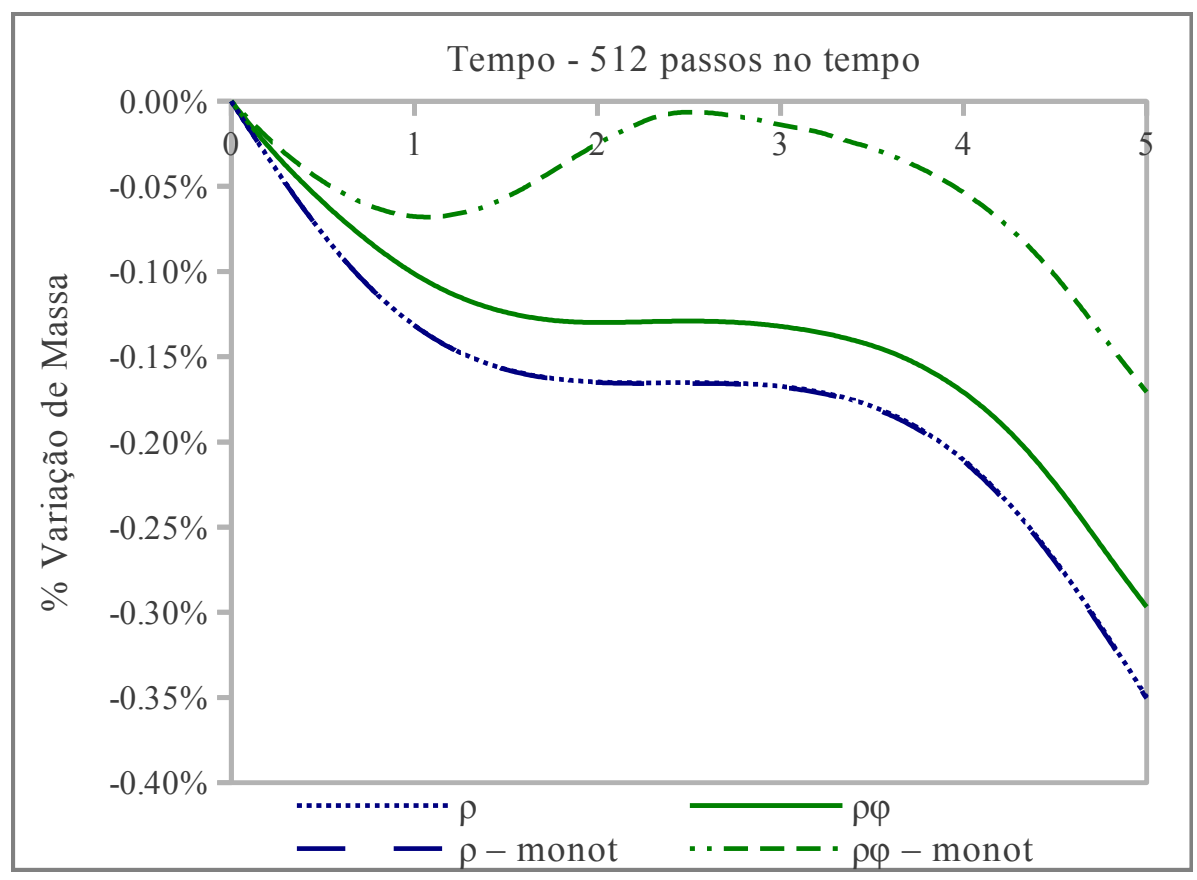

Figura 5.35: Evolução do percentual de variação de massa para o teste de transporte com divergência com condição inicial de sinos cossenoidais com e sem controle de monotonicidade. Foram usados 512 passos no tempo e uma malha de nível 6 . 


\subsection{Comentários}

Analisamos o modelo semi-lagrangiano proposto em relação a diversos aspectos. Mostramos, teoricamente, que o cálculo da trajetória pode ser feito com terceira ordem se usarmos 2 iterações na resolução da equação não linear e um método de interpolação vetorial de segunda ordem (apêndice C). Se a interpolação escalar for feita também com terceira ordem, então o método resultante, mantendo um número de Courant fixado (espaçamento temporal da ordem do espaçamento físico), será de segunda ordem.

Utilizando um teste de rotação com velocidade variável validamos o método em cada uma das suas componentes. A discretização temporal é de terceira ordem, considerando o campo de velocidades conhecido em qualquer ponto e instante. Ao consideramos o campo vetorial dado somente em determinados pontos de malha, usando métodos de interpolações vetoriais de segunda ordem, observamos terceira ordem de aproximação no cálculo das trajetórias. Em modelos atmosféricos globais geralmente a velocidade é fornecida para o modelo de transporte como solução das equações de momento, assim a terceira ordem observada pode ser reduzida, dependendo da precisão obtida para o campo de velocidades. A interpolação escalar $C^{1}$ de Renka mostrou-se adequada ao método e confirmamos se tratar de um método de terceira ordem. Contudo, na análise de deformação com rotação, verificamos a segunda ordem de aproximação do método para o transporte do traçador, considerando todas as componentes de erros e número de Courant fixado.

O maior desafio na construção do método semi-lagrangiano em malhas deslocadas do tipo HC é a reconstrução vetorial. Analisamos dois dos métodos descritos no capítulo anterior, agora no contexto da modelagem de transporte. O método de reconstrução vetorial polinomial para os circuncentros dos triângulos (LSQTRC), seguido de interpolações vetoriais usando coordenadas de Wachspress (WCHX), mostrou-se adequado para os cálculos do campo vetorial fora dos pontos de malha. O método de reconstrução de Perot para células de Voronoi carrega uma interferência de malha para o cálculo do ponto de partida, que resulta em aproximações ruins em células mal alinhadas. Por outro lado, gera aproximações muito boas para células alinhadas, a um custo baixo. Neste sentido, o método de reconstrução híbrido, envolvendo o método de Perot para células de Voronoi (PERHX) em células melhor alinhadas e o método de reconstrução polinomial para os vértices dos triângulos (LSQHXE) em células mal alinhadas, mostrou-se uma excelente alternativa de baixo custo.

Mesmo com passos de tempo grandes (números de Courant altos), o método semi-lagrangiano foi capaz de reproduzir bem as deformações induzidas nos testes propostos em Nair e Lauritzen [2010].

A discretização do divergente na equação da continuidade gera um padrão ligado a características da malha na densidade. Percebe-se que o padrão de interferência de malha é criado a cada iteração, e ainda é transportado ao longo das trajetórias. Isso faz com o que a interferência de malha afete globalmente o cálculo da densidade, gerando um ruído de alta frequência na solução.

O método proposto não é monotônico a priori, porém vimos como induzir a monotonicidade impondo restrições de mínimo e máximo a interpolação escalar. A monotonicidade se mostra essencial no transporte de traçadores com descontinuidade na condição inicial, como o cilindro cortado, para evitar oscilações próximo às regiões de descontinuidades. A conservação de massa global pode ser obtida usando um corretor a cada iteração, distribuindo a massa perdida/ganha proporcionalmente nos pontos de malha.

Apesar do custo de um método semi-lagrangiano ser maior que o de um método euleriano, principalmente devido ao cálculo das trajetórias, as trajetórias são comuns a todos os traçadores. Logo, como em modelos atmosféricos temos muitos traçadores, esse custo fica diluído. Além disso, os passos de tempo podem ser significativamente maiores que nos métodos eulerianos, fazendo com que o método seja potencialmente eficiente em modelo atmosféricos com muitos traçadores. 


\section{Capítulo 6}

\section{Conclusões}

Nas últimas décadas houve um interesse crescente em malhas mais isotrópicas para a esfera, a fim de se obter um melhor aproveitamento de recursos computacionais com processamento distribuído. Neste sentido, as malhas geodésicas se mostraram promissoras, principalmente as geradas a partir do icosaedro. Apesar de existirem modelos atmosféricos na literatura que usam malhas icosaédricas, não há consenso sobre as metodologias mais adequadas a esse tipo de malha. Nós nos propusemos, portanto, a entender em detalhe diversos fatores envolvidos no desenvolvimento de modelos atmosféricos globais usando malhas geodésicas icosaédricas.

Desenvolvemos um gerador de malhas icosaédricas considerando uma estrutura de dados baseada em listas de nós, arestas, triângulos e polígonos. O gerador de malhas permite a geração de outras malhas geodésicas, como a octaédrica, e também a possibilidade de refinamentos locais. Implementamos também um conjunto de ferramentas de geometria computacional para auxiliar no desenvolvimento de métodos numéricos nesse tipo de malha.

Começamos as análises do uso de malhas icosaédricas na resolução numérica de modelos atmosféricos investigando uma discretização usual do operador diferencial divergente. Análises preliminares revelaram que essa discretização era apenas de primeira ordem, enquanto a mesma discretização em malhas com células retangulares (longitude-latitude) é de segunda ordem. Além disso, sua precisão estava correlacionada com estruturas da malha, sendo possível observar padrões de malhas mais grossas mesmo quando as discretizações eram feitas em malhas muito finas. Passamos então a investigar propriedades geométricas da malha a fim de compreender suas relações com discretizações.

Na literatura, as principais métricas de propriedades de malhas estão relacionadas com áreas e distorções das células computacionais. Porém, essas métricas não são suficientes para explicar os padrões observadas na discretização do divergente. Analisamos diversas propriedades da malha, como medidas de distâncias, áreas, distorções, posicionamento de centros de massa e relações entre arestas da triangulação com a malha dual de Voronoi. Percebe-se que essas propriedades não variam suavemente, e há evidências numéricas na literatura de que isso seria responsável por interferir na precisão de certas discretizações. Para contornar o problema, algumas otimizações de malha foram propostas. A otimização de spring dynamics foi proposta em Tomita et al. [2001] justamente para melhorar a precisão da discretização do divergente, para a qual afirmaram que nessa malha a aproximação seria de segunda ordem. Essa otimização reduz as distorções na malha e também suaviza diversas propriedades, melhorando o grau de homogeneidade da malha icosaédrica. Porém, nossas análises revelam que ainda assim a discretização do divergente é de primeira ordem e, além disso, nota-se interferência de malha no padrão do erro.

Investigamos outras otimizações existentes na literatura. A discretização do laplaciano feita de forma análoga à do divergente gera uma aproximação assintoticamente inconsistente na malha icosaédrica. Para sanar esse problema, foi proposta uma otimização (Heikes e Randall [1995a]) que melhora o desvio entre os pontos médios das arestas da triangulação em relação às do diagrama de Voronoi, revelando convergência da discretização do laplaciano em experimentos numéricos. Além disso, essa otimização suaviza as distribuições de outras propriedades, como áreas e distorções, e melhora a homogeneidade da malha. Ainda assim, a discretização do divergente é de primeira 
ordem e há presença de interferência de malha na distribuição do erro. Uma outra otimização proposta para malhas icosaédricas é a centroidal de Voronoi (SCVT). Essa otimização gera os menores valores de distorções, sacrificando, porém, um pouco da homogeneidade. Em todas as otimizações observamos distorções maiores próximo aos pentágonos. De forma geral, nos casos estudados, observamos melhores resultados nas malhas otimizadas com SCVT. Contudo, apesar das otimizações melhorarem um pouco a precisão da discretização do divergente, ainda ocorrem claras inferências de malha na solução.

Analisamos o fenômeno de interferência de malha na discretização do divergente do ponto de vista teórico. Identificamos uma característica geométrica da célula computacional, que denominamos por alinhamento, claramente relacionada ao fenômeno. Mostramos que em células alinhadas obtemos segunda ordem de convergência para a discretização usual do divergente. Usando projeções para planos tangentes, definimos o conceito de células alinhadas para a esfera e mostramos que nelas a aproximação do divergente será de segunda ordem. Definimos o conceito de índice de alinhamento para avaliar o quão perto de alinhada uma célula está. Com base nisso, identificamos que o padrão de interferência de malha é causado por uma diferença na ordem de convergência de células com diferentes características de alinhamento. Verificamos a análise de convergência numericamente, inclusive em malhas otimizadas, confirmando os resultados teóricos. O conjunto de definições e resultados gerou uma teoria que explica o padrão de interferência de malha encontrado na discretização do divergente. Além disso, essa teoria pode ser naturalmente generalizada para discretizações do rotacional e laplaciano e é aplicável para qualquer malha geodésica. Mostramos que malhas com células melhor alinhadas são desejáveis. Porém, acreditamos não ser possível construir uma malha somente com células alinhadas, devido à geometria da esfera. Nas malhas icosaédricas, apresentamos um exemplo que ilustra que não há como garantir segunda ordem de aproximação do divergente nas células pentagonais com a discretização usual. Assim, acreditamos que o problema de interferência de malha não possa ser trivialmente resolvido apenas com modificações na malha. Por outro lado, a teoria de alinhamento pode ajudar no desenvolvimento de métodos que levem em conta a geometria da célula na discretização. Esses resultados foram publicados em Peixoto e Barros [2013].

A não regularidade da malha icosaédrica gera desafios em outros aspectos importantes da modelagem numérica, como a interpolação de valores. Analisamos diversos métodos de interpolações escalares para a esfera geodésica icosaédrica. As coordenadas baricêntricas para triângulos, muito usadas em elementos finitos, fornecem um método de interpolação de segunda ordem para o plano. As generalizações para a esfera encontradas na literatura preservam a linearidade do sistema de coordenadas, mas violam a representação exata de funções constantes, essencial para métodos de interpolação. Nós propusemos uma generalização para a esfera que viola a linearidade do sistema de coordenadas na esfera, mas que preserva segunda ordem de aproximação. As coordenadas baricêntricas são uma forma de baixo custo para obter interpolações de segunda ordem em triângulos, porém, não encontramos generalizações para serem usadas em polígonos, como células de Voronoi, na literatura de modelagem numérica para a atmosfera. Descobrimos na literatura de computação gráfica $(\mathrm{CAD})$ uma série de métodos que generalizam as coordenadas baricêntricas para polígonos quaisquer. O método conhecido por coordenadas naturais gera boas aproximações, mas exige um custo alto para os cálculos das coordenadas. Por outro lado, o método baseado em coordenadas de Wachspress gera aproximações de segunda ordem e depende apenas de cálculos de áreas de triângulos. O método de Wachspress é uma generalização direta do sistema de coordenadas baricêntricas triangulares. As coordenadas de Wachspress são uma opção de baixo custo, muito flexíveis, para interpolações de segunda ordem em células computacionais encontradas em malhas icosaédricas.

Algumas aplicações, como o modelo de transporte semi-lagrangiano que desenvolvemos, exigem interpolações do campo escalar de ordem maior que dois. Investigamos algumas possibilidades. Os métodos de funções de base radial (RBFs) apresentam bom custo-benefício. É possível obtermos métodos de alta ordem (3a. ou 4a.), com interpolações muito precisas, escolhendo adequadamente o conjunto de pontos usados na interpolação. Porém, não há garantias de convergência assintótica do método, por conta de problemas de instabilidades numéricas. Outra abordagem é usarmos aproxima- 
ções locais por polinômios quadráticos, que podem ser obtidos com métodos de mínimos quadrados. É possível combinarmos linearmente essas aproximações quadráticas usando funções radiais como peso (Método Quadrático de Shepard Modificado) para obtenção de funções interpoladoras globalmente contínuas. Porém, esse método apresenta um custo maior que os demais métodos analisados. Renka [1997] propôs um método que usa os gradientes de polinômios quadráticos nos vértices dos triângulos para obter uma aproximação baseada em interpolações de Hermite globalmente $C^{1}$ na esfera. Esse método revelou um excelente custo-benefício como método de terceira ordem.

Verificamos na literatura que uma boa forma de reduzir modos computacionais em modelos atmosféricos é usando malhas deslocadas do tipo HC, onde o campo escalar é conhecido nos vértices dos triângulos e o vetorial é parcialmente conhecido nas arestas das células de Voronoi (têm-se somente as componentes normais às arestas). Esse tipo de colocação de campos na malha fornece uma representação mais precisa de ondas rápidas em modelos atmosféricos. Porém, como conhecemos apenas componentes do campo de velocidades, para obtermos o campo completo em qualquer ponto da esfera, temos que reconstruir o campo vetorial a partir de suas componentes.

Analisamos diversos métodos de reconstrução vetorial e propusemos alternativas ao que vem sendo usado na literatura. Os métodos de reconstrução baseados em elementos finitos mistos em triângulos (RT0 e WHT) geram aproximações de primeira ordem, e são pouco precisos para a maior parte das aplicações que exigem interpolações vetoriais em modelos atmosféricos. Por outro lado, os métodos de funções de base radial tem boa precisão e, por isso, têm sido adotados em modelos que usam malhas deslocadas. Porém, assim como descrito para o caso de interpolações escalares, apresentam o problema de possíveis instabilidades numéricas em malhas muito finas. Hoje, esse problema é aparentemente apenas teórico, pois na literatura o método vem sendo usado sem problemas práticos, mas acreditamos que possa se tornar relevante em modelos com malhas finas o suficiente para resolver nuvens.

O método de Perot [2000] é uma formulação construída com base no Teorema da Divergência que garante aproximação de primeira ordem a um custo baixo. A precisão do método depende fortemente da geometria da célula e, com base na teoria de alinhamento proposta nesta tese, verificamos que o método é de segunda ordem em células alinhadas. Nas malhas icosaédricas, que possuem majoritariamente células alinhadas, ou quase alinhadas, a precisão é boa em grande parte do domínio. Porém, na minoria de células mal alinhadas, temos baixa precisão nas reconstruções. Em Vidovic [2009] foram descritos métodos de reconstruções vetoriais polinomiais para malhas deslocadas triangulares (TC) no plano. Generalizamos essa abordagem para células HC e, usando projeções ortogonais para planos tangentes, mostramos como o método pode ser aplicado na esfera. Para a reconstrução vetorial por um polinômio de grau um é necessário resolver um sistema linear de tamanho pelo menos $6 \times 6$, o que torna o método mais custoso que os demais métodos analisados. Porém, atrelando esse método ao método de Perot, usando a reconstrução polinomial apenas nas células mal alinhadas, temos um método híbrido de baixo custo e boa precisão. Propomos essa abordagem como forma de reconstrução em malhas HC a fim de garantir segunda ordem de aproximação a um custo aceitável. A combinação entre o método de reconstrução polinomial para os circuncentros dos triângulos (usando 9 componentes) seguido de interpolações vetoriais com coordenadas de Wachspress também mostrou-se interessante, apesar de ser computacionalmente mais cara que o método híbrido.

O transporte de substâncias (ou traçadores) na esfera é um problema relevante por si só, além de ser parte fundamental na dinâmica atmosférica. Muitos modelos de previsão de tempo usam atualmente esquemas semi-lagrangianos, principalmente por permitirem passos de tempos não limitados pela condição de CFL e por fornecerem boa precisão. O uso desse tipo de esquema em malhas icosaédricas depende fortemente de métodos de interpolações. Assim, as análises de interpolações e reconstruções realizadas neste estudo fornecem uma base necessária para a construção de um modelo de transporte semi-lagrangiano.

Propomos um método semi-lagrangiano de transporte de dois níveis de tempo, considerando uma malha icosaédrica deslocada do tipo HC. Para as interpolações escalares adotamos o método $C^{1}$ de Renka e, para as reconstruções vetoriais, usamos o método híbrido, aqui introduzido, e o de 
reconstrução polinomial associado ao método de Wachspress. As reconstruções vetoriais mostraram precisão numérica muito similares, ambas sendo adequadas para o esquema semi-lagrangiano, porém o método híbrido possui custo computacional menor. Supondo as componentes normais do campo de velocidades conhecidas nos pontos médios das células de Voronoi, mostramos que o método de cálculo da trajetória é de terceira ordem no tempo para um número de Courant fixado. Para testes de transporte cíclicos, nos quais a substância retorna à sua condição inicial ao final de um período fixado, demonstramos que o erro cometido ao final de um ciclo é de segunda ordem. Os resultados teóricos foram verificados numericamente por meio de um teste de rotação com velocidade variável e por testes de deformações propostos em Nair e Lauritzen [2010].

A discretização do divergente na equação da continuidade utiliza-se dos fluxos nos pontos médios das arestas, o que pode acarretar problemas de interferência de malha. Usando o modelo observamos a formação de um padrão de malha gerado e transportado a cada passo de tempo, levando a um ruído computacional na solução numérica. Por outro lado, o modelo é capaz de captar grandes deformações, mesmo com grandes passos de tempo (para números de Courant altos).

O método proposto não é intrinsecamente monotônico, propriedade que é desejável no transporte de substâncias com gradientes fortes ou descontinuidades. Modificando o método de interpolação de Renka, podemos garantir monotonicidade. Demonstramos esse fato no transporte de um "cilindro cortado" sob influência de um campo de velocidade que o deforma.

O método proposto também não é intrinsecamente conservativo (no sentido de conservação de massa global), o que é relevante para problemas de transporte por longos períodos, por exemplo, em modelos climáticos. Mostramos como obter conservação de massa global com um corretor (fixer) de massa, que é aplicado a cada passo de tempo para que a massa global seja preservada.

Através do modelo de transporte semi-lagrangiano, escolhemos, analisamos e em alguns casos desenvolvemos técnicas que mostram a viabilidade do uso de malhas icosaédricas em modelos atmosféricos. Porém, para compreendermos melhor outros aspectos do impacto dessa malha em modelos de previsão de tempo global, é necessário um modelo mais complexo. Um próximo passo natural é considerar um modelo de água rasa, que, apesar de simples, representa boa parte da dinâmica horizontal presente na atmosfera. A plataforma de trabalho desenvolvida nesta tese, incluindo a estrutura de geração de malhas, interpolações, reconstruções vetoriais e o próprio modelo de transporte, fornece uma boa base para o futuro desenvolvimento de um modelo de água rasa em malhas icosaédricas, como um próximo passo na direção de modelos globais de previsão do tempo. 


\section{Apêndice A}

\section{Modelos que usam malhas icosaédricas}

Neste apêndice descrevemos algumas características de modelos de previsão de tempo que usam malhas icosaédricas. As informações contidas aqui são fundamentadas em artigos publicados pelos grupos de pesquisa de cada modelo, portanto podem não caracterizar as condições mais atuais dos modelos. Dentro do levantamento bibliográfico que fizemos a respeito de modelos que usam malhas icosaédricas, estes foram os modelos mais relevantes encontrados. Detalhamos aqui as componentes dos modelos para que este apêndice sirva de referência rápida sobre cada um deles.

\section{A.1 GME}

O modelo de previsão de tempo do serviço meteorológico alemão (DWD-Deutscher Wetterdienst), denominado GME, é o primeiro modelo global operacional com malhas icosaédricas. Sua primeira versão foi lançada operacionalmente em $1999 \mathrm{com}$ espaçamento médio de $60 \mathrm{~km}$ na malha horizontal e 31 camadas para a altura. A partir de 2004 passou a ter $40 \mathrm{~km}$ de malha horizontal e 40 níveis de altura. Vamos descrever aqui as características da versão do modelo em operação desde Setembro de 2008. Sua sigla provém de duas sub-siglas: GM - Global Model e EM - European Model. Detalhes técnicos sobre o modelo podem ser encontrados em Majewski et al. [2008], e aspectos mais teóricos em Majewski et al. [2002].

O modelo usa malha icosaédrica decompondo os triângulos iniciais do icosaedro em $n_{i}$ segmentos (não recursiva). A resolução atual do GME adota $n_{i}=192$, o que corresponde a 368642 pontos de malha e espaçamento médio de $40 \mathrm{~km}$. Utiliza malha estruturada em forma de losangos. É usada uma malha do tipo A de Arakawa para os hexágonos. O modelo é paralelo usadno MPI e aproveita a estruturação da malha icosaédrica para isso. O modelo é hidrostático e a discretização vertical emprega uma coordenada híbrida (sigma-pressão).

De acordo com Majewski et al. [2002], o modelo um método semi-lagrangiano é usado para advecção de vapor de água e nuvens. O esquema semi-lagrangiano usa interpolação linear para a trajetória e bi-quadrática para o ponto de partida. Porém, a implementação só garante que o método funcione para números de Courant até 1 , por causa do padrão de comunicação usado no paralelismo e de outras partes do modelo. Por causa disso o método euleriano fica mais rápido (20\%), e é usado no núcleo da dinâmica, com um método semi-implícito. O método semi-implícito leva a uma equação de Helmholtz 3D para o divergente do campo horizontal, que é decomposta em um conjunto de equações $2 \mathrm{D}$ usando os autovalores da matriz de estrutura vertical. As equações bi-dimensionais são resolvidas com SOR (Successive Over Relaxation).

Outros trabalhos usam o modelo e analisam ou propõem melhorias, como em Frank e Majewski [2003] onde diversos testes são apresentados, ou em Joppich e Pott [2008], onde é descrito um método semi-lagrangiano conservativo para o GME. 


\section{A.2 ICON}

O modelo ICON, de ICOsaédrico Não hidrostático, pretende ser a nova geração do modelo GME. O projeto é realizado em conjunto pelo centro de previsão do tempo alemão (DWD) e o instituto Max Planck de Meteorologia de Hamburgo (MPI-M). O propósito do projeto é ter um modelo unificado para a dinâmica global e regional. Usará volumes finitos para as equações de NavierStokes totalmente elásticas, não-hidrostáticas em uma malha geodésica icosaédrica com refinamento local (Bonaventura et al. [2004], Rípodas et al. [2009], Website do projeto: http://icon.enes.org/). O modelo ainda está em desenvolvimento, mas possui diversos resultados para as equações de água rasa (Rípodas et al. [2009]), modelo 3D hidrostático (Wan [2009]) e métodos de transporte (ver http://www.mpimet.mpg.de/en/wissenschaft/modelle/icon.html).

A principal mudança está na estruturação dos dados na malha. O grupo pretende usar uma malha do tipo C de Arakawa em triângulos, descrita por Bonaventura e Ringler [2005]. Usa uma discretização implícita para o gradiente do geopotencial, Coriolis e divergente dos ventos, e explicita para os termos de advecção não lineares. Conserva massa e vorticidade potencial. Mais recentemente passou a ter discretização temporal semi-implícita de 2 níveis de tempo. Por usar malha do tipo HC, há uma série de considerações para reconstrução dos vetores que são levadas em conta, sendo considerado o uso de uma técnica de elementos finitos de ordem zero de Raviart-Thomas para a reconstrução em triângulos, ou mais recentemente, usando funções de base radial (Ruppert [2007]).

\section{A.3 OLAM}

O modelo OLAM, cuja sigla representa Ocean Land Atmosphere Model, é um modelo que se propõe a acoplar modelos oceânicos, terrestres e atmosféricos, como já diz o seu nome. A parte de dinâmica atmosférica tem como base o Sistema de Modelagem Atmosférica Regional (Regional Atmospheric Modeling System - RAMS). O modelo inicialmente proposto em Walko e Avissar [2008a] usa malha icosaédrica estruturada, com células computacionais triangulares e deslocamento do tipo C, caracterizando assim uma malha do tipo TC. É usada a otimização de malha conhecida por spring dynamics. Para a discretização espacial é usado um método de volumes finitos, e para a temporal um método de diferenças finitas explícito.

Esse modelo tem sido testado no Brasil, em alguns centros, por exemplo no Centro de Previsão de Tempo e Estudos Climáticos (CPTEC-INPE) com colaborações com outros institutos (Silva et al. [2009]).

\section{A.4 FIM-NIM}

O FIM e o NIM são modelos de previsão de tempo globais em desenvolvimento pela divisão de sistemas globais do NOAA. FIM é um anacronismo para coordenada vertical do tipo flow following (quasi-langrangiano), com volumes finitos e malha icosaédrica (ver Bao et al. [2011] e http://fim. noaa.gov/).

A malha usada é a icosaédrica, aparentemente sem otimizações. A célula computacional considerada é do tipo HA e usa um sistema de coordenadas locais para as discretizações (Lee e MacDonald [2009]). A discretização temporal é feita com um método do tipo Adams-Bashforth de terceira ordem.

O modelo NIM é uma versão não hidrostática focada em resolver nuvens, pensado para ser rodado com alto grau de paralelismo, inclusive em GPUs (ver http://www.esrl.noaa.gov/gsd/ab/ ac/GPU_Parallelization_NIM.html).

\section{A.5 NICAM}

Modelo atmosférico icosaédrico não hidrostático (Nonhydrostatic ICosahedral Atmospheric Model - NICAM) desenvolvido por um esforço conjunto de dois centros japoneses de estudos em 
meteorologia: Centro de Pesquisas Frontier para Mudanças Globais (JAMSTEC) e Centro de Pesquisas em Sistemas Climáticos da universidade de Tokyo (Tomita e Satoh [2004], Satoh et al. [2008], Tomita et al. [2008]).

Usa uma malha icosaédrica modificada por spring dynamics Tomita et al. [2002]. O propósito aqui é que com as modificações, além de redução de ruídos, os operadores diferenciais são melhor discretizados. Usa células pentagonais/hexagonais e realoca os pontos de malha para o seu centro gravitacional. Usa malha do tipo HA, mas com variáveis nos centros de massa ao invés dos vértices dos triângulos. Usa a estrutura de losangos para o paralelismo. Para reconstrução de vetores usa média simples.

Para a discretização temporal usa um método do tipo time-splitting, isto é, os modos rápidos são avaliados com passos pequenos e os modos lentos com passos maiores. Considera em geral um split de 4. Usa um esquema explícito na horizontal e implícito na vertical (Horizontally explicit and vertically implicit - HEVI) para os passos de tempo menores (ondas rápidas) e Runge-Kutta (2a ou 3a ordem) para os passos maiores (Satoh et al. [2008]).

\section{A.6 CCoSM}

Assim como o OLAM, o CCoSM é um modelo em desenvolvimento pela universidade do Colorado, em conjunto com o NCAR, que pretende integrar terra, oceano, atmosfera e outras componentes que afetam o clima. A sigla se refere a Coupled Colorado State Model (CCoSM). Todas as componentes do modelo são discretizadas em malhas geodésicas de hexágonos e pentágonos. Usa malhas icosaédricas com uma otimização para melhorar as propriedades do operador laplaciano discreto (Heikes e Randall [1995a], Heikes e Randall [1995b]). Um diferencial interessante é o uso de um método multigrid geométrico 3D para resolver os sistemas elípticos.

\section{A.7 MPAS}

O modelo MPAS (Model for Prediction Across Scales) é um projeto de desenvolvimento conjunto entre o NCAR e o Los Alamos Laboratory fundamentado em malhas esféricas centroidais de Voronoi (ver http://mpas.sourceforge.net/. O modelo usa malhas deslocadas do tipo HC, e é o que mais se aproxima do escopo abordado nesta tese. O modelo acopla oceano e atmosfera no mesmo tipo de malha, e usa refinamentos locais para regiões costeiras no oceano e sobre áreas continentais de interesse para a atmosfera (Ju et al. [2011]). Em Ringler et al. [2010] são descritos os conceitos básicos do modelo para as equações de água rasa. Em Skamarock et al. [2012] é apresentado um modelo atmosférico 3D não hidrostático. 
APÊNDICE A 


\section{Apêndice B}

\section{Coordenadas geográficas e ferramentas de geometria esférica}

\section{B.1 Coordenadas geográficas}

Vamos descrever algumas notações e propriedades relevantes das coordenadas esféricas ou geográficas (latitude - longitude). A longitude de um ponto na esfera é o ângulo, medido no plano do equador, entre o meridiano de Greenwich (geodésica que liga o polo norte ao sul passando pela localidade de Greenwich, localizada nos arredores de Londres na Inglaterra) e o meridiano do ponto. A convenção usual é que no meridiano de Greenwich a longitude seja nula, a oeste negativa, e a leste positiva, variando portanto entre $-\pi$ e $\pi$ radianos. Usaremos a letra grega $\lambda$ para nos referir a coordenada de longitude. A latitude de um ponto é a medida do ângulo (em graus ou radianos) entre um vetor no plano do equador e o vetor que conecta o centro da esfera ao ponto, seguindo um mesmo meridiano. Iremos denotar a latitude por $\theta$. Convencionaremos que a latitude é nula no equador, positiva no hemisfério norte, e negativa no hemisfério sul. Assim sendo, $-\pi / 2 \leq \theta \leq \pi / 2$ em radianos.

Podemos ver a esfera como uma superfície em $\mathbb{R}^{3}$, sendo conveniente relacionar os sistemas de coordenadas geográficas e cartesianas. Vamos supor a esfera unitária (esta pode ser facilmente reescalada para ter o raio médio da terra). Supondo o $\mathbb{R}^{3}$ decomposto nas suas coordenadas canônicas $\vec{x}, \vec{y}, \vec{z}$, convencionamos que o zero do sistema cartesiano fique no centro da esfera. O eixo $\vec{z}$ é orientado no sentido polo sul para o polo norte, sendo portanto o polo sul dado pelo ponto $(0,0,-1)$, e o norte pelo ponto $(0,0,1)$. Definimos o ponto de longitude e latitude zero como sendo o ponto $(1,0,0)$, o que define a orientação do eixo $\vec{x}$. Com isso o eixo $\vec{y}$ fica naturalmente definido, e temos que o ponto de longitude $\pi / 2$ e latitude zero será dado pelo ponto $(0,1,0)$.

Dado um ponto no sistema de coordenadas geográficas, $(\lambda, \theta)$, o ponto no sistema de coordenadas cartesianas será dado por $(x, y, z)$ com

$$
\begin{aligned}
& x=\cos (\theta) \cos (\lambda), \\
& y=\cos (\theta) \sin (\lambda), \\
& z=\sin (\theta),
\end{aligned}
$$

Dado um ponto $(x, y, z)$ em $\mathbb{R}^{3}$, as suas coordenadas geográficas serão dadas por:

$$
\begin{aligned}
r & =\sqrt{x^{2}+y^{2}+z^{2}} \\
\lambda & = \begin{cases}\tan ^{-1}\left(\frac{y}{x}\right), & \text { se } x \neq 0 \\
0, & \text { se } x=0\end{cases} \\
\theta & =\sin ^{-1}\left(\frac{z}{r}\right)
\end{aligned}
$$




\section{B.2 Distâncias geodésicas}

Para dois pontos dados em coordenadas geográficas $\left(\lambda_{1}, \theta_{1}\right)$ e $\left(\lambda_{2}, \theta_{2}\right)$ utilizamos a Fórmula de Vincenty para calcular distâncias geodésicas. A Fórmula de Vincenty é dada por

$$
d=\arctan \left(\frac{\sqrt{\left(\cos \left(\theta_{2}\right) \sin (d \lambda)\right)^{2}+\left(\cos \left(\theta_{1}\right) \sin \left(\theta_{2}\right)-\sin \left(\theta_{1}\right) \cos \left(\theta_{2}\right) \cos (d \lambda)\right)^{2}}}{\sin \left(\theta_{1}\right) \sin \left(\theta_{2}\right)+\cos \left(\theta_{1}\right) \cos \left(\theta_{2}\right) \cos (d \lambda)}\right)
$$

onde $d \lambda=\lambda_{1}-\lambda_{2}$.

Como assumiremos que as coordenadas referem-se à esfera unitária, temos $r=1$. Os cálculos de distâncias geodésicas entre dois pontos $p_{1}$ e $p_{2}$ na esfera unitária em coordenadas cartesianas poderiam ser calculadas pela equação

$$
d=\arccos \left(\left\langle p_{1}, p_{2}\right\rangle\right),
$$

mas utilizamos a equação

$$
d=2 \arctan \left(\sqrt{\frac{4-r}{r}}\right)
$$

onde $r=\left\langle p_{1}+p_{2}, p_{1}+p_{2}\right\rangle$. Fizemos isso para evitar problemas na inversa do cosseno. As distâncias resultantes são dadas em radianos, pois estamos considerando a esfera unitária. Para termos a medida para a aproximação esférica da terra basta multiplicar a distância pelo raio da terra. Assumimos o raio da terra como sendo $6371,22 \mathrm{~km}$ neste estudo.

Numericamente, para não perdermos informações sobre o quadrante quando calculamos o arco tangente, devemos usar a função usualmente conhecida por ATAN2(x,y) em Fortran, ou também em outras linguagem de programação.

\section{B.3 Áreas geodésicas}

As áreas de triângulos esféricos podem ser calculadas com base no excesso esférico $(e)$ obtido pelo Teorema de L'Huilier, de onde temos que

$$
e=4 \arctan \left(\sqrt{\tan \left(\frac{s}{2}\right) \tan \left(\frac{s-a}{2}\right) \tan \left(\frac{s-b}{2}\right) \tan \left(\frac{s-c}{2}\right)}\right),
$$

onde $s=\frac{(a+b+c)}{2}$ é o semi-perímetro e $a, b$ e $c$ são os comprimentos de arcos do triângulos para a esfera unitária. Para obter a área para uma esfera com o mesmo raio da terra basta multiplicar o excesso pelo raio da terra ao quadrado.

Para o cálculo de áreas de polígonos geodésicos, basta decompor o polígono em triângulos geodésicos e somar as áreas dos triângulos.

\section{B.4 Vetores na esfera}

Vejamos agora as conversões de vetores entre os sistemas de coordenadas geográfico e cartesiano. Seja $p=(x, y, x)$ um ponto da esfera, e seja $\vec{v}=\left(v_{x}, v_{y}, v_{z}\right)=v_{x} \vec{x}+v_{y} \vec{y}+v_{z} \vec{z}$ em vetor neste ponto. Sua conversão para coordenadas geográficas, como sendo um vetor $\vec{v}=w_{r} \vec{r}+w_{\theta} \vec{\theta}+w_{\lambda} \vec{\lambda}$, onde $\vec{r}$, $\vec{\theta}$ e $\vec{\lambda}$ são os vetores canônicos locais em coordenadas geográficas, pode ser feita com a transposta da matriz

$$
A=\left[\begin{array}{ccc}
\cos (\theta) \cos (\lambda) & -\sin (\theta) \cos (\lambda) & -\sin (\lambda) \\
\cos (\theta) \sin (\lambda) & -\sin (\theta) \sin (\lambda) & \cos (\lambda) \\
\sin (\theta) & \cos (\theta) & 0
\end{array}\right]=\left[\begin{array}{ccc}
\frac{x}{r} & -\frac{z x}{\rho r} & -\frac{y}{\rho} \\
\frac{y}{r} & -\frac{z y}{\rho r} & \frac{x}{\rho} \\
\frac{z}{r} & \frac{\rho}{r} & 0
\end{array}\right]
$$


Onde $\rho=\sqrt{x^{2}+y^{2}}$. A matriz $A$ é ortogonal, logo a inversa é a sua transposta, $A^{t}$. Assim temos as transformações

$$
\left[\begin{array}{l}
v_{x} \\
v_{y} \\
v_{z}
\end{array}\right]=A\left[\begin{array}{l}
w_{r} \\
w_{\theta} \\
w_{\lambda}
\end{array}\right]
$$

e

$$
\left[\begin{array}{l}
w_{r} \\
w_{\theta} \\
w_{\lambda}
\end{array}\right]=A^{t}\left[\begin{array}{l}
v_{x} \\
v_{y} \\
v_{z}
\end{array}\right]
$$

\section{B.5 Operadores diferenciais}

Os vetores $\vec{r}, \vec{\theta}$ e $\vec{\lambda}$ definem um sistema de coordenadas local, que depende do ponto da esfera. Seja $\Phi$ um campo escalar definido em coordenadas geográficas. Então o seu gradiente em coordenadas geográficas pode ser calculado da seguinte forma

$$
\nabla \Phi=\frac{1}{r \cos (\theta)} \frac{\partial \Phi}{\partial \lambda} \vec{\lambda}+\frac{1}{r} \frac{\partial \Phi}{\partial \theta} \vec{\theta}+\frac{\partial \Phi}{\partial r} \vec{r}
$$

e se estivermos restritos a esfera, então $\frac{\partial \Phi}{\partial r}=0$.

Seja $\vec{v}$ um campo vetorial em coordenadas geográficas, com $\vec{v}=u \vec{\lambda}+v \vec{\theta}+w \vec{r}$. O seu divergente horizontal será dado por

$$
\nabla \cdot \vec{v}=\frac{1}{r \cos (\theta)}\left[\frac{\partial u}{\partial \lambda}+\frac{\partial(v \cos (\theta))}{\partial \theta}\right]
$$

Com isso podemos escrever o Laplaciano horizontal como

$$
\begin{aligned}
\Delta \Phi=\nabla \cdot \nabla \Phi & =\nabla \cdot\left(\frac{1}{r \cos (\theta)} \frac{\partial \Phi}{\partial \lambda} \vec{\lambda}+\frac{1}{r} \frac{\partial \Phi}{\partial \theta} \vec{\theta}\right) \\
& =\frac{1}{r \cos (\theta)}\left(\frac{1}{\cos (\theta)} \frac{\partial^{2} \Phi}{\partial \lambda^{2}}+\frac{\partial}{\partial \theta}\left(\cos (\theta) \frac{\partial \Phi}{\partial \theta}\right)\right) .
\end{aligned}
$$


APÊNDICE B 


\section{Apêndice C}

\section{Ordem de aproximação do método semi-lagrangiano}

Neste apêndice vamos analisar os erros cometidos no método semi-lagrangiano. Uma análise semelhante para reta é apresentada em McDonald [1987].

\section{C.1 Análise do cálculo da trajetória}

Descrevemos na seção 5.3 o método para cálculo do ponto de partida em uma trajetória usando um esquema de dois níveis no tempo. Nesta seção vamos analisar a ordem do erro obtido resultante dessa aproximação. Vamos restringir as análises para o plano, supondo suficiente regularidade da trajetória.

Seja $\mathbf{r}(t) \in \mathbb{R}^{2}$ a trajetória lagrangiana de uma partícula no plano. Para $t \in[0, T]$ fixado, sejam

$$
\begin{aligned}
\mathbf{r}_{p} & =\mathbf{r}(t), \text { o ponto de partida; } \\
\mathbf{r}_{m} & =\mathbf{r}(t+\Delta t / 2), \text { o ponto médio; e } \\
\mathbf{r}_{c} & =\mathbf{r}(t+\Delta t), \text { o ponto de chegada, }
\end{aligned}
$$

da trajetória lagrangiana, conforme ilustrado na Figura 5.1.

Definimos também a velocidade, aceleração e sobre-aceleração no ponto médio como

$$
\begin{aligned}
\mathbf{v}_{m} & =\dot{\mathbf{r}}(t+\Delta t / 2), \\
\mathbf{a}_{m} & =\ddot{\mathbf{r}}(t+\Delta t / 2), \\
\mathbf{h}_{m} & =\dddot{\mathbf{r}}(t+\Delta t / 2) .
\end{aligned}
$$

Analogamente definimos as velocidades, acelerações e sobre-acelerações para o ponto de partida (usando o subíndice ${ }_{p}$ ) e de chegada (usando o subíndice ${ }_{c}$ ), nos seus respectivos instantes de tempo. Usando expansões em séries de Taylor de $\mathbf{r}_{p}$ e $\mathbf{r}_{c}$, em torno de $\mathbf{r}_{m}$, temos que

$$
\mathbf{r}_{p}=\mathbf{r}_{m}-\frac{\Delta t}{2} \mathbf{v}_{m}+\frac{\Delta t^{2}}{8} \mathbf{a}_{m}-\frac{\Delta t^{3}}{48} \mathbf{h}_{m}+O\left(\Delta t^{4}\right)
$$

e

$$
\mathbf{r}_{c}=\mathbf{r}_{m}+\frac{\Delta t}{2} \mathbf{v}_{m}+\frac{\Delta t^{2}}{8} \mathbf{a}_{m}+\frac{\Delta t^{3}}{48} \mathbf{h}_{m}+O\left(\Delta t^{4}\right) .
$$

Pelo método semi-lagrangiano de dois níveis do tempo conhecemos $\mathbf{r}_{c}$ e estimamos $\mathbf{r}_{m}$ como $\mathbf{r}_{m}^{*}$, que satisfaz a relação

$$
\mathbf{r}_{m}^{*}=\mathbf{r}_{c}-\frac{\Delta t}{2} \mathbf{v}_{m}^{*}
$$


onde $\mathbf{v}_{m}^{*}$ é uma aproximação da velocidade em $\mathbf{r}_{m}^{*}$. Usando a expansão em série de Taylor de $\mathbf{r}_{c}$ em torno de $\mathbf{r}_{m}$ (equação (C.2)), temos que

$$
\mathbf{r}_{m}^{*}=\mathbf{r}_{m}+\frac{\Delta t}{2}\left(\mathbf{v}_{m}-\mathbf{v}_{m}^{*}\right)+\frac{\Delta t^{2}}{8} \mathbf{a}_{m}+\frac{\Delta t^{3}}{48} \mathbf{h}_{m}+O\left(\Delta t^{4}\right)
$$

No método semi-lagrangiano, o ponto de partida é estimado como

$$
\mathbf{r}_{p}^{*}=2 \mathbf{r}_{m}^{*}-\mathbf{r}_{c}=\mathbf{r}_{m}^{*}-\frac{\Delta t}{2} \mathbf{v}_{m}^{*}
$$

$\log \mathrm{O}$

$$
\mathbf{r}_{p}^{*}=\mathbf{r}_{m}+\frac{\Delta t}{2}\left(\mathbf{v}_{m}-2 \mathbf{v}_{m}^{*}\right)+\frac{\Delta t^{2}}{8} \mathbf{a}_{m}+\frac{\Delta t^{3}}{48} \mathbf{h}_{m}+O\left(\Delta t^{4}\right) .
$$

Usando a expansão em série de Taylor de $\mathbf{r}_{p}$ em torno de $\mathbf{r}_{m}$ (equação (C.1)), temos que o erro cometido no cálculo do ponto de partida será

$$
\mathbf{e}=\mathbf{r}_{p}^{*}-\mathbf{r}_{p}=\Delta t\left(\mathbf{v}_{m}-\mathbf{v}_{m}^{*}\right)+\frac{\Delta t^{3}}{24} \mathbf{h}_{m}+O\left(\Delta t^{4}\right) .
$$

As velocidades das trajetórias lagrangianas definem um campo vetorial para cada instante $\mathbf{v}(t, \mathbf{x})=(u(t, \mathbf{x}), v(t, \mathbf{x}))$, que vamos supor suficientemente suave no espaço, onde $(u, v)$ são as componentes ortogonais de $\mathbf{v}$ no sistema cartesiano usual do $\mathbb{R}^{2}$. Vamos supor, por hora, que esse campo de velocidades seja conhecido em qualquer ponto e instante. A estimativa $\mathbf{v}_{m}^{*}=\left(u_{m}^{*}, v_{m}^{*}\right)$ depende de um método iterativo, no qual parte-se da velocidade no ponto de chegada no instante $t_{m}=t+\Delta t / 2$ e itera-se até obter-se uma aproximação para a velocidade no ponto médio. Supondo que usamos apenas uma iteração, então

$$
\mathbf{v}_{m}^{*}=\mathbf{v}\left(t_{m}, \mathbf{r}_{c}\right)
$$

Usando expansão em série de Taylor de $\mathbf{r}_{c}$ em torno de $\mathbf{r}_{m}$ temos que

$$
\mathbf{v}_{m}^{*}=\mathbf{v}\left(t_{m}, \mathbf{r}_{m}+\frac{\Delta t}{2} \mathbf{v}_{m}+O\left(\Delta t^{2}\right)\right)
$$

Agora usando uma expansão de $\mathbf{v}$ na segunda variável (a variável espacial) em torno de $\mathbf{r}_{m}$, componente a componente, temos que

$$
\begin{aligned}
& u_{m}^{*}=u\left(t_{m}, \mathbf{r}_{m}\right)+\frac{\Delta t}{2} \mathbf{v}_{m} \cdot \nabla_{2} u\left(t_{m}, \mathbf{r}_{m}\right)+O\left(\Delta t^{2}\right), \\
& v_{m}^{*}=v\left(t_{m}, \mathbf{r}_{m}\right)+\frac{\Delta t}{2} \mathbf{v}_{m} \cdot \nabla_{2} v\left(t_{m}, \mathbf{r}_{m}\right)+O\left(\Delta t^{2}\right),
\end{aligned}
$$

onde $\nabla_{2}$ é a diferencial com relação à segunda variável e o símbolo "." indica o produto interno. Logo,

$$
\mathbf{v}_{m}^{*}=\mathbf{v}_{m}+\frac{\Delta t}{2} \mathbf{D}_{\mathbf{v}} \mathbf{v}_{m}+O\left(\Delta t^{2}\right)
$$

onde

$$
\mathbf{D}_{\mathbf{v}}=\left[\begin{array}{l}
\nabla_{2} u\left(t_{m}, \mathbf{r}_{m}\right) \\
\nabla_{2} v\left(t_{m}, \mathbf{r}_{m}\right)
\end{array}\right]
$$

Contudo, quando consideramos apenas uma iteração para a estimativa do ponto médio, o erro obtido no ponto de partida será

$$
\mathbf{e}_{1}=-\frac{\Delta t^{2}}{2} \mathbf{D}_{\mathbf{v}} \mathbf{v}_{m}+O\left(\Delta t^{3}\right)
$$


Vamos analisar agora o caso com duas iterações. Nesse caso,

$$
\mathbf{v}_{m}^{*}=\mathbf{v}\left(t_{m}, \mathbf{r}_{c}-\frac{\Delta t}{2} \mathbf{v}\left(t_{m}, \mathbf{r}_{c}\right)\right)
$$

Expandindo $\mathbf{v}\left(t_{m}, \mathbf{r}_{c}\right)$ em série de Taylor na primeira variável, em torno do tempo $t+\Delta t$, temos que

$$
\begin{aligned}
\mathbf{v}\left(t+\Delta t / 2, \mathbf{r}_{c}\right) & =\mathbf{v}\left(t+\Delta t, \mathbf{r}_{c}\right)-\frac{\Delta t}{2} \partial_{1} \mathbf{v}\left(t+\Delta t, \mathbf{r}_{c}\right)+O\left(\Delta t^{2}\right) \\
& =\mathbf{v}_{c}-\frac{\Delta t}{2} \mathbf{a}_{c}+O\left(\Delta t^{2}\right)
\end{aligned}
$$

Assim,

$$
\mathbf{v}_{m}^{*}=\mathbf{v}\left(t_{m}, \mathbf{r}_{c}-\frac{\Delta t}{2} \mathbf{v}_{c}+\frac{\Delta t^{2}}{4} \mathbf{a}_{c}+O\left(\Delta t^{3}\right)\right) .
$$

Usando a série de Taylor de $\mathbf{r}_{m}$ em torno de $\mathbf{r}_{c}$, dada por,

$$
\mathbf{r}_{m}=\mathbf{r}_{c}-\frac{\Delta t}{2} \mathbf{v}_{c}+\frac{\Delta t^{2}}{8} \mathbf{a}_{c}+O\left(\Delta t^{3}\right)
$$

teremos

$$
\mathbf{v}_{m}^{*}=\mathbf{v}\left(t_{m}, \mathbf{r}_{m}+\frac{\Delta t^{2}}{8} \mathbf{a}_{c}+O\left(\Delta t^{3}\right)\right) .
$$

Agora usando uma expansão de $\mathbf{v}$ na segunda variável em torno de $\mathbf{r}_{m}$ temos que

$$
\mathbf{v}_{m}^{*}=\mathbf{v}_{m}+\frac{\Delta t^{2}}{8} \mathbf{D}_{\mathbf{v}} \mathbf{a}_{c}+O\left(\Delta t^{3}\right)
$$

e portanto o erro no cálculo do ponto de partida considerando duas iterações será

$$
\mathbf{e}_{2}=-\frac{\Delta t^{3}}{8} \mathbf{D}_{\mathbf{v}} \mathbf{a}_{c}+\frac{\Delta t^{3}}{24} \mathbf{h}_{m}+O\left(\Delta t^{4}\right)
$$

Isso mostra que com apenas duas iterações o esquema de cálculo de ponto de partida tem terceira ordem de convergência no tempo.

Nas demonstrações acima usamos a hipótese que o campo de velocidades era conhecido em qualquer ponto e instante. Vamos supor agora que o campo de velocidade seja aproximado espacialmente usando interpolações/reconstruções de ordem $p$, isso é, para um espaçamento de malha $h$, suficientemente pequeno, conhecemos apenas $\tilde{v}$ dado por,

$$
\tilde{\mathbf{v}}(t, \mathbf{x})=\mathbf{v}(t, \mathbf{x})+h^{p} \mathbf{k}
$$

onde $\mathbf{k}$ depende do método de interpolação, da malha e do próprio campo de velocidades, além disso, estamos desconsiderando os termos de ordens maiores que $p$.

No caso em que usamos apenas uma iteração para obter a solução da equação não linear temos que (note que, na malha deslocada, a velocidade não conhecida no ponto de chegada)

$$
\mathbf{v}_{m}^{*}=\tilde{\mathbf{v}}\left(t_{m}, \mathbf{r}_{c}\right)=\mathbf{v}\left(t_{m}, \mathbf{r}_{c}\right)+h^{p} \mathbf{k}
$$

e portanto,

$$
\mathbf{e}_{1, p}=-\frac{\Delta t^{2}}{2} \mathbf{D}_{\mathbf{v}} \mathbf{v}_{m}-\Delta t h^{p} \mathbf{k}+O\left(\Delta t^{3}\right) .
$$

Se $h \propto \Delta t$ e $p \geq 1$, então o método com uma iteração terá segunda ordem de aproximação no cálculo do ponto de partida. 


\begin{tabular}{|c|c|c|c|}
\hline Iterações & Campo Vetorial & Erro & Ordem- $p=2$ \\
\hline 1 & Exato & $-\frac{\Delta t^{2}}{2} \mathbf{D}_{\mathbf{v}} \mathbf{v}_{m}$ & 2 \\
\hline 2 & Exato & $-\frac{\Delta t^{3}}{8} \mathbf{D}_{\mathbf{v}} \mathbf{a}_{c}+\frac{\Delta t^{3}}{24} \mathbf{h}_{m}$ & 3 \\
\hline 1 & $h^{p}$ & $-\frac{\Delta t^{2}}{2} \mathbf{D}_{\mathbf{v}} \mathbf{v}_{m}-\Delta t h^{p} \mathbf{k}$ & 2 \\
\hline 2 & $h^{p}$ & $-\frac{\Delta t^{3}}{8} \mathbf{D}_{\mathbf{v}} \mathbf{a}_{c}+\frac{\Delta t^{2} h^{p}}{2} \mathbf{D}_{\mathbf{v}} \mathbf{k}_{1}-\Delta t h^{p} \mathbf{k}_{2}+\frac{\Delta t^{3}}{24} \mathbf{h}_{m}$ & 3 \\
\hline
\end{tabular}

Tabela C.1: Erro no cálculo do ponto de partida. Os termos de ordens altas foram desconsiderados.

Vejamos agora o caso com duas iterações. Nesse caso,

$$
\begin{aligned}
\mathbf{v}_{m}^{*} & =\tilde{\mathbf{v}}\left(t_{m}, \mathbf{r}_{c}-\frac{\Delta t}{2} \tilde{\mathbf{v}}\left(t_{m}, \mathbf{r}_{c}\right)\right) \\
& =\tilde{\mathbf{v}}\left(t_{m}, \mathbf{r}_{c}-\frac{\Delta t}{2} \mathbf{v}\left(t_{m}, \mathbf{r}_{c}\right)-\frac{\Delta t h^{p}}{2} \mathbf{k}_{1}\right) \\
& =\mathbf{v}\left(t_{m}, \mathbf{r}_{c}-\frac{\Delta t}{2} \mathbf{v}\left(t_{m}, \mathbf{r}_{c}\right)-\frac{\Delta t h^{p}}{2} \mathbf{k}_{1}\right)+h^{p} \mathbf{k}_{2} \\
& =\mathbf{v}\left(t_{m}, \mathbf{r}_{c}-\frac{\Delta t}{2} \mathbf{v}_{c}+\frac{\Delta t^{2}}{4} \mathbf{a}_{c}-\frac{\Delta t h^{p}}{2} \mathbf{k}_{1}+O\left(\Delta t^{3}\right)\right)+h^{p} \mathbf{k}_{2} \\
& =\mathbf{v}\left(t_{m}, \mathbf{r}_{m}+\frac{\Delta t^{2}}{8} \mathbf{a}_{c}-\frac{\Delta t h^{p}}{2} \mathbf{k}_{1}+O\left(\Delta t^{3}\right)\right)+h^{p} \mathbf{k}_{2} \\
& =\mathbf{v}_{m}+\frac{\Delta t^{2}}{8} \mathbf{D}_{\mathbf{v}} \mathbf{a}_{c}-\frac{\Delta t h^{p}}{2} \mathbf{D}_{\mathbf{v}} \mathbf{k}_{1}+h^{p} \mathbf{k}_{2}+O\left(\Delta t^{3}\right) .
\end{aligned}
$$

Logo, o erro no cálculo da trajetória será

$$
\mathbf{e}_{2, p}=-\frac{\Delta t^{3}}{8} \mathbf{D}_{\mathbf{v}} \mathbf{a}_{c}+\frac{\Delta t^{2} h^{p}}{2} \mathbf{D}_{\mathbf{v}} \mathbf{k}_{1}-\Delta t h^{p} \mathbf{k}_{2}+\frac{\Delta t^{3}}{24} \mathbf{h}_{m}+O\left(\Delta t^{4}\right) .
$$

Portanto, se $h \propto \Delta t$ e $p \geq 2$, o método será de terceira ordem.

A hipótese que fizemos a respeito de conhecermos a velocidade nos pontos de malha em qualquer instante, apesar de válida para avaliar modelos de transporte, não será verdadeira em modelos atmosféricos mais complexos. Nesses casos, além do erro espacial na aproximação da velocidade, teremos erros temporais ao aproximarmos a velocidade no tempo médio. Se considerarmos que o erro temporal seja da mesma ordem do espacial, e que $h \propto \Delta t$, então as análises serão válidas para esse caso também.

Resumimos os resultados de erros de aproximação no cálculo da trajetória na Tabela C.1, onde desconsideramos os termos de ordens mais altas.

\section{C.2 Erro na concentração do traçador}

Seja $\phi(\mathbf{r}(t))$ a concentração do traçador ao longo da trajetória $\mathbf{r}(t)$, com $t \in[0, T]$. Nos testes que estamos utilizando para o método semi-lagrangiano, a solução exata no tempo $t$ será $\phi(\mathbf{r}(T))=$ $\phi(\mathbf{r}(0))$. Supondo que as trajetórias fossem calculadas exatamente, teríamos somente erros devido a interpolações escalares. Supondo um método de interpolação escalar de terceira ordem, desprezando termos de ordens altas, temos que

$$
\begin{aligned}
\phi(\mathbf{r}(T)) & =\phi(\mathbf{r}(T-d t))+\beta_{1} h^{3} \\
& =\phi(\mathbf{r}(T-2 d t))+\beta_{2} h^{3}+\beta_{1} h^{3} \\
& =\phi(\mathbf{r}(0))+\sum_{i=1}^{n} \beta_{i} h^{3},
\end{aligned}
$$


onde $n$ é o número de passos no tempo e $d t=T / n$. Assim,

$$
e_{\phi}=|\phi(\mathbf{r}(T))-\phi(\mathbf{r}(0))|=\left|\sum_{i=1}^{n} \beta_{i} h^{3}\right| \leq \beta n h^{3}=\beta T \frac{h^{3}}{d t}
$$

onde $\beta=\max _{i=1, n}\left|\beta_{i}\right|$. Portanto, se $h \propto \Delta t, \phi$ ao final de uma revolução terá uma erro da ordem de $h^{2}$.

Suponha agora que o cálculo do ponto de partida seja feito de forma aproximada, tal que, o erro cometido no cálculo do ponto de partida $\mathbf{r}_{i}=\mathbf{r}(T-i d t)$ seja $\mathbf{e}_{i}, i=1,2, \ldots, n$. Então

$$
\begin{aligned}
\phi(\mathbf{r}(T)) & =\phi\left(\mathbf{r}(T-d t)+\mathbf{e}_{1}\right)+\beta_{1} h^{3} \\
& =\phi\left(\mathbf{r}_{1}\right)+\mathbf{e}_{1} \cdot \nabla \phi\left(\mathbf{r}_{1}\right)+\beta_{1} h^{3} \\
& =\phi(\mathbf{r}(0))+\sum_{i=1}^{n} \mathbf{e}_{i} \cdot \nabla \phi\left(\mathbf{r}_{i}\right)+\sum_{i=1}^{n} \beta_{i} h^{3} .
\end{aligned}
$$

Contudo,

$$
e_{\phi}=|\phi(\mathbf{r}(T))-\phi(\mathbf{r}(0))|=\left|\sum_{i=1}^{n} \mathbf{e}_{i} \cdot \nabla \phi\left(\mathbf{r}_{i}\right)+\sum_{i=1}^{n} \beta_{i} h^{3}\right| \leq T \frac{\mathbf{e}_{\max }}{d t} \cdot \mathbf{D}_{\max }+\beta T \frac{h^{3}}{d t},
$$

onde $\mathbf{e}_{\max }=\max _{i=1, n}\left|\mathbf{e}_{i}\right|$ e $\mathbf{D}_{\max }=\max _{i=1, n} \nabla \phi\left(\mathbf{r}_{i}\right)$.

Para que o erro na variável $\phi$ seja de segunda ordem, é necessário que $\mathbf{e}_{\max }$ seja de terceira ordem. Como vimos anteriormente, no cálculo de trajetórias obtemos ordem três se usamos um método de interpolação vetorial de segunda ordem e duas iterações na resolução da equação não linear. Nesse caso, supondo novamente que $d t \propto h$, temos que $e_{\phi}$ terá segunda ordem em $h$. 
APÊNDICE C 


\section{Apêndice D}

\section{Considerações técnicas}

Os experimentos numéricos realizados neste estudo foram feitos principalmente em um notebook Samsumg RF511 com as seguintes especificações:

- Processador : Intel ${ }^{\circledR}$ Core (TM) i7 - 2630 QM @ $2.00 \mathrm{GHz}$ ( 8/4 processadores )

- Memória : $6 \mathrm{~Gb}$

- Sistema Operacional : Ubuntu 12.04 LTS 64 bits

- Compilador : Intel ${ }^{\circledR}$ Fortran Compiler 12.1.3

Os programas computacionais foram todos desenvolvidos em Fortran 90 usando o compilador da Intel ${ }^{\circledR}$ descrito acima. As partes computacionalmente mais caras foram paralelizadas com OpenMP a fim de se obter melhor desempenho da arquitetura multi-core. Alguns experimentos que demandavam mais processamento ou memória foram realizados em um servidor numérico do laboratório de computação científica em matemática aplicada (LabMap) do IME-USP.

Para o desenvolvimento dos mapas, gráficos, figuras e animações foi usado o software GMT The Generic Mapping Tools data processing and display software package, Versão 4.5.7 para Linux.

Os diagramas bidimensionais de geometria foram feitos no software GeoGebra 5. Os tridimensionais (em perspectiva) foram feitos no Google SketchUp. 
APÊNDICE D 


\section{Referências Bibliográficas}

Alfeld et al.(1996a) P. Alfeld, M. Neamtu, e L. L. Schumaker. Fitting scattered data on spherelike surfaces using spherical splines. J. Comput. Appl. Math., 73:5-43. ISSN 0377-0427. Citado na pág. 84

Alfeld et al.(1996b) P. Alfeld, M. Neamtu, e L. L. Schumaker. Bernstein-bezier polynomials on spheres and sphere-like surfaces. Comput. Aided Geom. D., 13(4):333-349. Citado na pág. 89

Bacon et al.(2000) D. P. Bacon, N. N. Ahmad, Z. Boybeyi, T. J. Dunn, M. S. Hall, P. C. S. Lee, R. A. Sarma, M. D. Turner, K. T. Waight, S. H. Young, e J. W. Zack. A dynamically adapting weather and dispersion model: the operational multiscale environment model with grid adaptivity (OMEGA). Mon. Wea. Rev., 128(7):2044-2076. Citado na pág. 32

Bao et al.(2011) J.-W. Bao, S. Benjamin, R. Bleck, J. Brown, J. Lee, A. MacDonald, J. Middlecoff, e N. Wang. FIM documentation. Relatório técnico, Earth System Research Laboratory - National Oceanic and Atmospheric Administration (NOAA). Citado na pág. 2, 32, 204

Bates et al.(1990) J. R. Bates, F. H. M. Semazzi, R. W. Higgins, e S. R. M. Barros. Integration of the shallow water equations on the sphere using a vector semi-lagrangian scheme with a multigrid solver. Mon. Wea. Rev., 118(8):1615-1627. Citado na pág. 7

Baumgardner e Frederickson(1985) J. R. Baumgardner e P. O. Frederickson. Icosahedral discretization of the two-sphere. SIAM J. Numer. Anal., 22(6):1107-1115. Citado na pág. 1, 10

Baxter e Hubbert(2001) B. J. C. Baxter e S. Hubbert. Radial basis functions for the sphere. Em Recent progress in multivariate approximation (Witten-Bommerholz, 2000), volume 137 of Internat. Ser. Numer. Math., páginas 33-47. Birkhäuser, Basel. Citado na pág. 112, 113

Bobach et al.(2006) T. Bobach, M. Bertram, e G. Umlauf. Comparison of Voronoi based scatterd data interpolation schemes. Em J. Villanueva, editor, Proceedings of the Internationl Conference on Visualization, Imaging and Image Processing, páginas 342-349. Citado na pág. 83, 90

Boissonnat e Flototto(2002) J.-D. Boissonnat e J. Flototto. A local coordinate system on a surface. Em Proceedings of the seventh ACM symposium on Solid modeling and applications, SMA 2002, páginas 116-126, New York, NY, USA. ACM. Citado na pág. 89

Bonaventura et al.(2004) L. Bonaventura, L. Kornblueh, M. Giorgetta, E. Roeckner, T. Heinze, D. Majewski, P. Ripodas, B. Ritter, T. D. Ringler, e J. Baudisch. The ICON Shallow Water Model: Scientific documentation and benchmark tests. Relatório técnico, MPI-M/DWD. http: //icon.enes.org/. Citado na pág. 2, 114, 204

Bonaventura et al.(2011) L. Bonaventura, A. Iske, e E. Miglio. Kernel-based vector field reconstruction in computational fluid dynamic models. Int. J. Numer. Meth. Fl., 66(6):714-729. Citado na pág. 3,144

Bonaventura e Ringler(2005) L. Bonaventura e T. D. Ringler. Analysis of discrete shallow-water models on geodesic delaunay grids with C-type staggering. Mon. Wea. Rev., 133(8):2351-2373. Citado na pág. 2, 31, 204 
Buhmann(2003) M. D. Buhmann. Radial Basis Functions. Cambridge University Press, New York, NY, USA. Citado na pág. 84, 112, 113

Carfora(2007a) M. F. Carfora. Interpolation on spherical geodesic grids: A comparative study. J. Comput. Appl. Math., 210:99-105. Citado na pág. 83

Carfora(2007b) M. F. Carfora. Semi-lagrangian advection on a spherical geodesic grid. International Journal for Numerical Methods in Fluids, 55(2):127-142. Citado na pág. 4, 161

Cavoretto e De Rossi(2010) R. Cavoretto e A. De Rossi. Fast and accurate interpolation of large scattered data sets on the sphere. J. Comput. Appl. Math., 234:1505-1521. ISSN 0377-0427. Citado na pág. 84

Chen et al.(2012) C. Chen, J. Bin, e F. Xiao. A Global Multimoment Constrained Finite-Volume Scheme for Advection Transport on the Hexagonal Geodesic Grid. Mon. Wea. Rev., 140:941-955. Citado na pág. 161

Chen e Xiao(2008) C. Chen e F. Xiao. Shallow water model on cubed-sphere by multi-moment finite volume method. J. Comput. Phys., 227(10):5019-5044. ISSN 0021-9991. Citado na pág. 9

Derose e Meyer(2006) T. Derose e M. Meyer. Harmonic coordinates. Em Pixar Technical Memo 06-02, Pixar Animation Studios. Citado na pág. 90

Devadoss e O'Rourke(2011) S. L. Devadoss e J. O'Rourke. Discrete and computational geometry. Princeton University Press. Citado na pág. 94

Du et al.(2003) Q. Du, M. D. Gunzburger, e L. Ju. Constrained centroidal Voronoi tessellations for surfaces. SIAM J. Sci. Comput., 24:1488-1506. Citado na pág. 22, 36

Farin(1990) G. Farin. Surfaces over dirichlet tessellations. Comput. Aided Geom. D., 7(1-4): 281-292. Citado na pág. 94, 100

Fasshauer e McCourt(2012) G. Fasshauer e M. McCourt. Stable evaluation of gaussian radial basis function interpolants. SIAM J. Sci. Comput., 34(2):A737-A762. Citado na pág. 119, 144

Fasshauer(2011) G. Fasshauer. Positive Definite Kernels: Past, Present and Future. Dolomites Research Notes on Approximation, 4:21-63. Citado na pág. 112, 113, 144

Fasshauer(2012) G. Fasshauer. Mathematica CDF for positive definite kernels. Online computational documents, 2012. http://www.math.iit.edu/ fass/PDKernelsMathematica.html. Citado na pág. 113, 114

Fasshauer e Schumaker(1998) G. E. Fasshauer e L. L. Schumaker. Scattered data fitting on the sphere. Em Proceedings of the international conference on Mathematical methods for curves and surfaces II Lillehammer, 1997, páginas 117-166, Nashville, TN, USA. Vanderbilt University. Citado na pág. 83, 113

Floater(2003) M. Floater. Mean value coordinates. Comput. Aided Geom. D., 20(1):19 - 27. Citado na pág. 83,90

Floater et al.(2006) M. S. Floater, K. Hormann, e G. Kós. A general construction of barycentric coordinates over convex polygons. Adv. Comput. Math., 24(1-4):311-331. Citado na pág. 90, 92

Fornberg e Piret(2008) B. Fornberg e C. Piret. A stable algorithm for flat radial basis functions on a sphere. SIAM J. Sci. Comput., 30(1):60-80. Citado na pág. 119, 144

Frank e Majewski(2003) H. P. Frank e D. Majewski. Early warning capabilities of the global model GME of DWD: a case study. Atmospheric Research, 67-68:215 - 229. European Conference on Severe Storms 2002. Citado na pág. 203 
Franke(1982) R. Franke. Scattered data interpolation: tests of some methods. Math. Comp., 38 (157):181-200. Citado na pág. 84

Franke e Nielson(1980) R. Franke e G. Nielson. Smooth interpolation of large sets of scattered data. International Journal for Numerical Methods in Engineering, 15(11):1691-1704. Citado na pág. 119

Fuselier e Wright(2009) E. Fuselier e G. Wright. Stability and error estimates for vector field interpolation and decomposition on the sphere with rbfs. SIAM J. Numer. Anal., 47(5):32133239. Citado na pág. 144

Garcia(2001) C. I. Garcia. Métodos de refinamento local em modelos globais de previsão numérica do tempo. Tese de Doutorado, Instituto de Matemática e Estatística da Universidade de São Paulo. Citado na pág. 161, 165

Gillette et al.(2012) A. Gillette, A. Rand, e C. Bajaj. Error estimates for generalized barycentric interpolation. Adv. Comput. Math., 37:417-439. ISSN 1019-7168. Citado na pág. 4, 90, 94

Giraldo(1997) F. X. Giraldo. Lagrange-Galerkin Methods on Spherical Geodesic Grids. J. Comput. Phys., 136(1):197 - 213. Citado na pág. 10

Govett et al.(2010) M. W. Govett, J. Middlecoff, e T. Henderson. Running the NIM NextGeneration Weather Model on GPUs. Em Proceedings of the 2010 10th IEEE/ACM International Conference on Cluster, Cloud and Grid Computing, CCGRID '10, páginas 792-796, Washington, DC, USA. IEEE Computer Society. Citado na pág. 2

Gregory et al.(2008) M. J. Gregory, A. J. Kimerling, D. White, e K. Sahr. A comparison of intercell metrics on discrete global grid systems. Computers, Environment and Urban Systems, 32(3):188 - 203. Citado na pág. 9

Heikes e Randall(1995a) R. Heikes e D. A. Randall. Numerical integration of the shallow-water equations on a twisted icosahedral grid. Part I: basic design and results of tests. Mon. Wea. Rev., 123(6):1862-1880. Citado na pág. 2, 10, 26, 32, 36, 46, 47, 78, 199, 205

Heikes e Randall(1995b) R. Heikes e D. A. Randall. Numerical Integration of the Shallow-Water Equations on a Twisted Icosahedral Grid. Part II. A Detailed Description of the Grid and an Analysis of Numerical Accuracy. Mon. Wea. Rev., 123(6):1881-1887. Citado na pág. 205

Hesse e Le Gia(2008) K. Hesse e Q. T. Le Gia. Local radial basis function approximation on the sphere. Bull. Aust. Math. Soc., 77(2):197-224. Citado na pág. 112

Hiyoshi e Sugihara(2004) H. Hiyoshi e K. Sugihara. Improving the global continuity of the natural neighbor interpolation. Em A. Laganà, M. L. Gavrilova, V. Kumar, Y. Mun, C. J. K. Tan, e O. Gervasi, editors, ICCSA (3), volume 3045 of Lecture Notes in Computer Science, páginas 71-80. Springer. Citado na pág. 94

Ii e Xiao(2010) S. Ii e F. Xiao. A global shallow water model using high order multi-moment constrained finite volume method and icosahedral grid. J. Comput. Phys., 229(5):1774 - 1796. Citado na pág. 13

Joppich e Pott(2008) W. Joppich e S. Pott. Results obtained with a semi-lagrangian massintegrating transport algorithm by using the GME grid. Em I. Lirkov, S. Margenov, e J. Waśniewski, editors, Large-Scale Scientific Computing, páginas 417-424. Springer-Verlag, Berlin, Heidelberg. Citado na pág. 161, 203

Ju et al.(2011) L. Ju, T. D. Ringler, e M. Gunzburger. Voronoi tessellations and their application to climate and global modeling. Em P. Lauritzen, C. Jablonowski, M. Taylor, e R. Nair, editors, $N u$ merical Techniques for Global Atmospheric Models, volume 80 of Lecture Notes in Computational 
Science and Engineering, páginas 313-342. Springer Berlin Heidelberg. ISBN 978-3-642-11640-7. Citado na pág. 15, 35, 205

Ju et al.(2005) T. Ju, S. Schaefer, e J. Warren. Coordinates for closed triangular meshes. ACM Trans. Graph., 24:561-566. Citado na pág. 90

Klausen et al.(2012) R. Klausen, A. Rasmussen, e A. Stephansen. Velocity interpolation and streamline tracing on irregular geometries. Computat. Geosci., 16:261-276. Citado na pág. 84, 133, $134,135,136,137,154$

Lauritzen et al.(2010) P. H. Lauritzen, R. D. Nair, e P. A. Ullrich. A conservative semi-lagrangian multi-tracer transport scheme (cslam) on the cubed-sphere grid. J. Comput. Phys., 229(5):1401 - 1424. Citado na pág. 161

Lawson(1984) C. L. Lawson. $C^{1}$ surface interpolation for scattered data on a sphere. Rocky Mountain J. Math., 14(1):177-202. Surfaces (Stanford, Calif., 1982). Citado na pág. 14, 84, 100, 110

Lawson e Hanson(1974) C. L. Lawson e R. J. Hanson. Solving least squares problems. Series in Automatic Computation. Prentice-Hall. Citado na pág. 102

Lee e MacDonald(2009) J.-L. Lee e A. E. MacDonald. A Finite-Volume Icosahedral ShallowWater Model on a Local Coordinate. Mon. Wea. Rev., 137:1422. Citado na pág. 204

Lidberg(2011) P. Lidberg. Barycentric and wachspress coordinates in two dimensions: theory and implementation for shape transformations, 2011. Citado na pág. 90

Lipscomb e Ringler(2005) W. H. Lipscomb e T. D. Ringler. An incremental remapping transport scheme on a spherical geodesic grid. Mon. Wea. Rev., 133(8):2335-2350. Citado na pág. 4, 161

Majewski et al.(2008) D. Majewski, H. Frank, e D. Liermann. GME User's Guide. DWD, 2008. Corresponding to model version gmtri 2.17 and higher. Citado na pág. 2, 203

Majewski et al.(2002) D. Majewski, D. Liermann, P. Prohl, B. Ritter, M. Buchhold, T. Hanisch, G. Paul, W. Wergen, e J. Baumgardner. The operational global icosahedral-hexagonal gridpoint model GME: description and high-resolution tests. Mon. Wea. Rev., 130(2):319-338. Citado na pág. $1,2,4,10,32,84,85,104,110,161,203$

McDonald(1987) A. McDonald. Accuracy of Multiply-Upstream Semi-Lagrangian Advective Schemes II. Mon. Wea. Rev., 115(7):1446-1450. Citado na pág. 211

Mesinger e Arakawa(1976) F. Mesinger e A. Arakawa, editors. Numerical methods used in atmospheric models, volume 1, Global Atmospheric Research Program World Meteorological Organization, Geneva (Switzerland). Citado na pág. 28

Meyer et al.(2002) M. Meyer, A. Barr, H. Lee, e M. Desbrun. Generalized barycentric coordinates on irregular polygons. J. Graph. Tools, 7:13-22. Citado na pág. 90

Miura(2007) H. Miura. An Upwind-Biased Conservative Advection Scheme for Spherical Hexagonal Pentagonal Grids. Mon. Wea. Rev., 135:4038. Citado na pág. 4, 161

Miura e Kimoto(2005) H. Miura e M. Kimoto. A comparison of grid quality of optimized spherical hexagonal-pentagonal geodesic grids. Mon. Wea. Rev., 133(10):2817-2833. Citado na pág. $10,22,36,41,46,82$

Nair e Lauritzen(2010) R. D. Nair e P. H. Lauritzen. A class of deformational flow test cases for linear transport problems on the sphere. J. Comput. Phys., 229(23):8868 - 8887. Citado na pág. 162, 177, 190, 197, 202 
Nair et al.(2005) R. D. Nair, S. J. Thomas, e R. D. Loft. A Discontinuous Galerkin Global Shallow Water Model. Mon. Wea. Rev., 133(4):876-888. Citado na pág. 9

Neamtu e Schumaker(2004) M. Neamtu e L. L. Schumaker. On the approximation order of splines on spherical triangulations. Adv. Comput. Math., 21:3-20. Citado na pág. 84

Nedelec(1980) J. C. Nedelec. Mixed finite elements in R3. Numerische Mathematik, 35:315-341. Citado na pág. 84, 129

Nickovic et al.(2002) S. Nickovic, M. B. Gavrilov, e I. A. Tosic. Geostrophic adjustment on hexagonal grids. Mon. Wea. Rev., 130:668 - 683. Citado na pág. 3, 31

Ohnishi e Masuda(1986) H. Ohnishi e Y. Masuda. An integration scheme of the primitive equation model with an icosahedral-hexagonal grid system and its application to the shallow water equations. Short- and medium-range numerical weather prediction, International Symposium, Tokyo, Japan, páginas 317-326. Citado na pág. 1, 10

Peixoto e Barros(2013) P. S. Peixoto e S. R. M. Barros. Analysis of grid imprinting on geodesic spherical icosahedral grids. J. Comput. Phys., 237:61 - 78. Citado na pág. 3, 5, 51, 200

Perot(2000) B. Perot. Conservation properties of unstructured staggered mesh schemes. J. Comput. Phys., 159(1):58-89. Citado na pág. 84, 137, 201

Pottmann e Eck(1990) H. Pottmann e M. Eck. Modified multiquadric methods for scattered data interpolation over a sphere. Comput. Aided Geom. Des., 7:313-321. Citado na pág. 84

Putman e Lin(2007) W. M. Putman e S.-J. Lin. Finite-volume transport on various cubed-sphere grids. J. Comput. Phys., 227:55-78. Citado na pág. 9

Rancic et al.(1996) M. Rancic, R. J. Purser, e F. Mesinger. A global shallow-water model using an expanded spherical cube: Gnomonic versus conformal coordinates. Quart. J. R. Met. Soc., 122:959-982. Citado na pág. 9

Randall(1994) D. A. Randall. Geostrophic Adjustment and the Finite-Difference Shallow-Water Equations. Mon. Wea. Rev., 122:1371-+. Citado na pág. 28, 31, 33

Randall et al.(1998) D. A. Randall, J. Curry, D. Battisti, G. Flato, R. Grumbine, S. Hakkinen, D. Martinson, R. Preller, J. Walsh, e J. Weatherly. Status of and outlook for large-scale modeling of atmosphere-ice-ocean interactions in the arctic. B. Am. Meteorol. Soc., 79(2):197-219. Citado na pág. 7

Randall et al.(2002) D. A. Randall, T. D. Ringler, R. P. Heikes, P. Jones, e J. Baumgardner. Climate modeling with spherical geodesic grids. Comput. Sci. Eng., 4(5):32-41. Citado na pág. 2

Raviart e Thomas(1977) P. Raviart e J. Thomas. A mixed finite element method for 2-nd order elliptic problems. Em I. Galligani e E. Magenes, editors, Mathematical Aspects of Finite Element Methods, volume 606 of Lecture Notes in Mathematics, páginas 292-315. Springer Berlin / Heidelberg. Citado na pág. 84, 128

Renka(1984) R. J. Renka. Interpolation of data on the surface of a sphere. ACM Trans. Math. Softw., 10:417-436. Citado na pág. 14, 84, 100, 103, 107, 110, 148

Renka(1988a) R. J. Renka. Multivariate interpolation of large sets of scattered data. ACM Trans. Math. Softw., 14(2):139-148. Citado na pág. 84, 120

Renka(1988b) R. J. Renka. Algorithm 660: Qshep2d: Quadratic shepard method for bivariate interpolation of scattered data. ACM Trans. Math. Softw., 14(2):149-150. Citado na pág. 120 
Renka(1988c) R. J. Renka. Algorithm 661: Qshep3d: quadratic shepard method for trivariate interpolation of scattered data. ACM Trans. Math. Softw., 14(2):151-152. Citado na pág. 120

Renka(1997) R. J. Renka. Algorithm 773: SSRFPACK: interpolation of scattered data on the surface of a sphere with a surface under tension. ACM Trans. Math. Softw., 23:435-442. Citado na pág. 4, 14, 84, 86, 103, 110, 201

Ringler e Randall(2002) T. D. Ringler e D. A. Randall. The ZM Grid: An Alternative to the Z Grid. Mon. Wea. Rev., 130:1411-+. Citado na pág. 33

Ringler et al.(2000) T. D. Ringler, R. P. Heikes, e D. A. Randall. Modeling the Atmospheric General Circulation Using a Spherical Geodesic Grid: A New Class of Dynamical Cores. Mon. Wea. Rev., 128:2471. Citado na pág. 2

Ringler et al.(2010) T. D. Ringler, J. Thuburn, J. B. Klemp, e W. C. Skamarock. A unified approach to energy conservation and potential vorticity dynamics for arbitrarily-structured Cgrids. J. Comput. Phys., 229(9):3065 - 3090. Citado na pág. 31, 205

Rípodas et al.(2009) P. Rípodas, A. Gassmann, J. Förstner, D. Majewski, M. Giorgetta, P. Korn, L. Kornblueh, H. Wan, G. Zängl, L. Bonaventura, e T. Heinze. Icosahedral shallow water model (ICOSWM): results of shallow water test cases and sensitivity to model parameters. Geosci. Model Dev. Discuss., 2(1):581-638. Citado na pág. 32, 204

Ritchie(1987) H. Ritchie. Semi-lagrangian advection on a gaussian grid. Mon. Wea. Rev., 115(2): 608-619. Citado na pág. 4, 161, 165

Ronchi et al.(1996) C. Ronchi, R. Iacono, e P. S. Paolucci. The cubed sphere: a new method for the solution of partial differential equations in spherical geometry. J. Comput. Phys., 124(1): 93-114. Citado na pág. 9

Ruppert(2007) T. Ruppert. Vector field reconstruction by radial basis functions. Diploma thesis, Technical University Darmstadt. Citado na pág. 118, 119, 144, 204

Rustamov(2010) R. M. Rustamov. Barycentric coordinates on surfaces. Comput. Graph. Forum, 29(5):1507-1516. Citado na pág. 89

Sadourny(1972) R. Sadourny. Conservative finite-difference approximations of the primitive equations on quasi-uniform spherical grids. Mon. Wea. Rev., 100(2):136-144. Citado na pág. 9

Sadourny et al.(1968) R. Sadourny, A. Arakawa, e Y. Mintz. Integration of the nondivergent barotropic vorticity equation with an icosahedral-hexagonal grid for the sphere. Mon. Wea. Rev., 96(6):351-356. Citado na pág. 1, 10

Sahr et al.(2003) K. Sahr, D. White, e A. J. Kimerling. Geodesic discrete global grid systems. Cartography and Geographic Information Science, 30:121-134(14). Citado na pág. 7, 8, 10

Satoh et al.(2008) M. Satoh, T. Matsuno, H. Tomita, H. Miura, T. Nasuno, e S. Iga. Nonhydrostatic icosahedral atmospheric model (NICAM) for global cloud resolving simulations. J. Comput. Phys., 227(7):3486-3514. Citado na pág. 2, 32, 205

Shepard(1968) D. Shepard. A two-dimensional interpolation function for irregularly-spaced data. Em Proceedings of the 1968 23rd ACM national conference, ACM '68, páginas 517-524, New York, NY, USA. ACM. Citado na pág. 119

Sibson(1980) R. Sibson. A vector identity for the dirichlet tessellation. Mathematical Proceedings of the Cambridge Philosophical Society, 87:151-155. ISSN 1469-8064. Citado na pág. 93 
Silva et al.(2009) R. R. Silva, P. L. Silva Dias, D. S. Moreira, e E. B. Souza. Modelo OLAM (oceanland-atmosphere-model): descrição, aplicações, e perspectivas. Revista Brasileira de Meteorologia, 24:144 - 157. Citado na pág. 2, 204

Skamarock e Gassmann(2011) W. C. Skamarock e A. Gassmann. Conservative Transport Schemes for Spherical Geodesic Grids: High-Order Flux Operators for ODE-Based Time Integration. Mon. Wea. Rev., 139:2962-2975. Citado na pág. 161

Skamarock et al.(2012) W. C. Skamarock, J. B. Klemp, M. G. Duda, L. D. Fowler, S.-H. Park, e T. D. Ringler. A Multiscale Nonhydrostatic Atmospheric Model Using Centroidal Voronoi Tesselations and C-Grid Staggering. Mon. Wea. Rev., 140:3090-3105. Citado na pág. 4, 31, 32, 114, 144,205

Skamarock e Menchaca(2010a) W. Skamarock e M. Menchaca. Conservative transport schemes for spherical geodesic grids: High-order reconstructions for forward-in-time schemes. Mon. Wea. Rev., 138(12):4497-4508. ISSN 0027-0644. Citado na pág. 4

Skamarock e Menchaca(2010b) W. C. Skamarock e M. Menchaca. Conservative Transport Schemes for Spherical Geodesic Grids: High-Order Reconstructions for Forward-in-Time Schemes. Mon. Wea. Rev., 138(12):4497-4508. Citado na pág. 161

Solin(2005) P. Solin. Partial Differential Equations and the Finite Element Method. Pure and Applied Mathematics. Hoboken, NJ : Wiley. Citado na pág. 129

Staniforth e Côté(1991) A. Staniforth e J. Côté. Semi-Lagrangian Integration Schemes for Atmospheric Models - A Review. Mon. Wea. Rev., 119(9):2206-2223. Citado na pág. 4, 161, 164

Steppeler et al.(2008) J. Steppeler, P. Ripodas, B. Jonkheid, e S. Thomas. Third-order finitedifference schemes on icosahedral-type grids on the sphere. Mon. Wea. Rev., 136(7):2683-2698. Citado na pág. 1

Stuhne e Peltier(1999) G. Stuhne e W. Peltier. New icosahedral grid-point discretizations of the shallow water equations on the sphere. J. Comput. Phys., 148(1):23-58. Citado na pág. 2

Thacker et al.(2010) W. I. Thacker, J. Zhang, L. T. Watson, J. B. Birch, M. A. Iyer, e M. W. Berry. Algorithm 905: SHEPPACK: Modified Shepard Algorithm for Interpolation of Scattered Multivariate Data. ACM Trans. Math. Softw., 37(3):34:1-34:20. Citado na pág. 84

Thompson et al.(1999) J. F. Thompson, B. K. Soni, e N. P. Weatherill, editors. Handbook of grid generation. CRC Press, Boca Raton, FL. Citado na pág. 41

Thuburn et al.(2009) J. Thuburn, T. D. Ringler, W. C. Skamarock, e J. B. Klemp. Numerical representation of geostrophic modes on arbitrarily structured C-grids. J. Comput. Phys., 228: 8321-8335. Citado na pág. 3, 31

Thuburn(1997) J. Thuburn. A PV-Based Shallow-Water Model on a Hexagonal-Icosahedral Grid. Mon. Wea. Rev., 125(9):2328-2347. Citado na pág. 2, 10

Tomita e Satoh(2004) H. Tomita e M. Satoh. A new dynamical framework of nonhydrostatic global model using the icosahedral grid. Fluid Dynamics Research, 34(6):357 - 400. Citado na pág. 2,205

Tomita et al.(2001) H. Tomita, M. Tsugawa, M. Satoh, e K. Goto. Shallow water model on a modified icosahedral geodesic grid by using spring dynamics. J. Comput. Phys., 174(2):579-613. Citado na pág. 3, 20, 36, 51, 78, 82, 199

Tomita et al.(2002) H. Tomita, M. Satoh, e K. Goto. An optimization of the icosahedral grid modified by spring dynamics. J. Comput. Phys., 183(1):307 - 331. Citado na pág. 41, 205 
Tomita et al.(2008) H. Tomita, K. Goto, e M. Satoh. A New Approach to Atmospheric General Circulation Model: Global Cloud Resolving Model NICAM and its Computational Performance. SIAM J. Sci. Comput., 30(6):2755-2776. Citado na pág. 2, 10, 34, 85, 205

Tran e Gia(2008) T. Tran e Q. T. L. Gia. Interpolation on the sphere: a fast solution technique. ANZIAM Journal, 50(nov). Citado na pág. 84

Ullrich e Jablonowski(2012) P. A. Ullrich e C. Jablonowski. Mcore: A non-hydrostatic atmospheric dynamical core utilizing high-order finite-volume methods. J. Comput. Phys., 231 (15):5078 - 5108. Citado na pág. 9

Ullrich et al.(2010) P. A. Ullrich, C. Jablonowski, e B. van Leer. High-order finite-volume methods for the shallow-water equations on the sphere. J. Comput. Phys., 229(17):6104 - 6134. Citado na pág. 9

Vidovic(2009) D. Vidovic. Polynomial reconstruction of staggered unstructured vector fields. Theoretical and Applied Mechanics, 36:85-99. Citado na pág. 148, 201

Villiers(2006) M. d. Villiers. More on hexagons with opposite sides parallel. Math Gazette, páginas 517-518. Citado na pág. 52

Villiers(2007) M. d. Villiers. A hexagon result and its generalization via proof. The Montana Mathematics Enthusiast, 4(2):138-267. Citado na pág. 52

Wachspress(1975) E. L. Wachspress. A rational finite element basis. Mathematics in Science and Engineering 114. Academic Press. Citado na pág. 83, 90

Walko e Avissar(2008a) R. L. Walko e R. Avissar. The Ocean-Land-Atmosphere Model (OLAM). Part I: shallow-water tests. Mon. Wea. Rev., 136(11):4033-4044. Citado na pág. 2, 10, 32, 33, 204

Walko e Avissar(2008b) R. L. Walko e R. Avissar. The Ocean-Land-Atmosphere Model (OLAM). Part II: Formulation and Tests of the Nonhydrostatic Dynamic Core. Mon. Wea. Rev., 136(11): 4045-4062. Citado na pág. 32

Walters et al.(2009) R. Walters, E. Hanert, J. Pietrzak, e D. L. Roux. Comparison of unstructured, staggered grid methods for the shallow water equations. Ocean Model., 28(1-3):106-117. Citado na pág. 128

Wan(2009) H. Wan. Developing and testing a hydrostatic atmospheric dynamical core on triangular grids. Tese de Doutorado, International Max Planck Research School on Earth System Modelling, Max Planck Institute for Meteorology, Hamburg, Germany. Citado na pág. 3, 82, 119, 144, 204

Wang et al.(2011) B. Wang, G. Zhao, e O. Fringer. Reconstruction of vector fields for semilagrangian advection on unstructured, staggered grids. Ocean Model., 40(1):52-71. Citado na pág. 126,128

Washington et al.(2009) W. M. Washington, L. Buja, e A. Craig. The computational future for climate and Earth system models: on the path to petaflop and beyond. Philosophical Transactions of the Royal Society A: Mathematical, Physical and Engineering Sciences, 367(1890):833-846. Citado na pág. 7

Weller et al.(2012) H. Weller, J. Thuburn, e C. J. Cotter. Computational modes and grid imprinting on five quasi-uniform spherical C-grids. Mon. Wea. Rev., 140(8):2734-2755. Citado na pág. 3,30

Whitney(1957) H. Whitney. Geometric Integration Theory. Princeton University Press. Citado na pág. 84, 129 
Williamson(1968) D. L. Williamson. Integration of the barotropic vorticity equation on a spherical geodesic grid. Tellus, 20:642-653. Citado na pág. 1, 10

Williamson(2007) D. L. Williamson. The evolution of dynamical cores for global atmospheric models. J. Meteorol. Soc. Jpn., 85B:241-269. Citado na pág. 1, 7, 10

Williamson et al.(1992) D. L. Williamson, J. B. Drake, J. J. Hack, R. Jakob, e P. N. Swarztrauber. A standard test set for numerical approximations to the shallow water equations in spherical geometry. J. Comput. Phys., 102(1):211-224. Citado na pág. 126, 164

Wright(2003) G. Wright. Radial Basis Function Interpolation: Numerical and Analytical Developments. Tese de Doutorado, University of Colorado at Boulder. works.bepress.com/grady wright/8. Citado na pág. 113

Zienkiewicz e Taylor(2005) O. C. Zienkiewicz e R. L. Taylor. Finite Element Method for Solid and Structural Mechanics (6th Edition). Elsevier. Citado na pág. 84 